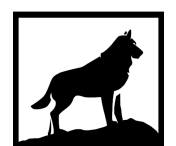

Michigan Technological

18 8 5 University
Michigan Technological University Digital Commons @ Michigan Tech

Dissertations, Master's Theses and Master's Reports

2020

\title{
EFFECT OF COBALT IN THIN WALL DUCTILE IRON AND SOLID SOLUTION STRENGTHENED FERRITIC DUCTILE IRON
}

Alejandra I. Almanza

Michigan Technological University, aalmanza@mtu.edu

Copyright 2020 Alejandra I. Almanza

Recommended Citation

Almanza, Alejandra I., "EFFECT OF COBALT IN THIN WALL DUCTILE IRON AND SOLID SOLUTION

STRENGTHENED FERRITIC DUCTILE IRON", Open Access Dissertation, Michigan Technological University, 2020.

https://doi.org/10.37099/mtu.dc.etdr/1099

Follow this and additional works at: https://digitalcommons.mtu.edu/etdr

Part of the Materials Science and Engineering Commons 


\title{
EFFECT OF COBALT IN THIN WALL DUCTILE IRON AND SOLID SOLUTION STRENGTHENED FERRITIC DUCTILE IRON
}

\author{
By \\ Alejandra I. Almanza \\ A DISSERTATION \\ Submitted in partial fulfillment of the requirements for the degree of \\ DOCTOR OF PHILOSOPHY \\ In Materials Science and Engineering
}

MICHIGAN TECHNOLOGICAL UNIVERSITY

2020

(C) 2020 Alejandra I. Almanza 
This dissertation has been approved in partial fulfillment of the requirements for the Degree of DOCTOR OF PHILOSOPHY in Materials Science and Engineering.

Department of Materials Science and Engineering

Dissertation Advisor: $\quad$ Dr. Paul Sanders

Committee Member: $\quad$ Dr. María Pérez López

Committee Member: Dr. Douglas Swenson

Committee Member: $\quad$ Dr. Stephen Hackney

Department Chair: $\quad$ Dr. Stephen Kampe 


\section{Table of Contents}

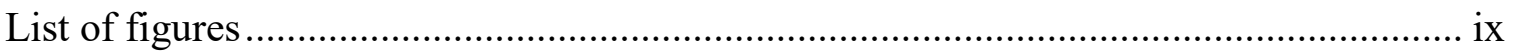

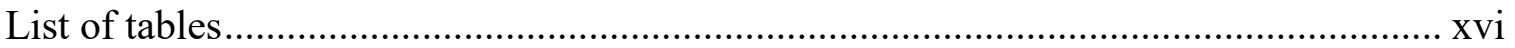

Preface

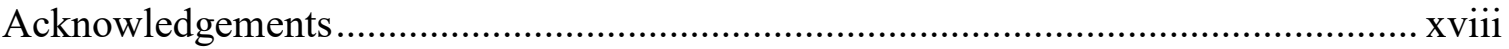

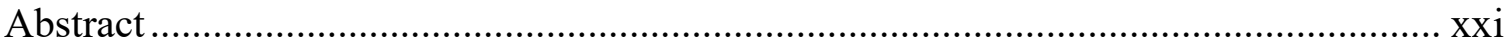

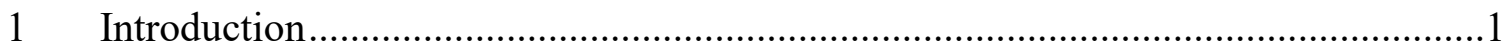

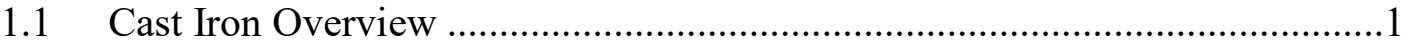

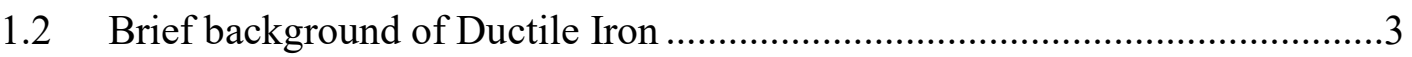

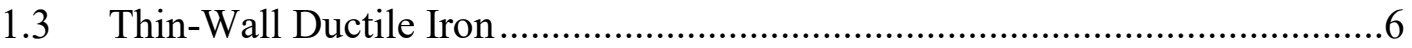

1.4 Solid Solution Strengthened Ferritic Ductile Irons .........................................

1.5 Motivation and Research Objectives..............................................................

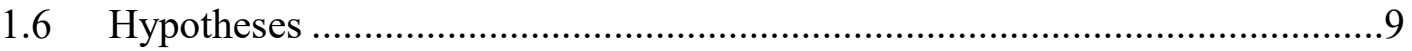

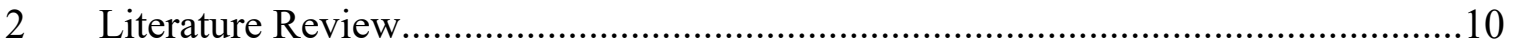

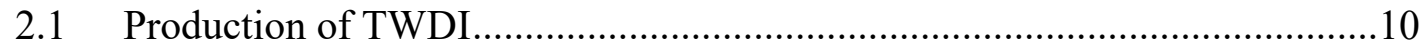

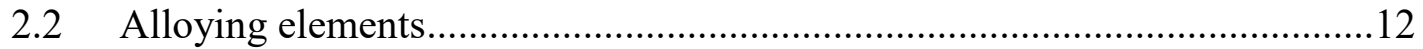

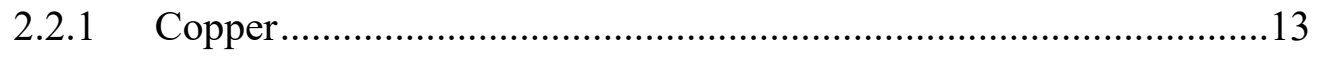

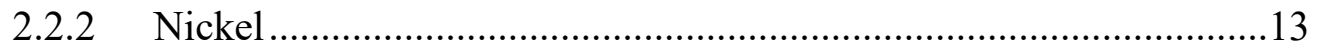

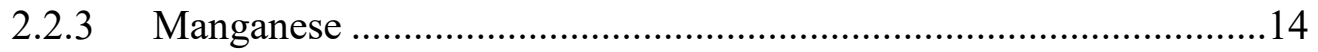

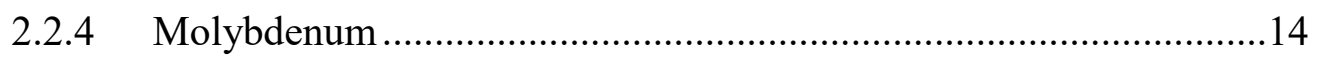

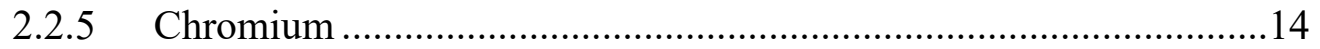

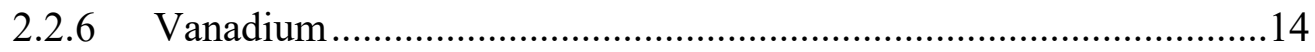

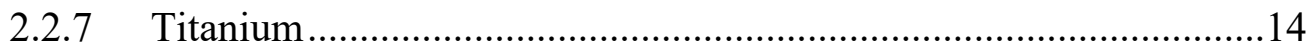

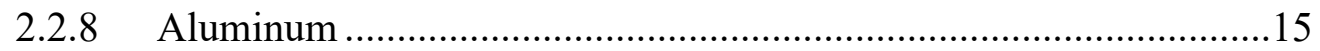

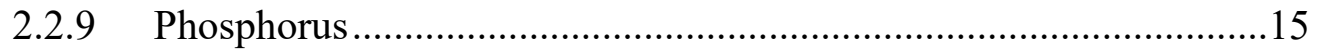

2.2.10 Magnesium...................................................................................

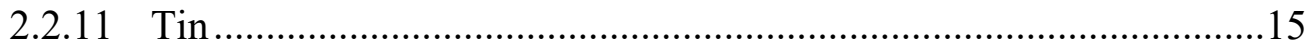




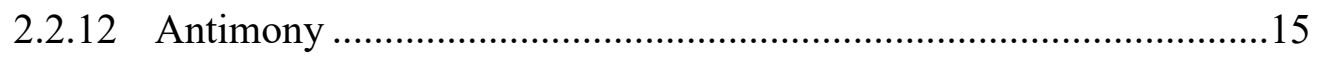

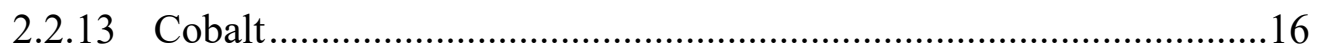

2.2.13.1 Effect in traditional ferritic-pearlitic grades ...................17

2.2.13.2 Effect in SSFDI grades .................................................18

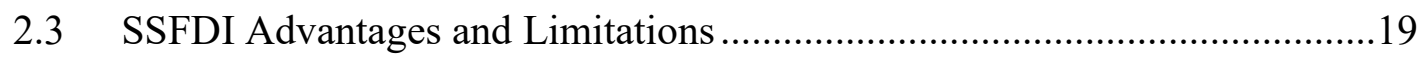

2.3.1 Graphite Morphology....................................................................19

2.3.2 Mechanical Properties......................................................................19

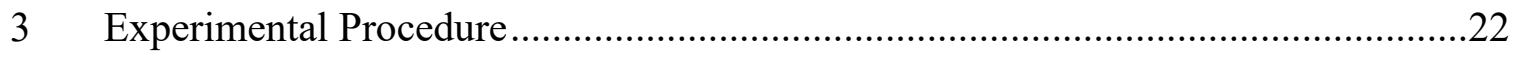

3.1 Effect of Cobalt in Thin Wall Ductile Iron ................................................22

3.1.1 Target Chemistry Selection and Furnace/Ladle Additions ................22

3.1.2 Mold Preparation ………………………………………………....24

3.1.3 Melting and Pouring Procedure …………….................................26

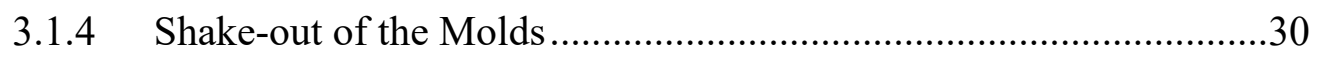

3.1.5 Microstructure Evaluation ..............................................................

3.1.5.1 Rectangular Plates...........................................................

3.1.5.1.1 Location of Metallographic Samples ..........31

3.1.5.1.2 Graphite Analysis..........................................33

3.1.5.1.3 Ferrite and Pearlite Analysis .........................33

3.1.5.1.4 Carbide Analysis ............................................33

3.1.5.2 ASTM $1 \frac{1}{2}$ inch Y-blocks.................................................... 34

3.1.5.2.1 Location of Metallographic Samples ..........34

3.1.5.2.2 Graphite Analysis........................................36

3.1.5.2.3 Ferrite and Pearlite Analysis.........................36

3.1.6 Tensile Properties Evaluation ..........................................................36

3.1.6.1 Rectangular Plates............................................................36

3.1.6.1.1 Location of Flat Tensile Samples ...............36

3.1.6.1.2 Loading and Testing ……….........................38

3.1.6.2 ASTM $1 \frac{1}{2}$ inch Y-blocks..................................................... 
3.1.6.2.1 Location of Round Tensile Samples ..........38

3.1.6.2.2 Loading and Testing ...............................40

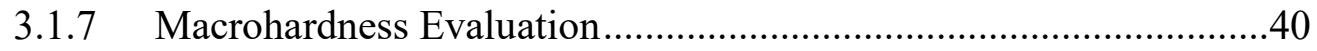

3.1.7.1 Rectangular Plates..................................................40

3.1.7.1.1 Location of Hardness Indentations ............40

3.1.7.2 ASTM $1 / 2$ inch Y-blocks .............................................41

3.1.7.2.1 Location of Hardness Indentations ............41

3.1.7.3 Brinell Hardness Testing..............................................41

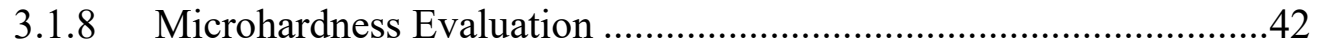

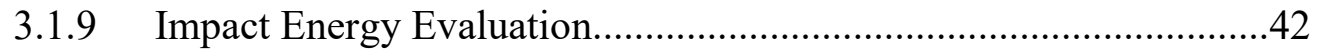

3.1.10 Fracture Toughness Evaluation................................................45

3.1.10.1 Location of Fracture Toughness Samples.....................45

3.1.10.2 Fatigue Pre-cracking of C(T) Samples ........................46

3.1.10.3 Loading and Testing ..................................................4

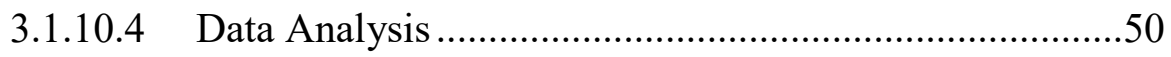

3.1.11 Microscopic Fracture Surface Examination.................................52

3.1.11.1 Fracture Surface Analysis of Flat Tensile Samples ........52

3.1.11.2 Fracture Surface Analysis of Charpy Samples ..............53

3.1.11.3 Fracture Surface Analysis of C(T) Samples ..................53

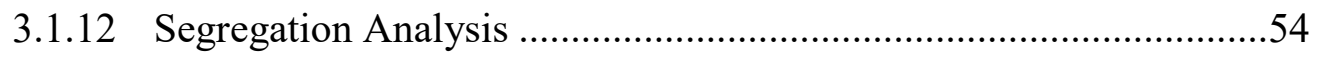

3.2 Effect of Cobalt in Solid Solution Strengthened Ferritic Ductile Iron...........55

3.2.1 Target Chemistry Selection and Furnace/Ladle Additions ................55

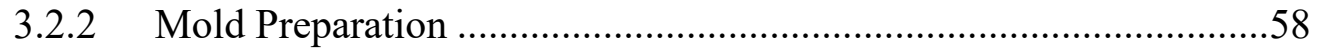

3.2.3 Melting and Pouring Procedure ....................................................58

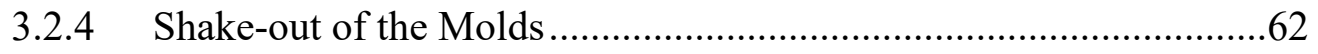

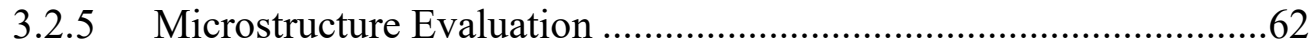

3.2.5.1 Location of Metallographic Sample...............................62

3.2.5.2 Graphite Analysis...................................................63 
3.2.5.3 Ferrite and Pearlite Analysis ......................................63

3.2.6 Tensile Properties Evaluation ....................................................64

3.2.6.1 Location of Round Tensile Samples ............................64

3.2.6.2 Loading and Testing ...............................................66

3.2.7 Macrohardness Evaluation........................................................66

3.2.8 Microhardness Evaluation .....................................................67

3.2.9 Impact Energy Evaluation.....................................................6

3.2.10 Fracture Toughness Evaluation................................................69

3.2.10.1 Location of Fracture Toughness Samples.....................69

3.2.10.2 Fatigue Pre-cracking of C(T) Samples ........................71

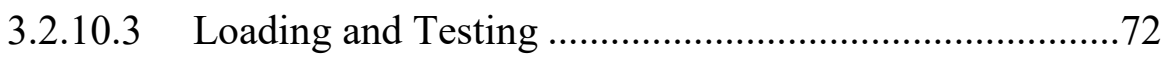

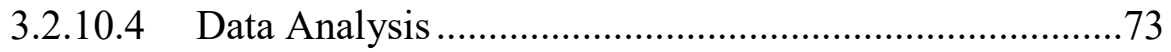

3.2.11 Microscopic Fracture Surface Examination....................................73

3.2.11.1 Fracture Surface Analysis of C(T) Samples ..................73

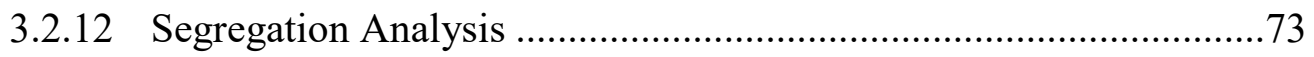

4.1 Effect of Cobalt in Thin Wall Ductile Iron ................................................74

4.1.1 Chemical Composition.................................................................74

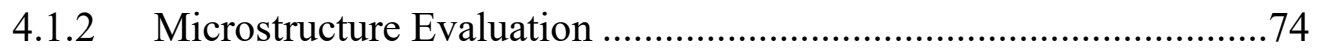

4.1.2.1 Metallography of Rectangular Plates...........................74

4.1.2.1.1 Graphite Analysis...................................74

4.1.2.1.2 Ferrite, Pearlite, and Carbide Analysis 77

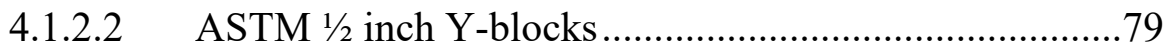

4.1.2.2.1 Graphite Analysis...................................79

4.1.2.2.2 Ferrite and Pearlite Analysis ....................82

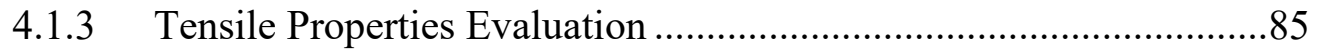

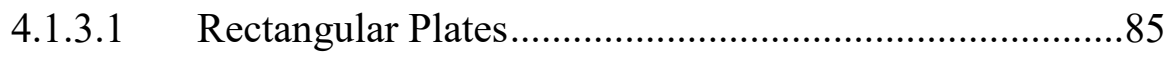




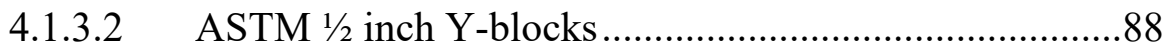

4.1.4 Macrohardness Evaluation...........................................................92

4.1.4.1 Rectangular Plates..........................................................92

4.1.4.2 ASTM $1 / 2$ inch Y-blocks...................................................

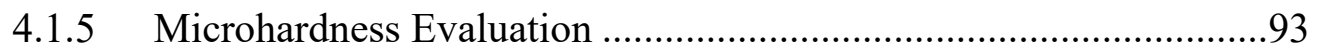

4.1.6 Impact Energy Evaluation..............................................................94

4.1.6.1 V-notched samples.........................................................94

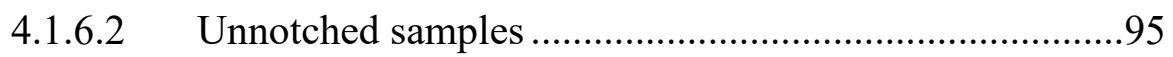

4.1.7 Fracture Toughness Evaluation.....................................................96

4.1.8 Microscopic Fracture Surface Examination.......................................97

4.1.8.1 Fracture Surface Analysis of Flat Tensile Samples .........97

4.1.8.1.1 Two-mm Thick Samples..............................97

4.1.8.1.2 Six-mm Thick Samples................................99

4.1.8.2 Fracture Surface Analysis of Charpy Samples .............102

4.1.8.2.1 V-notched Charpy Samples ......................102

4.1.8.2.2 Unnotched Charpy Samples........................103

4.1.8.3 Fracture Surface Analysis of C(T) samples ..................106

4.1.8.3.1 $\quad \mathrm{C}(\mathrm{T})$ Samples at Room Temperature .......106

4.1.9 Segregation Analysis ..................................................................109

4.2 Effect of Cobalt in Solid Solution Strengthened Ferritic Ductile Iron..........112

4.2.1 Chemical Composition.................................................................112

4.2.2 Microstructure Evaluation .............................................................112

4.2.2.1 Graphite Analysis..........................................................112

4.2.2.2 Ferrite and Pearlite Analysis ..........................................116

4.2.3 Tensile Properties Evaluation .......................................................118

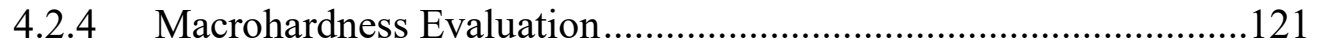

4.2.5 Microhardness Evaluation ........................................................122

4.2.6 Impact Energy Evaluation...............................................................123 
4.2.7 Fracture Toughness Evaluation.....................................................124

4.2.8 Microscopic Fracture Surface Examination.....................................128

4.2.8.1 Fracture Surface Analysis of C(T) samples ..................128

4.2.8.1.1 $\quad \mathrm{C}(\mathrm{T})$ Samples at $150^{\circ} \mathrm{C} \ldots \ldots \ldots \ldots \ldots \ldots \ldots \ldots \ldots . . . .128$

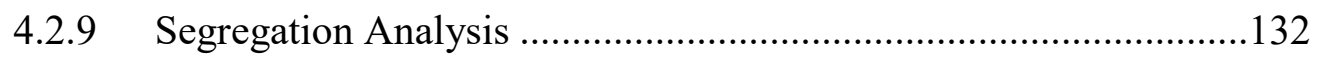

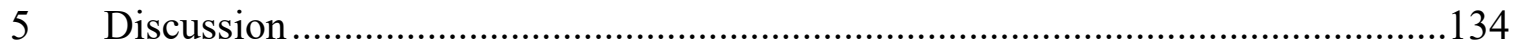

5.1 Effect of Cobalt in Thin Wall Ductile Iron .................................................134

5.1.1 Influence of Cobalt in the Microstructure.......................................134

5.1.1.1 Rectangular Plates......................................................134

5.1.1.2 ASTM $1 / 2$ inch Y-blocks................................................137

5.1.2 Influence of Cobalt in the Tensile Behavior ....................................141

5.1.2.1 Rectangular Plates.........................................................141

5.1.2.2 ASTM $1 / 2$ inch Y-blocks................................................142

5.1.3 Influence of Cobalt in the Impact and Fracture Toughness Properties 143

5.1.3.1 V-notched and Unnotched Samples...............................143

5.1.3.2 Fracture toughness ........................................................ 145

5.2 Effect of Cobalt in Solid Solution Strengthened Ferritic Ductile Iron..........149

5.2.1 Influence of Cobalt in the Microstructure........................................149

5.2.2 Influence of Cobalt in the Tensile Behavior .....................................149

5.2.3 Influence of Cobalt in the Impact Properties ...................................152

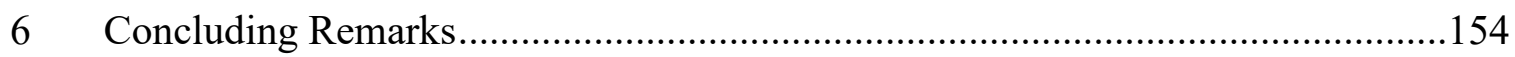

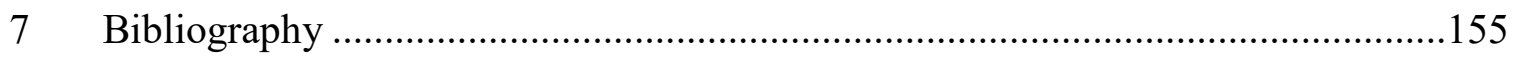

A Metallography of As-cast Thin Wall Ductile Iron..................................................165

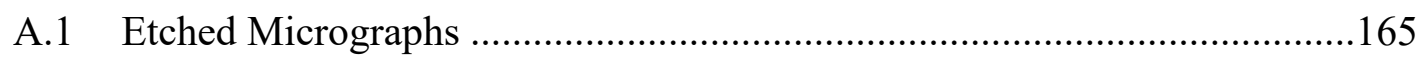

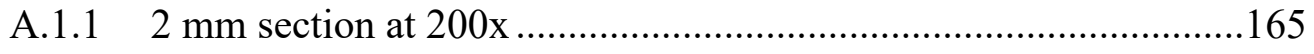

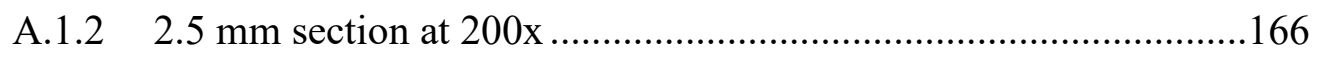

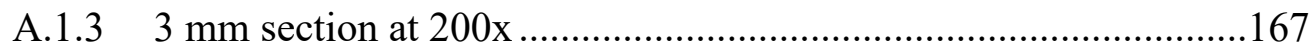


A.1.4 $3.5 \mathrm{~mm}$ section at $200 \mathrm{x}$ 168

A.1.5 $4 \mathrm{~mm}$ section at $200 \mathrm{x}$

A.1.6 $6 \mathrm{~mm}$ section at $200 \mathrm{x}$ 170

B $\quad$ Minitab ${ }^{\circledR}$ Statistical Software Results 171

B.1 Effect of Cobalt in Thin Wall Ductile Iron 171

B.1.1 General Linear Model: Nodule Count versus Co Level, Thickness (mm) 171

B.1.2 General Linear Model: Ferrite versus Co Level, Thickness (mm).174

B.1.3 General Linear Model: Pearlite versus Co Level, Thickness (mm)177

B.1.4 General Linear Model: Carbides versus Co Level, Thickness (mm) 180

B.1.5 General Linear Model: Nodularity (\%) versus Co Level, Position 183

B.1.6 General Linear Model: Nodule Count (N/mm2) versus Co Level, Position 185

B.1.7 General Linear Model: Nodule Diameter $(\mu \mathrm{m})$ versus Co Level, Position 188

B.1.8 General Linear Model: Ferrite (\%) versus Co Level, Position .......191

B.1.9 General Linear Model: Pearlite (\%) versus Co Level, Position......193

B.1.10 General Linear Model: Tensile Strength (MPa) versus Co Level, Thickness (mm)

B.1.11 General Linear Model: Yield Strength (MPa) versus Co Level, Thickness (mm)

B.1.12 General Linear Model: Elongation (\%) versus Co Level, Thickness (mm) 203

B.1.13 One-Way ANOVA: Tensile Strength (MPa) versus Co Level.......207

B.1.14 One-Way ANOVA: Yield Strength (MPa) versus Co Level..........208

B.1.15 One-Way ANOVA: Elongation (\%) versus Co Level .....................209

B.1.16 General Linear Model: HV versus Co Level, Position ....................210

B.1.17 General Linear Model: Absorbed Energy (J) versus Co Level, Temperature $\left({ }^{\circ} \mathrm{C}\right)-\mathrm{V}$-notched samples 
B.1.18 General Linear Model: Absorbed Energy (J) versus Co Level, Temperature $\left({ }^{\circ} \mathrm{C}\right)$ - Unnotched samples

B.1.19 General Linear Model: $\mathrm{K}_{\mathrm{JC}} \mathrm{MPa} \sqrt{ } \mathrm{m}$ versus Co Level, Temperature $\left({ }^{\circ} \mathrm{C}\right) \quad 218$

B.2 Effect of Cobalt in Solid Solution Strengthened Ferritic Ductile Iron.........221

B.2.1 General Linear Model: Nodule Diameter versus Co Level, Position 221

B.2.2 One-way ANOVA: Tensile Strength (MPa) versus Co Level........223

B.2.3 One-way ANOVA: Yield Strength (MPa) versus Co Level...........224

B.2.4 One-way ANOVA: Brinell Hardness (HB) versus Co Level .........225

B.2.5 One-way ANOVA: HV versus Co Level.......................................226

B.2.6 General Linear Model: Impact Toughness (J) versus Co Level,

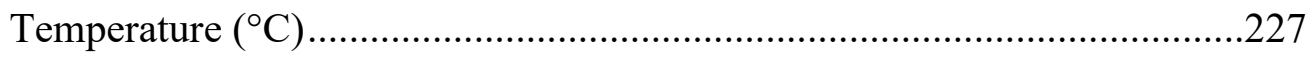

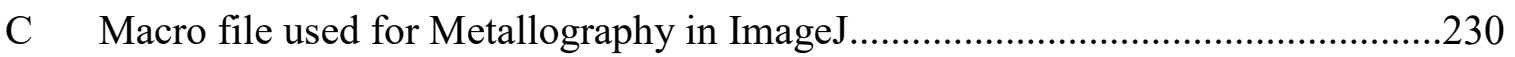




\section{List of figures}

Figure 1.1 Iron-Iron carbide phase diagram showing the range of cast irons [1] ...............1

Figure 1.2 Micrographs of typical cast iron types: (a) grey iron, (b) compacted iron, and

(c) ductile iron [3].

Figure 1.3 Influence of graphite morphology on the stress-strain curve of several cast

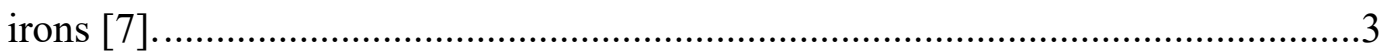

Figure 1.4 Thermo-Calc $\mathrm{Fe}-\mathrm{C}-2.5$ wt.\% Si metastable phase diagram.........................

Figure 1.5 Typical range for carbon and silicon contents for ductile irons [7] ..................5

Figure 1.6 Microstructure and tensile strengths for various types of ductile iron [13] ......6

Figure 1.7 Influence of silicon content DBTT of ferritic ductile iron [19].........................

Figure 2.1 Influence on different alloying elements on the stable and metastable eutectic

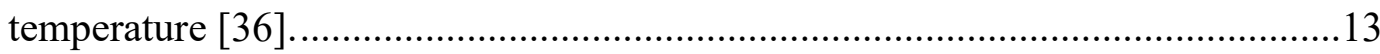

Figure 2.2 The Fe-Si system showing the formation of B2 and D03 ordered phases with

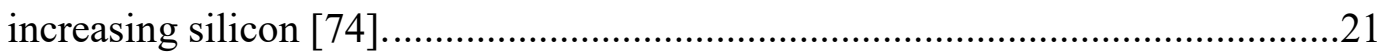

Figure 3.1 (a) CAD model illustration with dimensions ( $\mathrm{mm}$ ) [77], and (b) a finished chemically bonded mold.

Figure 3.2 (a) CAD model picture showing the 3 Y-block patterns [79], and (b) a finished Y-block mold. .25

Figure 3.3 Tinker Omega NexGen2 ${ }^{\mathrm{TM}}$ mixing system used to produce the chemically

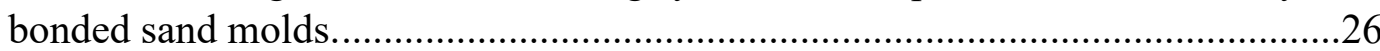

Figure 3.4 (a) 300-pound furnace used for all heats, with (b) the charge loaded..............27

Figure 3.5 The 300-pound tundish ladle used for all the treatments. ................................28

Figure 3.6 Pouring of (a) rectangular plates, and (b) $1 \frac{1}{2}$ inch Y-block.................................29

Figure 3.7 Photograph after pouring a total of 23 molds..................................................30

Figure 3.8 (a) Rectangular plates, and (b) $1 / 2$ inch Y-blocks after sandblasting..................30

Figure 3.9 TR100 INOX LAPMASTER abrasive cutter used to cut the cross-sections for metallography of the rectangular plates...............................................................

Figure 3.10 Location of the cross-section samples used for metallography.......................32

Figure 3.11 Leco AP-300 machine used for the metallographic preparation of the

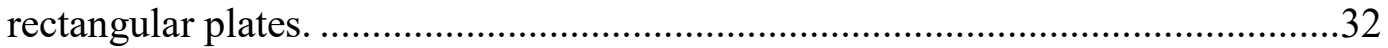

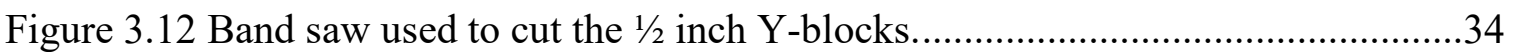


Figure 3.13 A and B bars showing the middle cross-section used for metallography per Y-block.

Figure 3.14 Two machined subsize flat tensile samples placed on top of the pattern for the rectangular plates.

Figure 3.15 Dimensions (mm) of the flat subsize tensile samples per ASTM E8 [82]....37

Figure 3.16 Instron 4206 machine setup (a) overall and close up (b).............................38

Figure 3.17 Location of the subsize round tensile bars in the $1 / 2$ inch Y-blocks...............39

Figure 3.18 Subsize round tensile bar drawing per ASTM E8 [82], dimensions are in inches.

Figure 3.19 Instron 4206 machine setup for subsize round tensile samples....................40

Figure 3.20 Dyna hardness tester and B.O.S.S used in measuring Brinell hardness.........41

Figure 3.21 LECO M-400-G1 Vickers hardness microhardness tester...........................42

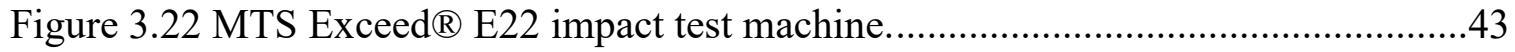

Figure 3.23 Location of unnotched and v-notched samples in the $1 / 2$ inch Y-blocks.........44

Figure 3.24 Dimensions (mm) used for (a) unnotched, and (b) v-notched samples per

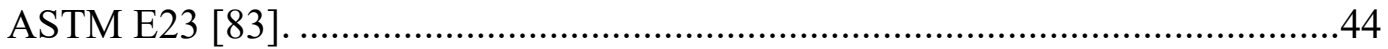

Figure 3.25 Location of the $\mathrm{C}(\mathrm{T})$ samples in the $1 / 2$ inch Y-blocks. ..............................45

Figure 3.26 Dimensions (mm) used for the C(T) samples per ASTM E1820 Annex 3 [85].

Figure 3.27 Fatigue frame configuration used to pre-crack the $C(T)$ samples from $1 / 2$ inch

Y-blocks.

Figure 3.28 Instron 4206 machine used for the $\mathrm{C}(\mathrm{T})$ testing at room temperature. ..........48

Figure 3.29 Close-up view of a C(T) sample mounted before testing...........................49

Figure 3.30 Portable LAB-TEMPTM furnace used for the low temperature testing. .........49

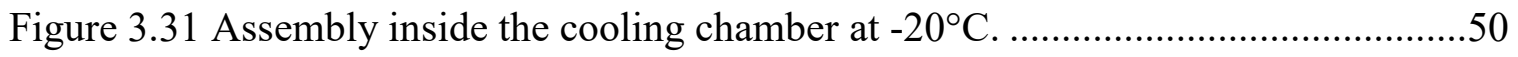

Figure 3.32 Wild Heerbrugg stereoscope used for analysis of the broken $\mathrm{C}(\mathrm{T})$ samples. 51

Figure 3.33 Philips/FEI XL30 ESEM used for the fracture surface analysis.

Figure 3.34 Cressington 208HR high-resolution sputter coater used to coat all the samples for fracture surface evaluation.

Figure 3.35 Denton DV-502A sputter coater used to carbon-coat the samples for EDS analysis

Figure 3.36 Chemically bonded 1-inch Y-block sand mold. 
Figure 3.37 Furnace charge (a) before, and (b) after meltdown. ..................................59

Figure 3.38 Tapping of the furnace to the tundish ladle...............................................60

Figure 3.39 Metal stream inoculation using Inolate-40 enclosed in red..........................60

Figure 3.40 Pouring of one ASTM A536 1-inch Y-block mold......................................61

Figure 3.41 Arrangement of the molds after pouring. .................................................61

Figure 3.42 Set of three 1-inch Y-blocks after shaking out one mold.............................62

Figure 3.43 Location of the metallographic sample in the 1 -inch Y-blocks. ...................63

Figure 3.44 Hacksaw used to cut the 1-inch Y-blocks. .................................................64

Figure 3.45 Location of the bottom inch section removed from the Y-block to machine

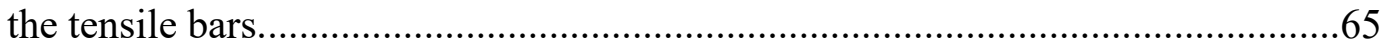

Figure 3.46 Dimensions ( $\mathrm{mm})$ of the round tensile bar per ASTM E8 [82]....................65

Figure 3.47 Tinius Olsen tensile testing machine used for the round tensile samples of the

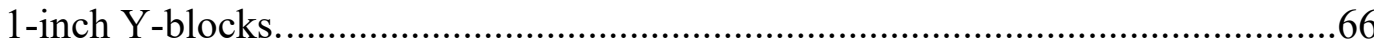

Figure 3.48 Brinell hardness test of the bottom inch of the Y-blocks. ...........................67

Figure 3.49 Location of unnotched Charpy samples in the 1-inch Y-block.....................68

Figure 3.50 Oven for high-temperature impact testing............................................68

Figure 3.51 Location of the C(T) samples in the 1-inch Y-blocks...............................69

Figure 3.52 Dimensions ( $\mathrm{mm})$ used for the $\mathrm{C}(\mathrm{T})$ samples from the 1-inch Y-blocks per ASTM E1820 Annex 3 [85].................................................................... 70

Figure 3.53 Fatigue frame configuration used to pre-crack the $\mathrm{C}(\mathrm{T})$ samples from 1-inch

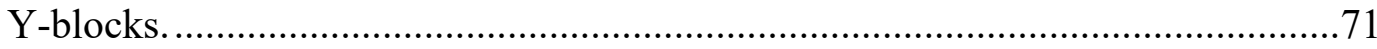

Figure 3.54 Assembly for the fracture toughness test of $\mathrm{C}(\mathrm{T})$ samples from the 1-inch $\mathrm{Y}$ -

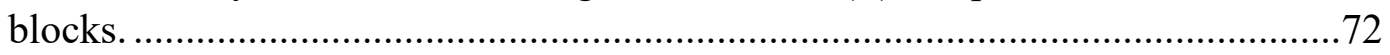

Figure 4.1 Unetched micrographs of the $3 \mathrm{~mm}$ section at 200x [77] ............................75

Figure 4.2 Main effects plot for the effect of cobalt and thickness in nodule count. ........76

Figure 4.3 Interaction plot between cobalt and thickness in nodule count [77] ..............76

Figure 4.4 Etched micrographs from the $3 \mathrm{~mm}$ section at 200x [77] ...........................77

Figure 4.5 Ferrite, pearlite, and carbide percentages for all section thicknesses [77]......78

Figure 4.6 Unetched micrographs at 50x of the first and last $1 / 2$ inch Y-blocks poured [79].

Figure 4.7 Percent nodularity of the first and last $1 / 2$ inch Y-blocks poured. Error bars are $95 \%$ standard error of the mean [79]. .81 
Figure 4.8 Nodule count of the first and last $1 / 2$ inch Y-blocks poured. Error bars are $95 \%$ standard error of the mean [79].

Figure 4.9 Nodule diameter of the first and last $1 / 2$ inch Y-blocks poured. Error bars are $95 \%$ standard error of the mean [79].

Figure 4.10 Nital etched micrographs at 50x of the first and last $1 / 2$ inch Y-blocks poured [79].

Figure 4.11 (a) Ferrite and (b) pearlite percentages of the first and last $1 \frac{1}{2}$ inch Y-blocks poured. Error bars are $95 \%$ standard error of the mean [79].

Figure 4.12 Main effects plot for the effect of cobalt and thickness on tensile strength [77].

Figure 4.13 Interaction plot between cobalt and thickness on tensile strength [77]..........86

Figure 4.14 Main effects plot for the effect of cobalt and thickness on yield strength [77].

Figure 4.15 Interaction plot between cobalt and thickness on yield strength [77].

Figure 4.16 Main effects plot for the effect of cobalt and thickness on elongation [77]...88

Figure 4.17 Interaction plot between cobalt and thickness on elongation [77] .................88

Figure 4.18 Effect of cobalt on the tensile strength of the $1 / 2$ inch Y-blocks [79]..............89

Figure 4.19 Tensile strength of the $1 / 2$ inch Y-blocks without the 3 wt.\% Co heat............89

Figure 4.20 Effect of cobalt on the yield strength of $1 / 2$ inch Y-blocks [79] .....................90

Figure 4.21 Yield strength of the $1 / 2$ inch Y-blocks without the 3 wt.\% Co heat...............90

Figure 4.22 Effect of cobalt on the percent elongation of $1 / 2$ inch Y-blocks [79] ..............91

Figure 4.23 Elongation of the $1 / 2$ inch Y-blocks without the 3 wt.\% Co heat....................91

Figure 4.24 Effect of cobalt additions on the Brinell hardness of the rectangular plates.

Error bars are $95 \%$ Std error of the mean [77]

Figure 4.25 Effect of cobalt on the Brinell hardness of the $1 / 2$ inch Y-blocks. Error bars are $95 \%$ Std error of the mean.

Figure 4.26 Effect of cobalt on the ferrite hardness of the $1 / 2$ inch Y-blocks. Error bars are $95 \%$ Std error of the mean [79]

Figure 4.27 Charpy V-notched impact energy of the $1 / 2$ inch Y-blocks. Error bars are 95\% Std error of the mean.

Figure 4.28 Charpy unnotched impact energy of the $1 / 2$ inch Y-blocks. Error bars are $95 \%$ Std error of the mean. .96

Figure 4.29 Fracture toughness of the $1 / 2$ inch Y-blocks. .97 
Figure 4.30 Fracture surface SEM images of the $2 \mathrm{~mm}$ flat tensile sample [77]. .99

Figure 4.31 Fracture surface SEM images of the $6 \mathrm{~mm}$ flat tensile sample [77]. 101

Figure 4.32 Fracture surface SEM images of V-notched Charpy samples...... 103

Figure 4.33 Fracture surface SEM images of Unnotched Charpy samples. .105

Figure 4.34 Stereoscopic fractography of a broken $\mathrm{C}(\mathrm{T})$ sample showing the two analyzed zones. .106

Figure 4.35 Fracture surface SEM images of the base ductile iron heat $\mathrm{C}(\mathrm{T})$ sample. ...107

Figure 4.36 Fracture surface SEM images of the 3 wt.\% Co heat C(T) sample. .108

Figure 4.37 Fracture surface SEM images of the 4 wt.\% Co heat C(T) sample. 109

Figure 4.38 EDS measurements for the (a) 3 wt.\% Co, and (b) 4 wt.\% Co heats .110

Figure 4.39 Modified EDS measurements for the 4 wt.\% Co heat (points 6 and 7 were excluded).

Figure 4.40 Unetched micrographs at 100x of the first and last 1-inch Y-blocks poured.

Figure 4.41 Percent nodularity of the first and last 1-inch Y-blocks poured. Error bars are $95 \%$ Std error of the mean.

Figure 4.42 Nodule count of the first and last 1-inch Y-blocks poured. Error bars are 95\% Std error of the mean.

Figure 4.43 Nodule diameter of the first and last 1-inch Y-blocks poured. Error bars are $95 \%$ Std error of the mean.

Figure 4.44 Nital etched micrographs at 100x of the first and last 1-inch Y-blocks poured.

Figure 4.45 Effect of cobalt on the tensile strength of 1-inch Y-blocks. Error bars are $95 \%$ Std error of the mean.

Figure 4.46 Effect of cobalt on the yield strength of 1-inch Y-blocks. Error bars are 95\%

Std error of the mean.

Figure 4.47 Effect of cobalt on the percent elongation of 1-inch Y-blocks. Error bars are $95 \%$ Std error of the mean.

Figure 4.48 Effect of cobalt on the Brinell hardness of the 1-inch Y-blocks. Error bars are $95 \%$ Std error of the mean.

Figure 4.49 Effect of cobalt on the ferrite microhardness of the 1-inch Y-blocks. Error bars are $95 \%$ Std error of the mean. 
Figure 4.50 Charpy unnotched impact energy for the 1-inch Y-blocks. Error bars are 95\% Std error of the mean.

Figure 4.51 Base SSF C(T) sample after fracture toughness test at room temperature...125

Figure 4.52 Base SSF C(T) sample after fracture toughness test at $150^{\circ} \mathrm{C}$. 125

Figure 4.53 Fracture toughness of the 1-inch Y-blocks. Error bars are 95\% Std error of the mean.

Figure 4.54 Fracture surfaces of the $\mathrm{C}(\mathrm{T})$ samples at $150^{\circ} \mathrm{C}$ for all heats.

Figure 4.55 (a) Fracture surface of C(T) sample highlighting important zones and (b)

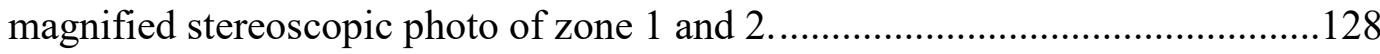

Figure 4.56 Fracture surface SEM images of the base SSF heat C(T) sample...............129

Figure 4.57 Fracture surface SEM images of the 3 wt.\% Co heat C(T) sample.............130

Figure 4.58 Fracture surface SEM images of the 4 wt.\% Co heat C(T) sample.............131

Figure 4.59 EDS measurements for the (a) $3 \mathrm{wt} \%$ Co, and (b) 4 wt.\% Co high silicon heats.

Figure 5.1 Factorial Plots from Minitab ${ }^{\circledR}$ analyzing the (a) ferrite, (b) pearlite, and (c) carbide percentages of the rectangular plates [77].

Figure 5.2 Factorial plots from Minitab ${ }^{\circledR}$ analyzing the graphite features (a) percent nodularity, (b) nodule count, and (c) nodule diameter of the first and last $1 / 2$ inch Y-blocks poured [79].

Figure 5.3 Factorial plots from Minitab ${ }^{\circledR}$ analyzing the (a) ferrite, and (b) pearlite percentages of the first and last $1 / 2$ inch Y-blocks poured [79].

Figure 5.4 Factorial plots from Minitab ${ }^{\circledR}$ on the effect of cobalt on the ferrite microhardness of the $1 / 2$ inch Y-blocks [79].

Figure 5.5 Factorial plots from Minitab ${ }^{\circledR}$ analyzing the (a) v-notched and (b) unnotched impact energies of the $1 / 2$ inch Y-blocks.

Figure 5.6 Factorial plots from Minitab ${ }^{\circledR}$ analyzing the fracture toughness of the $1 / 2$ inch Y-blocks.

Figure 5.7 Silicon distribution showing the negative segregation between two graphite nodules [94].

Figure 5.8 Effect of nodule count on the fracture toughness of ferritic ductile iron [19].

Figure 5.9 Solidification times calculated with Inspire Cast for the $1 / 2$ inch Y-blocks....148

Figure 5.10 Factorial plots from Minitab ${ }^{\circledR}$ on the effect of cobalt in the nodule diameter of the SSFDI heats. 
Figure 5.11 Tensile properties without the 3 wt.\% Co heat.........................................151

Figure 5.12 Factorial plots from Minitab ${ }^{\circledR}$ analyzing the impact toughness of the SSFDI

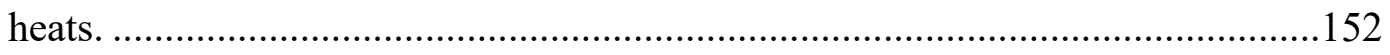

No table of figures entries found. 


\section{List of tables}

Table 1.1 Cast iron compositions (wt.\%) and microstructures [2] .................................2

Table 1.2 Silicon content and tensile properties for wall thicknesses below $30 \mathrm{~mm}$ in

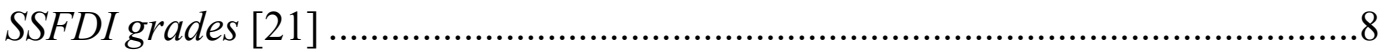

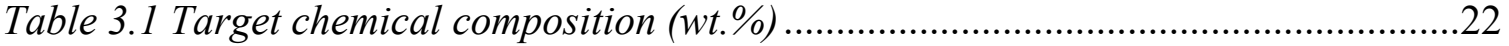

Table 3.2 Chemical composition for furnace charge materials (wt.\%)...........................23

Table 3.3 Chemical composition of the ladle additions (wt.\%) .....................................23

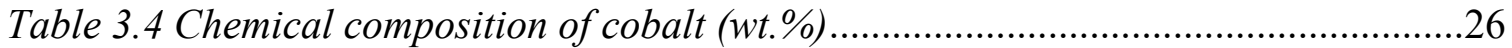

Table 3.5 Metallographic procedure used with the Leco AP-300 machine ......................33

Table 3.6 Metallographic procedure used manually for the $1 / 2$ inch Y-blocks...................35

Table 3.7 Aimed base chemical composition (wt.\%) ......................................................55

Table 3.8 Chemical composition of the materials used to fabricate the heats (wt.\%) ......56

Table 3.9 Chemical composition of the materials used in the ladle (wt.\%) .......................57

Table 4.1 Final chemical composition for thin castings (wt.\%) .....................................74

Table 4.2 Final chemical composition for high silicon grades (wt.\%)...........................112

Table 5.1 Liquidus and solidus temperature of the base DI and 4 wt.\% Co heats..........138

Table 5.2 One-Way ANOVA results for the mechanical properties, significant p-value

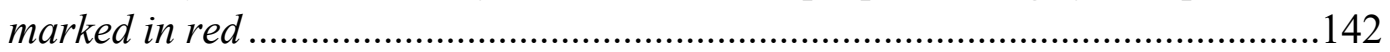

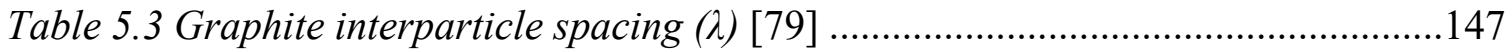

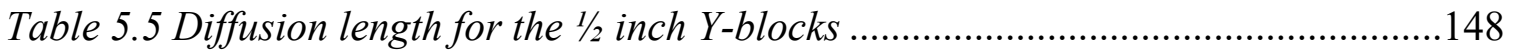

Table 5.6 Degenerated graphite content in the SSFDI heats $(\%)$.................................153 


\section{Preface}

The following research work is composed of previously published data and material that is planned for submission soon. Two papers were published in the International Journal of Metalcasting, and the full citations are provided below

1. Almanza, A., Dewald, D., Licavoli, J., and Sanders, P. Effect of Cobalt Additions on the Microstructure and Mechanical Properties of As-Cast Thin-Wall Ductile Iron. Inter Metalcast (2020). https://doi.org/10.1007/s40962-020-00513-3

2. Almanza, A., Dewald, D., Licavoli, J., and Sanders, P. Influence of Cobalt in the Tensile Properties of $1 \frac{1}{2}$ inch Ductile Iron Y-blocks. Inter Metalcast (2020). https://doi.org/10.1007/s40962-020-00521-3

Author contributions

Almanza, A. conducted all the experiments, performed the analysis and interpretation of the data, wrote the papers, and was responsible for the submission and review of the journal articles.

Dewald, D. helped in the production of all the heats that were subsequently investigated. Licavoli, J. helped with the review and editing of the journal articles.

Sanders, P. provided general input throughout the work and helped with the review and editing of the journal articles.

The following people helped with the execution of different mechanical testing, and their results are found in this dissertation. Yet, the current author performed the analysis and interpretation of the data.

- Tom Wood performed the fracture toughness test at room temperature and $0^{\circ} \mathrm{C}$ of the samples with low silicon content.

- Kassia Prystalski carried out the tensile testing of the samples with high silicon contents at Waupaca Foundry.

- Dr. Travis Welt from the University of St. Thomas conducted impact testing at high temperatures of the samples with high silicon contents. 


\section{Acknowledgements}

I want to express my sincere gratitude to my advisor Dr. Paul Sanders for giving me the opportunity to pursue my $\mathrm{PhD}$. Thank you for enlightening me that although the results are not what I expected it does not mean they are bad. Thank you for all your guidance throughout my research work, and for always believing in me.

I am deeply grateful to the MSE department for their financial support during the first years of my PhD. Additionally, I want to thank the Ductile Iron Society for funding the two projects that are presented here. Finally, thank you to the Graduate School for awarding me with the Fall 2020 finishing fellowship, allowing me to fulfill my $\mathrm{PhD}$ degree.

Thank you to all the MTU students who helped with the pouring, molding, cutting, machining, recording, and CAD modeling of all my castings: Adam Kallioinen, Alex Basaj, Carson Williams, Devin Deaton, Erin VanDusen, Jacob Namyst, Mason Coy, Matt Thomas, Nick Martin, Oliver Schichl, Phil Staublin, Samuel Dlugoss, Sam Vellequette, and Spencer Seeley.

Additionally, I want to extend my gratitude to all the DIS members who provided technical support and advice during the two research projects: Cathrine Hartung, Cesar Braga, Jim Csonka, John Tartaglia, Kathy Hayrynen, Lizeth Medina, Lyle Heberling, Matt Meyer, Mike Riabov, and Richard Gundlach.

A special thank you to all the companies that donated materials to produce the castings: Aarrowcast, Inc., Badger Mining, Carpenter Brothers, Inc., Elkem, Ferroglobe, HA International, Hickman, Williams and Company, Neenah Foundry, Superior Graphite, and Waupaca Foundry.

Furthermore, I would like to give sincere thanks and recognition to the following individuals that in addition to providing knowledge and assistance to my research project, made this journey so much fun: 
i. Dr. Dale Dewald, thank you for helping me with the planning and execution of all my pourings. Also, I appreciate that you have shared with me your passion for helping and teaching.

ii. Paul Fraley, I appreciate your help with the setup and troubleshooting of all my mechanical testing. Additionally, thank you because you always helped me find an easier way to do things.

iii. Tom Wood, thank you very much for helping me with the fracture toughness test during quarantine only you and I know how time-consuming and tedious this test is. Besides that, thank you for helping with all my pourings.

iv. Russ Stein, I appreciate that you were always available to help me with my pourings. Also, thank you for creating the schmuck board that forced you to think twice about the things you were planning to do.

v. Dr. Joe Licavoli, thank you for always giving me your point of view on my projects and have me thinking about it for a while. Thank you for your friendship and all the gaming nights at your place. By the way, I am going to miss Naga too much.

vi. Dr. Dan Seguin, I deeply appreciate the time that you provided to figure out everything about the fracture toughness test. Also, thank you for all those hours in your office that we spent trying to figure out the ASTM standard and for always being so optimistic.

vii. Nick Hendrickson, thank you very much for helping me with the planning and machining of all my samples. The machine shop was an essential part of this research project.

viii. Liz Miller, thank you for always being willing to help me but above all thank you because you made the long hours at SEM so much fun.

ix. Dr. Kathy Hayrynen, thank you for being a mentor to me and for all the advice and long talks we had.

x. Julia Scruton, thank you for being a great officemate back in 2018. But especially thank you for your friendship and all the fun trips we have made. 
xi. Matt Thomas, thank you for your wonderful friendship, for all the hours we spent in our office drinking lots of coffee, and for all the fun reunions that made grad school so much easier.

xii. Erin VanDusen, I want to thank you for your wonderful friendship, for all the times you cooked for Matt and me. I will never forget your delicious cookies, and I will always take Sven with me.

xiii. Mike Sulwer, thank you for the few but very funny moments that you shared with me. My best wishes with your PhD and remember to never give up.

Additionally, I am very grateful for my non-MSE friends. Thank you so much, Ulises Gracida, Meena Chandrasekar, and Sergio Lopez for all the laughs, deep talks, and dancing that we had. All the experiences with you guys were unique and full of joy. I learned a lot from your cultures and to see life from a different perspective.

I want to deeply thank my family for all their support. Firstly, thank you, Dad, for guiding me in the moments when I felt lost. Secondly, thank you, Mom, for always believing in me. And finally, thank you to my two beautiful sisters, Mony and Chio who always sent me messages of encouragement and love.

Lastly, I want to dedicate with all my love this dissertation to my spouse Aby. Without your support, this would not have been possible. Thank you for encouraging me, for believing in me, and for making me a better person every day. You are the most important person in my life. I love you with all my heart. 


\section{Abstract}

Ductile Iron is a material that is constantly evolving. Consequently, the ferrous industry is not only focusing on lightweighting but also on improving the impact strength and fracture toughness of typical ferritic-pearlitic ductile iron grades and solid solution strengthened ferritic ductile irons. Recently, the demand for thin-wall ductile iron and solid solution strengthened ferritic ductile iron grades has increased. The challenges behind the fabrication of these two ductile iron materials are the presence of carbides and the embrittlement of ferrite. In response, research has been focused on looking at alternative methods that can mitigate carbide formation in thin sections and counteract the detrimental effects of high silicon contents in the impact toughness of these materials. One way to reduce carbides is by increasing the silicon, but high silicon contents embrittle the ferrite and result in low static and dynamic mechanical properties. Cobalt in ductile iron is known to increase the nodule count resulting in a higher ferrite content in the as-cast condition, and it also hardens the ferrite via solid solution strengthening. Therefore, the ability of cobalt to inhibit carbide formation and its effect on the toughness of two different types of ductile irons was studied. Firstly, it was found that the addition of 4 wt. \% Co reduces carbides in thin sections with a silicon level around 2.41 wt.\% Si. Secondly, partial substitution of silicon with $2 \mathrm{wt} . \%$ and $3 \mathrm{wt} \%$ Co provided higher strength in a 600-10 SSFDI grade. Nonetheless, the impact strength and fracture toughness were not improved with cobalt additions. It was established that cobalt increases the ductile to brittle transition temperature. 


\section{Introduction}

\subsection{Cast Iron Overview}

Cast irons are ferrous alloys known for their excellent castability, machinability, and lowcost production. Cast iron is considered one of the oldest engineering materials that are continuously evolving despite the growing competition for new materials. These alloys are mainly composed of iron, carbon, and silicon. The carbon contents are above $2 \mathrm{wt} . \%$ C, typically around $3.6 \mathrm{wt} . \% \mathrm{C}$ and silicon contents above $2 \mathrm{wt} . \% \mathrm{Si}$. Carbon is present either as graphite (pure carbon-stable) or cementite ( $\mathrm{Fe}_{3} \mathrm{C}$-metastable). Besides that, elements such as manganese, copper, nickel, aluminum, molybdenum are added in small quantities to modify the metallic matrix, and therefore the mechanical properties. Figure 1.1 shows the metastable iron-iron carbide phase diagram, where the cast iron section has been highlighted with the use of annotations.

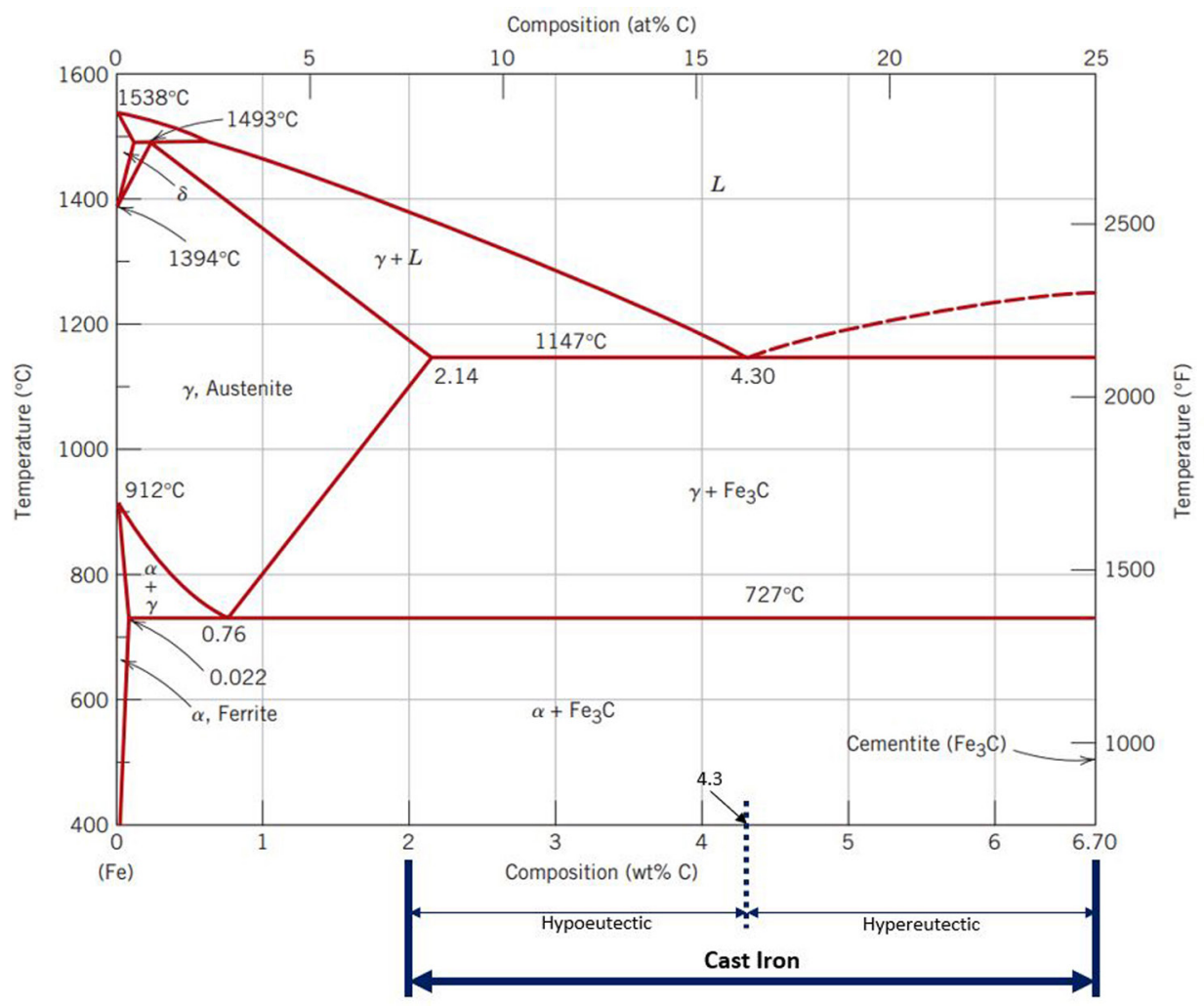

Figure 1.1 Iron-Iron carbide phase diagram showing the range of cast irons [1]. 
Cast iron is classified based on its graphite shape. In cast iron, the stable form of carbon precipitates as graphite, which are weak and soft particles with different shapes embedded in a metallic matrix. Table 1.1, provides the carbon and silicon ranges of the different types of cast irons, as well as the eutectic product (stable or metastable) and the graphite shapes.

Table 1.1 Cast iron compositions (wt.\%) and microstructures [2]

\begin{tabular}{ccccc}
\hline Type of Iron & $\mathbf{C}$ & $\mathbf{S i}$ & $\begin{array}{c}\text { Eutectic Product } \\
\text { (Graphite vs } \\
\text { Fe3C) }\end{array}$ & Graphite Shape \\
\hline Grey Iron & $2.5-4.0$ & $1.0-3.0$ & Graphite & Platelets \\
\hline Ductile Iron & $3.0-4-0$ & $1.8-2.8$ & Graphite & Spheres \\
\hline Malleable Iron & $2.0-2.6$ & $1.1-1.6$ & $\mathrm{Fe}_{3} \mathrm{C}$ & Popcorn \\
\hline White Iron & $1.8-3.6$ & $0.5-1.9$ & $\mathrm{Fe}_{3} \mathrm{C}$ & Rods \\
\hline Compacted Iron & $3.0-4.0$ & $1.8-2.8$ & Graphite & \\
\hline
\end{tabular}

It is important to highlight that the graphite shapes will also provide different mechanical properties, this is another reason why cast irons have a wide variety of applications. The three types of cast irons that are most used nowadays are grey, compacted, and ductile iron (Figure 1.2).
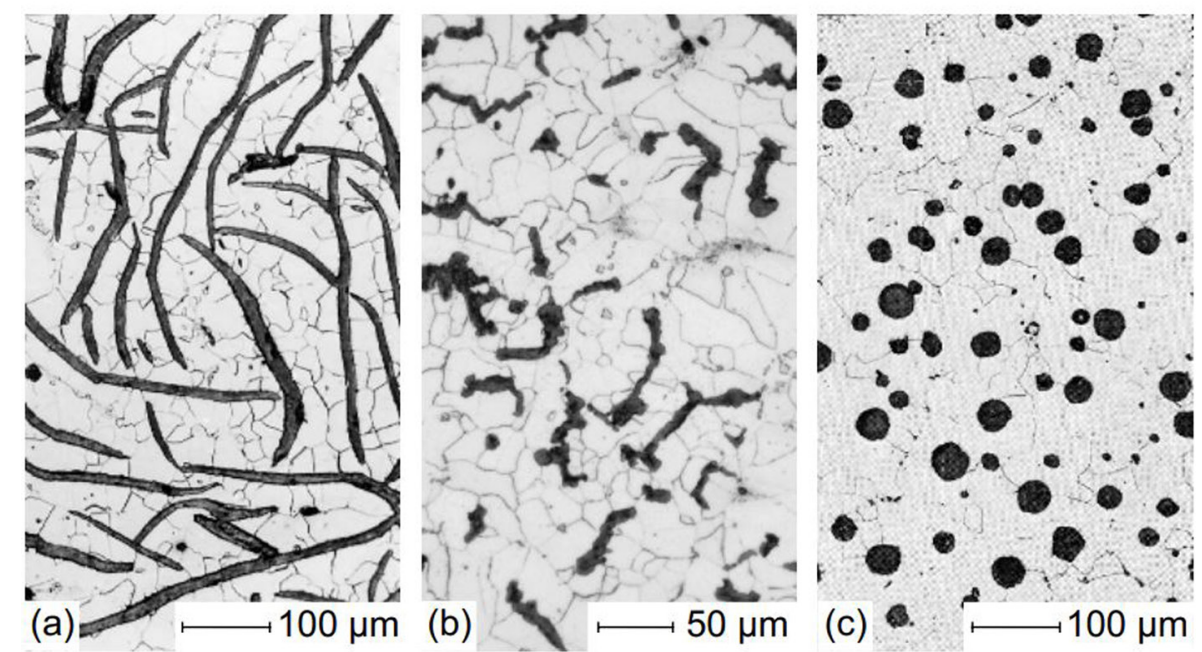

Figure 1.2 Micrographs of typical cast iron types: (a) grey iron, (b) compacted iron, and (c) ductile iron [3]. 
As previously mentioned, the graphite shape plays an important role in the tensile properties of cast irons. Ductile iron consists of graphite spheroids that are dispersed in a matrix of ferrite, pearlite, or both, providing the highest tensile strength. The round shape of the graphite nodules is also beneficial to mitigate crack nucleation/stress concentrations acting like crack arrestors. Meanwhile, grey iron results in the lowest tensile strength since the graphite flakes are sharper, which results in high local stresses at the graphite tips. Lastly, compacted graphite iron results in intermediate strengths because the vermicular graphite tips are blunted [4]-[6]. Figure 1.3 shows the beforehand discussed influence of graphite shape on the tensile behavior.

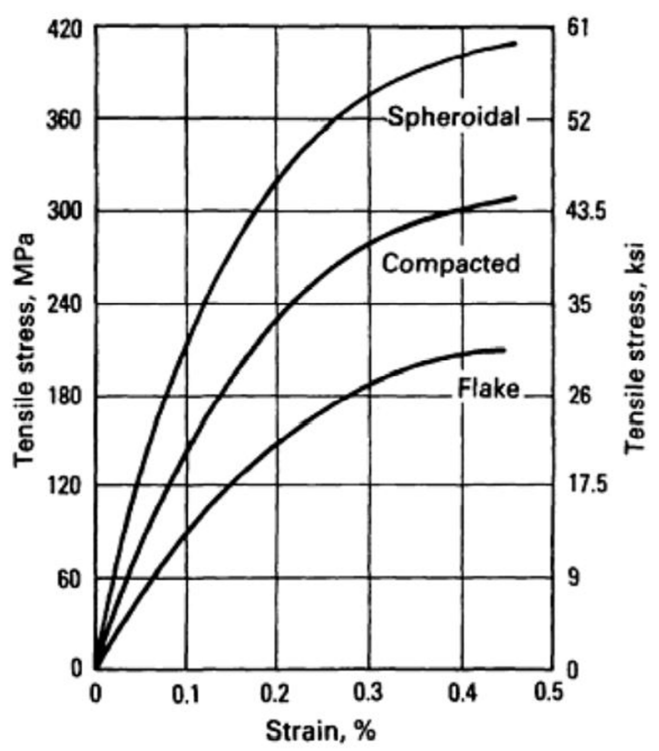

Figure 1.3 Influence of graphite morphology on the stress-strain curve of several cast irons [7].

\subsection{Brief background of Ductile Iron}

Ductile iron or nodular cast iron (also known as spheroidal graphite iron in Europe) was born in 1943 when Keith Dwight Millis added magnesium (as a copper-magnesium alloy) to the ladle, which resulted in graphite spheres [8]. Later in 1948, Henton Morrogh from the British Cast Iron Research Association (BCIRA) announced the successful production of ductile iron with cerium additions [9]. 
Chemical composition is one of the main factors that play a significant role in the final microstructure of ductile iron. The solidification of this material can follow two different paths: (a) stable transformation of austenite to a mixture of ferrite and graphite or (b) metastable transformation of austenite to pearlite. Besides that, adding silicon to ductile iron introduces a three-phase region (ferrite + austenite + graphite or ferrite + cementite + austenite). An example of the effect of silicon on the Fe-C phase diagram is shown in Figure 1.4.

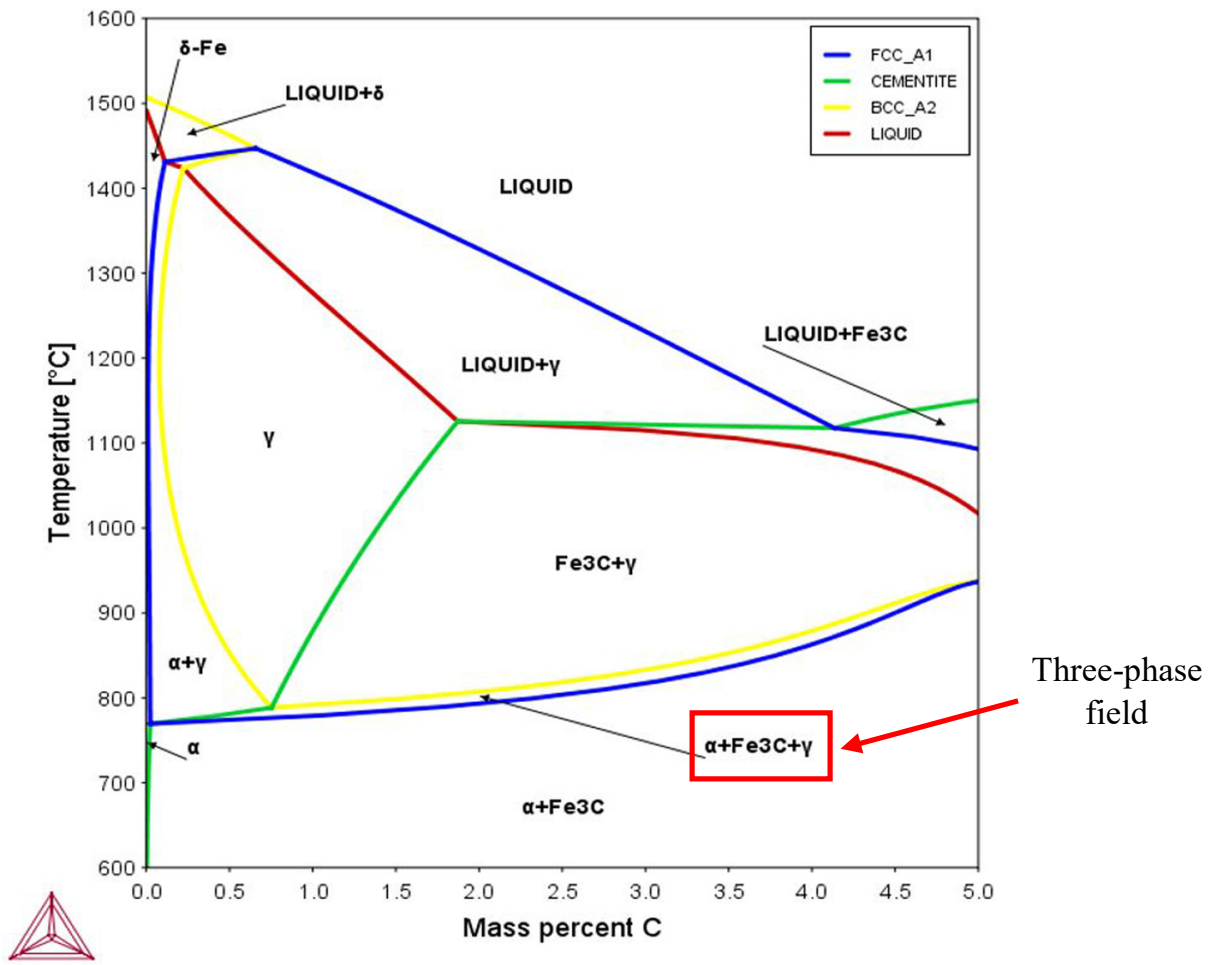

Figure 1.4 Thermo-Calc Fe - C - 2.5 wt.\% Si metastable phase diagram.

When thinking about the solidification of ductile iron and its resulting microstructure, the main elements that influence the composition of the melt are carbon and silicon. Thus, the term carbon equivalent $(\mathrm{CE})$ has been adopted where the most used relationship is given by:

$$
C E=\% C+\frac{1}{3} \% S i
$$


Depending on the above relationship, ductile iron can be classified as eutectic $(\mathrm{CE}=4.3)$, hypoeutectic $(\mathrm{CE}<4.3)$, or hypereutectic $(\mathrm{CE}>4.3)$. The combined effects of these two elements may be described using the Henderson diagram shown in Figure 1.5. This diagram provides some guidelines for metallurgists in terms of knowing the best range of $\mathrm{CE}$ for ductile iron production. Basically, this diagram gives the $\mathrm{CE}$ values necessary to avoid carbides, shrinkage, and graphite flotation, which are detrimental to the mechanical properties of ductile iron [10]-[12]. It is important to point out from this diagram the negative effect of high silicon contents, which results in high impact transition temperatures.

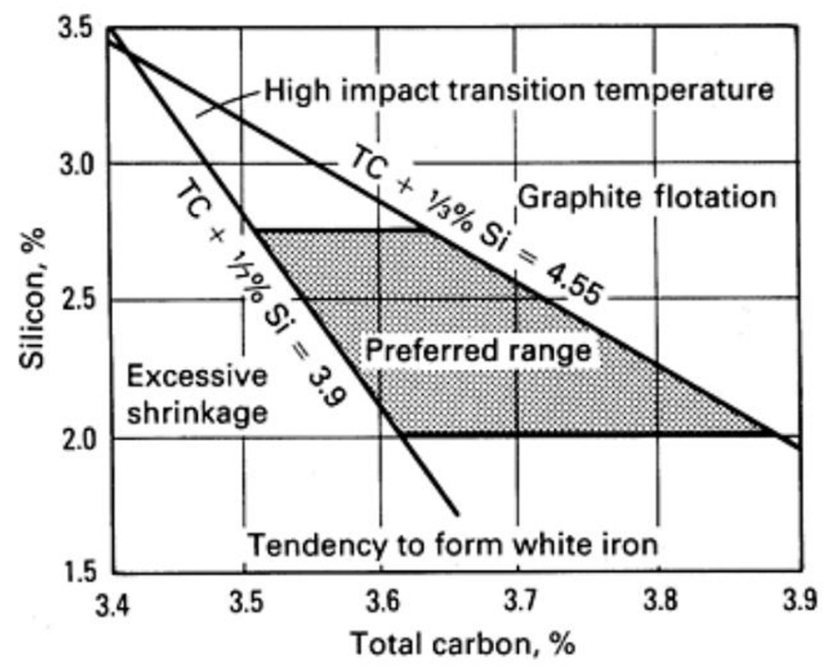

Figure 1.5 Typical range for carbon and silicon contents for ductile irons [7].

Ductile iron is not a single material, but rather it is considered a family of materials since it offers a wide variety of properties that are obtained through microstructure control. This control of the microstructure depends mainly on molten metal processing, chemical composition, cooling rate, and heat treatment. Figure 1.6 displays the most common ductile iron types with their respective names and tensile strengths. These grades have in common the spherical graphite shapes, also known as graphite nodules. Additionally, the 
name of these grades depends on the final matrix that forms upon cooling or heat treatment.

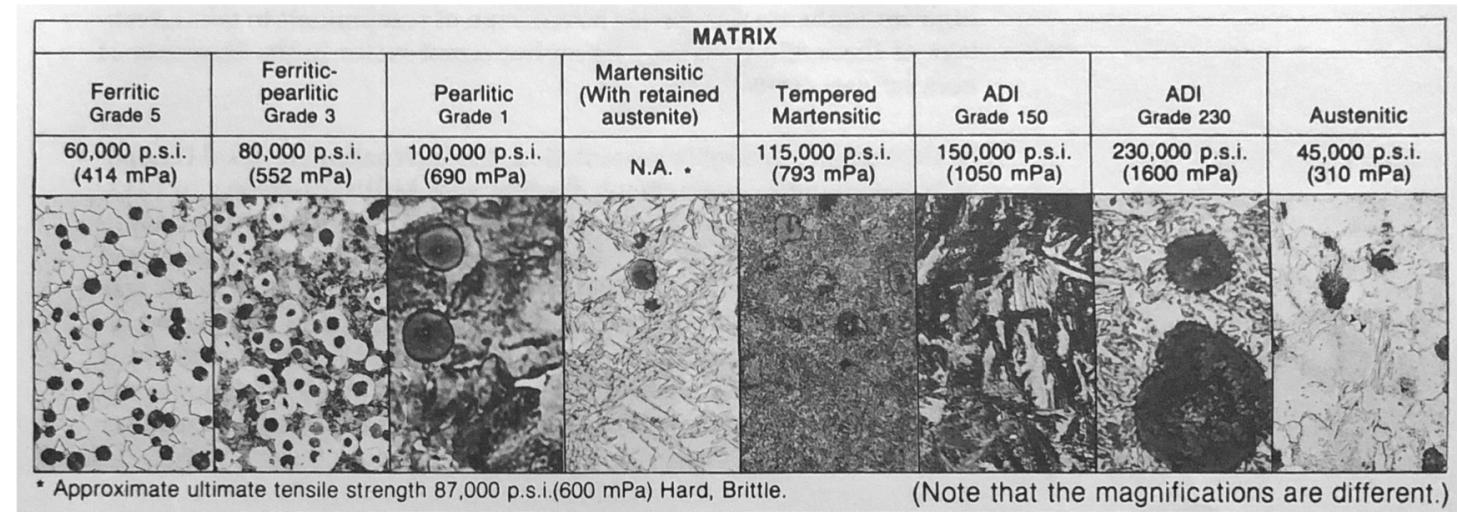

Figure 1.6 Microstructure and tensile strengths for various types of ductile iron [13].

\subsection{Thin-Wall Ductile Iron}

The transportation industry accounts for $14 \%$ of global greenhouse gas (GHG) emissions [14]. The international energy agency (IEA) suggests that global transport emissions should be reduced by more than 34\% of current levels by 2050 to reduce global warming [15]. Due to this, there is a high interest in the automotive industry to reduce the weight of the vehicles to contribute to a lower percentage of $\mathrm{CO}_{2}$ emissions and meet the established fuel economy standards. Reducing the weight of a vehicle by $10 \%$ in mass leads to a $2-4 \%$ enhancement in fuel economy and a corresponding reduction in $\mathrm{GHG}$ emissions [16].

Ductile iron is strong, tough, and cost-effective, but is usually not considered a lightweight material. Consequently, the ferrous industry has invested in the optimization and development of thin-wall ductile iron (TWDI) castings with sections below $5 \mathrm{~mm}$. The greatest challenge in the production of TWDI castings that most of the industry faces is the presence of carbides due to the high cooling rates. The best TWDI manufacturing techniques (using high purity charge materials and inoculating at several stages of the melting process) have been studied for years, where the main objective is obtaining 
carbide-free castings. As observed in the Henderson diagram (Figure 1.5), one of the most common ways to mitigate carbide formation is to increase the silicon content. This happens because silicon is a strong graphitizing element that increases the $\Delta \mathrm{T}$ between the stable and metastable eutectics, promoting graphite nucleation and growth [10], [17]. Nonetheless, one of the drawbacks of high silicon contents is a reduction in the impact toughness. As observed in Figure 1.7, increasing the silicon content results in an increase of the Ductile to Brittle Transition Temperature (DBTT) and a reduction in the upper shelf impact energy. The addition of $2 \mathrm{wt} . \% \mathrm{Si}$ to a bainitic steel has been found to suppress dislocation cross-slip resulting in cleavage fracture and a high DBTT. Emphasizing that this material experiences a ductile behavior at $100^{\circ} \mathrm{C}$ because, at high temperatures, thermal activation increases dislocation mobility, which means that crossslip of screw dislocations is allowed [18].

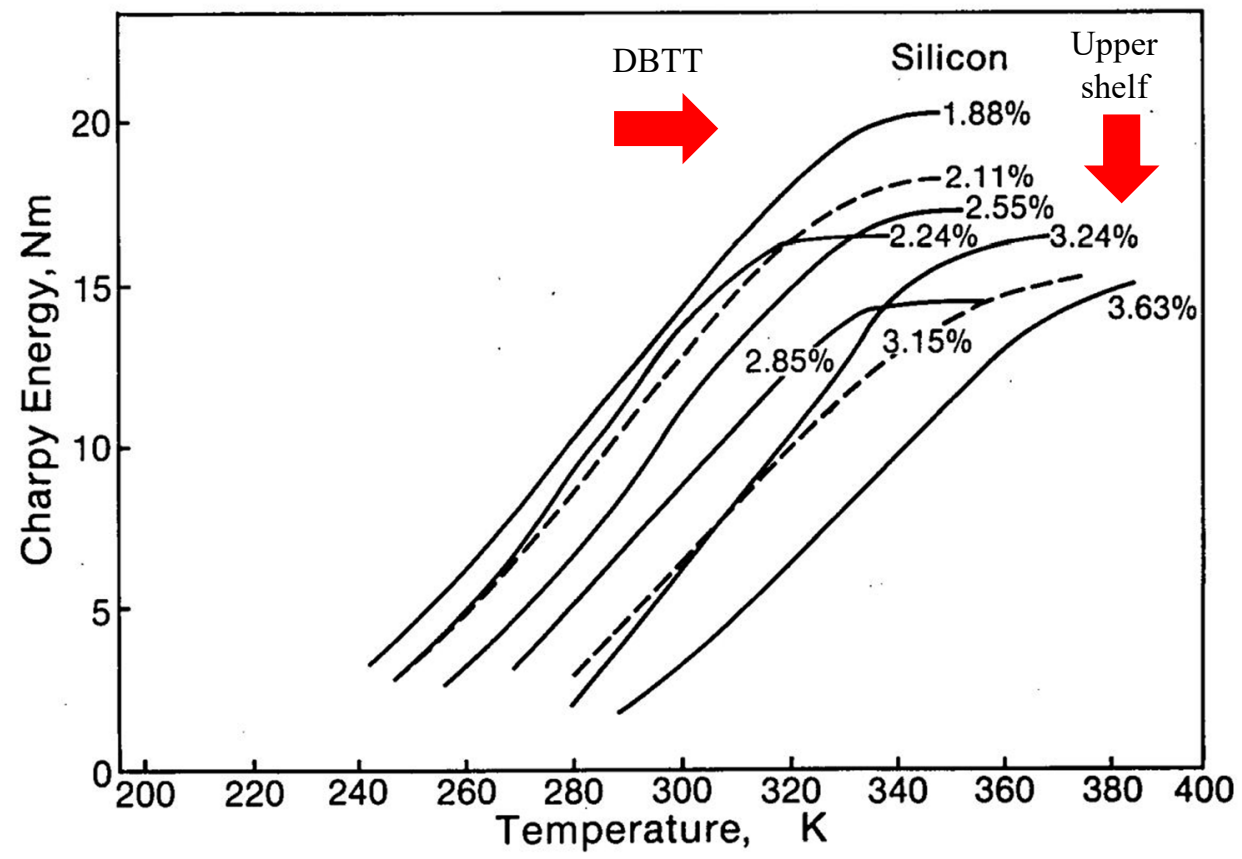

Figure 1.7 Influence of silicon content DBTT of ferritic ductile iron [19]. 


\subsection{Solid Solution Strengthened Ferritic Ductile Irons}

Solid Solution Strengthened Ferritic Ductile Iron (SSFDI) emerged from the need to find a material that had a good combination of strength and elongation, which was not possible with the traditional ferritic-pearlitic ductile iron grades (first generation of the ductile iron family). The first attempt of increasing the strength of ductile iron using high silicon contents goes all the way back to the late 1950s. White et al. found that additions of 4 wt.\% and $5 \mathrm{wt} . \%$ Si to ductile iron resulted in high tensile strength and Brinell hardness [20]. Nonetheless, it was not until 2012 when three SSFDI grades were added to the European standard DIN EN 1563. The silicon values of these second-generation grades and their tensile properties are given in Table 1.2.

Table 1.2 Silicon content and tensile properties for wall thicknesses below $30 \mathrm{~mm}$ in SSFDI grades [21]

\begin{tabular}{ccccc}
\hline $\begin{array}{c}\text { SSFDI } \\
\text { GRADE }\end{array}$ & $\begin{array}{c}\text { Si } \\
\text { (wt.\%) }\end{array}$ & $\begin{array}{c}\text { Tensile } \\
\text { Strength, } \\
\text { MPa }\end{array}$ & $\begin{array}{c}\text { 0.2\% Proof } \\
\text { Strength, } \\
\text { MPa }\end{array}$ & $\begin{array}{c}\text { Elongation } \\
\text { (\%) }\end{array}$ \\
\hline EN-GJS-450-18 & 3.20 & 450 & 350 & 18 \\
\hline EN-GJS-500-14 & 3.80 & 500 & 400 & 14 \\
\hline EN-GJS-600-10 & 4.30 & 600 & 470 & 10 \\
\hline
\end{tabular}

As previously mentioned, silicon is a graphitizing element that promotes ferrite. Silicon is also an efficient element for hardening ferrite via solid solution strengthening. The high silicon content in these second-generation grades results in a fully ferritic matrix with a unique combination of high strength and high elongation in the as-cast condition. Previous studies have found that when silicon content is above $4.3 \mathrm{wt} . \% \mathrm{Si}$, the tensile strength and elongation decrease due to embrittlement of the ferrite [22], [23], but the use of these SSFDI grades is still limited due to the damaging effect of high silicon on the impact toughness discussed in the previous section. 


\subsection{Motivation and Research Objectives}

The motivation of this research arises from the idea of manufacturing carbide-free TWDI castings with an alloying element that stabilizes ferrite, resulting in an as-cast ferritic matrix with low silicon contents. Thus, evaluating the potential of this element in improving the impact strength of this material. Due to the detrimental effect that high silicon contents have on the impact properties of SSFDI grades, the quest for an element that assists in the partial substitution of silicon is of great interest. The main objective is not sacrificing the high strength and elongation of these grades and improving the impact and fracture toughness properties.

The objectives of this research work are as follows:

- To evaluate the effect of cobalt on the microstructure and tensile properties of thin wall ductile iron castings.

- To investigate the possibility of lowering the silicon content in a 600-10 SSFDI grade by partial substitution of the silicon with cobalt as an alternative strengthening element to improve the impact properties while maintaining high strength and elongation.

- To perform a full assessment of the impact strength and fracture toughness of ductile iron with low and high silicon contents alloyed with cobalt.

\subsection{Hypotheses}

Two hypotheses were developed for this research project:

1. If cobalt is added to TWDI, then carbides will be reduced because cobalt enhances the carbon diffusion rate, which increases the nodule count decreasing the internodular spacing between the graphite nodules and reducing the diffusion path of carbon, resulting in more ferrite.

2. If silicon content is lowered in SSFDI, then cobalt can partially substitute for silicon without sacrificing the static properties because cobalt hardens the ferrite. 


\section{Literature Review}

\subsection{Production of TWDI}

The manufacturing of TWDI castings requires careful attention to the entire molten metal processing conditions, which makes it very complex. For this reason, there is an enormous amount of literature that focuses on different melting methods to fabricate TWDI castings. To produce TWDI castings without defects such as micro-shrinkage, graphite alignment, or carbides it is necessary to consider three main things:

1. Chemical composition and type of metallic charge.

2. Inoculation of the molten metal (pre-conditioning, inoculation, and postinoculation of the melt).

3. High cooling rates of thin sections.

The most common practices found by different researchers to mitigate carbide formation in thin sections include the use of several inoculation steps that increase the number of nuclei sites for graphite during solidification, which results in higher nodule counts that favor the formation of ferrite. Javaid et al. showed that several inoculation steps were more effective in producing high nodule counts, which led to an increase in the ferrite content in 3 and $12 \mathrm{~mm}$ sections [24]. Plates ranging from 1.5 to $7 \mathrm{~mm}$ thick produced with one inoculation step resulted in higher carbide contents, which highlights the importance of having a highly inoculated molten metal [25].

Loper describes the factors that influence the development of high nodule counts, which are carbon equivalent $(\mathrm{CE})$, section thickness, magnesium treatment, post-inoculation, variation in time, and temperature cycle. Even though high $\mathrm{CE}$ values are required to increase the nodule count, this can result in graphite flotation. Long holding times should be avoided because they result in magnesium and inoculant fading effects [26], [27]. For a $2 \mathrm{~mm}$ section, carbides disappeared with a CE above 4.80 and a nodule count of around 3000 nodules $/ \mathrm{mm}^{2}$. Having high nodule counts in thin sections assists with carbide reduction due to a decrease in the diffusion path of carbon to the graphite nodules [28]. 
However, high nodule counts are known to decrease the upper shelf energy when changing the nodule count from 220 to 1700 nodules $/ \mathrm{mm}^{2}$ [29]. So, depending on the final application of the casting, this must be considered.

A key to avoid carbides is having a high nodule count, which as described by Loper, can be achieved by modifying the $\mathrm{CE}$ and the amount of inoculant added to the melting procedure. Mampaey and $\mathrm{Xu}$ used a nucleation model to determine the minimum nodule count and silicon content needed to avoid carbides in a $3 \mathrm{~mm}$ section, which was experimentally validated. A nodule count above $3000 / \mathrm{mm}^{2}$ with a $2.5 \mathrm{wt} . \% \mathrm{Si}$ is needed to avoid carbides [30]. Additionally, Labrecque and Gagné produced a $3 \mathrm{~mm}$ thick section without carbides and a nodule count of around 1400 nodules $/ \mathrm{mm}^{2}$. This was possible due to post-inoculation steps that increased the nucleation potential of the metal. This section was produced with a $\mathrm{CE}$ of $4.79 \%$ (3.78 wt.\% C and 3.05 wt.\% Si) using a metallic charge composed of $80 \mathrm{wt} . \%$ high purity iron and $15 \mathrm{wt} \%$ steel added to the furnace [31]. The type of metallic charge plays a significant role in the achievement of carbide-free castings because most of the carbide forming elements are introduced in the steel scarp used to produce ductile iron. For this reason, most of the research done at the beginning used a high purity metallic charge, but the cost of these types of charges makes it an unreasonable method for industry use. So, the quest for cost-effective melting practices to further manufacture this type of castings is continually under development.

Another factor that needs to be considered is the high cooling rates, which will have a direct impact on the as-cast structure along with the mechanical properties. A carbidefree $3 \mathrm{~mm}$ section was produced with the use of insulating sand that assisted in providing a slower cooling rate [32]. Javid et al. observed how different molding materials alter the high cooling rates, which are directly related to the carbide formation. Chemically bonded and shell molds resulting in the most effective binder systems to eliminate carbides in 1 and $1.5 \mathrm{~mm}$ sections [33]. Górny and Tyrala found that the cooling rate in TWDI castings ranges from $80-15^{\circ} \mathrm{C} / \mathrm{s}$ when changing the wall thickness from 2 to $5 \mathrm{~mm}$. These high cooling rates were accompanied by low ferrite contents [34]. Thin castings 
result in more pearlite due to the high cooling rates, which do not allow carbon diffusion to the nodules both before and during the eutectoid transformation [35].

Based on the above literature, it can be stated that the main causes of carbide formation in TWDI castings are as follows:

1. High cooling rates

2. Low CE values and/or silicon content

3. Insufficient inoculation

4. Long holding times in the furnace (burning of the nuclei sites available)

5. Magnesium contents above 0.040 wt. $\%$ exert a powerful tendency to promote carbide formation in thin sections.

\subsection{Alloying elements}

The mechanical properties of ductile iron can be determined based on the ratio of ferrite and pearlite in the matrix, and the alloying elements play a significant role in this final ratio. Ductile iron can solidify as stable with the phases austenite $(\gamma)$ and graphite $(\mathrm{G})$ or as metastable with the phases austenite $(\gamma)$ and carbide $\left(\mathrm{Fe}_{3} \mathrm{C}\right)$. The temperature difference between stable and metastable eutectics $(\Delta \mathrm{T})$ for Fe-C alloys is normally around $4^{\circ} \mathrm{C}[2]$. As observed in Figure 2.1, some elements increase or decrease the $\Delta \mathrm{T}$ between the stable and metastable eutectics, which changes the solidification conditions promoting different types of matrix. If the temperature during solidification drops below the metastable temperature, the solidification will change from stable to metastable. An addition of $2 \mathrm{wt} . \% \mathrm{Si}$ increases the $\Delta \mathrm{T}$ by $30^{\circ} \mathrm{C}$ [2], emphasizing why silicon is commonly added to ductile iron to avoid carbide formation. 


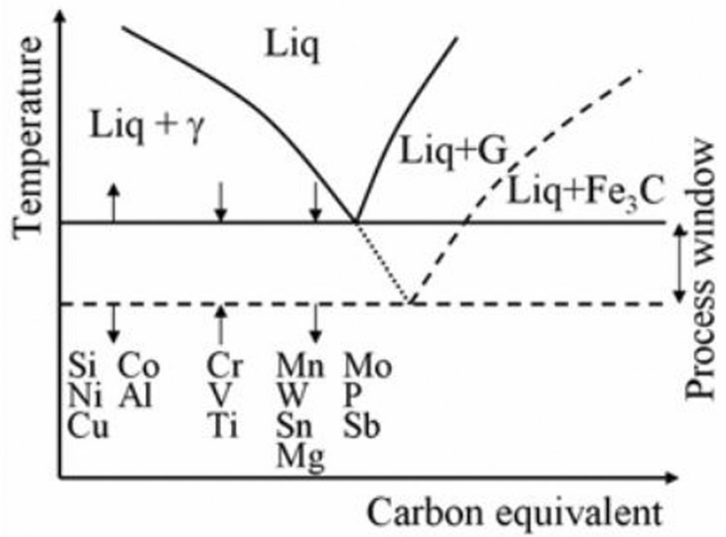

Figure 2.1 Influence on different alloying elements on the stable and metastable eutectic temperature [36].

The effects of the commonly added alloying elements and those elements that come from the production and/or metallic charge in ductile iron are outlined below:

\subsubsection{Copper}

Copper is an austenite stabilizer that promotes pearlite formation, which most of the time is added to increase the tensile and yield strength as well as hardness. This increase in ascast strength and hardness is caused by pearlite refinement, but $\mathrm{Cu}$ decreases ductility, impact resistance, and increases the DBTT [10], [37]-[43].

\subsubsection{Nickel}

Nickel is also an austenite stabilizer, but it weakly promotes pearlite. Yet, if an as-cast ferritic matrix is desired, then Ni should be avoided. Nickel is normally added to provide hardenability and for low-temperature applications where silicon content is low (1.5 wt.\% $\mathrm{Si}$ ) to provide strength. It increases the $\Delta \mathrm{T}$ between stable and metastable eutectics reducing carbides [10], [37], [39], [40], [42]-[45]. 


\subsubsection{Manganese}

Manganese is an austenite stabilizer but is five times more effective in promoting pearlite than nickel. It significantly increases the as-cast tensile properties and is used to provide hardenability. The Mn content should be controlled in thick sections because it segregates to form intercellular carbides [10], [37]-[41].

\subsubsection{Molybdenum}

Molybdenum lowers the stable and metastable eutectic temperatures, but it is a ferrite stabilizer because it increases the eutectoid temperature. In annealed ferritic ductile iron grades, it increases the yield strength and hardness by solid solution hardening of ferrite. Despite this, molybdenum is considered a mild carbide forming element that results in intercellular carbides in thick sections. Contents of $0.5 \%$ can result in grain boundary carbides, which is enhanced in the presence of other carbide forming elements such as $\mathrm{Cr}$, Mn, and V [10], [37], [39], [40], [42], [43], [46].

\subsubsection{Chromium}

Chromium is an extremely potent carbide forming element. This element is normally an impurity in the metallic charge used to produce ductile iron, so it is important to control the charge materials. Tolerance of this harmful element varies with the type of ductile iron being fabricated [10], [37], [39].

\subsubsection{Vanadium}

Vanadium is another carbide promoting element, which also comes from the metallic charge (normally from the steel scrap). Contents above $0.02 \%$ result in a large amount of carbides, which results from a reduction between stable and metastable eutectics as observed in Figure 2.1 [10], [37], [39].

\subsubsection{Titanium}

Titanium normally comes from the pig iron and steel (used for the metallic charge). It is known that thin sections can tolerate up to $0.07 \%$, but thick sections show a detrimental 
effect at $0.02 \%$. This element hinders spheroidal graphite growth and causes vermicular graphite formation [10], [37], [39].

\subsubsection{Aluminum}

Aluminum comes mostly from inoculants used and promotes vermicular graphite but to a lesser extent than Ti. This element is known to cause hydrogen pinhole defects [10], [37], [39].

\subsubsection{Phosphorus}

The segregation of phosphorus produces a brittle phosphide (steadite) network, which results in lower ductility and toughness. An increase in DBTT was found at $0.8 \% \mathrm{P}$. However, phosphorus increases the yield strength and hardness due to the stabilization and refinement of pearlite [10], [37], [47].

\subsubsection{Magnesium}

Magnesium is added in the treatment of ductile iron, which results in spherical graphite nodules. Depending on the sulfur content, the magnesium content to produce spheroidal graphite structures can vary from 0.02 to $0.06 \%$. If the final magnesium in solution is above $0.06 \%$ there is a tendency to form carbides but in thin sections $\mathrm{Mg}$ should be kept below $0.040 \%$ [7], [10], [37], [39], [48].

\subsubsection{Tin}

Tin is a pearlite promoter with ten times the effectiveness of copper. Tin accumulates around the graphite nodules acting as a barrier for carbon diffusion, which inhibits ferrite formation. A content above $0.1 \%$ thickens and embrittles the layer around the graphite nodule, which becomes detrimental to ductility [10], [37], [39], [49].

\subsubsection{Antimony}

Antimony is another section-size-sensitive element that tends to segregate to the intercellular regions forming mesh-type flake graphite. Its content is limited to a 
maximum of $0.04 \%$ in thick sections. Antimony is a strong pearlite promoter and should be avoided if a fully ferritic matrix is desired [10], [37], [49].

\subsubsection{Cobalt}

The first studies that examined the role of cobalt as an alloying element were carried out on steels. A summary of these findings is provided below:

- In 1942, Smoluchowski, who worked at GE Research laboratory, which was a well-respected place to perform physical metallurgy, found by the Grube method that and addition of around 4\% Co doubles the diffusion rate of $\mathrm{C}$ in $\gamma$-Fe [50]. The above supports the idea that if cobalt is increasing the diffusion of carbon, there will be more carbon out of solution, and then there will not be as much carbon left for pearlite formation.

- Brown and Hawkes studied the effect of alloying elements on carbide stability. They postulated that graphitizing elements such as cobalt and nickel in solution expand the iron lattice and reduce cementite stability. On the other hand, chromium contracts the iron lattice stabilizing cementite [51].

- Appleton investigated the kinetics of graphitization in $\mathrm{Fe}-\mathrm{C}$ and $\mathrm{Fe}-\mathrm{Co}-\mathrm{C}$ alloys using dilatometric and microscopic techniques. He found that cobalt increases the graphite growth rate [52].

- Solov'ev and Kuragin evaluated the influence of cobalt on the graphitizing effect in Fe-C-X alloys. They discovered that cobalt increased the activity and mobility of carbon atoms promoting graphite growth [53].

- Srinivas, Malakondaiah, and Rama Rao found that Fe-Co alloys (0.5 wt.\% and $5 \mathrm{wt} . \% \mathrm{Co}$ ) resulted in lower yield strength but no effect on the tensile strength compared to the base material unalloyed ARMCO Iron. In contrast 
to molybdenum, nickel, and silicon, cobalt significantly increased the fracture toughness $\left(\mathrm{J}_{\mathrm{IC}}\right)[54]$.

- Cobalt restricts dislocation cross-slip in maraging steels, which increases the DBTT [55], [56].

\subsubsection{Effect in traditional ferritic-pearlitic grades}

The research conducted on first-generation irons alloyed with cobalt is outlined below:

- Thury, Hummer, and Nechtelberger were the first ones to add cobalt to ductile iron in 1967. They observed an increase in the ferrite content with $2 \% \mathrm{Co}$, but the tensile and yield strength did not increase substantially, and a small drop in elongation was found. A decrease in the notched impact strength with cobalt additions at room temperature, -20 , and $-40^{\circ} \mathrm{C}$ was detected [57].

- Modl investigated cobalt additions from 0 to $15 \mathrm{wt} . \%$ Co and observed that the yield strength and hardness increased steadily with the addition of cobalt up to 15 wt.\% Co. However, elongation decreased sharply above 6 wt.\% Co. Cobalt additions resulted in smaller nodule sizes [58].

- The study by Shen, Harris, and Noble studied ductile irons containing 0.07 wt.\% and 0.34 wt.\% Co. They found an improvement in the graphite shape with cobalt additions, along with an increase in the nodule size and a decrease in the nodule count [59].

- Yazdani, Bayati, and Elliot investigated the influence of two cobalt concentrations ( $0.20 \mathrm{wt} . \%$ and $0.40 \mathrm{wt} . \% \mathrm{Co})$ in the austempering reaction in austempered ductile iron (ADI). They observed that cobalt accelerates the stage I reaction, reducing the time needed for austempering enabling the heat treatment of heavy sections [60]. 
- Chen-Hsun Hsu, Chen, and Hu found an increase in mechanical properties such as tensile strength, yield strength, impact strength, and impact toughness with the addition of $4 \mathrm{wt} . \%$ Co. No increase in the percent nodularity was observed, but the nodule count was increased substantially [61].

- Duwe and Tonn studied the effect of cobalt additions to increase strength and impact toughness at low temperatures. However, they did not find any improvement in the impact toughness with cobalt additions in the range of $0 \mathrm{wt} . \%$ to $3 \mathrm{wt} . \% \mathrm{Co}$ at low silicon contents (1.6 wt.\% to $2 \mathrm{wt} \% \mathrm{Si}$ ) [62].

\subsubsection{Effect in SSFDI grades}

The effect of cobalt in these second-generation ductile iron grades have lately been investigated, and the highlights of the findings are as follows:

- Okunnu was the first to alloy a 600-10 SSFDI grade with 2 and 4 wt.\% Co. With increasing cobalt, he found an increase in the percent nodularity and nodule count, with a decrease in nodule size leading to an increase in tensile strength, yield strength, elongation, and hardness [63].

- Wei $\beta \beta$, Brachmann, Bührig-Polaczek, and Fischer observed an improvement in the percent nodularity of two SSFDI grades (500-14 and 600-10) with 2 and 4 wt.\% Co, but cobalt did not significantly increase the nodule count [64], [65].

- Fischer, Brachmann, Bührig-Polaczek, and Weißß found a meaningful increase in tensile strength for 500-14 and 600-10 SSFDI grades with 2 and 4 wt.\% Co additions, but only a small increase in the yield strength. For the 600-10 SSFDI grade, elongation decreased $22 \%$ with 2 wt. $\%$ Co and 50\% with 4 wt. $\%$ Co [66].

- González-Martínez, Sertucha, and Lacaze recently determined that high silicon and high cobalt contents lead to the embrittlement of ferrite decreasing the 
ductility of these grades. They attributed this reduction in tensile properties to the presence of ordered phases [67].

\subsection{SSFDI Advantages and Limitations}

\subsubsection{Graphite Morphology}

The negative effect of high silicon contents in SSFDI grades is graphite degeneration. González-Martínez et al. found that as silicon was increased, the amount of degenerated graphite and tendency to form chunky graphite was greater [68]. Similarly, Bauer et al. mentioned that as silicon is increased, the chunky graphite area fraction grows. And above 4 wt.\% Si chunky graphite is observed even for thin sections [69].

As mentioned in Chapter 1, graphite morphology exerts a great influence on the mechanical properties of ductile iron. However, C. Hartung reported that the detrimental effect of the graphite shape is on elongation, while tensile and yield strength remain unaffected [70].

There are some considerations given in the EN 1563 Annex A [21] about the graphite morphology in these ductile iron grades:

1. High levels of silicon deteriorate the graphite morphology, so some vermicular graphite might be present in the final casting.

2. These SSFDI grades are less sensitive to low percent nodularity compared to the common ferritic-pearlitic grades. Therefore, SSFDI grades can tolerate down to $50 \%$ nodularity before seeing a drop in the mechanical properties, mainly due to silicon strengthening in the matrix.

\subsubsection{Mechanical Properties}

One of the main advantages of high silicon irons is that compared to the ferritic-pearlitic grades, they exhibit a more uniform hardness due to the single-phase matrix. Björkegren 
et al. found improved machinability on these grades reduced machining cost by $10 \%$ [71], [72].

SSFDI grades exhibit increased tensile strength, yield strength, and hardness with silicon additions up to $4.3 \mathrm{wt} . \%$, after which mechanical properties decline. Sets and Glavas found that when silicon content rises to $5 \mathrm{wt} . \%$, elongation was no longer measurable[22], [23]. Moreover, de la Torre et al. discovered that the optimum mechanical properties for high silicon alloys were at $3 \mathrm{wt} . \% \mathrm{Si}$. Above this silicon level, there was a continuous drop in the percent elongation and a continual decrease in impact energy [73].

Hammersberg et al. found that the tensile and yield strength increased linearly up to 5.3 wt.\% Si while the elongation decreased gradually, resulting in zero elongation at the 5.3 wt.\% Si value [74]. González-Martínez et al. observed similar behavior with a maximum tensile and yield strength around $5.2 \mathrm{wt} . \% \mathrm{Si}$. The hardness kept increasing with silicon additions up to $9.12 \mathrm{wt} . \% \mathrm{Si}$ [75].

Regardless of the different maximum silicon contents found by the previous researchers, all of them attribute the decreases in static and dynamic mechanical properties to the formation of ordered phases associated with silicon. As silicon increases above $5.2 \mathrm{wt} . \%$, the A2 phase (disordered solid solution phase) transforms into the ordered $\mathrm{B} 2$ phase (Figure 2.2). Silicon contents beyond 11 wt.\% lead to the D03 phase. The B2 and D03 ordered phases are brittle and are detrimental to the strength, ductility and impact toughness of high silicon alloys [76]-[78]. 


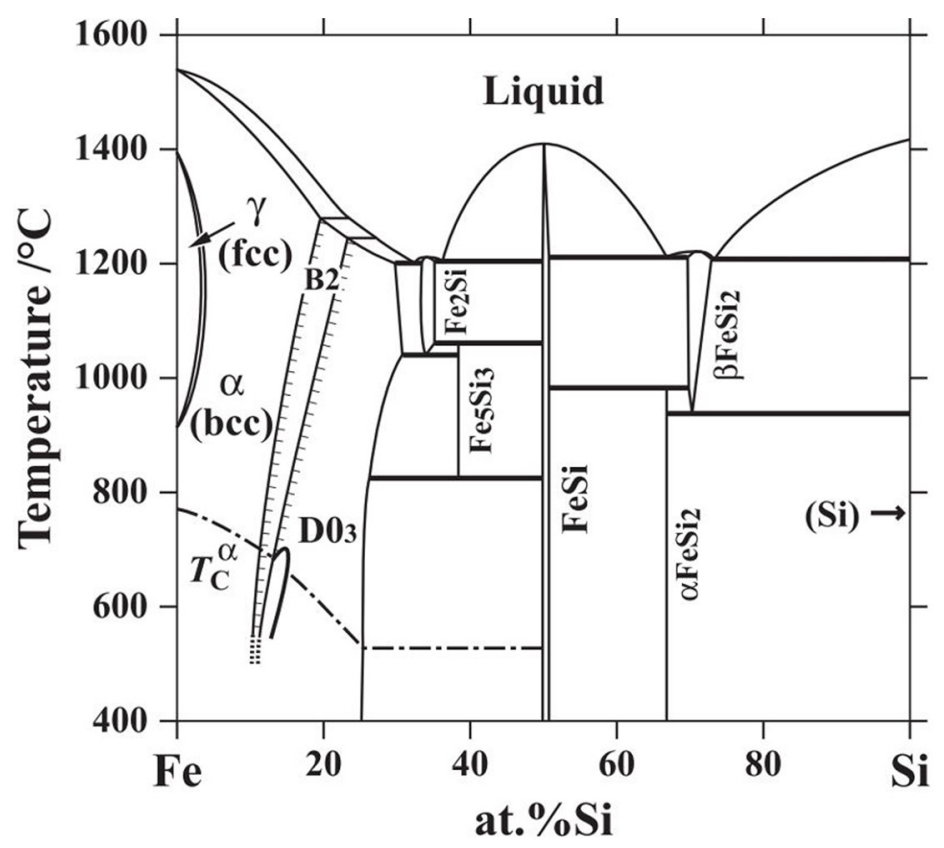

Figure 2.2 The Fe-Si system showing the formation of B2 and D03 ordered phases with increasing silicon [76]. 


\section{Experimental Procedure}

\subsection{Effect of Cobalt in Thin Wall Ductile Iron}

\subsubsection{Target Chemistry Selection and Furnace/Ladle Additions}

The objective was to produce carbide-free thin-wall ductile iron castings with lower silicon content. The target chemical composition of all heats was held constant, and only the cobalt level was varied (Table 3.1).

Table 3.1 Target chemical composition (wt.\%)

\begin{tabular}{|c|c|c|c|c|c|c|c|c|c|}
\hline Element & $\mathrm{C}$ & Si & ${ }^{\mathrm{a}} \mathrm{CE}$ & $\mathrm{Mg}$ & Mn & $\mathrm{Cu}$ & $\mathbf{P}$ & $\mathbf{S}$ & ${ }^{b} \mathrm{Co}$ \\
\hline wt. $\%$ & 3.73 & 2.50 & 4.56 & $<0.04$ & $<0.25$ & $<0.08$ & 0.025 & 0.01 & - \\
\hline
\end{tabular}

Ductile iron is extremely sensitive to trace elements, so close control of the charge materials is necessary. The metallic charge for all heats consisted of $25 \mathrm{wt}$ \% pig iron, 55 wt.\% ductile iron returns, and $20 \mathrm{wt} . \%$ steel punchings, with additions of Desulco ${ }^{\circledR}$ (recarburizer) and 75 wt.\% FeSi (Table 3.2). 
Table 3.2 Chemical composition for furnace charge materials (wt.\%)

\begin{tabular}{cccccc}
\hline $\begin{array}{c}\text { Element } \\
\text { (wt.\%) }\end{array}$ & $\begin{array}{c}\text { Pig } \\
\text { Iron }\end{array}$ & $\begin{array}{c}\text { aDI } \\
\text { Returns }\end{array}$ & $\begin{array}{c}\text { Steel } \\
\text { punchings }\end{array}$ & Desulco $^{\circledR}$ & $\mathbf{7 5 \%}$ FeSi \\
\hline $\mathrm{C}$ & 4.38 & 3.70 & 0.09 & 99.7 & 0.005 \\
\hline $\mathrm{Si}$ & 0.62 & 2.50 & 0.08 & - & 76.55 \\
\hline $\mathrm{P}$ & 0.041 & 0.031 & 0.008 & - & 0.007 \\
\hline $\mathrm{S}$ & 0.027 & 0.004 & - & 0.030 & - \\
\hline $\mathrm{Mn}$ & 0.03 & 0.29 & 0.39 & - & 0.13 \\
\hline $\mathrm{Cu}$ & 0.0005 & 0.12 & 0.024 & - & - \\
\hline $\mathrm{Ni}$ & 0.003 & 0.022 & 0.013 & - & - \\
\hline $\mathrm{Cr}$ & 0.004 & 0.17 & - & - & - \\
\hline $\mathrm{Al}$ & - & 0.02 & - & - & 0.38 \\
\hline $\mathrm{Ca}$ & - & - & - & - & 0.06 \\
\hline
\end{tabular}

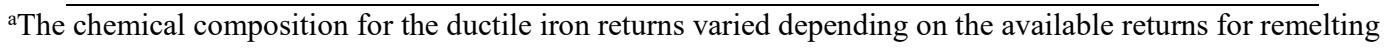

After the base metal is melted in the furnace, the $\mathrm{Mg}$ treatment is performed in a tundish ladle with a pocket that contains the nodulizer and conditioner, covered with steel. Inolate-40 is used for metal stream inoculation while tapping from the furnace to the ladle. The chemical composition of the ladle materials (Table 3.3) was considered in calculated the final alloy composition.

Table 3.3 Chemical composition of the ladle additions (wt.\%)

\begin{tabular}{ccccc}
\hline $\begin{array}{c}\text { Element } \\
\text { (wt.\%) }\end{array}$ & $\begin{array}{c}\text { 6 wt.\% } \\
\text { MgFeSi }\end{array}$ & $\begin{array}{c}\text { Cover } \\
\text { Steel }\end{array}$ & TopSeed ${ }^{\circledR}$ & Inolate-40 \\
\hline $\mathrm{C}$ & - & 0.18 & 0.094 & - \\
\hline $\mathrm{Si}$ & 45.66 & 0.15 & 49.04 & 72.54 \\
\hline $\mathrm{Mg}$ & 6.06 & - & - & - \\
\hline $\mathrm{Al}$ & 0.93 & - & 1.04 & 0.062 \\
\hline $\mathrm{Ca}$ & 0.98 & - & 0.99 & 1.24 \\
\hline${ }^{\mathrm{a} E}$ & 1.00 & - & - & 0.60 \\
\hline $\mathrm{Bi}$ & - & - & - & 0.98 \\
\hline $\mathrm{Ba}$ & - & - & 1.03 & - \\
\hline $\mathrm{P}$ & - & 0.008 & - & - \\
\hline $\mathrm{S}$ & - & 0.013 & - & - \\
\hline $\mathrm{Mn}$ & - & 0.47 & - & - \\
\hline $\mathrm{Cu}$ & - & 0.024 & - & - \\
\hline $\mathrm{Ni}$ & - & 0.013 & - & - \\
\hline & & ${ }^{2} \mathrm{RE}:$ rare earths &
\end{tabular}




\subsubsection{Mold Preparation}

Two types of molds were made using chemically bonded sand. The first mold consisted of six rectangular plates with thicknesses of 2, 2.5, 3, 3.5, 4, and $6 \mathrm{~mm}$ (Figure 3.1). Each sand mold weighed a total of 66 pounds, and 12 molds were poured per heat for 60 molds total. All the molds were clamped in sets of four and placed on the pouring line.

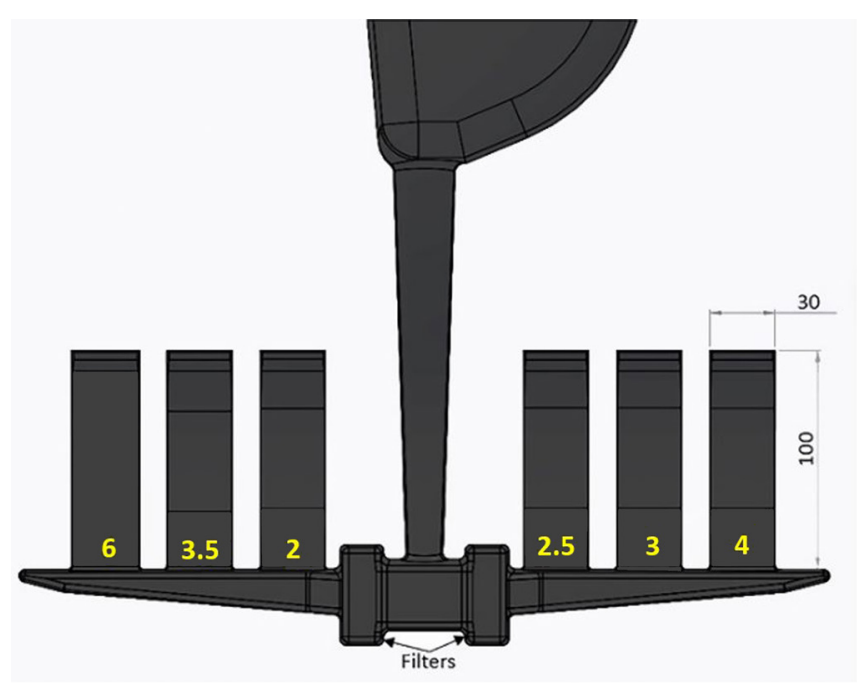

(a)

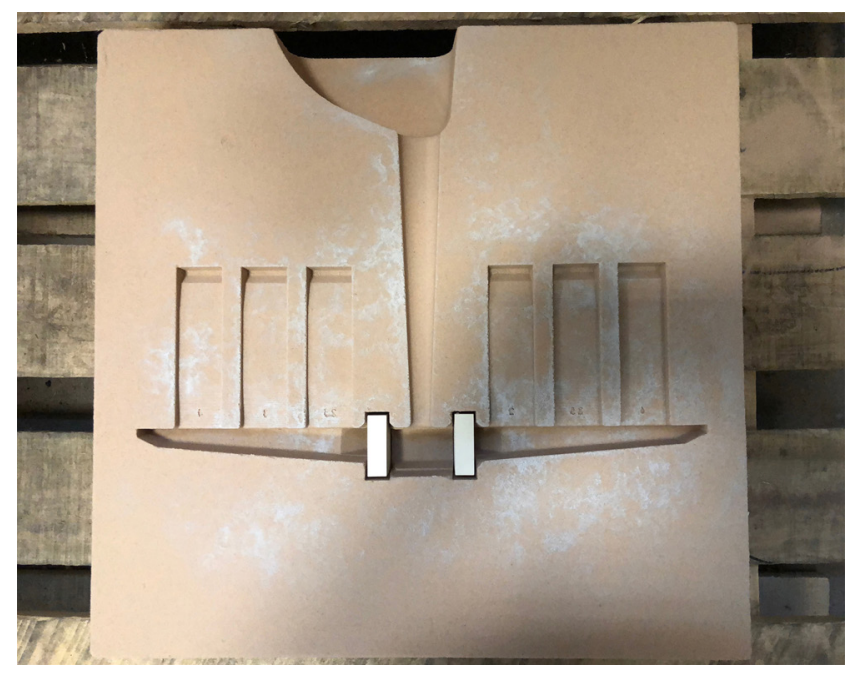

(b)

Figure 3.1 (a) CAD model illustration with dimensions (mm) [79], and (b) a finished chemically bonded mold. 
The second mold contained three ASTM A536 [80] 1/2 inch Y-blocks (Figure 3.2). Each sand mold weighs 34 pounds, and 11 molds were poured per heat for a total of 55 molds.

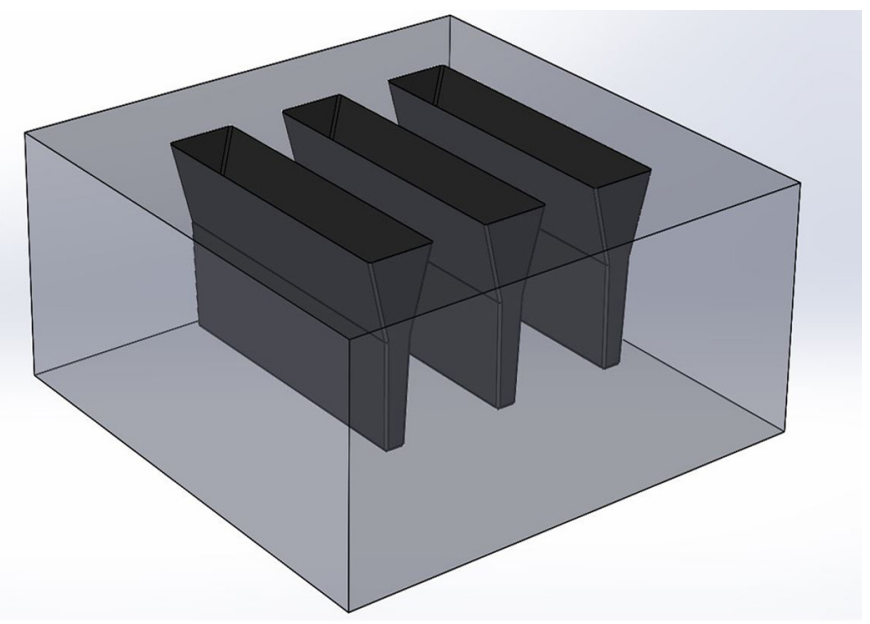

(a)

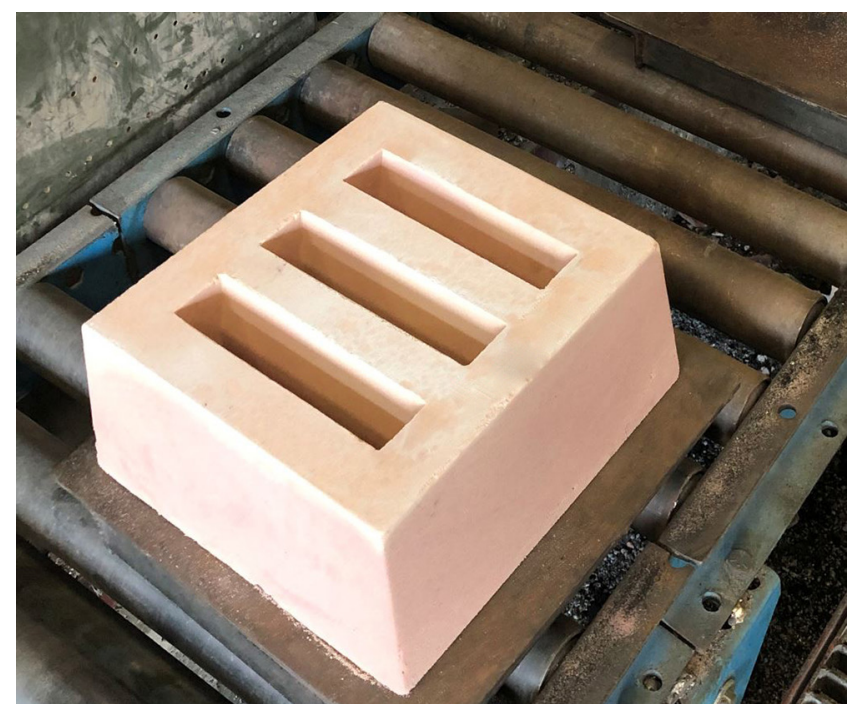

(b)

Figure 3.2 (a) CAD model picture showing the 3 Y-block patterns [81], and (b) a finished Y-block mold.

The molds were made using the air set molding method with silica sand mixed with ALPHASET $^{\circledR} 9010$ resin and catalyst using a Tinker Omega NexGen2 ${ }^{\mathrm{TM}}$ mixing system (Figure 3.3 ). The total addition of sand was $1.25 \%$ by weight with $30 \%$ catalyst and $70 \%$ resin. 


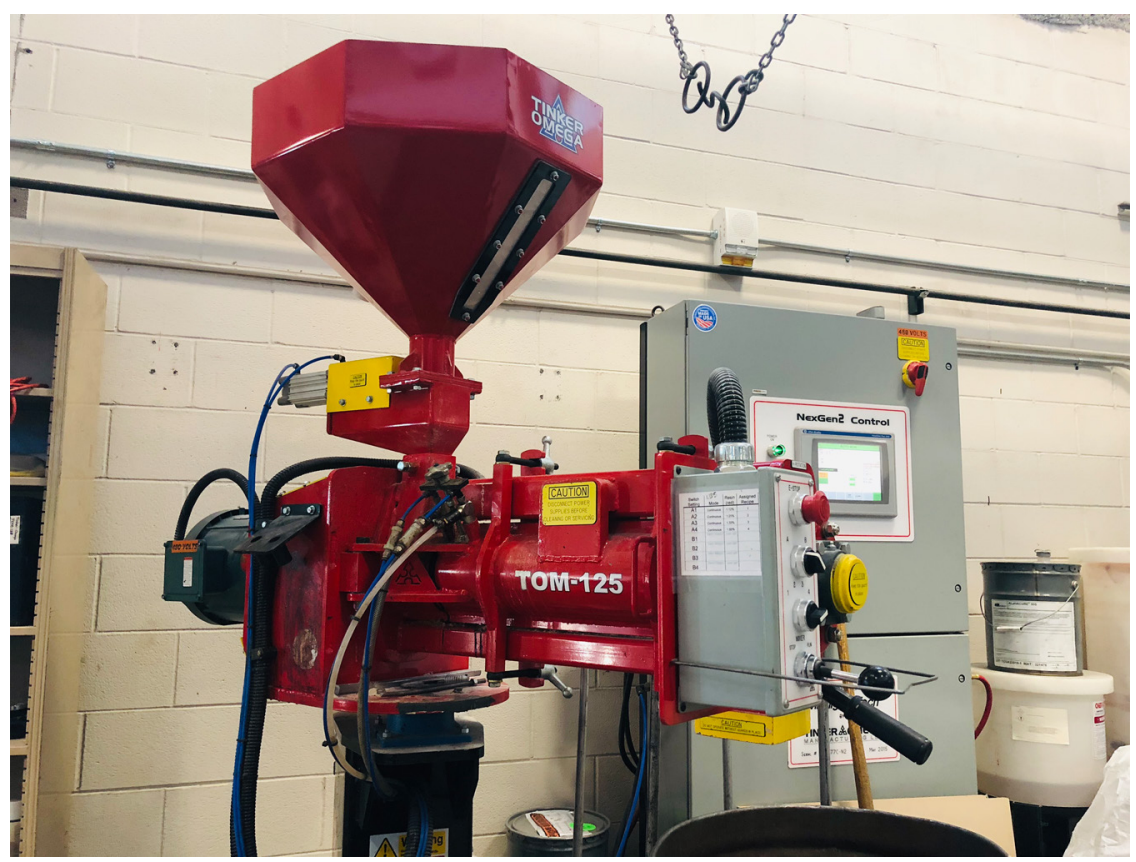

Figure 3.3 Tinker Omega NexGen2 ${ }^{\mathrm{TM}}$ mixing system used to produce the chemically bonded sand molds.

\subsubsection{Melting and Pouring Procedure}

All heats were produced in the Michigan Technological Foundry using a 300-pound coreless induction furnace (Figure 3.4). The furnace is first loaded with the metallic charge (pig iron, ductile iron returns, and steel punchings) plus Desulco ${ }^{\circledR}$ recarburizer and $75 \mathrm{wt} . \% \mathrm{FeSi}$. The furnace was heated to $1450^{\circ} \mathrm{C}$, and then $1 \mathrm{x} 1$ inch cobalt chunks were added to the melt. The chemical composition of the cobalt used for all the heats is given in Table 3.4 .

\begin{tabular}{cccccc}
\multicolumn{2}{c}{ Table 3.4 } & Chemical composition of cobalt & (wt.\%) \\
\hline Element & $\mathbf{C}$ & $\mathbf{C u}$ & $\mathbf{N i}$ & $\mathbf{F e}$ & $\mathbf{C o}$ \\
\hline wt.\% & 0.002 & 0.003 & 0.01 & 0.0004 & 99.98 \\
\hline
\end{tabular}




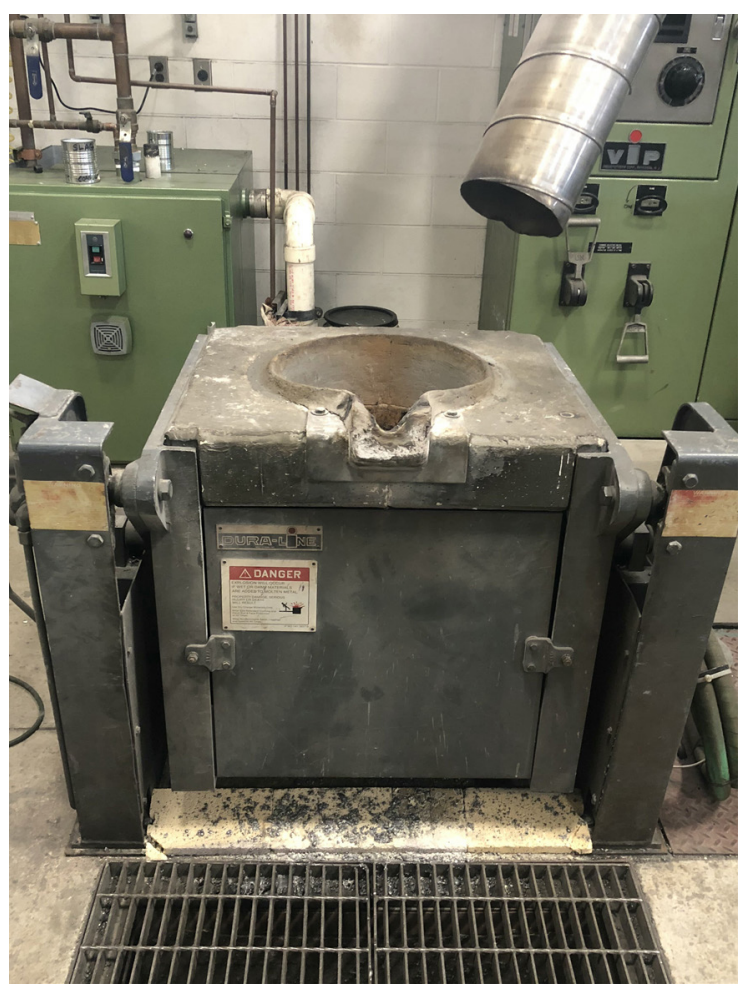

(a)

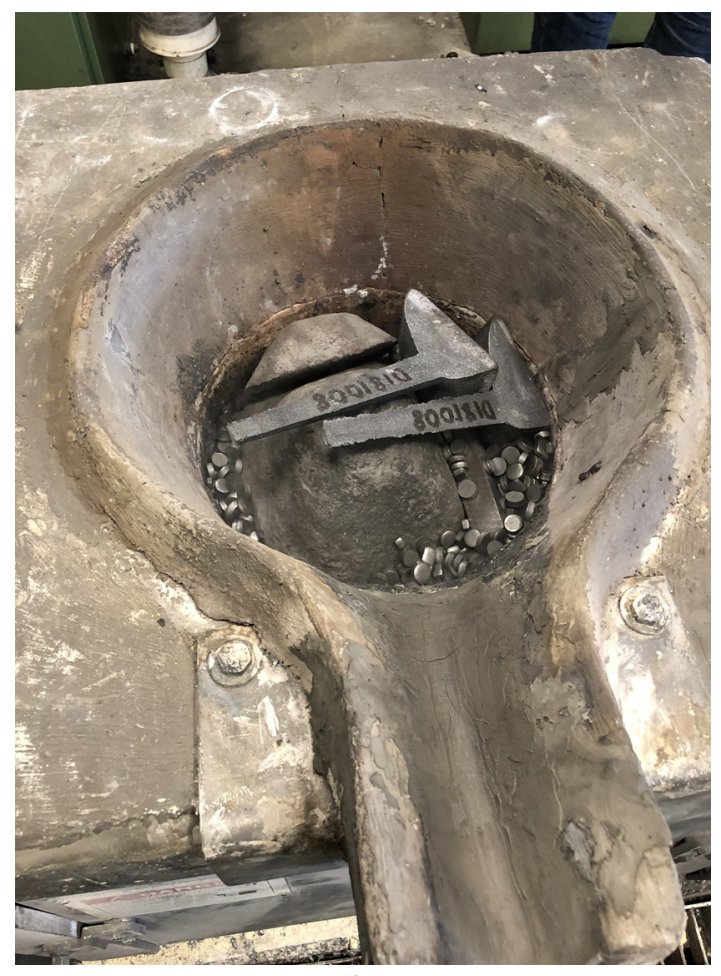

(b)

Figure 3.4 (a) 300-pound furnace used for all heats, with (b) the charge loaded.

The base iron composition is checked with a thermal analysis cup that contains sulfur to obtain the carbon, silicon, and carbon equivalent values using MeltLab thermal analysis software. Also, a copper mold is used to chill-cast a coin sample that is used to analyze the chemistry using a Bruker Q4 Tasman Advanced Charged Coupled Device (CCD) based Optical Emission Spectrometer (OES) instrument. If the chemical composition needs to be adjusted, further additions are made.

Once the base iron chemistry is adequate, preconditioning of the melt is performed by adding $75 \mathrm{wt} . \%$ FeSi five minutes before tapping. Then the furnace is ramped to a temperature of $1510^{\circ} \mathrm{C}$. The Mg-treatment is added to the preheated 300-pound tundish ladle (Figure 3.5), and the furnace is tapped into the ladle, with Inolate-40 inoculant added to the metal stream. 


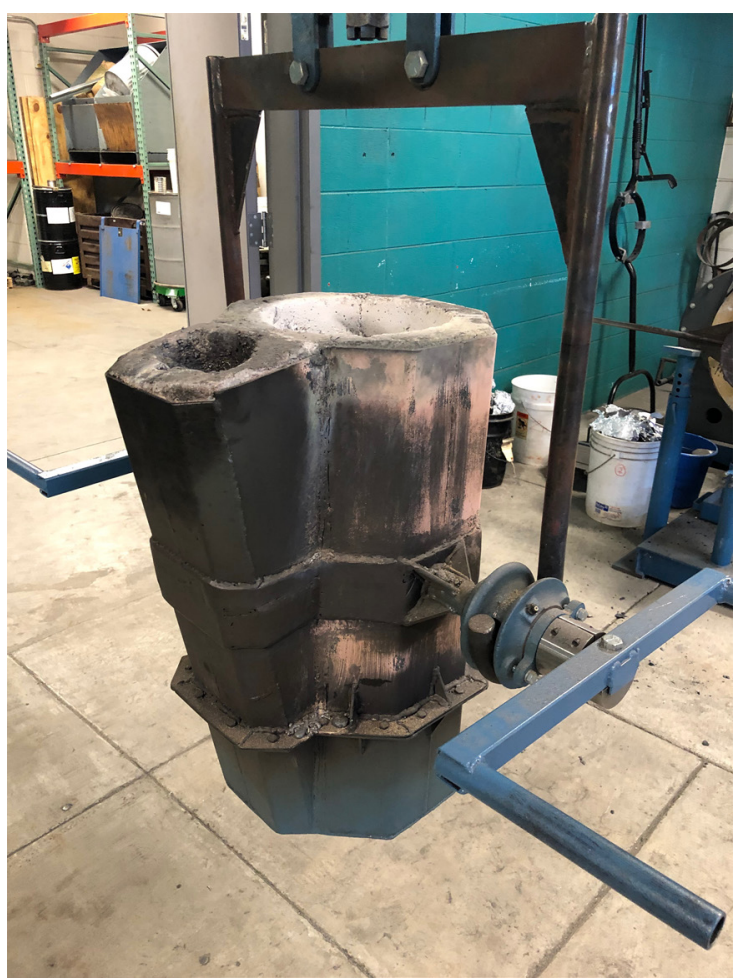

Figure 3.5 The 300-pound tundish ladle used for all the treatments.

Once the Mg-reaction complete, the filling of the molds on the pouring line begins. First, a scrap mold is poured, and then a thermal analysis cup that contains sulfur plus tellurium is poured, followed by two-coin samples to measure the final chemistry. Figure 3.6 displays the pouring of the two mold types, and a total of 23 molds per heat were poured (Figure 3.7)

All the base and final chemical compositions were analyzed using a Bruker Q4 Tasman Advanced CCD based OES instrument. Then the samples were sent out to Neenah Foundry to perform combustion analysis (Leco) and confirmed the OES results. 


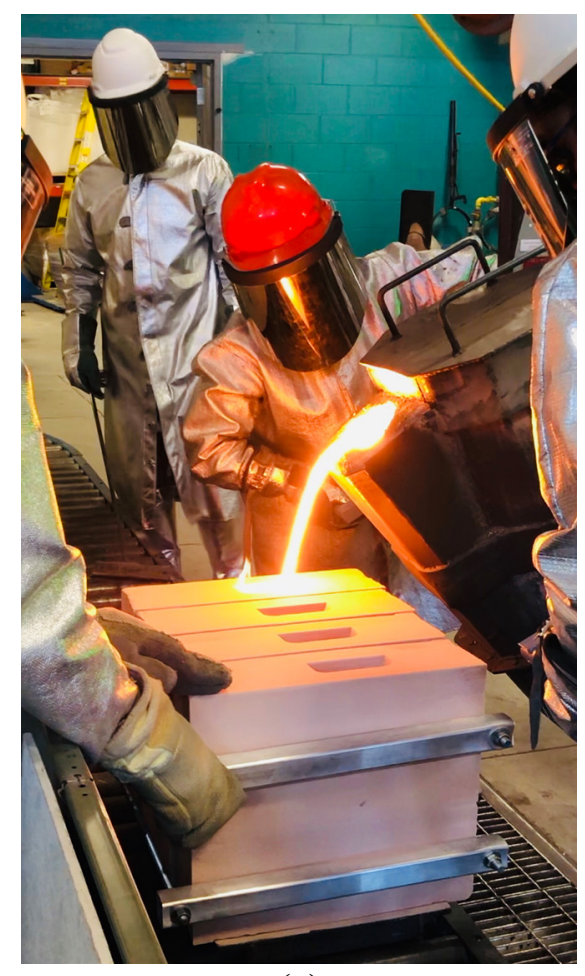

(a)

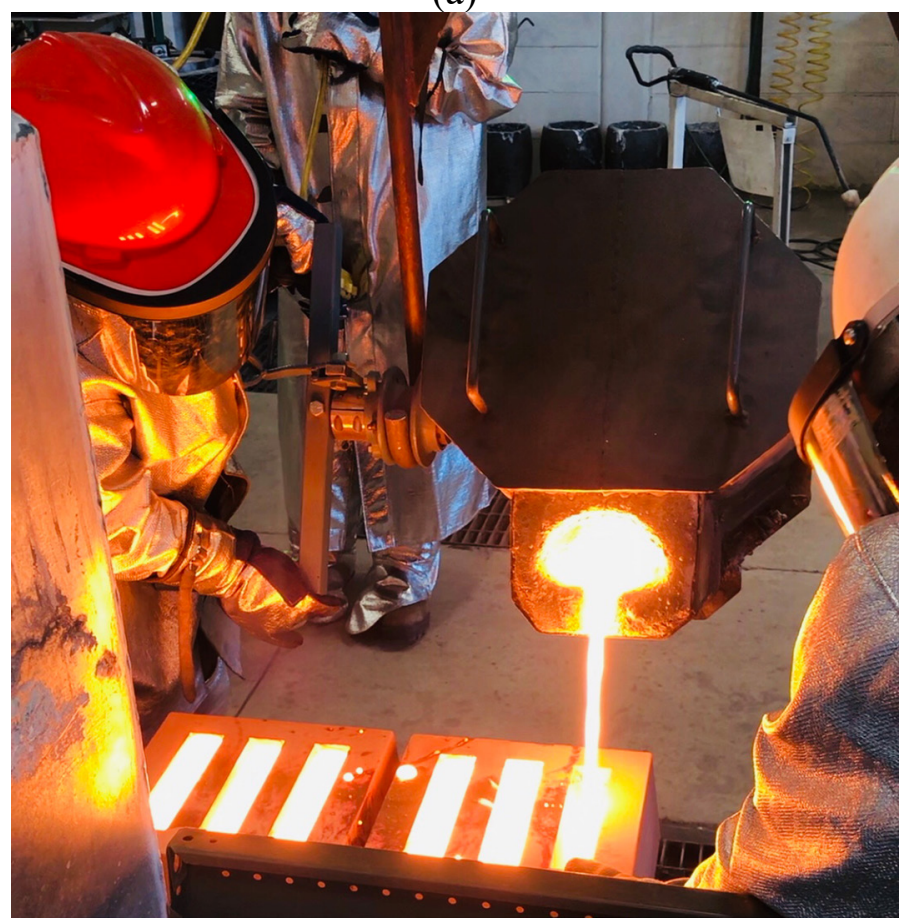

(b)

Figure 3.6 Pouring of (a) rectangular plates, and (b) $1 / 2$ inch Y-block. 


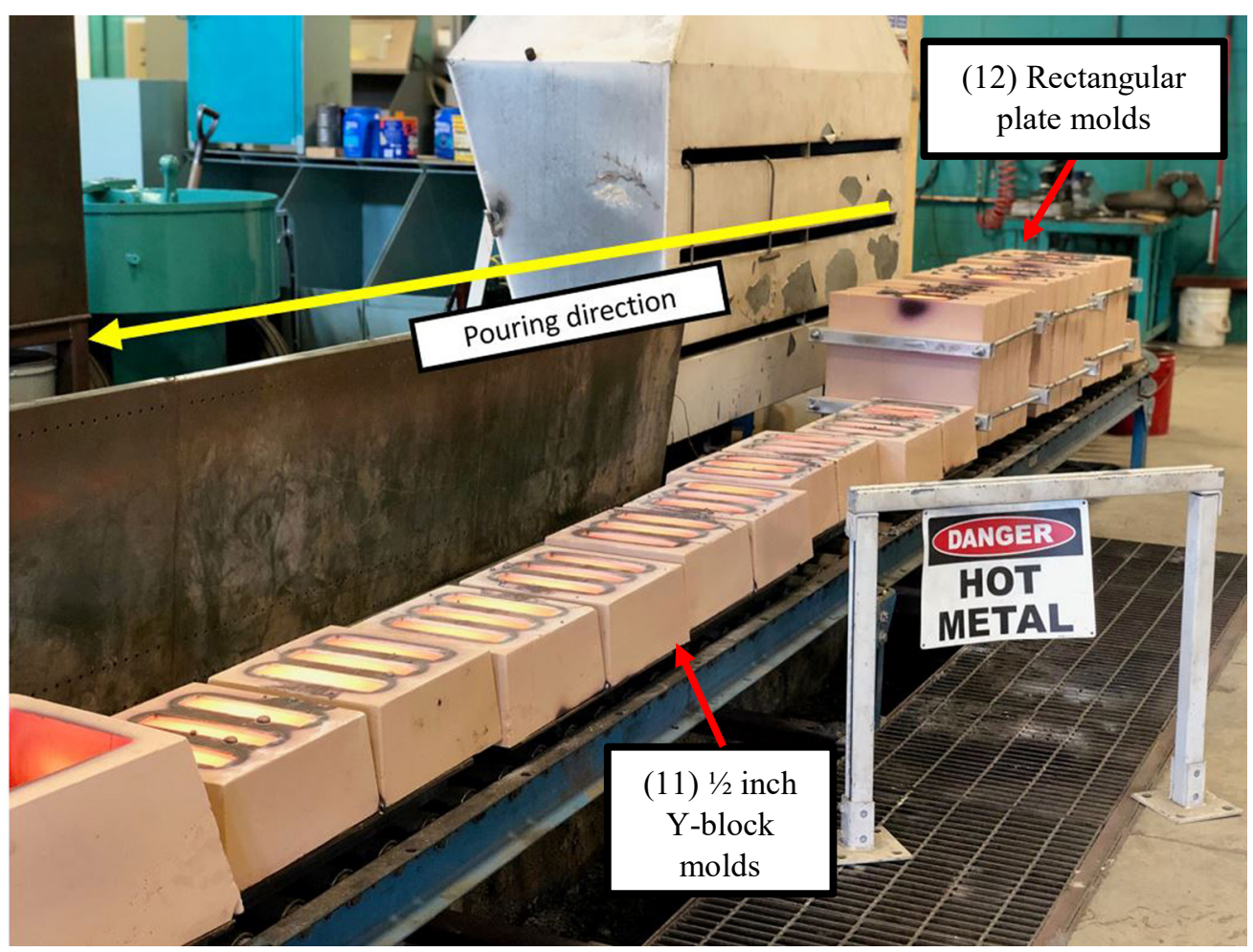

Figure 3.7 Photograph after pouring a total of 23 molds.

\subsubsection{Shake-out of the Molds}

After pouring, all the molds were left overnight to cool. After shakeout, the castings were sandblasted to remove any remaining sand (Figure 3.8).

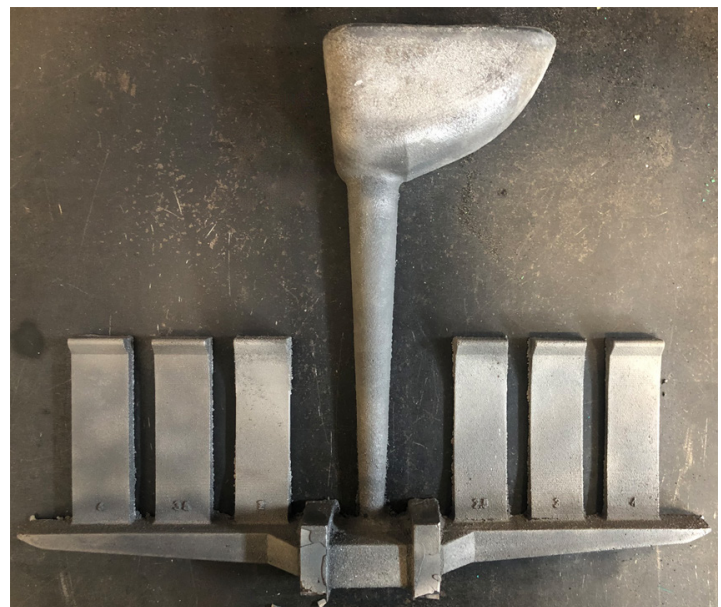

(a)

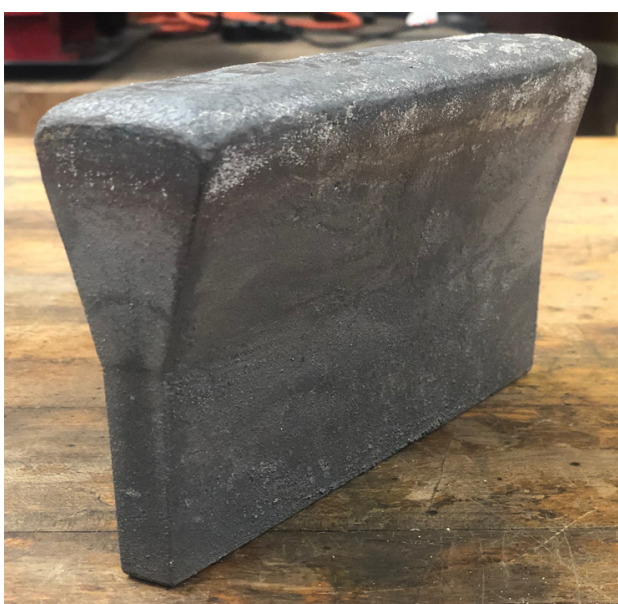

(b)

Figure 3.8 (a) Rectangular plates, and (b) $1 / 2$ inch Y-blocks after sandblasting. 


\subsubsection{Microstructure Evaluation}

\subsubsection{Rectangular Plates}

\subsection{Location of Metallographic Samples}

The gating system was removed using an angle grinder cut-off tool. All the rectangular plates were cut using a TR100 INOX LAPMASTER abrasive cutter with a Hudson aluminum oxide rubber bond 14" diameter abrasive cut-off wheel model CF14200 (Figure 3.9) to obtain the cross-section of each plate for metallography (Figure 3.10).

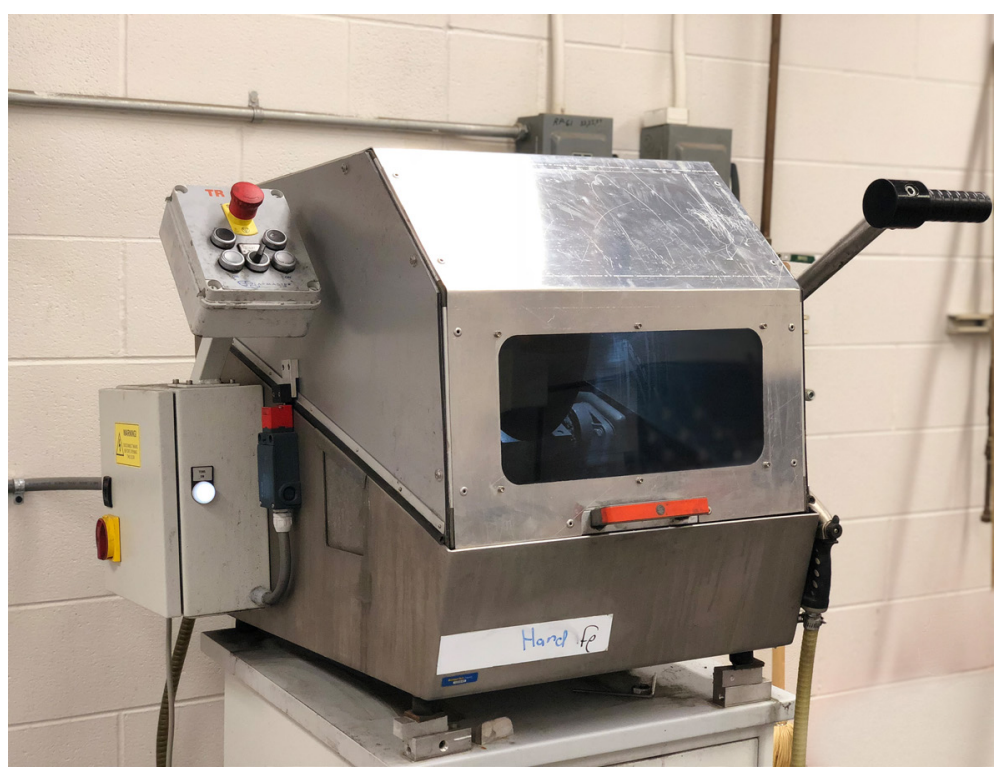

Figure 3.9 TR100 INOX LAPMASTER abrasive cutter used to cut the cross-sections for metallography of the rectangular plates.

The cross-sections were mounted using a US Composites 635 thin epoxy resin system with a 3:1 ratio medium epoxy hardener. A Leco AP-300 9-sample auto polisher was used for grinding (Figure 3.11) with the settings in Table 3.5. For polishing, a 12-inch Kempad non-woven polishing cloth was used with a $1 \mu \mathrm{m}$ polycrystalline diamond paste followed by a Hudcloth PC5 synthetic short nap with a $0.05 \mu \mathrm{m}$ alumina suspension. A total of 30 samples were examined. 


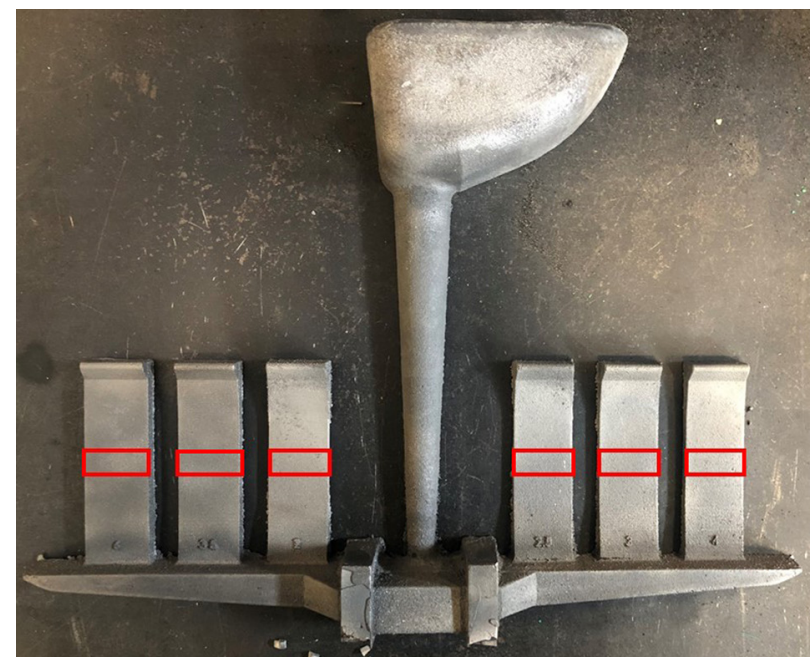

Figure 3.10 Location of the cross-section samples used for metallography.

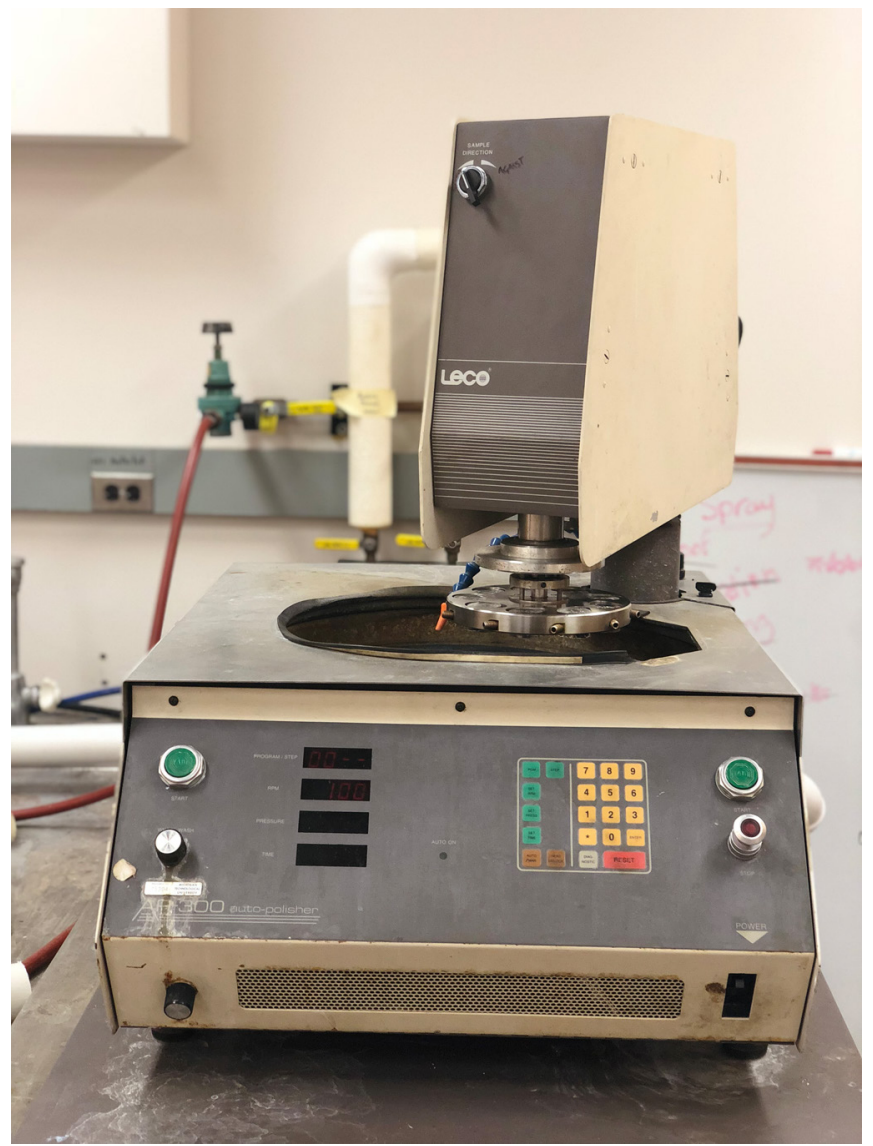

Figure 3.11 Leco AP-300 machine used for the metallographic preparation of the rectangular plates. 
Table 3.5 Metallographic procedure used with the Leco AP-300 machine

\begin{tabular}{cccc}
\hline Grit \# & Pressure (psi) & Time (sec) & RPM \\
\hline 120 & 50 & Until Flat & 300 \\
\hline 180 & 50 & 120 & 300 \\
\hline 300 & 50 & 120 & 300 \\
\hline 600 & 40 & 120 & 250 \\
\hline 800 & 30 & 120 & 260 \\
\hline 1200 & 25 & 120 & 240 \\
\hline $1 \mu \mathrm{m} \mathrm{diamond}$ & 15 & 120 & 150 \\
\hline $0.05 \mu \mathrm{m} \mathrm{Al}_{2} \mathrm{O}_{3}$ & Manual & 60 & 150 \\
\hline
\end{tabular}

\subsection{Graphite Analysis}

Unetched samples were analyzed at 100x to examine the percent nodularity and the nodule count $(\mathrm{N} / \mathrm{mm} 2)$. ImageJ was used to perform the analysis using a macro file created at Michigan Tech (Appendix C). This macro file considers a minimum shape factor of 0.6 per ASTM E2567 [82]. Moreover, this built-in file provides the form and size of graphite per ISO 945-1 [83]. For these samples, all the particles above $5 \mu \mathrm{m}$ were considered. The results are the average of 10 fields per sample.

\subsection{Ferrite and Pearlite Analysis}

A $2 \%$ Nital etchant was prepared using $98 \mathrm{ml}$ of ethanol and $2 \mathrm{ml}$ of nitric acid. The samples were etched by immersion for 15 to 20 seconds to yield a visibly cloudy surface. Images were taken at $100 x$ to conduct the analysis. The macro file created in ImageJ was used to obtain the ferrite and pearlite percentages. A total of 10 fields per sample were analyzed.

\subsection{Carbide Analysis}

For carbide percentage determination, a 10\% ammonium persulfate etchant was made with 1 gram of ammonium persulfate (ACROS ORGANICS 98\%, extra pure) dissolved in 10 milliliters of distilled water. The samples were etched by immersion for 2 to 4 minutes. The ImageJ macro file was used, and the carbides were outlined by hand in every micrograph. A total of 10 images per sample were taken. 


\subsubsection{ASTM $1 \frac{1}{2}$ inch Y-blocks}

\subsection{Location of Metallographic Samples}

The first and last Y-blocks poured were assessed to ensure good quality ductile iron in all the Y-blocks for subsequent machining of mechanical test specimens. All the Y-blocks were sectioned using a Baileigh band saw (Figure 3.12).

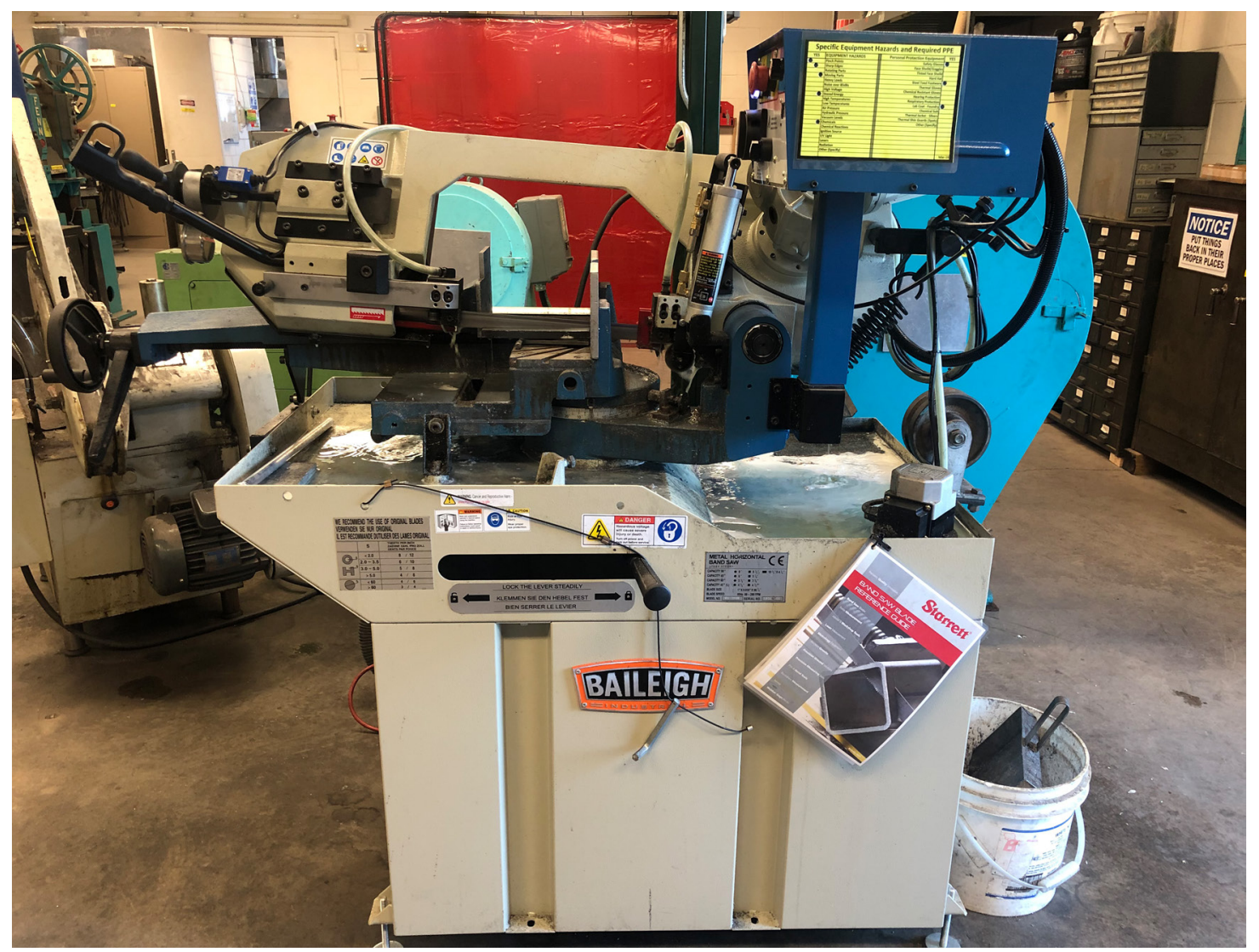

Figure 3.12 Band saw used to cut the $1 / 2$ inch Y-blocks. 
The 1-inch A (bottom) and B bars were obtained, with the middle cross-section of the A bar used for metallographic analysis (Figure 3.13).

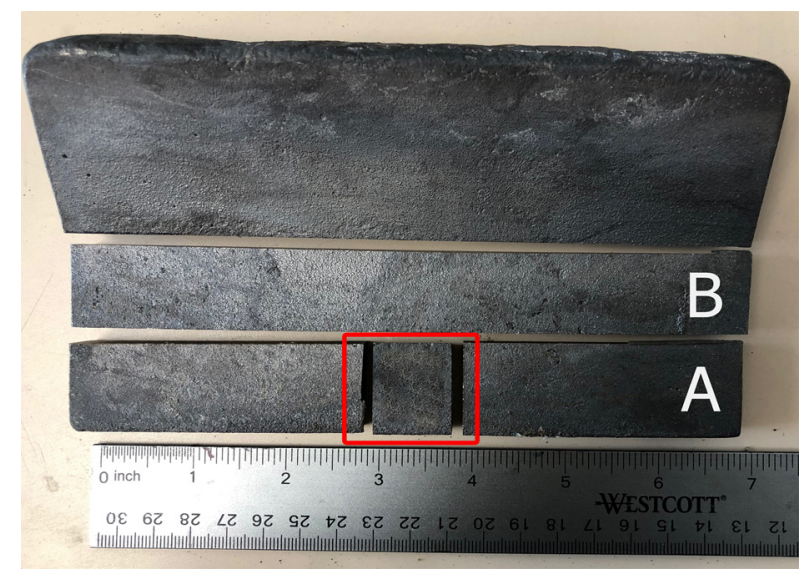

Figure 3.13 A and B bars showing the middle cross-section used for metallography per Y-block.

All the cross-section samples were ground and polished manually per Table 3.6. For polishing, an 8-inch dense Pan B non-woven cloth with a $1 \mu \mathrm{m}$ polycrystalline diamond paste and a Hudson synthetic short nap with a $0.05 \mu \mathrm{m}$ alumina suspension was employed. A total of 10 samples were analyzed.

Table 3.6 Metallographic procedure used manually for the $1 / 2$ inch Y-blocks

\begin{tabular}{ccc}
\hline Grit \# & Time (sec) & RPM \\
\hline 120 & Until Flat & 300 \\
\hline 240 & 120 & 300 \\
\hline 320 & 120 & 300 \\
\hline 400 & 120 & 250 \\
\hline 600 & 120 & 250 \\
\hline 800 & 120 & 200 \\
\hline 1200 & & 150 \\
\hline $1 \mu \mathrm{m} \mathrm{diamond}$ & 120 & 150 \\
\hline $0.05 \mu \mathrm{m} \mathrm{Al} \mathrm{O}_{3}$ & 60 & 150 \\
\hline
\end{tabular}




\subsection{Graphite Analysis}

ImageJ, with the built-in macro file developed at Michigan Tech, was used to analyze the percent nodularity and nodule count. A total of 10 images per heat at 100x were taken. The minimum particle size for these samples was set to $6 \mu \mathrm{m}$.

\subsection{Ferrite and Pearlite Analysis}

All samples were etched with $2 \%$ Nital by immersion for around 20 seconds.

Micrographs were taken at 100x to perform ferrite and pearlite percentages using ImageJ. The results are the average of 10 fields per sample.

\subsubsection{Tensile Properties Evaluation}

\subsubsection{Rectangular Plates}

\subsection{Location of Flat Tensile Samples}

Two subsize tensile samples were machined per rectangular plate (Figure 3.14). A total of 240 samples were made with dimensions per ASTM E8 [84] (Figure 3.15). 


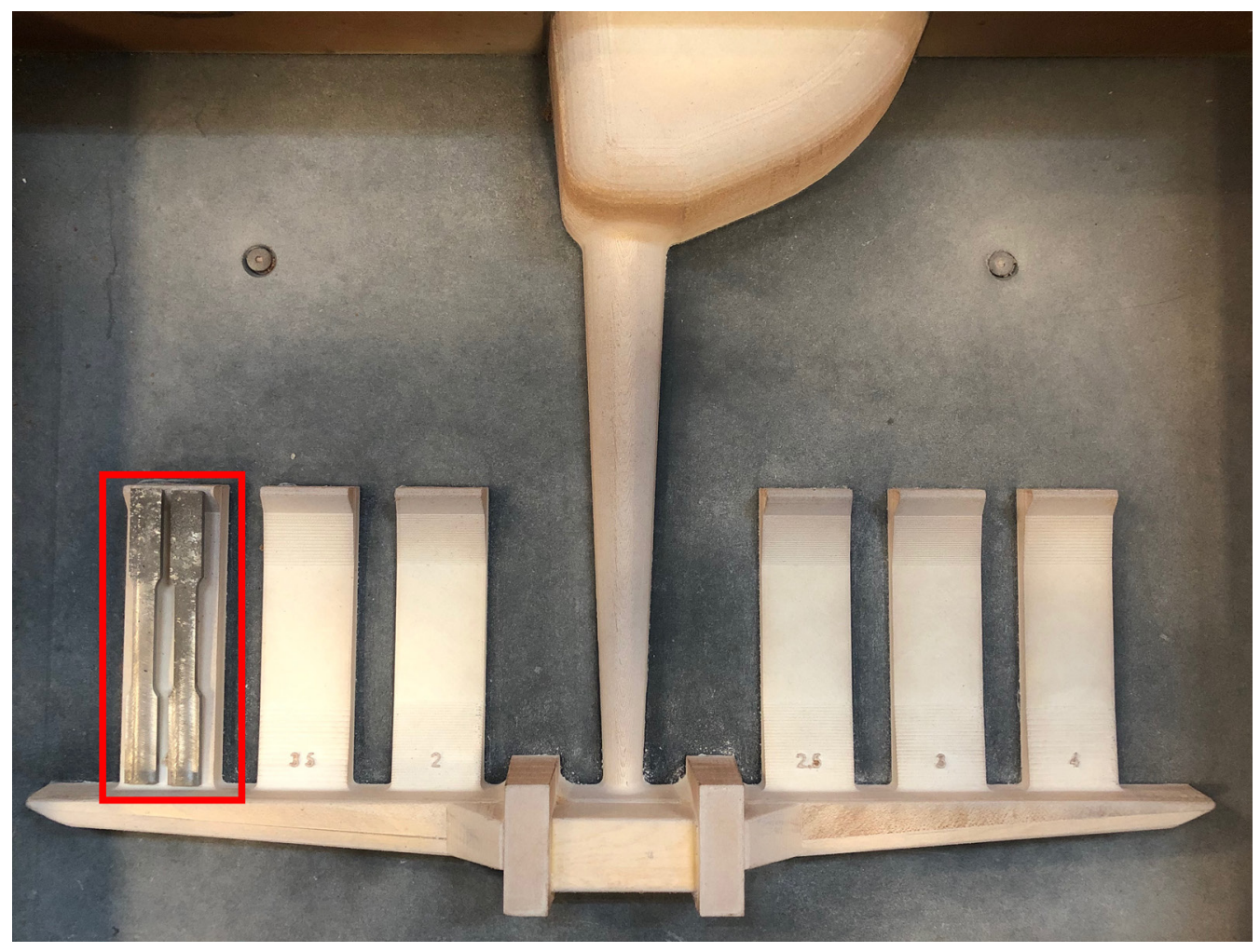

Figure 3.14 Two machined subsize flat tensile samples placed on top of the pattern for the rectangular plates.

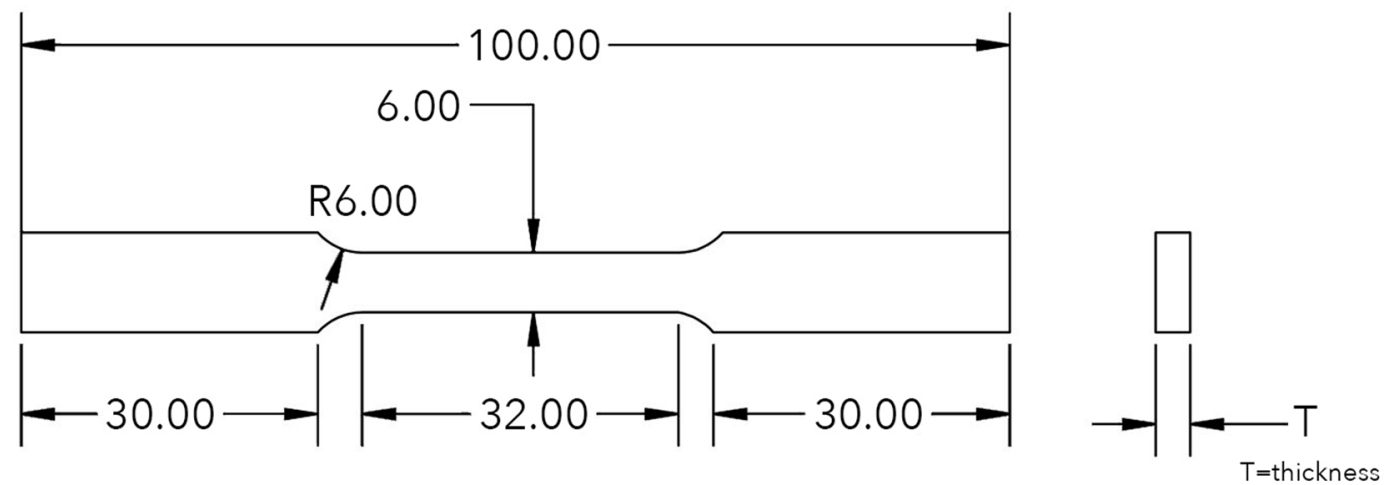

Figure 3.15 Dimensions (mm) of the flat subsize tensile samples per ASTM E8 [84]. 


\subsection{Loading and Testing}

Uniaxial tensile tests were performed using an Instron 4206 machine with a 10,000pound FUTEK universal pancake load cell and an Epsilon 1-inch extensometer (Figure 3.16). All the flat subsize tensile samples were pulled at a test rate of $2.54 \mathrm{~mm} / \mathrm{min}$. The results are the average of 8 samples per section thickness.

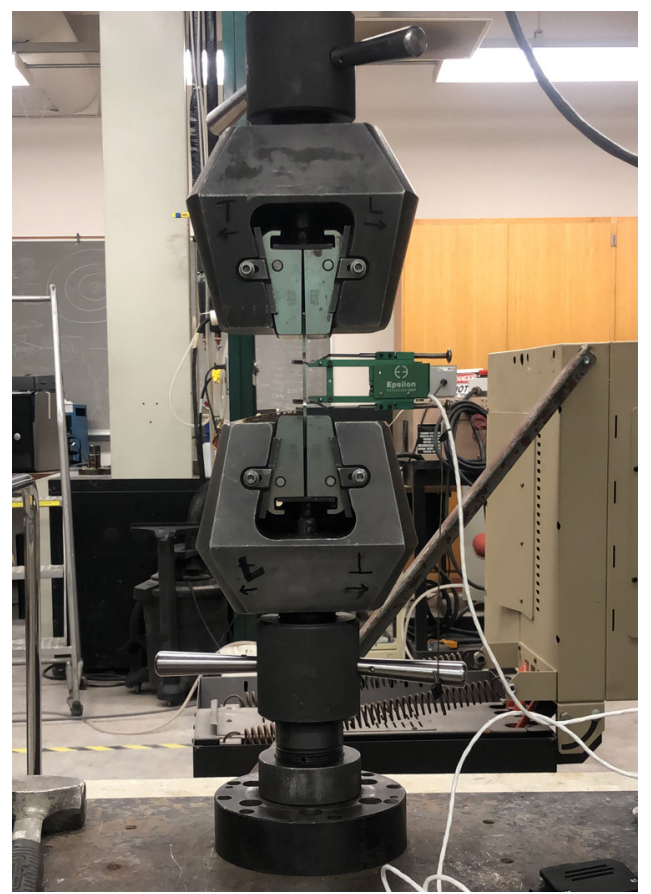

(a)

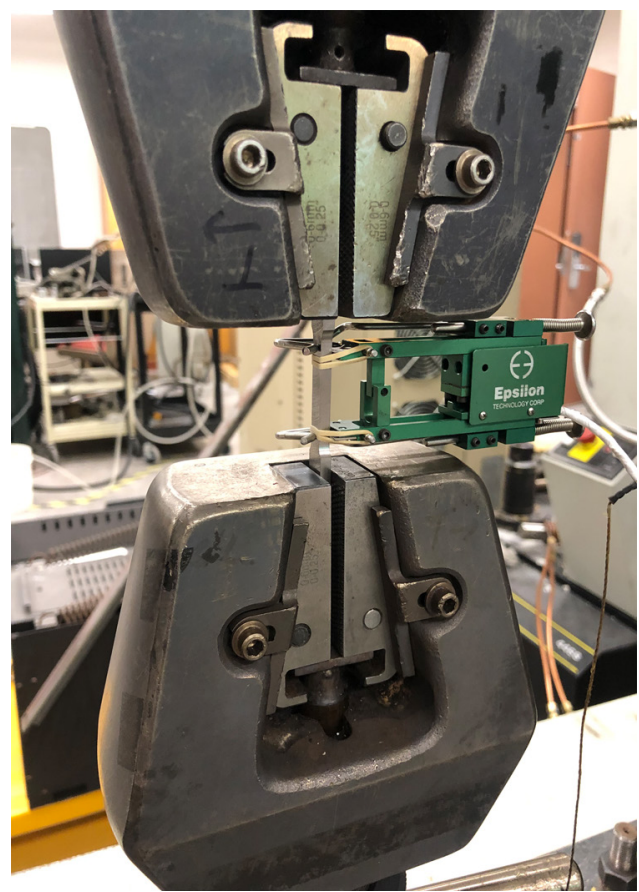

(b)

Figure 3.16 Instron 4206 machine setup (a) overall and close up (b).

\subsubsection{ASTM $1 \frac{1}{2}$ inch Y-blocks}

\subsection{Location of Round Tensile Samples}

Two subsize round tensile samples were machined per $1 / 2$ inch Y-block (Figure 3.17). A total of 60 samples were made according to ASTM E8 [84], with the dimensions given in Figure 3.18 . 


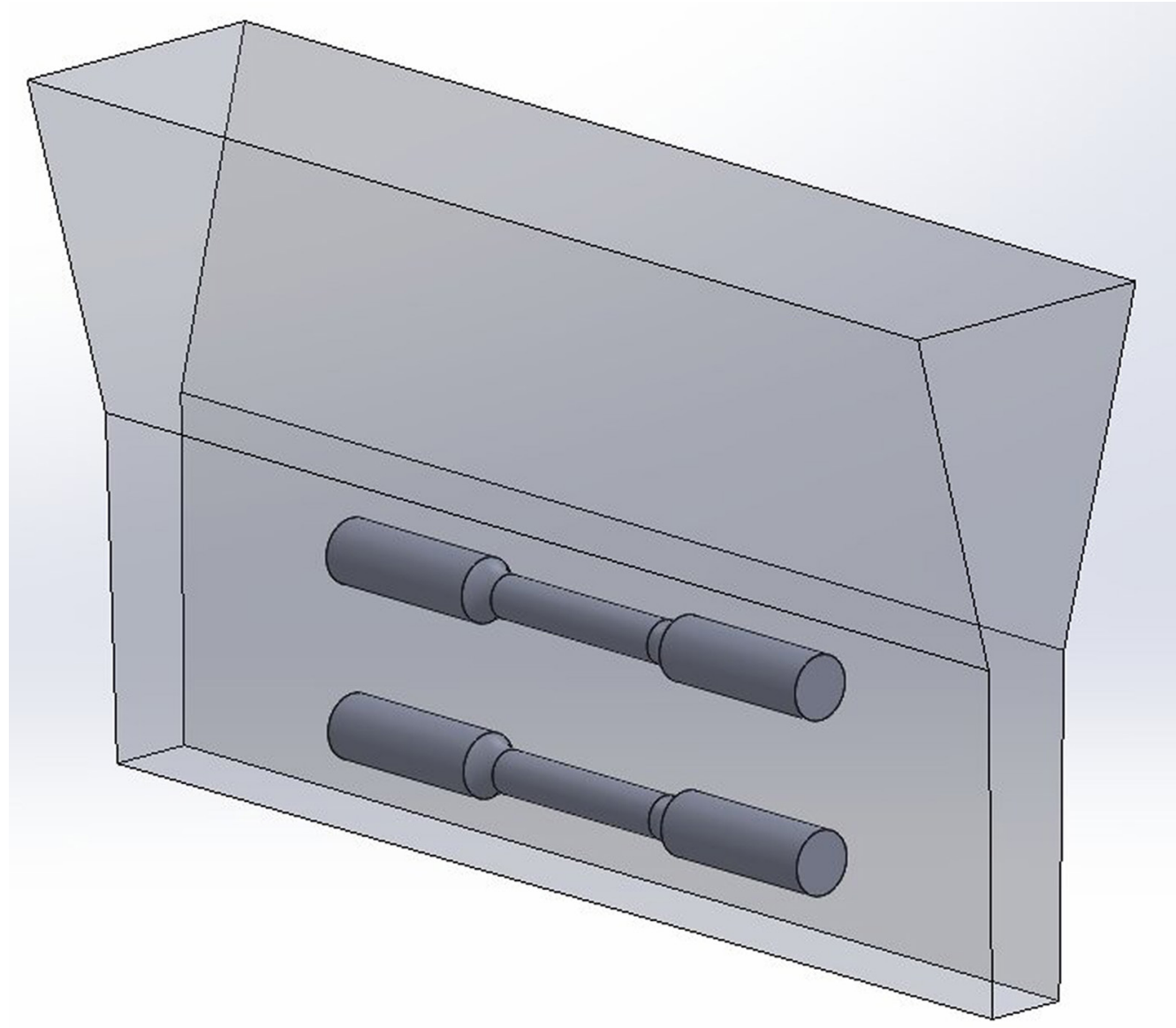

Figure 3.17 Location of the subsize round tensile bars in the $1 / 2$ inch Y-blocks.

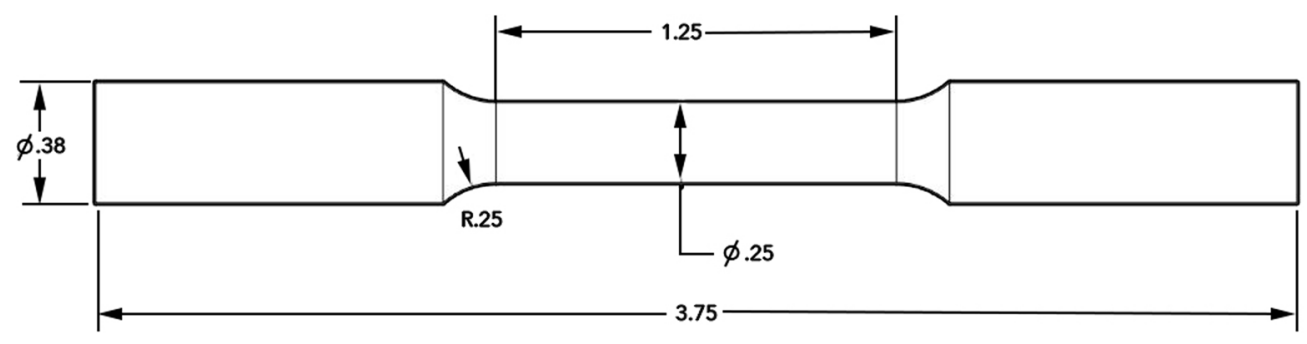

Figure 3.18 Subsize round tensile bar drawing per ASTM E8 [84], dimensions are in inches. 


\subsection{Loading and Testing}

An Instron 4206 machine with an Epsilon 1-inch gauge extensometer and a 10,000-pound FUTEK load cell (Figure 3.19) was used to perform tensile testing. A total of 12 subsize round tensile samples per heat were tested.

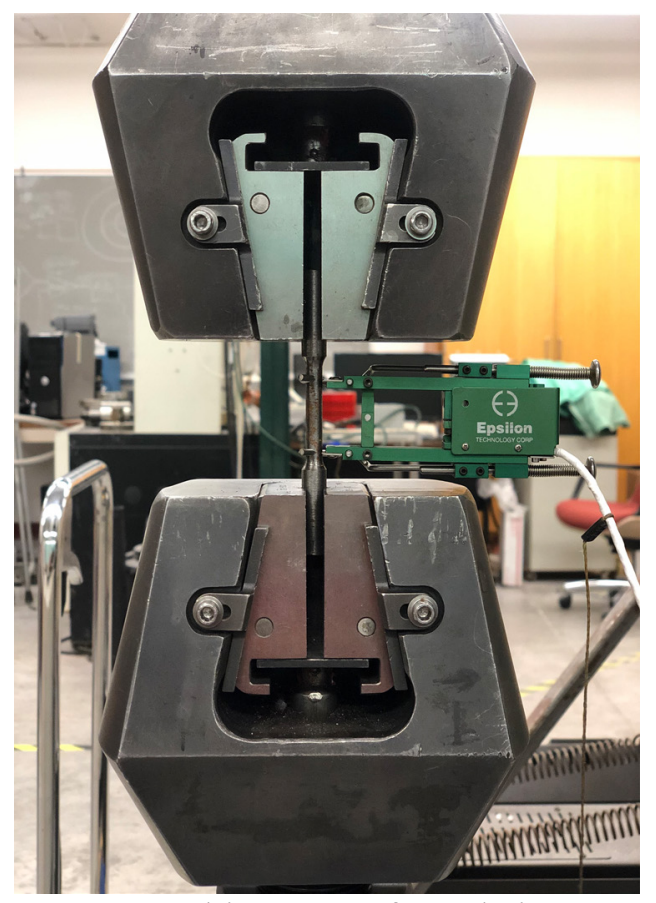

Figure 3.19 Instron 4206 machine setup for subsize round tensile samples.

\subsubsection{Macrohardness Evaluation}

\subsubsection{Rectangular Plates}

\subsection{Location of Hardness Indentations}

The Brinell hardness was measured using the middle section of each rectangular plate after grinding through the casting skin. A total of seven indentations per sample were made. 


\subsubsection{ASTM $1 / 2$ inch Y-blocks}

\subsection{Location of Hardness Indentations}

The cross-section of the $1 / 2$ inch Y-blocks was used to measure the Brinell hardness. The results are the average of six indentations.

\subsubsection{Brinell Hardness Testing}

A portable Dyna hardness tester with a $5 \mathrm{~mm}$ diameter tungsten carbide ball indenter was used to perform Brinell hardness on the rectangular plates and the $1 / 2$ inch Y-blocks (Figure 3.20). All the samples were held under a $750 \mathrm{~kg}$ load for 15 seconds. The indentations were measured using a Brinell Optical Scanning System (B.O.S.S). This system includes a high-resolution video scanning head and imaging software that allows quick and accurate readings of indentations.

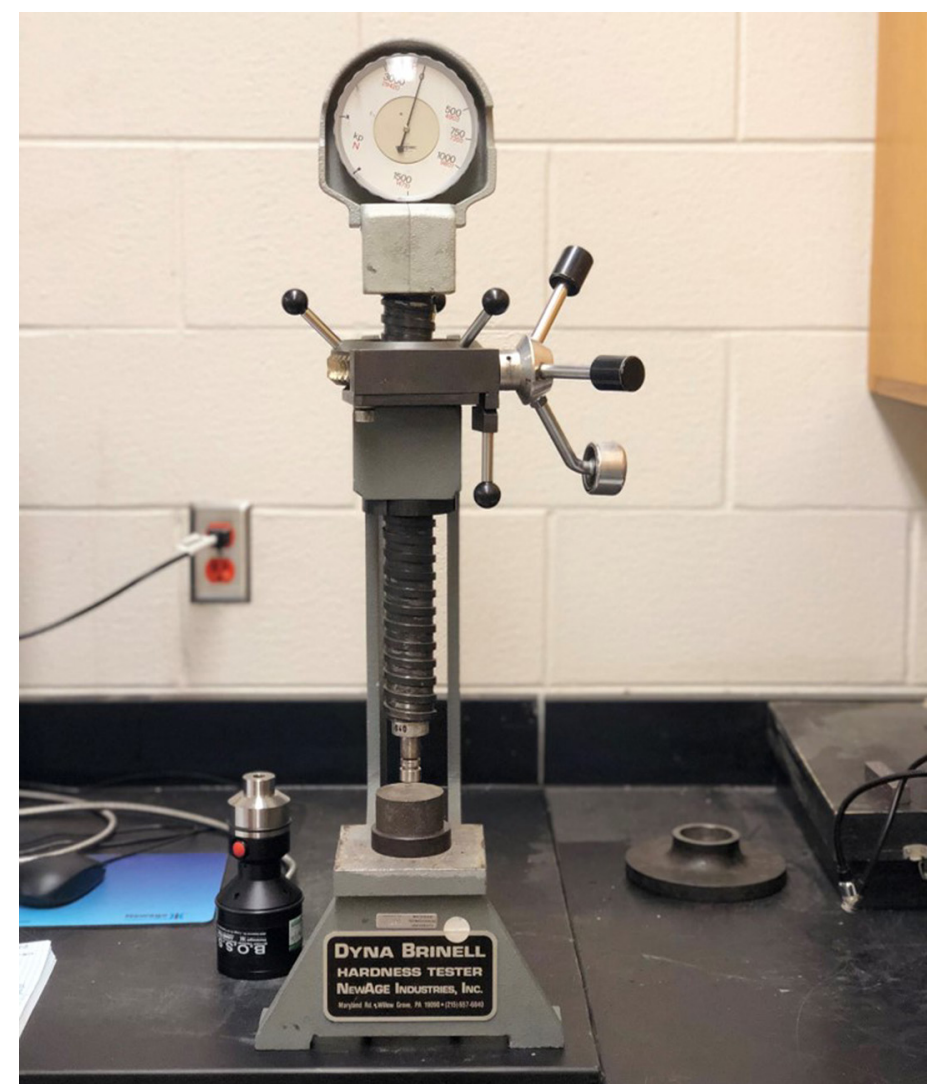

Figure 3.20 Dyna hardness tester and B.O.S.S used in measuring Brinell hardness. 


\subsubsection{Microhardness Evaluation}

The first and last $1 / 2$ inch Y-block cross-sections that were etched with $2 \%$ Nital were used to measure the microhardness of the ferrite phase. Vickers hardness test was applied using a LECO M-400-G1 Vickers tester (Figure 3.21) with a 100-gram load and a dwell time of 10 seconds. A total of ten indentations per sample was performed.

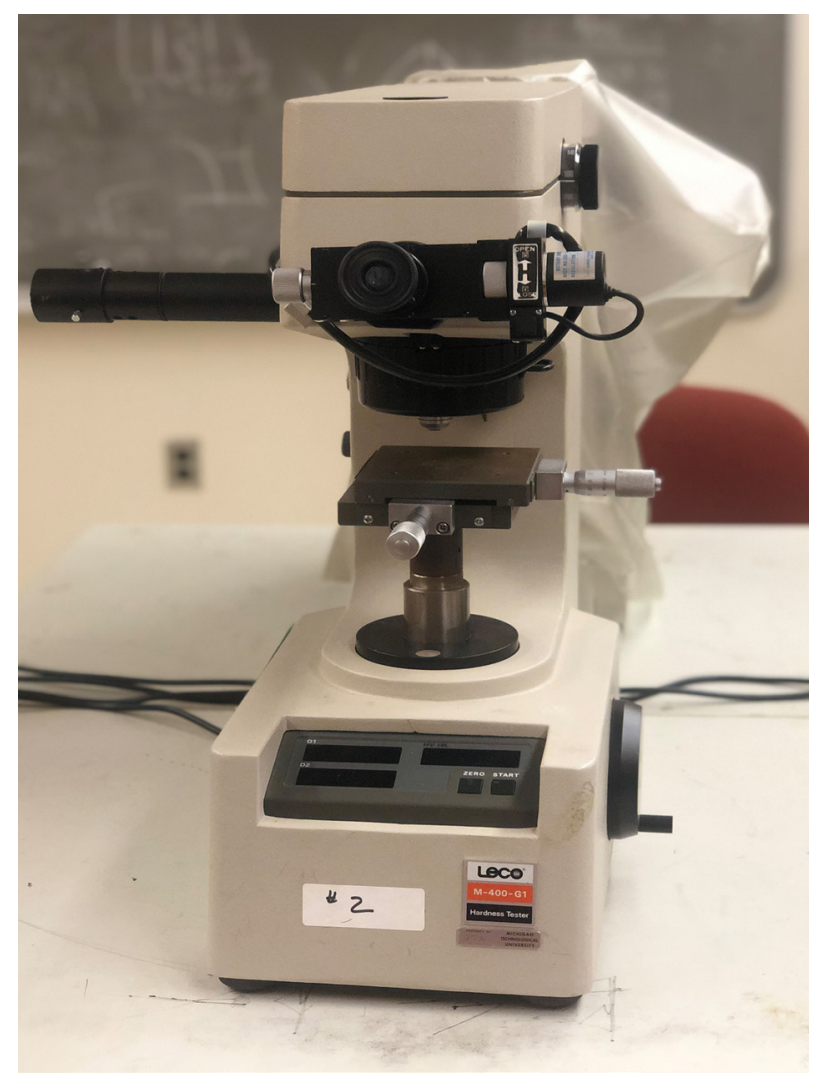

Figure 3.21 LECO M-400-G1 Vickers hardness microhardness tester.

\subsubsection{Impact Energy Evaluation}

Charpy impact testing was performed per ASTM E23 [85] using an MTS Exceed ${ }^{\circledR}$ E22 machine at the University of Saint Thomas in Minneapolis, Minnesota (Figure 3.22). The maximum impact energy of this machine is $450 \mathrm{~J}$, with an impact speed of $5.24 \mathrm{~m} / \mathrm{s}$. 
Four different temperatures were tested: $22.6,0,-20$, and $-40^{\circ} \mathrm{C}$. Unnotched and vnotched samples were machined out from the $1 / 2$ inch Y-blocks (Figure 3.23 and Figure 3.34). The reported values at each temperature are the average of 9 tests, resulting in a total of 360 samples. The DBTT was defined by determining the temperature at half of the upper shelf energy per ISO 148-1 Annex D [86].

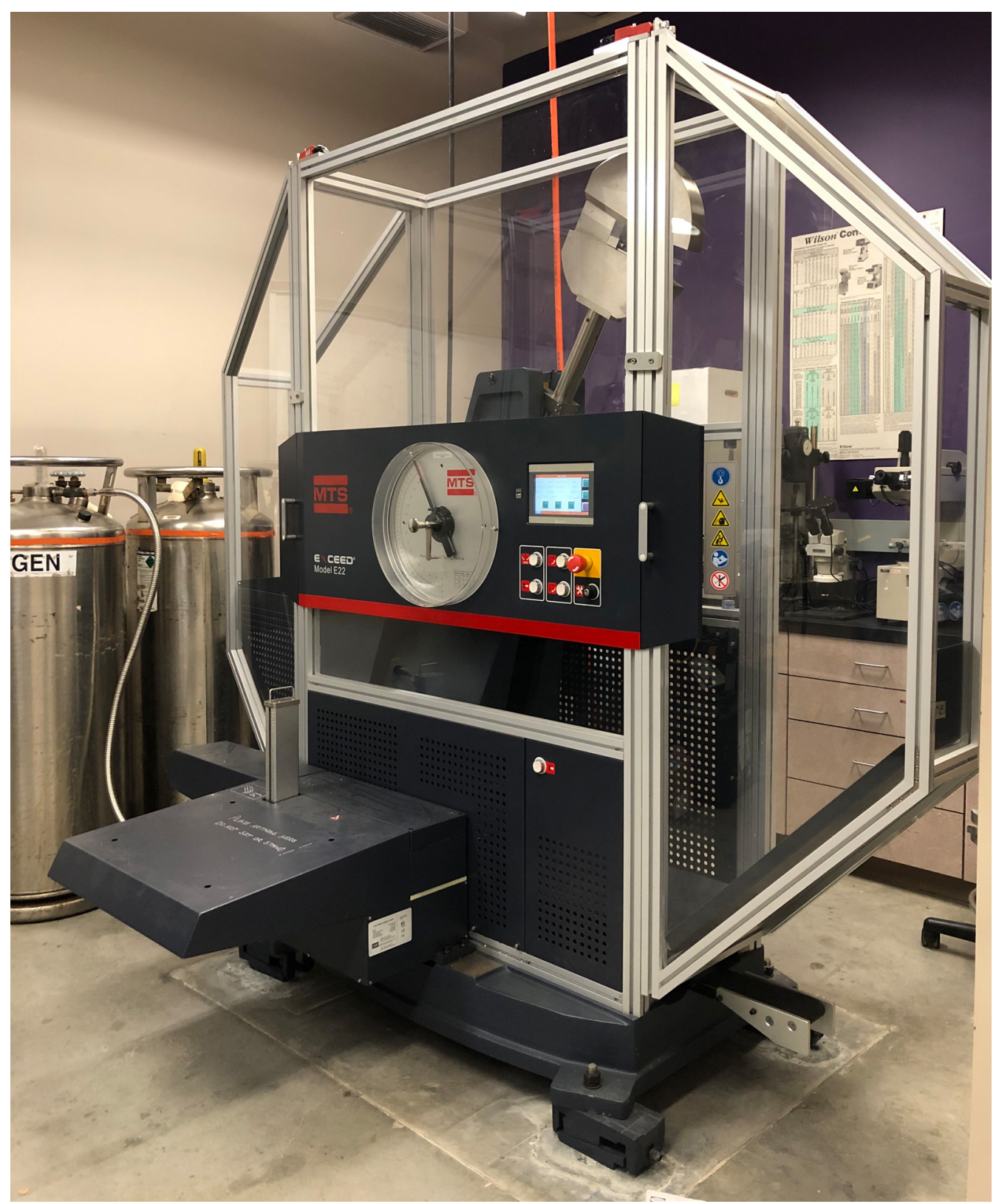

Figure 3.22 MTS Exceed ${ }^{\circledR}$ E22 impact test machine. 


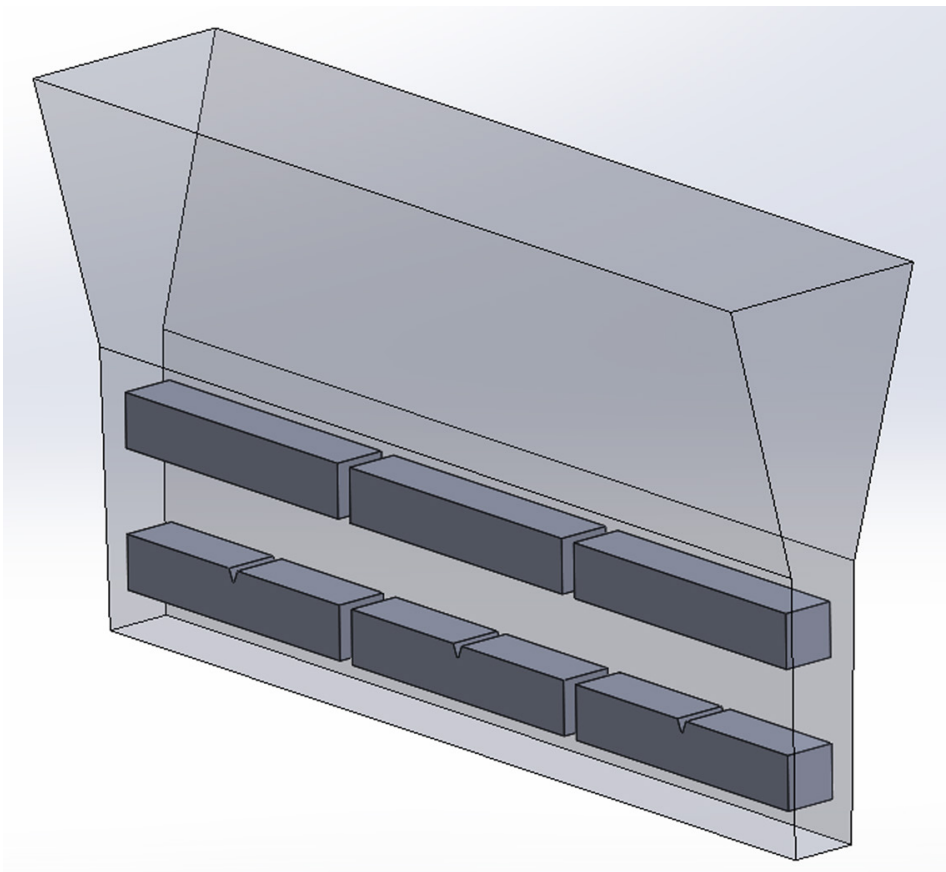

Figure 3.23 Location of unnotched and v-notched samples in the 1/2 inch Y-blocks.
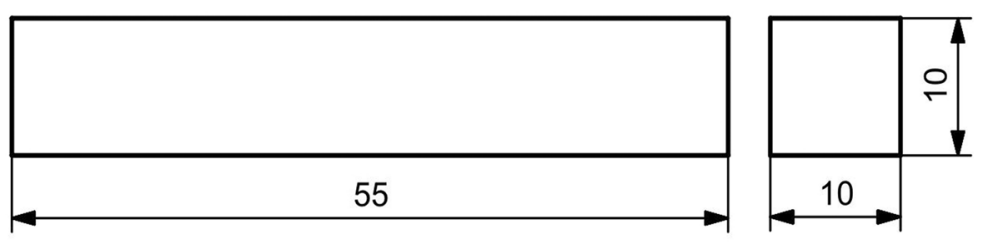

(a)

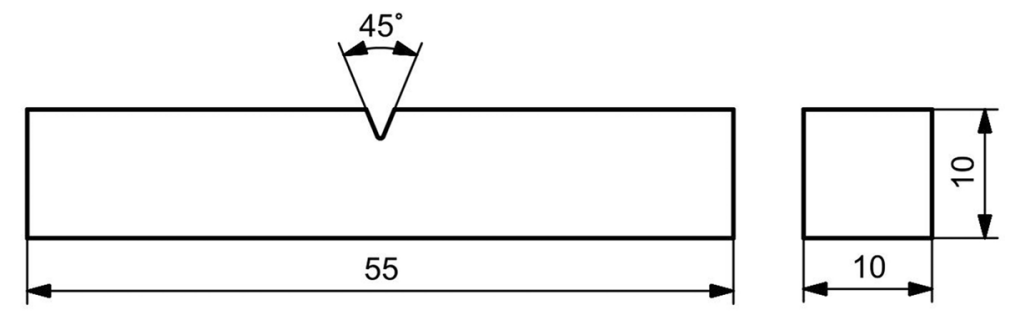

(b)

Figure 3.24 Dimensions (mm) used for (a) unnotched, and (b) v-notched samples per ASTM E23 [85]. 


\subsubsection{Fracture Toughness Evaluation}

\subsubsection{Location of Fracture Toughness Samples}

Fracture toughness tests were executed per ASTM E1820 [87], applying the J-integral method using compact tension $(\mathrm{C}(\mathrm{T})$ ) samples. Five samples were machined per $1 / 2$ inch Y-block (Figure 3.25). A total of 100 samples were made with the dimensions given in Figure 3.26.

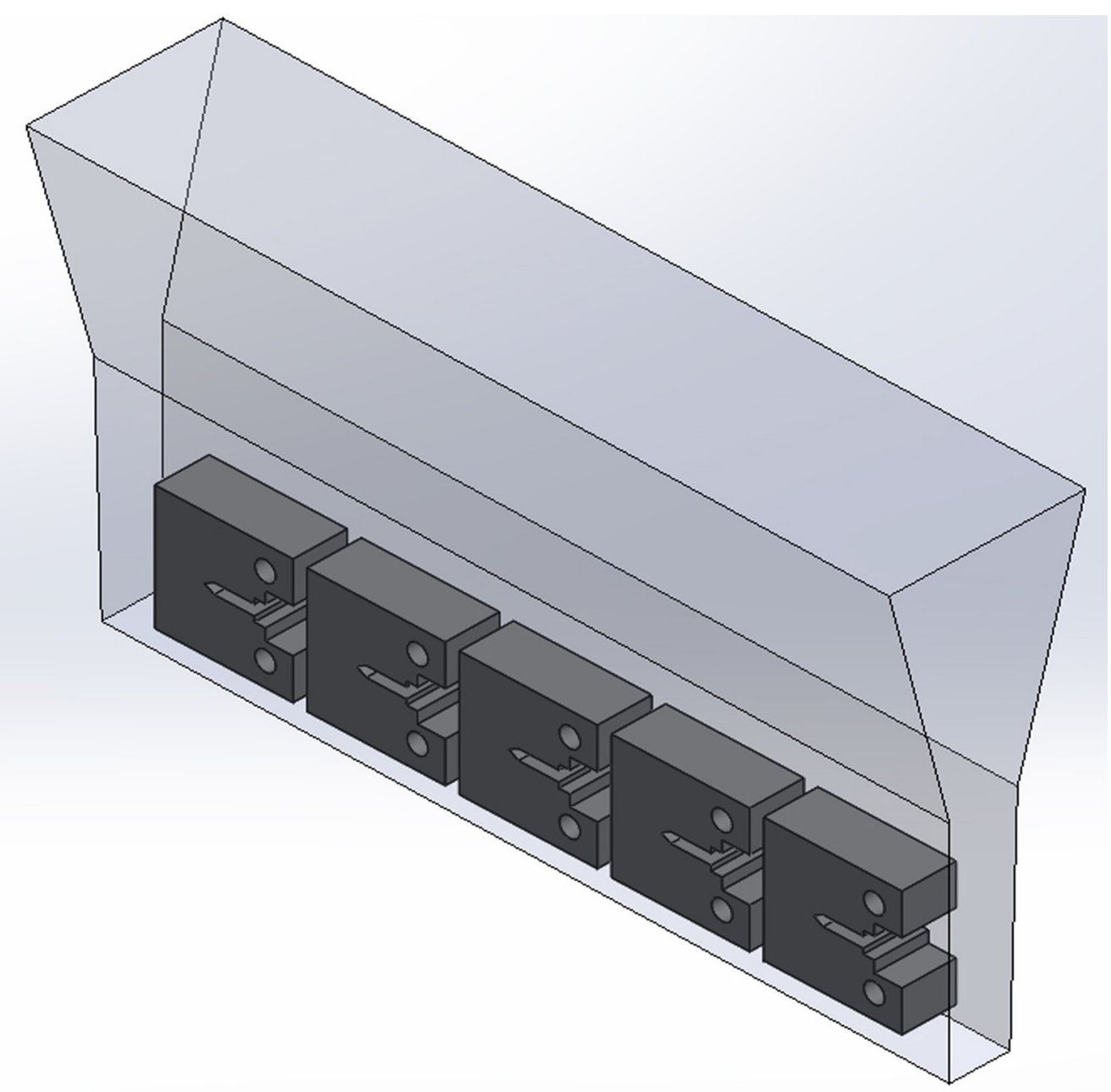

Figure 3.25 Location of the $\mathrm{C}(\mathrm{T})$ samples in the $1 / 2$ inch Y-blocks. 

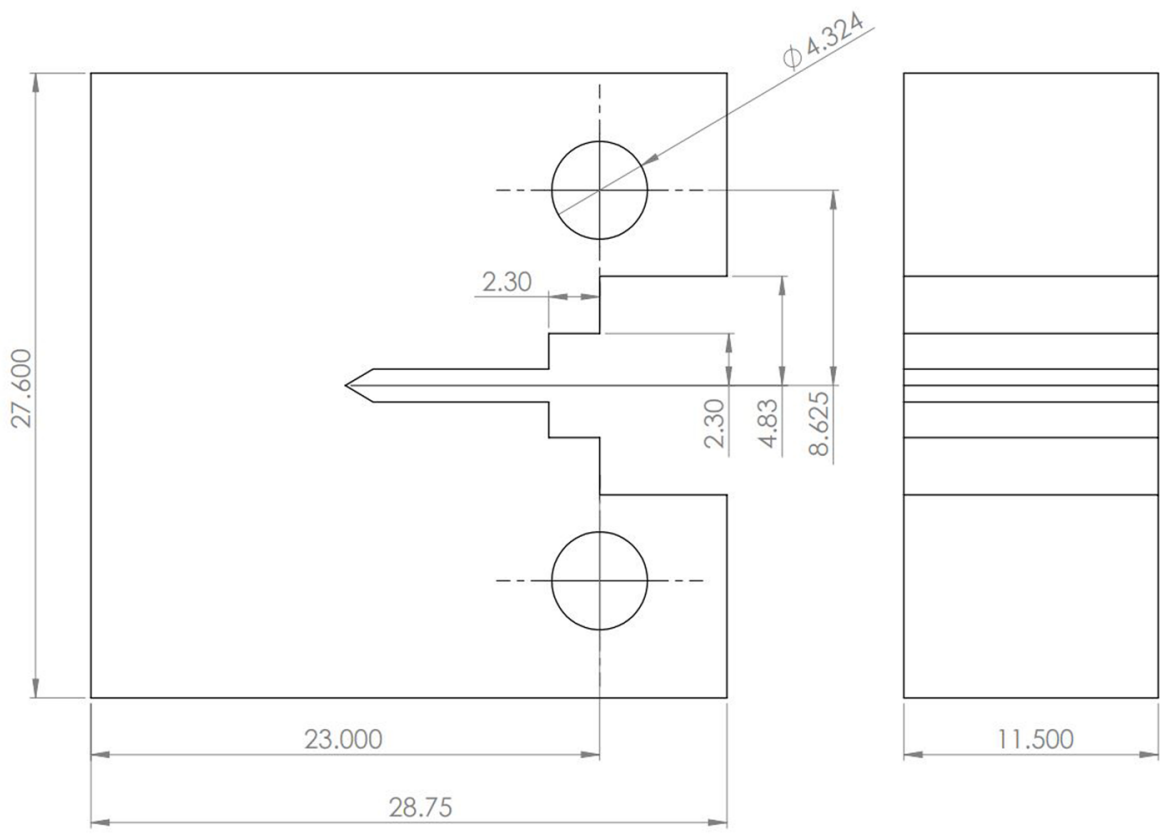

Figure 3.26 Dimensions (mm) used for the C(T) samples per ASTM E1820 Annex 3 [87].

\subsubsection{Fatigue Pre-cracking of C(T) Samples}

According to ASTM E1820 [87], the first step is to pre-crack in fatigue all the samples. Fatigue pre-cracking was performed using an MTS 312.21 floor standing fatigue frame with two MTS 647 hydraulic wedge grips (Figure 3.27). Tests are performed under force control using the MTS Flex Test (Series 793) Controller Software-Station Manager Application, with a sinusoidal load applied at a frequency of $8 \mathrm{~Hz}$. 


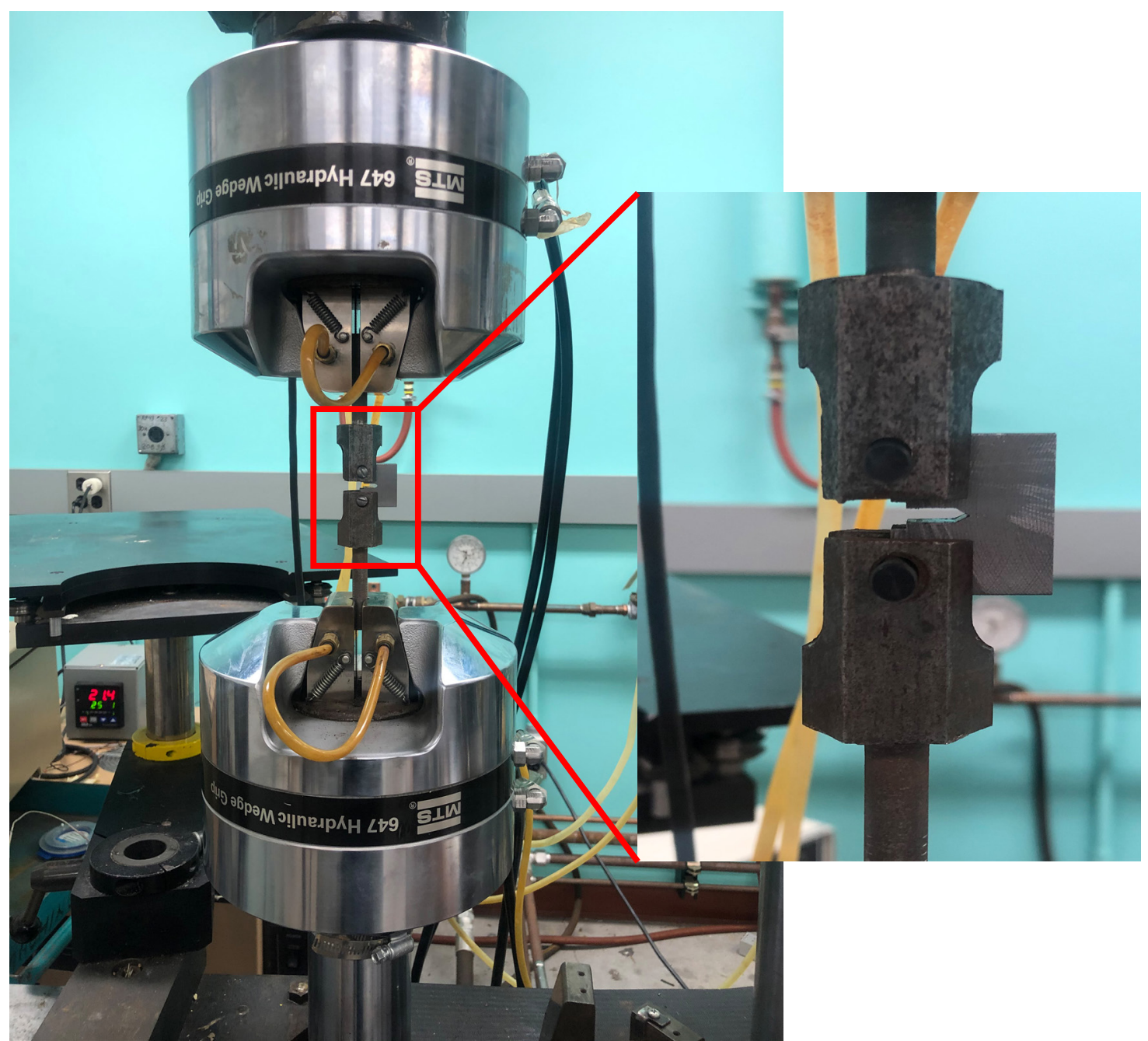

Figure 3.27 Fatigue frame configuration used to pre-crack the $C(T)$ samples from $1 / 2$ inch Y-blocks.

\subsubsection{Loading and Testing}

The second step is loading and testing. The test at room temperature $\left(22.6^{\circ} \mathrm{C}\right)$ was performed in an Instron 4206 machine (Figure 3.28). A 10,000-pound FUTEK load cell and an epsilon model 3541 crack opening displacement (COD) gauge were used. Figure 3.29 shows a close-up view of a C(T) sample mounted in the Instron machine and with the COD gauge before starting the test. 


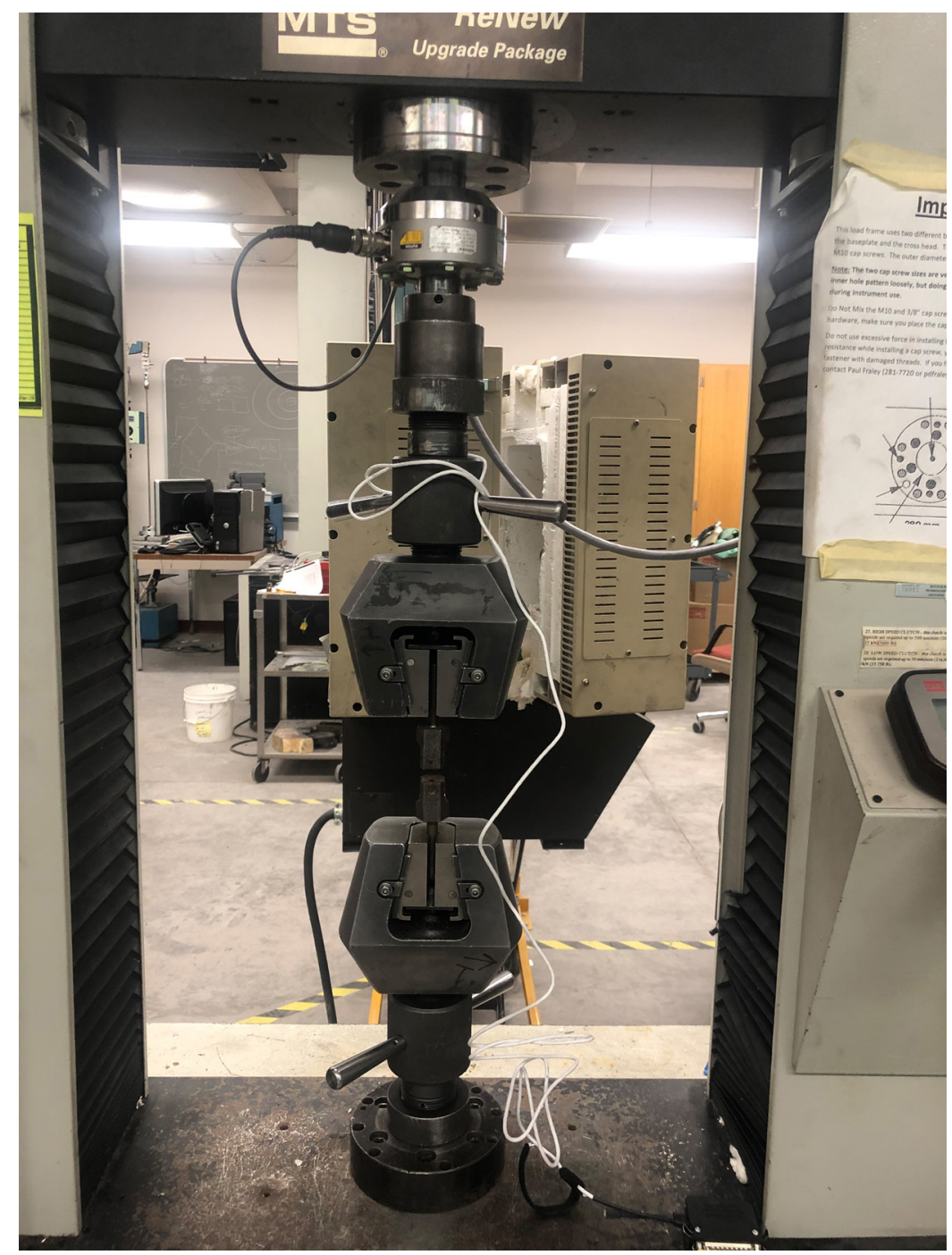

Figure 3.28 Instron 4206 machine used for the $\mathrm{C}(\mathrm{T})$ testing at room temperature. 


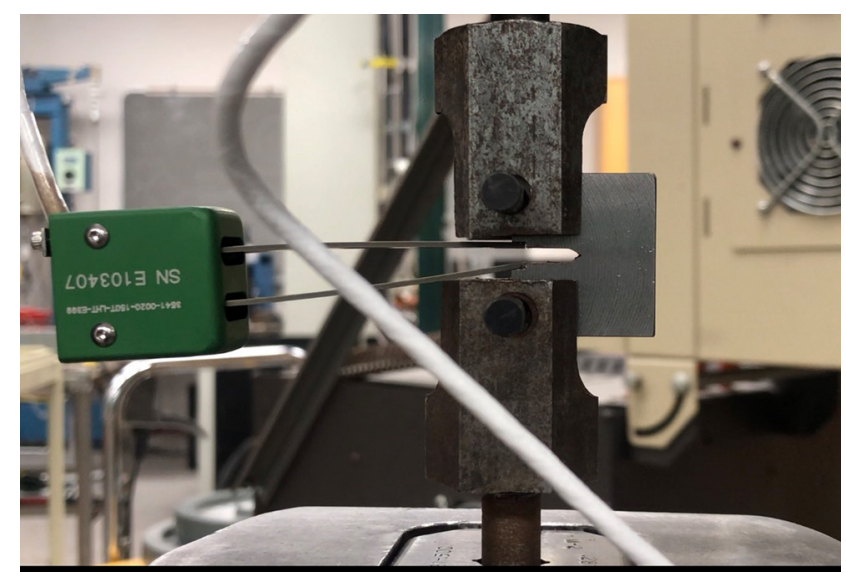

Figure 3.29 Close-up view of a C(T) sample mounted before testing.

The low-temperature tests $\left(0,-20\right.$, and $\left.-40^{\circ} \mathrm{C}\right)$ were performed using an Instron 4210 machine frame with a mounted portable LAB-TEMPTM LBO-Series medium-range furnace (Figure 3.30), which has a wide temperature working range from $-185^{\circ} \mathrm{C}$ to $425^{\circ} \mathrm{C}$. Liquid $\mathrm{N}_{2}$ was used in the cryogenic cooling system, and an Omega USB thermocouple was attached to the $\mathrm{C}(\mathrm{T})$ sample to monitor the temperature. An example of the assembly used at -20 is shown in Figure 3.31 .

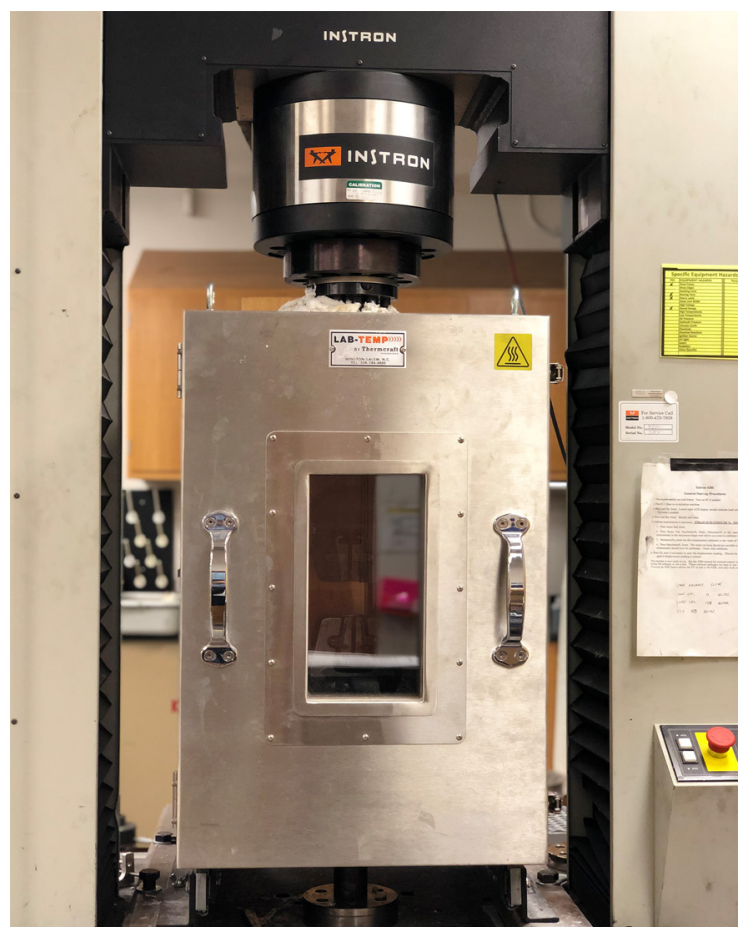

Figure 3.30 Portable LAB-TEMPTM furnace used for the low temperature testing. 


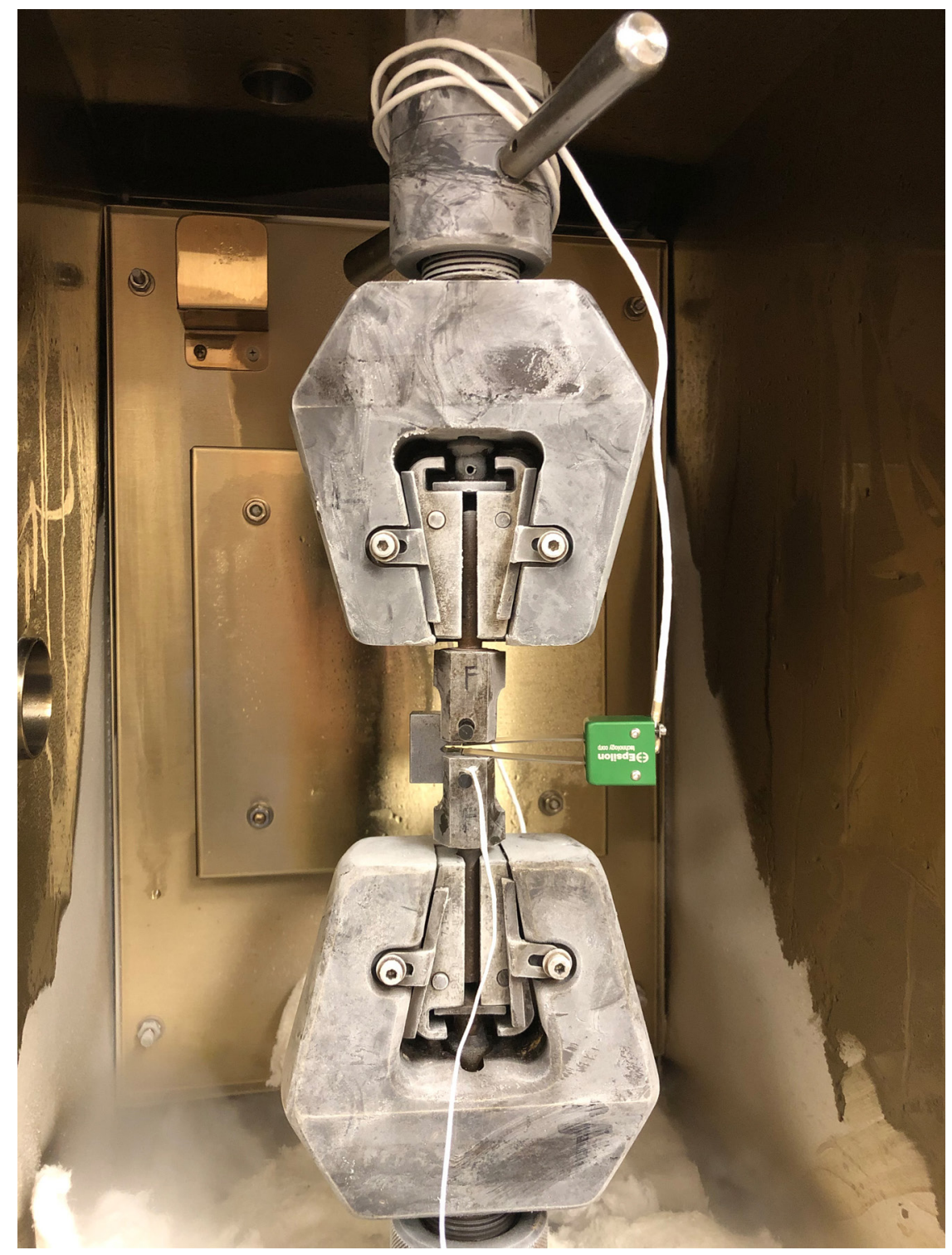

Figure 3.31 Assembly inside the cooling chamber at $-20^{\circ} \mathrm{C}$.

\subsubsection{Data Analysis}

The final step is to analyze the data according to the Normalization Data Reduction technique supplied in Annex 15 of ASTM E1820 [87]. This technique is used to obtain a $\mathrm{J}-\mathrm{R}$ curve from the force-displacement data. The initial and final crack size measurements should be taken from the fracture surface of the samples. A Wild Heerbrugg stereoscope with a PixeLink camera (Figure 3.32) was used to take pictures of the broken samples. 
The PixeLink capture software was used to acquire the images, and ImageJ was used to measure the crack lengths. The normalization data reduction analysis was carried out using open-source, automated software developed by Oak Ridge National Laboratory [88] with the provided step-by-step procedure [89].

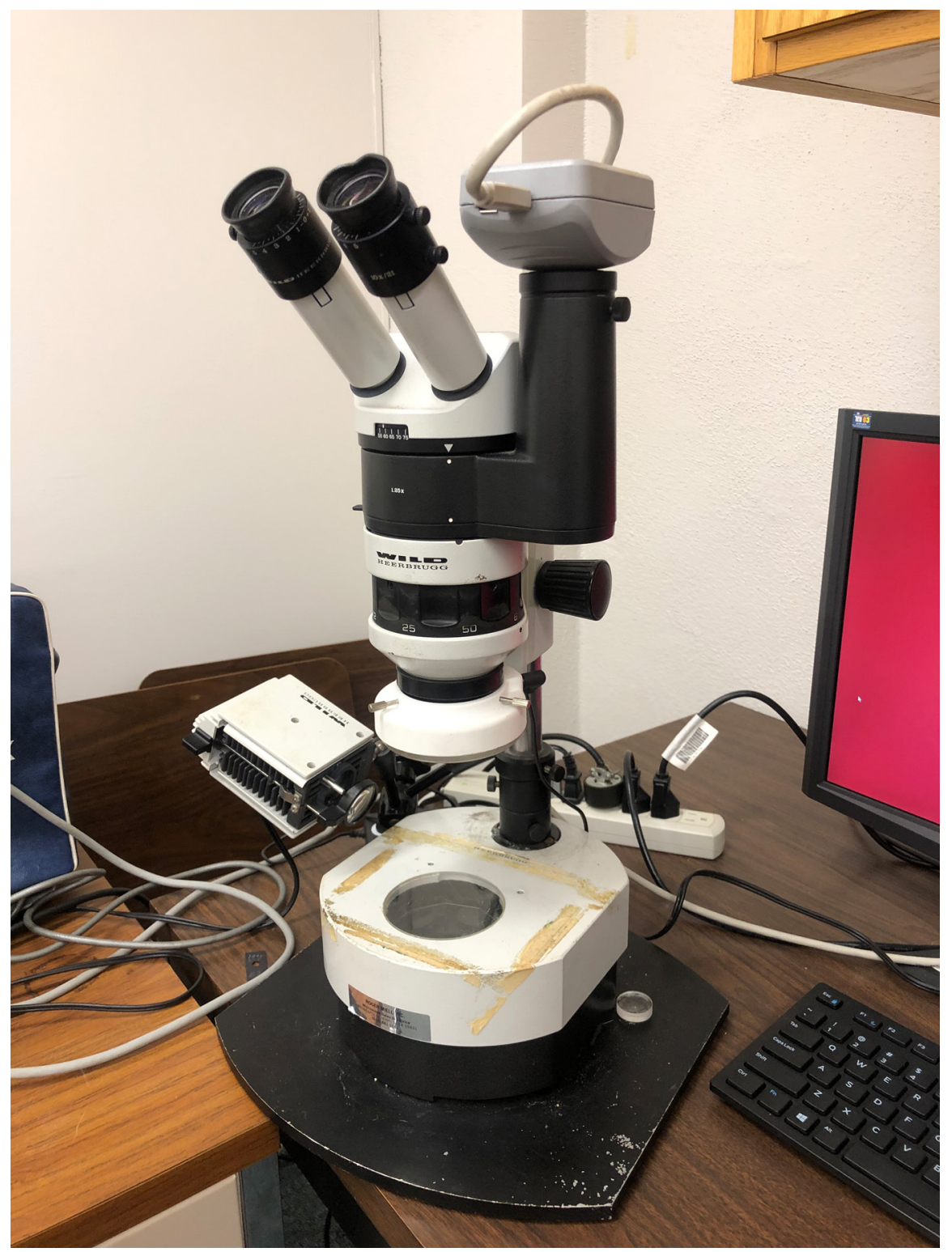

Figure 3.32 Wild Heerbrugg stereoscope used for analysis of the broken C(T) samples. 


\subsubsection{Microscopic Fracture Surface Examination}

The effect of cobalt on the fracture behavior was analyzed using a Philips/FEI XL30 Environmental Scanning Electron Microscope (ESEM) (Figure 3.33). Images of the samples were taken using secondary electrons (SE), as these are good at showing morphology and topography.

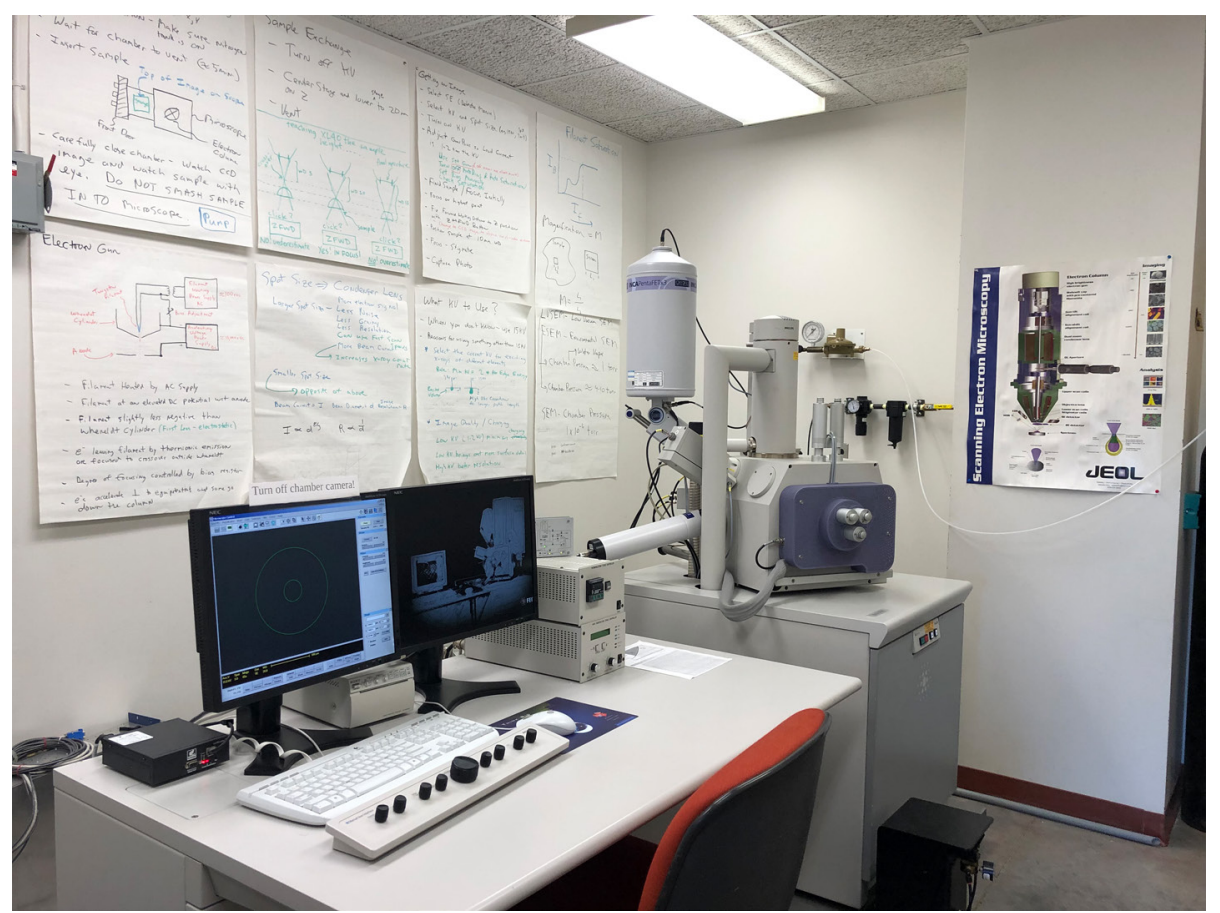

Figure 3.33 Philips/FEI XL30 ESEM used for the fracture surface analysis.

\subsubsection{Fracture Surface Analysis of Flat Tensile Samples}

The 2 and $6 \mathrm{~mm}$ broken samples from all heats, were coated with a Cressington 208HR high-resolution sputter coater (Figure 3.34) by applying a $10 \mathrm{~nm}$ thick layer of $\mathrm{Pt} / \mathrm{Pd}$. Then images were taken at a magnification of 500X and 1200X. 


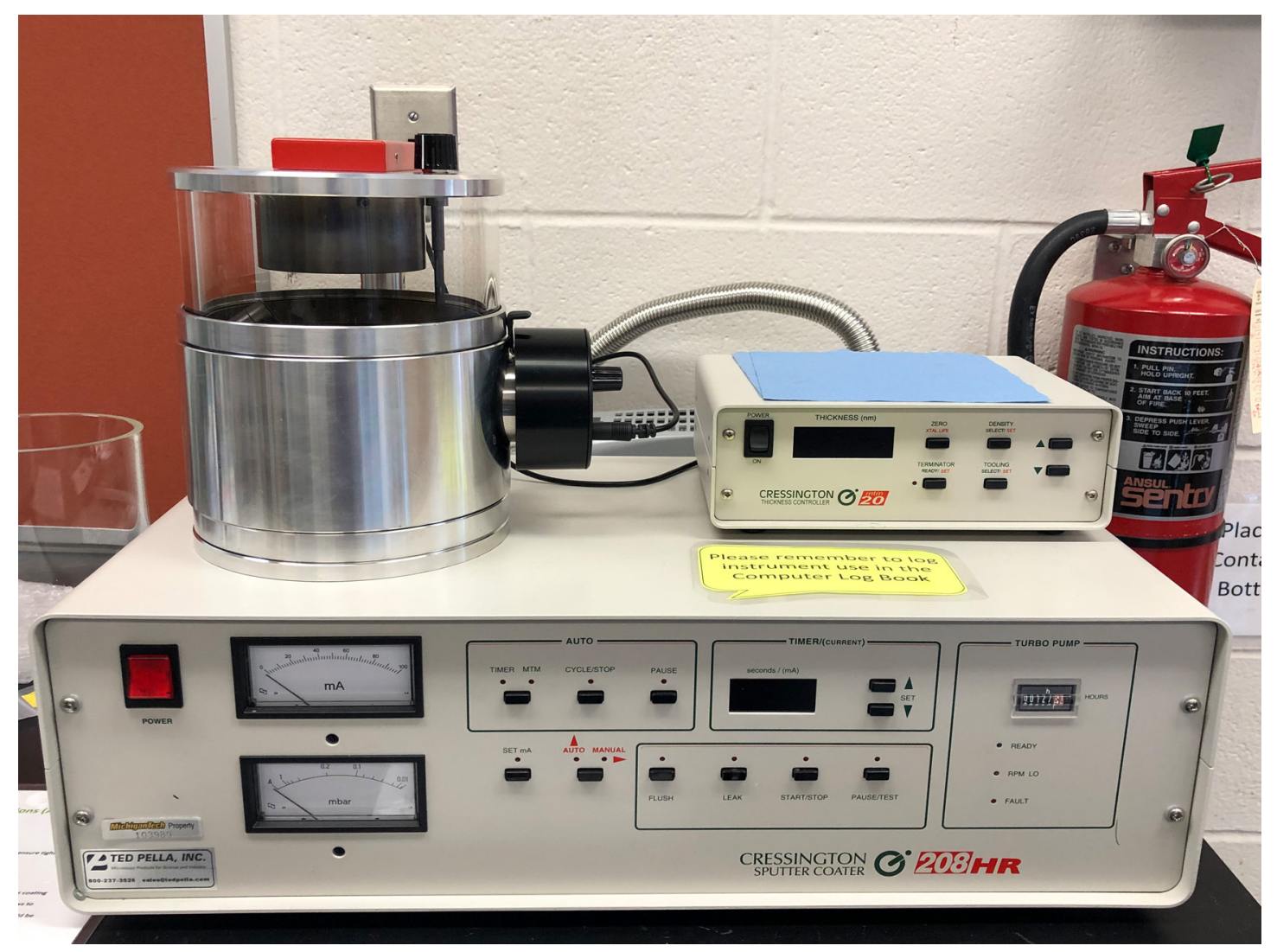

Figure 3.34 Cressington 208HR high-resolution sputter coater used to coat all the samples for fracture surface evaluation.

\subsubsection{Fracture Surface Analysis of Charpy Samples}

The v-notched and unnotched samples at $0^{\circ} \mathrm{C}$ of all heats were examined after coating with a $10 \mathrm{~nm}$ thick layer of Pt-Pd using the Cressington 208HR coater (Figure 3.34). For these samples, images were taken at $350 \mathrm{X}$ and $1000 \mathrm{X}$.

\subsubsection{Fracture Surface Analysis of C(T) Samples}

The broken $\mathrm{C}(\mathrm{T})$ samples tested at room temperature were coated with a $15 \mathrm{~nm}$ layer of Pt-Pd using the Cressington 208HR. Only the base ductile iron, 3 wt.\%, and 4 wt.\% Co samples were analyzed. A total of four images were taken at a magnification of $350 \mathrm{X}$ and $1000 X$. 


\subsubsection{Segregation Analysis}

As-polished samples were carbon-coated using a Denton DV-502A sputter coater (Figure 3.35) to examine the distribution of cobalt in the matrix between the graphite nodules. Energy Dispersive X-Ray Spectroscopy (EDS) was performed on the Philips/FEI XL30 ESEM (Figure 3.33). Quantitative EDS analysis was conducted using AZtec software. The operating conditions used for this analysis were an accelerating voltage of $15 \mathrm{kV}$ and a beam size of $1 \mu \mathrm{m}$. The $3 \mathrm{wt} . \%$ Co and $4 \mathrm{wt} . \%$ Co samples were analyzed. A total of three scans per sample were conducted showing similar behavior.

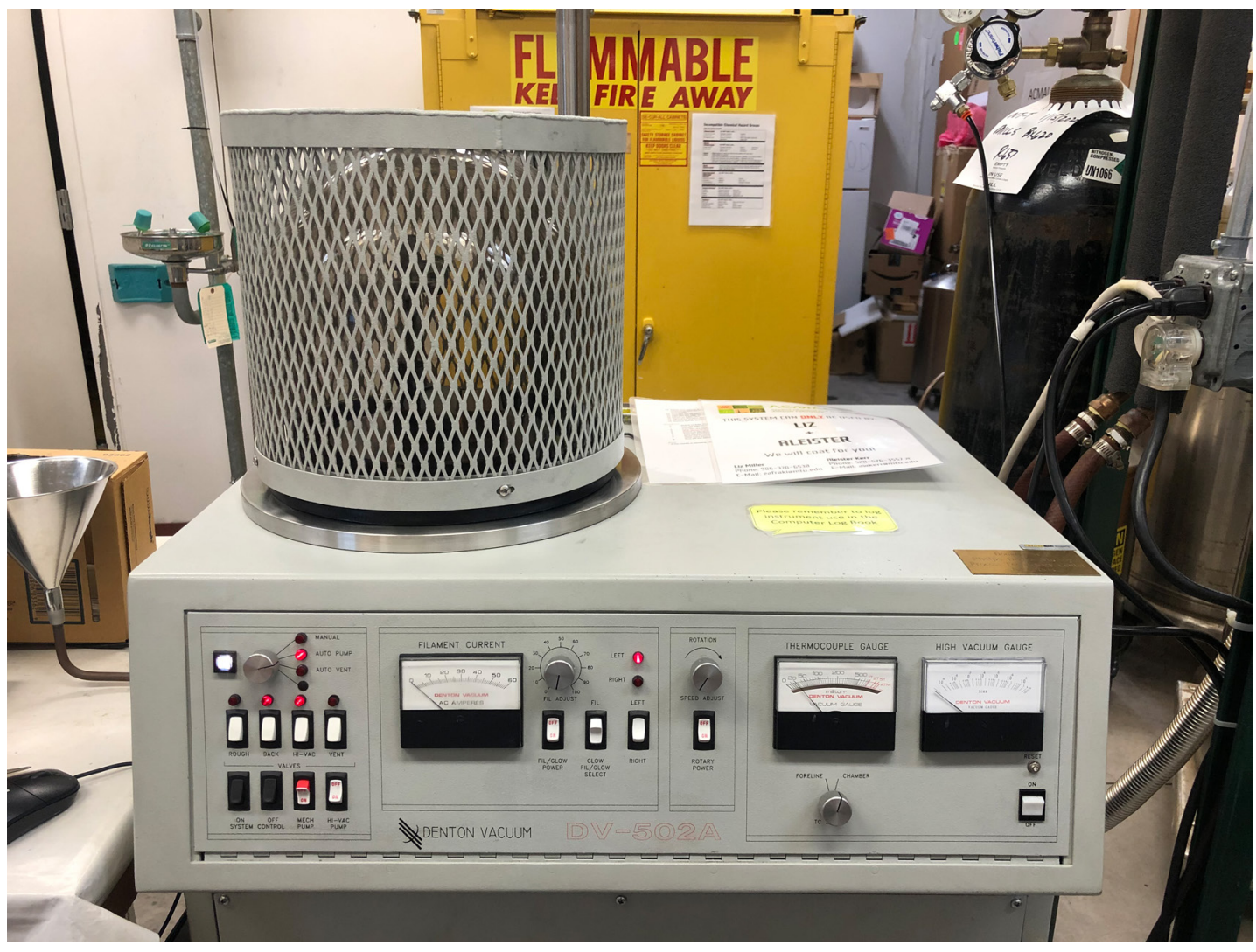

Figure 3.35 Denton DV-502A sputter coater used to carbon-coat the samples for EDS analysis. 


\subsection{Effect of Cobalt in Solid Solution Strengthened Ferritic Ductile Iron}

\subsubsection{Target Chemistry Selection and Furnace/Ladle Additions}

For this project, the EN-GJS-600-10 grade was fabricated with a lower silicon content. A total of four heats were carried out, and the aimed base chemical composition is given in Table 3.7. Three different cobalt additions were established ( 2 wt.\%, 3 wt.\%, and 4 wt.\% Co).

Table 3.7 Aimed base chemical composition (wt.\%)

\begin{tabular}{|c|c|c|c|c|c|c|c|c|}
\hline Element & C & Si & ${ }^{\mathrm{a}} \mathbf{C E}$ & Mg & Mn & $\mathrm{Cu}$ & $\mathbf{P}$ & ${ }^{b} \mathrm{Co}_{0}$ \\
\hline wt. $\%$ & 3.0 & $<4.3$ & 4.43 & $<0.06$ & $<0.25$ & $<0.10$ & 0.025 & - \\
\hline
\end{tabular}

A constant metallic charge for all heats was used to reduce the variation in chemical composition. The metallic charge consisted of $23 \mathrm{wt} . \%$ pig iron, $58 \mathrm{wt} . \%$ ductile iron returns, and $15 \mathrm{wt} . \%$ steel punchings, with additions of $1 \mathrm{x} 1$ inch cobalt chunks, Desulco ${ }^{\circledR}$ recarburizer, and 75 wt.\% FeSi (Table 3.8). 
Table 3.8 Chemical composition of the materials used to fabricate the heats (wt.\%)

\begin{tabular}{ccccccc}
\hline $\begin{array}{c}\text { Element } \\
\text { (wt.\%) }\end{array}$ & $\begin{array}{c}\text { Pig } \\
\text { Iron }\end{array}$ & $\begin{array}{c}\text { aDI } \\
\text { Returns }\end{array}$ & $\begin{array}{c}\text { Steel } \\
\text { punchings }\end{array}$ & $\begin{array}{c}\text { Cobalt } \\
\mathbf{1 x 1} \text { inch }\end{array}$ & Desulco $^{\circledR}$ & $\begin{array}{c}\text { 75 wt.\% } \\
\text { FeSi }\end{array}$ \\
\hline $\mathrm{C}$ & 4.35 & 3.61 & 0.08 & 0.002 & 99.7 & 0.005 \\
\hline $\mathrm{Si}$ & 0.12 & 2.66 & 0.22 & - & - & 76.55 \\
\hline $\mathrm{P}$ & 0.039 & 0.021 & 0.008 & - & - & 0.007 \\
\hline $\mathrm{S}$ & 0.013 & 0.007 & 0.005 & - & 0.030 & - \\
\hline $\mathrm{Mn}$ & 0.030 & 0.23 & 0.38 & - & - & 0.13 \\
\hline $\mathrm{Cu}$ & 0.016 & 0.07 & - & 0.003 & - & - \\
\hline $\mathrm{Ni}$ & 0.053 & 0.02 & - & 0.01 & - & - \\
\hline $\mathrm{Cr}$ & 0.036 & 0.03 & - & - & - & - \\
\hline $\mathrm{Al}$ & 0.003 & 0.015 & - & - & - & 0.38 \\
\hline $\mathrm{Ti}$ & 0.037 & 0.01 & - & - & & \\
\hline $\mathrm{V}$ & 0.044 & 0.011 & - & - & & \\
\hline $\mathrm{Ce}$ & - & 0.0019 & - & - & & \\
\hline $\mathrm{La}$ & - & 0.003 & - & - & & \\
\hline $\mathrm{Nb}$ & - & 0.002 & - & - & & \\
\hline $\mathrm{Sn}$ & - & 0.006 & - & - & & \\
\hline $\mathrm{Co}$ & - & - & - & 99.98 & & \\
\hline $\mathrm{Fe}$ & - & - & - & 0.0004 & & \\
\hline $\mathrm{Ca}$ & - & - & - & - & - & \\
\hline
\end{tabular}

${ }^{a}$ The chemical composition for the ductile iron returns varied depending on the available returns for remelting 
The chemistry of all the materials used in the 300-pound tundish ladle is shown in Table 3.9. Again, Inolate-40 was used as an inoculant.

Table 3.9 Chemical composition of the materials used in the ladle (wt.\%)

\begin{tabular}{ccccc}
\hline $\begin{array}{c}\text { Element } \\
(\mathbf{w t .} \%)\end{array}$ & $\begin{array}{c}\text { Elkem } \\
\text { LAMET } \\
\mathbf{4 6 1 9}\end{array}$ & $\begin{array}{c}\text { Cover } \\
\text { Steel }\end{array}$ & TopSeed ${ }^{\circledR}$ & Inolate-40 \\
\hline $\mathrm{C}$ & - & 0.08 & 0.094 & - \\
\hline $\mathrm{Si}$ & 45.59 & 0.22 & 49.04 & 72.54 \\
\hline $\mathrm{Mg}$ & 4.89 & - & - & - \\
\hline $\mathrm{Al}$ & 0.91 & - & 1.04 & 0.062 \\
\hline $\mathrm{Ca}$ & 1.083 & - & 0.99 & 1.24 \\
\hline $\mathrm{La}$ & 0.58 & & & \\
\hline${ }^{\mathrm{a} E}$ & - & - & - & 0.60 \\
\hline $\mathrm{Bi}$ & - & - & - & 0.98 \\
\hline $\mathrm{Ba}$ & - & - & 1.03 & - \\
\hline $\mathrm{P}$ & - & 0.008 & - & - \\
\hline $\mathrm{S}$ & - & 0.005 & - & - \\
\hline $\mathrm{Mn}$ & - & 0.38 & - & - \\
\hline $\mathrm{Cu}$ & - & - & - & - \\
\hline $\mathrm{Ni}$ & - & - & - & - \\
\hline
\end{tabular}

${ }^{a}$ RE: rare earths 


\subsubsection{Mold Preparation}

For this project, 1-inch ASTM A536 [80] Y-blocks were prepared using chemically bonded sand with a Tinker Omega NexGen2 ${ }^{\mathrm{TM}}$ mixing system (Figure 3.3). The mold used had a set of three Y-block patterns in it. Figure 3.36, shows several stacked molds made before casting. Each sand mold weighs 92 pounds, and six molds per heat were made, resulting in a total of 24 molds.

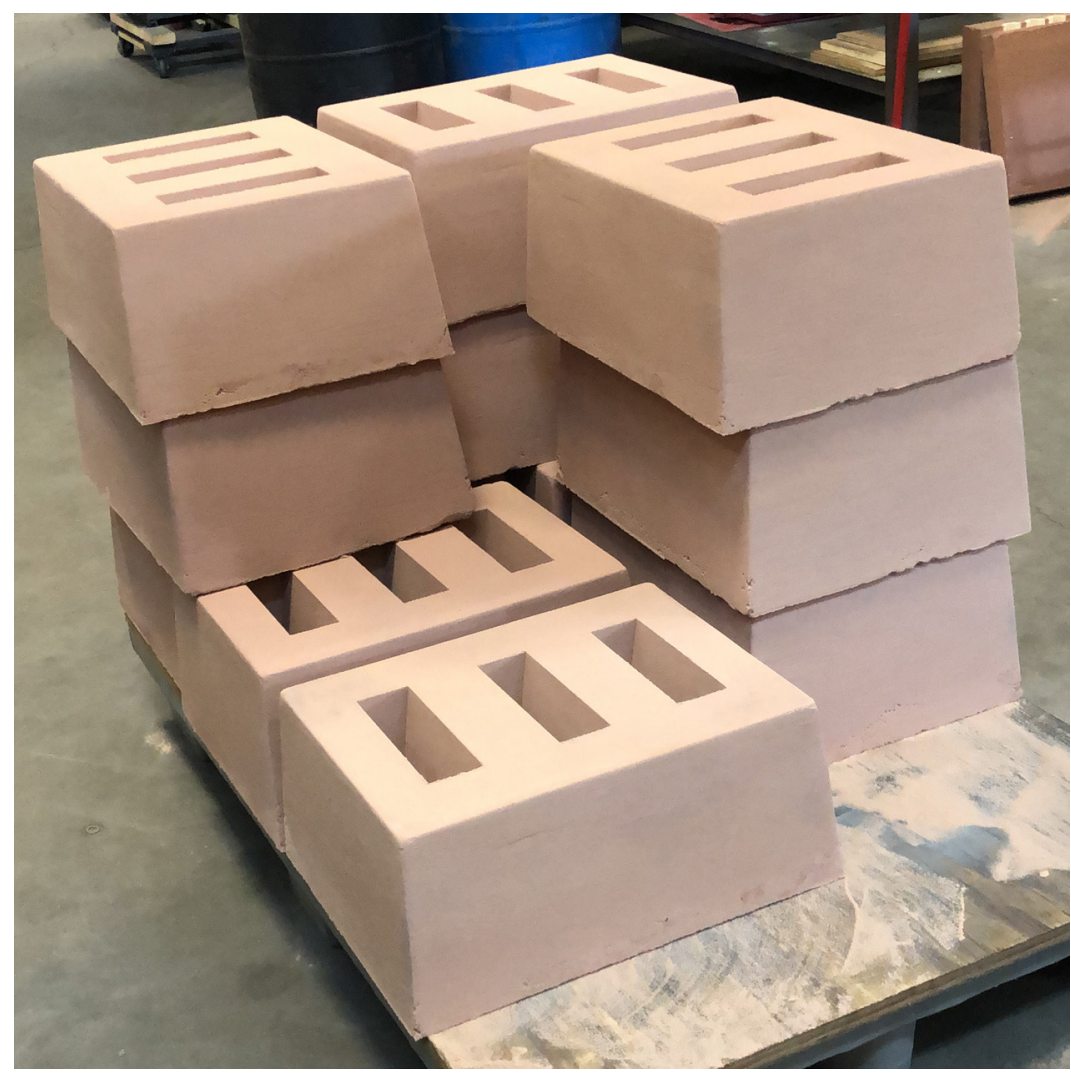

Figure 3.36 Chemically bonded 1-inch Y-block sand mold.

\subsubsection{Melting and Pouring Procedure}

The heats were fabricated using the 300-pound coreless induction furnace shown in Figure 3.4 at Michigan Tech. After weighing all the materials needed to produce these heats, the furnace is loaded with ductile iron returns, pig iron, $1 \mathrm{x} 1$ inch cobalt chunks, steel punchings, Desulco ${ }^{\circledR}$ recarburizer, and $75 \mathrm{wt} . \% \mathrm{FeSi}$. The furnace is heated to 
$1420^{\circ} \mathrm{C}$, and when everything is melted the base iron composition is taken. If the chemistry is not within specification, the necessary adjustments are made. Figure 3.37 shows how the furnace charge materials look before and after being melted.

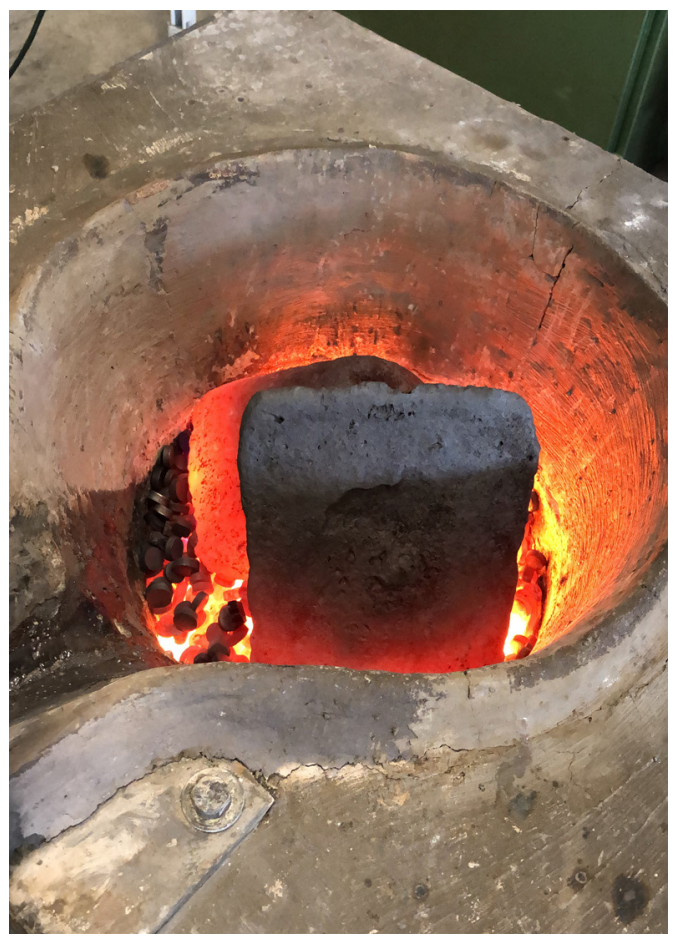

(a)

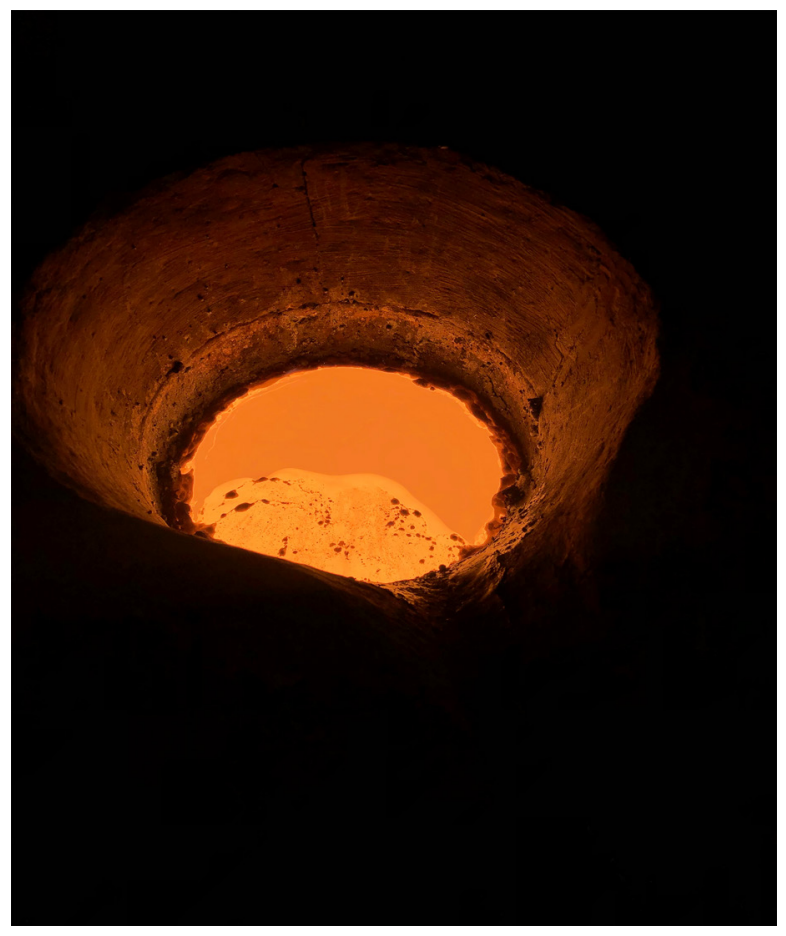

(b)

Figure 3.37 Furnace charge (a) before, and (b) after meltdown.

Once the base iron chemistry is within the target, $75 \mathrm{wt} . \% \mathrm{FeSi}$ is added to the furnace to precondition the melt five minutes before tapping. Then, the tundish ladle is positioned near the furnace (Figure 3.38) to start tapping at $1500^{\circ} \mathrm{C}$. Inoculation of the melt is done by adding the Inolate- 40 to the stream of the metal while tapping from the furnace to the ladle (Figure 3.39). 


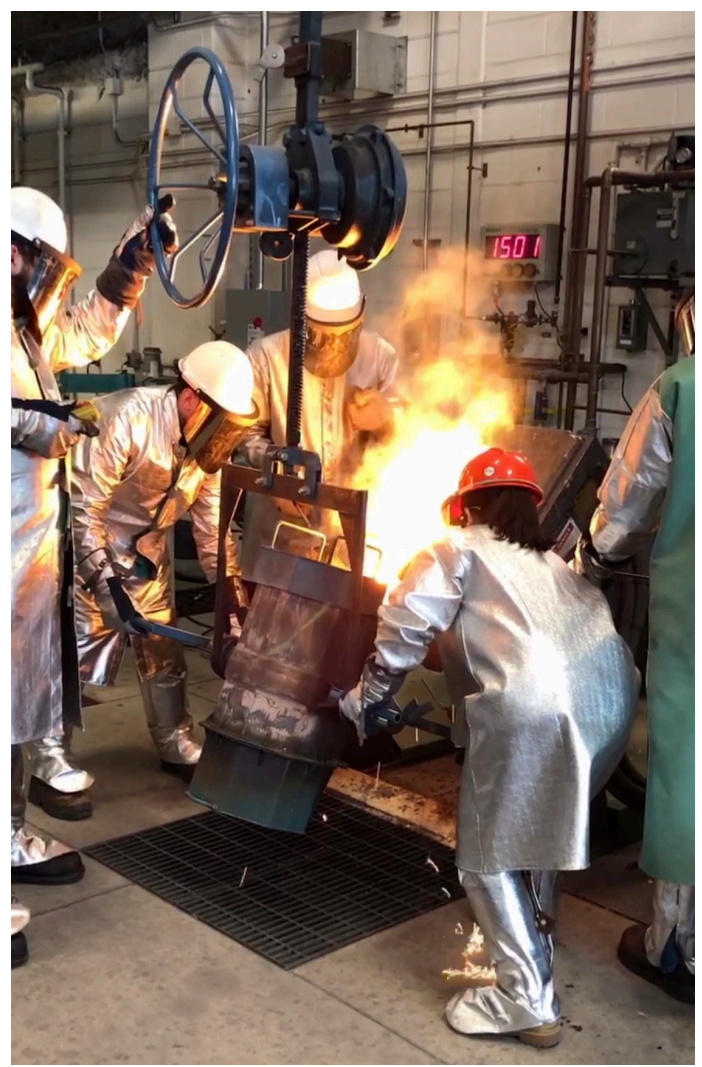

Figure 3.38 Tapping of the furnace to the tundish ladle.

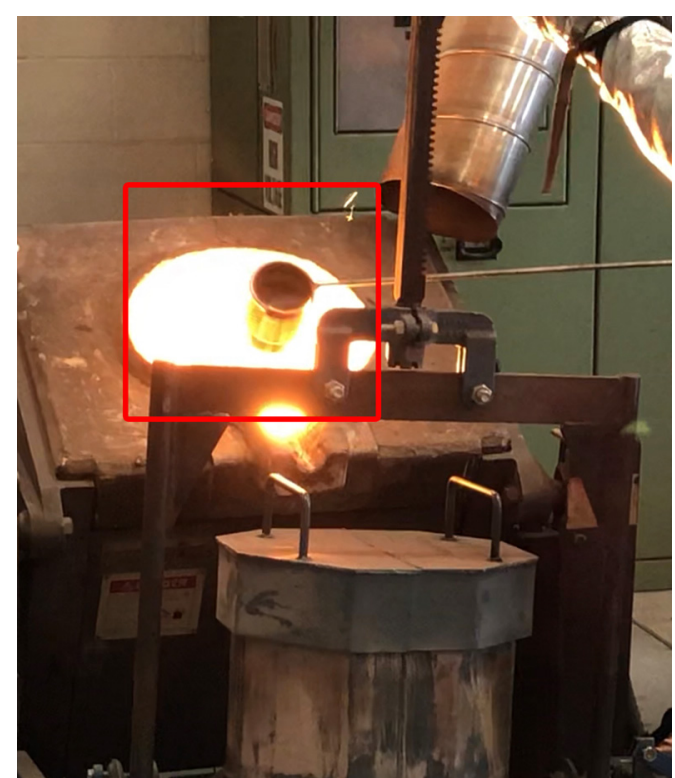

Figure 3.39 Metal stream inoculation using Inolate-40 enclosed in red. 
The pouring of the 1-inch Y-block molds starts once the Mg-reaction in the tundish ladle is over. The thermal analysis and spectrometer sample for the final chemistry are taken after pouring one mold. An extra spectrometer sample is conducted at the end to ensure that the magnesium is above $0.040 \mathrm{wt} . \%$. Figure 3.40 shows the pouring of one mold, and the final pouring line is observed in Figure 3.41.

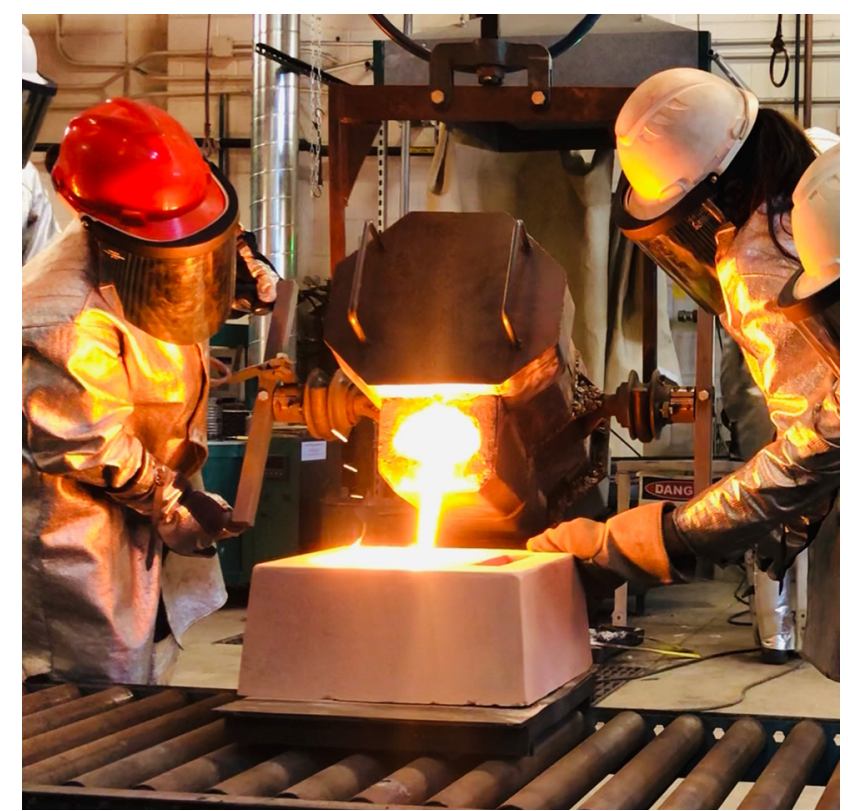

Figure 3.40 Pouring of one ASTM A536 1-inch Y-block mold.

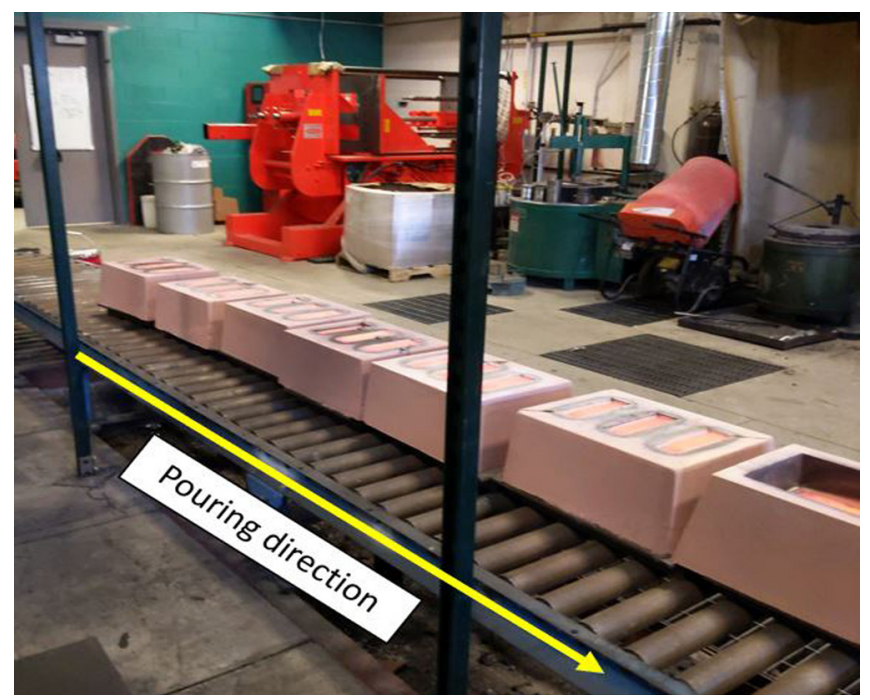

Figure 3.41 Arrangement of the molds after pouring. 
The final chemical compositions were performed by Lehigh Testing Laboratories Inc., using inductively coupled plasma atomic emission spectroscopy (ICP-AES). Then, samples were sent out to Aarrowcast, Inc., to execute combustion analysis (Leco).

\subsubsection{Shake-out of the Molds}

The molds were left overnight, and wire brushing was used to remove the excess of sand (Figure 3.42). A total of $18 \mathrm{Y}$-blocks per heat were made, resulting in 72 castings.

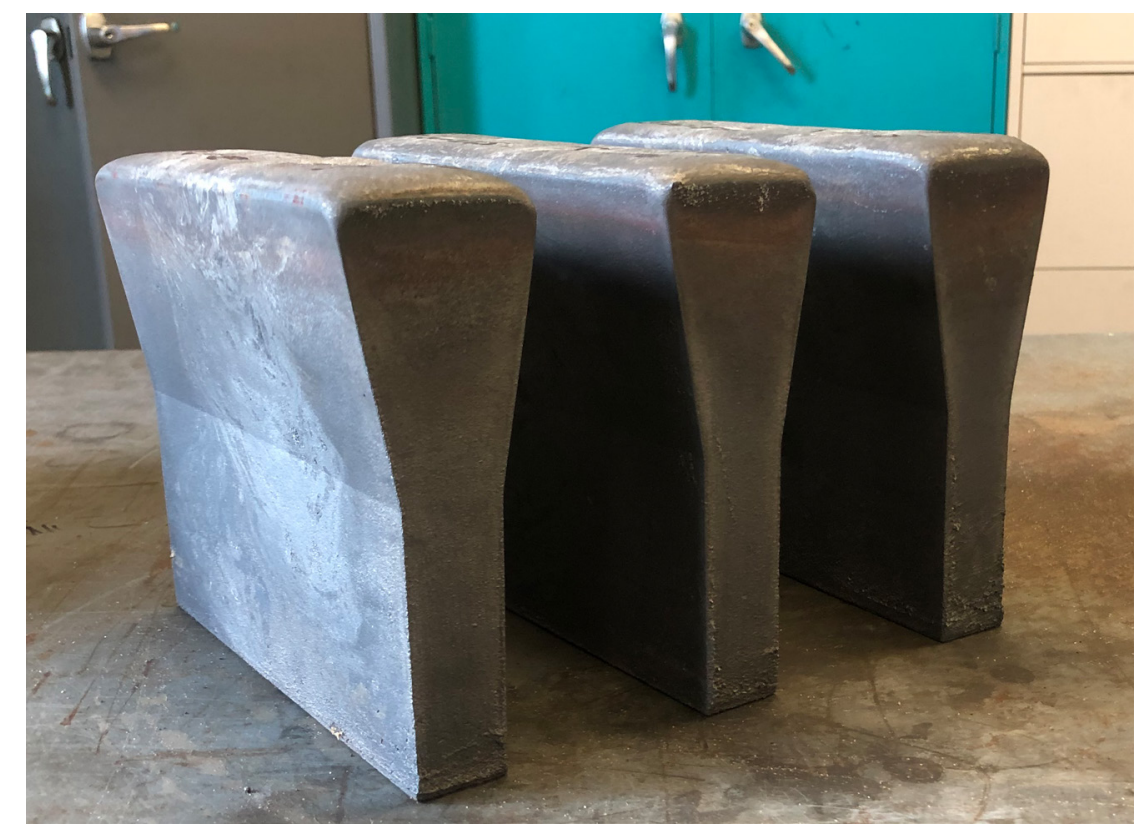

Figure 3.42 Set of three 1-inch Y-blocks after shaking out one mold.

\subsubsection{Microstructure Evaluation}

\subsubsection{Location of Metallographic Sample}

The bottom inch of the Y-blocks was sectioned with the Baileigh band saw shown in Figure 3.12. The middle cross-section of the first and last Y-blocks poured was used to perform the metallographic analysis (Figure 3.43). 


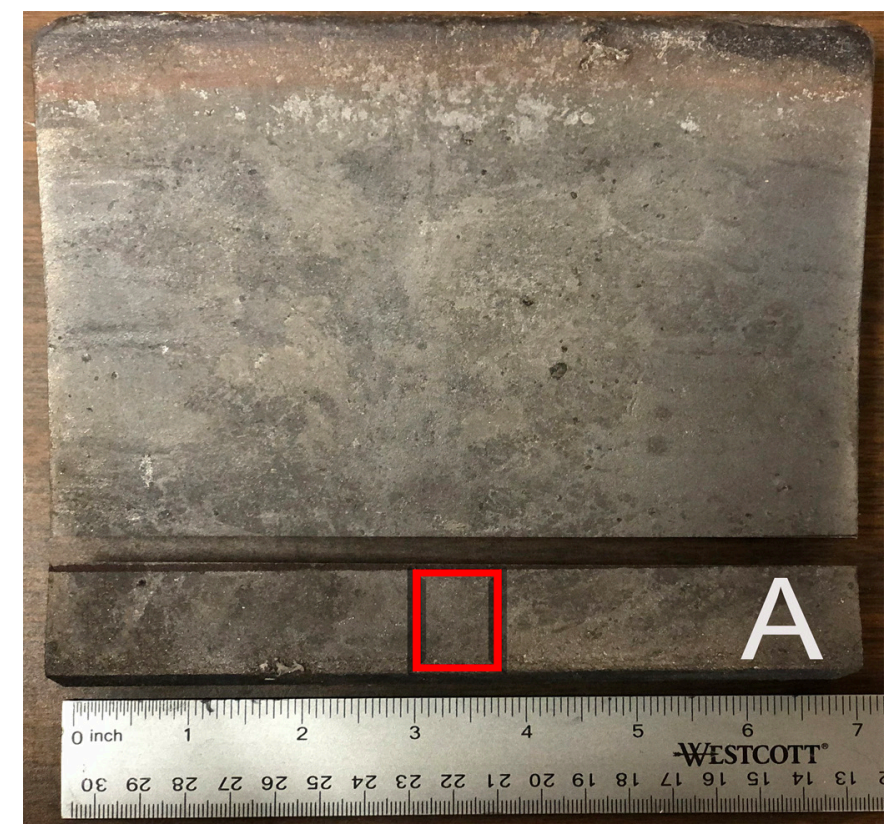

Figure 3.43 Location of the metallographic sample in the 1-inch Y-blocks.

The cross-section samples were ground and polished manually using a Leco Spectrum System ${ }^{\circledR} 1000$ polisher/grinder 8-inch machine. The metallographic procedure used was the same as the one provided in Table 3.6 for the $1 / 2$ inch Y-blocks. A total of 8 samples were analyzed.

\subsubsection{Graphite Analysis}

A total of five images were taken at $100 x$ to perform percent nodularity and nodule count with ImageJ following ASTM E2567 [82] and ISO 945-1 [83].

\subsubsection{Ferrite and Pearlite Analysis}

The cross-section samples were etched with $2 \%$ Nital. The built-in macro file described earlier was used to analyze the percentages of ferrite and pearlite. The results provided are the average of five fields. 


\subsubsection{Tensile Properties Evaluation}

\subsubsection{Location of Round Tensile Samples}

The round tensile samples were obtained by sectioning the bottom inch of the Y-blocks with a Peerless LHM-280 metal horizontal hacksaw (Figure 3.44). Figure 3.45 shows the location of the round bars that were machined out of the 1-inch Y-blocks. The dimensions are per ASTM E8 [84] (Figure 3.46), and the results are the average of six samples per heat.

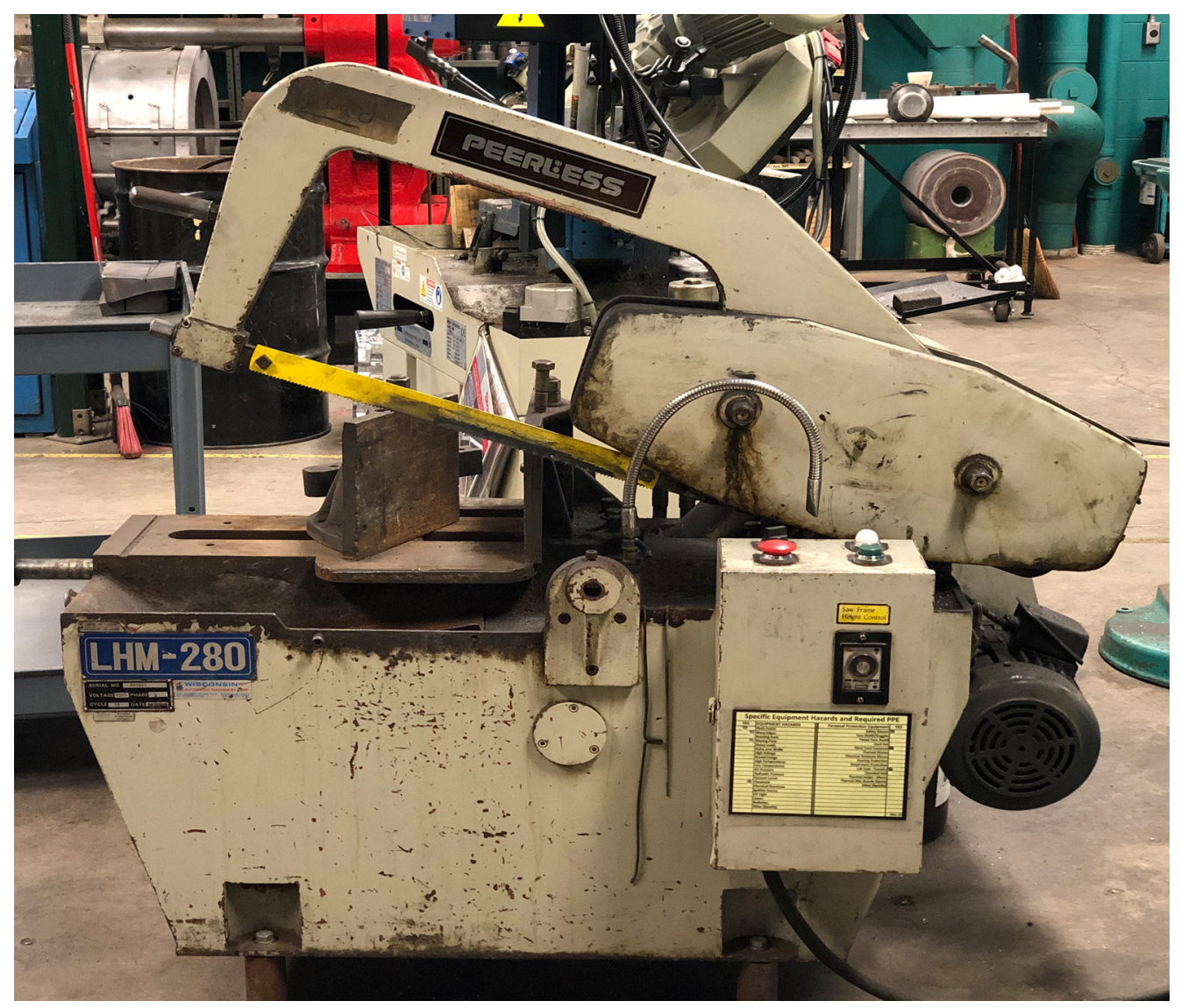

Figure 3.44 Hacksaw used to cut the 1-inch Y-blocks. 


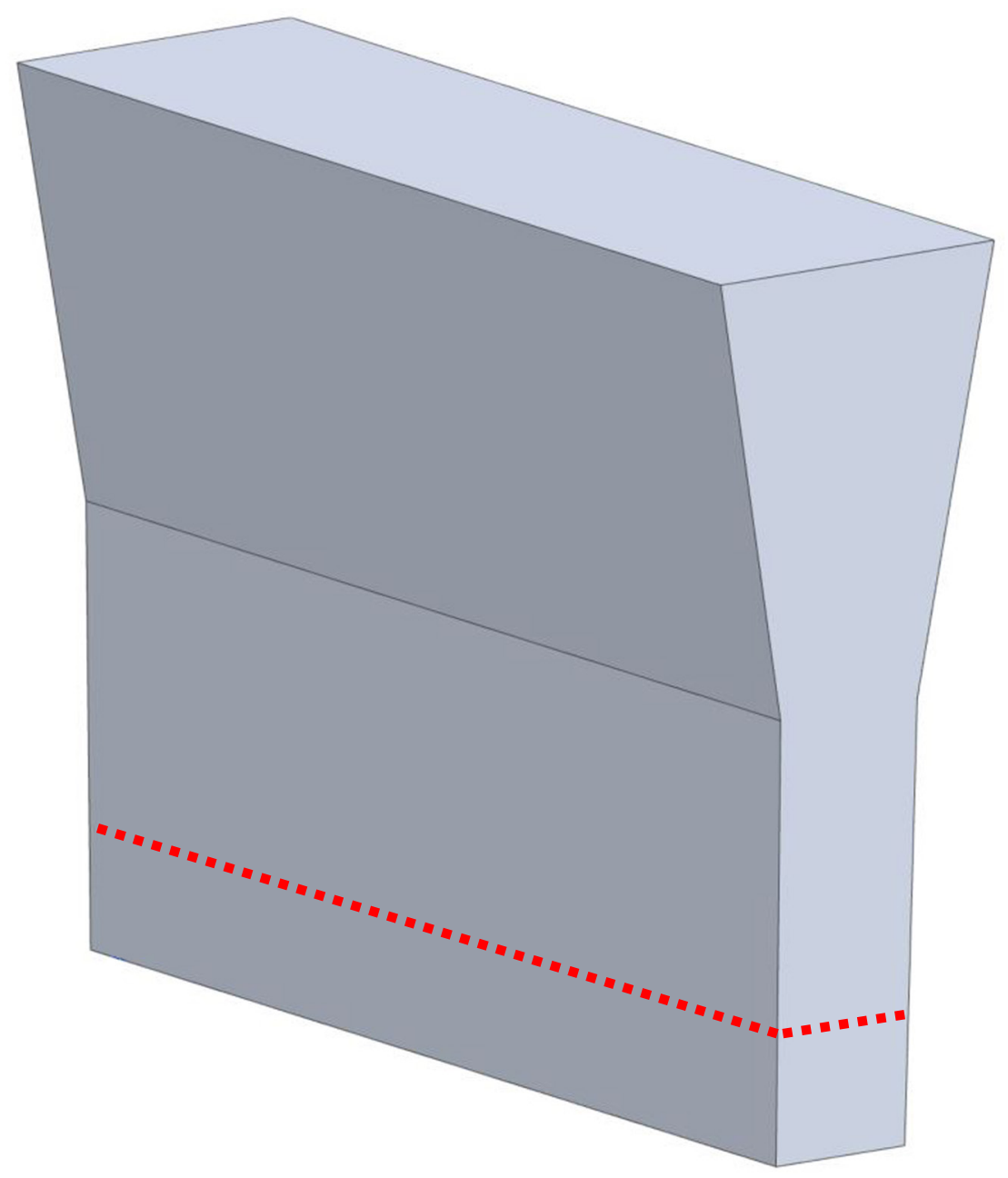

Figure 3.45 Location of the bottom inch section removed from the Y-block to machine the tensile bars.
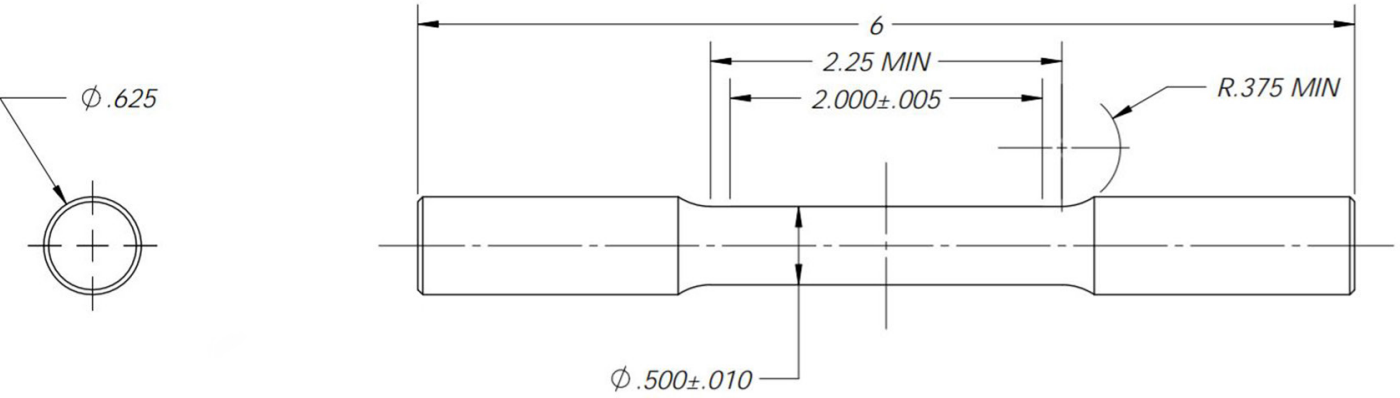

Figure 3.46 Dimensions (mm) of the round tensile bar per ASTM E8 [84]. 


\subsubsection{Loading and Testing}

The tensile test was performed per ASTM E8 [84] at Waupaca Foundry by Kassia Prystalski. A Tinius Olsen tensile testing machine was used (Figure 3.47) with a crosshead displacement speed of $2 \mathrm{~mm} / \mathrm{min}$ and a 2 -inch gauge length extensometer.

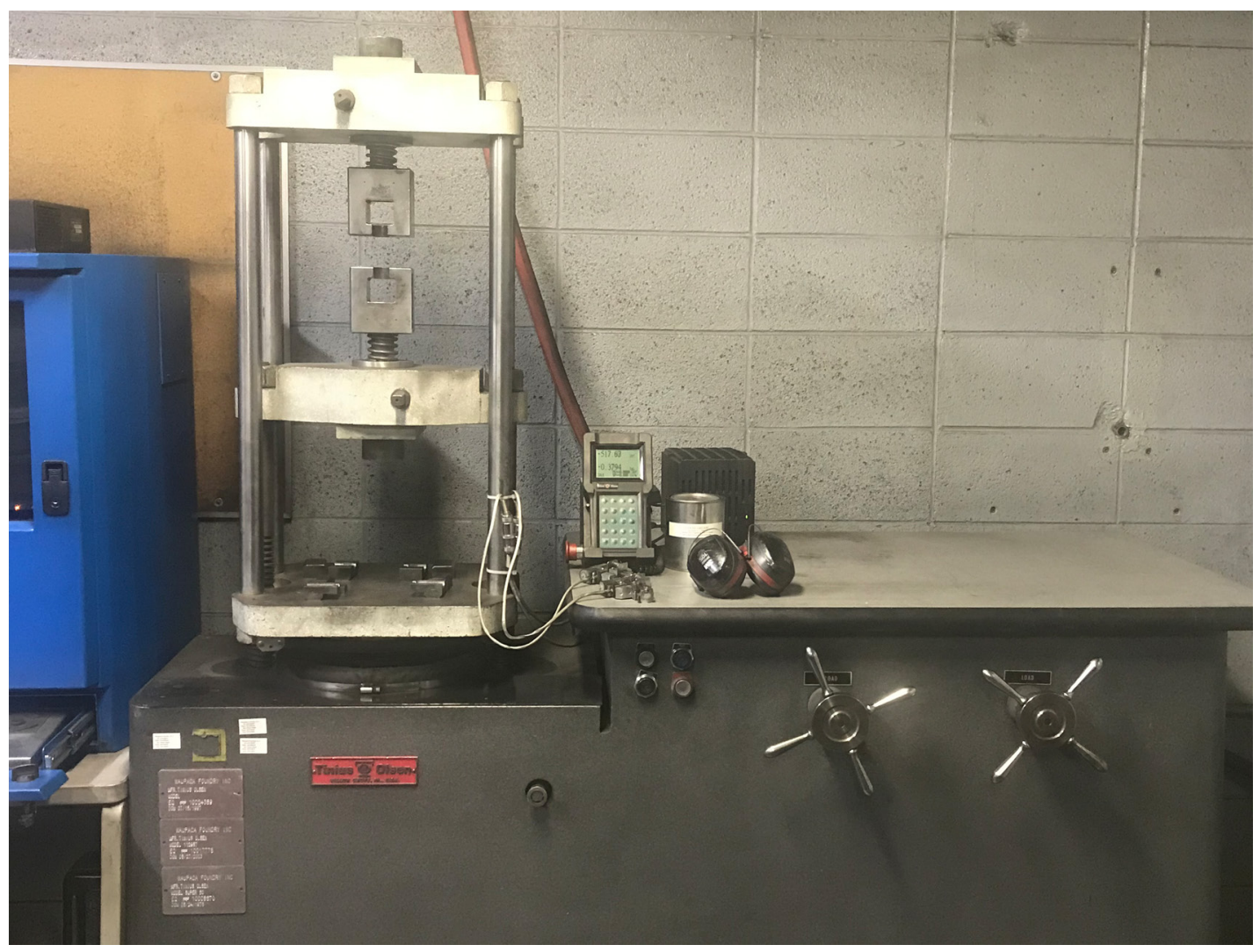

Figure 3.47 Tinius Olsen tensile testing machine used for the round tensile samples of the 1-inch Y-blocks.

\subsubsection{Macrohardness Evaluation}

The bottom inch of the Y-blocks was ground until the casting skin was removed. Brinell hardness was performed using the portable Dyna tester shown in Figure 3.20. A $3000 \mathrm{~kg}$ load with a $10 \mathrm{~mm}$ ball indenter and a dwell time of 15 seconds was applied. The results are the average of nine readings (Figure 3.48). 


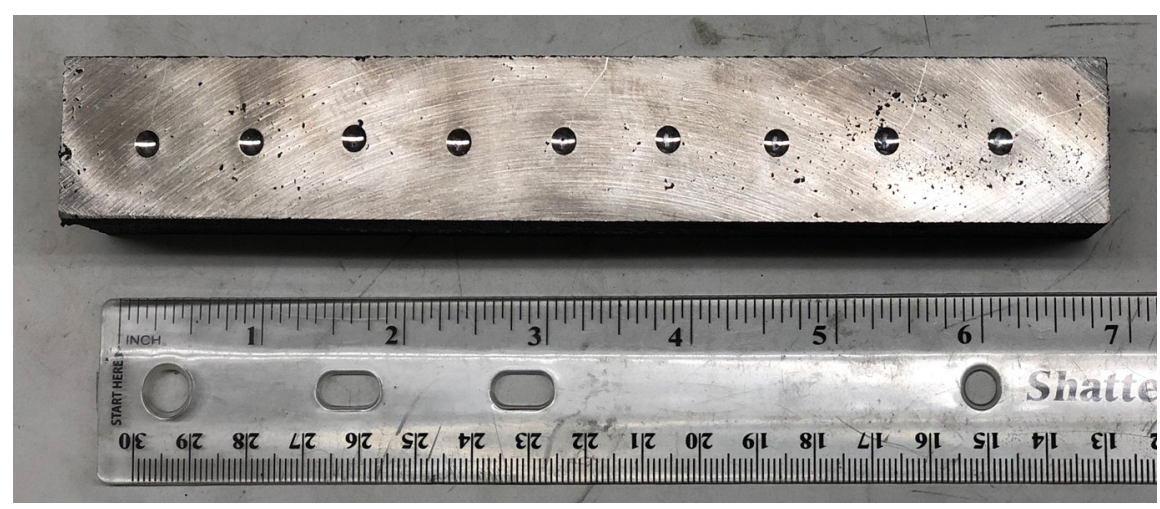

Figure 3.48 Brinell hardness test of the bottom inch of the Y-blocks.

\subsubsection{Microhardness Evaluation}

The $2 \%$ Nital etched cross-section of the 1-inch Y-blocks were used to perform Vickers hardness using the LECO M-400-G1 hardness tester shown in Figure 3.21 applying a 100-gram load with a 10 second dwell time. The results are the average of ten indentations per sample.

\subsubsection{Impact Energy Evaluation}

Impact testing was performed per ASTM E23 [85] by Dr. Welt Travis using the MTS Exceed $^{\circledR}$ E22 machine shown in Figure 3.22 at the University of Saint Thomas. Figure 3.49 shows the location of the unnotched Charpy samples that were machined from the bottom inch of the Y-blocks. The dimensions for the unnotched samples are given in Figure 3.24a. Four temperatures were tested: $22.6,50,100$, and $150^{\circ} \mathrm{C}$. For the hightemperature testing, a Gilson forced-air convection oven was used (Figure 3.50). The oven was calibrated using a thermocouple and a spot check of a sample at each temperature till the temperature of interest was reached. The reported values at each temperature are the average of 3 tests, resulting in 12 samples per heat. 


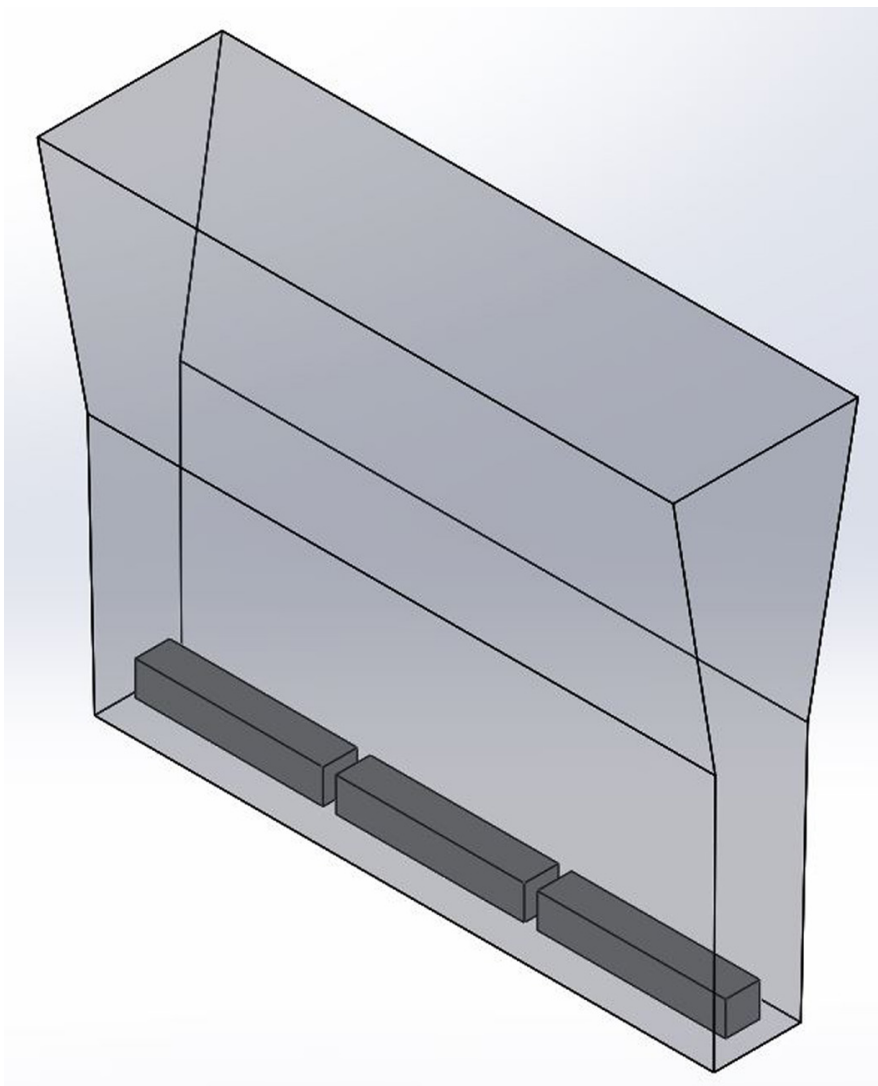

Figure 3.49 Location of unnotched Charpy samples in the 1-inch Y-block.

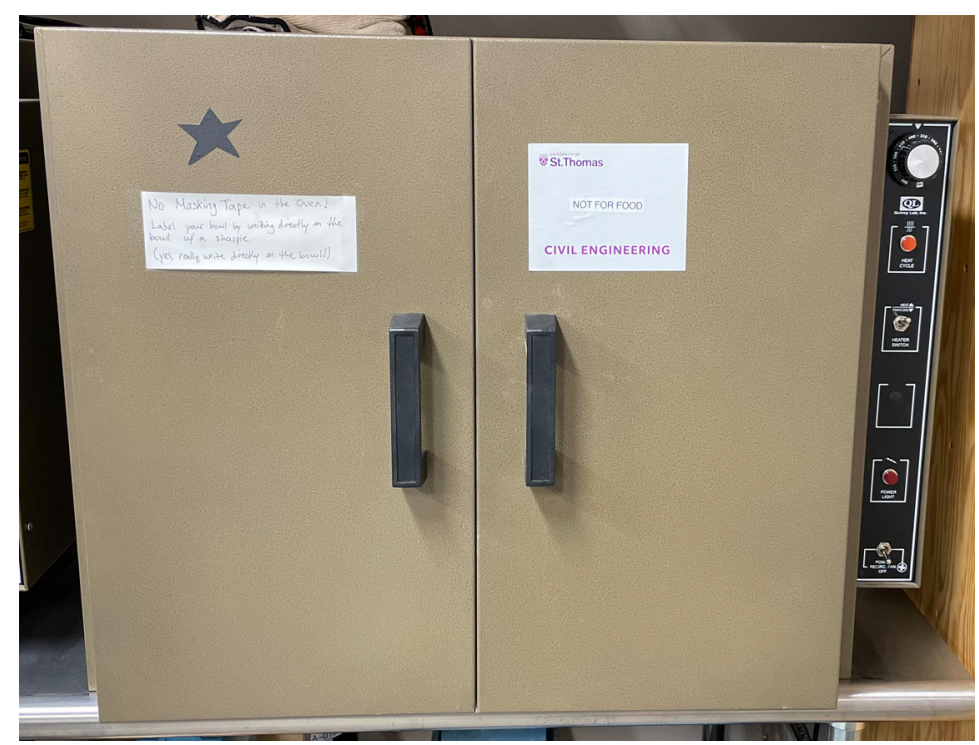

Figure 3.50 Oven for high-temperature impact testing. 


\subsubsection{Fracture Toughness Evaluation}

\subsubsection{Location of Fracture Toughness Samples}

Fracture toughness testing was carried out according to ASTM E1820 [87], applying the J-integral method. Three $\mathrm{C}(\mathrm{T})$ samples were machined out from the 1-inch Y-blocks (Figure 3.51). The dimensions of the $\mathrm{C}(\mathrm{T})$ samples are shown in Figure 3.52.

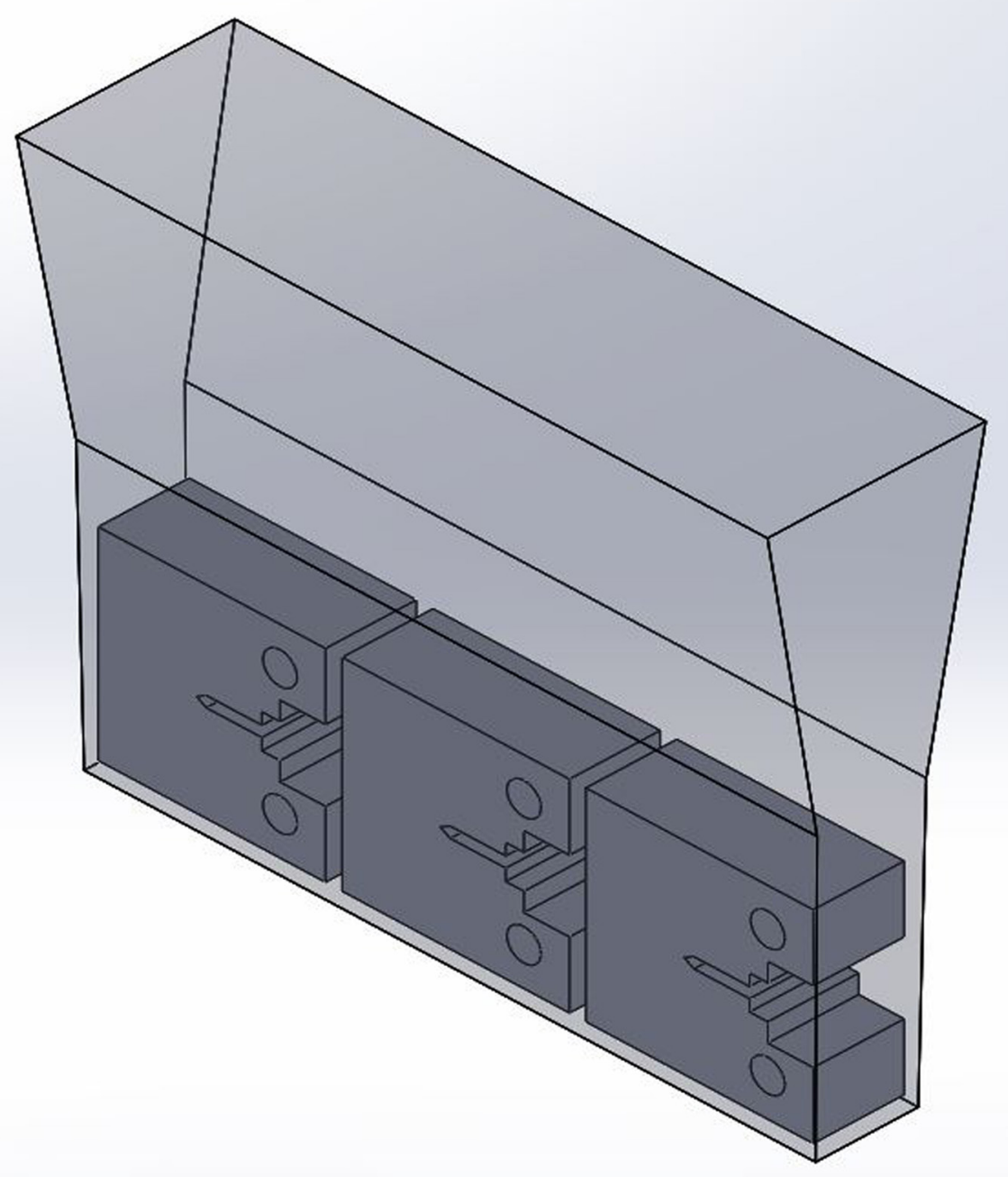

Figure 3.51 Location of the $\mathrm{C}(\mathrm{T})$ samples in the 1-inch Y-blocks. 

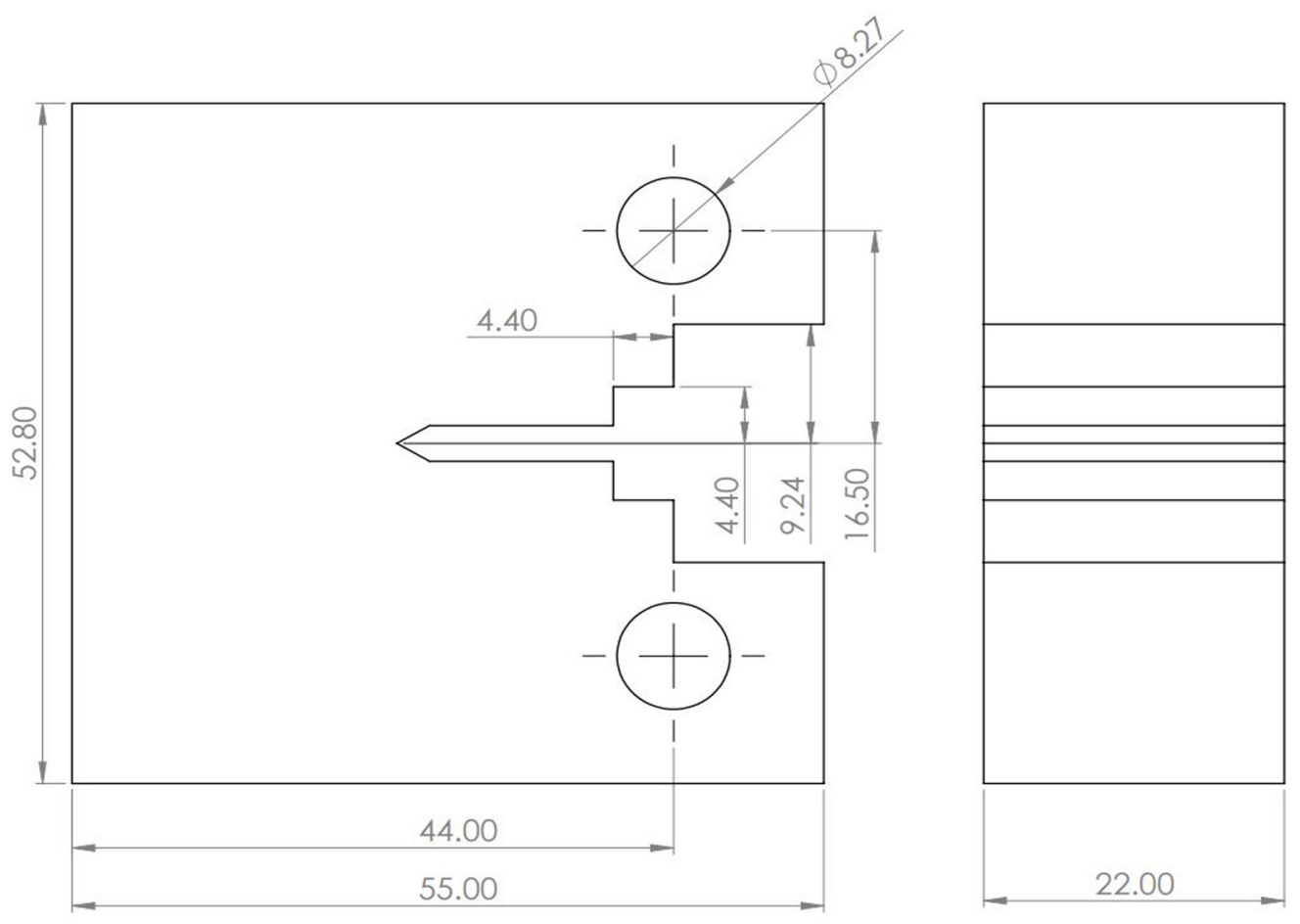

Figure 3.52 Dimensions ( $\mathrm{mm})$ used for the $\mathrm{C}(\mathrm{T})$ samples from the 1-inch Y-blocks per ASTM E1820 Annex 3 [87]. 


\subsubsection{Fatigue Pre-cracking of C(T) Samples}

Fatigue pre-cracking per ASTM E1820 [87] was conducted under force control with a sinusoidal loading waveform and a frequency of $10 \mathrm{~Hz}$. The $\mathrm{C}(\mathrm{T})$ samples are carefully loaded and aligned in an MTS 312.21 floor standing fatigue frame (Figure 3.53).

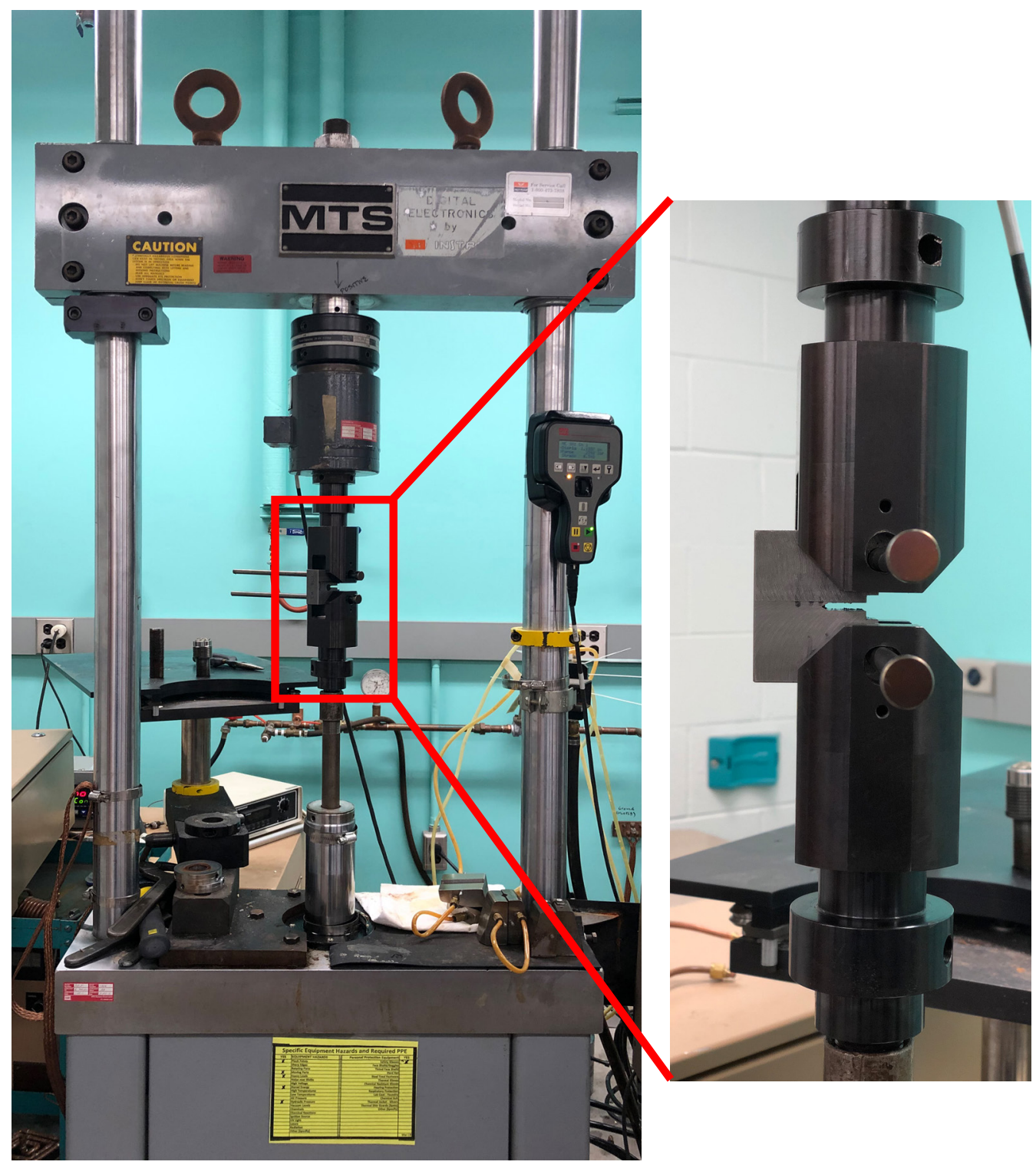

Figure 3.53 Fatigue frame configuration used to pre-crack the $\mathrm{C}(\mathrm{T})$ samples from 1-inch Y-blocks. 


\subsubsection{Loading and Testing}

The testing was performed at $22.6,50,100$, and $150^{\circ} \mathrm{C}$ using an Instron 4210 machine.

For the high-temperature tests, a portable Lab-Temp ${ }^{\mathrm{TM}} \mathrm{LBO}$-Series medium-range furnace was assembled into the Intron 4210 frame. A thermocouple was placed on each sample to monitor the temperature, and testing was started once the targeted temperature was attained. A 10,000-pound FUTEK load cell and an epsilon model 3541 COD gauge were employed. Figure 3.54, shows the setup of the machine and a magnified view of the sample before executing the test.

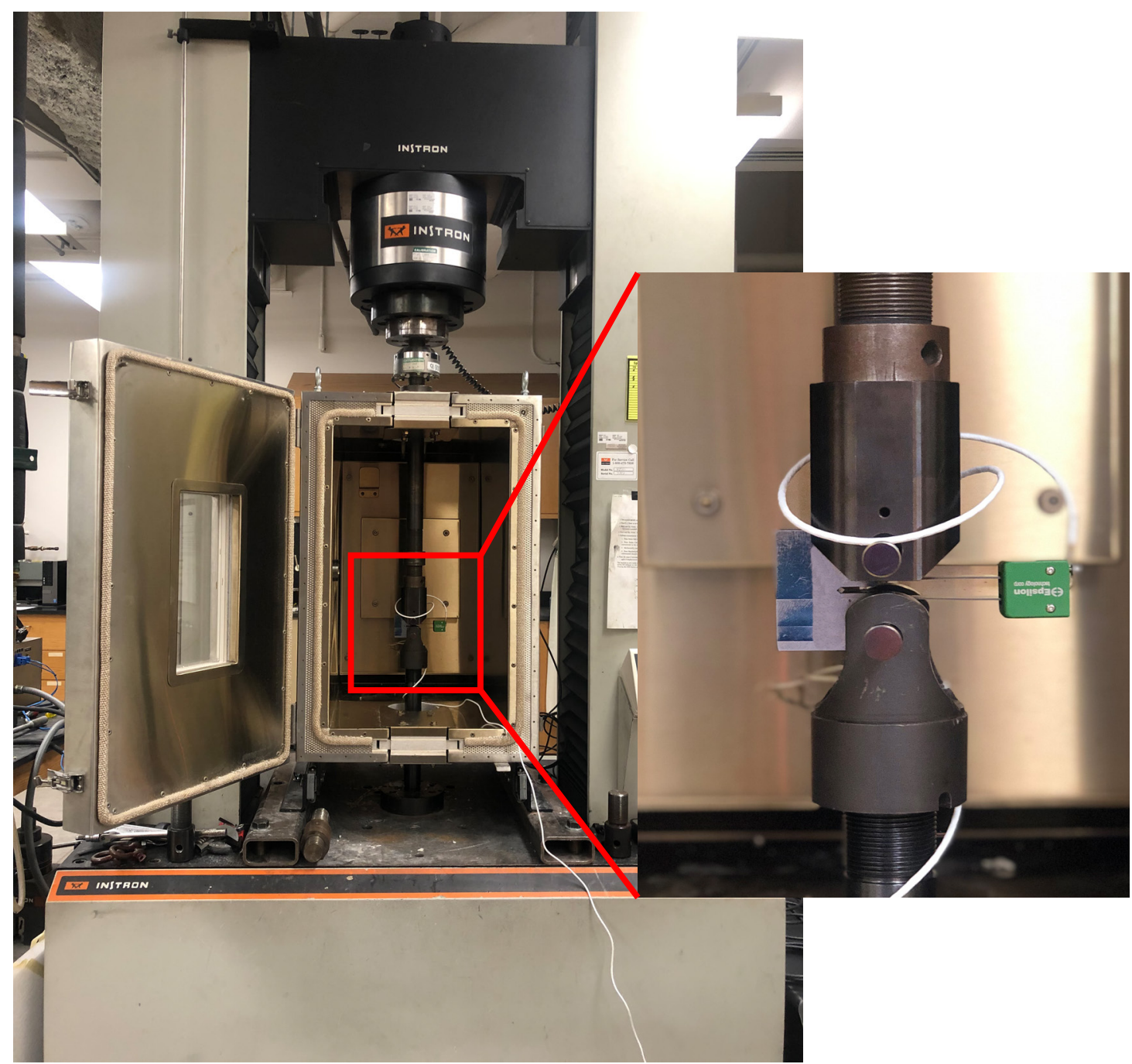

Figure 3.54 Assembly for the fracture toughness test of $\mathrm{C}(\mathrm{T})$ samples from the 1-inch $\mathrm{Y}$ blocks. 


\subsubsection{Data Analysis}

After all the testing was completed, the $\mathrm{C}(\mathrm{T})$ samples that displayed a ductile fracture were examined using the Wild Heerbrugg stereoscope (Figure 3.32). Images were taken via PixeLink software to measure the initial and final crack size per ASTM E1820 [87] using ImageJ. Finally, the normalization data reduction analysis was conducted using the open-source software developed by Oak Ridge National Laboratory [88].

\subsubsection{Microscopic Fracture Surface Examination}

\subsubsection{Fracture Surface Analysis of C(T) Samples}

The base SSF, 3 wt. $\%$, and 4 wt. $\%$ Co fractured samples tested at $150^{\circ} \mathrm{C}$ were analyzed using the Philips/FEI XL30 ESEM (Figure 3.33). The samples were coated with a $15 \mathrm{~nm}$ layer of Pt-Pd using the Cressington 208HR high-resolution sputter coater (Figure 3.34), and four SE images per sample at a magnification of 350X and 1000X were taken.

\subsubsection{Segregation Analysis}

The 3 wt.\% and 4 wt.\% Co as-polished samples were carbon-coated using the Denton DV-502A sputter coater (Figure 3.35) to perform EDS and analyze the segregation profile of cobalt in the ferritic matrix of high silicon ductile iron. An accelerating voltage of $15 \mathrm{kV}$ and a beam size of $1 \mu \mathrm{m}$ was used for this analysis. A total of three scans per sample were conducted showing similar behavior. 


\section{Results}

\subsection{Effect of Cobalt in Thin Wall Ductile Iron}

\subsubsection{Chemical Composition}

The measured chemical compositions are close to the targets (Table 4.1), with the carbon and silicon varying slightly. The Leco carbon and sulfur agree well with the OES results. The Mg levels are all $<0.040$. Cobalt values were on target, while the manganese and copper contents were kept as low as possible.

Table 4.1 Final chemical composition for thin castings (wt.\%)

\begin{tabular}{ccccccc}
\hline Element & Target & $\begin{array}{c}\text { Base } \\
\text { DI }\end{array}$ & $\begin{array}{c}\text { 1 wt.\% } \\
\text { Co }\end{array}$ & $\begin{array}{c}\text { 2 wt.\% } \\
\text { Co }\end{array}$ & $\begin{array}{c}\text { 3 wt.\% } \\
\text { Co73 }\end{array}$ & $\begin{array}{c}\text { 4 wt.\% } \\
\text { Co }\end{array}$ \\
\hline Leco C & & 3.76 & 3.74 & 3.73 & 3.68 & 3.75 \\
\hline $\mathrm{C}$ & 3.73 & 3.72 & 3.64 & 3.71 & 3.74 & 3.79 \\
\hline $\mathrm{Si}$ & 2.50 & 2.58 & 2.45 & 2.40 & 2.57 & 2.41 \\
\hline${ }^{\mathrm{a}} \mathrm{CE}$ & 4.56 & 4.61 & 4.55 & 4.52 & 4.53 & 4.55 \\
\hline $\mathrm{Mg}$ & $<0.040$ & 0.032 & 0.035 & 0.039 & 0.037 & 0.038 \\
\hline $\mathrm{Mn}$ & $<0.25$ & 0.21 & 0.20 & 0.22 & 0.25 & 0.24 \\
\hline $\mathrm{Cu}$ & $<0.08$ & 0.08 & 0.06 & 0.07 & 0.08 & 0.07 \\
\hline $\mathrm{P}$ & 0.025 & 0.02 & 0.02 & 0.02 & 0.02 & 0.02 \\
\hline $\mathrm{S}$ & 0.01 & 0.02 & 0.02 & 0.02 & 0.02 & 0.02 \\
\hline $\mathrm{Leco} \mathrm{S}$ & & 0.01 & 0.01 & 0.01 & 0.01 & 0.01 \\
\hline${ }^{\mathrm{b}} \mathrm{Co}$ & & - & 1.03 & 2.06 & 3.00 & 4.08 \\
\hline
\end{tabular}

${ }^{a}$ The equation used for this calculation was $\mathrm{CE}=$ wt. $\% \mathrm{C}+1 / 3 \mathrm{wt} . \% \mathrm{Si}$

${ }^{\mathrm{b}}$ The established cobalt targets were $1 \mathrm{wt} . \%, 2$ wt.\%, 3 wt. $\%$, and 4 wt.\% Co

\subsubsection{Microstructure Evaluation}

\subsubsection{Metallography of Rectangular Plates}

\subsection{Graphite Analysis}

Figure 4.1 shows the unetched micrographs of the $3 \mathrm{~mm}$ section at 200x. In general, as the cobalt addition increases, the nodule size decreases, and the nodule count increases. 


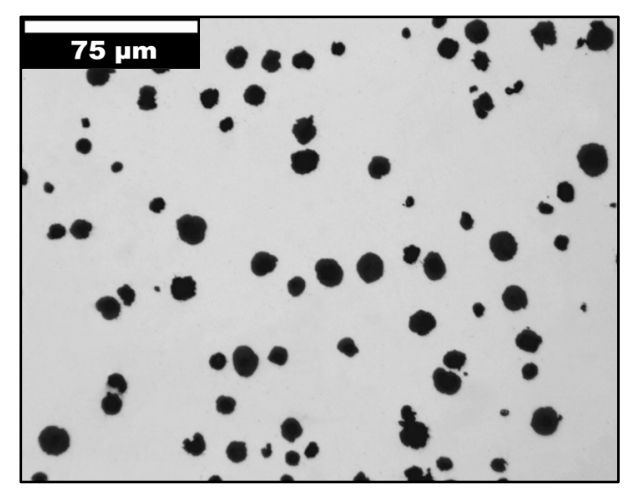

(a) Base DI

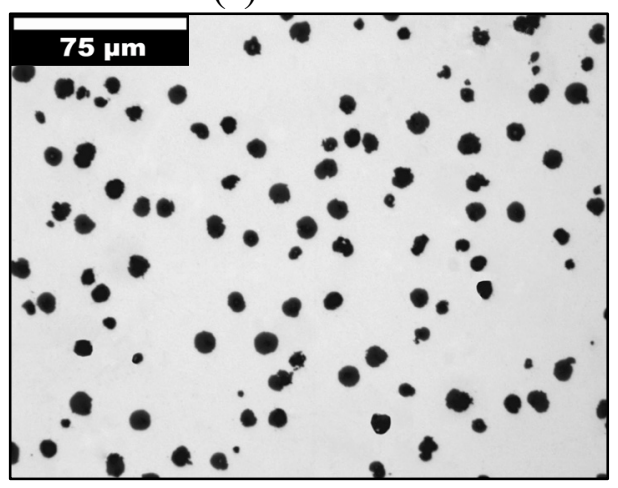

(c) 2 wt. $\% \mathrm{Co}$

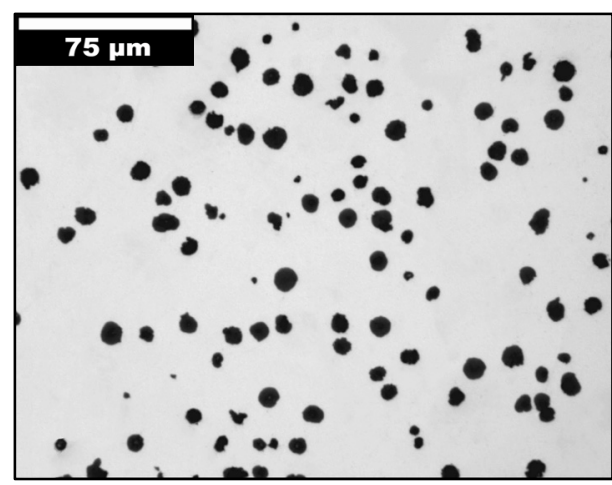

(b) 1 wt.\% Co

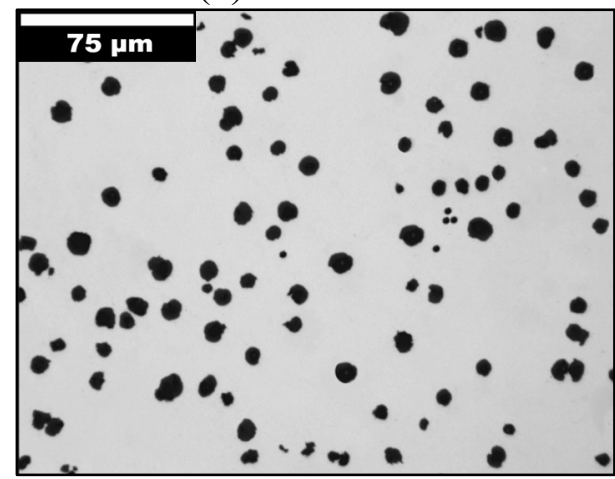

(d) 3 wt. $\%$ Co

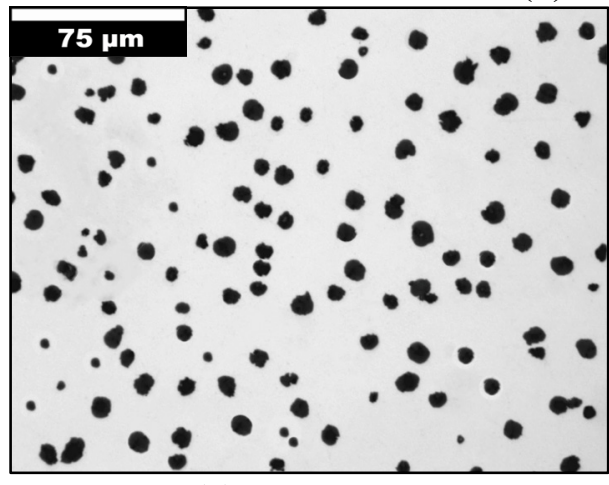

(e) 4 wt. $\%$ Co

Figure 4.1 Unetched micrographs of the $3 \mathrm{~mm}$ section at 200x [79].

The nodularity for all sections was above $90 \%$, with no statistically significant effect of cobalt as a function of section thickness. An increase in nodule count was observed at 4 wt.\% Co, and as expected the nodule count decreased as thickness increased (Figure 4.2). The increase in nodule count with 4 wt.\% Co is observed for all thicknesses (Figure 4.3). 


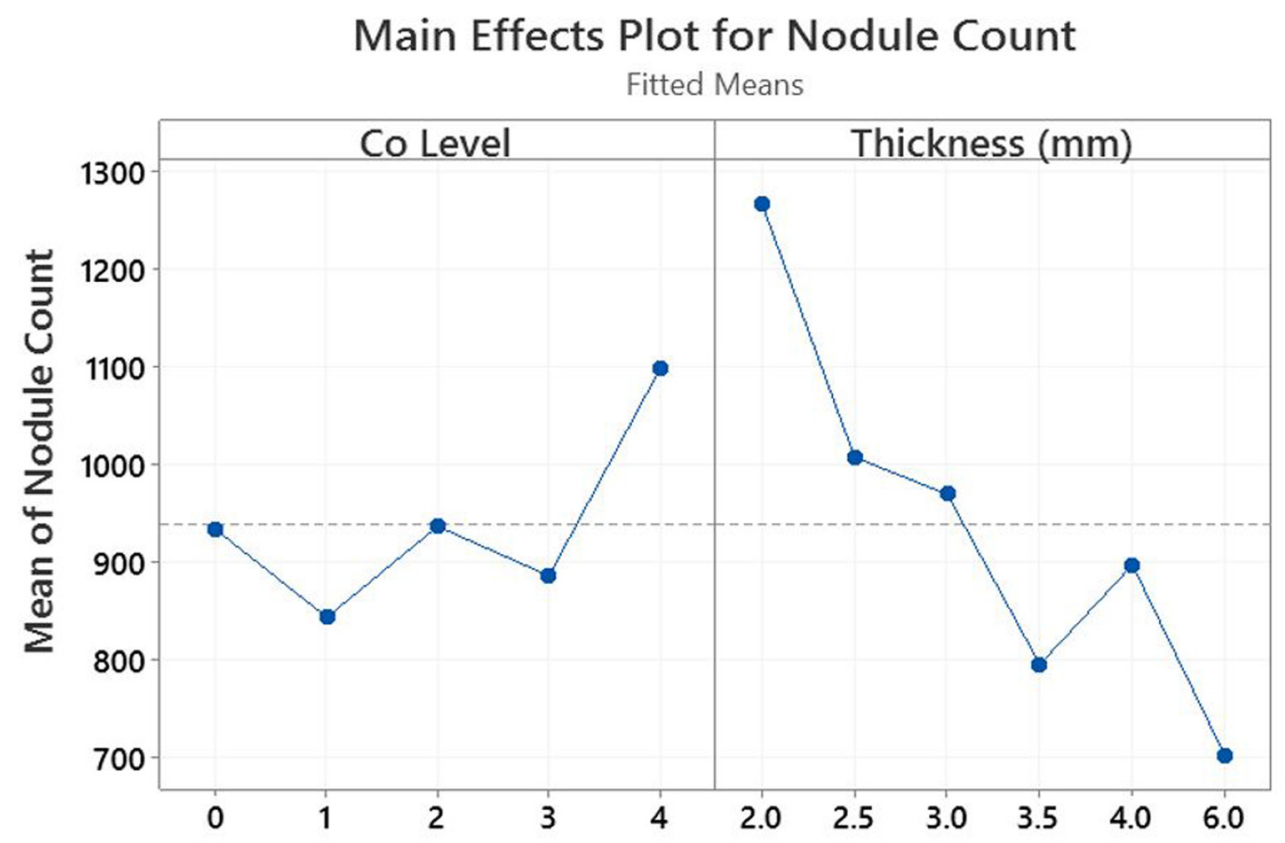

Figure 4.2 Main effects plot for the effect of cobalt and thickness in nodule count.

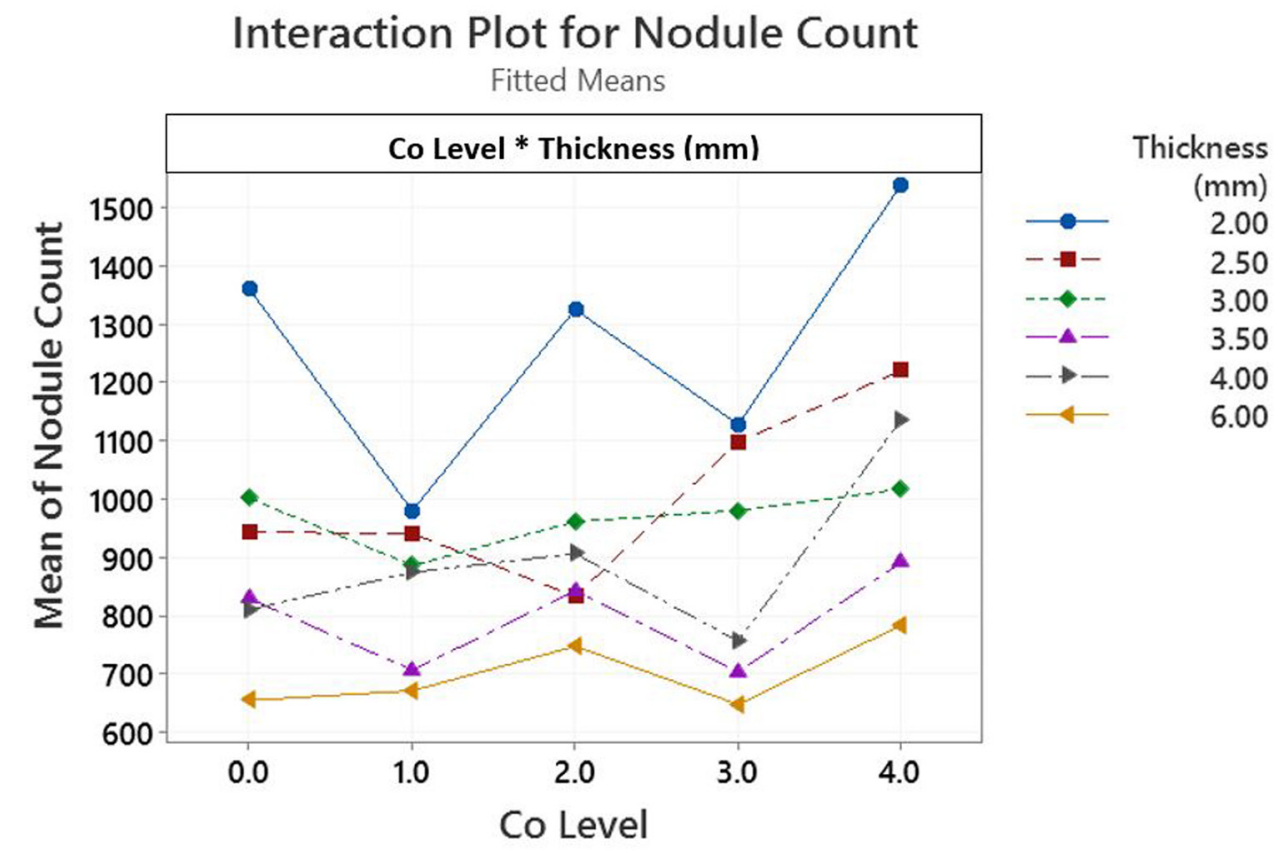

Figure 4.3 Interaction plot between cobalt and thickness in nodule count [79]. 


\subsection{Ferrite, Pearlite, and Carbide Analysis}

The $3 \mathrm{~mm}$ sections etched with 2\% Nital are shown in Figure 4.4, with all etched micrographs for the other thicknesses provided in Appendix A. Carbides were found for the base ductile iron, 1 wt.\% Co, and 2 wt.\% Co heats, but the 3 wt.\% and 4 wt.\% Co heats had no carbides and an increase in ferrite percentage.

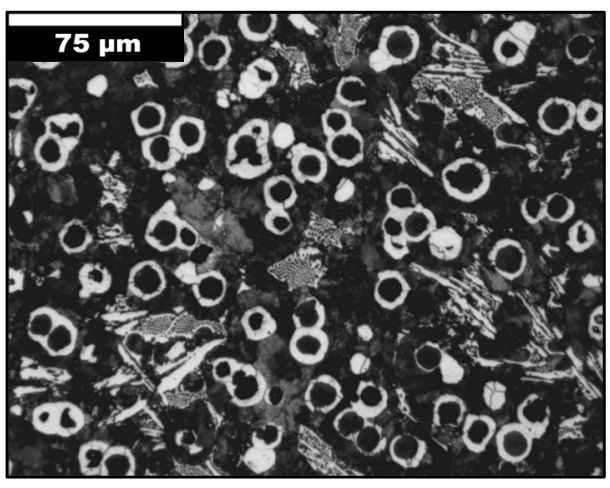

(a) Base DI

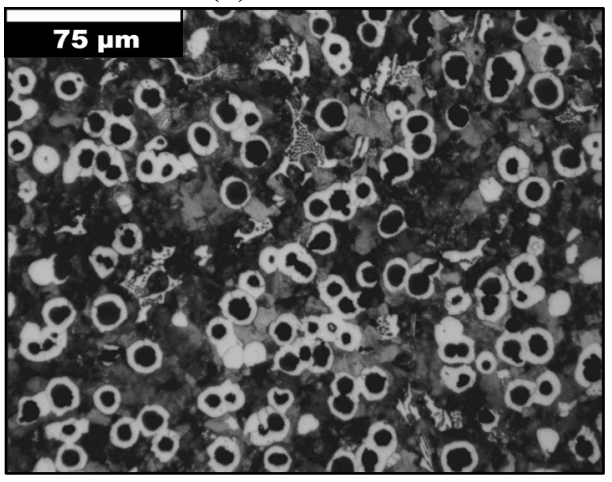

(c) 2 wt. $\% \mathrm{Co}$

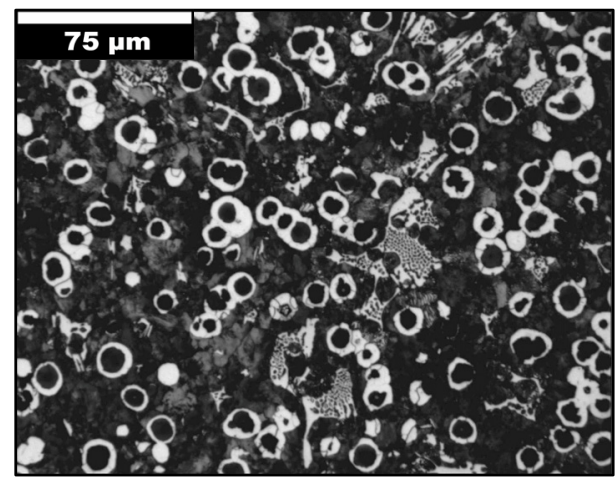

(b) 1 wt. \% Co

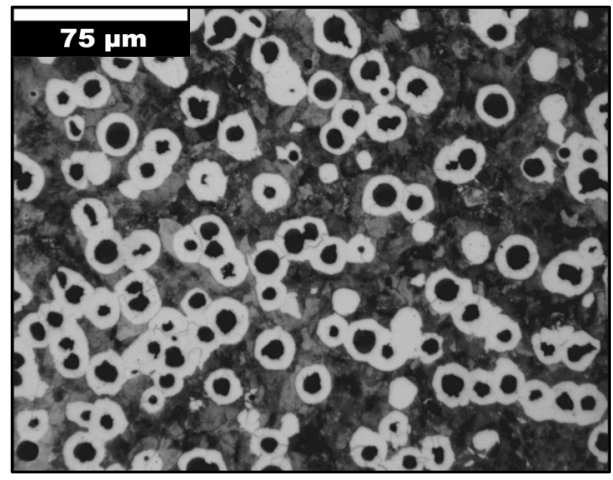

(d) 3 wt. $\% \mathrm{Co}$

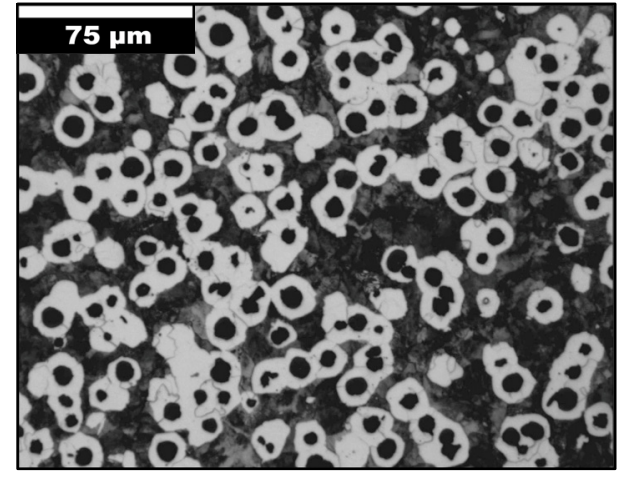

(e) 4 wt. \% Co

Figure 4.4 Etched micrographs from the $3 \mathrm{~mm}$ section at 200x [79]. 
From Figure 4.5, all thicknesses from the base ductile iron heat (no Co) showed carbides along the entire cross-section. Compared to the base ductile iron heat, there was an increase in the carbide percentage for the $1 \mathrm{wt} . \%$ and $2 \mathrm{wt} . \%$ Co heats at the 2, 2.5, and $3 \mathrm{~mm}$ sections, with an increase in ferrite content for the 4 , and $6 \mathrm{~mm}$ thicknesses. Increasing the thickness slows the cooling rate and decreases the nodule count. The larger distance between the nodules increases the diffusion distance between carbon sinks resulting in higher pearlite fractions. Since cobalt increases the nodule count, it leads to shorter diffusion paths and more ferrite. and less carbides for all thicknesses with 3 wt.\% and 4 wt.\% Co. The carbides in these two heats are located at the edges of the cross-section.

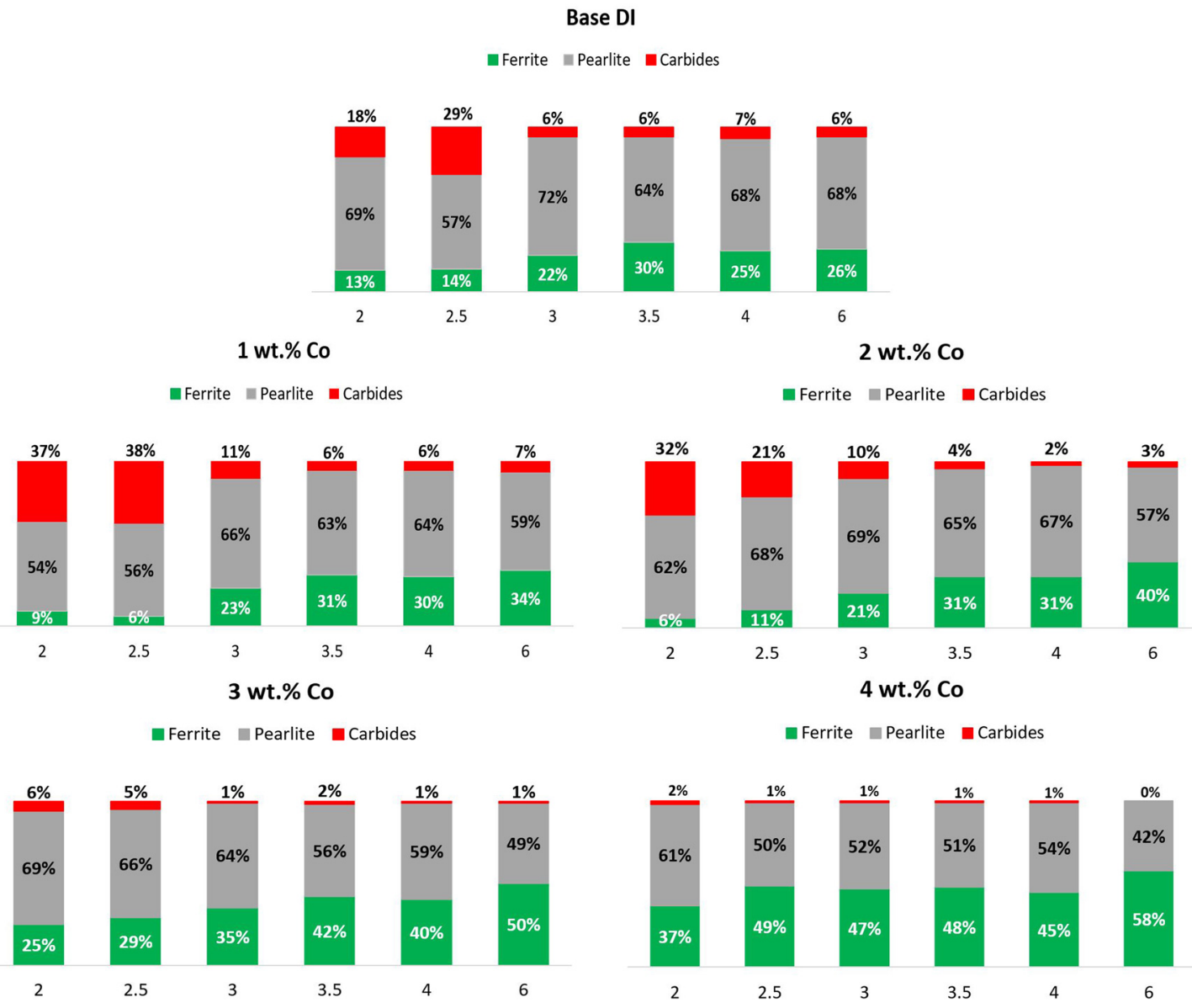

Figure 4.5 Ferrite, pearlite, and carbide percentages for all section thicknesses [79]. 


\subsubsection{ASTM $1 / 2$ inch Y-blocks}

\subsection{Graphite Analysis}

The unetched micrographs at 50x of the first and last Y-blocks poured show that adding cobalt results in an increase in nodule count and a decrease in the nodule size (Figure 4.6).
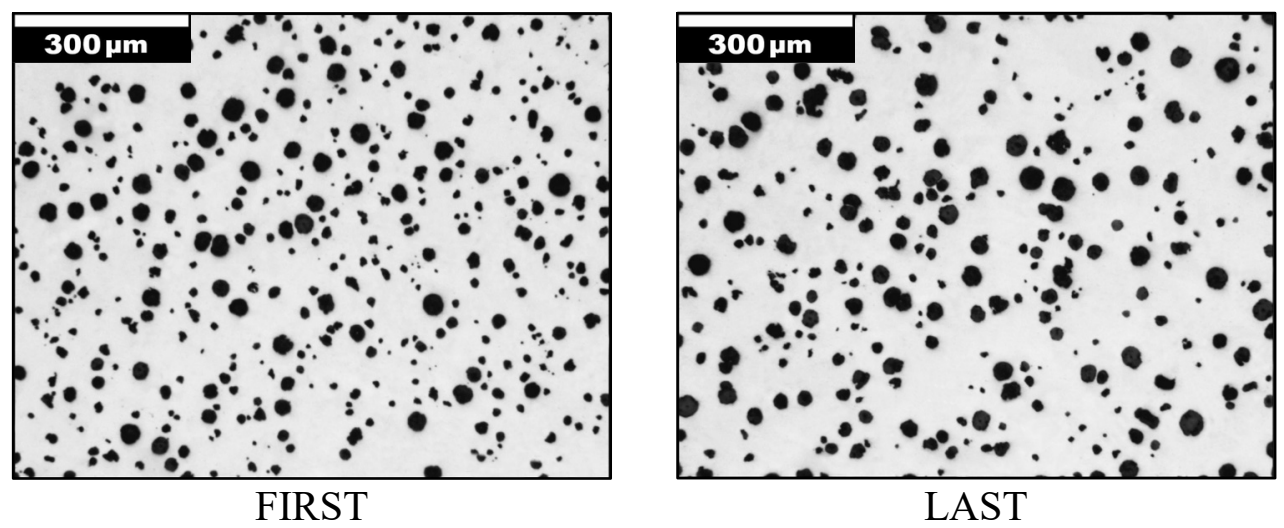

(a) Base DI
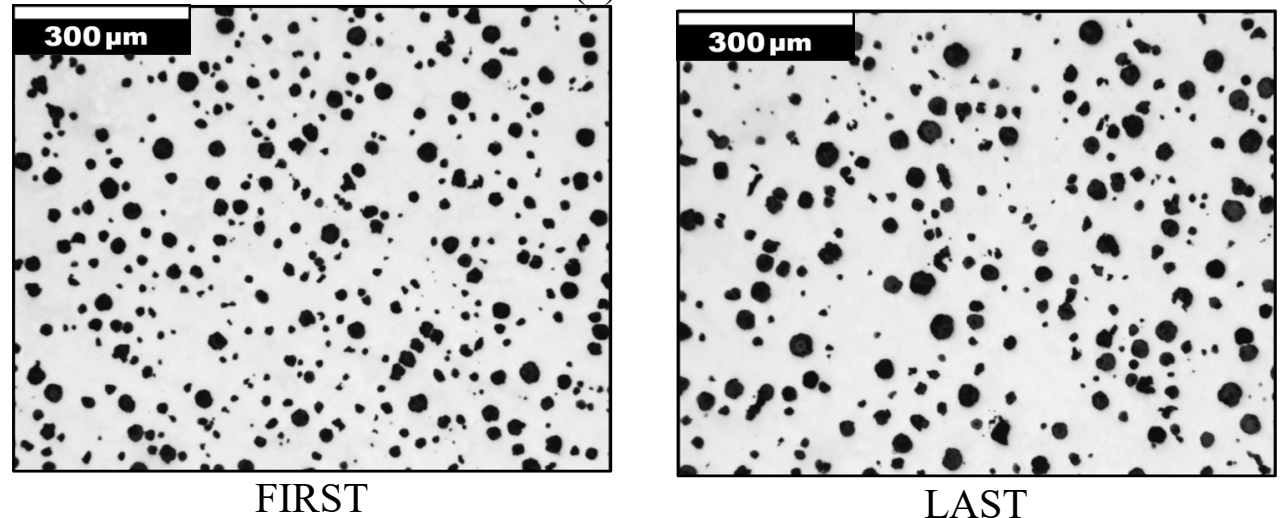

(b) 1 wt. $\%$ Co
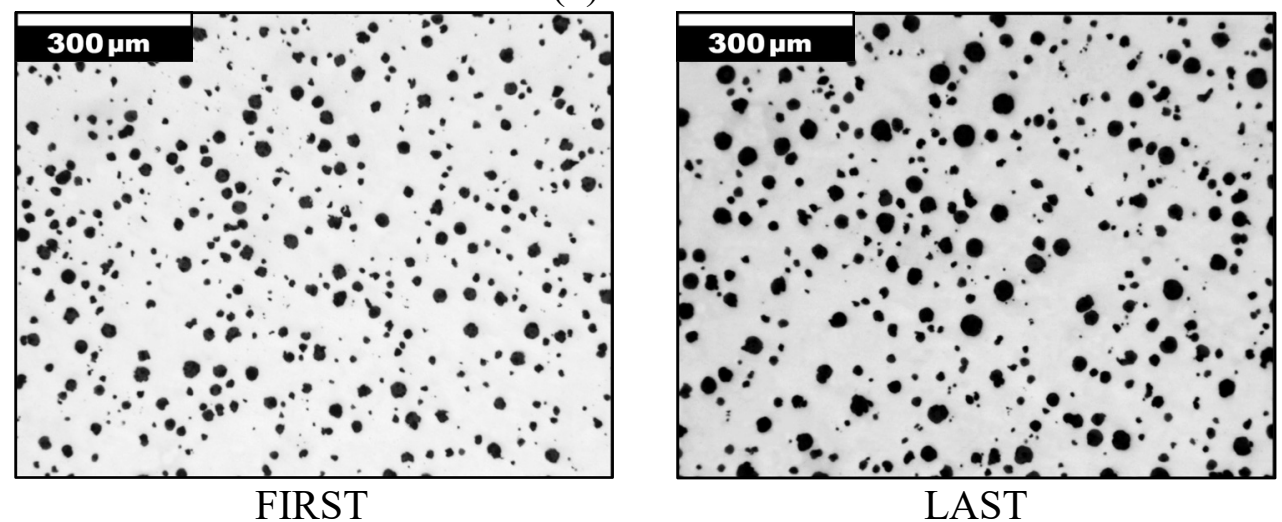

(c) 2 wt. $\% \mathrm{Co}$ 


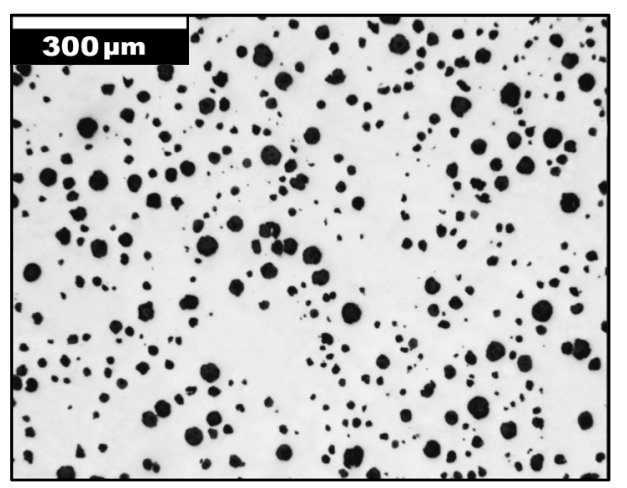

FIRST

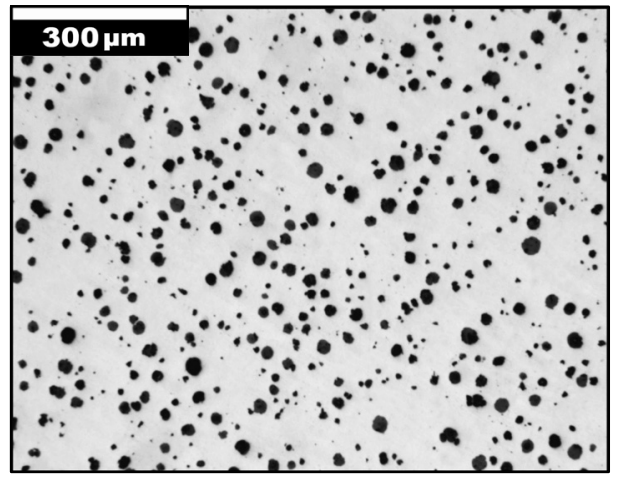

FIRST

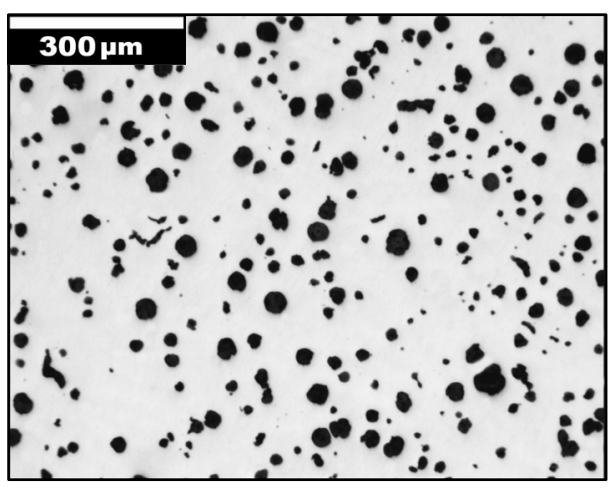

LAST

(d) 3 wt.\% Co

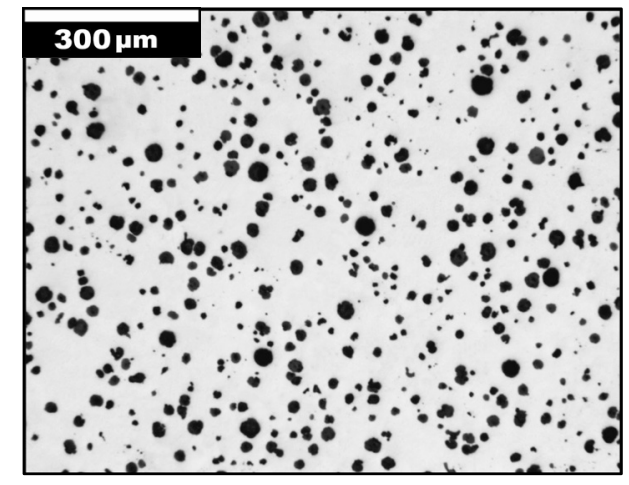

(e) 4 wt. $\%$ Co

Figure 4.6 Unetched micrographs at 50x of the first and last $1 / 2$ inch Y-blocks poured [81].

For the first Y-blocks poured, there was not a substantial difference in nodularity among all the heats (Figure 4.7). A decrease in nodularity with time is observed when comparing the first and last $\mathrm{Y}$-blocks poured likely due to $\mathrm{Mg}$ fade (Figure 4.7). The nodule count increased considerably with the addition of $4 \mathrm{wt} . \% \mathrm{Co}$ in comparison with the other heats (Figure 4.8). As the nodule count increases the percent nodularity increases, consistent with the present study at $4 \mathrm{wt} . \% \mathrm{Co}$ [90]. As Co is increased, the average nodule diameter is consistently reduced, while longer pouring times lead to increased nodule size (Figure $4.9)$. 


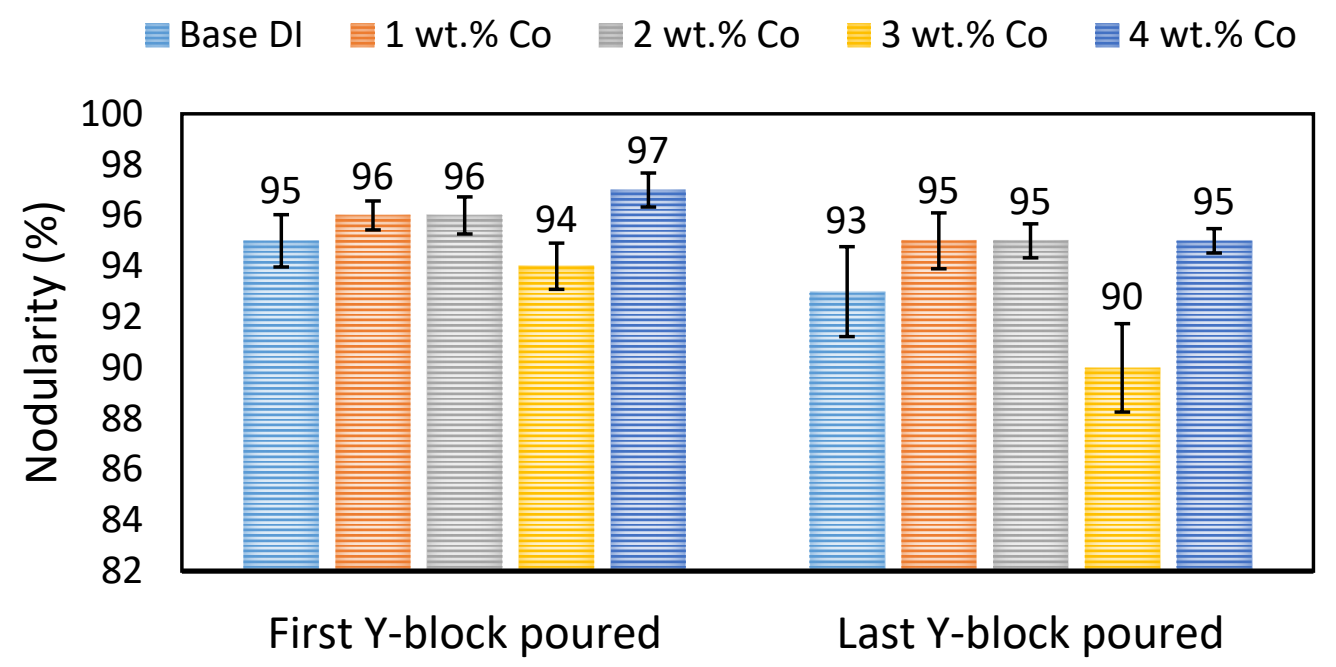

Figure 4.7 Percent nodularity of the first and last $1 / 2$ inch Y-blocks poured. Error bars are $95 \%$ standard error of the mean [81].

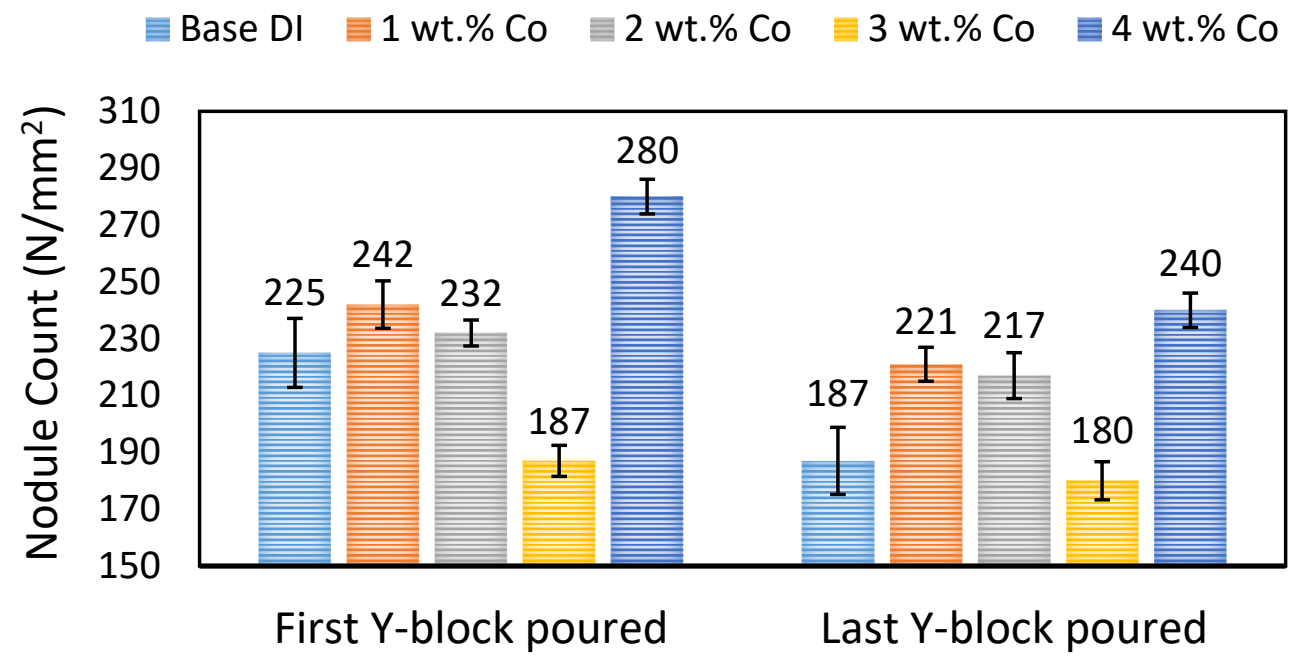

Figure 4.8 Nodule count of the first and last $1 / 2$ inch Y-blocks poured. Error bars are 95\% standard error of the mean [81]. 


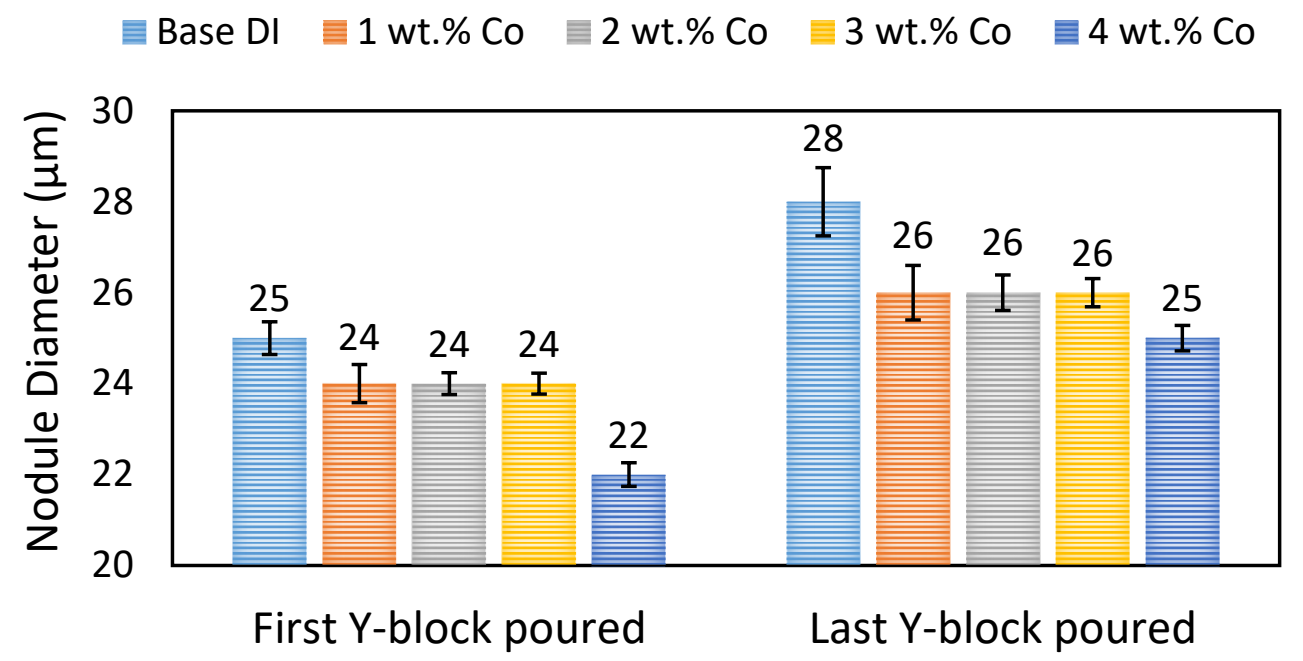

Figure 4.9 Nodule diameter of the first and last $1 / 2$ inch Y-blocks poured. Error bars are $95 \%$ standard error of the mean [81].

\subsection{Ferrite and Pearlite Analysis}

Compared to the base ductile iron heat, the $4 \mathrm{wt} . \%$ Co heat showed an increase in ferrite percentage for the first and last Y-blocks poured (Figure 4.10).

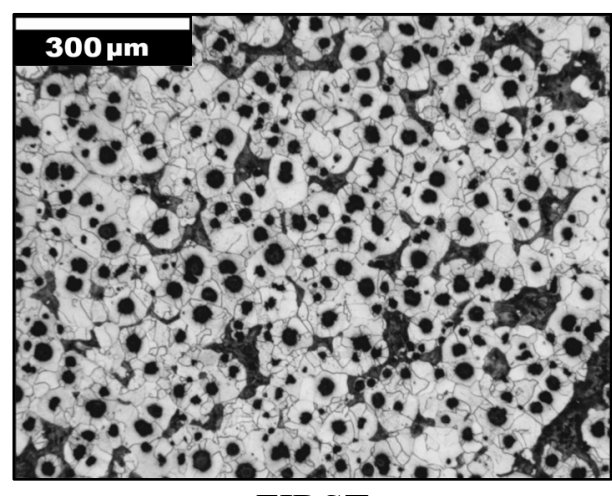

FIRST

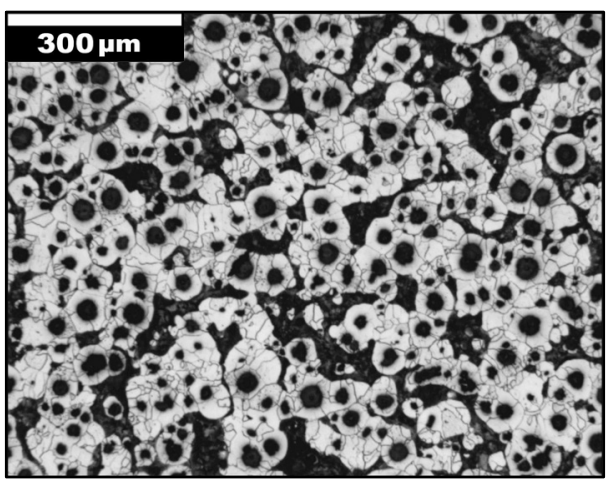

LAST

(a) Base DI 

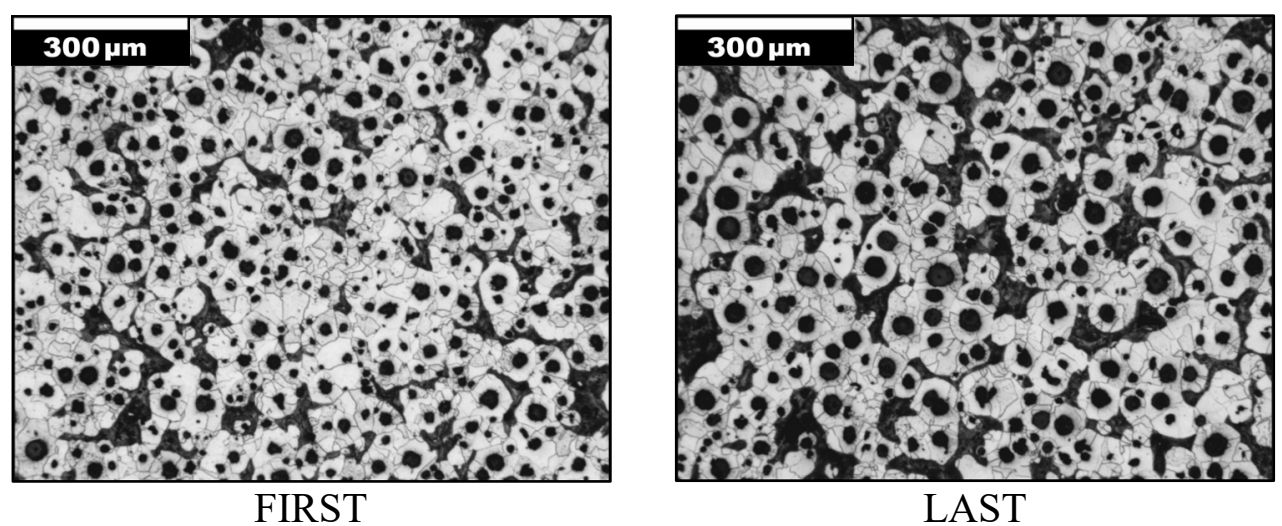

(b) 1 wt. $\% \mathrm{Co}$

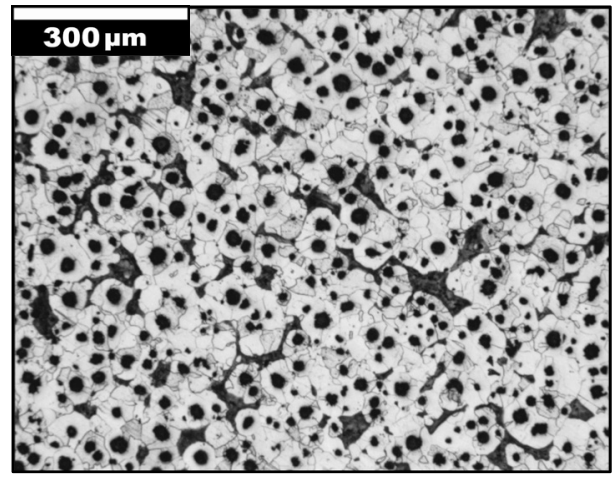

FIRST

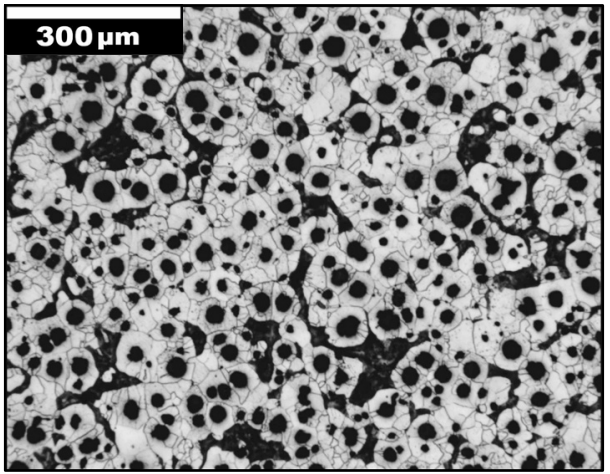

(c) 2 wt. $\% \mathrm{Co}$

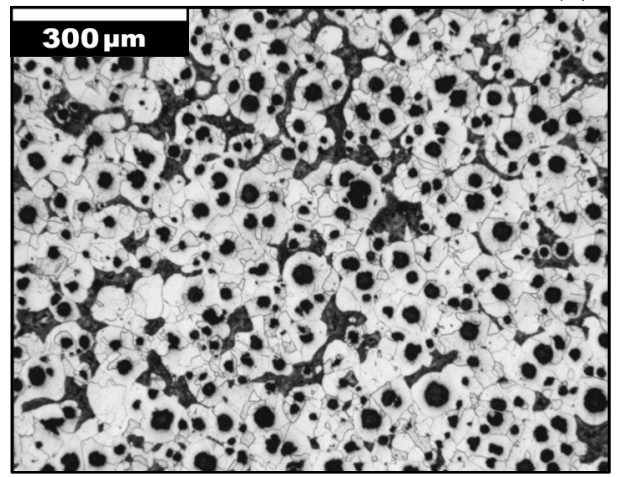

FIRST

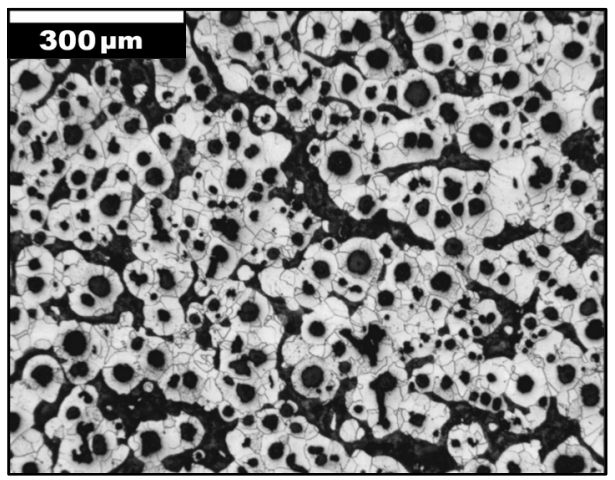

LAST

(d) 3 wt. $\% \mathrm{Co}$ 


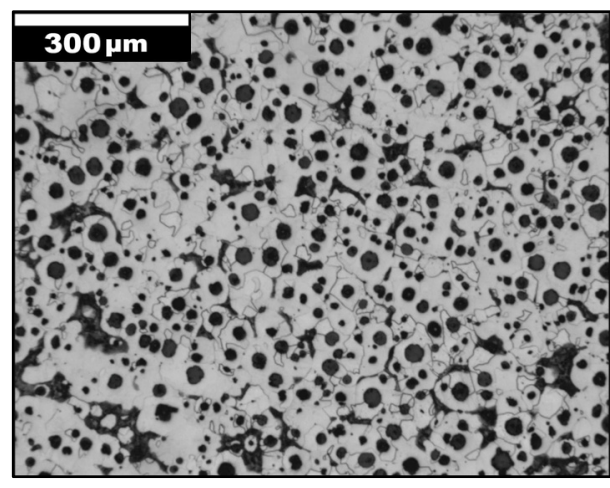

FIRST

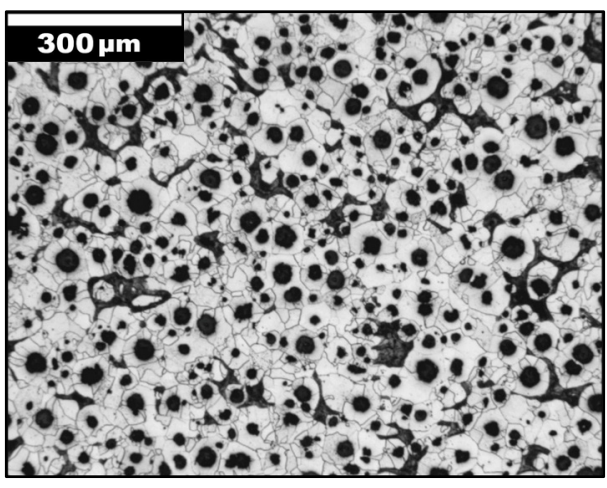

LAST

(e) 4 wt. \% Co

Figure 4.10 Nital etched micrographs at $50 \mathrm{x}$ of the first and last $1 / 2$ inch $\mathrm{Y}$-blocks poured [81].

An increase in ferrite and a decrease in pearlite is observed for the first Y-blocks poured with cobalt additions (Figure 4.11). For the last Y-blocks poured, the $1 \mathrm{wt} . \%$, and $3 \mathrm{wt} . \%$ Co additions showed a significant reduction in ferrite percentage. With longer pouring times, nodule count decreases resulting in more pearlite [34]. Although the 3 wt.\% Co heat had a lower nodule count, the first Y-block poured displayed a ferrite percentage akin to the other heats.

$\square$ Base DI $\square 1$ wt.\% Co $\square 2$ wt.\% Co $\square 3$ wt.\% Co $\square 4$ wt.\% Co

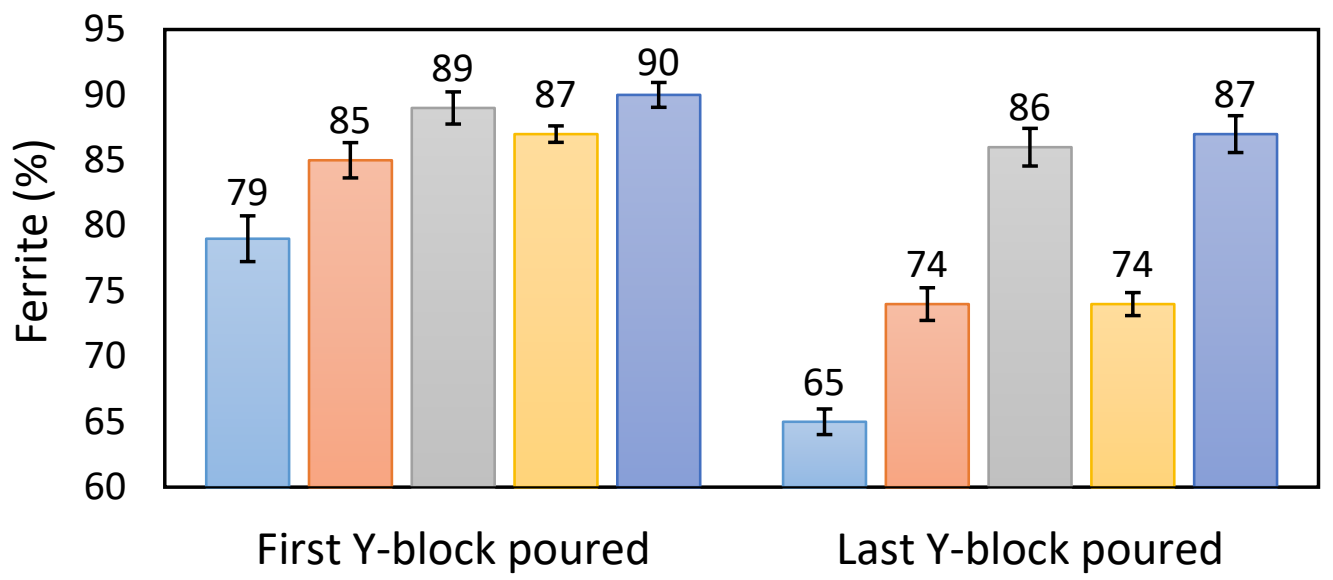

(a) 


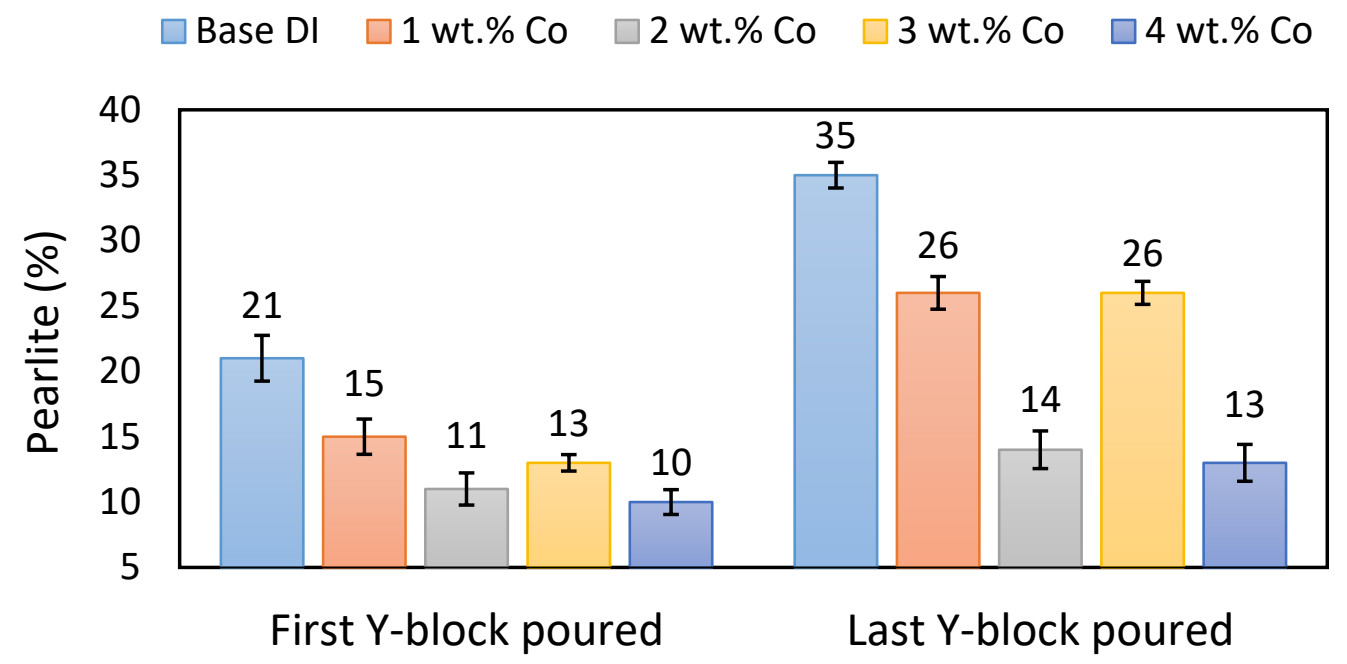

(b)

Figure 4.11 (a) Ferrite and (b) pearlite percentages of the first and last $1 / 2$ inch Y-blocks poured. Error bars are 95\% standard error of the mean [81].

\subsubsection{Tensile Properties Evaluation}

\subsubsection{Rectangular Plates}

Factorial plots were created in Minitab ${ }^{\circledR}$ to evaluate the effect of cobalt and thickness on the tensile strength, the yield strength, and the percent elongation of all heats. From the main effects plot (Figure 4.12), a slight increase in tensile strength with Co above 2 wt.\% is observed, but this is not statistically significant. There was no clear trend found for the tensile strength in the interaction plot, although thinner sections were generally stronger (Figure 4.13). 


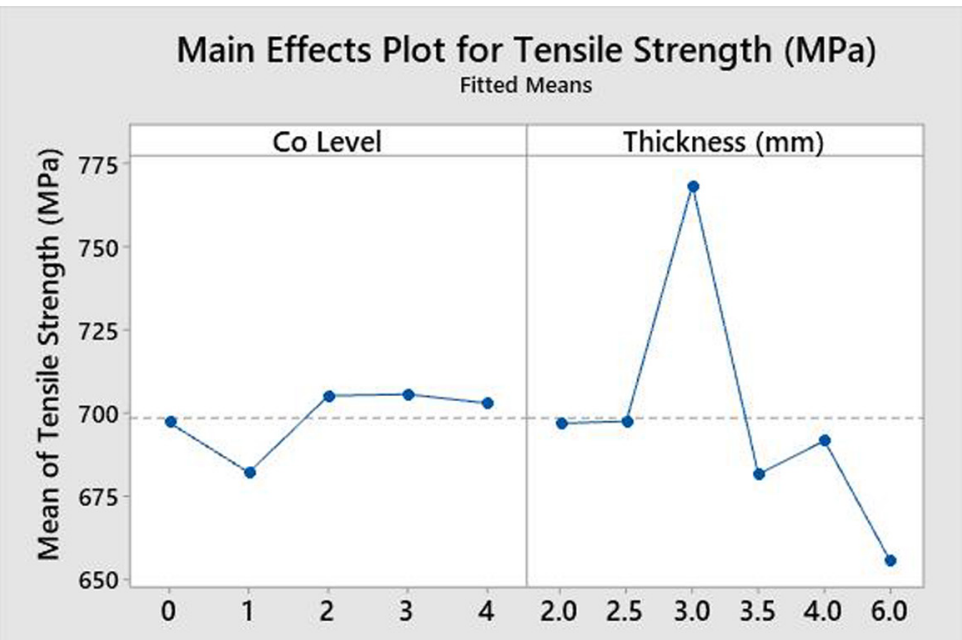

Figure 4.12 Main effects plot for the effect of cobalt and thickness on tensile strength [79].

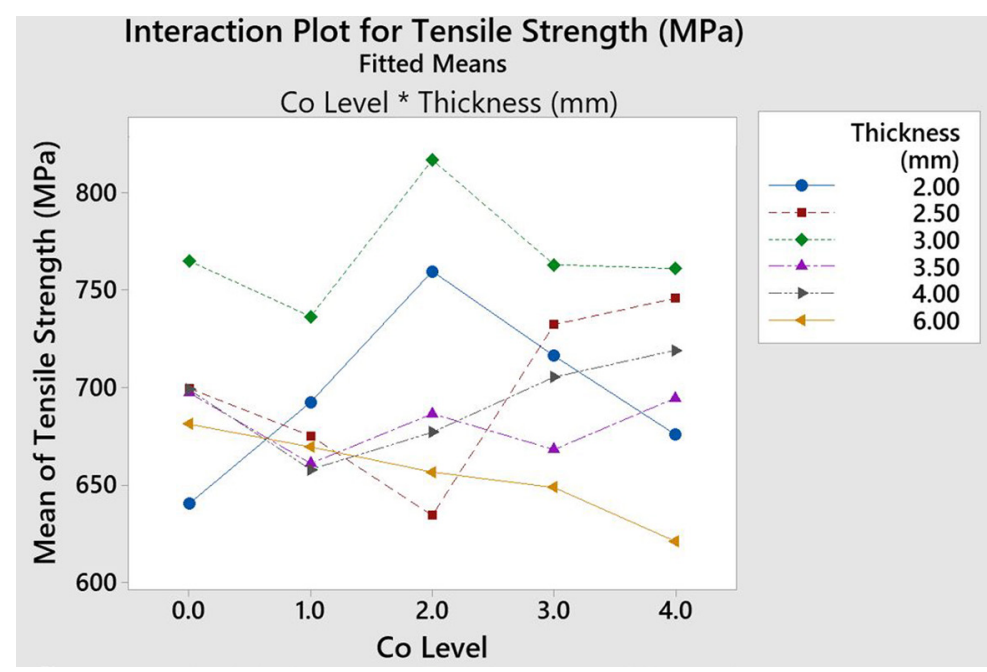

Figure 4.13 Interaction plot between cobalt and thickness on tensile strength [79].

The addition of 4 wt.\% Co resulted in a decrease of the yield strength as observed in the main effects plot (Figure 4.14). A drop in yield strength for all thicknesses with 4 wt.\% Co is confirmed in the interaction plot (Figure 4.15). 


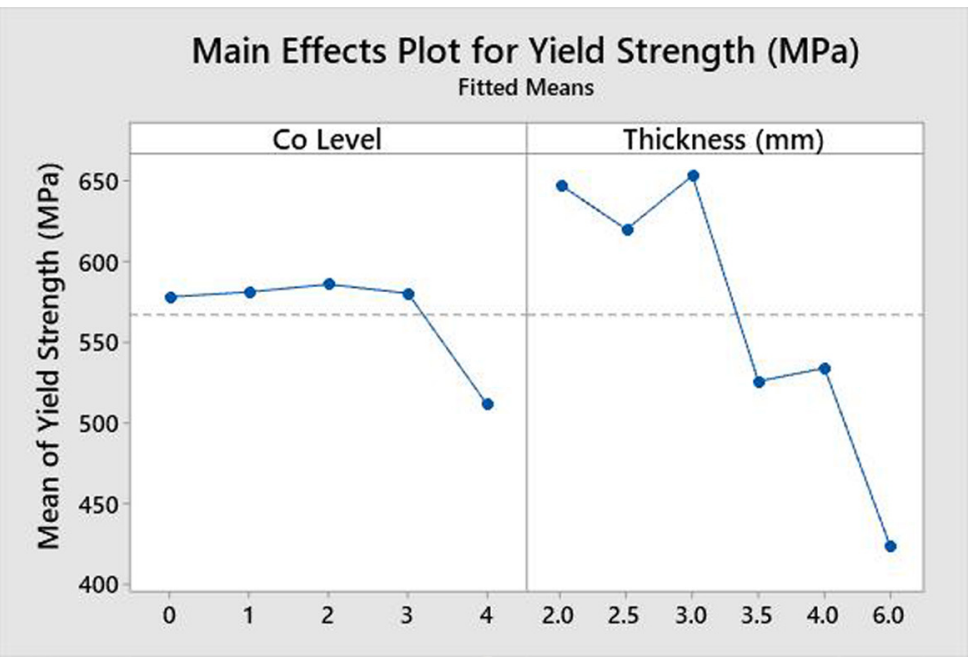

Figure 4.14 Main effects plot for the effect of cobalt and thickness on yield strength [79].

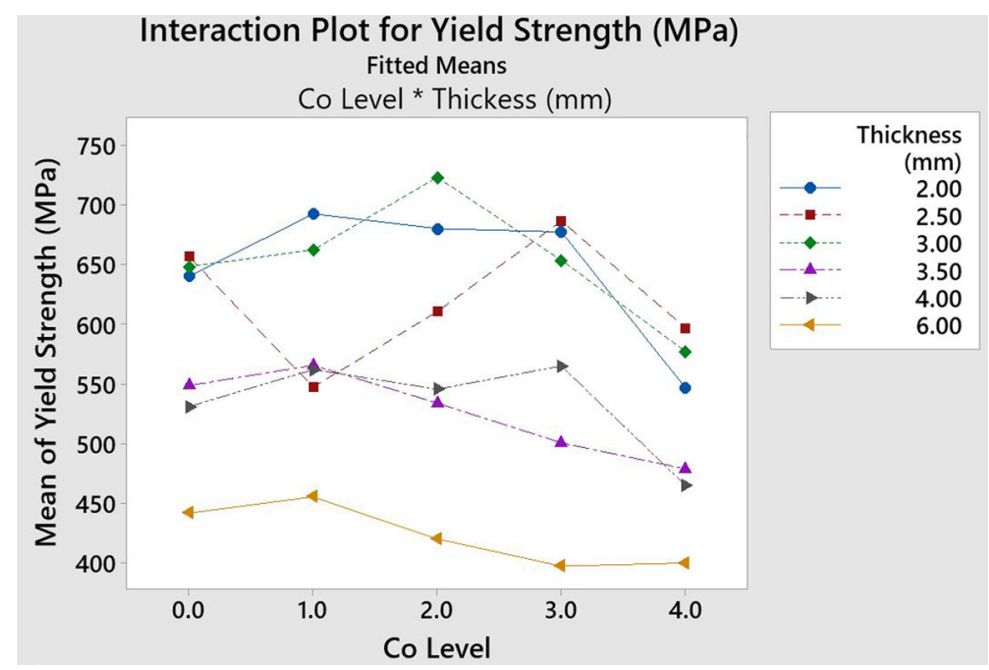

Figure 4.15 Interaction plot between cobalt and thickness on yield strength [79].

The percent elongation started to increase with additions above 2 wt.\% Co (Figure 4.16). Also, a considerable rise in the percent elongation with 4 wt.\% Co is observed in Figure 4.17. This improvement in elongation is mainly due to an increase in the ferrite percentage. These results agree with what Javaid et al. found. High ferrite contents lead to lower strength and high elongation in 3 and $12 \mathrm{~mm}$ sections [24]. 


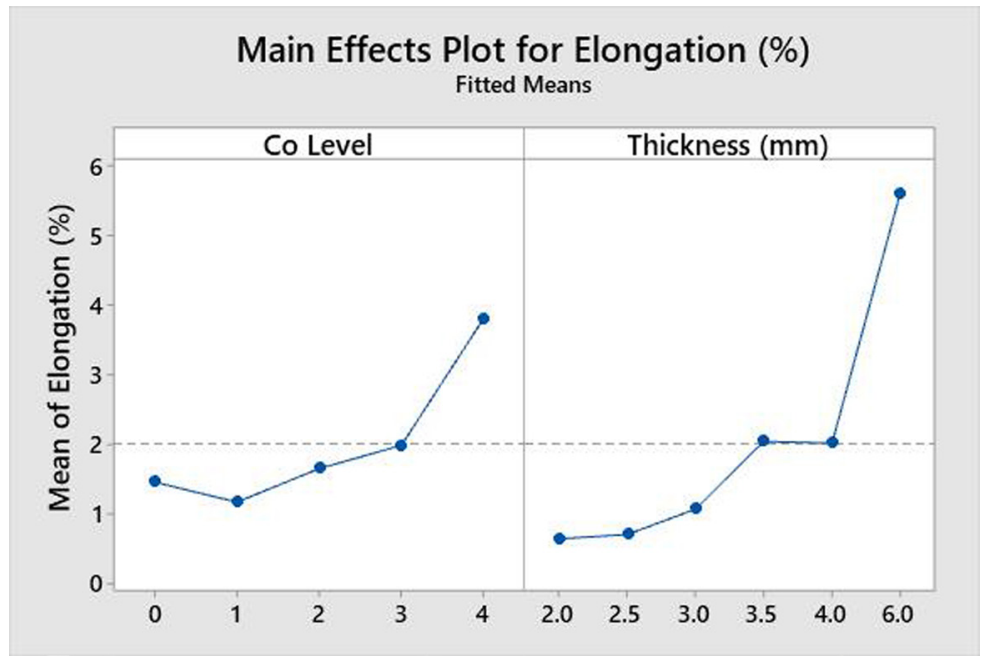

Figure 4.16 Main effects plot for the effect of cobalt and thickness on elongation [79].

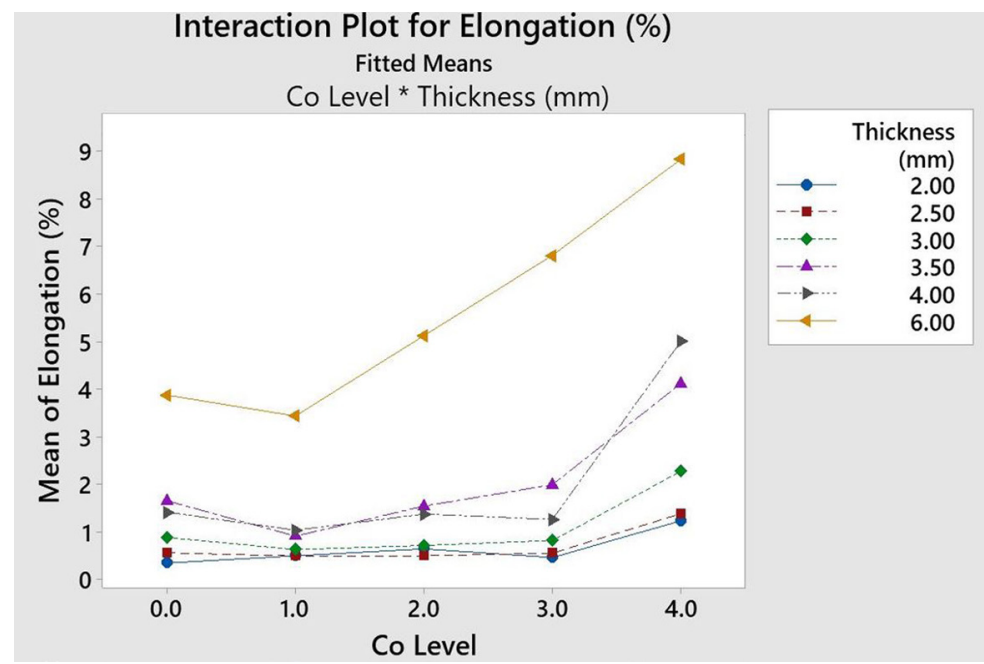

Figure 4.17 Interaction plot between cobalt and thickness on elongation [79].

\subsubsection{ASTM $1 / 2$ inch Y-blocks}

In Figure 4.18, a small increase in the tensile strength is observed with $3 \mathrm{wt} . \% \mathrm{Co}$, which is mainly a result of the lower nodule count of this heat which leads to a higher pearlite content. This observation is in line with what Doubrava et al. found, in which high pouring temperatures result in low nodule counts that contribute to an increase in pearlite [90]. In contrast, a drop in the tensile strength is observed for the 4 wt.\% Co heat, which could potentially be attributed to the higher ferrite percentage. However, if the $3 \mathrm{wt} . \%$ Co 
heat is excluded from the graph (Figure 4.19) there is really no decrease in the tensile strength with cobalt additions. The broad scatter of the base ductile iron and $1 \mathrm{wt} . \%$ Co heat could be due to a large variation in the ferrite and pearlite ratios, which seems to get smaller with the addition above $2 \mathrm{wt} . \%$ Co due to a higher ferrite percentage that leads to a more uniform matrix. Salzbrenner also observed a large dispersion in the tensile strength with a series of ductile iron heats with silicon contents ranging from $0.66 \mathrm{wt} . \%$ to 2.29 wt.\% Si [91].

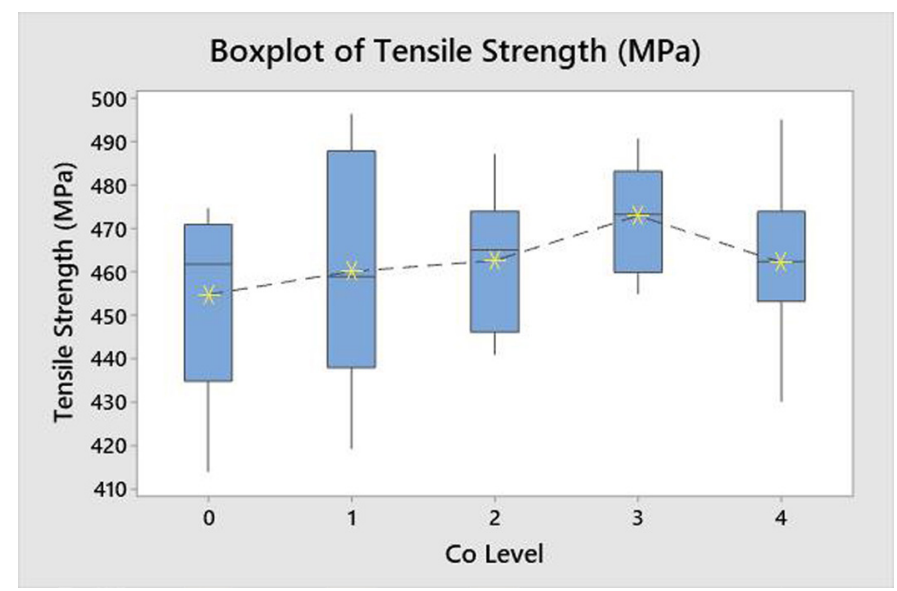

Figure 4.18 Effect of cobalt on the tensile strength of the $1 / 2$ inch Y-blocks [81].

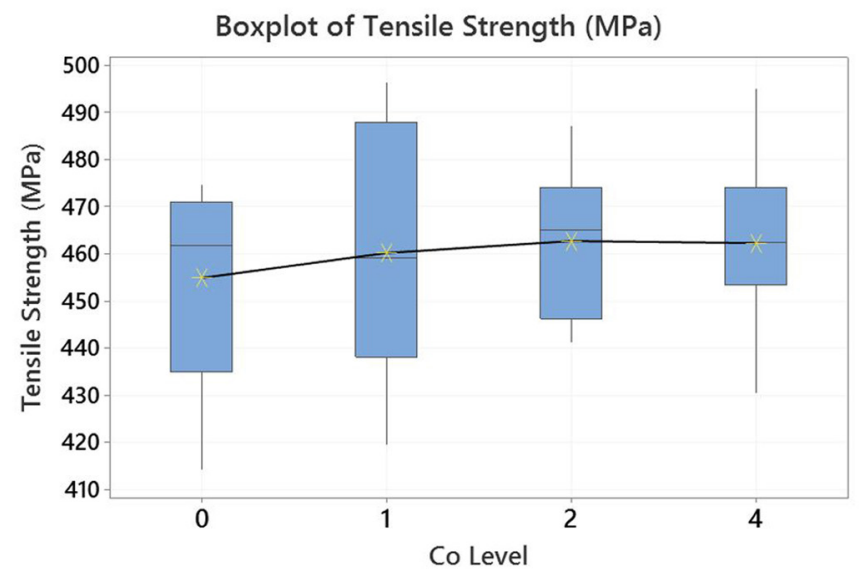

Figure 4.19 Tensile strength of the $1 / 2$ inch Y-blocks without the 3 wt. $\%$ Co heat. 
Figure 4.20 shows an increase in the yield strength with cobalt additions. However, this increment in the yield strength is only significant with 4 wt.\% Co. These results are consistent with Mold's research, which found a constant increase in the yield strength with cobalt contents up to 15 wt.\% Co [58]. Furthermore, if the 3 wt.\% Co heat is removed from the data set in the same way that was excluded for the tensile strength data due to the long holding time in the furnace, which resulted in lower nodule count, the increase in yield strength is still observed (Figure 4.21).

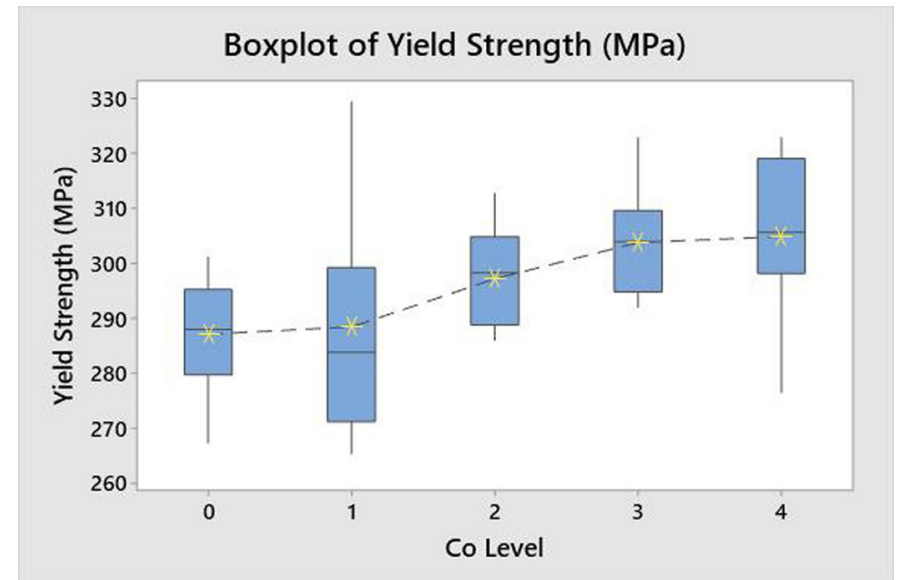

Figure 4.20 Effect of cobalt on the yield strength of $1 / 2$ inch Y-blocks [81].

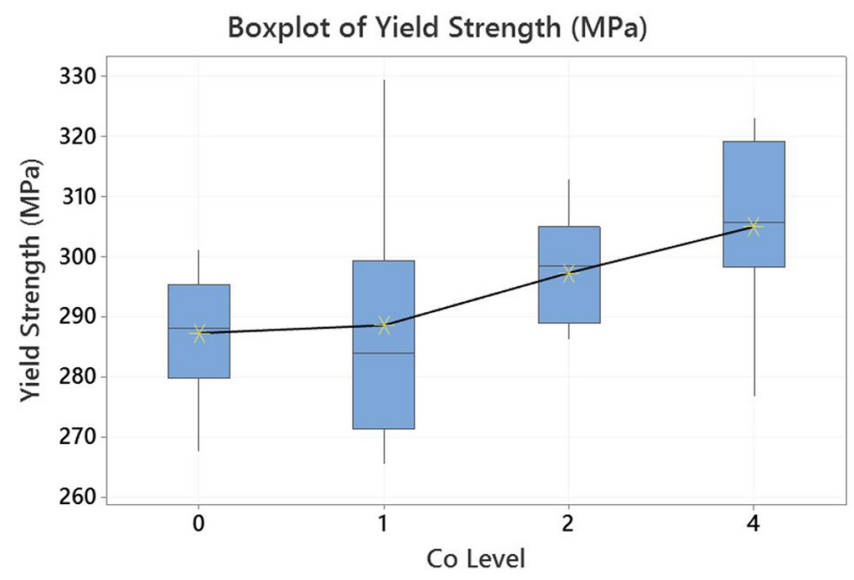

Figure 4.21 Yield strength of the $1 / 2$ inch Y-blocks without the 3 wt. $\%$ Co heat. 
As previously mentioned, high nodule counts lead to greater ferrite contents, which cause an increase in the percent elongation. However, there was no significant change in percent elongation with cobalt additions (Figure 4.22). By removing the 3 wt.\% Co heat in Figure 4.23, a slight increase in the percent elongation is observed, yet still not statistically significant.

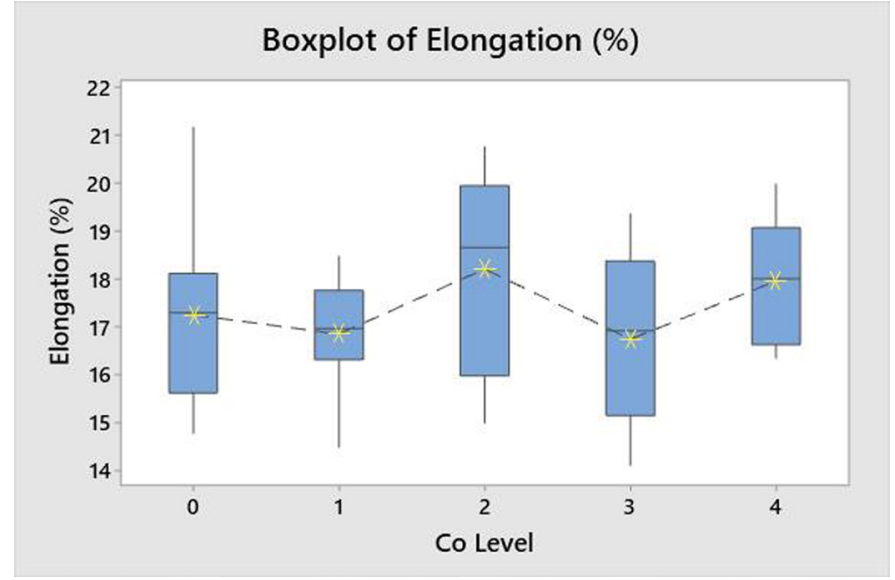

Figure 4.22 Effect of cobalt on the percent elongation of $1 / 2$ inch Y-blocks [81].

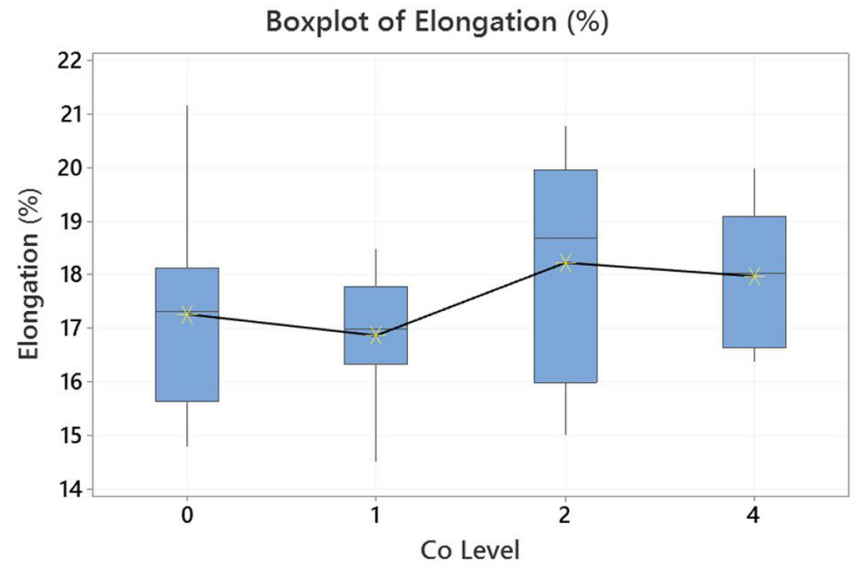

Figure 4.23 Elongation of the $1 / 2$ inch Y-blocks without the 3 wt.\% Co heat. 


\subsubsection{Macrohardness Evaluation}

\subsubsection{Rectangular Plates}

Throughout Brinell testing, $2 \mathrm{~mm}$ sections with $1 \mathrm{wt} . \%, 2$ wt.\%, and 3 wt.\% Co samples cracked because of high carbide contents. The scatter in the data observed for the base ductile iron and $1 \mathrm{wt} . \%$ Co heats could be attributed to the variation in the microstructure, especially with respect to carbide content (Figure 4.24.). The data variation begins to decrease above $3 \mathrm{wt} . \%$ Co and this might be due to a more homogenous matrix of more ductile microconstituents. The 3 wt. $\%$ and 4 wt.\% Co sections have a higher ferrite percentage compared to the other heats resulting in lower hardness values.

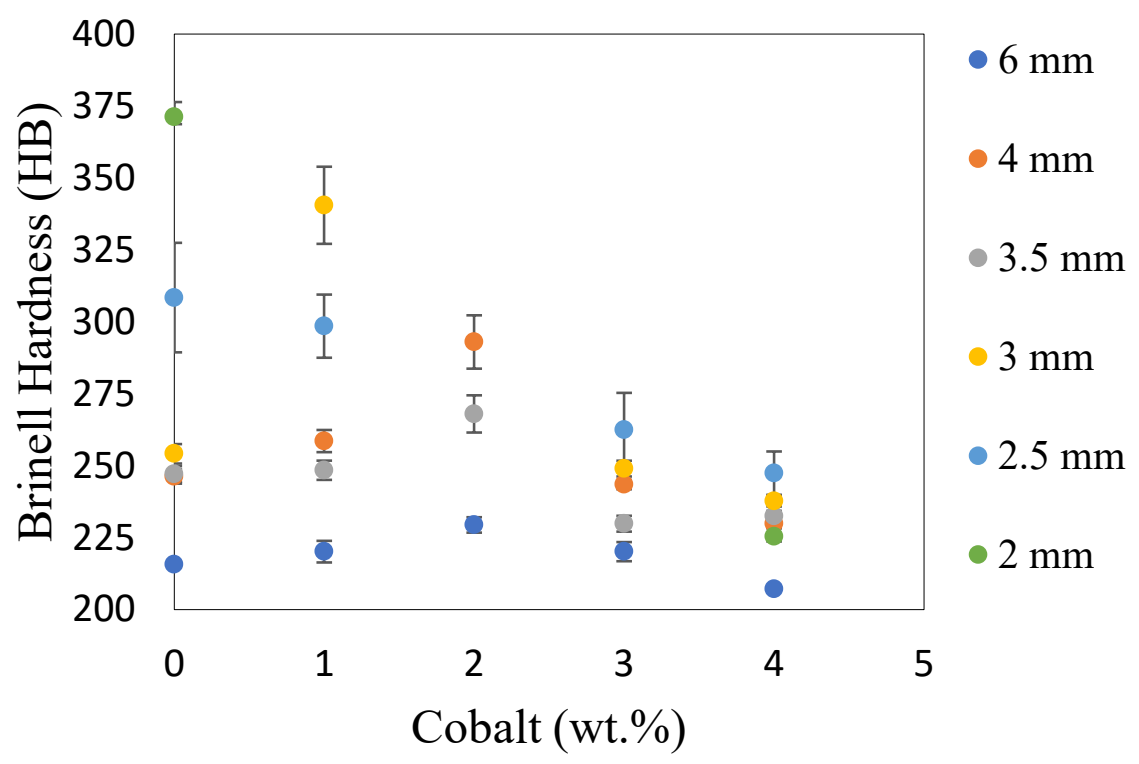

Figure 4.24 Effect of cobalt additions on the Brinell hardness of the rectangular plates. Error bars are $95 \%$ Std error of the mean [79].

\subsubsection{ASTM $1 \frac{1}{2}$ inch Y-blocks}

The 2 wt.\% and 4 wt.\% Co heats showed less variation in the Brinell hardness values compared to the other heats (Figure 4.25). These could potentially be attributed to a more homogeneous matrix. As has been reported by Gonzaga et al., a rise in hardness is 
observed with increasing pearlite percentage [41], [92]. From the metallographic analysis, the base ductile iron, $1 \mathrm{wt} . \% \mathrm{Co}$, and $3 \mathrm{wt} . \%$ Co heats displayed similar pearlite contents for the first and last Y-blocks poured. However, the 4 wt.\% Co heat had a high ferrite content leading to a significant increase in hardness. Microhardness testing in the next section will help evaluate the hardness of the microconstituents.

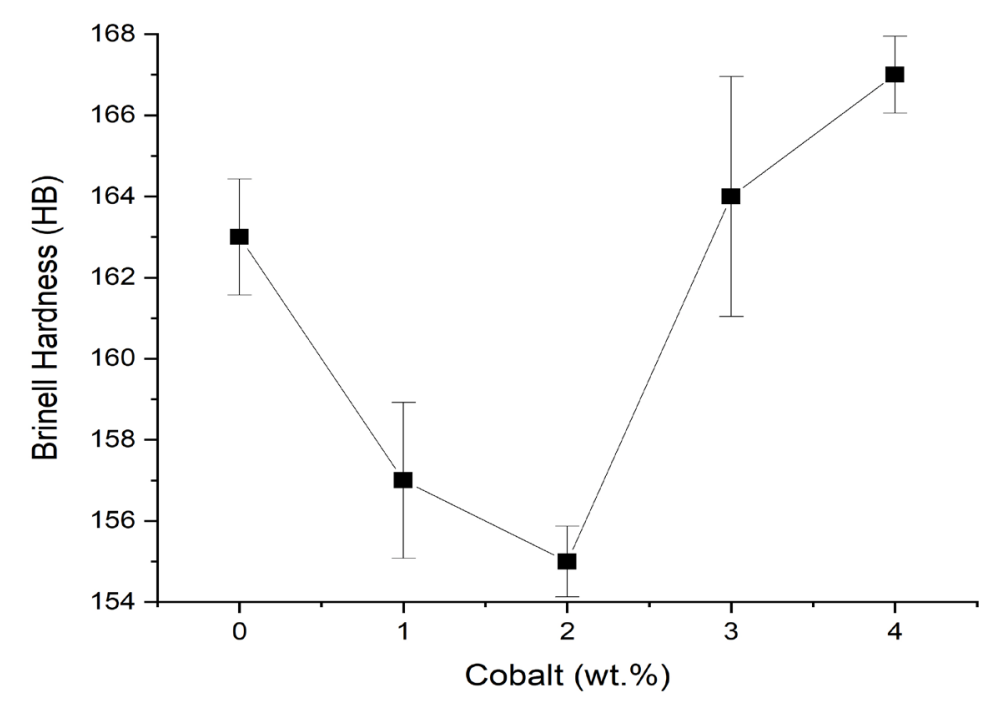

Figure 4.25 Effect of cobalt on the Brinell hardness of the $1 / 2$ inch Y-blocks. Error bars are $95 \%$ Std error of the mean.

\subsubsection{Microhardness Evaluation}

A significant increase in the ferrite hardness is observed with cobalt additions for the first and last Y-blocks poured (Figure 4.26). This hardening of ferrite by cobalt in solution is in agreement with what Modl found in his microhardness measurements [58]. 


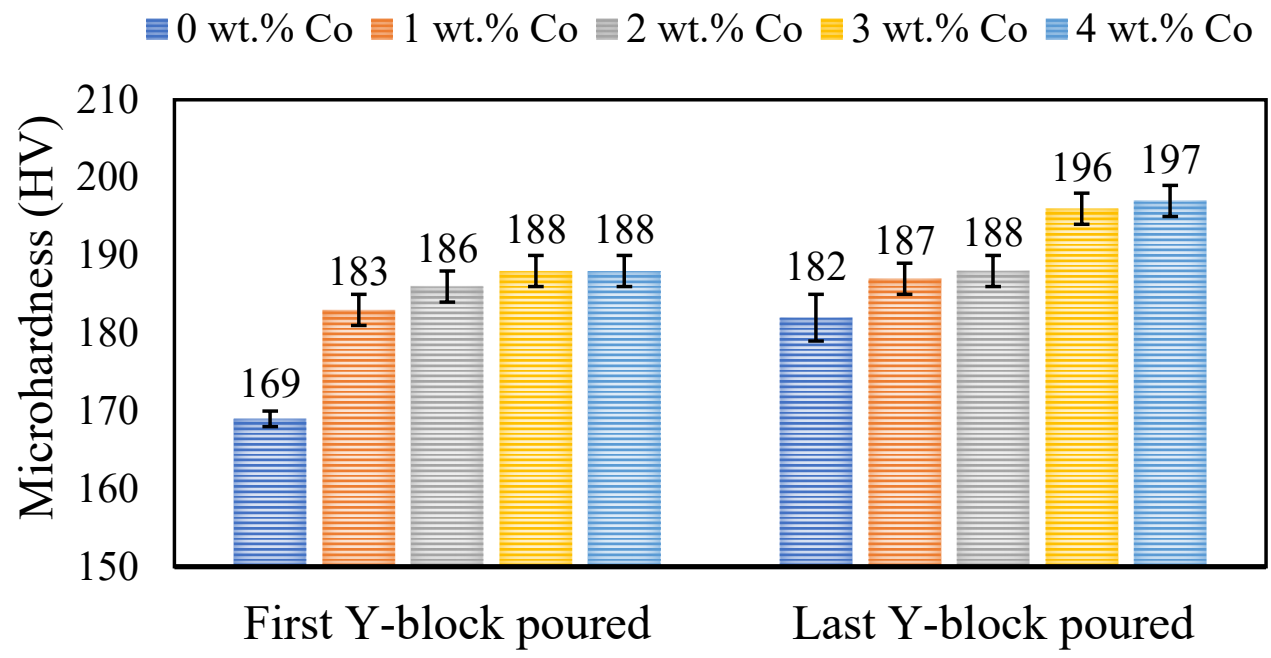

Figure 4.26 Effect of cobalt on the ferrite hardness of the $1 / 2$ inch Y-blocks. Error bars are $95 \%$ Std error of the mean [81].

\subsubsection{Impact Energy Evaluation}

\subsubsection{V-notched samples}

All heats showed a decrease in the absorbed energies with decreasing the temperature. The DBTT for the base ductile iron heat is about $-35^{\circ} \mathrm{C}$ and is shifted to $-30^{\circ} \mathrm{C}$ with 4 wt.\% Co (Figure 4.27). Compared to the cobalt bearing alloys, the base ductile iron heat displayed higher impact energy values over the entire range of temperatures.

Furthermore, the $3 \mathrm{wt} . \%$ and $4 \mathrm{wt} . \%$ Co heats resulted in the lowest absorbed energies. The absorbed energies from this test are in the range of 2.62 to 14.53 joules. Cobalt additions increase the DBTT and do not increase the impact energy for the v-notched samples. 


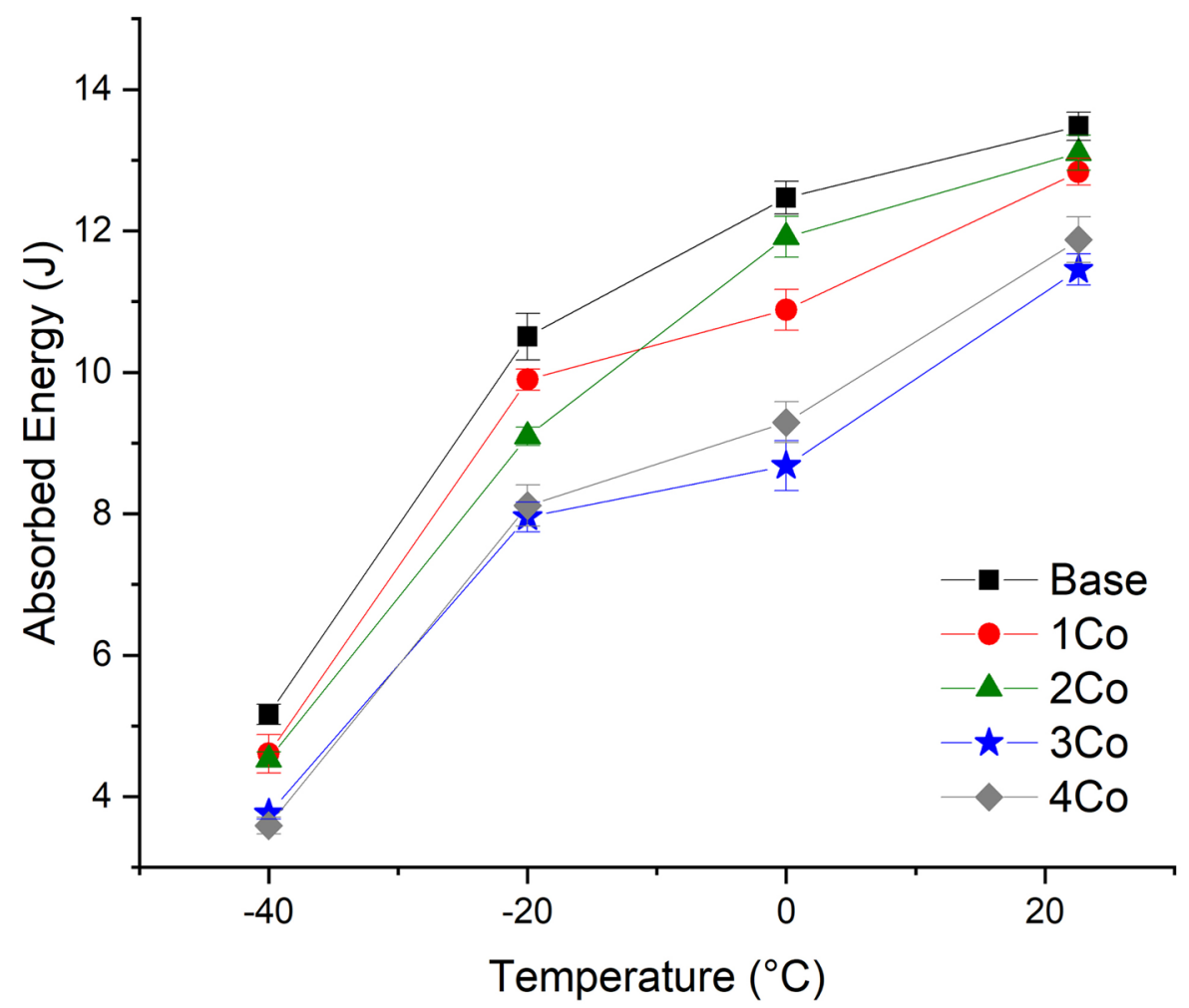

Figure 4.27 Charpy V-notched impact energy of the $1 / 2$ inch Y-blocks. Error bars are 95\% Std error of the mean.

\subsubsection{Unnotched samples}

In Figure 4.28, the absorbed energy for all compositions drops with lowering the temperature. The $2 \mathrm{wt} . \%$ Co heat had the highest impact energy among all the heats over the entire temperature range. The $4 \mathrm{wt} . \%$ Co heat was next highest, but the impact energy decreased at $-40^{\circ} \mathrm{C}$. Also, the 3 wt. $\%$ Co heat had the lowest absorbed energies over the entire temperature range, and the impact energy values of the base ductile iron heat are among the heats that resulted in the highest and lowest values. The absorbed energies for this samples were in a range of 60 to 133 joules. 


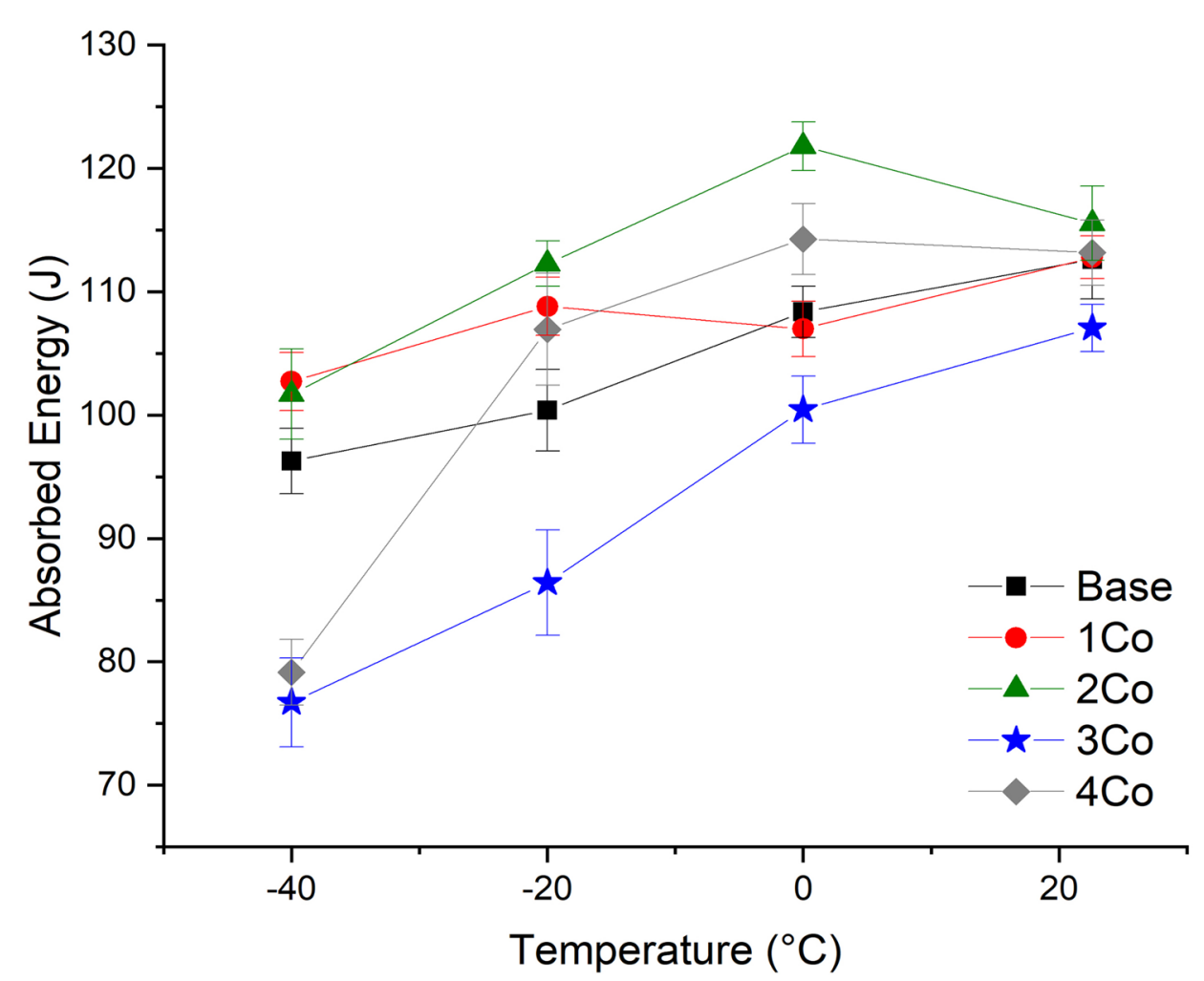

Figure 4.28 Charpy unnotched impact energy of the $1 / 2$ inch Y-blocks. Error bars are $95 \%$ Std error of the mean.

\subsubsection{Fracture Toughness Evaluation}

Over the temperature range of 0 to $-40^{\circ} \mathrm{C}$, the base ductile iron and $1 \mathrm{wt} . \%$ Co heats exhibited the highest fracture toughness values. Then, the $3 \mathrm{wt} . \%$ Co and $4 \mathrm{wt} . \% \mathrm{Co}$ heats presented similar values from 0 to $-40^{\circ} \mathrm{C}$. By increasing cobalt, the steep drop in fracture toughness is shifted to the right when compared to the base ductile iron heat. Also, the values of the $2 \mathrm{wt} . \%$ Co heat are among the heats that resulted in the highest and lowest fracture toughness values (Figure 4.29). 


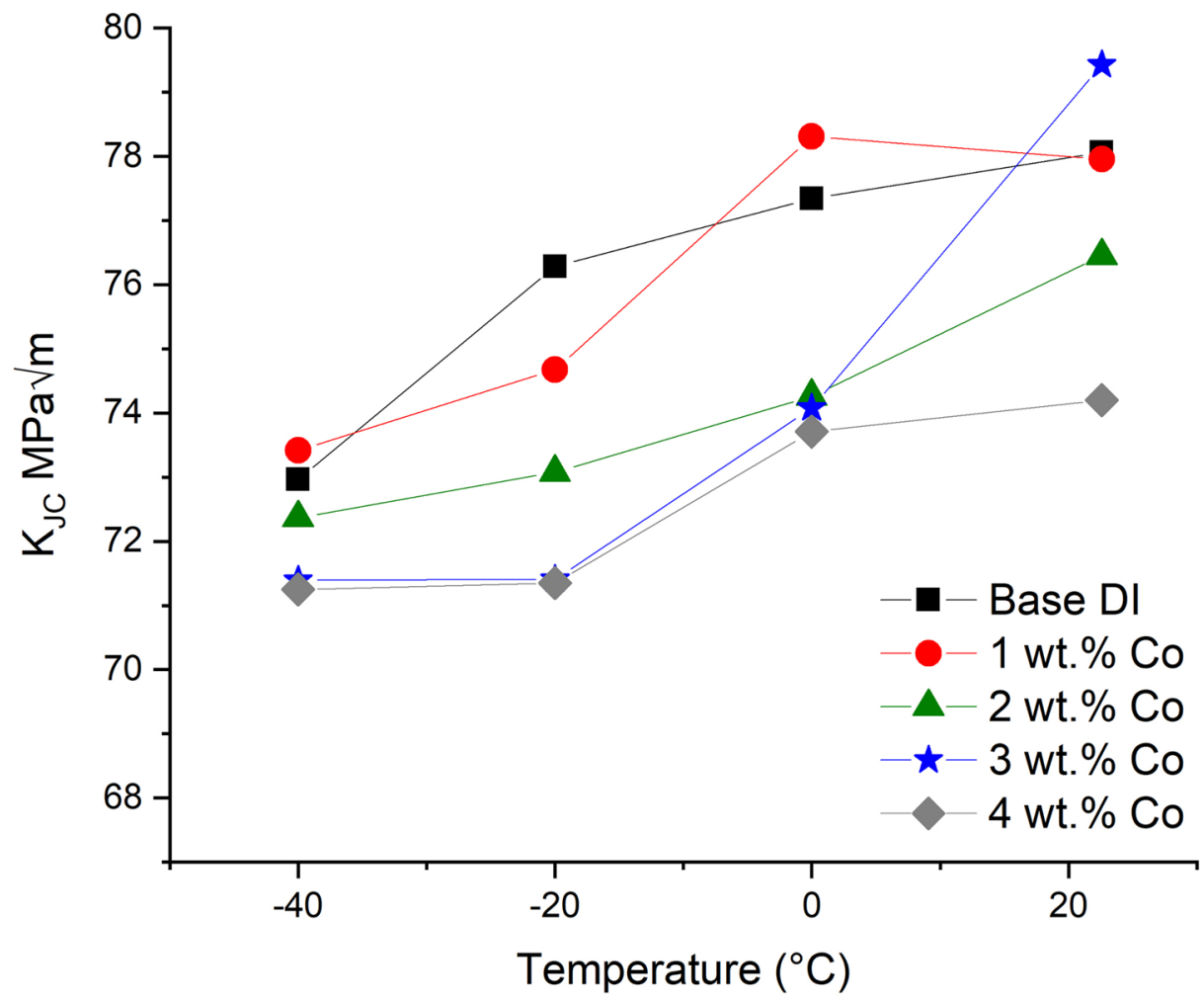

Figure 4.29 Fracture toughness of the $1 / 2$ inch Y-blocks.

\subsubsection{Microscopic Fracture Surface Examination}

\subsubsection{Fracture Surface Analysis of Flat Tensile Samples}

\subsection{Two-mm Thick Samples}

The fracture surfaces of the $2 \mathrm{~mm}$ tensile samples are shown in Figure 4.30. Brittle fracture by cleavage is observed for the base ductile iron sample, with few graphite nodules present (Figure 4.30a). The $1 \mathrm{wt} . \%$ Co heat exhibited a quasi-cleavage fracture, which is a unique fracture type that displays both cleavage and plastic deformation features. At a higher magnification, small cleavage steps and river patterns are observed (Figure 4.30b). This same type of fracture was found for the $2 \mathrm{wt.} \%, 3 \mathrm{wt} . \%$, and $4 \mathrm{wt} . \%$ Co heats. In Figure 4.30c at high magnification, the cleavage facets merge into areas with dimple rupture, resulting in tear ridges. A microcrack is seen at the matrix-nodule 
interface for the $3 \mathrm{wt} . \%$ Co heat (Figure 4.30d). Some areas of the $4 \mathrm{wt} . \%$ Co heat showed microporosity, as well as a combination of cleavage steps and plastic deformation near the graphite nodules (Figure 4.30e). From these fracture surfaces, it is clear that cobalt additions increase the nodule density when compared to the base ductile iron heat, and the fracture mechanism changes from cleavage to quasi-cleavage.
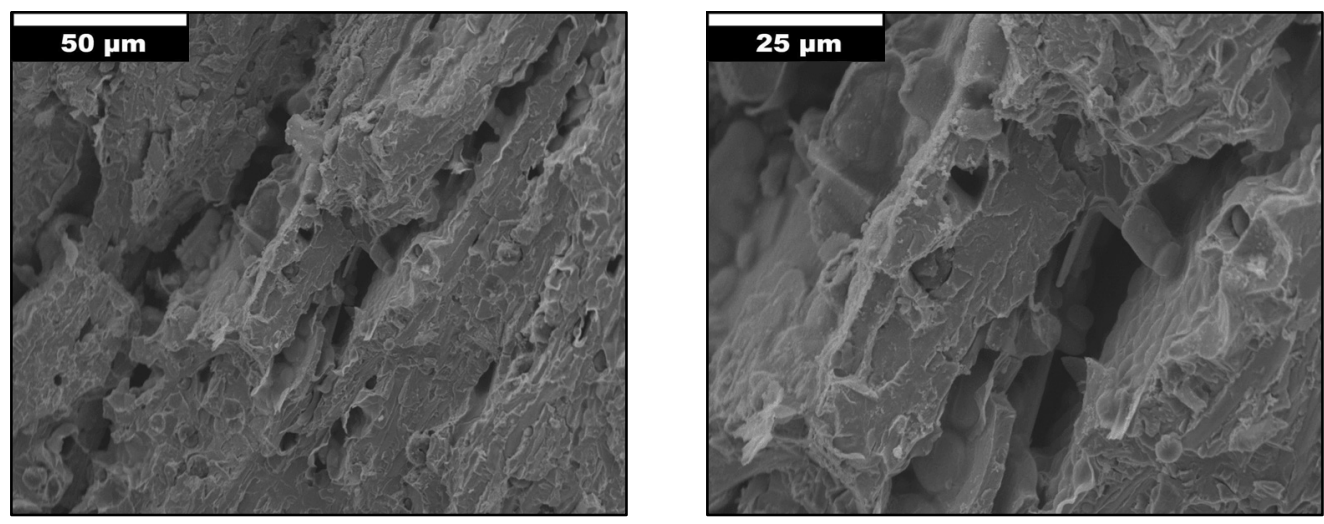

(a) Base DI
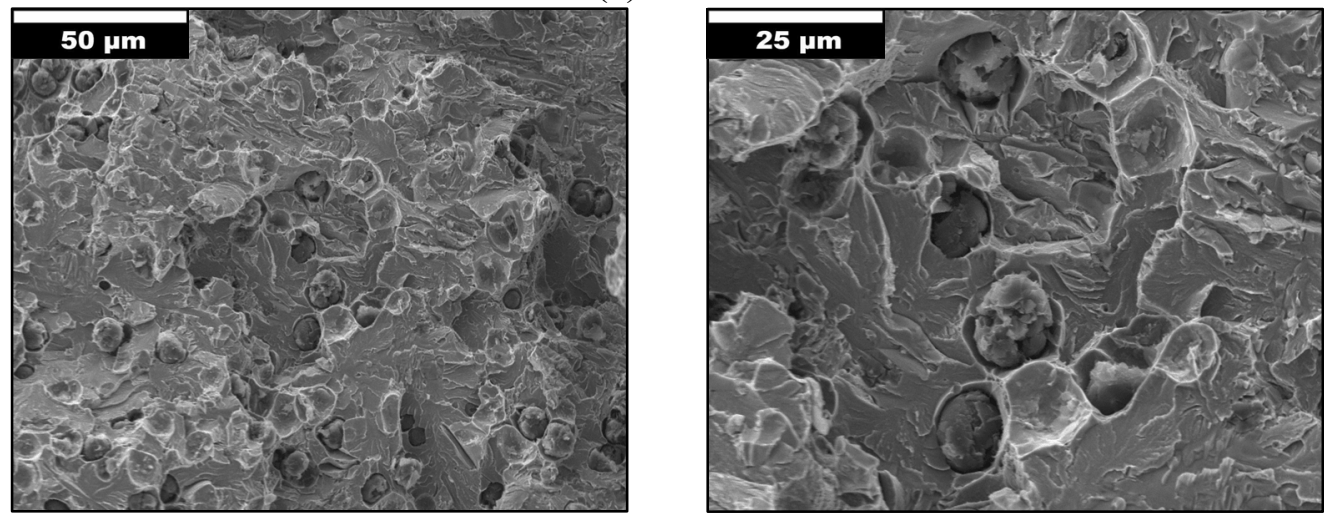

(b) 1 wt. $\%$ Co 

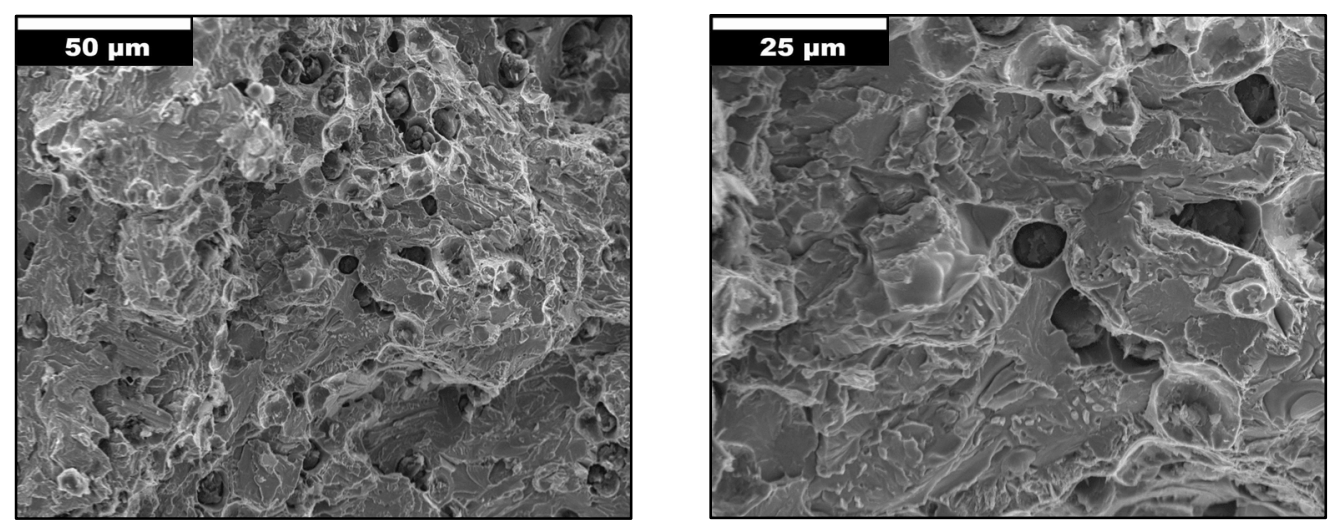

(c) 2 wt. $\% \mathrm{Co}$
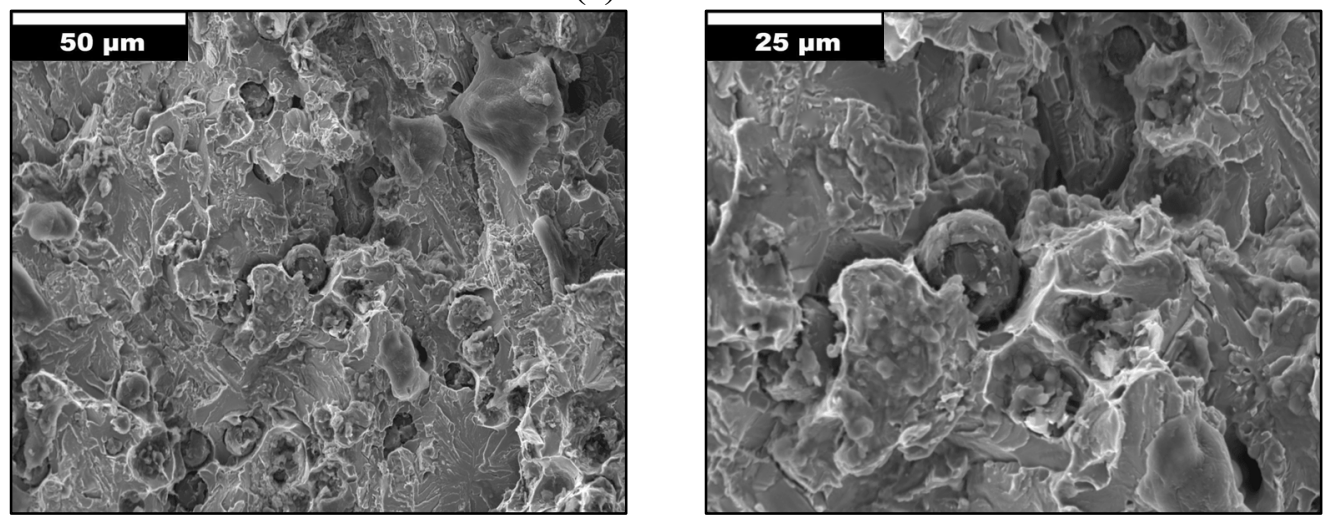

(d) 3 wt.\% Co
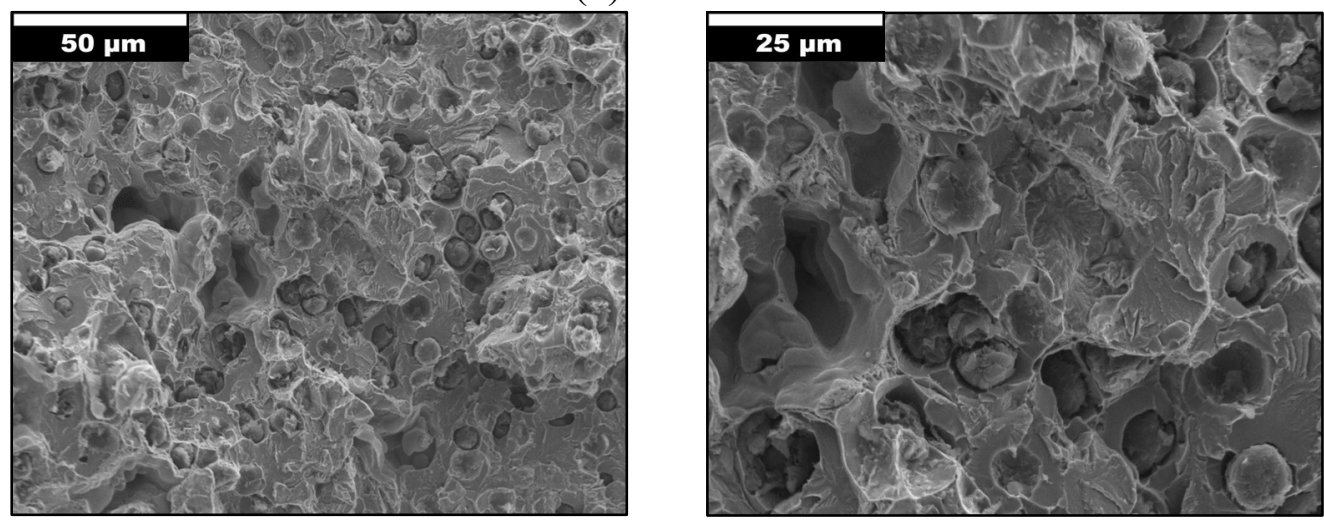

(e) 4 wt. \% Co

Figure 4.30 Fracture surface SEM images of the $2 \mathrm{~mm}$ flat tensile sample [79].

\subsection{Six-mm Thick Samples}

The SEM micrographs of the $6 \mathrm{~mm}$ flat tensile samples are shown in Figure 4.31. Quasicleavage fracture is observed for the base ductile iron heat, and some slight deformation 
with almost no stretching around the nodules is noted. The $1 \mathrm{wt} . \%$ and $2 \mathrm{wt} . \%$ Co heats show the same type of fracture as the base ductile iron heat. In Figure 4.31b, microvoids are seen around the dimples at high magnification. The $3 \mathrm{wt} . \%$ Co and $4 \mathrm{wt} . \%$ Co heats displayed ductile fracture. At higher magnifications, plastic deformation zones and microvoids are observed for the 3 wt.\% Co heat (Figure 4.31d). Once again, an increase in nodule count was observed with higher cobalt. The size of the dimples varies with the size of the graphite nodules. For this section thickness, the fracture mechanism changed from quasi-cleavage to ductile with increasing cobalt additions.
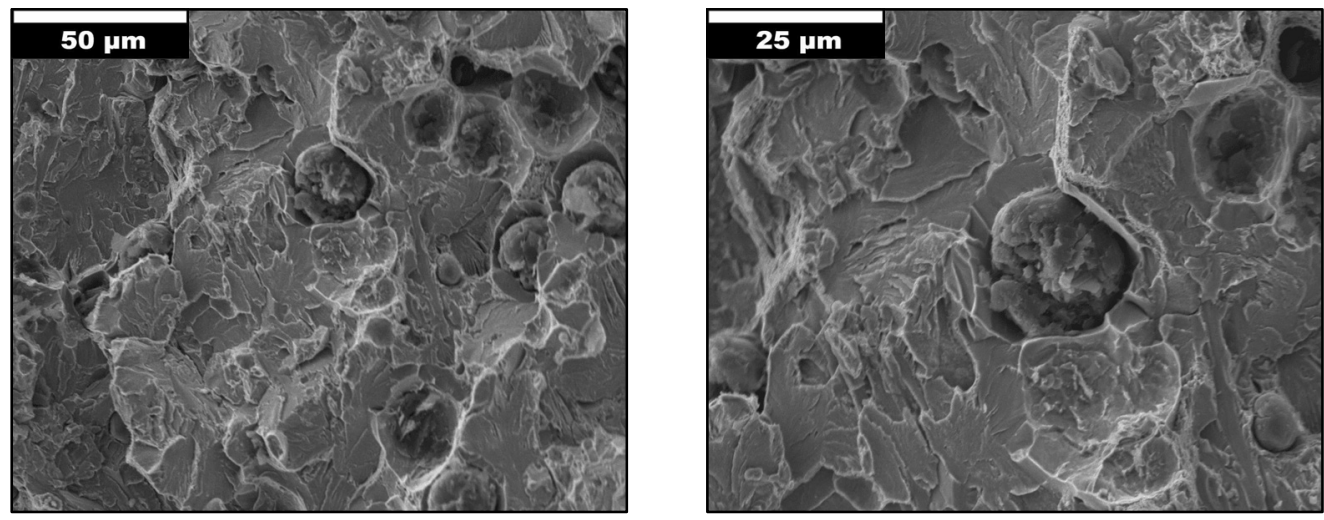

(a) Base DI
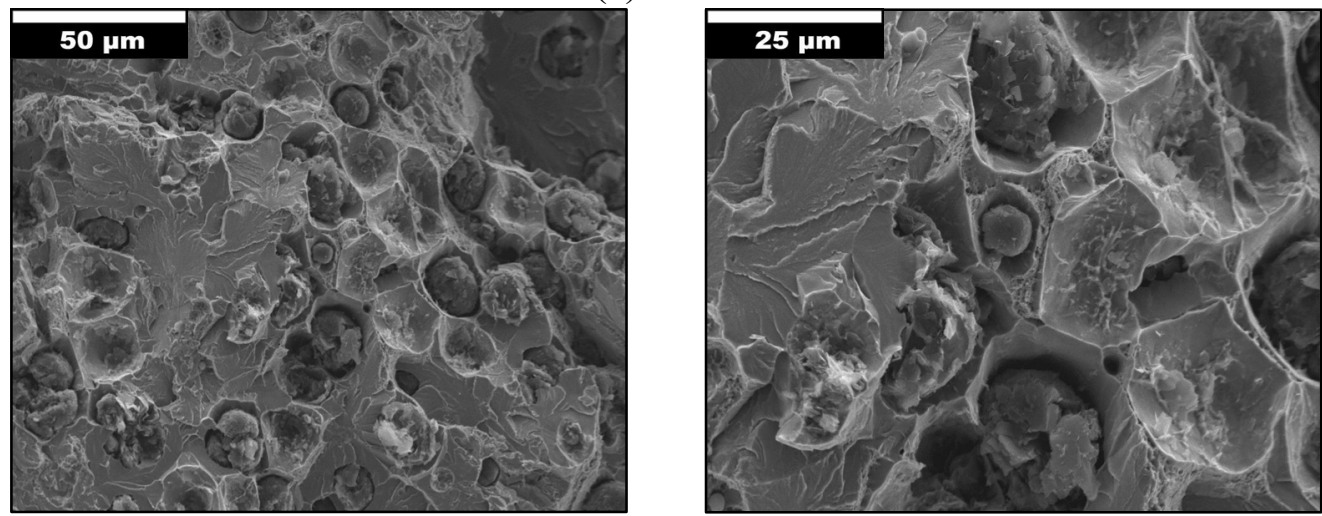

(b) $1 \mathrm{wt} . \% \mathrm{Co}$ 

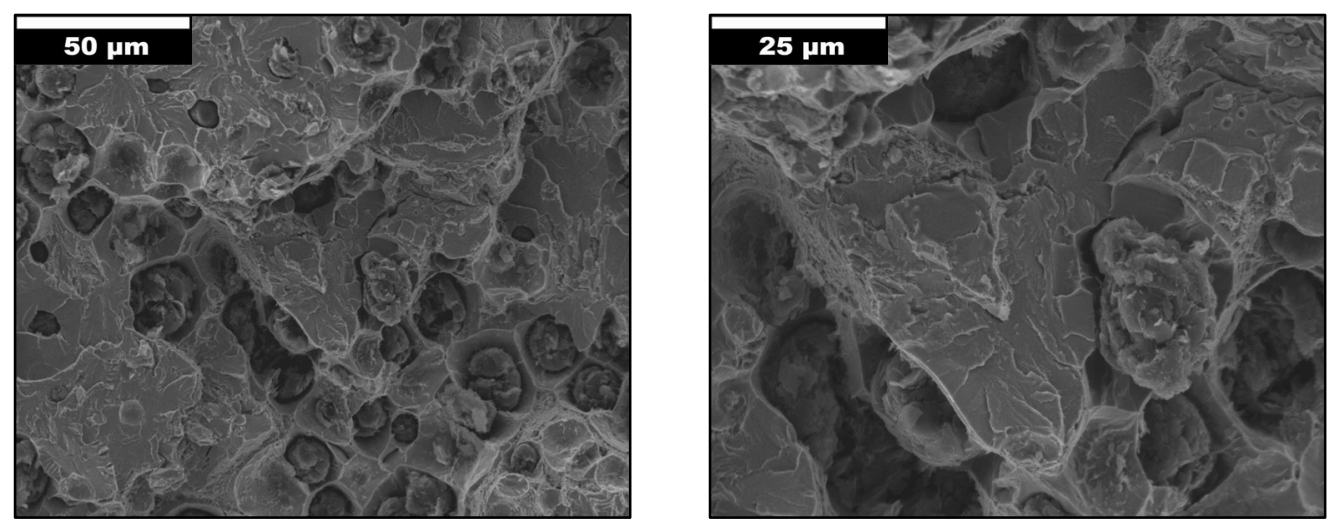

(c) $2 \mathrm{wt} . \% \mathrm{Co}$
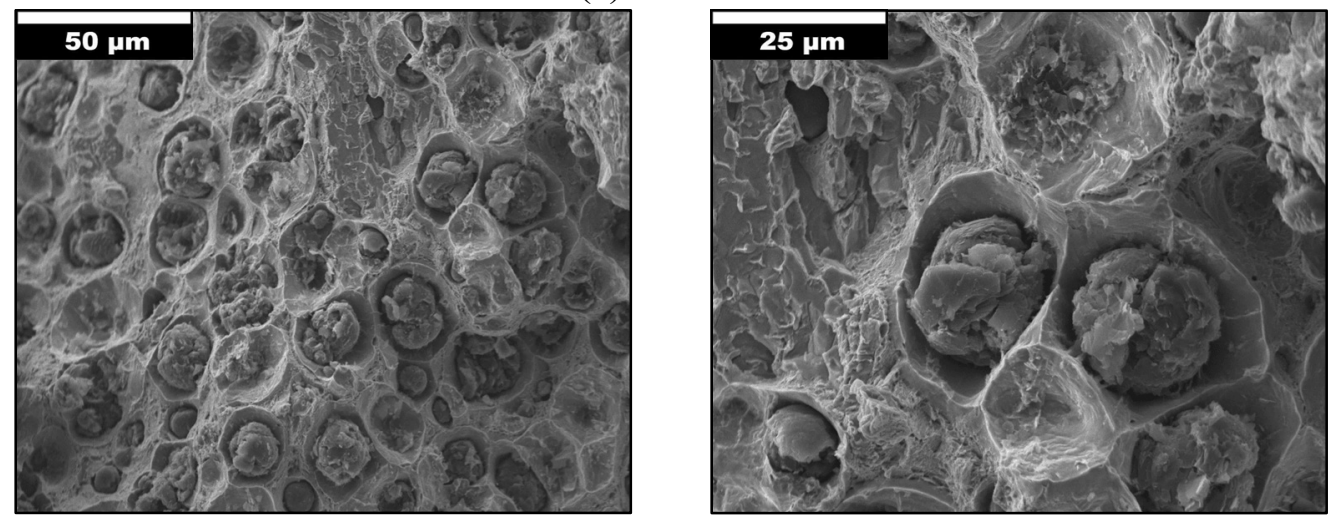

(d) 3 wt.\% Co
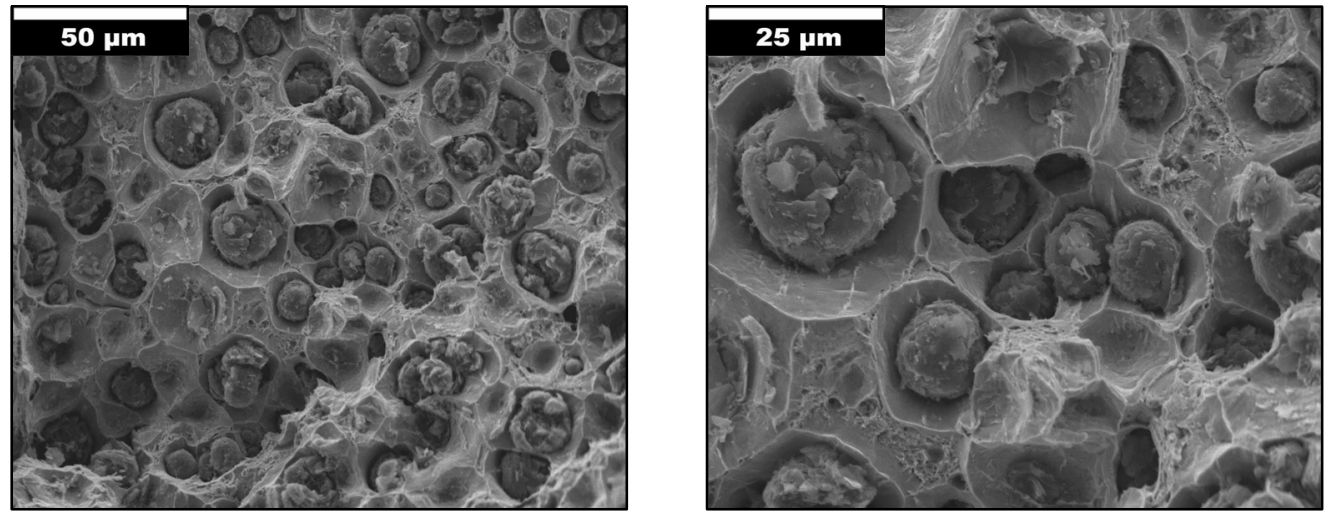

(e) 4 wt. \% Co

Figure 4.31 Fracture surface SEM images of the $6 \mathrm{~mm}$ flat tensile sample [79]. 


\subsubsection{Fracture Surface Analysis of Charpy Samples}

\subsection{V-notched Charpy Samples}

The base ductile iron sample exhibited a brittle fracture by cleavage with river patterns observed at higher magnifications on the cleavage facets (Figure 4.32a). The $1 \mathrm{wt} . \%$ Co heat had ductile fracture (Figure 4.32b). In Figure 4.32c, ductile fracture is observed with a small cleavage area for the $2 \mathrm{wt} . \%$ Co heat. The $3 \mathrm{wt} . \%$ Co heat exhibited ductile fracture with some cracks breaking into the surface (Figure 4.32d). In Figure 4.32e, the 4 wt.\% Co heat displayed a similar fracture surface as the $2 \mathrm{wt} . \%$ Co heat, showing areas of ductile and brittle fracture. All the samples had broken or partially disintegrated graphite nodules leaving residual graphite in the cavities. The fracture mechanism for these samples changed from brittle to ductile with cobalt additions. However, as mentioned earlier, the $2 \mathrm{wt} . \%$ and $4 \mathrm{wt} . \%$ Co had some areas with cleavage facets.
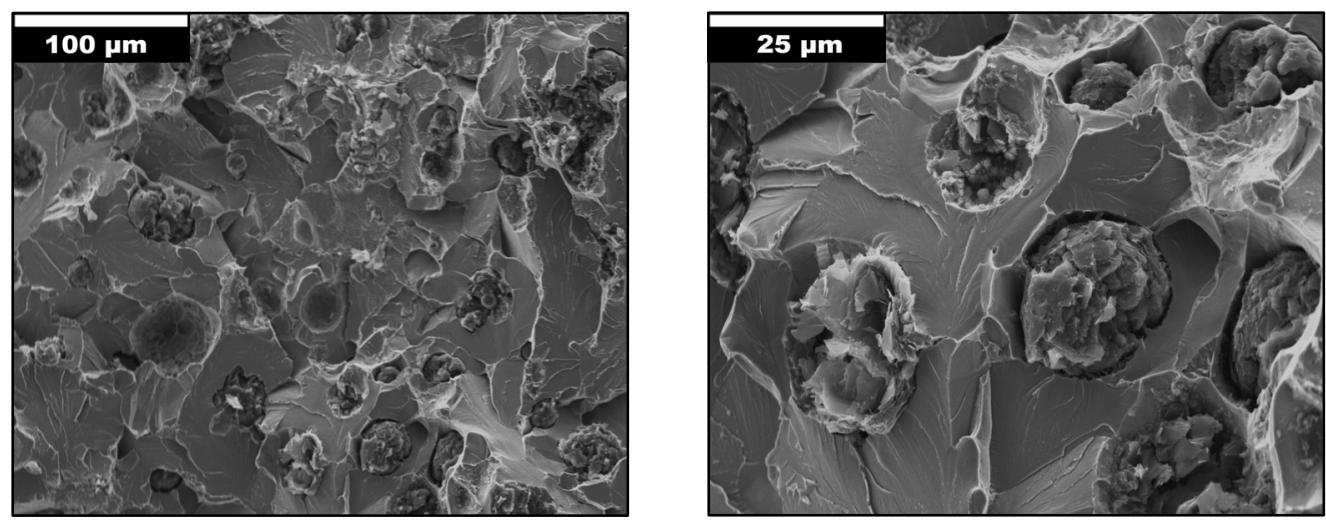

(a) Base DI
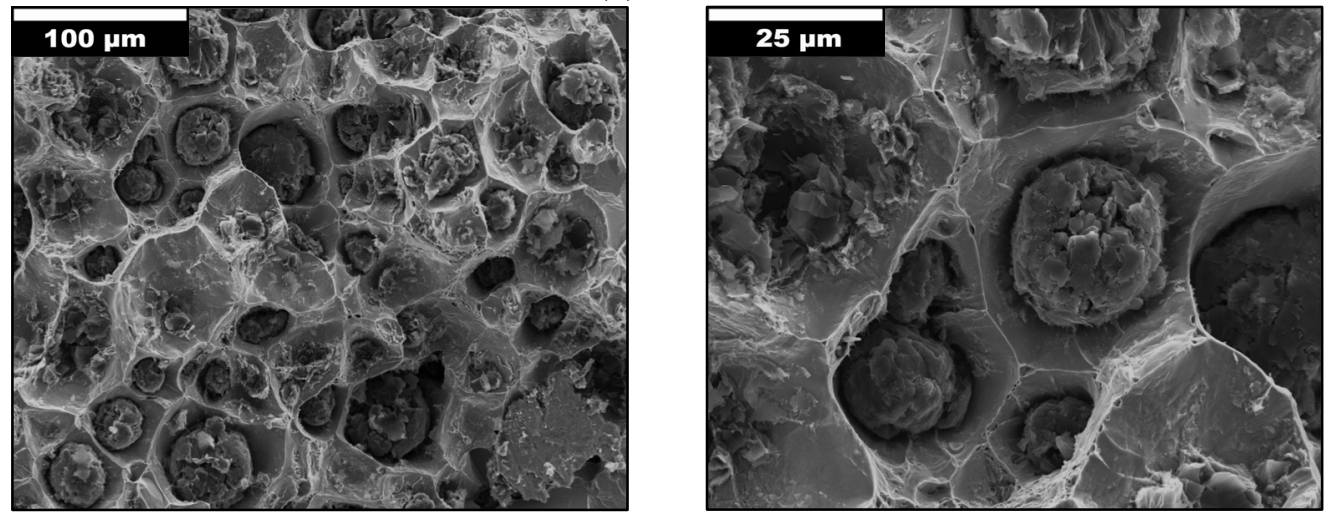

(b) 1 wt. $\% \mathrm{Co}$ 

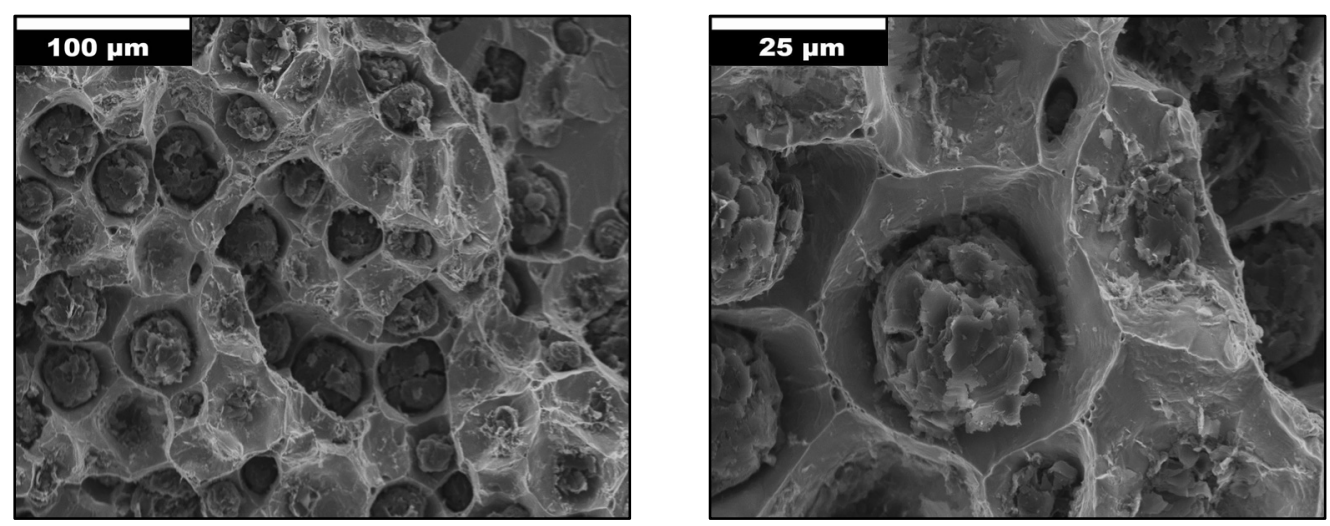

(c) 2 wt.\% Co
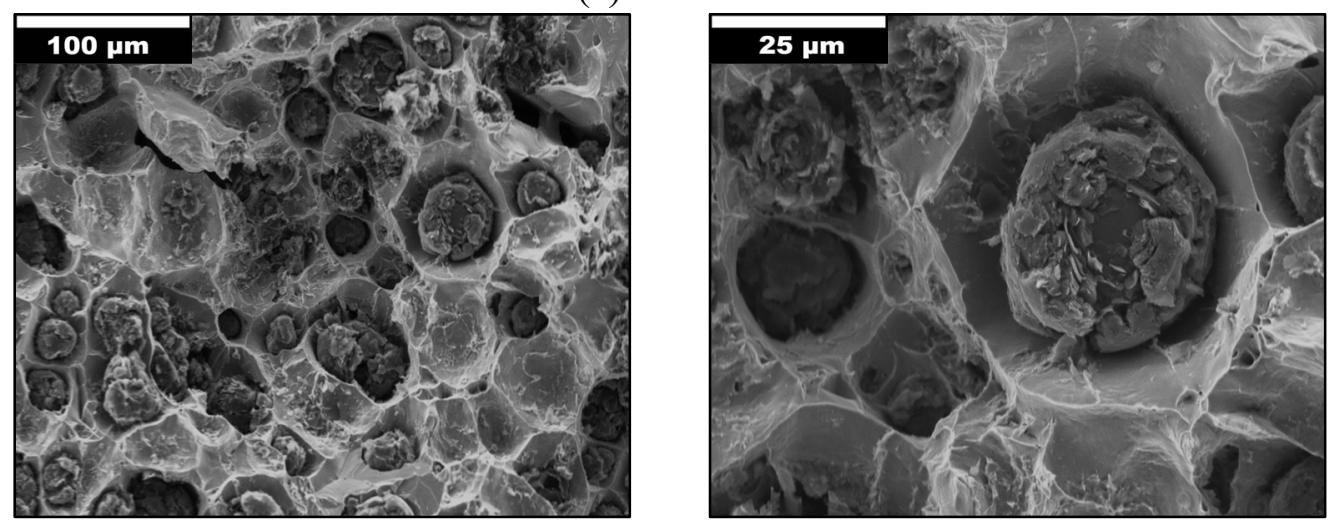

(d) 3 wt.\% Co
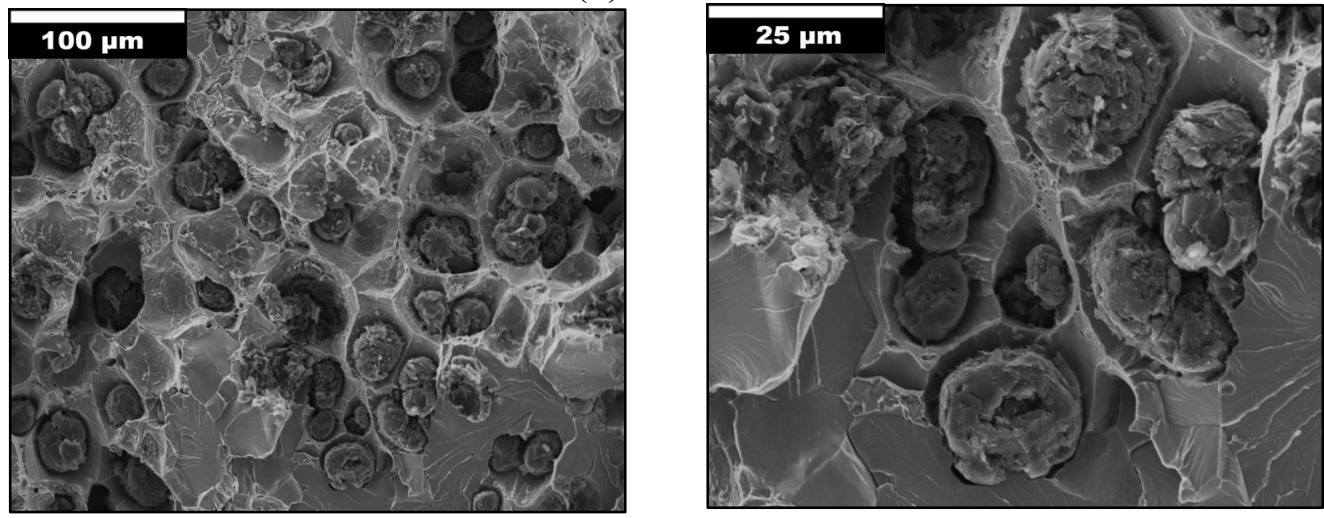

(e) 4 wt. $\%$ Co

Figure 4.32 Fracture surface SEM images of V-notched Charpy samples.

\subsection{Unnotched Charpy Samples}

The base ductile iron heat exhibited a quasi-cleavage fracture. Cleavage facets merging into the dimples were observed at low and high magnifications (Figure 4.33a). In Figure $4.33 \mathrm{~b}$, the $1 \mathrm{wt} . \%$ Co heat showed quasi-cleavage fracture, and at low magnifications, a mixture of cleavage facets and dimple rupture is observed. The $2 \mathrm{wt} \%$ Co heat displayed 
a significant portion of ductile fracture with a small area of cleavage facets (Figure 4.33c). The 3 wt.\% and 4 wt.\% Co heats exhibited some areas with a quasi-cleavage fracture, but the fracture surface is dominated by cleavage fracture. In Figure $4.33 \mathrm{~d}$, microcracks emanating from the graphite nodules are observed for the $3 \mathrm{wt} . \%$ Co heat, and the 4 wt.\% Co heat showed several cracks that are seen at low and high magnifications (Figure 4.33e). For these samples, the fracture mode changes from a quasi-cleavage fracture to ductile fracture with 2 wt.\% Co. However, the fracture mode for the other heats was a mixture of quasi-cleavage and cleavage fracture.
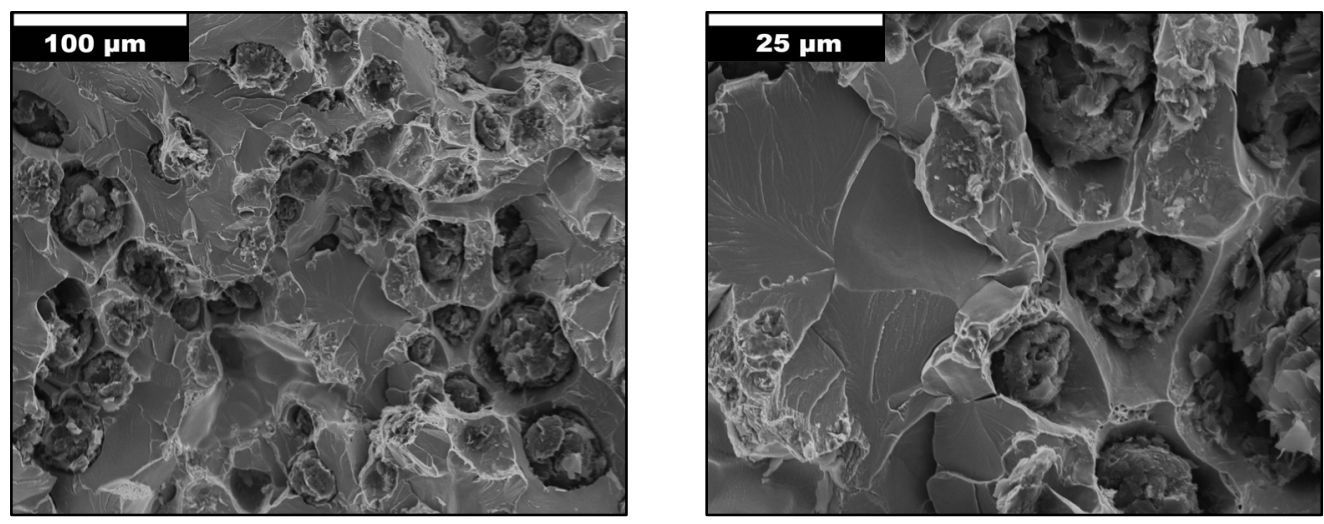

(a) Base DI
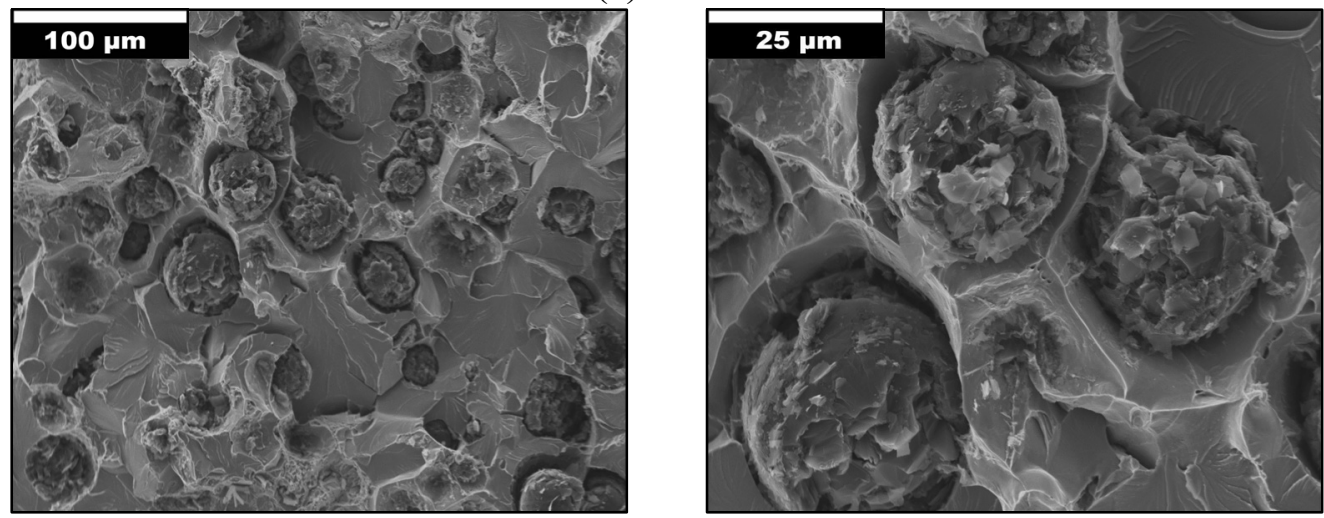

(b) $1 \mathrm{wt} . \% \mathrm{Co}$ 

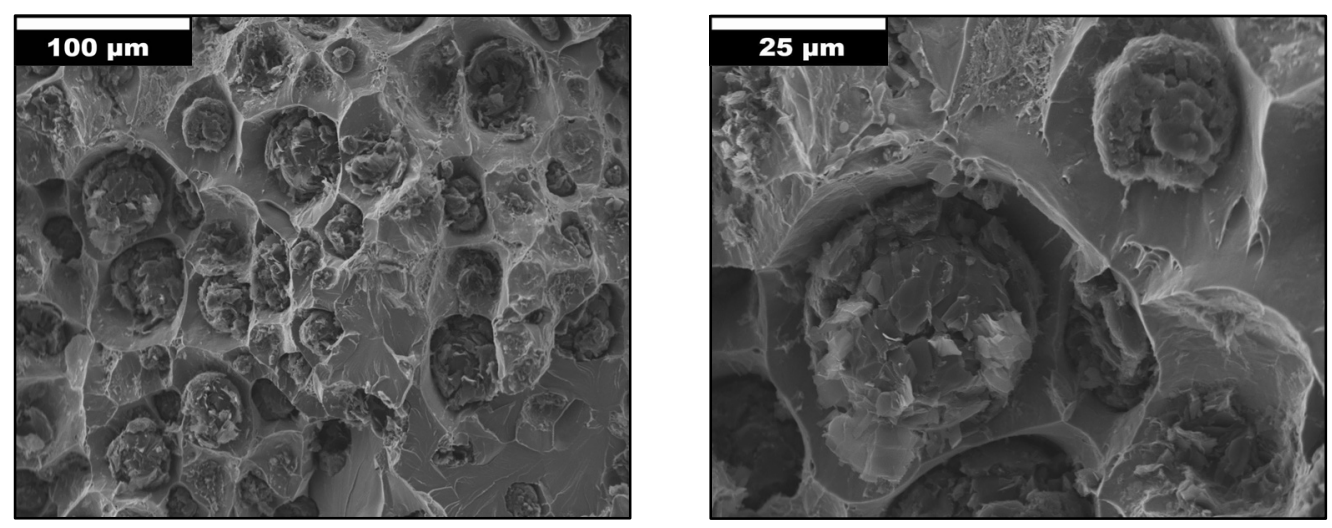

(c) 2 wt. \% Co
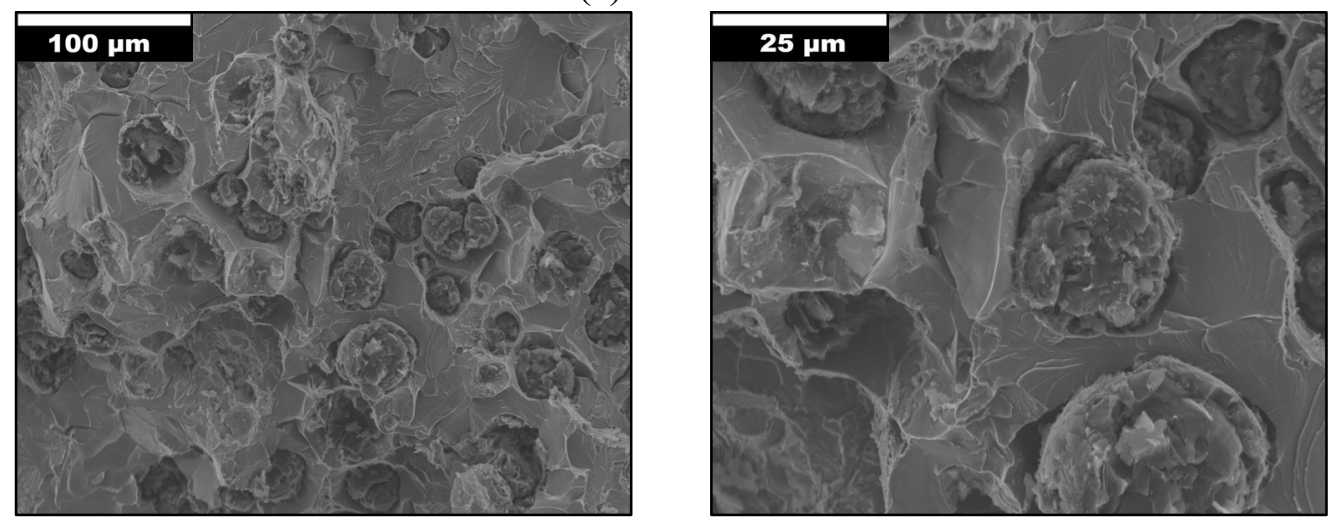

(d) 3 wt. $\% \mathrm{Co}$
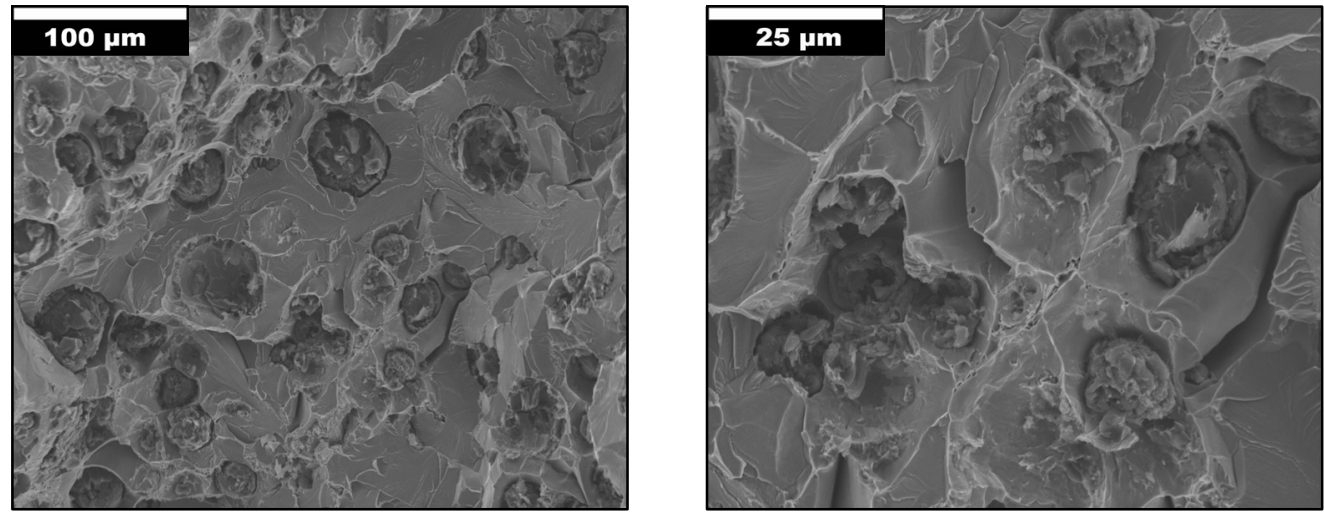

(e) 4 wt. \% Co

Figure 4.33 Fracture surface SEM images of Unnotched Charpy samples. 


\subsubsection{Fracture Surface Analysis of $C(T)$ samples}

\subsection{C(T) Samples at Room Temperature}

The broken surfaces of the $\mathrm{C}(\mathrm{T})$ samples have two different zones that are distinguishable with the naked eye. Figure 4.34 shows a macrofractograph of the $\mathrm{C}(\mathrm{T})$ sample, where the two zones that are examined are labeled: Zone 1 fatigue crack propagation area, and Zone 2 final fracture area.

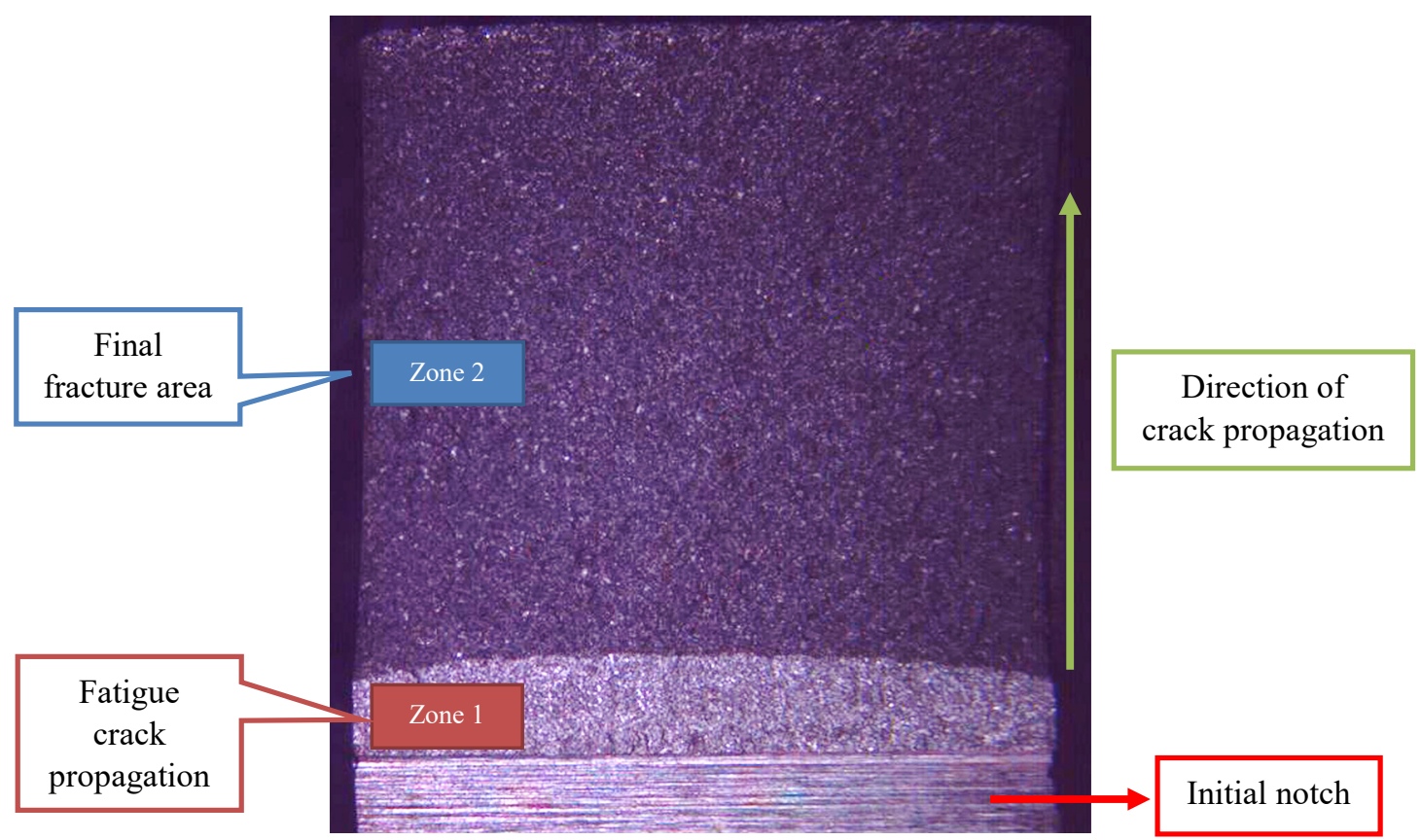

Figure 4.34 Stereoscopic fractography of a broken $\mathrm{C}(\mathrm{T})$ sample showing the two analyzed zones.

The SEM micrographs of the base ductile iron heat are shown in Figure 4.35. Zone 1 exhibited transgranular fracture with some cleavage facets. Also, small cracks emerging from the nodules are seen at low magnifications (marked by white arrows in Figure 4.35a). At high magnification, fatigue striations are rarely observed. In contrast, zone 2 displayed ductile fracture, in which microvoids around the dimples are seen at low and high magnifications (Figure 4.35b). 

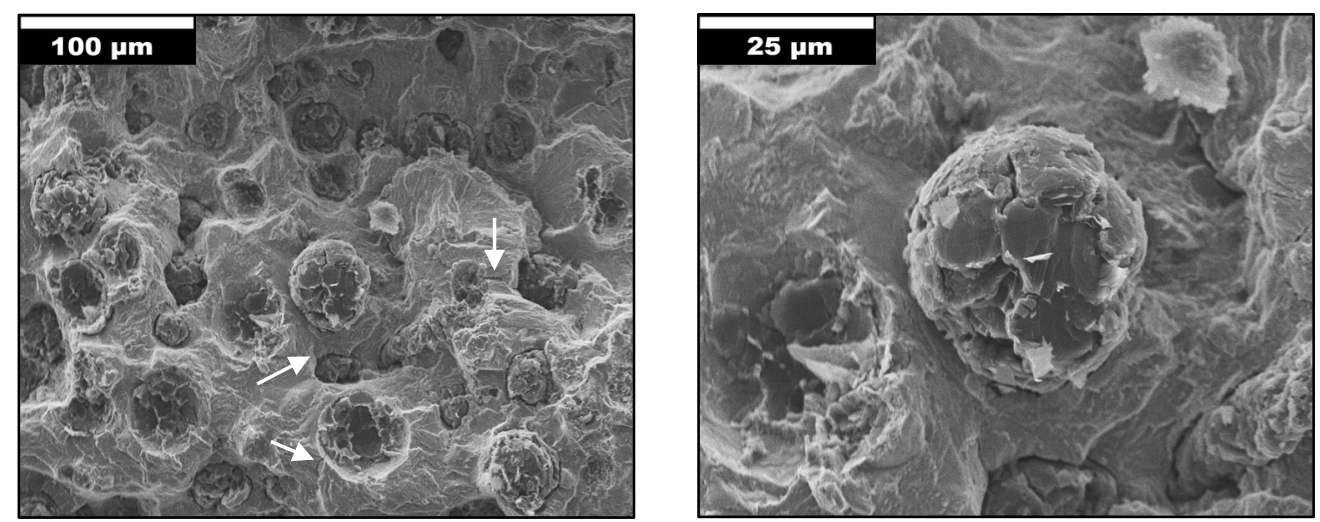

(a) Zone 1
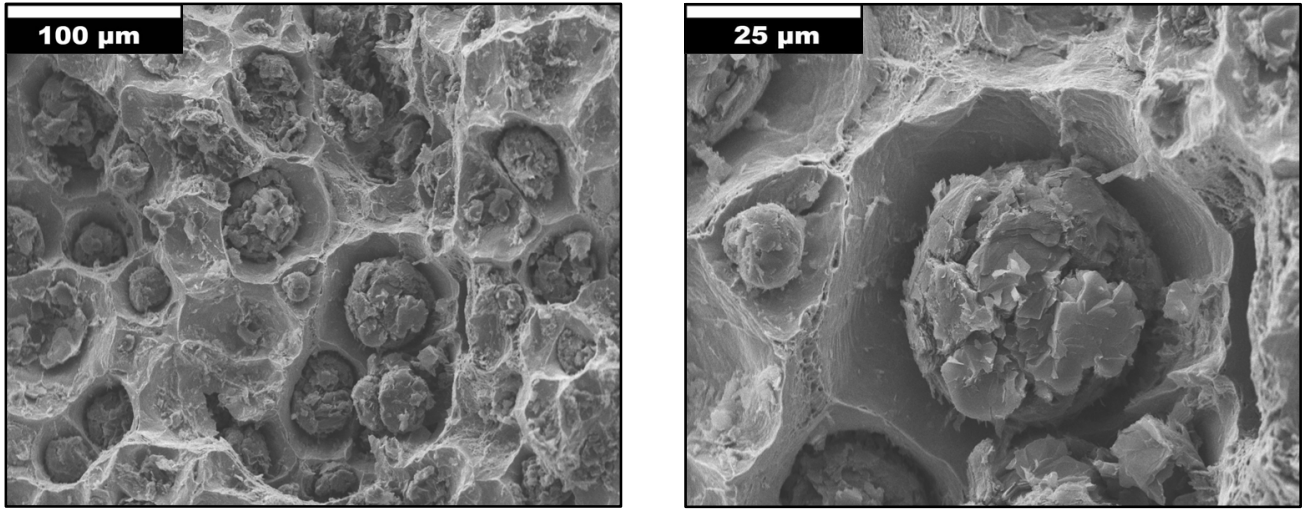

(b) Zone 2

Figure 4.35 Fracture surface SEM images of the base ductile iron heat $\mathrm{C}(\mathrm{T})$ sample.

For the 3 wt.\% Co heat, zone 1 displays the same type of fracture as the base ductile iron heat. At high magnification, the fatigue striations are clearly observed (white arrow in Figure 4.36a). At least for this area, not as many small cracks emanating around the graphite nodules were observed compared to the base ductile iron heat. However, a tiny crack was identified at high magnification and is marked by a red arrow in Figure 4.36a. On the other hand, zone 2 showed a typical ductile fracture (Figure 4.36b). 

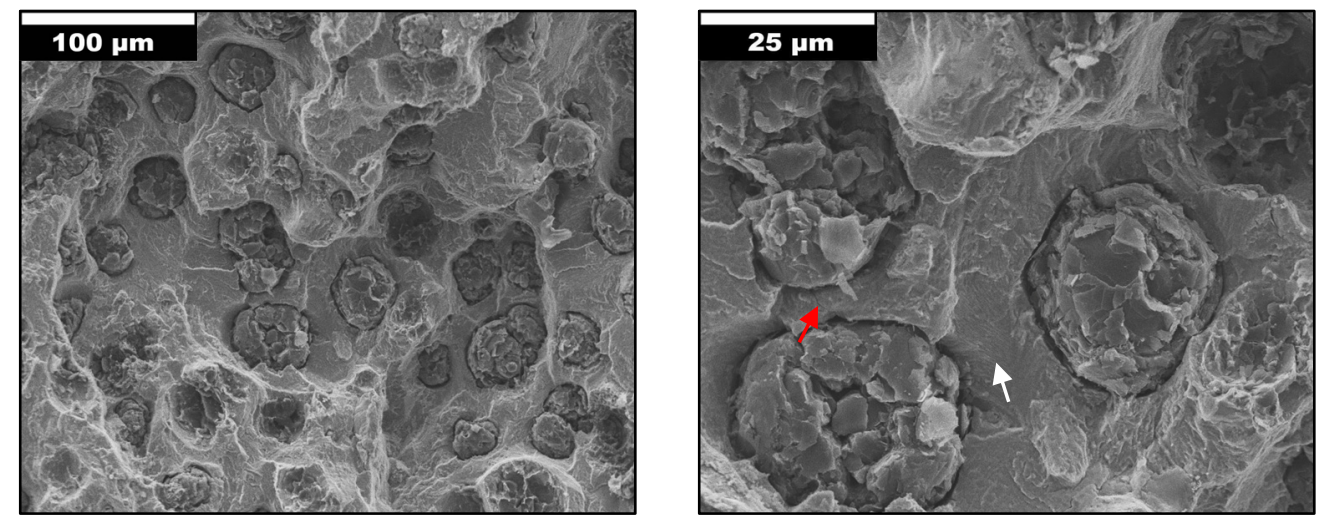

(a) Zone 1
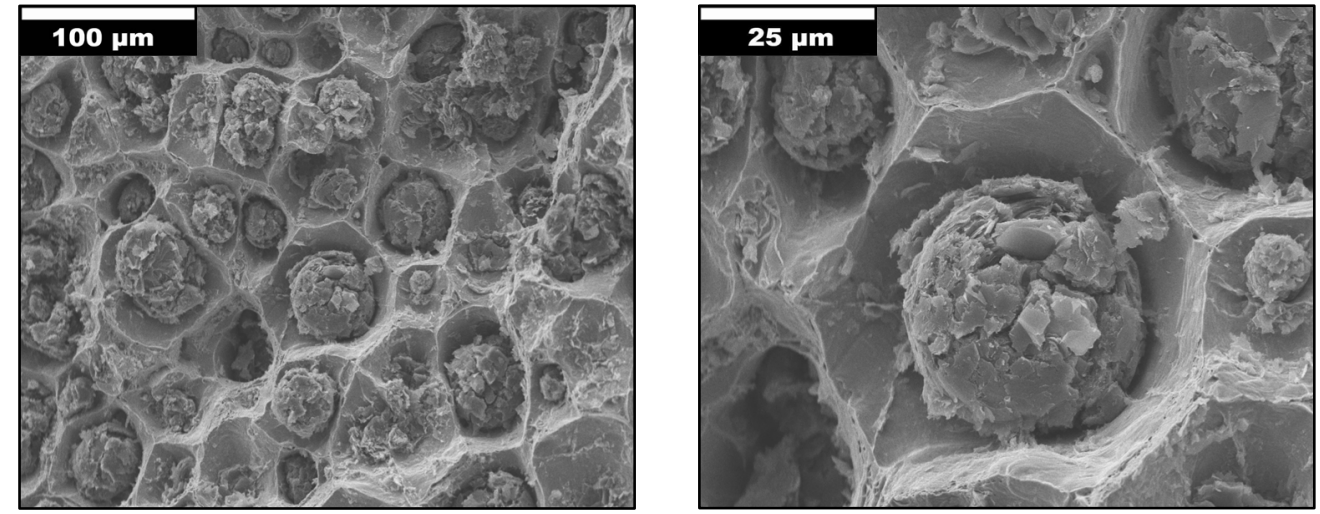

(b) Zone 2

Figure 4.36 Fracture surface SEM images of the 3 wt.\% Co heat C(T) sample.

In Figure 4.37a, the 4 wt.\% Co heat showed several cracks around the nodules along the nodule-matrix interface at low magnification (white arrows). Also, this sample exhibited numerous irregular shaped inclusions (yellow arrows). After performing EDS, the results showed that the inclusions were mainly oxide inclusions of $\mathrm{Mg}, \mathrm{Si}, \mathrm{Ca}, \mathrm{Al}$, and $\mathrm{Fe}$. At high magnification, fatigue striations marks are observed (white arrow). Zone 2 displays a predominant ductile fracture, but some areas show quasi-cleavage fracture. Cracks in the matrix and some inclusions are visible at low magnifications (Figure 4.37b). 

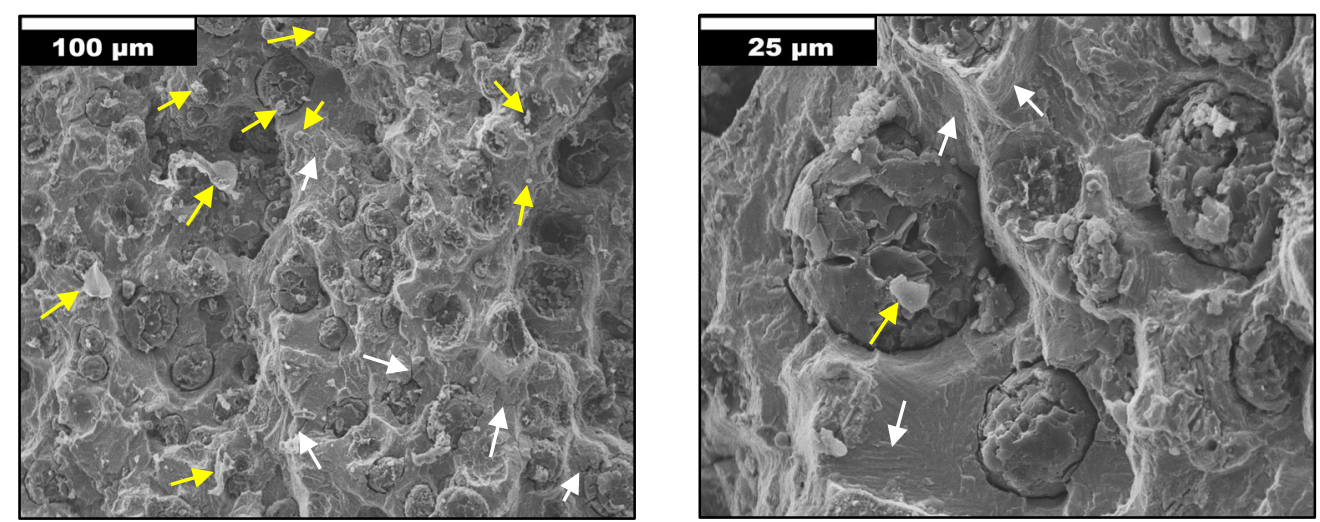

(a) Zone 1
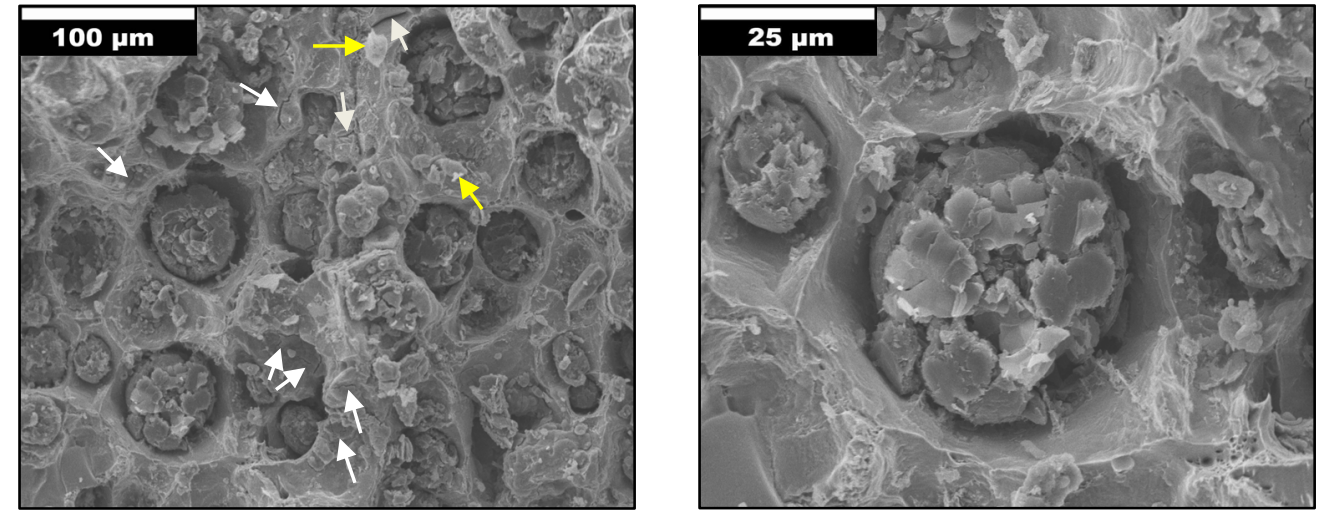

(b) Zone 2

Figure 4.37 Fracture surface SEM images of the 4 wt.\% Co heat C(T) sample.

\subsubsection{Segregation Analysis}

Figure 4.38 a shows the EDS measurements of the 3 wt.\% Co heat. A total of 8 points were measured to map the segregation profile of silicon and cobalt. Looking at these two elements, it seems that cobalt is segregating similarly to silicon, as cobalt and silicon are relatively higher near the graphite nodules. The segregation of silicon has been widely studied, and this element is known to have negative segregation, which means that the highest concentration is near the graphite nodules [93]-[100].

On the other hand, the $4 \mathrm{wt} . \%$ Co heat showed an unexpected increase in silicon and cobalt located in point 6 and point 7, perhaps due to a subsurface nodule (Figure 4.38b). However, if these two odd points are excluded from the plot, a more typical trend for 
cobalt and silicon segregation is observed (Figure 4.39). From Figure 4.39, the highest silicon concentration is found near the graphite nodules (point 1 and point 9).

Additionally, the maximum cobalt content is in points 2 and 8, which are in the ferrite matrix. This behavior of cobalt is contrary to what Yazdani et al. observed, in which cobalt segregates opposite to silicon, (positive segregation) [60].
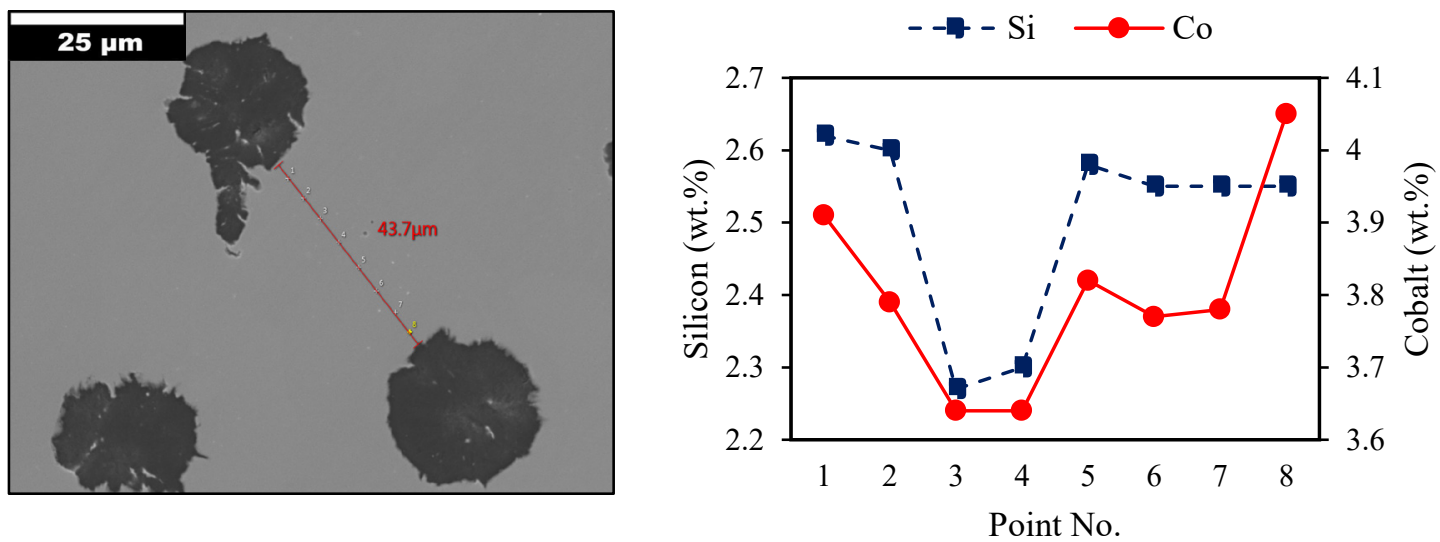

(a) 3 wt. $\% \mathrm{Co}$
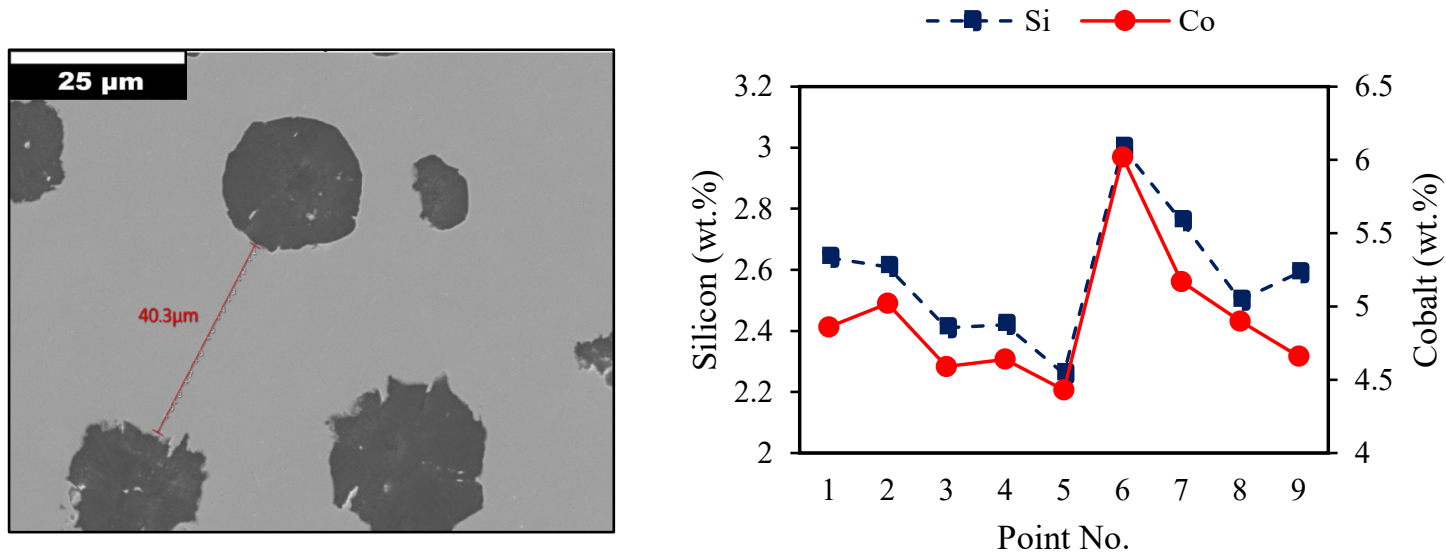

(b) 4 wt. \% Co

Figure 4.38 EDS measurements for the (a) 3 wt. \% Co, and (b) 4 wt.\% Co heats. 


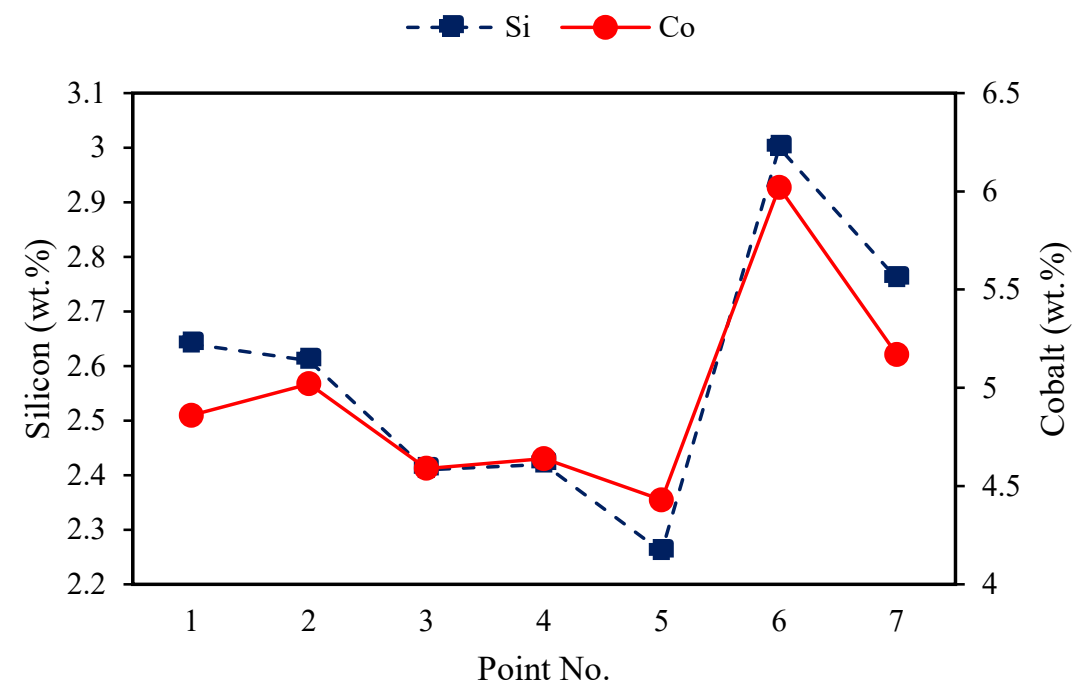

Figure 4.39 Modified EDS measurements for the 4 wt.\% Co heat (points 6 and 7 were excluded). 


\subsection{Effect of Cobalt in Solid Solution Strengthened Ferritic Ductile Iron}

\subsubsection{Chemical Composition}

The final chemical composition is close to the target (Table 4.2), with the four heats having very consistent $\mathrm{C}$ and $\mathrm{Si}$ and the cobalt values close to the target.

Table 4.2 Final chemical composition for high silicon grades (wt.\%)

\begin{tabular}{cccccc}
\hline Element & Target & Base SSF & 2 wt.\% Co & 3 wt.\% Co & 4 wt.\% Co \\
\hline $\mathrm{C}(\mathrm{Leco})$ & 3.0 & 3.10 & 3.05 & 3.04 & 3.06 \\
\hline $\mathrm{Si}$ & $<4.3$ & 4.13 & 4.14 & 4.12 & 4.14 \\
\hline${ }^{\mathrm{a}} \mathrm{CE}$ & 4.43 & 4.48 & 4.43 & 4.41 & 4.44 \\
\hline $\mathrm{Mg}$ & $<0.06$ & 0.05 & 0.06 & 0.06 & 0.06 \\
\hline $\mathrm{Mn}$ & $<0.25$ & 0.19 & 0.19 & 0.18 & 0.19 \\
\hline $\mathrm{Cu}$ & $<0.10$ & 0.04 & 0.05 & 0.06 & 0.06 \\
\hline $\mathrm{P}$ & 0.025 & 0.03 & 0.02 & 0.02 & 0.02 \\
\hline${ }^{\mathrm{b}} \mathrm{Co}$ & - & 1.94 & 2.86 & 3.82 \\
\hline \multicolumn{7}{c}{${ }^{\mathrm{a}}$ The equation used for this calculation was CE $=$ wt.\% C + 1/3 wt.\% Si } \\
\end{tabular}

\subsubsection{Microstructure Evaluation}

\subsubsection{Graphite Analysis}

The unetched micrographs from the first and last Y-blocks poured are shown in Figure 4.40. A reduction in the nodule size is observed with cobalt additions, while some degenerate graphite is observed in all the heats. 


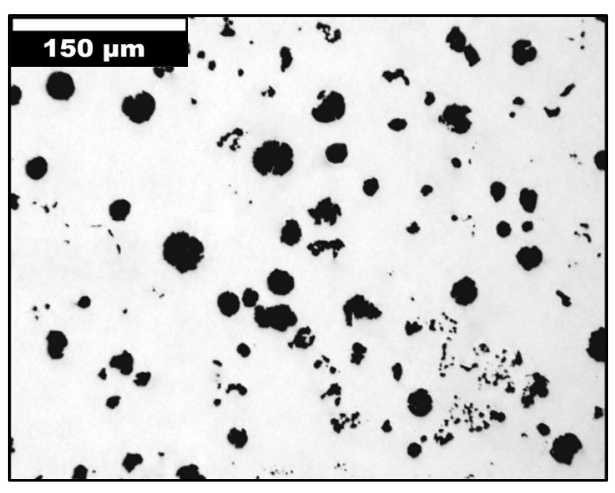

FIRST

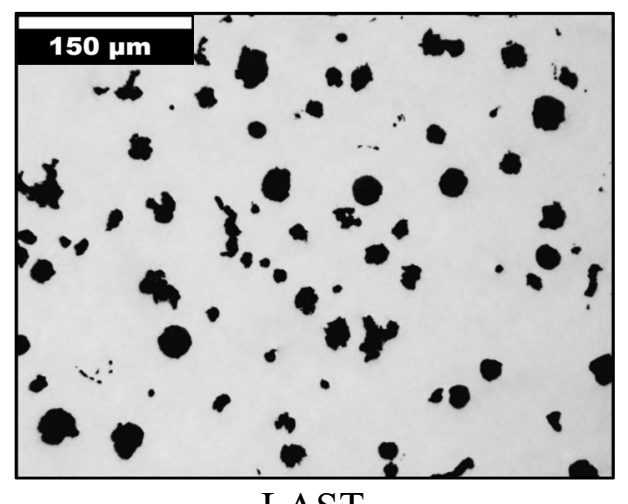

(a) Base SSF
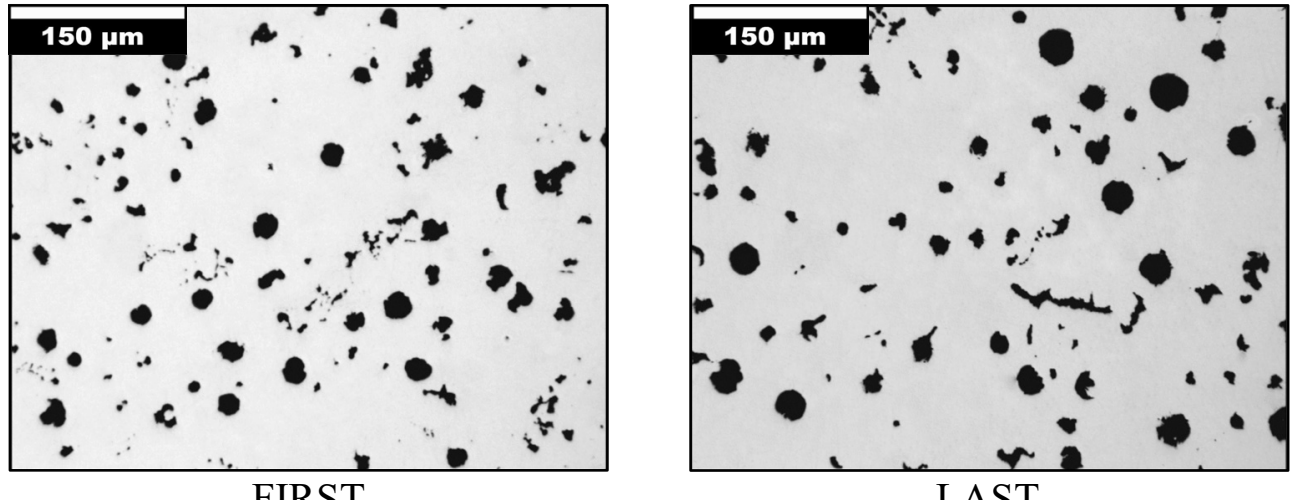

(b) 2 wt. $\% \mathrm{Co}$
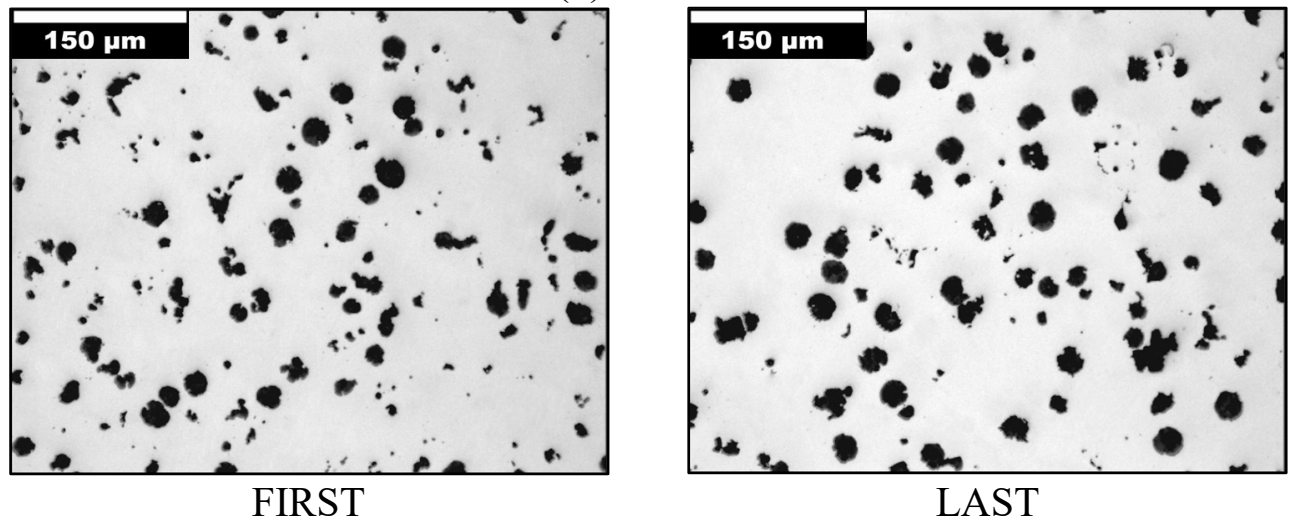

(c) 3 wt. $\% \mathrm{Co}$ 


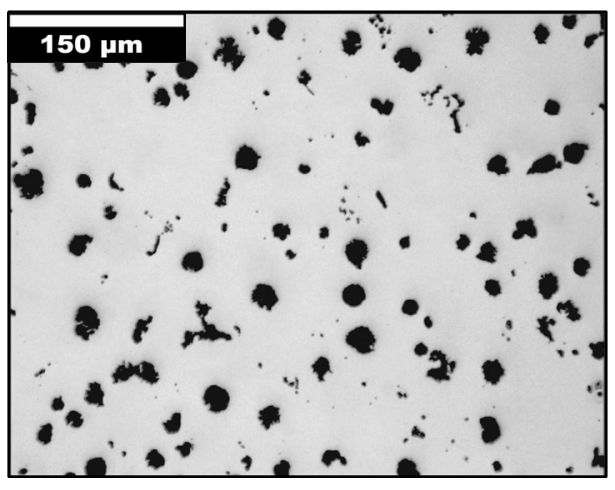

FIRST

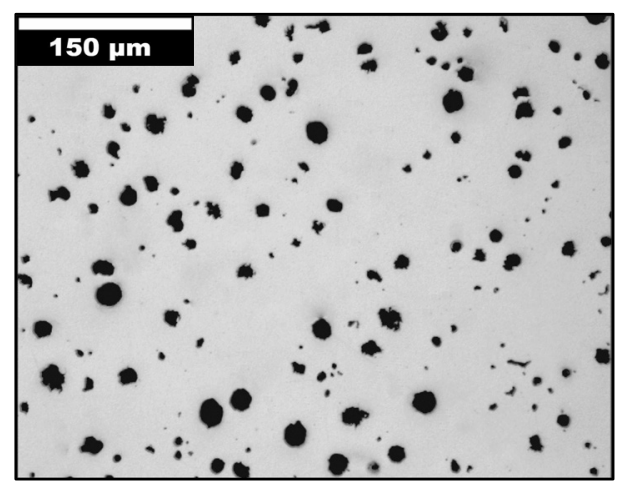

LAST

(d) 4 wt. $\%$ Co

Figure 4.40 Unetched micrographs at 100x of the first and last 1-inch Y-blocks poured.

For the first Y-blocks poured, the 4 wt.\% Co heat displayed the highest nodularity. The nodularity did not vary much in the last Y-blocks poured. Alloying SSF with cobalt produced no statistically significant improvements in the graphite shape. However, this finding does not support previous studies that found an increase in the percent nodularity for a 600-10 SSFDI grade alloyed with 2 wt.\% and 4 wt.\% Co [63], [64]. Although the results do not show an effect with cobalt additions, the percent nodularity for all heats was above $80 \%$ (Figure 4.41).

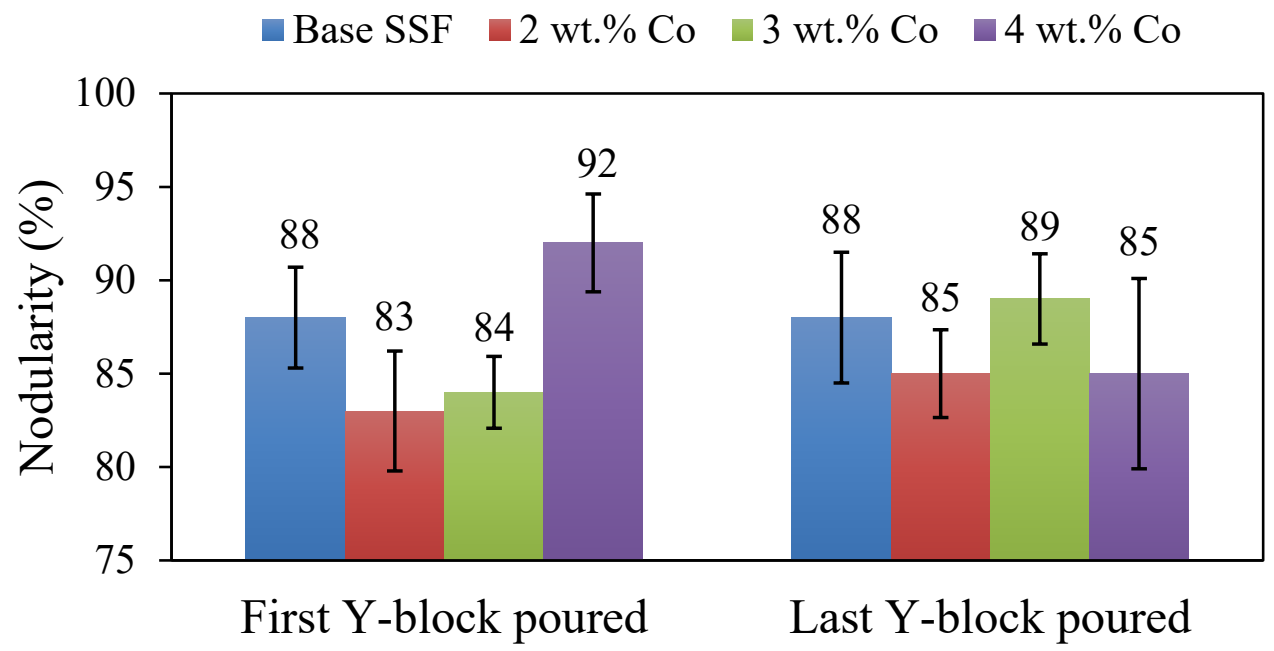

Figure 4.41 Percent nodularity of the first and last 1-inch Y-blocks poured. Error bars are $95 \%$ Std error of the mean. 
The 3 wt.\% Co heat in the first Y-blocks poured showed the highest nodule count, but this is thought to be random variation (Figure 4.42). Over time the nodule count is expected to decrease, and this was observed in all the last Y-blocks poured. No substantial increase in the nodule count was found with cobalt additions, which is consistent with Weißß et al., in which alloying high silicon ductile iron with cobalt showed no statistically significant effect [64]. In contrast, Okunnu reported an increase in the nodule count with 2 wt.\% and 4 wt.\% Co in the 600-10 grade [63]. Moreover, González-Martínez et al. found a slight increase in the nodule count of high silicon alloys only with 4 wt.\% Co [67].

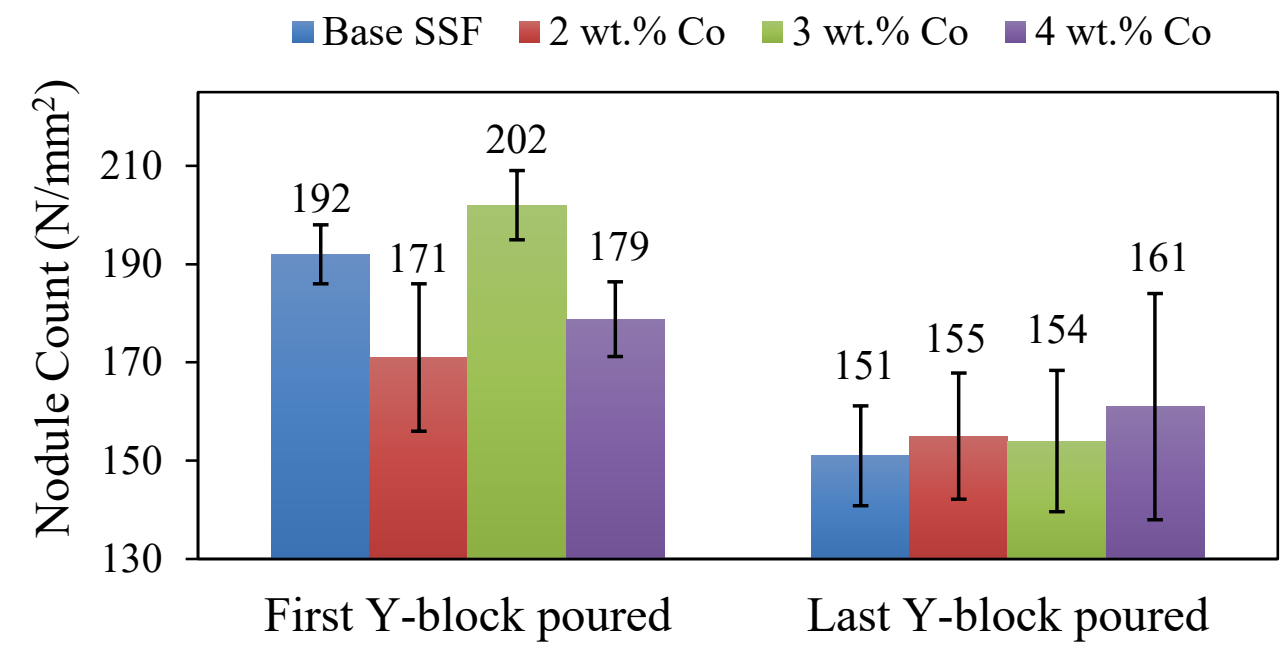

Figure 4.42 Nodule count of the first and last 1-inch Y-blocks poured. Error bars are 95\% Std error of the mean.

A consistent reduction in the nodule diameter with increasing cobalt was observed for both the first and last Y-blocks poured (Figure 4.43). This finding is in agreement with previous work that report a decrease in the nodule size with cobalt additions [58], [63], [81]. 


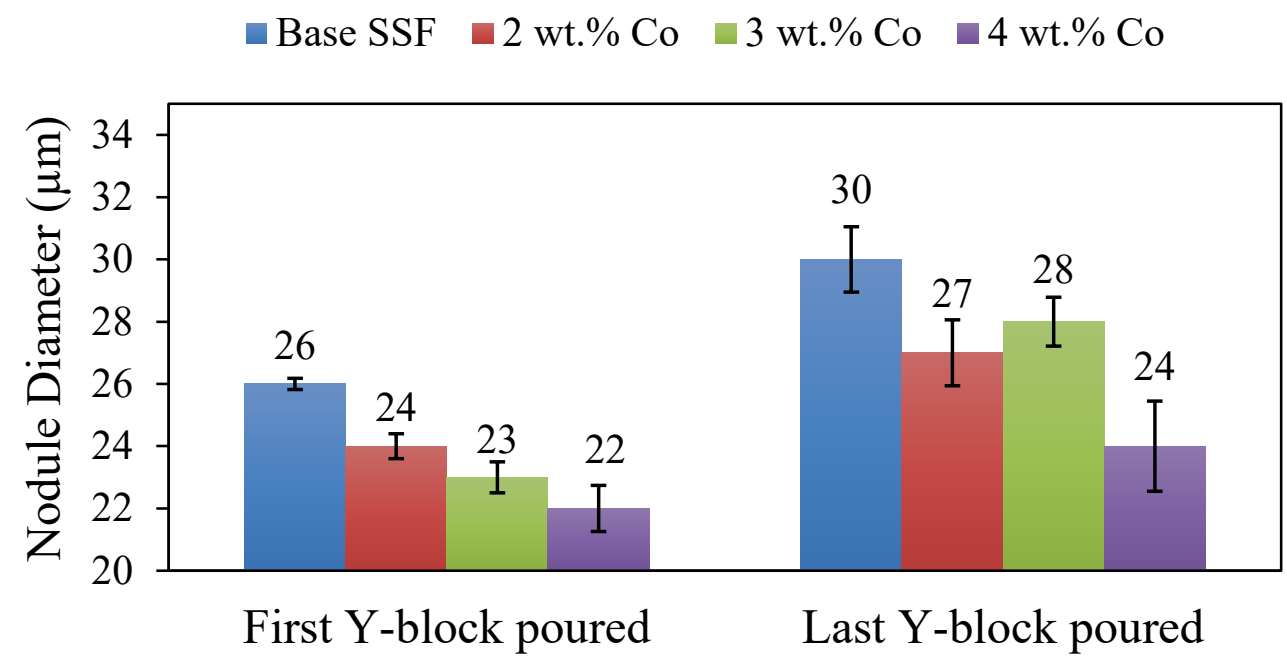

Figure 4.43 Nodule diameter of the first and last 1-inch Y-blocks poured. Error bars are $95 \%$ Std error of the mean.

\subsubsection{Ferrite and Pearlite Analysis}

The etched micrographs of the first and last Y-blocks poured are shown in Figure 4.44.

The base SSF and 2 wt.\% Co heats exhibited a negligible amount of pearlite $(<2 \%)$, while a fully ferritic matrix was obtained for the $3 \mathrm{wt} . \%$ and 4 wt.\% Co heats. Some chunky graphite $(\mathrm{CHG})$ and degenerated graphite (Type V) were observed in the first and last Y-blocks poured for all heats, but it was more pronounced in the cobalt-bearing heats. These results support previous findings from González-Martínez that cobalt increases the risk of $\mathrm{CHG}$ formation [67]. 


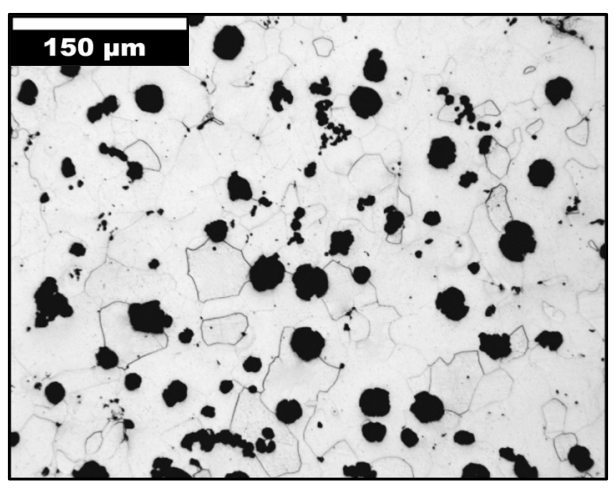

FIRST

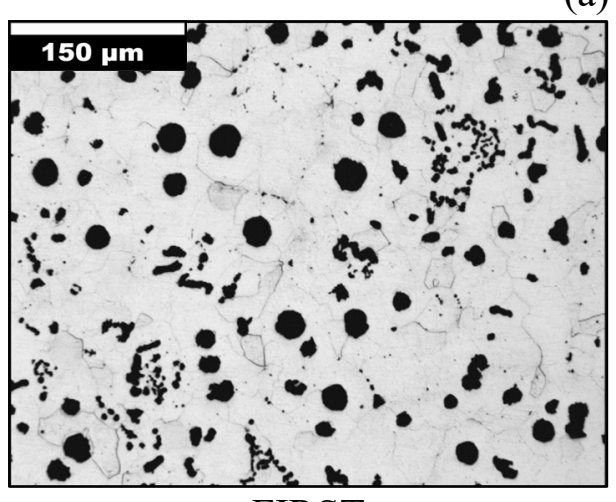

FIRST

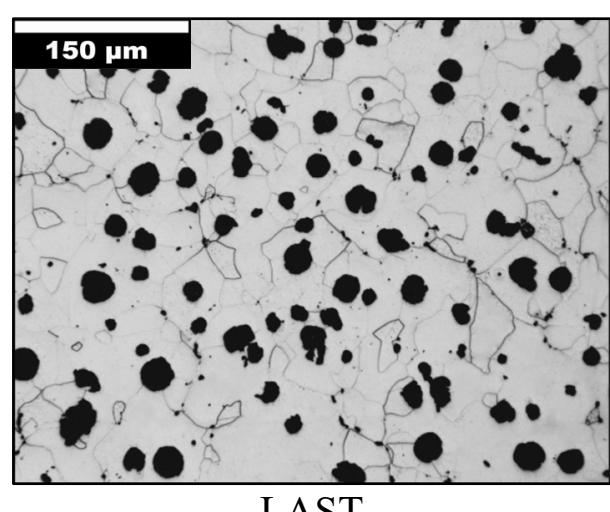

LAST

(a) Base SSF

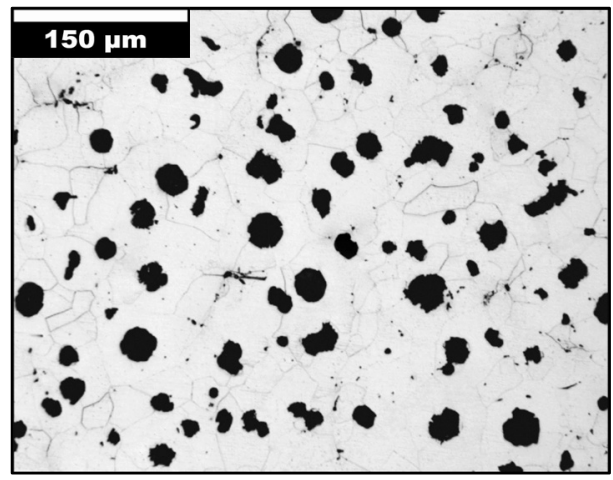

LAST

(b) 2 wt. $\% \mathrm{Co}$
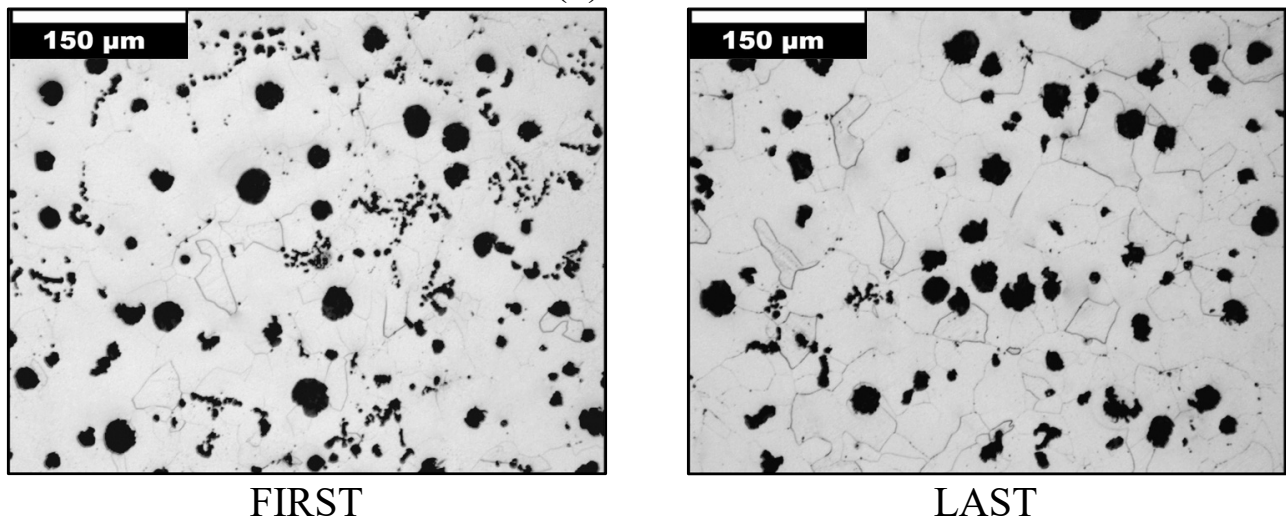

(c) 3 wt. $\% \mathrm{Co}$ 


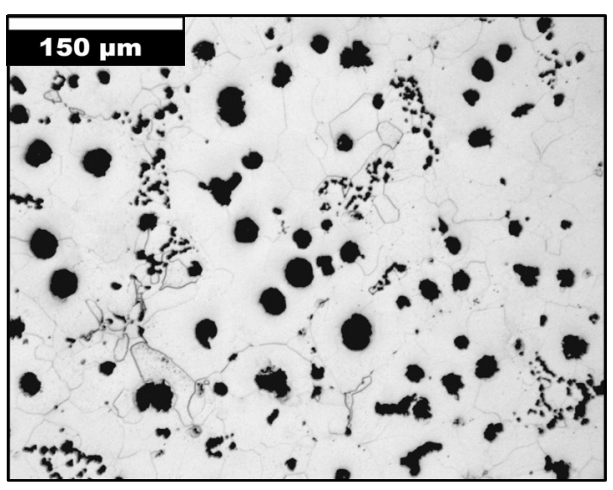

FIRST

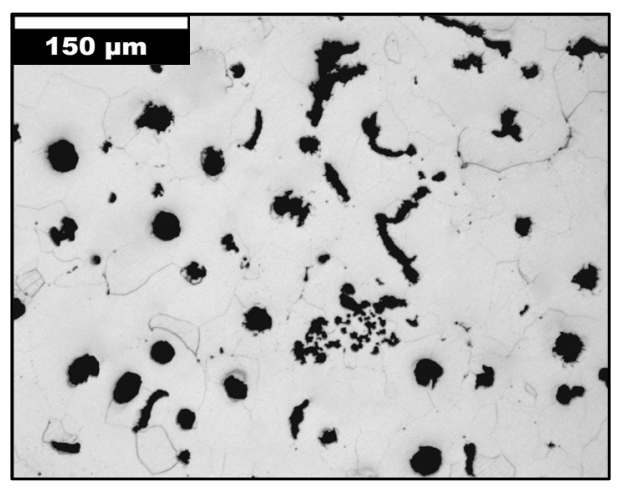

LAST

(d) 4 wt. $\%$ Co

Figure 4.44 Nital etched micrographs at 100x of the first and last 1-inch Y-blocks poured.

\subsubsection{Tensile Properties Evaluation}

A steady increase in the tensile strength is observed with cobalt addition (Figure 4.42).

Okunnu and Fischer et. Al reported an improvement in the tensile strength by alloying the 600-10 SSF grade with 2 wt.\% and 4 wt.\% Co [63], [66]. However, GonzálezMartínez found a drop in tensile strength above 4.4 wt.\% to 4.5 wt.\% Si for alloys containing $1.4 \mathrm{wt} . \%$ and $4 \mathrm{wt} . \% \mathrm{Co}$, but claimed that the maximum tensile strength was reached when alloying with cobalt at 4.3 wt.\% to 4.4 wt.\% Si [67], similar to the Si levels in this work. 


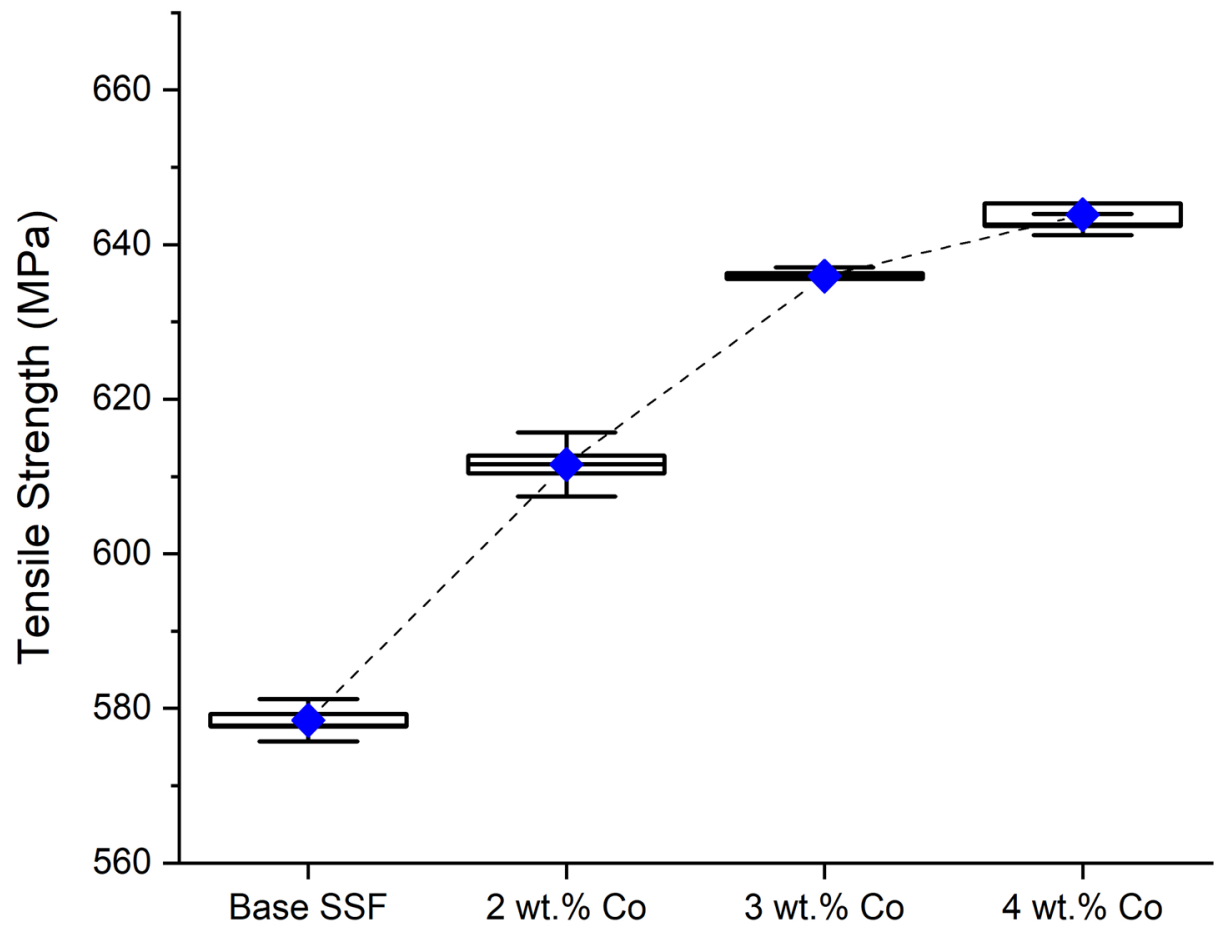

Figure 4.45 Effect of cobalt on the tensile strength of 1-inch Y-blocks. Error bars are $95 \%$ Std error of the mean.

An increase in the yield strength is observed up to $3 \mathrm{wt} \%$ Co (Figure 4.46). Then, the yield strength plateaus or decreases with the addition of $4 \mathrm{wt} . \%$ cobalt. This last finding is in conflict with previous studies that found an increase in yield strength with $4 \mathrm{wt. \%}$ Co [63], [66]. However, Fischer reported that additions of 2 wt.\% and 4 wt.\% Co to a 600-10 SSFDI heat (4.3 wt.\% Si) has a relatively small effect on the yield strength [66]. 


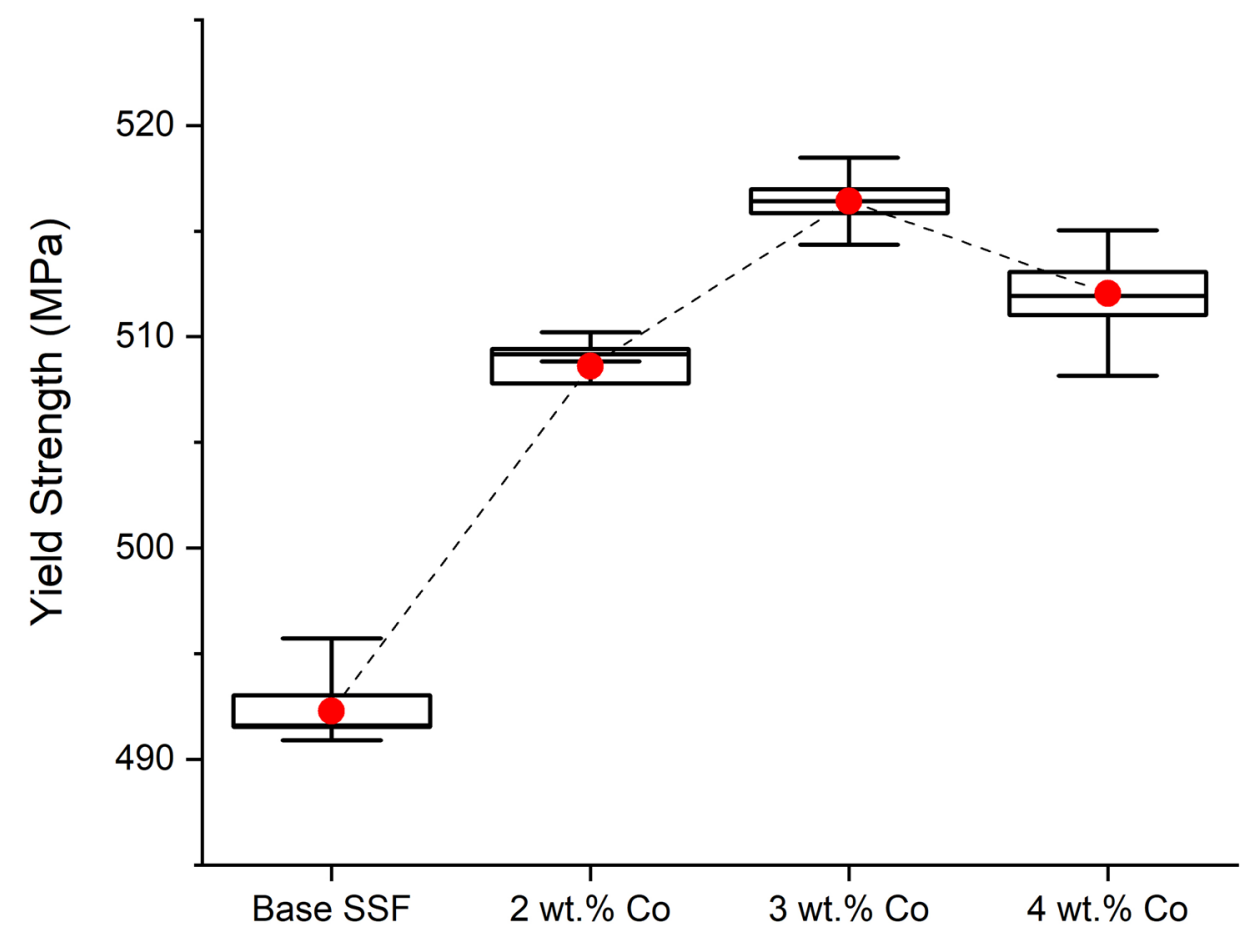

Figure 4.46 Effect of cobalt on the yield strength of 1-inch Y-blocks. Error bars are 95\% Std error of the mean.

The percent elongation increases slightly with cobalt additions (Figure 4.47) in agreement with Okunnu's who observed an increase in elongation with $2 \mathrm{wt} . \%$ and $4 \mathrm{wt} . \%$ Co additions to a 600-10 SSF grade [63]. On the other hand, Fischer et al. found that for a high silicon iron ( $4.3 \mathrm{wt} . \% \mathrm{Si})$, the elongation is reduced by 22 and $50 \%$, with $2 \mathrm{wt} . \%$ and 4 wt.\% Co, respectively [66]. González-Martínez et al. reported a drop in percent elongation above $4.3 \mathrm{wt} . \%$ Si for alloys with $1.4 \mathrm{wt.} \%$ and 4 wt.\% Co [67]. 


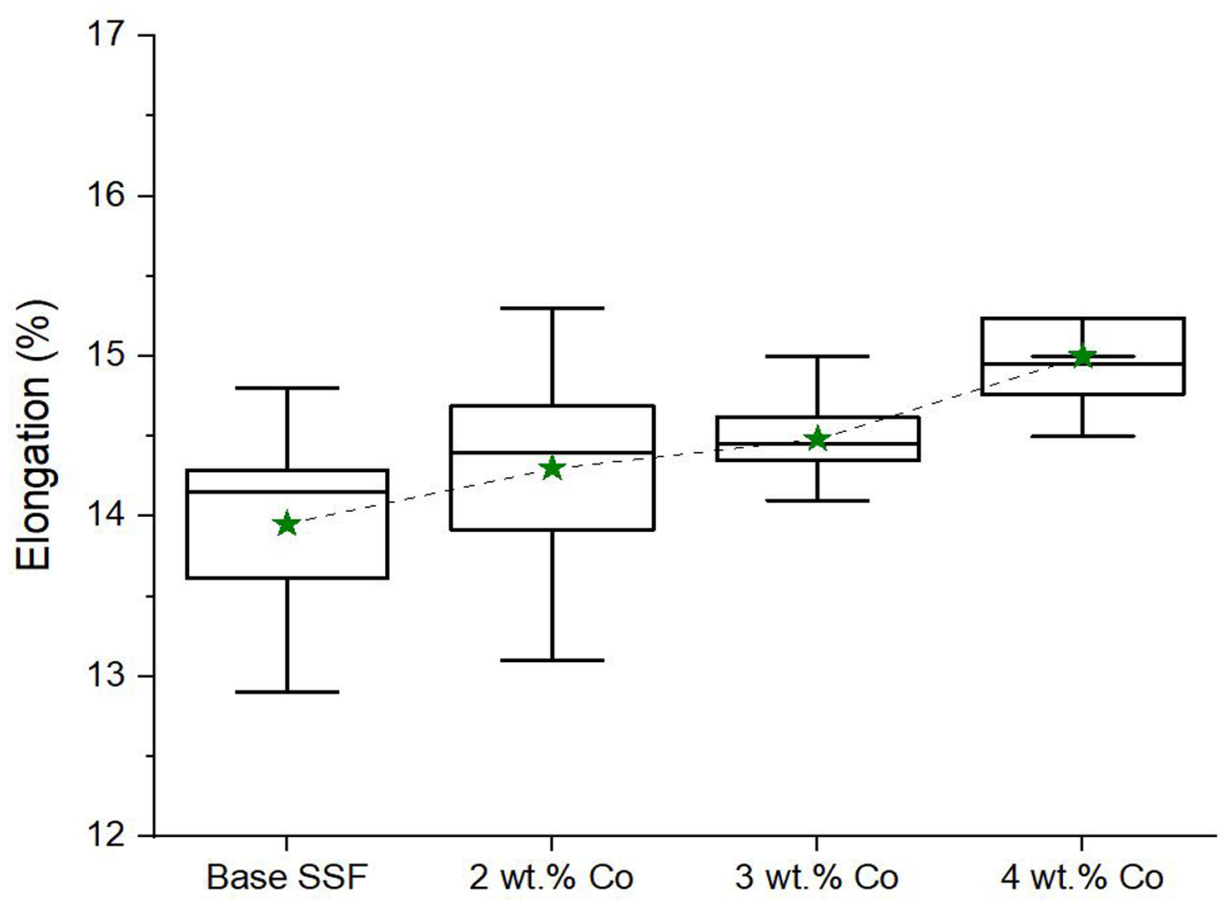

Figure 4.47 Effect of cobalt on the percent elongation of 1-inch Y-blocks. Error bars are $95 \%$ Std error of the mean.

\subsubsection{Macrohardness Evaluation}

An improvement in the Brinell hardness is observed with cobalt additions (Figure 4.48). However, the hardness increases substantially between additions of 2 and 3 wt.\% Co. High silicon ductile iron grades are known to have small variations in hardness values due to a more homogenous matrix, and this was observed for all heats. This increase in hardness is related to the strengthening effect of cobalt in ferrite. This finding is consistent with that of González-Martínez, who reported an increase in Brinell hardness for a series of high silicon alloys (from 3.99 wt.\% to 5.95 wt.\% Si) with low (1.31-1.44 wt.\% Co), and high (3.90-4.4wt.\% Co) cobalt contents [67]. 


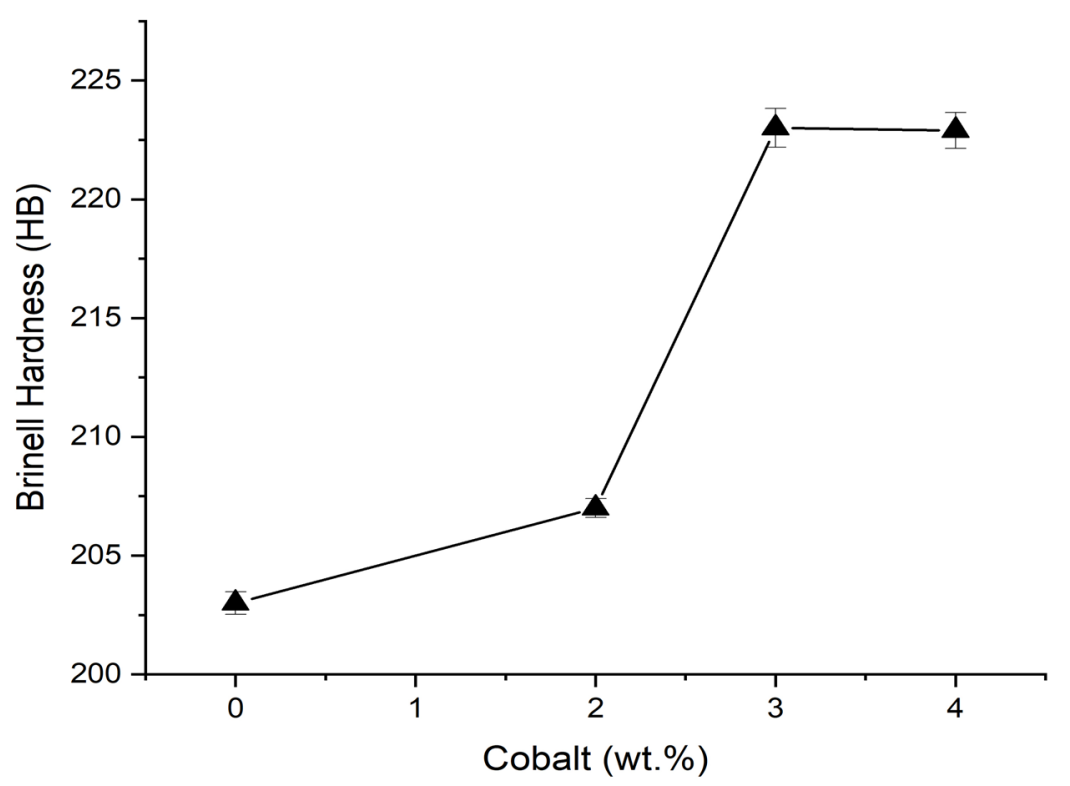

Figure 4.48 Effect of cobalt on the Brinell hardness of the 1-inch Y-blocks. Error bars are $95 \%$ Std error of the mean.

\subsubsection{Microhardness Evaluation}

SSF ductile irons display more consistent hardnesses as the matrix consists of only ferrite. Direct measurement of the ferrite microhardness confirms that cobalt additions increase the ferrite hardness (Figure 4.49). These results reflect those of Okunnu, who found an increase in the Vickers hardness for two 600-10 SSF grades alloyed with 2 wt.\% and 4 wt.\% Co [63]. Other researchers have found increasing hardness with increasing cobalt in ductile irons with lower silicon contents [58], [81]. 


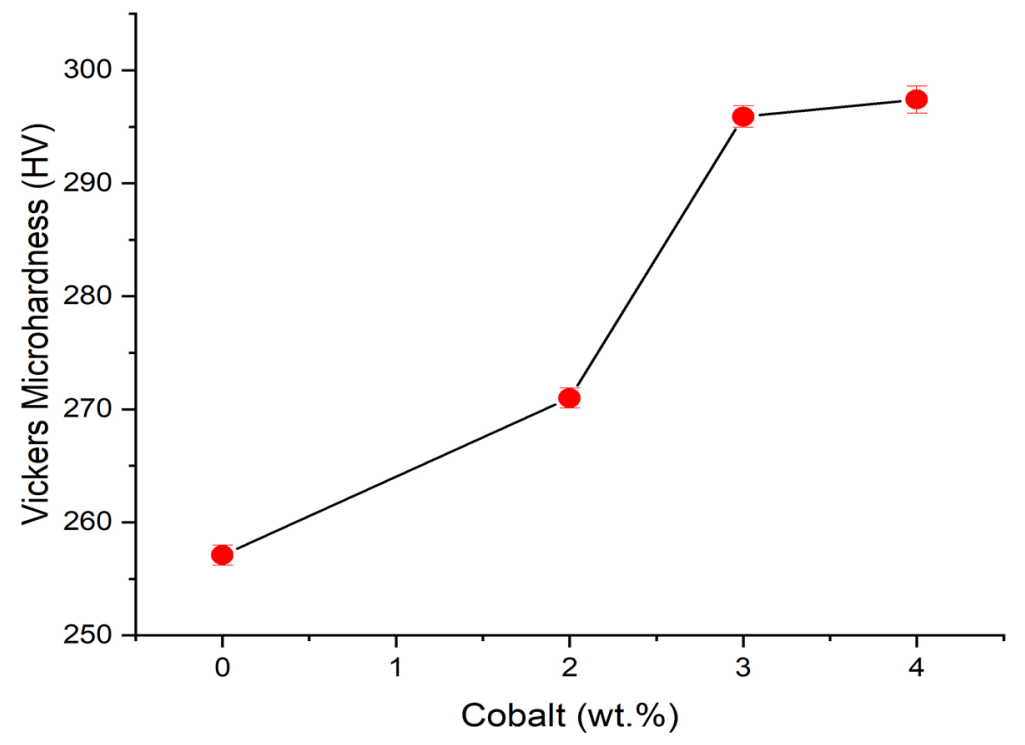

Figure 4.49 Effect of cobalt on the ferrite microhardness of the 1-inch Y-blocks. Error bars are $95 \%$ Std error of the mean.

\subsubsection{Impact Energy Evaluation}

All heats exhibited different DBTTs (Figure 4.50). The baseline SSF without Co had a DBTT of $30^{\circ} \mathrm{C}$, while the $2 \mathrm{wt} . \%$ Co was around $48^{\circ} \mathrm{C}$, and the 3 and $4 \mathrm{wt} \%$ Co alloys were 105 and $111^{\circ} \mathrm{C}$, respectively. The Base SSF heat had the highest absorbed impact energies over the entire temperature range. The $3 \mathrm{wt} . \%$ and 4 wt.\% Co heats showed the lowest energy values at room temperature and $50^{\circ} \mathrm{C}$ compared to the other heats. It is clear that cobalt increases the ductile to brittle transition temperature and reduces overall toughness in high silicon ductile iron grades. 


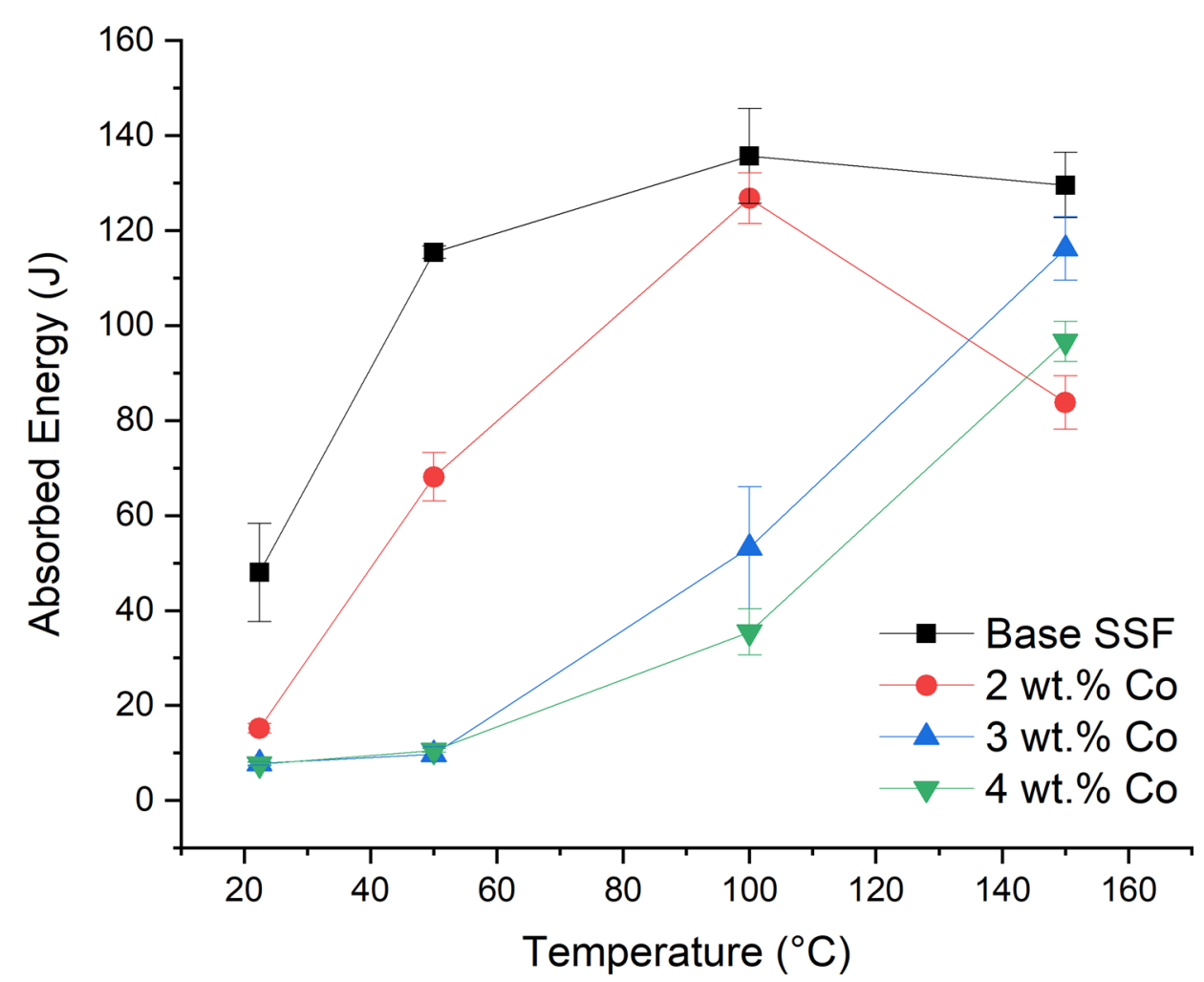

Figure 4.50 Charpy unnotched impact energy for the 1-inch Y-blocks. Error bars are 95\% Std error of the mean.

\subsubsection{Fracture Toughness Evaluation}

At room temperature, all four heats were brittle. An SSF baseline C(T) sample tested at room temperature exhibits brittle fracture with no signs of plastic deformation (Figure 4.51). As the temperature was increased ductile behavior was observed for the base SSF heat with the $150^{\circ} \mathrm{C}$ testing having ductile fracture (Figure 4.52). 


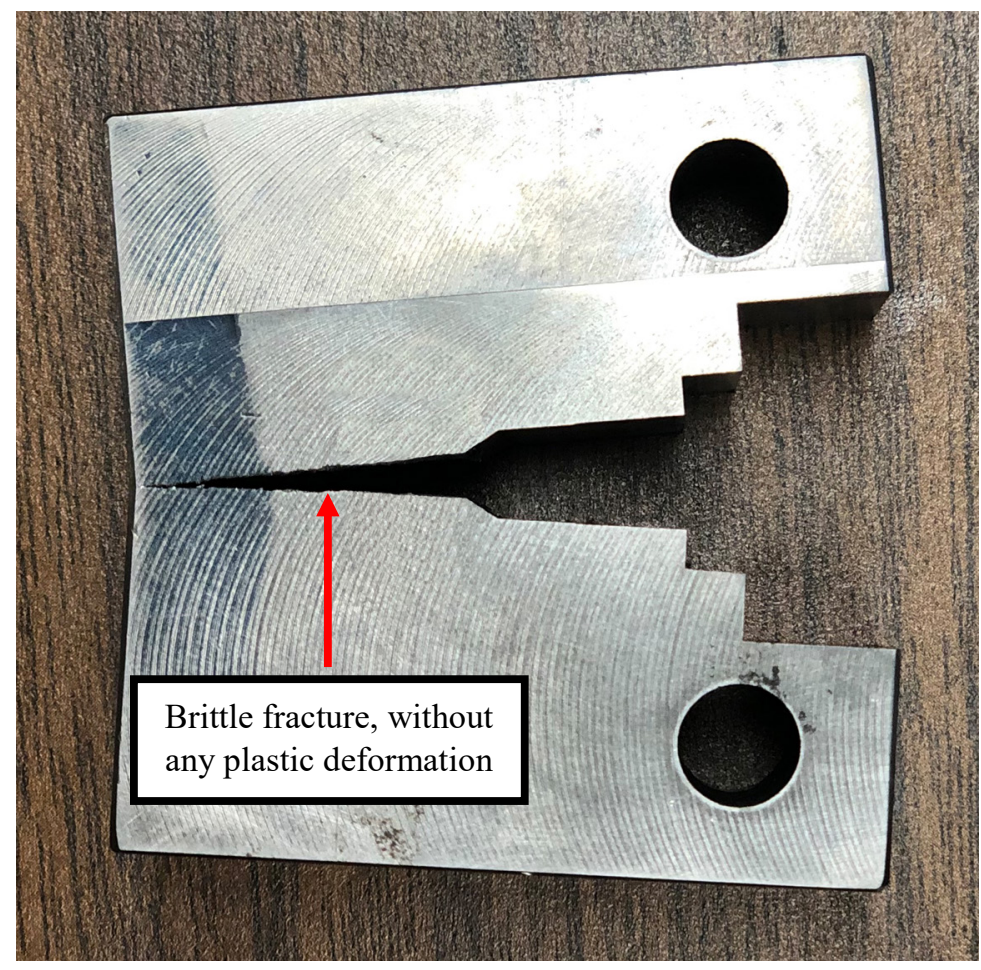

Figure 4.51 Base SSF C(T) sample after fracture toughness test at room temperature.

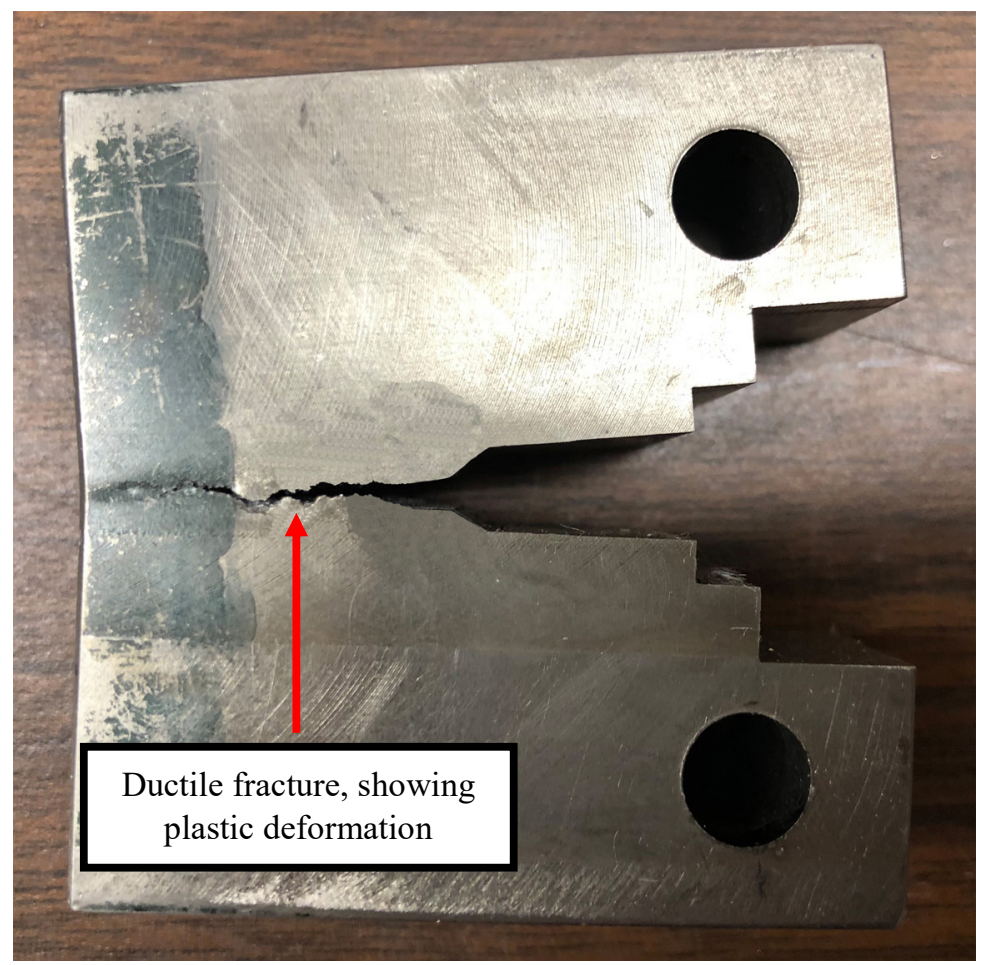

Figure 4.52 Base SSF C(T) sample after fracture toughness test at $150^{\circ} \mathrm{C}$. 
In Figure 4.53, the base SSF heat exhibited the highest fracture toughness values and was ductile for all the temperatures above $50^{\circ} \mathrm{C}$. The $2 \mathrm{wt} . \%$ Co heat was ductile above $100^{\circ} \mathrm{C}$ but showed more scatter in the data. The $3 \mathrm{wt} \%$ and $4 \mathrm{wt} . \%$ Co heats behaved in a ductile mode only at $150^{\circ} \mathrm{C}$. The $3 \mathrm{wt} . \%$ Co heat had the lowest fracture toughness among all the heats, which could potentially be attributed to the irregular crack shape this heat developed, as marked by red arrows in Figure 4.54. The other heats showed a more uniform crack front. It is evident that concentrations above $2 \mathrm{wt} . \%$ Co in high silicon ductile iron grades result in lower fracture toughness values.

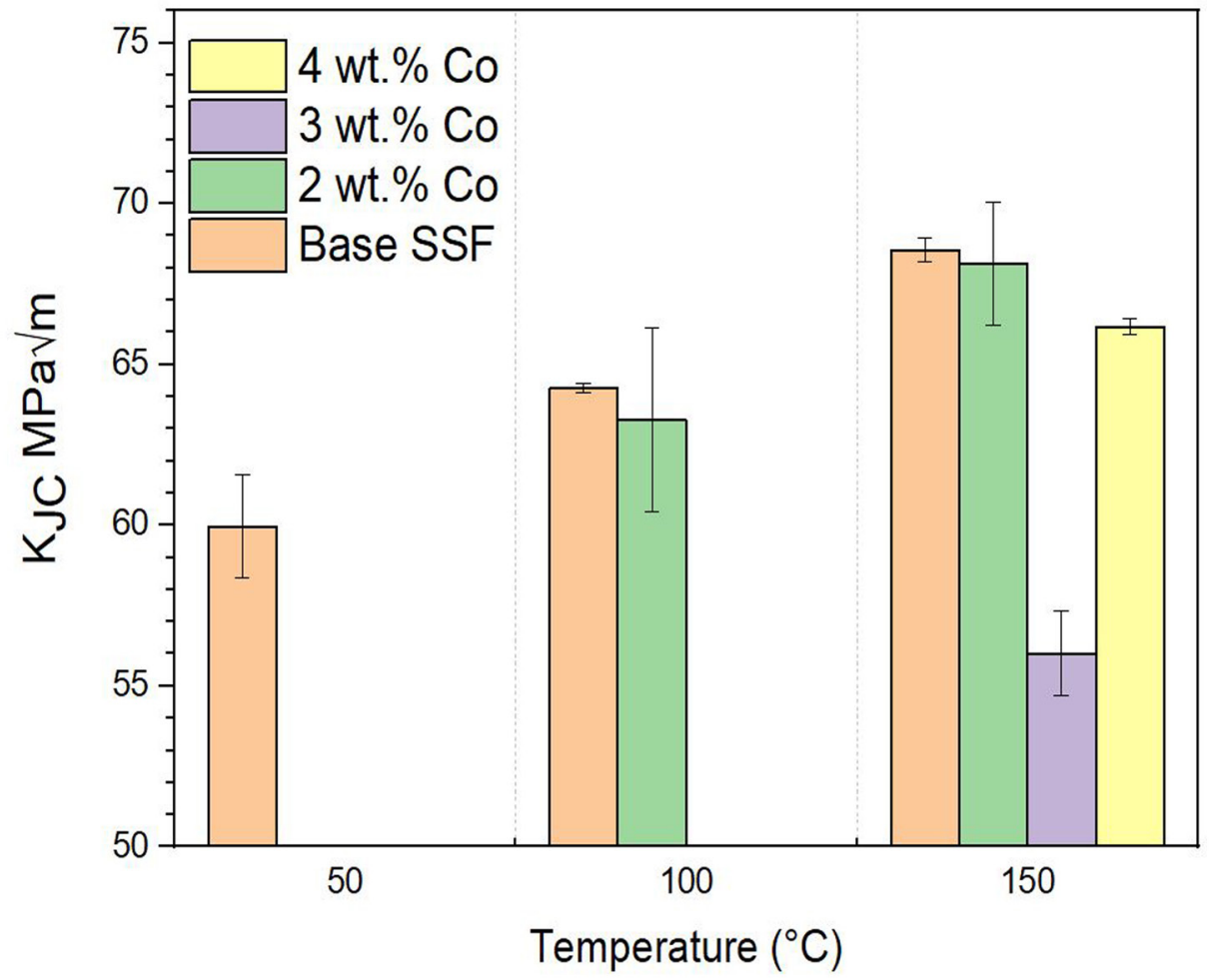

Figure 4.53 Fracture toughness of the 1-inch Y-blocks. Error bars are 95\% Std error of the mean. 


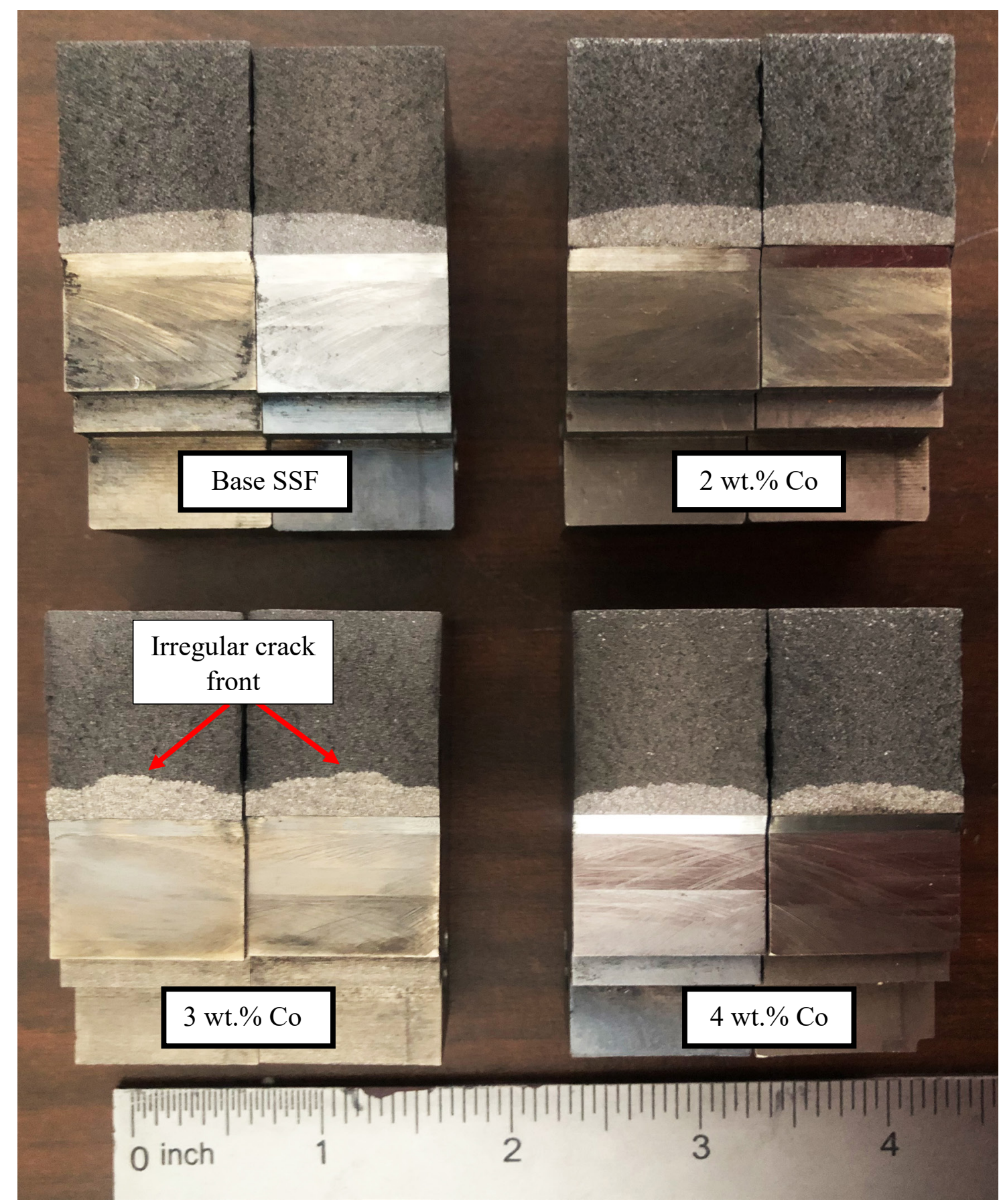

Figure 4.54 Fracture surfaces of the $\mathrm{C}(\mathrm{T})$ samples at $150^{\circ} \mathrm{C}$ for all heats. 


\subsubsection{Microscopic Fracture Surface Examination}

\subsubsection{Fracture Surface Analysis of $C(T)$ samples}

\subsection{C(T) Samples at $150^{\circ} \mathrm{C}$}

Two well-defined zones are clearly visible with the naked eye from the resulting parts of a $\mathrm{C}(\mathrm{T})$ sample (Figure 4.55a). These two zones were analyzed to evaluate the predominating fracture mechanism. Figure $4.55 \mathrm{~b}$ shows stereoscopic fractography of Zone 1 and part of Zone 2.

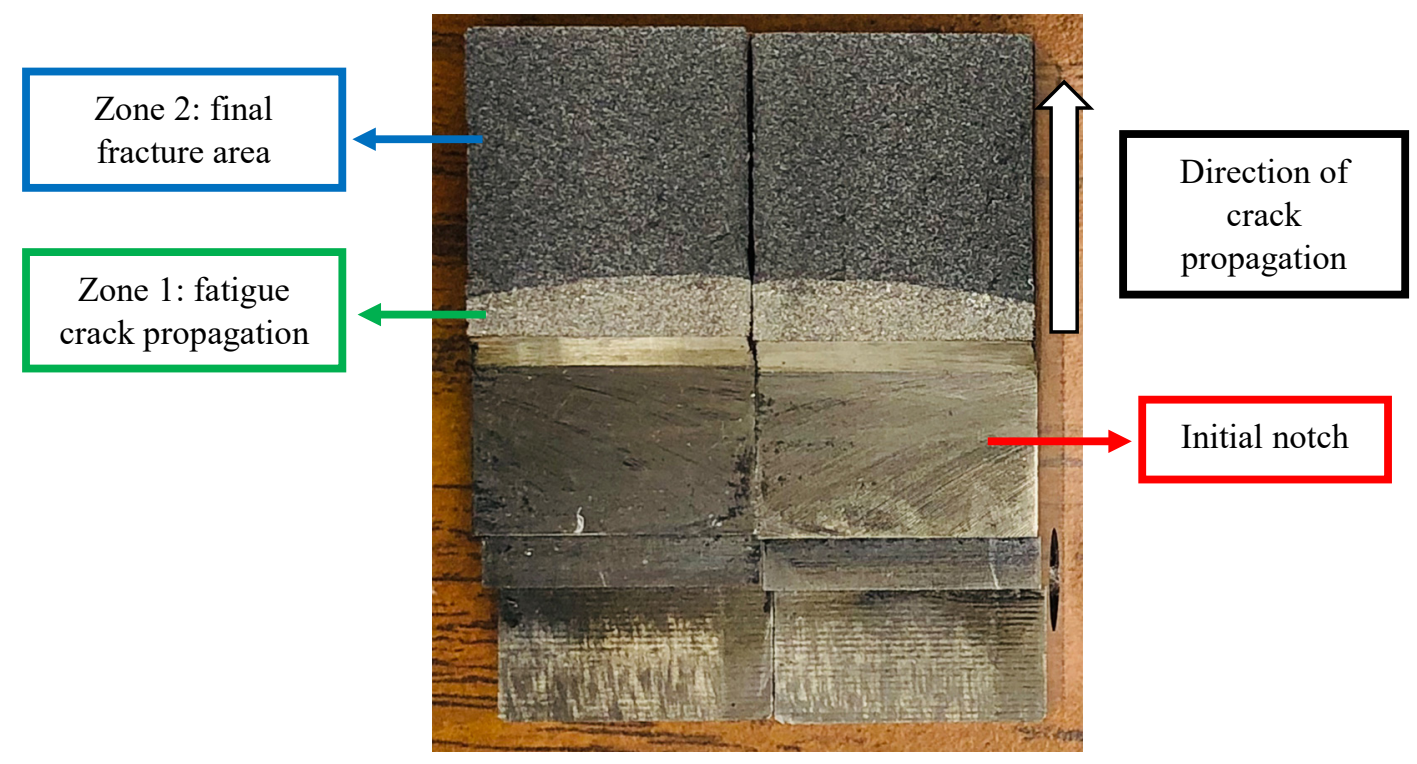

(a)

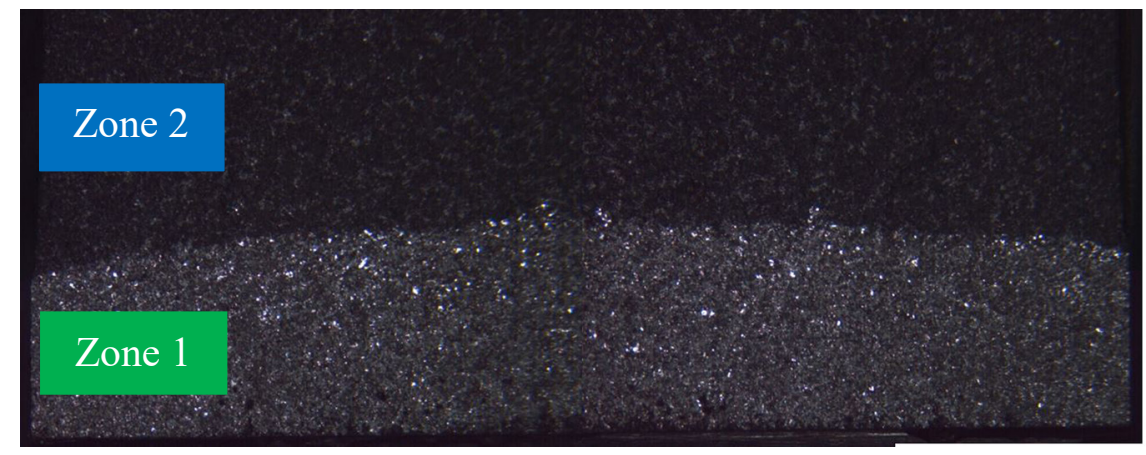

(b)

Figure 4.55 (a) Fracture surface of $\mathrm{C}(\mathrm{T})$ sample highlighting important zones and (b) magnified stereoscopic photo of zone 1 and 2. 
The SEM micrographs of the base SSF heat (Figure 4.56) have a Zone 1 that exhibits transgranular fracture with some cleavage facets and fatigue striations and some clusters of degenerate graphite. At low and high magnification graphite debonding as well as deformation of the nodular cavities is observed (yellow arrows). Small cracks originating at a nodule and traveling along the graphite-matrix interface are observed at low magnification (white arrows in Figure 4.56a). In contrast, zone 2 displayed ductile fracture, where the internodular ferrite matrix had some sharp boundaries or lips that are typical of ferrite given its ability to deform to a greater extent before the onset of fracture. Additionally, some deformation markings on the dimple walls, which are characteristic of metals that undergo considerable plastic deformation are observed (marked by yellow arrows in Figure 4.56b).
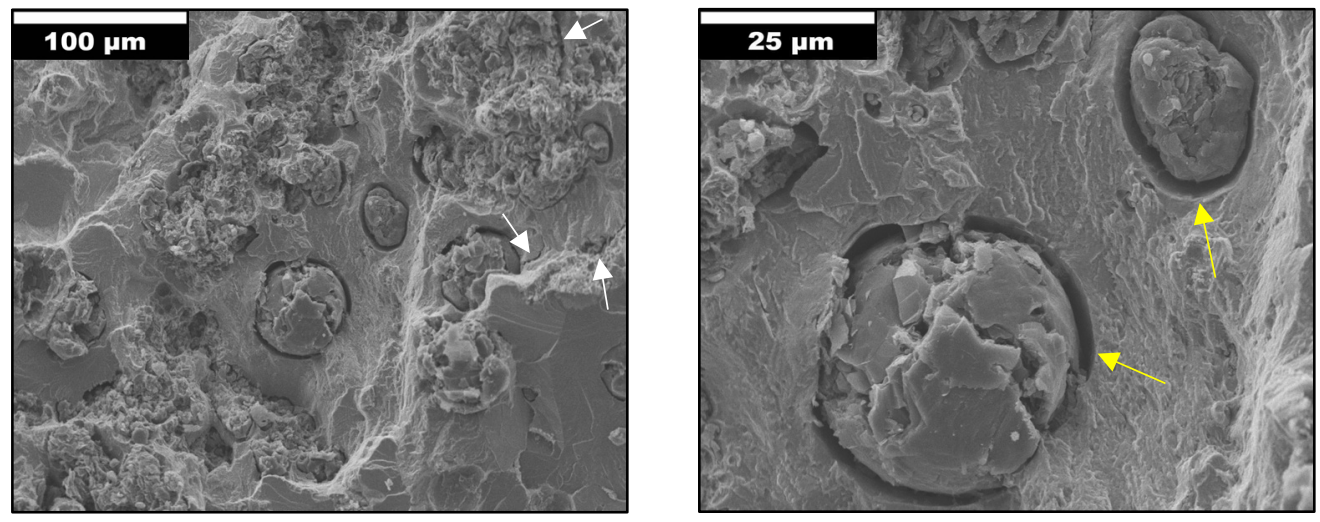

(a) Zone 1
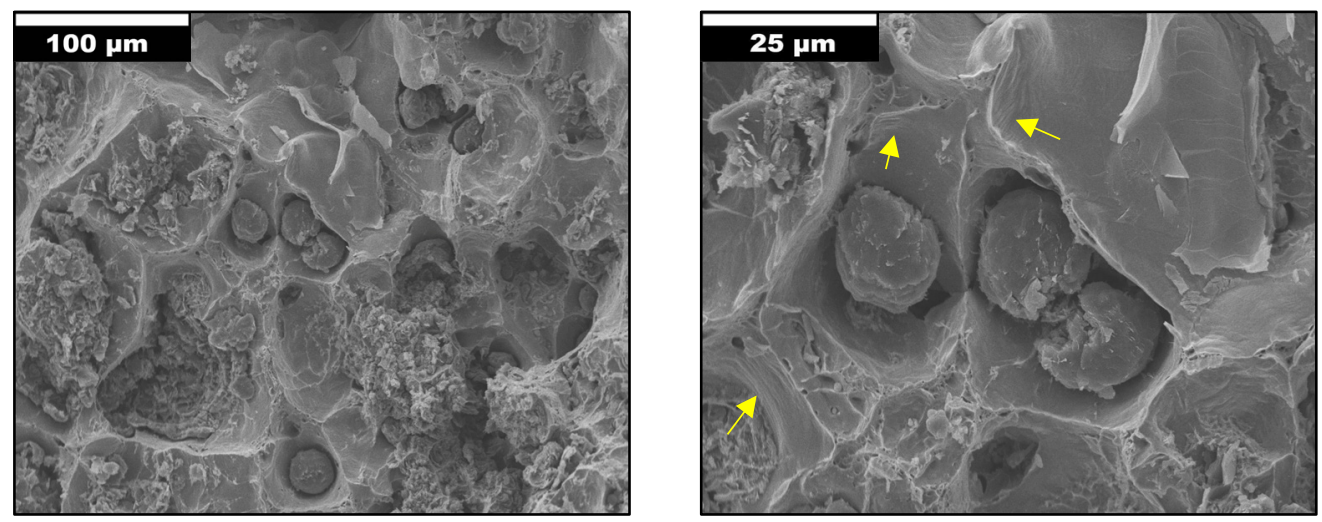

(b) Zone 2

Figure 4.56 Fracture surface SEM images of the base SSF heat C(T) sample. 
Zone 1 of the $3 \mathrm{wt} . \%$ Co heat, revealed a predominantly transgranular fracture with a cleavage-like facet surface. Also, areas with degenerate graphite and a small crack are observed at low magnification (white arrows in Figure 4.57a). Zone 2 exhibited dimple rupture (Figure 4.57b), and some mild markings on the dimple walls are seen at high magnifications (yellow arrows).
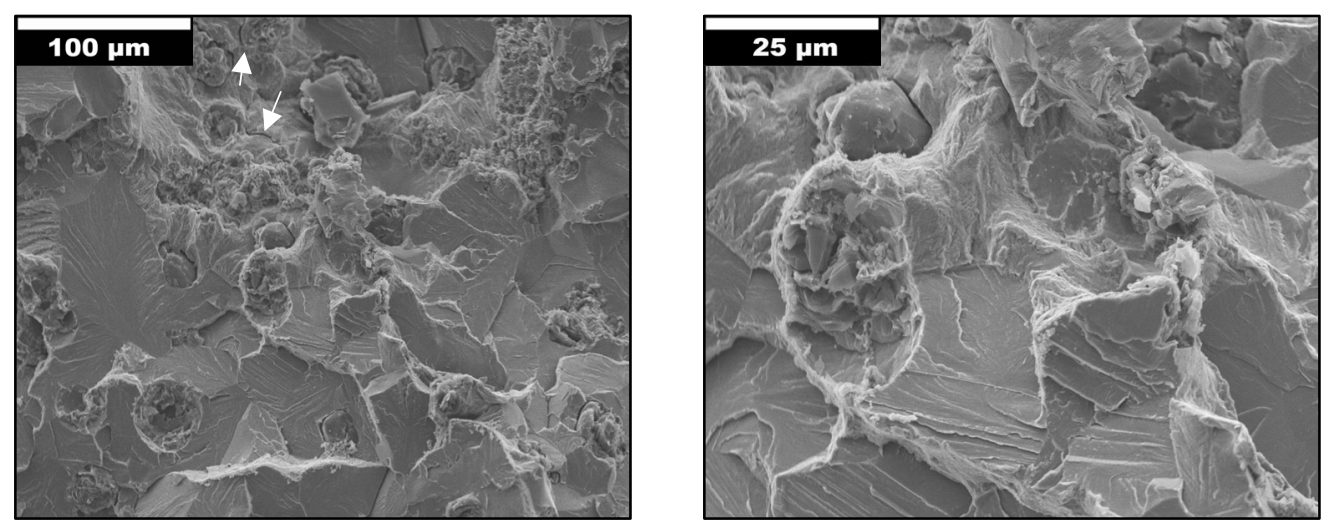

(a) Zone 1
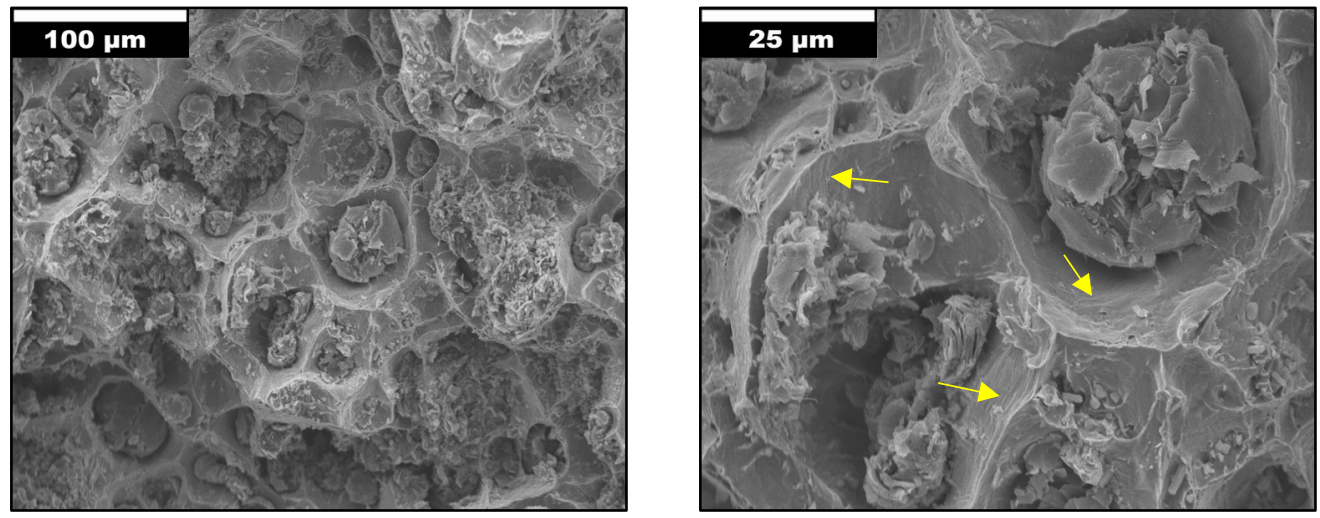

(b) Zone 2

Figure 4.57 Fracture surface SEM images of the 3 wt.\% Co heat C(T) sample.

In Figure 4.58a, the 4 wt. $\%$ Co heat exhibited brittle fracture by transgranular cleavage. At low and high magnifications, some partial graphite debonding (yellow arrow) and a small area of degenerated graphite were observed (white arrows). Conversely, Zone 2 displays ductile fracture, where some nodule cavities had an oval shape indicating 
deformation (marked by white arrows in Figure 4.58b). Well-defined markings on the dimple walls were observed at high magnifications (yellow arrows).
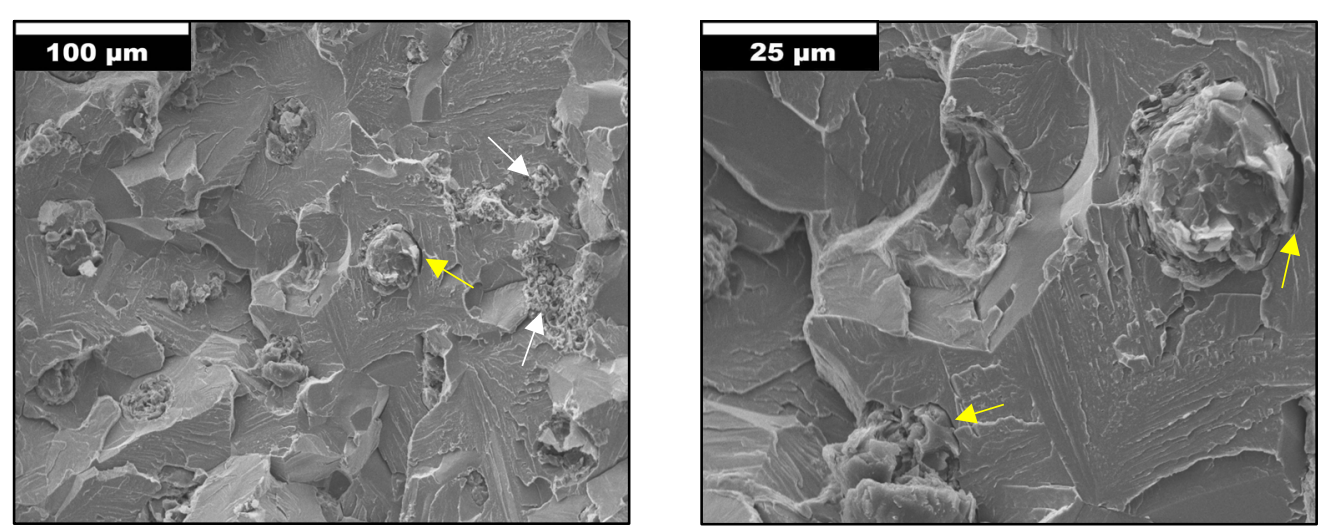

(a) Zone 1
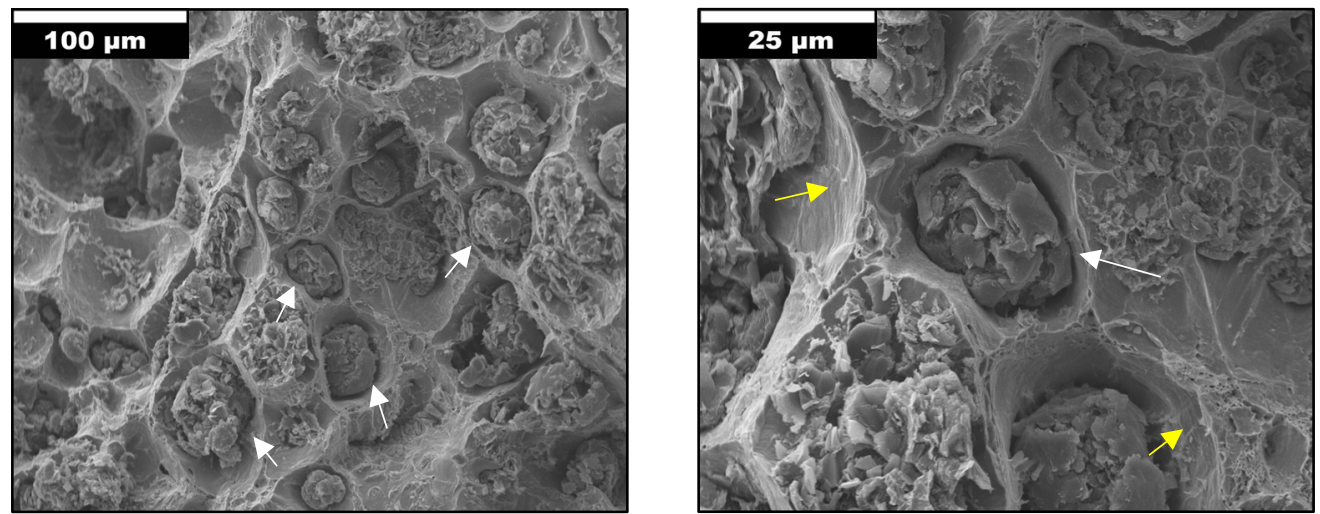

(b) Zone 2

Figure 4.58 Fracture surface SEM images of the 4 wt.\% Co heat C(T) sample.

From all the analyzed fracture surfaces, it is clear that Zone 1 becomes flatter with some step-like features with higher cobalt addition. Compared to the base SSF heat, a higher dimple density is observed in Zone 2 for the 3 wt.\% and 4 wt.\% Co. However, these three heats exhibited areas with degenerated graphite shapes. 


\subsubsection{Segregation Analysis}

Figure 4.59a shows the EDS measurements for the $3 \mathrm{wt} . \%$ Co heat. Although the silicon and cobalt contents are slightly different, it appears that they are segregating similarly. Additionally, point 5 exhibits the highest values for silicon and cobalt, which is in the middle of the two graphite nodules perhaps due to another graphite nodule's presence just below the polished surface. Despite this point, silicon and cobalt contents are high near the graphite nodules.

The 4 wt.\% Co heat displayed the more common negative segregation of silicon, and the cobalt segregated in the same way with higher levels near the graphite nodules. At the beginning (point 1 through point 3 ) the cobalt remains flat before decreasing sharply.
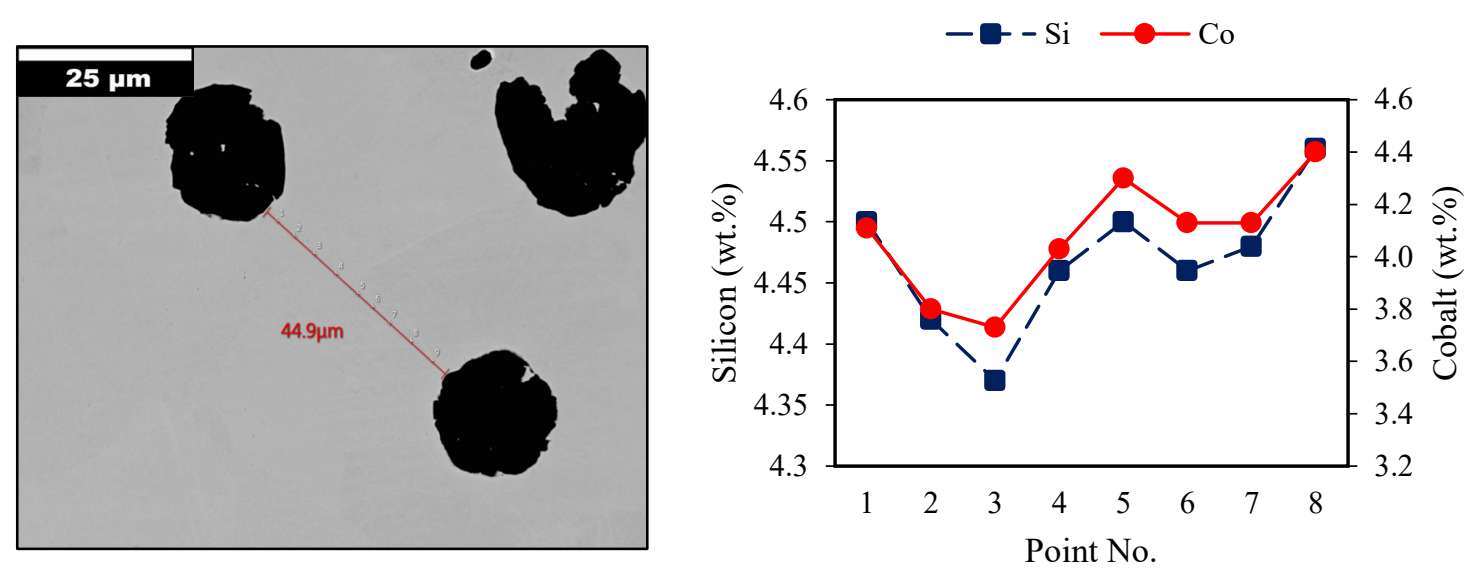

(a) 3 wt. $\% \mathrm{Co}$ 

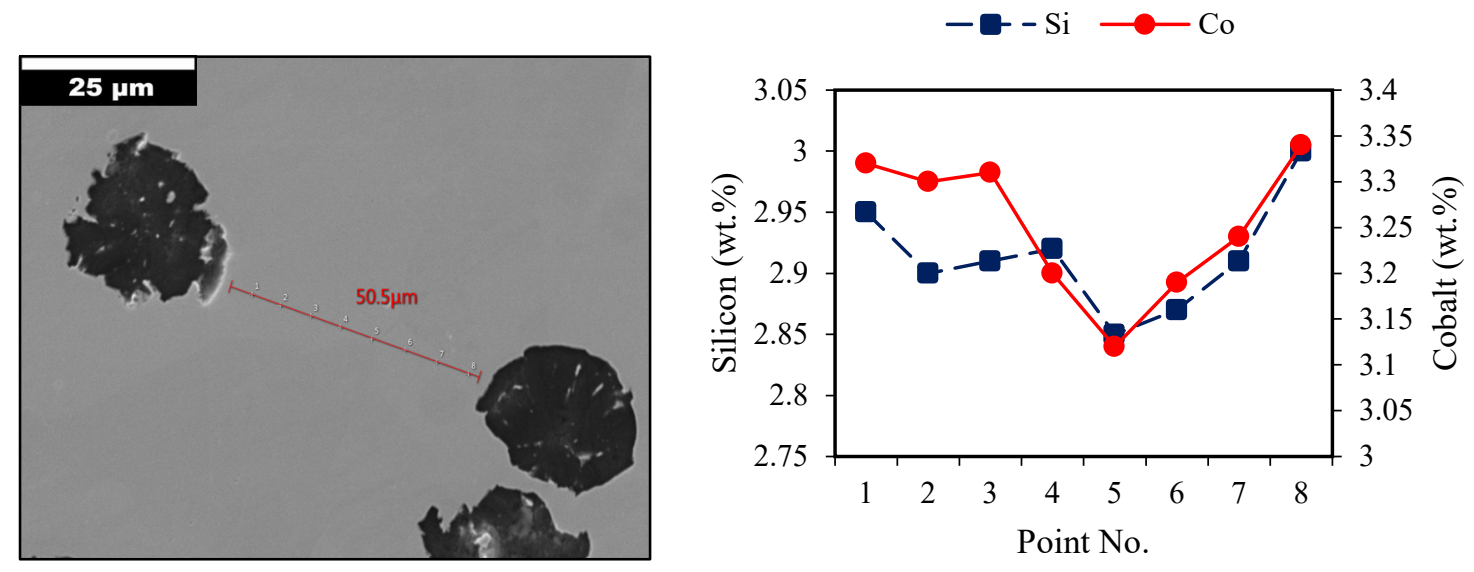

(b) 4 wt. $\% \mathrm{Co}$

Figure 4.59 EDS measurements for the (a) 3 wt.\% Co, and (b) 4 wt.\% Co high silicon heats. 


\section{Discussion}

\subsection{Effect of Cobalt in Thin Wall Ductile Iron}

\subsubsection{Influence of Cobalt in the Microstructure}

\subsubsection{Rectangular Plates}

The influence that section thickness has on the nodule count and the resulting type of matrix (ferrite/pearlite ratios) is well documented. In general, as the section thickness increases, the nodule count decreases, which results in lower ferrite contents. This reduction in ferrite content is associated with an increase in the diffusion path length of carbon atoms to graphite nodules, which results in more pearlite [34], [90], [101]-[103]. Therefore, to evaluate the influence of cobalt in the microstructure of the rectangular plates an ANOVA General Linear Model (GLM) was performed using Minitab Statistical Software ${ }^{\circledR}$ and the results are given in Appendix B (B1.1-B1.4). The different cobalt levels and the thicknesses were set as a factor, and the nodule count, ferrite, pearlite, and carbide percentages were set as the responses. Figure 4.2 shows the main effects plot from this GLM, and the nodule count increase is statistically significant with the addition of $4 \mathrm{wt} . \% \mathrm{Co}$. Also, the decrease in nodule count with increasing the section thickness is observed too, which agrees with the previously mentioned literature. Furthermore, the interaction model (Co level * Thickness (mm)) displayed in Figure 4.3, shows an increase in nodule count for all thicknesses with 4 wt.\% Co.

Figure 5.1 shows the factorial plots (main effects and interaction plots) corresponding to ferrite, pearlite, and carbide percentages from the performed GLM. From Figure 5.1a, the increase in ferrite content is statistically significant above $3 \mathrm{wt} . \% \mathrm{Co}$. This connects to the fact that cobalt is enhancing the nodule count and reducing the interparticle spacing, which decreases the diffusion path of carbon atoms and produces more ferrite. This increase in ferrite comes along with a decrease in pearlite and carbide percentages (Figure 5.1b, and 5.1c). 
Ferrite percent is lower in the 2, 2.5, and $3 \mathrm{~mm}$ sections due to the high cooling rates, which are in the order of $80-15^{\circ} \mathrm{C} / \mathrm{s}$ when changing the wall thickness from 2 to $5 \mathrm{~mm}$ according to Górny and Tyrala [34]. High cooling rates in thin sections will result in a greater tendency for carbide and pearlite formation, which was also observed in Figure $5.1 \mathrm{c}$ for the 2 , and $2.5 \mathrm{~mm}$ sections. 

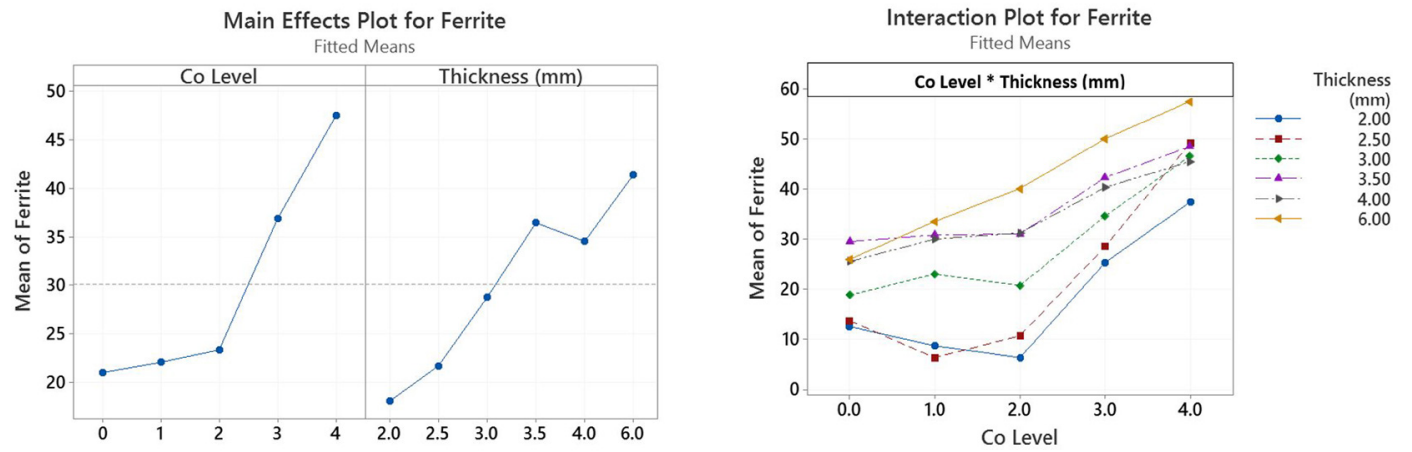

(a) Ferrite Percentage
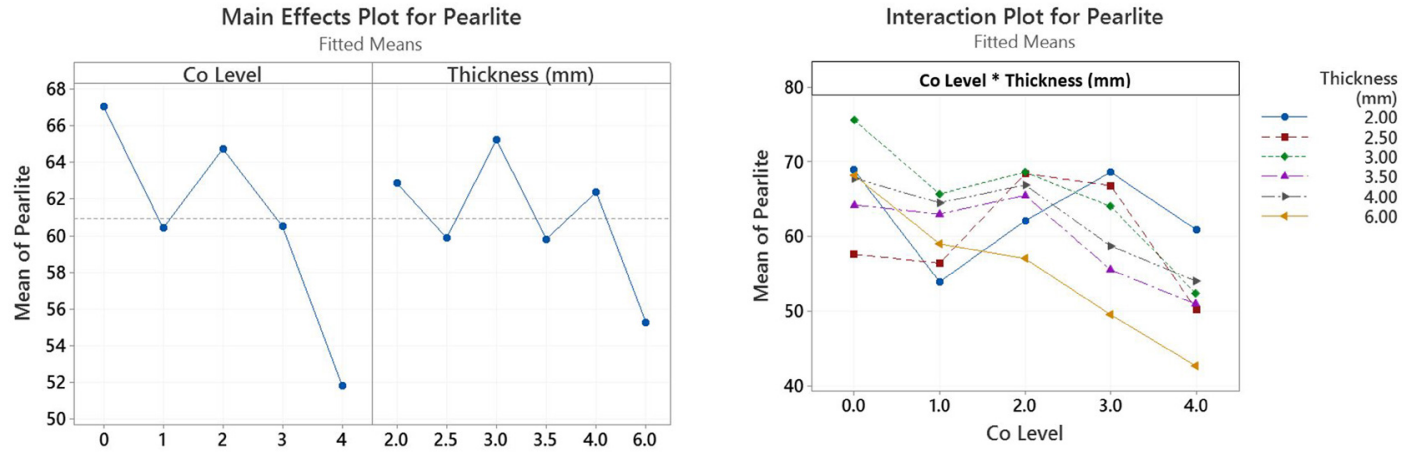

(b) Pearlite Percentage
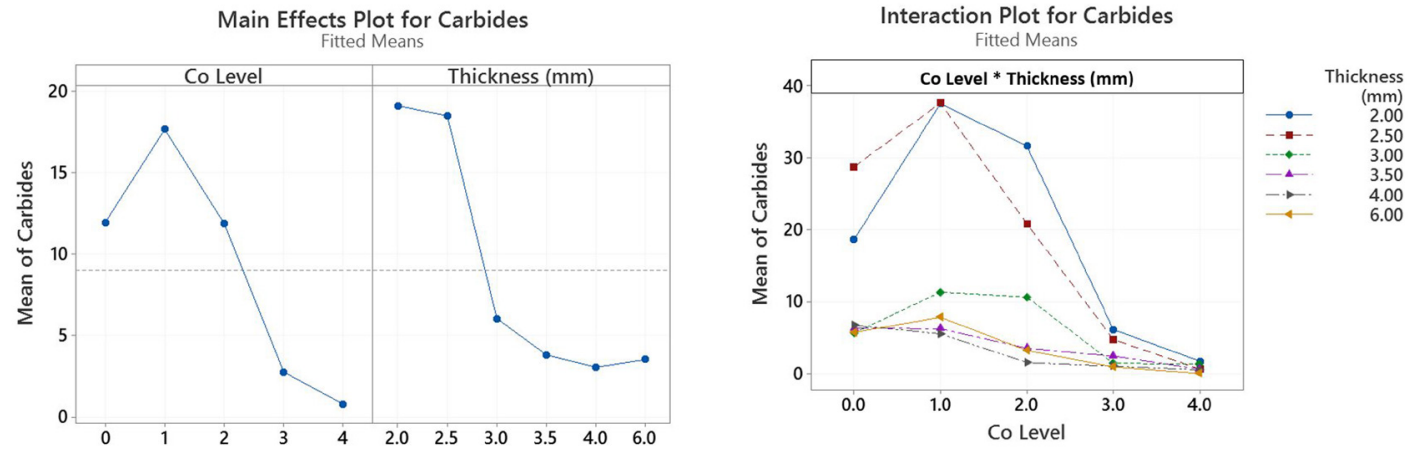

(c) Carbide Percentage

Figure 5.1 Factorial Plots from Minitab ${ }^{\circledR}$ analyzing the (a) ferrite, (b) pearlite, and (c) carbide percentages of the rectangular plates [79]. 


\subsubsection{ASTM $1 / 2$ inch Y-blocks}

An ANOVA GLM was performed (Appendix B Section B.1.5-B.1.9) with the different cobalt levels and the pouring positions (first and last Y-blocks poured) as factors, and the nodularity, nodule count, nodule size, ferrite, and pearlite percentages as responses.

The percent nodularity significantly increases with the addition of $4 \mathrm{wt.} \%$ Co (Figure 5.2a). In terms of pouring position, it is expected that with time the percent nodularity decreases due to magnesium fade. This was observed in the main effects plot. The interaction term (Co Level * Position) was not statistically significant, and over time the percent nodularity was not drastically reduced, as seen in the interaction plot.

The nodule count was substantially increased with the addition of $4 \mathrm{wt} . \%$ Co (Figure $5.2 \mathrm{~b})$. The positive correlation between nodularity and nodule count reported by Doubrava et al. [90] was observed with 4 wt.\% Co. Regarding pouring position, the nodule count decreases with time, which is related to sustaining inoculation in the melt. Inoculation is the procedure used to increase the nuclei sites for graphite nucleation [104] and over time, fading of the inoculant occurs [105].

Surprisingly, a considerable drop in the nodule count and percent nodularity of the $3 \mathrm{wt} . \%$ Co heat was observed. This finding was due to an unexpectedly long holding time of the melt in the induction furnace. As a result, the carbon fades through oxidation, decreasing its content in the melt and reducing the nuclei sites available for graphite precipitation, which consequently lowers the nodule count. The decrease in carbon content was confirmed from the chemical composition analysis, as this heat had carbon concentration of $3.68 \mathrm{wt} . \%$, which is below the average of $3.75 \mathrm{wt} . \% \mathrm{C}$. The above findings are consistent with prior studies [106]-[108] where they have noted the detrimental effects of long holding times of the base iron in the induction furnace, resulting in lower nodule counts and nodularity because the nucleation has been limited. 
As observed in Figure 5.2c, the nodule diameter decreases with cobalt additions. However, the reduction in the nodule size is significant only with 4 wt.\% Co.

With pouring time, the nodule size is expected to grow, and this was observed in the main effects plot (position) and interaction plot.

One theory of why it was thought that the nucleation process would be better with cobalt was that the liquidus temperature would decrease with cobalt additions, therefore enabling the formation of more graphite nuclei. However, after running a Thermo-Calc calculation, the opposite was found (Table 5.1).

\begin{tabular}{cccc} 
Table 5.1 Liquidus and solidus temperature of the base DI and 4 wt.\% Co heats \\
\hline $\begin{array}{c}\text { Liquidus } \\
\text { Temperature }\end{array}$ & $\begin{array}{c}\text { Solidus } \\
\text { Temperature } \\
\left({ }^{\circ} \mathbf{C}\right)\end{array}$ & $\begin{array}{c}\mathbf{\Delta} \text { T } \\
\left({ }^{\circ} \mathbf{C}\right)\end{array}$ \\
\hline Base DI & 1488 & 1440 & 48 \\
\hline 4 wt.\% Co & 1520 & 1451 & 69 \\
\hline
\end{tabular}

With the above, another potential hypothesis arises in the quest for explaining the mechanism behind why cobalt is increasing the nodule count in ductile iron. If the liquid is kept longer and the diffusion of carbon is much faster in the liquid this might be helpful from the solidus perspective. If the range of liquid expands (meaning higher liquidus and lower solidus), then there will be more time available for liquid diffusion. However, this needs further study and is beyond the scope of this research. 

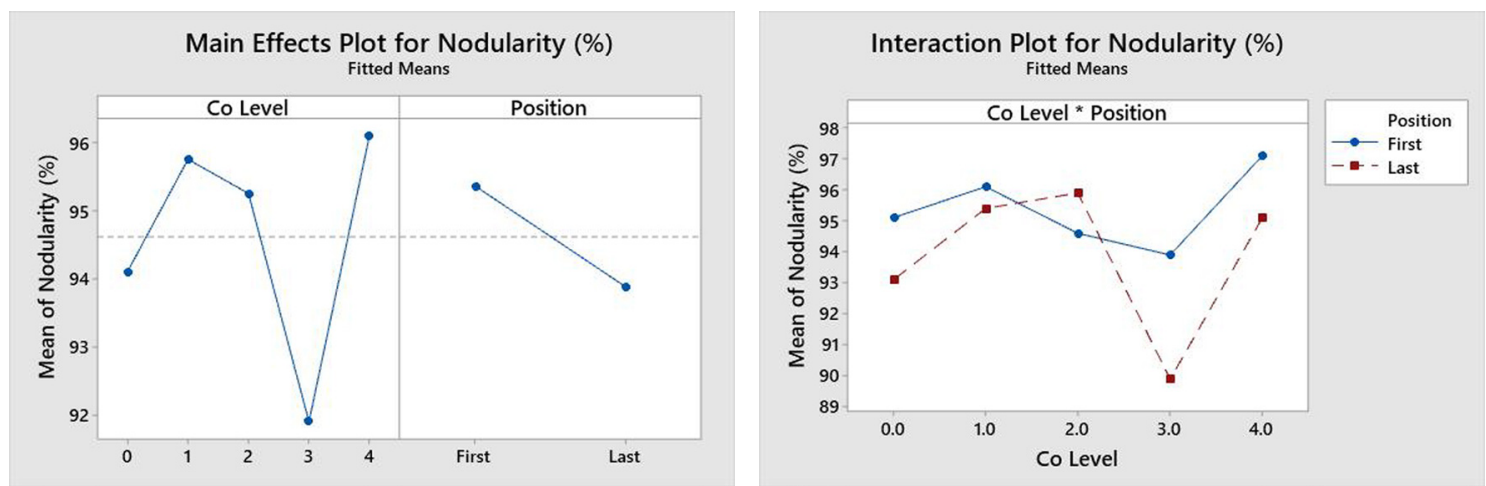

(a) Nodularity
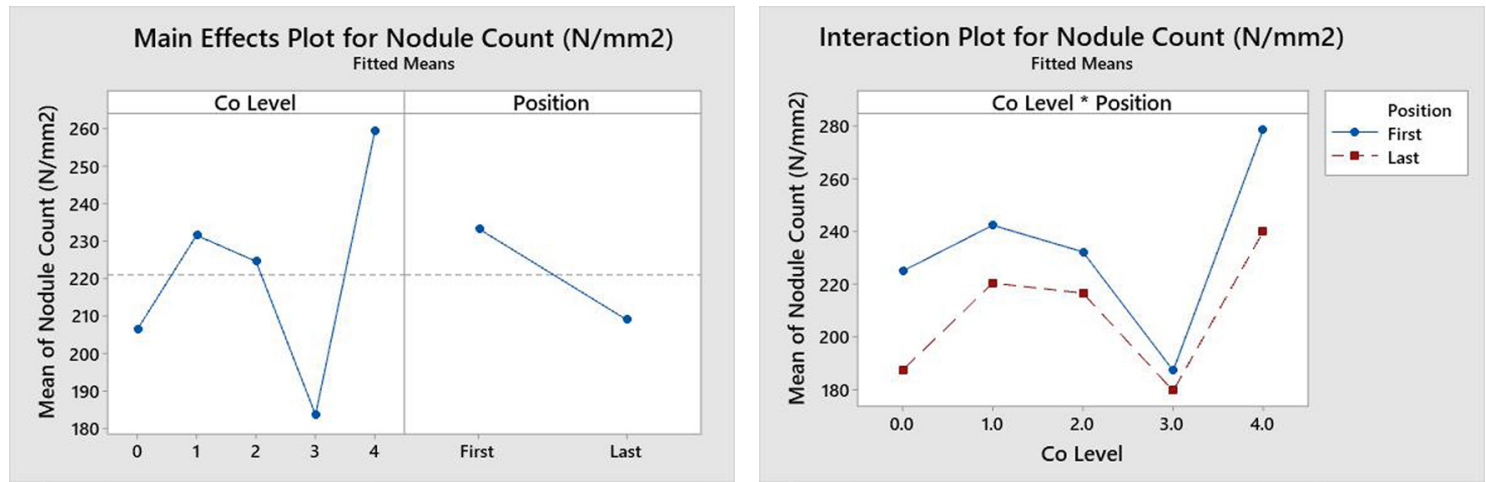

(b) Nodule count
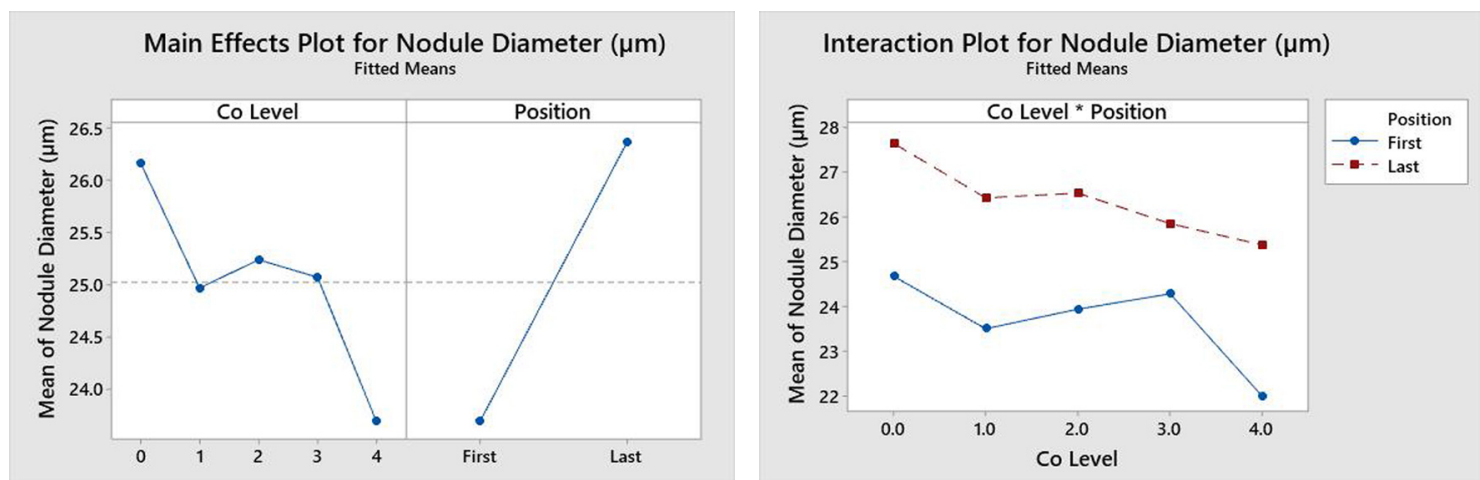

(c) Nodule diameter

Figure 5.2 Factorial plots from Minitab ${ }^{\circledR}$ analyzing the graphite features (a) percent nodularity, (b) nodule count, and (c) nodule diameter of the first and last $1 / 2$ inch Y-blocks poured [81]. 
As mentioned above, the addition of $4 \mathrm{wt} . \%$ Co increased the nodule count, which reduces the interparticle spacing between the graphite nodules, allowing the carbon atoms to diffuse to the graphite nodules more easily resulting in more ferrite [109], [110]. The significant increase in ferrite percentage upon cobalt addition, except for the $3 \mathrm{wt} . \%$ Co heat, is observed in Figure 5.3. Additionally, it is important to highlight that the microstructure for the $2 \mathrm{wt} . \%$ and $4 \mathrm{wt} . \%$ Co heats were less sensitive to fade related to pouring time as depicted in the interaction plot.

Consistent with the ferrite increases, the pearlite decreases with cobalt additions, with the exception of the $3 \mathrm{wt} . \%$ Co heat (Figure 5.3b). With respect to pouring time, an increase in pearlite content is observed for the last Y-blocks poured. This is associated with a decrease in the nodule count, which increases the distance between the nodules resulting in a greater pearlite content. Pearlite is known to vary more in castings with low nodule counts [109], [111]. This pearlite sensitivity at low nodule counts was observed for the base ductile iron, 1 wt.\% and 3 wt.\% Co heats.

As discussed previously, due to the unplanned long holding time of the furnace, the 3 wt.\% Co heat showed a decrease in the nodule count, which resulted in more pearlite, but not as high as the base ductile iron heat. 

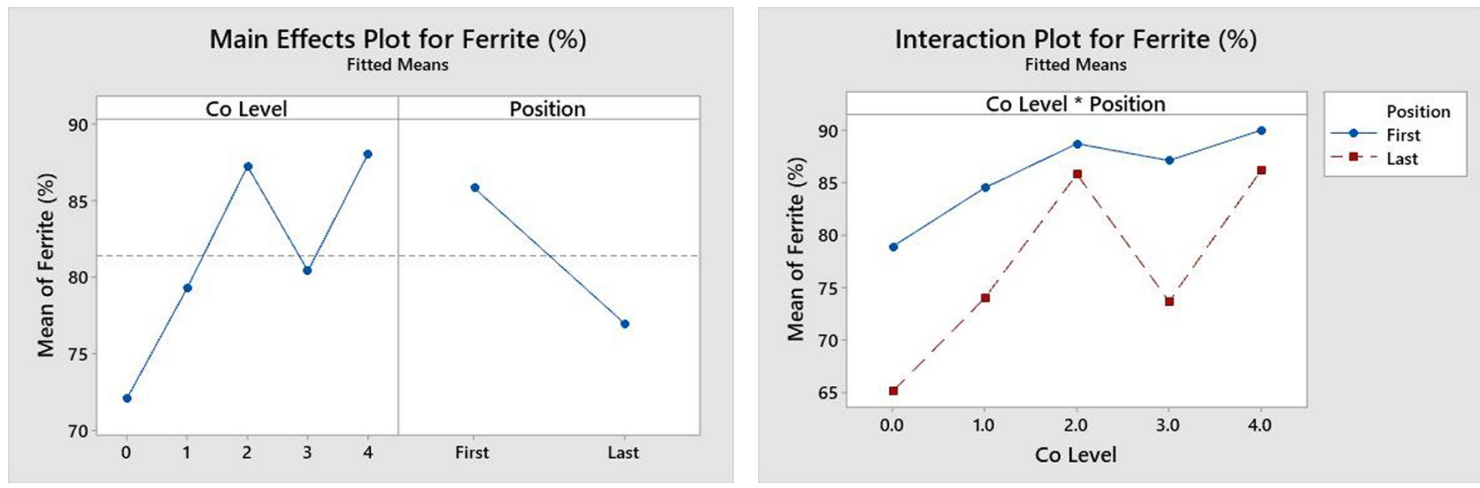

(a) Ferrite percentage
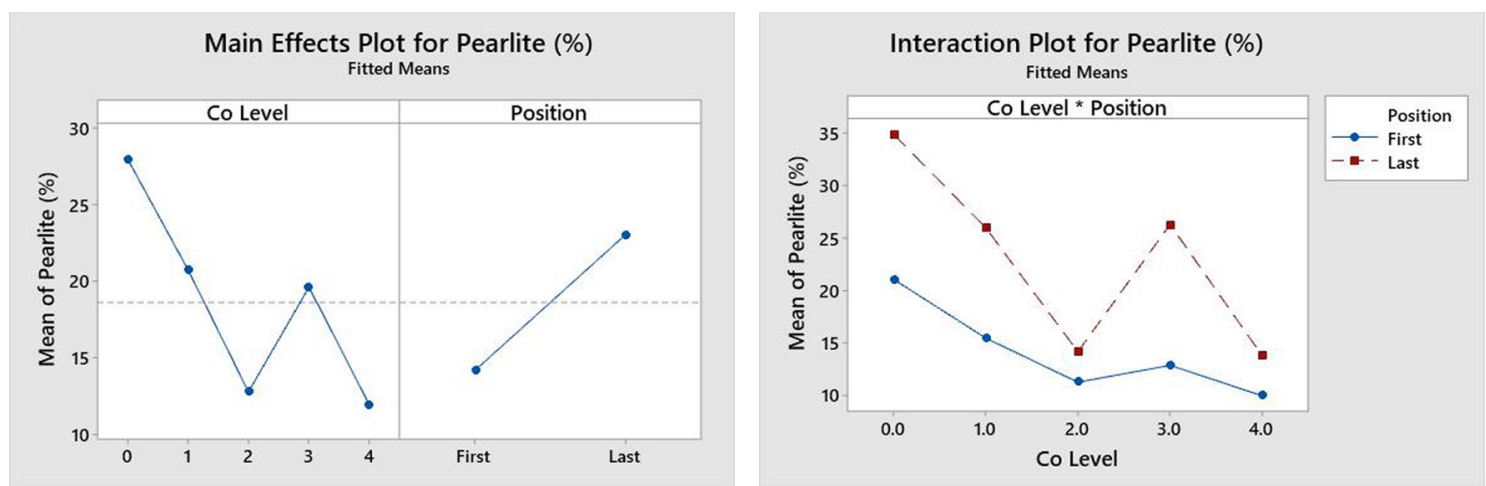

(b) Pearlite percentage

Figure 5.3 Factorial plots from Minitab ${ }^{\circledR}$ analyzing the (a) ferrite, and (b) pearlite percentages of the first and last $1 / 2$ inch Y-blocks poured [81].

\subsubsection{Influence of Cobalt in the Tensile Behavior}

\subsubsection{Rectangular Plates}

An ANOVA GLM was performed for the tensile behavior of the rectangular (Appendix B Section B.1.10-B.1.12), and all the factorial plots were provided in Chapter 4 (Figures 4.12-4.17). Recall that the cobalt level and section thicknesses were factors and the mechanical properties (tensile strength, yield strength, and elongation) were responses.

The yield strength significantly decreased while the percent elongation decreased with 4 wt.\% Co, which is correlated to rising ferrite content. It is well known that an increase in 
ferrite fraction results in a reduction in the tensile and yield strengths, accompanied by enhanced elongation [92], [110], [112]. Furthermore, when carbides are present in samples tested under tension, cracks will start in carbide-rich regions of the matrix with a brittle cleavage mode. In addition, these cracks start at low-stress values and rapidly link with cracks in other carbide regions resulting in elongations below $2 \%$ [113]. These low elongation values were observed primarily in those with high carbide contents.

\subsubsection{ASTM $1 / 2$ inch Y-blocks}

A one-way ANOVA was used to determine the effect of cobalt on the mechanical properties. The statistical analysis for this run is provided in Appendix B (Sections B.1.13-B.1.15). The cobalt content was the factor, and the mechanical properties were the responses.

The addition of cobalt has no statistically significant effect on tensile strength and elongation given the variation within each Co level (Table 5.2). However, the yield strength significantly increased with 4 wt.\% Co. Although it was previously mentioned that high ferrite contents result in a decrease of the yield strength, this was not true for these $1 / 2$ inch Y-blocks, demonstrating the solid solution strengthening effect of cobalt in ferrite, consistent with the increase in the ferrite hardness. Factorial plots depicting the substantial increase in ferrite microhardness with cobalt additions support this conclusion (Figure 5.4 with the ANOVA GLM is given in Appendix B Section B.1.16).

Table 5.2 One-Way ANOVA results for the mechanical properties, significant p-value marked in red

\begin{tabular}{cccccc}
\hline Mechanical Property & DF & Adj SS & Adj MS & F-Value & P-Value \\
\hline Tensile Strength (MPa) & 4 & 1695 & 423.8 & 1.25 & 0.304 \\
\hline Yield Strength (MPa) & 4 & 2995 & 748.8 & 4.46 & 0.004 \\
\hline Elongation (\%) & 4 & 18.86 & 4.716 & 1.67 & 0.172 \\
\hline
\end{tabular}



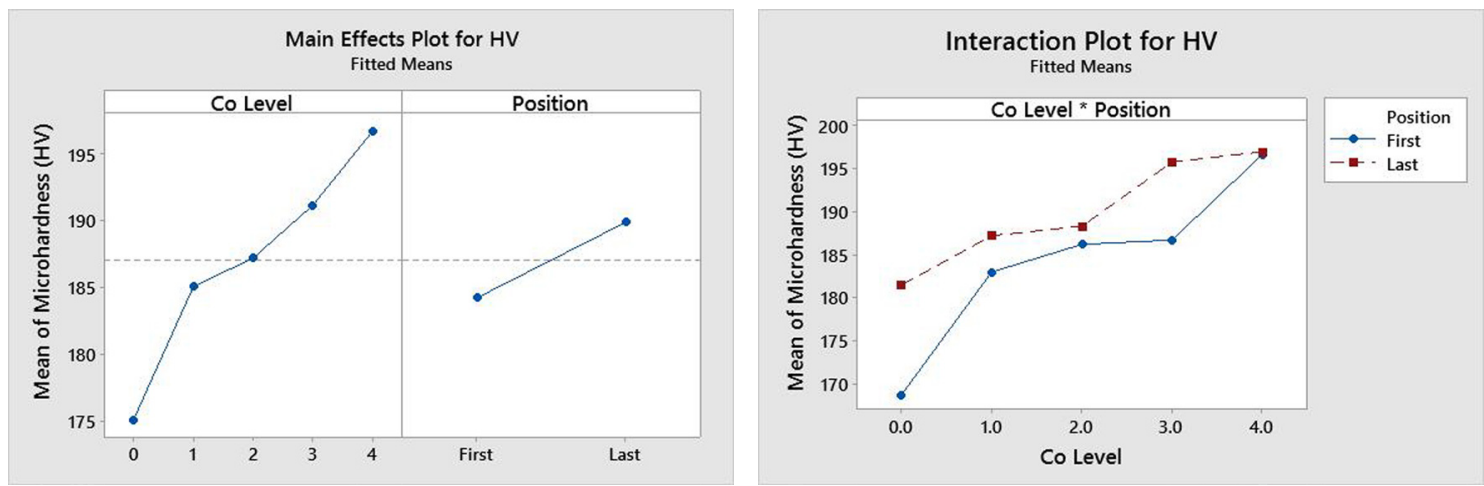

Figure 5.4 Factorial plots from Minitab ${ }^{\circledR}$ on the effect of cobalt on the ferrite microhardness of the $1 / 2$ inch Y-blocks [81].

\subsubsection{Influence of Cobalt in the Impact and Fracture Toughness Properties}

\subsubsection{V-notched and Unnotched Samples}

An ANOVA GLM (Appendix B Section B.1.17 to B.1.18) was performed with cobalt level and temperature as factors, and the absorbed energies of v-notched and unnotched samples as responses.

A gradual reduction in the absorbed energy is observed with cobalt additions for the vnotched samples (Figure 5.5a), while the impact energy declined above 2 wt.\% Co for the unnotched samples (Figure 5.5b). As expected, the absorbed energy drops with decreasing the temperature, but it seems more gradual in the unnotched case implying significant notch sensitivity. 

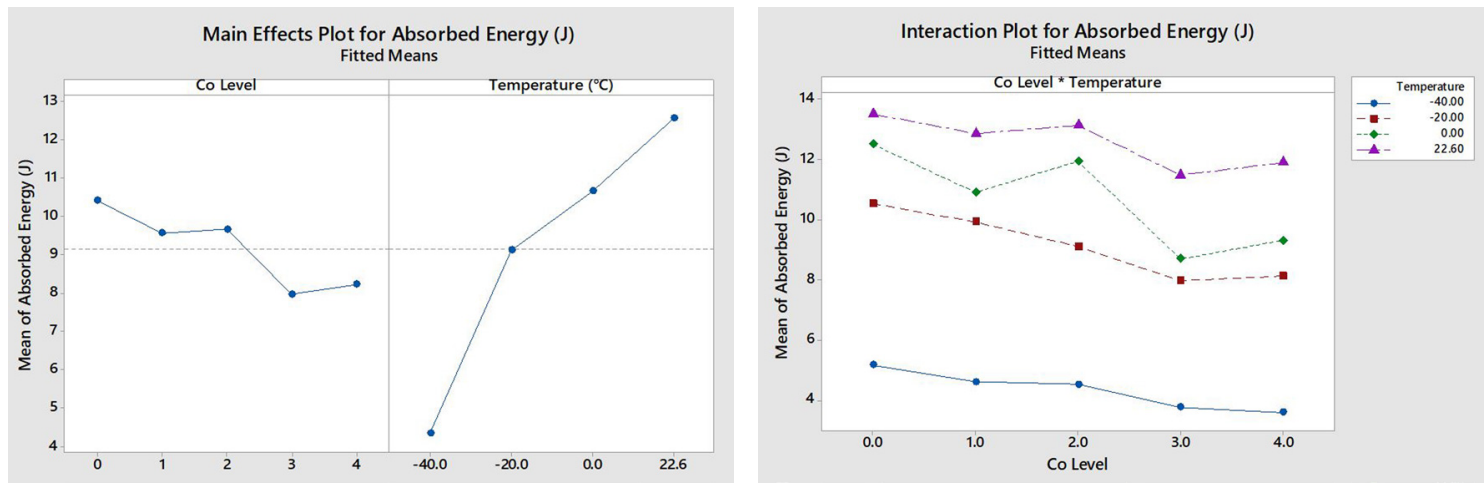

(a) V-notched samples
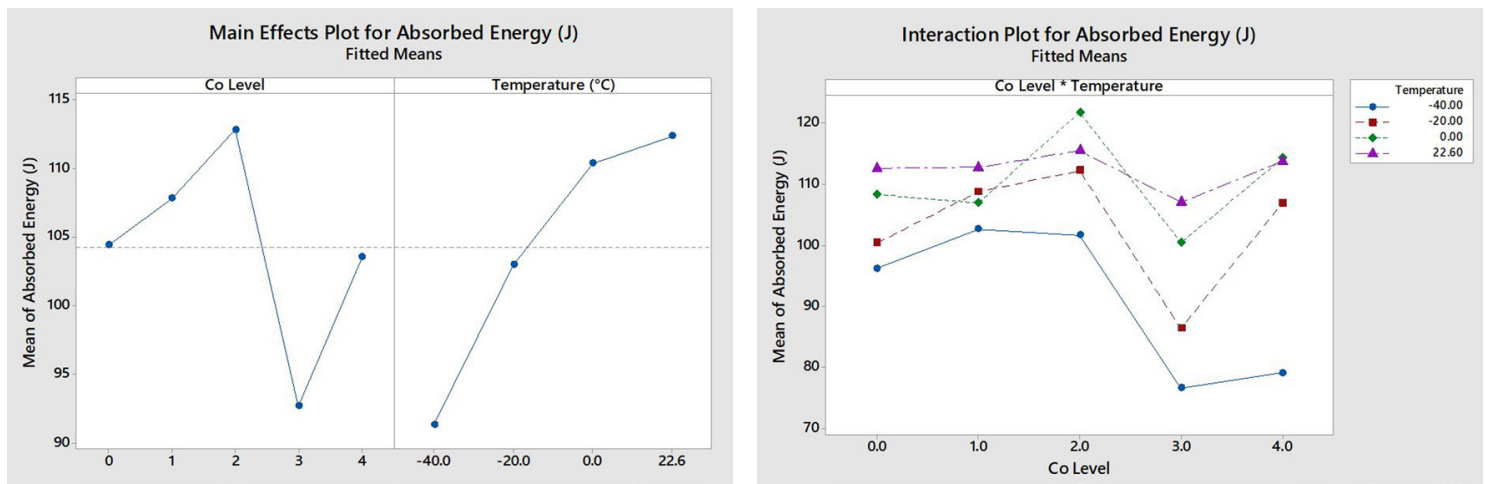

(b) Unnotched samples

Figure 5.5 Factorial plots from Minitab ${ }^{\circledR}$ analyzing the (a) v-notched and (b) unnotched impact energies of the $1 / 2$ inch Y-blocks.

Cracks initiate at regions of high stress concentration, and a geometric notch is used to assess stress concentration effects. The presence of a notch in ductile iron will always result in low impact values. Wallin explains that compared to steel, cast iron exhibits lower impact energies in v-notched samples. V-notches are basically large cracks, and since graphite nodules fail at small strains, this leads to multiple microcracks in front of the notch. The microcrack region overwhelms the notch acuity, making the notch effectively sharper than its effect in steel [114]. 


\subsubsection{Fracture toughness}

The ANOVA GLM performed for the fracture toughness test is given in Appendix B (Section B.1.19). The cobalt level and the temperature were factors, and the fracture toughness was the response. From Figure 5.6, a decrease in fracture toughness is observed with cobalt additions, as well as lower temperatures as expected.
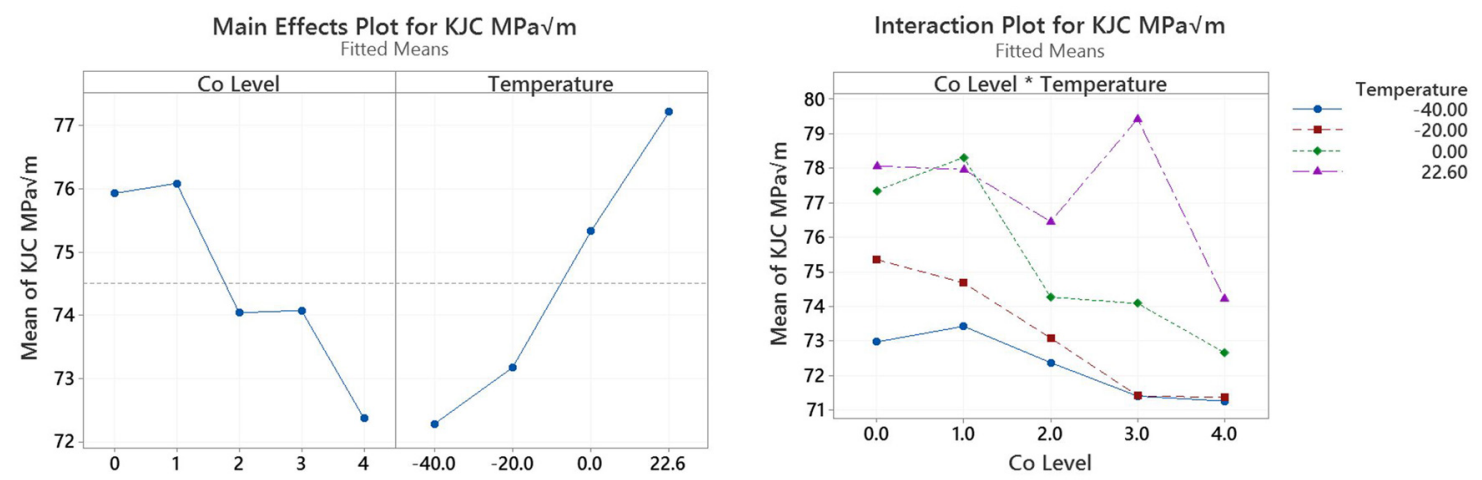

Figure 5.6 Factorial plots from Minitab ${ }^{\circledR}$ analyzing the fracture toughness of the $1 / 2$ inch Y-blocks.

Factors that influence the impact and fracture toughness results are associated with the chemical composition (mainly silicon, carbon, phosphorus, and manganese), microstructural features (such as graphite morphology, nodule count, and type of matrix), strain rate, and temperature. When analyzing these results, several of the above factors might be interacting at the same time and contributing to the fracture behavior, which provides additional complexity.

Before discussing some of the most important factors that are affecting the results, it is necessary to describe the general crack initiation and propagation mechanism that has been widely studied by several researchers in ductile irons [115]-[120]. This mechanism involves the following:

1. Graphite nodule decohesion

2. Microcracking originating from the graphite nodules 
3. Link-up of microcracks

4. And crack propagation by connecting graphite nodules

In terms of chemical composition, one of the most influential elements is silicon as discussed in Chapter 1 and 2. The main mechanism for silicon reducing the impact properties and the percent elongation is due to its negative segregation, in which the silicon concentration is higher around the graphite nodules. This embrittles the interface between the matrix and the graphite nodules, which is where cracks are initiated [93][97], [99]. Figure 5.7 shows the silicon segregation profile from work by Kanno [96] in a high silicon ductile iron grade which displays negative Si segregation. Their measurements are in agreement with those for the $4 \mathrm{wt} . \%$ Co SSFDI heat presented in Figure 4.59. The important thing to notice about this is that cobalt is segregating similarly to silicon, which would weaken even more the boundary between graphite nodules and the ferrite matrix, leading to lower fracture toughness.
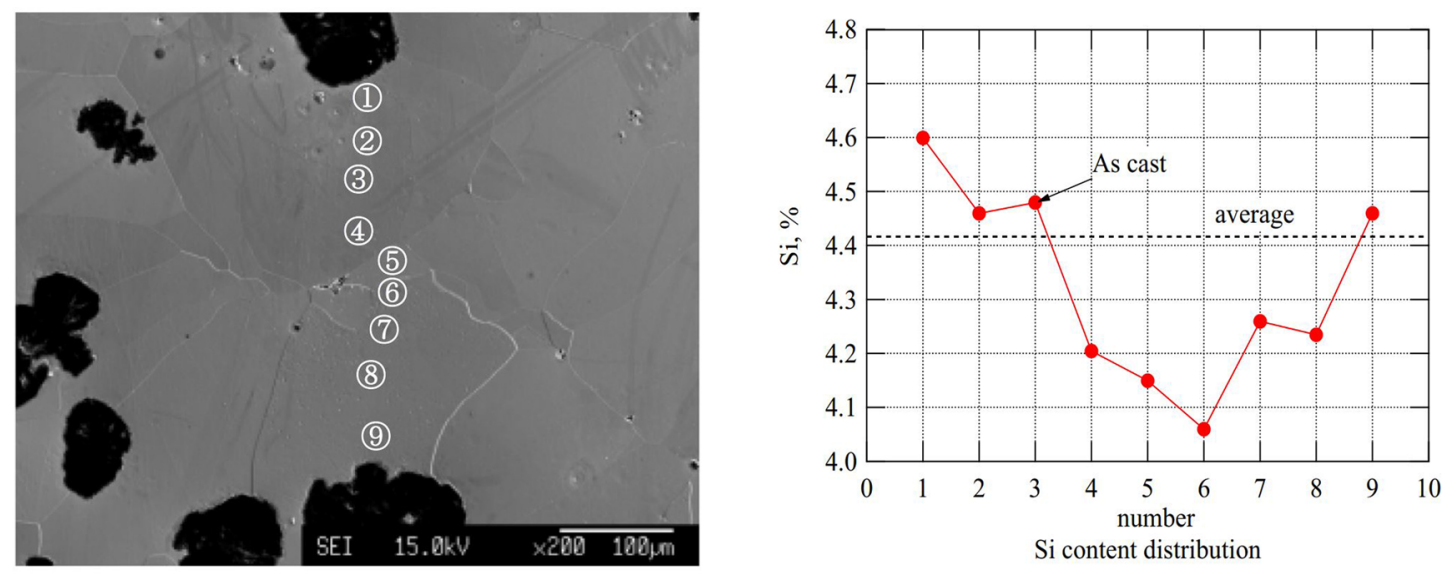

Figure 5.7 Silicon distribution showing the negative segregation between two graphite nodules [96]. 
Cracks will always propagate at the graphite-matrix interface, which highlights the weakness of the bond between the graphite nodules and the matrix. Hence, nodule count is another important factor in the final fracture toughness value. Several studies have indicated that high nodule counts (smaller internodular spacing) result in a lower upper shelf fracture toughness and a lower DBTT [19], [29], [121]-[123]. Therefore, the interparticle spacing $(\lambda)$ was calculated using Askeland's equation [109], and Table 5.3 shows the results for the two heats that resulted in the highest and lowest fracture toughness values (base ductile iron and 4 wt.\% Co). As the nodule count was significantly increased with the addition of $4 \mathrm{wt} . \% \mathrm{Co}$, the spacing was decreased making it easier it will be to achieve crack link-up and void coalescence leading to lower fracture toughness.

Table 5.3 Graphite interparticle spacing $(\lambda)[81]$

\begin{tabular}{cccc}
\hline Heat & $\begin{array}{c}\text { Nodule count } \\
\left(\mathbf{N} / \mathbf{m m}^{\mathbf{2}}\right)\end{array}$ & $\begin{array}{c}\text { Average graphite } \\
\text { radius }(\mathbf{m m})\end{array}$ & $\begin{array}{c}\text { Interparticle } \\
\text { Spacing }(\boldsymbol{\mu m})\end{array}$ \\
\hline Base DI & 187 & 0.014 & 46 \\
\hline 4 wt.\% Co & 240 & 0.0125 & 38 \\
\hline
\end{tabular}

Figure 5.8 displays the impact of high nodule count on the fracture toughness, and looking at Figure 4.29, the 4 wt.\% Co heat shows a comparable behavior to the Code B heat, which has a similar nodule count.

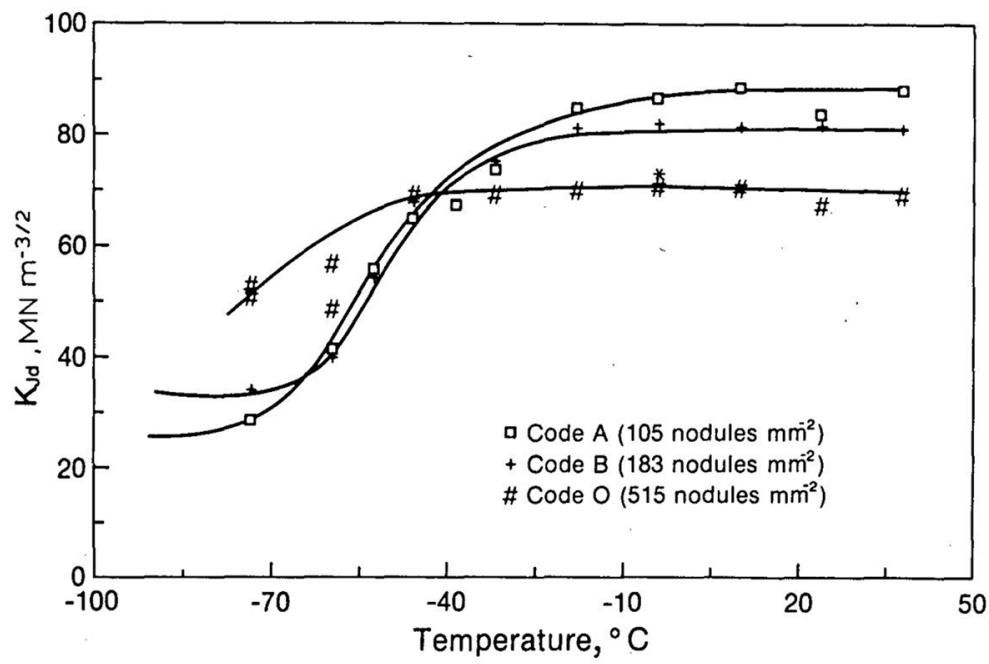

Figure 5.8 Effect of nodule count on the fracture toughness of ferritic ductile iron [19]. 
The solidification time for the $1 / 2$ inch Y-blocks was calculated using Inspire Cast (Figure 5.9) to determine the diffusion length of the base ductile iron and 4 wt.\% Co heats using the following equation:

Where:

$$
x=\sqrt{D t}
$$

$\mathrm{x}=$ diffusion length $(\mathrm{cm})$

$\mathrm{D}=$ diffusion coefficient $\left(\mathrm{D} \times 10^{7} \mathrm{~cm}^{2} / \mathrm{s}\right)$

$\mathrm{t}=$ solidification time (seconds)
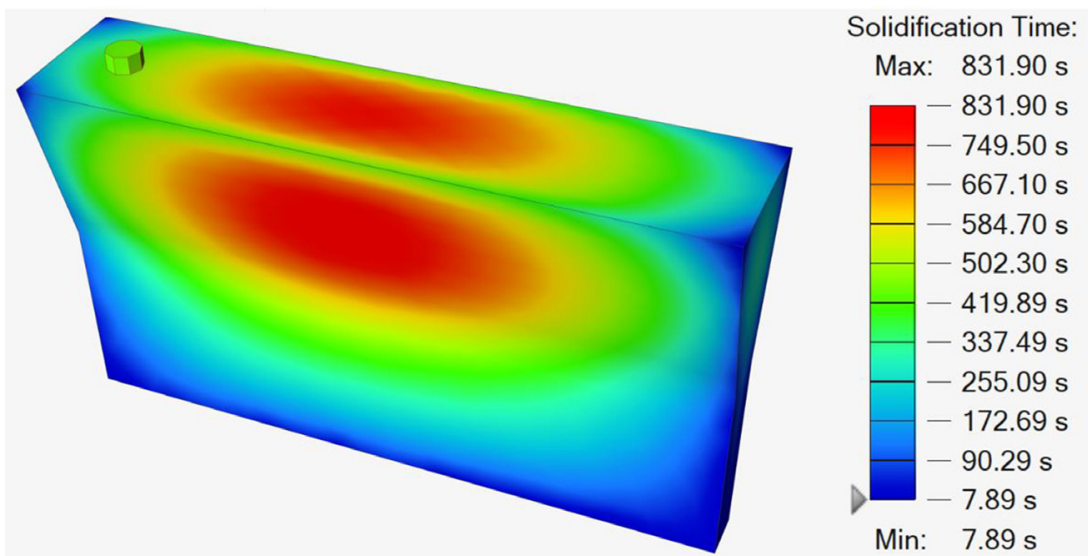

Figure 5.9 Solidification times calculated with Inspire Cast for the $1 / 2$ inch Y-blocks.

The solidification time for the $1 / 2$ inch Y-blocks is 134 seconds. After calculating the diffusion distances (Table 5.4) it seems that the interparticle spacing of the base ductile iron and 4 wt.\% Co heats (Table 5.3) are so much higher than the actual diffusion length.

Table 5.4 Diffusion length for the $1 / 2$ inch Y-blocks

\begin{tabular}{cccc}
\hline Heat & $\begin{array}{c}\text { aDiffusion Coefficient } \\
\left(\mathbf{D} \mathbf{~} \mathbf{1 0} \mathbf{~}^{\mathbf{7}} / \mathbf{s}\right)\end{array}$ & $\begin{array}{c}\text { Solidification } \\
\text { time }(\mathbf{s})\end{array}$ & $\begin{array}{c}\text { Diffusion length, } \\
\mathbf{x}(\boldsymbol{\mu} \mathbf{m})\end{array}$ \\
\hline Base DI & 3.15 & 134 & 0.06 \\
\hline 4 wt.\% Co & 6.4 & 134 & 0.09 \\
\hline
\end{tabular}

${ }^{a}$ The diffusion coefficients were taken from Smoluchowski research work [50] 


\subsection{Effect of Cobalt in Solid Solution Strengthened Ferritic Ductile Iron}

\subsubsection{Influence of Cobalt in the Microstructure}

The only significant microstructural influence observed with cobalt additions was a decrease in nodule diameter, especially at 4 wt.\% Co. Figure 5.10 shows the factorial plots that were obtained after performing an ANOVA GLM model (Appendix B Section B.2.1). Even though an increase in the percent nodularity and nodule count with cobalt additions has been reported previously [63]-[65], these trends were observed but they were not statistically significant due to within-sample variability.
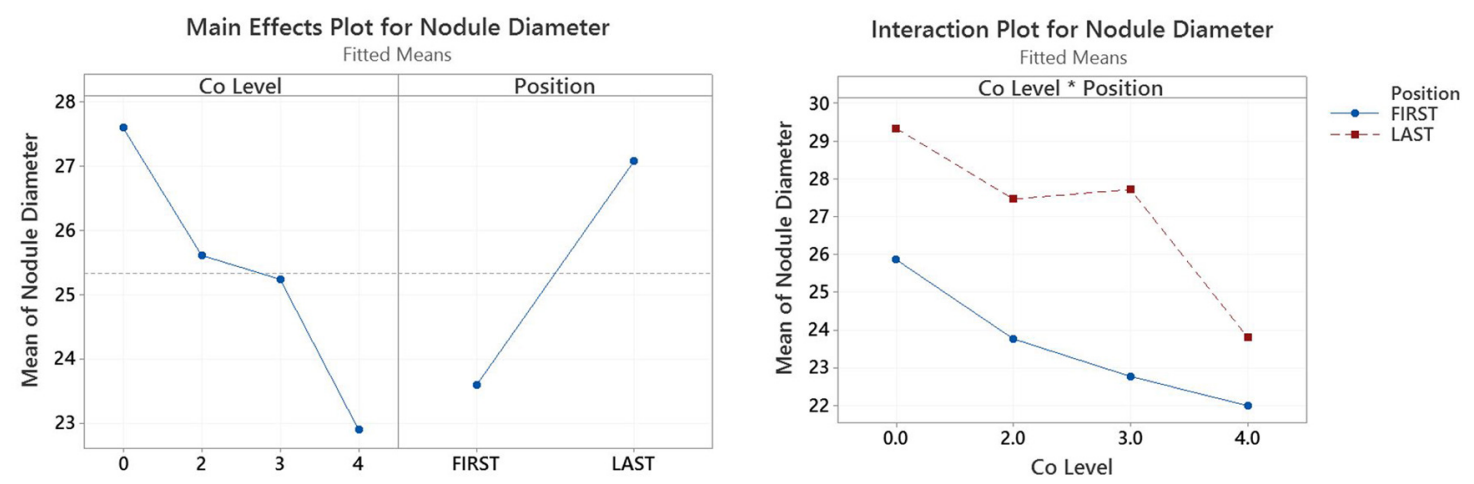

Figure 5.10 Factorial plots from Minitab ${ }^{\circledR}$ on the effect of cobalt in the nodule diameter of the SSFDI heats.

\subsubsection{Influence of Cobalt in the Tensile Behavior}

A one-way ANOVA showed that the tensile strength increased significantly with cobalt additions (Appendix B Section B.2.2). The model summary gives an R-squared adjusted term of $99.07 \%$, which is statistically significant $(\mathrm{p}=0.00)$. Even though the yield strength plateaued for the $4 \mathrm{wt} . \%$ Co heat, cobalt additions are statistically significant for yield strength but with a slightly lower R-squared adjusted term of 95.71 (Appendix B Section B.2.3). This increase in tensile and yield strength is mainly due to the solid solution hardening effect that cobalt has on the ferrite, as was confirmed by the Vickers hardness measurements (Figure 5.4). The one-way ANOVA models for Brinell and Vickers also 
show high correlation with increasing cobalt level (Appendix B Section B.2.4 to B.2.5). No statistically significant effects were found for the percent elongation with cobalt additions.

The cause for the decrease in the yield strength with 4 wt.\% Co (Figure 4.46) was not possible to determine. However, if the $3 \mathrm{wt} . \%$ Co heat is removed from the data set and only the $2 \mathrm{wt} . \%$ and $4 \mathrm{wt} . \%$ Co heat are considered, the increase in tensile and yield strength agree with Okunnu and Fischer et al. [63], [66] (Figure 5.11). The increase in yield strength is only significant when compared to the base SSF heat, and the percent elongation is not substantially increased. Nonetheless, González-Martinez et al. [67] reported one alloy that has a similar chemical composition to the $4 \mathrm{wt} . \%$ Co heat (4.14 wt.\% Si and $3.82 \mathrm{wt} . \% \mathrm{Co}$ ), which resulted in mechanical properties similar to the ones observed for this heat. Hence, this data set could potentially mean that the maximum static properties have been reached with $3 \mathrm{wt} . \%$ Co. 


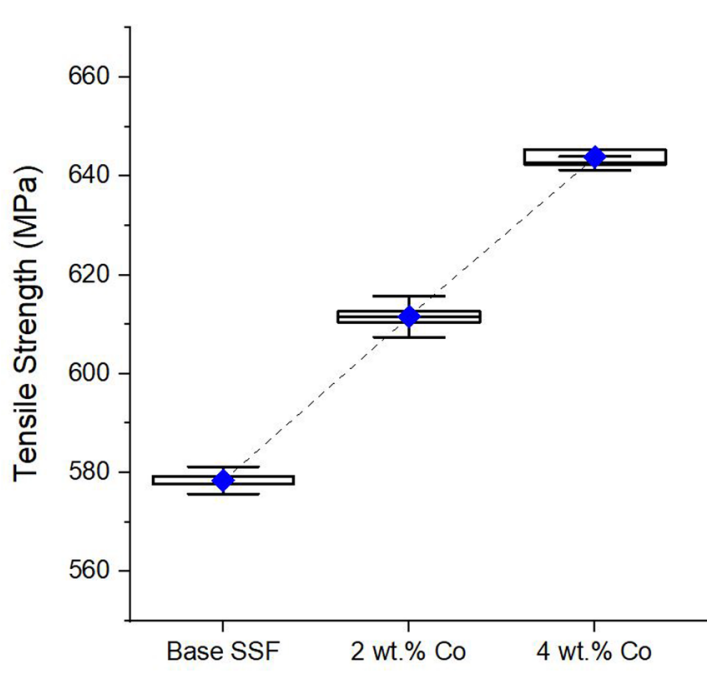

(a) Tensile Strength

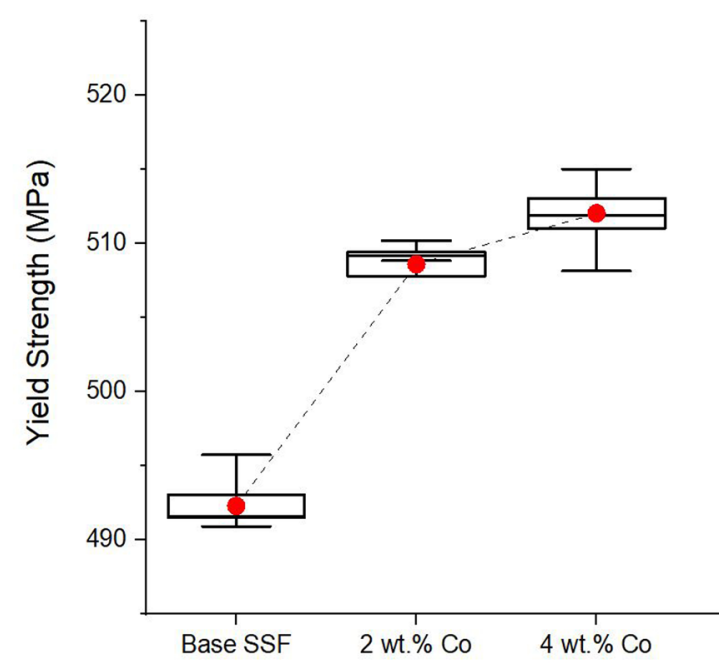

(b) Yield Strength

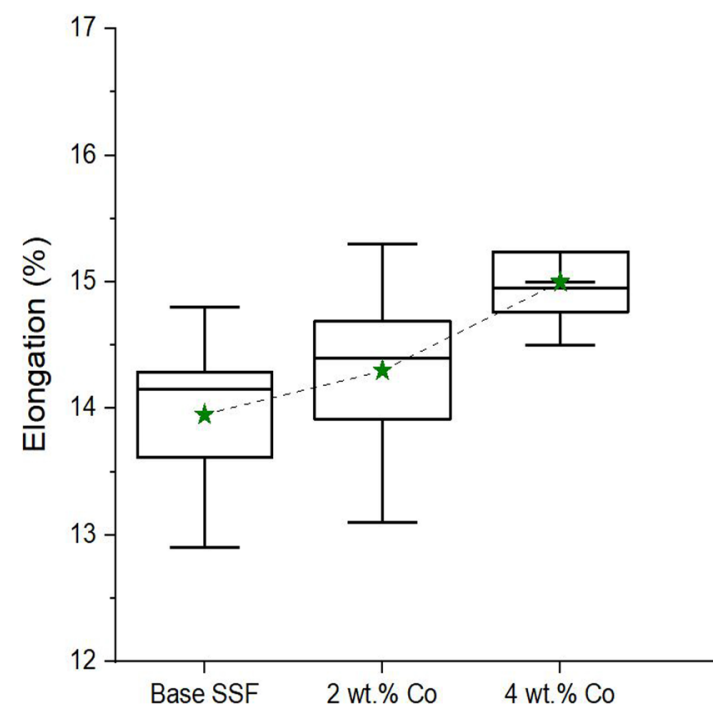

(c) Elongation

Figure 5.11 Tensile properties without the 3 wt.\% Co heat. 


\subsubsection{Influence of Cobalt in the Impact Properties}

Reducing the silicon content, from $4.3 \mathrm{wt} \%$ Si declared in DIN EN 1563 [21] for the production of the 600-10 SSFDI grade to $4.13 \mathrm{wt} . \% \mathrm{Si}$ was not enough to counteract the negative effect of high silicon contents on toughness properties. Consequently, the base SSF heat resulted in brittle fracture even at room temperature.

Additionally, as observed in Figure 5.12, the impact toughness was progressively reduced with cobalt additions. These results confirm that although cobalt increased the static properties, it does not improve the toughness. The ANOVA GLM model results are provided in Appendix B (Section B.2.6), where the cobalt content and temperature were factors, and the impact toughness was the response.
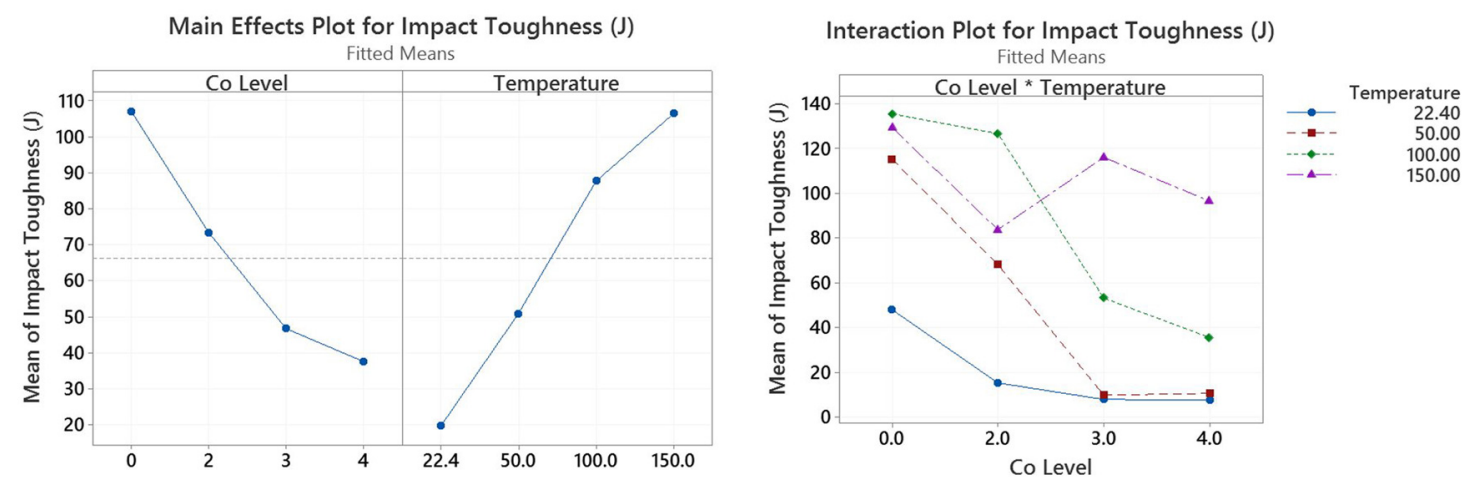

Figure 5.12 Factorial plots from Minitab ${ }^{\circledR}$ analyzing the impact toughness of the SSFDI heats.

As mentioned in Chapter 2, graphite morphology in SSFDI grades can have a detrimental effect on the impact properties. From the metallographic results shown in Chapter 4, the presence of degenerate graphite shapes (Type V per ASTM A247 [124]) was detected, so this was quantified with Olympus Stream Essentials software. All the cobalt bearing alloys resulted in higher levels of degenerate graphite (Table 5.5). This finding was also reported by González-Martínez et al. who observed that cobalt deteriorates the graphite shape and increases the tendency to CHG formation [67]. Early crack initiation can start 
from degenerated graphite nodules, given the notch effect on graphite nodules in ductile iron, which results in lower fracture toughness [125], [126].

Table 5.5 Degenerated graphite content in the SSFDI heats (\%)

\begin{tabular}{cc}
\hline Heat & Type V (\%) \\
\hline Base SSF & 4.8 \\
\hline 2 wt.\% Co & 8.7 \\
\hline 3 wt.\% Co & 8.1 \\
\hline 4 wt.\% Co & 7.7 \\
\hline
\end{tabular}

Another factor that can influence this outcome is that cobalt is known to increase chemical ordering in Fe-Co alloys [127]. A study of Fe-Si-Co alloys has shown that in addition to the B2 and D03 ordered phases that were discussed in Chapter 2, a two-phase region $(\mathrm{B} 2+\mathrm{D} 03)$ exists between these phases, which cobalt shifting the transition between disordered (A2-phase) to ordered (B2-phase) to lower silicon values [128]. This behavior was observed by González-Martínez et al., who found that the maximum tensile strength for cobalt-bearing alloys was around 4.3-4.4 wt.\% Si versus 5.2 wt.\% Si for alloys without cobalt, attributing the brittleness of these alloys to the presence of ordered phases [67]. For this reason, x-ray diffraction (XRD) was performed on the $4 \mathrm{wt} . \%$ Co sample to look for the presence of ordered phases. However, no superlattice peaks were observed. A possible explanation for this result might be that this characterization technique was unable to detect the low-intensity superlattice peaks. Transmission Electron Microscopy (TEM) or synchrotron XRD techniques may be better tools to identify these phases. Weiß et al., observed B2-superstructures by TEM in ductile iron samples with 3.95 wt.\% Si [129], which could indicate that the deterioration of the dynamic properties of the present heats is enhanced by the presences of ordered phases. 


\section{Concluding Remarks}

The structured and complete experimental work presented here provides the first investigation on alloying ductile iron with cobalt to reduce carbide formation in thin sections, and the production of carbide-free thin-wall ductile iron castings was possible with 4 wt.\% Co. Cobalt increases the nodule count, which reduces the interparticle spacing between the graphite nodules, reducing the carbon diffusion path length, and enabling the formation of more ferrite. It is recommended to explore the effect of $4 \mathrm{wt} . \%$ Co to castings with complex geometries (thin and thick sections) and evaluate the potential of cobalt in producing a casting without graphite flotation and carbides using a single $\mathrm{CE}$ value.

The strengthening effect that cobalt has on ferrite was confirmed not only for ductile irons with low silicon but also for high silicon ductile iron grades. Additionally, cobalt can be used to partially replace silicon while maintaining the tensile properties necessary to meet the 600-10 SSFDI grade. However, there is a greater detrimental effect on the impact properties when cobalt is present, which might limit its application. The insights gained from this study will be of assistance to ductile iron producers in terms of knowing the effects upon cobalt additions in the mechanical properties.

Another important contribution of this research is the measurement of impact and fracture toughness data over a wide range of compositions and temperatures for two types of ductile iron grades (TWDI and SSFDI). The negative effect of high silicon in SSFDI grades was confirmed with the fracture toughness testing, and the brittleness of these grades was observed at room temperature and above. A deeper understanding of the effect of cobalt on the impact and fracture toughness behavior was developed. Cobalt increases the ductile to brittle transition temperature, and when silicon and cobalt are together, the negative effects on impact properties are magnified. 


\section{Bibliography}

[1] W. D. Callister, Materials science, and engineering: an introduction, 7th ed. New York: John Wiley \& Sons, 2007.

[2] P. K. B. Rundman, PRINCIPLES OF METAL CASTING.

[3] H. Berns, W. Theisen, and G. Scheibelein, Ferrous materials: steel and cast iron. Berlin: Springer, 2008.

[4] A. I. Al-Ghonamy, M. Ramadan, N. Fathy, K. M. Hafez, and A. A. El-Wakil, "Effect of Graphite Nodularity on Mechanical Properties of Ductile Iron for Waterworks Fittings and Accessories," vol. 10, no. 03, p. 5.

[5] T. Sjogren, P. Vomacka, and I. L. Svensson, "Comparisson of Mechanical Properties in Flake Graphite and Compacted Graphite Cast Irons for Pistons Rings," Int. J. Cast Met. Res., vol. 17, no. 2, pp. 65-71, 2004.

[6] H. Nakae and H. Shin, "Effect of Graphite Morphology on Tensile Properties of Flake Graphite Cast Iron," Mater. Trans., vol. 42, no. 7, pp. 1428-1434, 2001.

[7] Properties and Selection: Irons, Steels, and High-Performance Alloys, vol. 1. ASM International, 1993.

[8] K. D. Millis, A. P. Gagnebin, R. Bank, and N. B. Pilling, "Cast Ferrous Alloy," 2485760 .

[9] H. Morrogh, "Nodular Cast Irons and the Manufacture Thereof," 2488511.

[10] Ductile Iron Handbook. American Foundry Society, 1992.

[11] R. B. Gundlach, "Effects of Carbon in Ductile Iron," Ductile Iron Society, 6, 2003.

[12] A. Alagarsamy, "Carbon and Silicon Level Control in Sand Cast Ductile Iron Castings,” Ductile Iron Society, 1, 2004.

[13] Ductile Iron Data for Design Engineers. Rio Tinto Iron \& Titanium Incorporated, 1990.

[14] M. Denchak, "Greenhouse Effect 101," NRDC.

https://www.nrdc.org/stories/greenhouse-effect-101 (accessed Nov. 19, 2020).

[15] "Energy Technology Perspectives 2015: Mobilising Innovation to Accelerate Climate Action,” International Energy Acengy, 2015. Accessed: Nov. 19, 2020. [Online]. Available: ://www.iea.org/reports/energy-echnology-perspectives-2015. 
[16] R. Wohlecker, M. Johannaber, and M. Espig, "Determination of Weight Elasticity of Fuel Economy for ICE, Hybrid and Fuel Cell Vehicles,” Apr. 2007, pp. 2007-010343, doi: 10.4271/2007-01-0343.

[17] "Silicon and its Effects in Ductile Iron," Ductile Iron Society, 10, 2000.

[18] J. C. Pang, B. Y. Xu, G. D. Wang, Q. Lu, J. F. Wang, and H. L. Yi, "Effect of silicon and aluminium in ferrite on tensile and impact properties," Mater. Sci.

Technol., vol. 33, no. 15, pp. 1806-1810, Oct. 2017, doi:

10.1080/02670836.2017.1320085.

[19] W. L. Bradley and M. N. Srinivasan, "Fracture and fracture toughness of cast irons," Int. Mater. Rev., vol. 35, no. 1, pp. 129-161, Jan. 1990, doi: $10.1179 / 095066090790324028$.

[20] W. H. White, L. P. Rice, and A. R. Elsea, "Influence of Silicon Content on Mechanical and High-Temperature Properties of Nodular Cast Iron," Trans. Am. Foundry Soc., pp. 337-347, 1951.

[21] “EUROPEAN STANDARD DIN EN 1563," 2012.

[22] W. Stets, H. Löblich, G. Gassner, and P. Schumacher, "Solution Strengthened Ferritic Ductile Cast Iron Properties, Production and Application," Int. J. Met., vol. 8, no. 2, pp. 35-40, Apr. 2014, doi: 10.1007/BF03355580.

[23] Z. Glavas, A. Strkalj, and A. Stojakovic, "The Properties of Silicon Alloyed Ferritic Ductile Irons,” Metalurgija, vol. 55, pp. 293-296, 2016.

[24] A. Javaid, J. Thomson, K. G. Davis, and M. Sahoo, "Effect of Microstructure on the Mechanical Properties of Thin-Wall Ductile Iron Castings," AFS Trans, vol. 109, pp. 1097-1114, 2001.

[25] D. M. Stefanescu, L. P. Dix, R. E. Ruxanda, C. Corbitt-Coburn, and T. S. Piwonka, "Tensile Properties of Thin Wall Ductile Iron," AFS Trans, vol. 110, pp. 1149-1162, 2002.

[26] C. R. Loper Jr, "Nodule Count is Important," 1966.

[27] C. R. Loper Jr, "Processing and Control of Ductile Cast Iron," AFS Trans., vol. 55 , pp. 1-7, 1969.

[28] A. Javaid, J. Thomson, and K. G. Davis, "Critical Conditions for Obtaining Carbide-Free Microstructures in Thin-Wall Ductile Irons," AFS Trans, vol. 110, pp. 889-898, 2002.

[29] M. Caldera, J. M. Massone, R. E. Boeri, and J. A. Sikora, "Impact Properties of Thin Wall Ductile Iron,” ISIJ Int., vol. 44, no. 4, pp. 731-736, 2004, doi: 10.2355/isijinternational.44.731. 
[30] F. Mampaey and Z. A. Xu, "Mold Filling and Solidification of a Thin-Wall Ductile Iron Casting," AFS Trans, vol. 105, pp. 95-103, 1997.

[31] C. Labrecque and M. Gagné, "Development of Carbide-Free Thin-Wall Ductile Iron Castings," AFS Trans, vol. 108, pp. 31-38, 2000.

[32] C. Labrecque, M. Gagné, and A. Javaid, "Optimizing the Mechanical Properties of Thin-Wall Ductile Iron Castings,” AFS Trans, vol. 113, pp. 677-686, 2005.

[33] A. Javaid, J. Thomson, M. Sahoo, and K. G. Davis, "Factors Affecting the Formation of Carbides in Thin-Wall DI Castings," AFS Trans, vol. 107, pp. 441-456, 1999.

[34] M. Górny and E. Tyrała, "Effect of Cooling Rate on Microstructure and Mechanical Properties of Thin-Walled Ductile Iron Castings," J. Mater. Eng. Perform., vol. 22, no. 1, pp. 300-305, Jan. 2013, doi: 10.1007/s11665-012-0233-0.

[35] C. Labrecque, M. Gagné, A. Javaid, and M. Sahoo, "Production and properties of thin-wall ductile iron castings," Int. J. Cast Met. Res., vol. 16, pp. 313-317, 2003, doi: 10.1080/13640461.2003.11819601.

[36] K. M. Pedersen and N. S. Tiedje, "Solidification and microstructure of thin walled ductile cast iron," Technical University of Denmark, 2006.

[37] Sorelmetal, The Sorelmetal book of ductile iron. Montréal (Québec): Rio Tinto iron \& titanium, 2004.

[38] M. M. Shea, "Influence of Cooling Rate and Manganese and Copper Content on Hardness of As-Cast Ductile Iron,” AFS Trans, vol. 86, pp. 7-12, 1978.

[39] C. Labrecque and M. Gagné, "Ductile Iron: Fifty Years of Continuous Development," Can. Metall. Q., vol. 37, no. 5, pp. 343-378, 1998, doi: 10.1179/cmq.1998.37.5.343.

[40] J. R. Davis, Ed., Alloying: understanding the basics. ASM International, 2001.

[41] R. A. Gonzaga, P. M. Landa, A. Perez, and P. Villanueva, "Mechanical properties dependency of the pearlite content of ductile irons," J. Achiev. Mater. Manuf. Eng., vol. 33, no. 2, p. 9, 2009.

[42] S. K. Yu and C. R. Loper Jr, "The Effect of Molybdenum, Copper, and Nickel on the Pearlitic, and Martensitic Hardenability of Ductile Cast Irons," AFS Trans, vol. 96, pp. 811-822, 1988.

[43] S. K. Yu and C. R. Loper, "The Effect of Molybdenum, Copper, and Nickel on the Microstructure, Hardness, and Hardenability of Ductile Cast Irons," AFS Trans, vol. 94, pp. 557-576, 1986. 
[44] I. A. Franson and R. D. Schelleng, "Nickel Alloyed Pearlitic Ductile Iron for Heavy Sections," AFS Trans, vol. 64, pp. 850-856, 1964.

[45] "Nickel as an alloy in cast iron," Modern Casting, 1977.

[46] J. Hernandez-Avila et al., "The Effect of Molybdenum on the Microstructure of Nodular Iron,” Eur. Sci. J., vol. 11, no. 36, pp. 377-388, 2015.

[47] "Phosphorus and its Effects in Ductile Iron," Ductile Iron Society, 11, 2000.

[48] R. Gundlach, "Effect of Magnesium in Ductile Iron," Ductile Iron Society, 12, 2003.

[49] R. B. Gundlach, "Effect of Antimony, Arsenic and Tin in Ductile Iron," Ductile Iron Society, 7, 2002.

[50] R. Smoluchowski, "Diffusion Rate of Carbon in Iron-Cobalt Alloys," Phys. Rev., vol. 62, no. 11-12, pp. 539-544, 1942, doi: 10.1103/PhysRev.62.539.

[51] B. F. Brown and M. F. Hawkes, "Kinetics of Graphitization in Cast Iron," AFS Trans, vol. 59, pp. 181-200, 1951.

[52] A. S. Appleton, "The Kinetics of first-stage graphitization in Fe-C and Fe-Co-C alloys," J. Iron Steel Inst., pp. 160-168, 1960.

[53] V. P. Solov'ev and O. V. Kuragin, "Evaluating the Influence of Different Elements on Iron Graphitization," Sov. Cast. Technol. USA, no. 7, pp. 10-11, 1991.

[54] M. Srinivas, G. Malakondaiah, and P. Rama Rao, "Influence of solute additions on the fracture behaviour of Armco iron," Proc. R. Soc. Lond. Ser. Math. Phys. Sci., vol. 447, no. 1930, pp. 223-236, Nov. 1994, doi: 10.1098/rspa.1994.0137.

[55] D. R. Squires, F. G. Wilson, and E. A. Wilson, "The influence of Mo and Co on the embrittlement of an Fe-Ni-Mn alloy," Metall. Trans. B, vol. 5, pp. 2569-2578, 1974.

[56] D. R. Squires and E. A. Wilson, "Effect of cobalt on impact toughness of steels," Mater. Sci. Technol., vol. 10, pp. 52-55, 1994.

[57] W. Thury, R. Hummer, and E. Nechtelberger, "Der Einfluss von Kobalt, Nickel un Kupfer auf das Gefüge und die mechanischen Eingenschaften von Gusseisen mit Kugelgraphit," Giesserei, vol. 15, pp. 273-279, 1967.

[58] E. K. Modl, "Kobaltlegiertes Gusseisen mit Kugelgraphit," Giesserei, vol. N. 10, pp. 244-251, 1968. 
[59] X. P. Shen, S. J. Harris, and B. Noble, "Influence of small vanadium and cobalt additions on microstructure and properties of ductile iron," Mater. Sci. Technol., vol. 11, no. 9, pp. 893-900, 1995, doi: 10.1179/mst.1995.11.9.893.

[60] S. Yazdani, H. Bayati, and R. Elliott, "The influence of cobalt on the austempering reaction in ductile cast iron," Int. J. Cast Met. Res., vol. 13, no. 6, pp. 317-326, 2001, doi: 10.1080/13640461.2001.11819413.

[61] C.-H. Hsu, M.-L. Chen, and C.-J. Hu, "Microstructure and mechanical properties of $4 \%$ cobalt and nickel alloyed ductile irons," Mater. Sci. Eng. A, vol. 444, pp. 339346, 2007, doi: 10.1016/j.msea.2006.09.027.

[62] S. Duwe and B. Tonn, "Ductile Cast Iron with High Toughness at Low Temperatures," Mater. Sci. Forum, vol. 925, pp. 334-341, Jun. 2018, doi: 10.4028/www.scientific.net/MSF.925.334.

[63] R. Okunnu, "High Strength Solution-Strengthened Ferritic Ductile Cast Iron," Aalto University, School of Engineering, Finland, 2015.

[64] P. Weißß, J. Brachmann, A. Bührig-Polaczek, and S. F. Fischer, "Influence of nickel and cobalt on microstructure of silicon solution strengthened ductile iron," Mater. Sci. Technol., vol. 31, no. 12, pp. 1479-1485, 2015, doi: 10.1179/1743284714Y.0000000735.

[65] S. Fischer, J. Brachmann, A. Bührig-Polaczek, and P. Weiß, "Metallurgische Verbesserung von mischkristallverfestigten Gusseisen mit Kugelgrafit: Einfluss von Cobalt und Nickel auf die Mikrostruktur. Teil 1: Stand der Technik, Auswirkungen von Co und Ni auf die Matrix, Grafitkugelzahl und-form von hochsiliziumhaltigem GJS," Giesserei, vol. 104, pp. 38-45, Jun. 2017.

[66] S. Fischer, J. Brachmann, A. Bührig-Polaczek, and P. Weiß, "Metallurgische Verbesserung von mischkristallverfestigten Gusseisen mit Kugelgrafit: Einfluss von Cobalt und Nickel auf die mechanischen Eigenschaften. Teil 2: Einfluss von Cobalt und Nickel auf die mechanischen Eigenschaften," Giesserei, vol. 104, pp. 40-51, Jul. 2017.

[67] R. González-Martínez, J. Sertucha, and J. Lacaze, "Effects of cobalt on mechanical properties of high silicon ductile irons," Mater. Sci. Technol., vol. 36, no. 12, pp. 1292-1300, 2020, doi: https://doi.org/10.1080/02670836.2020.1777509.

[68] R. González-Martínez, U. de la Torre, J. Lacaze, and J. Sertucha, "Effects of high silicon contents on graphite morphology and room temperature mechanical properties of as-cast ferritic ductile cast irons. Part I - Microstructure," Mater. Sci. Eng. A, vol. 712, pp. 794-802, Jan. 2018, doi: 10.1016/j.msea.2017.11.050. 
[69] B. Bauer, I. Mihalic Pokopec, M. Petrič, and P. Mrvar, "Effect of Cooling Rate on Graphite Morphology and Mechanical Properties in High-Silicon Ductile Iron Castings," Int. J. Met., vol. 14, no. 3, pp. 809-815, Jul. 2020, doi: 10.1007/s40962020-00432-3.

[70] C. Hartung, R. Logan, A. Plowman, D. Wilkinson, E. G. Hoel, and E. Ott, "Research on Solution Strengthened Ferritic Ductile Iron (SSFDI) Structure and Properties Using Different Treatment and Inoculation Materials," Int. J. Met., vol. 14, no. 4, pp. 1195-1209, Oct. 2020, doi: 10.1007/s40962-020-00469-4.

[71] L.-E. Björkegren, K. Hamberg, and B. Johannesson, "Mechanical Properties and Machinability of Si-Solution-Hardened Ferritic Ductile Iron," AFS Trans., pp. 139$145,1996$.

[72] L.-E. Björkegren and K. Hamberg, "Silicon Alloyed Ductile Iron with Exellent Ductility and Machinability," The Foundryman, vol. 94, pp. 42-51, 2001.

[73] U. de la Torre, A. Loizaga, J. Lacaze, and J. Sertucha, "As cast high silicon ductile irons with optimised mechanical properties and remarkable fatigue properties," Mater. Sci. Technol., vol. 30, no. 12, pp. 1425-1431, 2014, doi: https://doi.org/10.1179/1743284713Y.0000000483.

[74] P. Hammersberg, K. Hamberg, and H. et al Borgström, "Variation of Tensile Properties of High Silicon Ductile Iron," vol. 925, p. 9.

[75] R. González-Martínez, U. de la Torre, A. Ebel, J. Lacaze, and J. Sertucha, "Effects of high silicon contents on graphite morphology and room temperature mechanical properties of as-cast ferritic ductile cast irons. Part II - Mechanical properties," Mater. Sci. Eng. A, vol. 712, pp. 803-811, Jan. 2018, doi: 10.1016/j.msea.2017.11.051.

[76] I. Ohnuma, S. Abe, S. Shimenouchi, T. Omori, R. Kainuma, and K. Ishida, "Experimental and Thermodynamic Studies of the Fe-Si Binary System," ISIJ Int., vol. 52, no. 4, pp. 540-548, 2012, doi: 10.2355/isijinternational.52.540.

[77] J. S. Shin et al., "Ordering-disordering phenomena and micro-hardness characteristics of B2 phase in Fe- (5-6.5\%) Si alloys," Mater. Sci. Eng. A, vol. 407, no. 1-2, pp. 282-290, Oct. 2005, doi: 10.1016/j.msea.2005.07.012.

[78] J. Lacaze and B. Sundman, "An assessment of the Fe-C-Si system," Metall. Trans. A, vol. 22, no. 10, pp. 2211-2223, Oct. 1991, doi: 10.1007/BF02664987.

[79] A. Almanza, D. Dewald, J. Licavoli, and P. G. Sanders, "Effect of Cobalt Additions on the Microstructure and Mechanical Properties of As-Cast Thin-Wall Ductile Iron," Int. J. Met., Aug. 2020, doi: 10.1007/s40962-020-00513-3. 
[80] A04 Committee, "Specification for Ductile Iron Castings," ASTM International. doi: 10.1520/A0536-84R14.

[81] A. Almanza, D. Dewald, J. Licavoli, and P. G. Sanders, "Influence of Cobalt in the Tensile Properties of $1 / 2$ Inch Ductile Iron Y-blocks," Int. J. Met., pp. 1-14, Sep. 2020, doi: 10.1007/s40962-020-00521-3.

[82] A04 Committee, "Standard Test Method for Determining Nodularity and Nodule Count In Ductile Iron Using Image Analysis," ASTM International.

[83] ISO, "ISO-945-1975 Cast Iron - Designation of Microstructure of Graphite."

[84] E28 Committee, "Test Methods for Tension Testing of Metallic Materials," ASTM International. doi: 10.1520/E0008_E0008M-16A.

[85] E28 Committee, "Test Methods for Notched Bar Impact Testing of Metallic Materials,” ASTM International. doi: 10.1520/E0023-18.

[86] "BS-EN-ISO-148-1-2016 Metallic materials - Charpy pendulum impact test Part 1: Test method," ISO, 2016.

[87] E08 Committee, “Test Method for Measurement of Fracture Toughness," ASTM International. doi: 10.1520/E1820-17A.

[88] A. E. Linares, L. Clowers, X. Chen, M. Sokolov, and R. Nanstad, "Using Automated J-R Curve Analysis Software to Simplify Testing and Save Time," Adv. Mater. Process., vol. 177, no. No.2, Mar. 2019.

[89] L. N. Clowers, A. E. Linares, and X. Chen, "Technical Manual for Automated J-R Curve Analysis Program Based on the ASTM E1820-18 Normalization Method," ORNL/LTR--2018/1041, 1484983, Oct. 2018. doi: 10.2172/1484983.

[90] J. H. Doubrava, S. F. Carter, and J. F. Wallace, "The Influence of Processing Variables on the Matrix Structure and Nodularity of Ductile Iron," AFS Trans, vol. 89, pp. 229-250, 1981.

[91] R. J. Salzbrenner, "Tensile behavior of ferritic ductile cast iron," SAND-86-0470, 5760712, Apr. 1986. doi: 10.2172/5760712.

[92] R. A. Gonzaga, "Influence of ferrite and pearlite content on mechanical properties of ductile cast irons," Mater. Sci. Eng. A, vol. 567, pp. 1-8, 2013, doi:

10.1016/j.msea.2012.12.089.

[93] B. Y. Lin, E. T. Chen, and T. S. Lei, "The Effect of Segregation on the Austemper Transformation and Toughness of Ductile Irons," J. Mater. Eng. Perform., vol. 7, no. 3, pp. 407-419, Jun. 1998, doi: 10.1361/105994998770347864. 
[94] C. Selig and A. Lacaze, "Study of microsegregation buildup during solidification of spheroidal graphite cast iron," Metall. Mater. Trans. B, vol. 31, no. 4, pp. 827836, Aug. 2000, doi: 10.1007/s11663-000-0119-7.

[95] A. Alhussein, M. Risbet, A. Bastien, J. P. Chobaut, D. Balloy, and J. Favergeon, "Influence of silicon and addition elements on the mechanical behavior of ferritic ductile cast iron," Mater. Sci. Eng. A, vol. 605, pp. 222-228, May 2014, doi: 10.1016/j.msea.2014.03.057.

[96] T. Kanno, "Problems and Improvements on the Production of Large Casting with Hi-Si Ductile Iron," Int. J. Met., vol. 13, no. 3, pp. 491-499, Jul. 2019, doi: 10.1007/s40962-018-0283-7.

[97] S. N. Lekakh, V. L. Richards, and N. Medvedeva, "Effect of Si Segregation on Low Temperature Toughness of Ductile Iron,” p. 9, 2012.

[98] X. Guo and D. M. Stefanescu, "Partitioning of alloying elements during the eutectoid transformation of ductile iron," Int. J. Cast Met. Res., vol. 11, no. 5, pp. 437-441, Mar. 1999, doi: 10.1080/13640461.1999.11819313.

[99] G. Jolley, "Microsegregation in Nodular Cast Iron and its Effects on Mechanical Properties," Aston University, Birmingham, England, 1966.

[100] G. Angella, D. Ripamonti, M. Górny, S. Masaggia, and F. Zanardi, "The Role of Microstructure on Tensile Plastic Behavior of Ductile Iron GJS 400 Produced through Different Cooling Rates, Part I: Microstructure," Metals, vol. 9, no. 12, p. 1282, Nov. 2019, doi: 10.3390/met9121282.

[101] Z. Glavas, A. Strkalj, and K. Maldini, "Effects of Antimony and Wall Thickness on Graphite Morphology in Ductile Iron Castings," Metall. Mater. Trans. B, vol. 47, no. 4, pp. 2487-2497, Aug. 2016, doi: 10.1007/s11663-016-0690-1.

[102] H. Megahed, E. El-Kashif, A. Y. Shash, and M. A. Essam, "Effect of holding time, thickness and heat treatment on microstructure and mechanical properties of compacted graphite cast iron," J. Mater. Res. Technol., vol. 8, no. 1, pp. 1188-1196, Jan. 2019, doi: 10.1016/j.jmrt.2018.07.021.

[103] X. G. Diao, Z. L. Ning, F. Y. Cao, S. Z. Ren, and J. F. Sun, "Effects of antimony addition and section size on formation of chunky graphite in ductile iron," Mater. Sci. Technol., vol. 27, no. 4, pp. 834-838, Apr. 2011, doi:

$10.1179 / 026708309 X 12560332736557$.

[104] G. Goodrich, "Fading in Ductile Iron Processing,” Ductile Iron Society, 1, 2013.

[105] E. Fraś and M. Górny, "Fading of inoculation effects in ductile iron," Arch. Foundry Eng., vol. 8, no. 1, pp. 83-88, 2008. 
[106] Z. Glavas, "The Influence of metallic charge on metallurgical quality and properties of ductile iron," Met. Mater., vol. 50, no. 02, pp. 75-82, 2012, doi: 10.4149/km_2012_2_75.

[107] S. Bockus and A. Dobrovolskis, "Melting and modification by producing ductile iron castings," Proc. Est. Acad. Sci. Eng., vol. 10, pp. 10-17, 2004.

[108] S. Bockus and A. Dobrovolskis, "Effect of Melting Techniques on Ductile Iron Casting Properties," Metalurgija, vol. 45, pp. 13-16, 2006.

[109] D. R. Askeland and S. S. Gupta, "Effect of Nodule Count and Cooling Rate on the Matrix of Nodular Cast Iron," AFS Trans, vol. 83, pp. 313-320, 1975.

[110] G. M. Goodrich and D. P. Jones, "Factors Affecting Ductile Iron Nodule Count: A Literature Review," AFS Trans, vol. 101, pp. 1031-1037, 1993.

[111] R. Salazar, M. Herrera-Trejo, M. Castro, J. Mendez, J. Torres, and M. Mendez, "Effect of Nodule Count and Cooling Rate on As-Cast Matrix of a Cu-Mo Spheroidal Graphite," J. Mater. Eng. Perform., vol. 8, pp. 325-329, 1999.

[112] J. M. Tartaglia, R. B. Gundlach, and G. M. Goodrich, "Optimizing StructureProperty Relationships in Ductile Iron,” Int. J. Met., vol. 8, pp. 7-38, 2014, doi: 10.1007/BF03355592.

[113] J. O. T. Adewara and C. R. Loper Jr, "Effect of Carbides on Crack Initiation and Propagation in Ductile Iron," AFS Trans, vol. 84, pp. 507-512, 1976.

[114] K. R. W. Wallin, "Equivalent Charpy-V Impact Criteria for Nodular Cast Iron," Int. J. Met., vol. 8, no. 2, pp. 81-86, Apr. 2014, doi: 10.1007/BF03355584.

[115] R. C. Voigt and L. M. Eldoky, "Crack Initiation and Propagation in As-Cast and Fully Pearlitic Ductile Cast Irons," AFS Trans, vol. 94, pp. 637-644, 1986.

[116] J. O. T. Adewara and C. R. Loper Jr, "Crack Initiation and Propagation in Fully Ferritic Ductile Iron,” AFS Trans, vol. 84, pp. 527-534, 1976.

[117] J. O. T. Adewara and C. R. Loper Jr, "Effect of Pearlite on Crack Initiation and Propagation in Ductile Iron," AFS Trans, vol. 84, pp. 513-526, 1976.

[118] M. Caldera, M. Chapetti, J. M. Massone, and J. A. Sikora, "Fatigue propagation of long cracks in ferritic thin wall ductile iron castings," Mater. Sci. Technol., vol. 26, no. 9, pp. 1102-1107, Sep. 2010, doi: 10.1179/174328409X433822.

[119] L. Eldoky and R. C. Voigt, "Fracture of Ferritic Ductile Cast Iron," AFS Trans, vol. 93, pp. 365-372, 1985.

[120] M. F. Hafiz, A. Hammouda, and S. El-Gemae, "Impact Properties and Fractography of Spheroidal Graphite Cast Irons," p. 12, 2005. 
[121] I. Mogford, I. Brown, and D. Hull, "Fracture of Nodular Cast Iron," J. Iron Steel Inst., vol. 205, pp. 729-732, 1967.

[122] R. Salzbrenner and K. Sorenson, "Relationship of Fracture Toughness to Microstructure in Ferritic Ductile Cast Iron," AFS Trans., pp. 757-764, 1987.

[123] T. Månsson and F. Nilsson, "Nodule influence on fatigue crack growth thresholds in nodular cast iron," Int. J. Cast Met. Res., pp. 319-325, 1999.

[124] A04 Committee, "Standard Test Method for Evaluating the Microstructure of Graphite in Iron Castings," ASTM International.

[125] P. Čanžar, Z. Tonković, and J. Kodvanj, "Microstructure influence on fatigue behaviour of nodular cast iron," Mater. Sci. Eng. A, vol. 556, pp. 88-99, Oct. 2012, doi: 10.1016/j.msea.2012.06.062.

[126] S. Sujakhu et al., "On the fatigue damage micromechanisms in Si-solutionstrengthened spheroidal graphite cast iron," Fatigue Fract. Eng. Mater. Struct., vol. 41, no. 3, pp. 625-641, Mar. 2018, doi: 10.1111/ffe.12723.

[127] D. W. Clegg and R. A. Buckley, "The Disorder $\rightarrow$ Order Transformation in IronCobalt-Based Alloys,” Met. Sci. J., vol. 7, no. 1, pp. 48-54, Jan. 1973, doi: 10.1179/030634573790445541.

[128] M. Fukaya, T. Miyazaki, and T. Kozakai, "Phase diagrams calculated for Fe-rich Fe-Si-Co and Fe-Si-AI ordering alloy systems," p. 7.

[129] P. Weiß, A. Tekavčič, and A. Bührig-Polaczek, "Mechanistic approach to new design concepts for high silicon ductile iron," Mater. Sci. Eng. A, vol. 713, pp. 6774, Jan. 2018, doi: 10.1016/j.msea.2017.12.012. 


\section{A Metallography of As-cast Thin Wall Ductile Iron}

\section{A.1 Etched Micrographs}

\section{A.1.1 $2 \mathrm{~mm}$ section at $200 \mathrm{x}$}

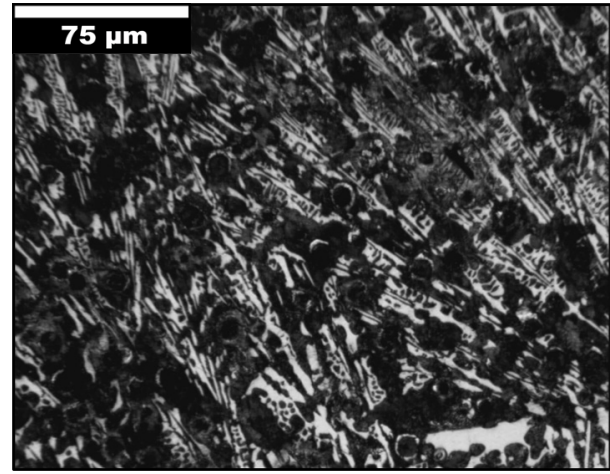

(a) Base DI

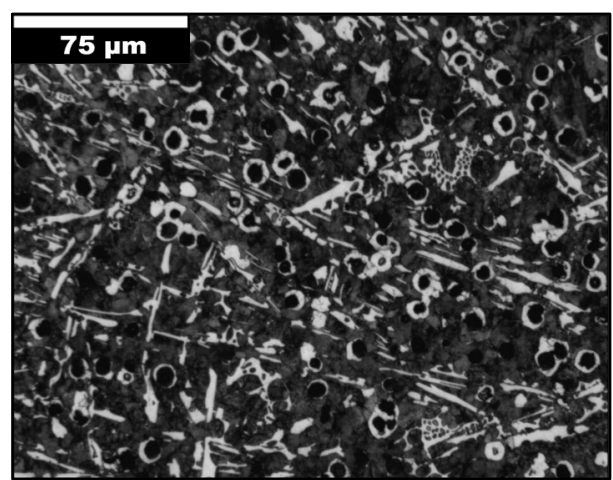

(c) 2 wt. $\% \mathrm{Co}$

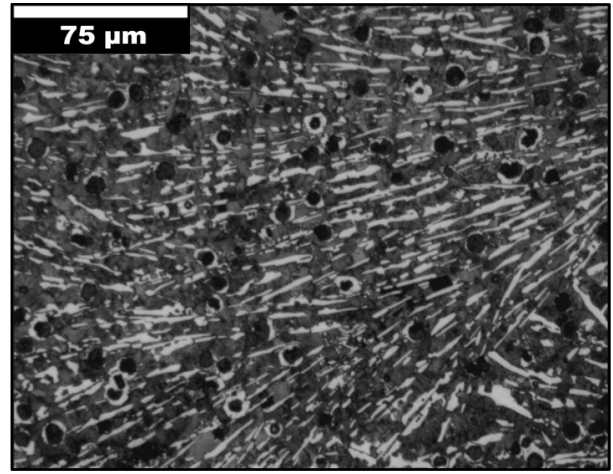

(b) 1 wt. $\% \mathrm{Co}$

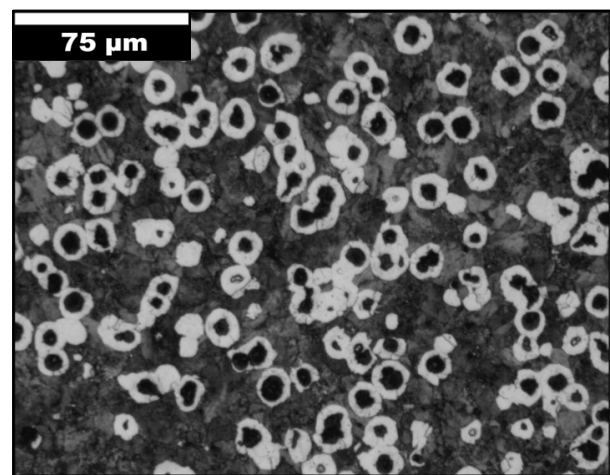

(d) 3 wt. $\% \mathrm{Co}$

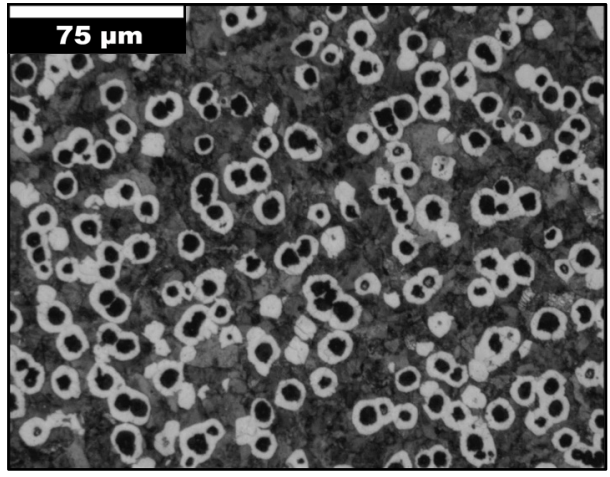

(e) 4 wt. \% Co 


\section{A.1.2 $2.5 \mathrm{~mm}$ section at $200 \mathrm{x}$}
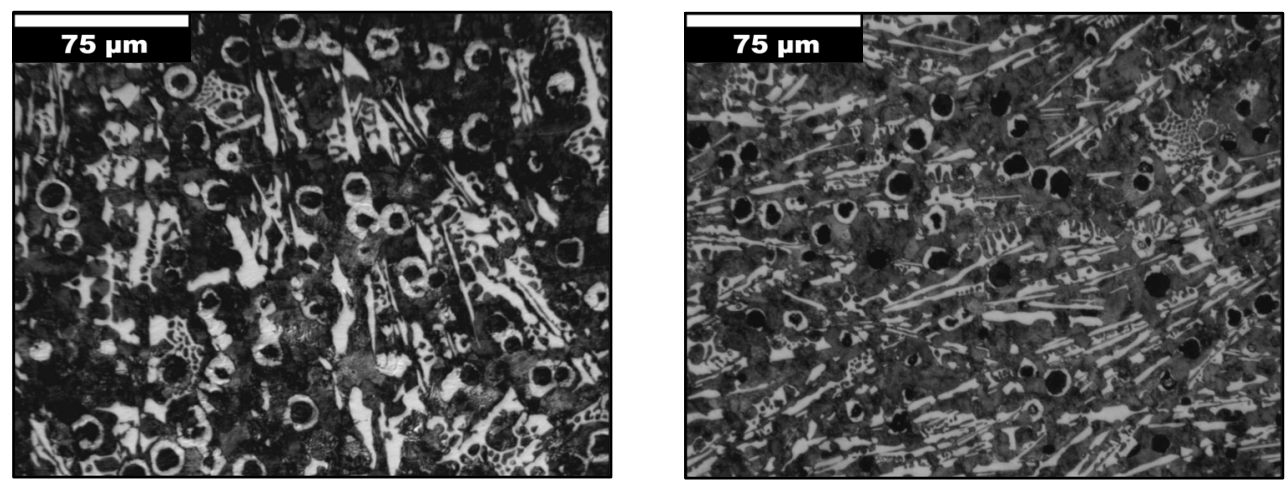

(a) Base DI

(b) 1 wt. \% Co

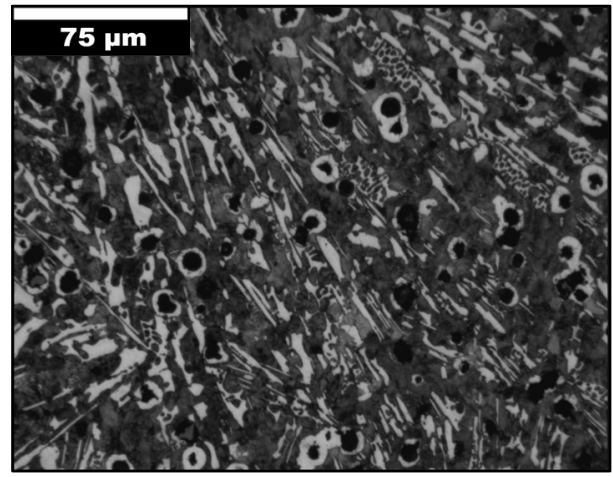

(c) 2 wt. $\% \mathrm{Co}$

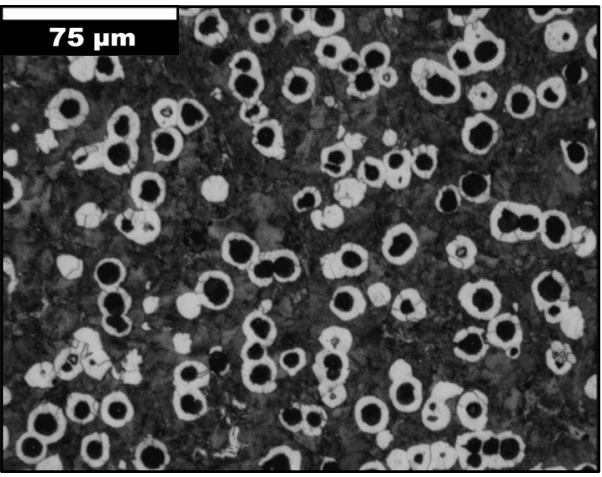

(d) 3 wt. $\%$ Co

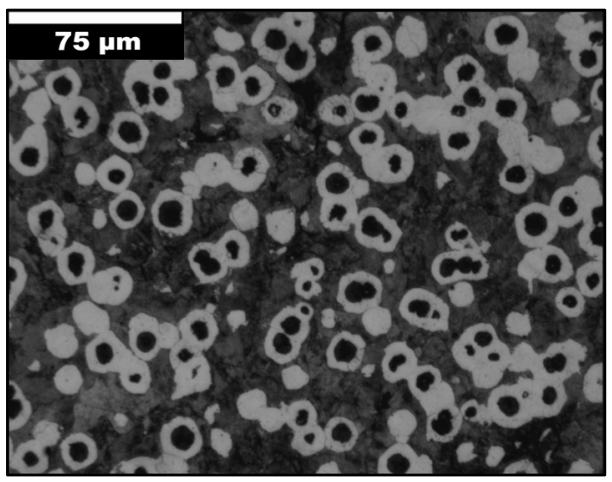

(e) 4 wt. \% Co 


\section{A.1.3 $3 \mathrm{~mm}$ section at $200 x$}

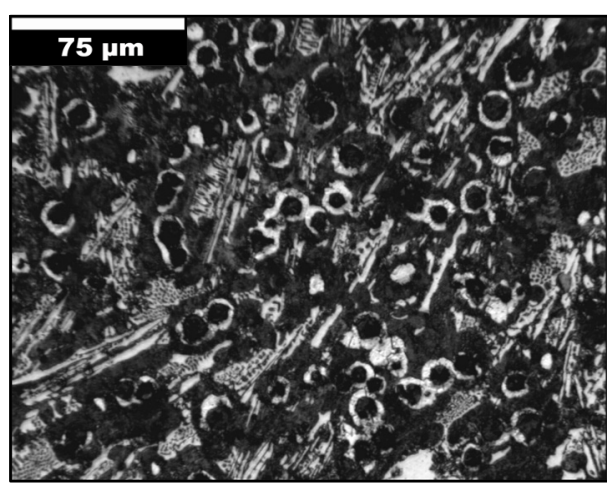

(a) Base DI

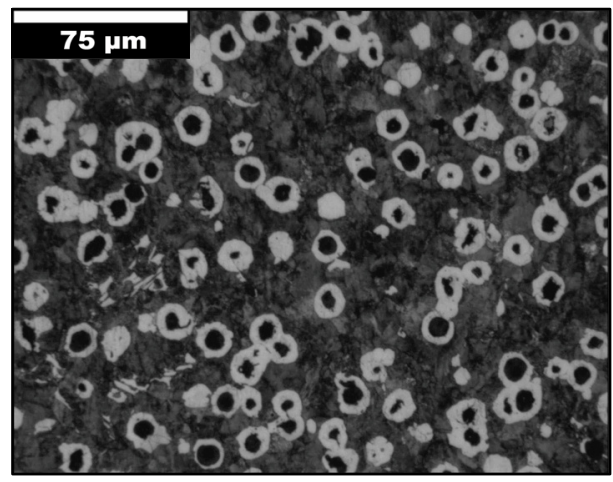

(c) 2 wt. $\% \mathrm{Co}$

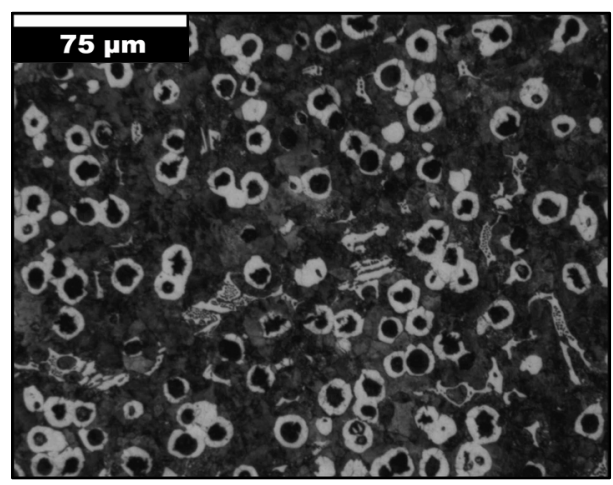

(b) 1 wt.\% Co

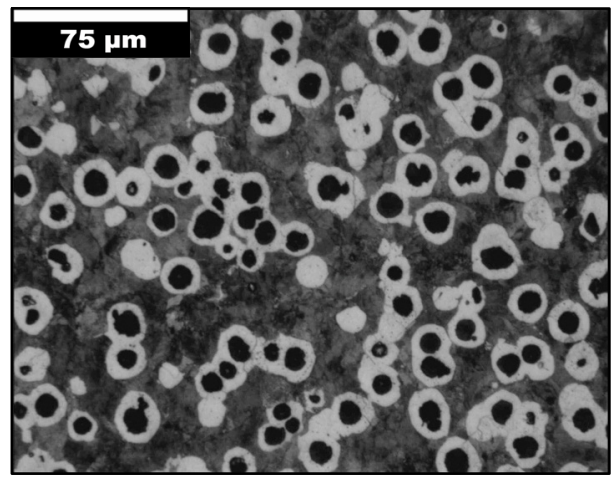

(d) 3 wt. \% Co

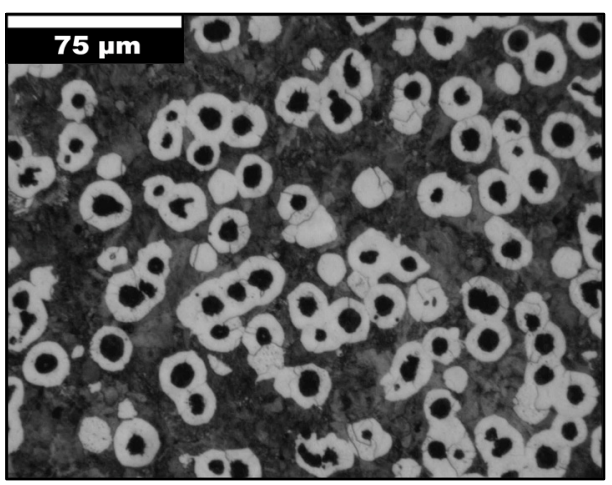

(e) 4 wt. $\%$ Co 


\section{A.1.4 $3.5 \mathrm{~mm}$ section at $200 \mathrm{x}$}

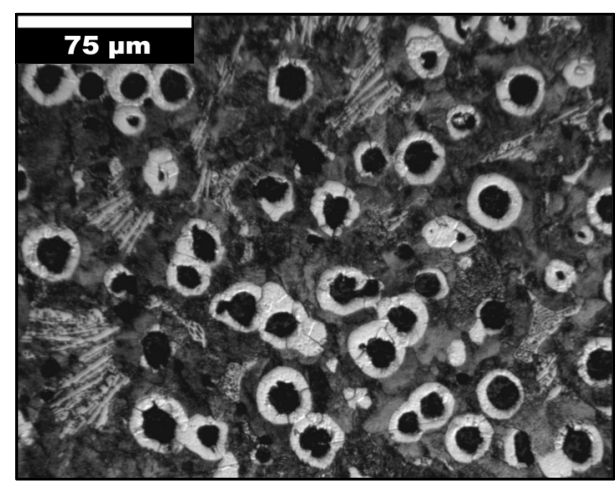

(a) Base DI

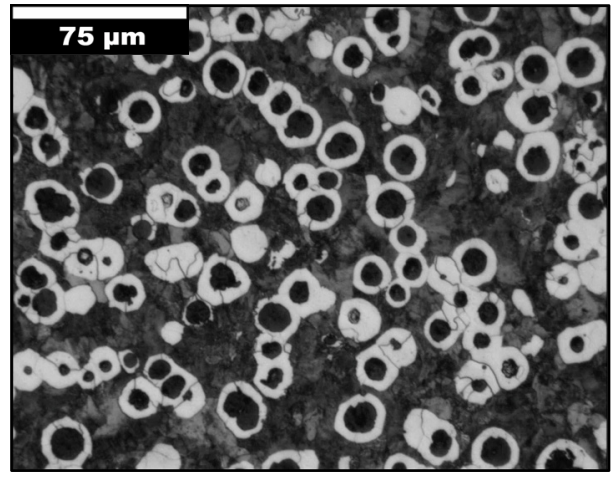

(c) 2 wt. $\% \mathrm{Co}$

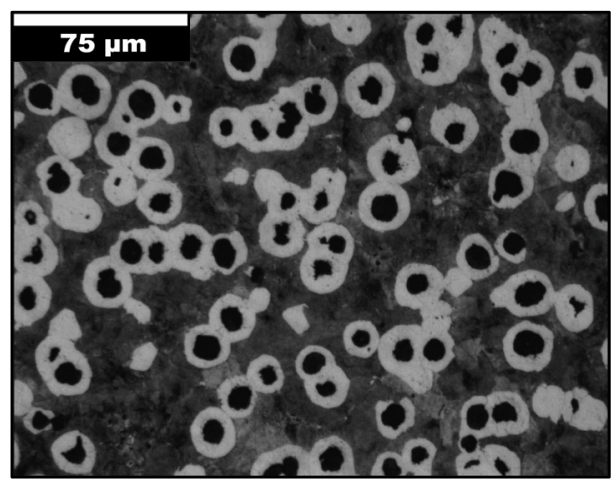

(b) 1 wt. $\% \mathrm{Co}$

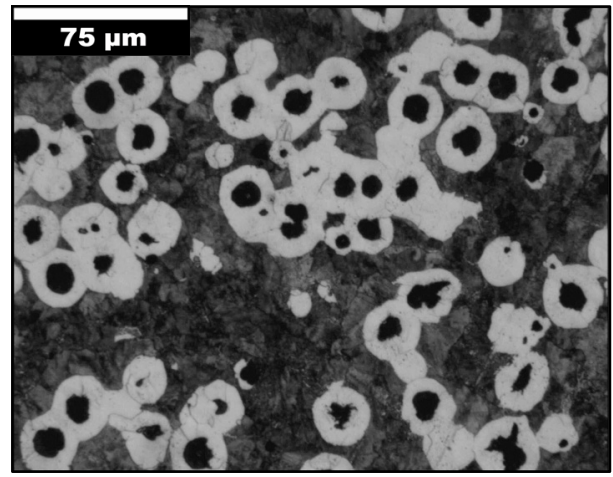

(d) 3 wt. $\%$ Co

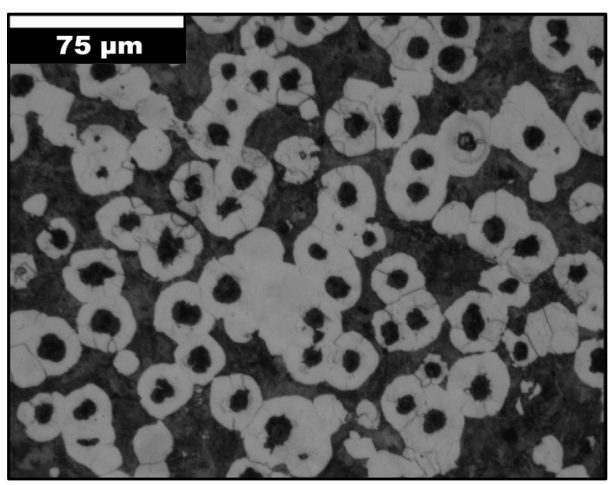

(e) 4 wt. \% Co 


\section{A.1.5 $4 \mathrm{~mm}$ section at $200 \mathrm{x}$}

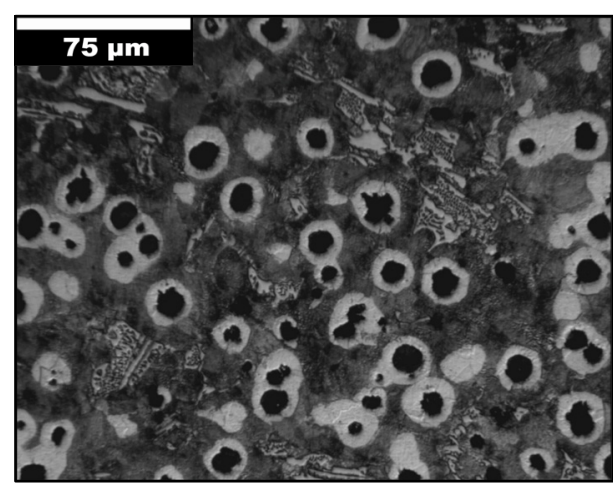

(a) Base DI

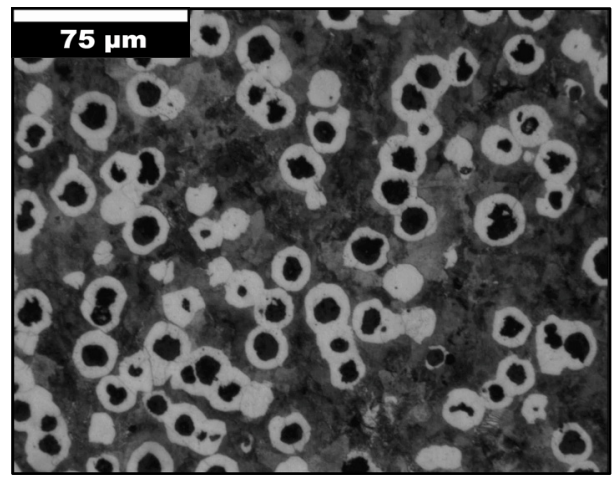

(c) 2 wt. $\% \mathrm{Co}$

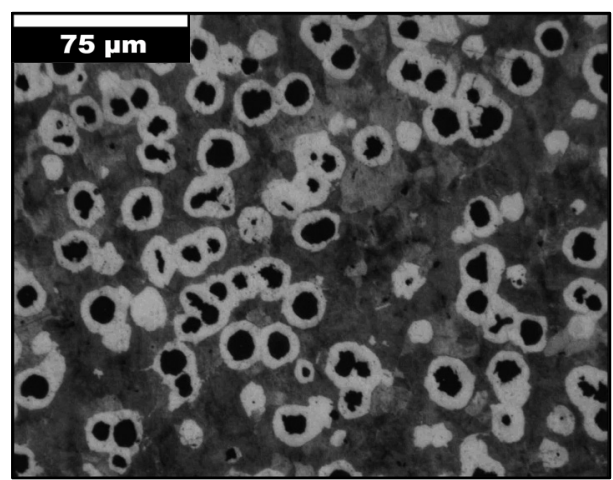

(b) 1 wt. $\% \mathrm{Co}$

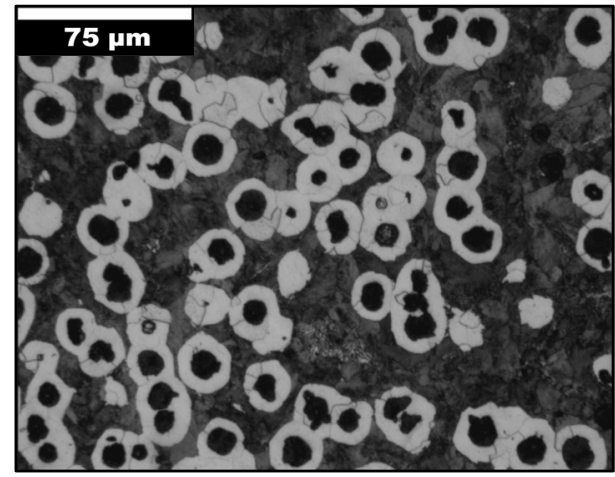

(d) 3 wt.\% Co

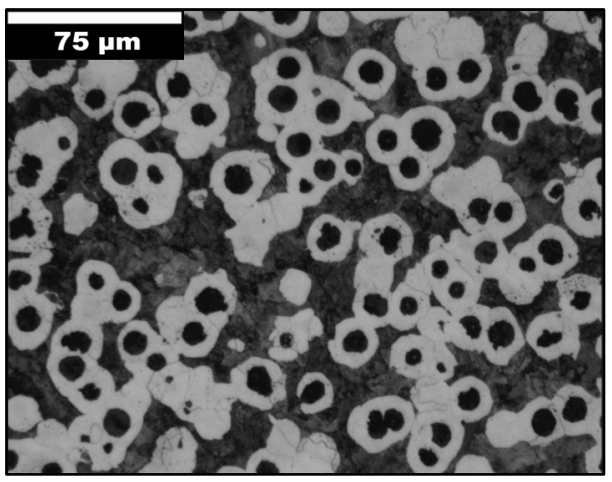

(e) 4 wt. \% Co 


\section{A.1.6 $6 \mathrm{~mm}$ section at $200 \mathrm{x}$}

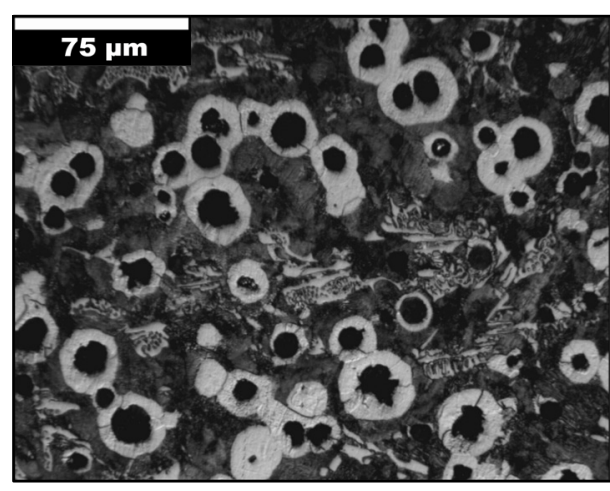

(a) Base DI

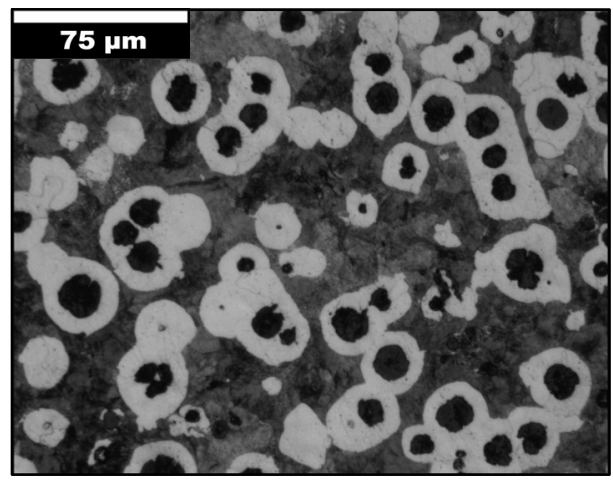

(c) 2 wt. $\% \mathrm{Co}$

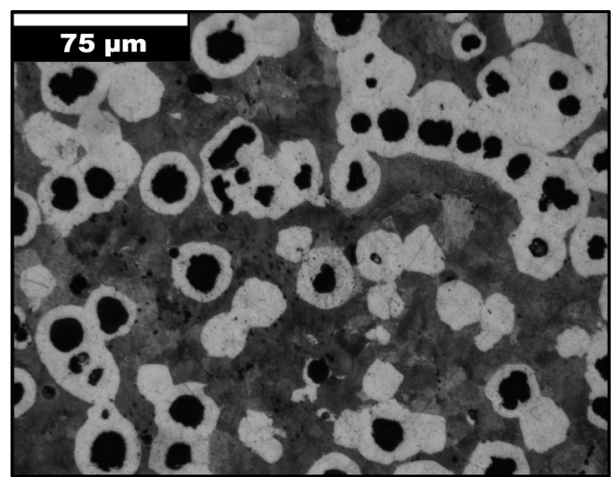

(b) 1 wt.\% Co

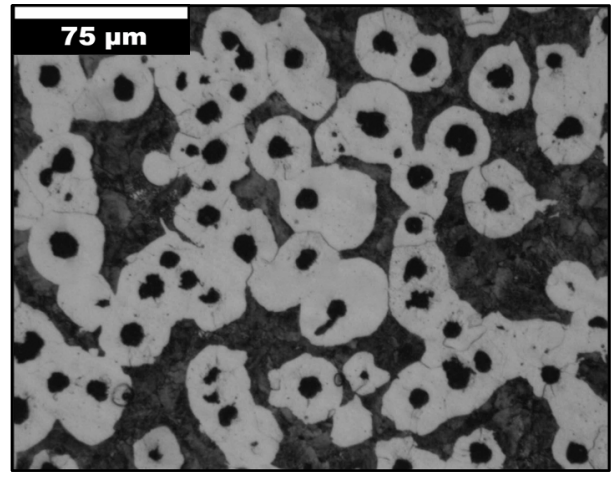

(d) 3 wt. $\%$ Co

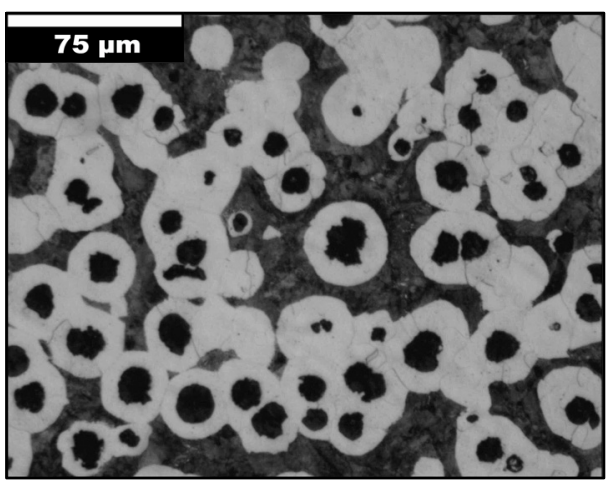

(e) 4 wt.\% Co 


\section{B $\quad$ Minitab ${ }^{\circledR}$ Statistical Software Results \\ B.1 Effect of Cobalt in Thin Wall Ductile Iron \\ B.1.1 General Linear Model: Nodule Count versus Co Level, Thickness (mm)}

Method

Factor coding $(-1,0,+1)$

Factor Information

\begin{tabular}{llcc} 
Factor & Type & Levels & Values \\
\hline Co Level & Fixed & 5 & $0,1,2,3,4$ \\
Thickness (mm) & Fixed & 6 & $2.0,2.5,3.0,3.5,4.0,6.0$
\end{tabular}

Analysis of Variance

\begin{tabular}{lccccc} 
Source & DF & Adj SS & Adj MS & F-Value & P-Value \\
\hline Co Level & 4 & 2236201 & 559050 & 84.37 & 0.000 \\
Thickness (mm) & 5 & 9574685 & 1914937 & 288.98 & 0.000 \\
Co Level*Thickness (mm) & 20 & 1952255 & 97613 & 14.73 & 0.000 \\
Error & 270 & 1789167 & 6627 & & \\
Total & 299 & 15552307 & & &
\end{tabular}

Model Summary

\begin{tabular}{cccc} 
S & R-sq & R-sq(adj) & R-sq(pred) \\
\hline 81.4036 & $88.50 \%$ & $87.26 \%$ & $85.80 \%$
\end{tabular}

\section{Coefficients}

\begin{tabular}{lccccc} 
Term & Coef & SE Coef & T-Value & P-Value & VIF \\
\hline Constant & 939.66 & 4.70 & 199.93 & 0.000 & \\
Co Level & & & & & \\
0 & -6.03 & 9.40 & -0.64 & 0.522 & 1.60 \\
1 & -95.88 & 9.40 & -10.20 & 0.000 & 1.60 \\
2 & -3.08 & 9.40 & -0.33 & 0.744 & 1.60 \\
3 & -53.63 & 9.40 & -5.71 & 0.000 & 1.60 \\
4 & 158.61 & 9.40 & 16.87 & 0.000 & $*$ \\
Thickness (mm) & & & & & \\
2.0 & 326.8 & 10.5 & 31.10 & 0.000 & 1.67 \\
2.5 & 67.8 & 10.5 & 6.45 & 0.000 & 1.67 \\
3.0 & 29.9 & 10.5 & 2.85 & 0.005 & 1.67 \\
3.5 & -144.2 & 10.5 & -13.72 & 0.000 & 1.67 \\
4.0 & -42.5 & 10.5 & -4.04 & 0.000 & 1.67 \\
6.0 & -237.9 & 10.5 & -22.63 & 0.000 & $*$ \\
& & 171 & & &
\end{tabular}


Co Level*Thickness (mm)

\begin{tabular}{|c|c|c|c|c|}
\hline 02.0 & 99.8 & 21.0 & 4.75 & 0.000 \\
\hline 02.5 & -57.7 & 21.0 & -2.75 & 0.006 \\
\hline 03.0 & 37.9 & 21.0 & 1.81 & 0.072 \\
\hline 03.5 & 40.4 & 21.0 & 1.92 & 0.056 \\
\hline 04.0 & -80.2 & 21.0 & -3.82 & 0.000 \\
\hline 06.0 & -40.2 & 21.0 & -1.91 & 0.057 \\
\hline 12.0 & -190.3 & 21.0 & -9.06 & 0.000 \\
\hline 12.5 & 29.6 & 21.0 & 1.41 & 0.160 \\
\hline 13.0 & 13.0 & 21.0 & 0.62 & 0.537 \\
\hline 13.5 & 7.8 & 21.0 & 0.37 & 0.710 \\
\hline 14.0 & 73.6 & 21.0 & 3.50 & 0.001 \\
\hline 16.0 & 66.3 & 21.0 & 3.15 & 0.002 \\
\hline 22.0 & 61.7 & 21.0 & 2.93 & 0.004 \\
\hline 22.5 & -170.6 & 21.0 & -8.12 & 0.000 \\
\hline 23.0 & -4.7 & 21.0 & -0.22 & 0.823 \\
\hline 23.5 & 51.2 & 21.0 & 2.44 & 0.015 \\
\hline 24.0 & 12.9 & 21.0 & 0.61 & 0.539 \\
\hline 26.0 & 49.5 & 21.0 & 2.35 & 0.019 \\
\hline 32.0 & -85.1 & 21.0 & -4.05 & 0.000 \\
\hline 32.5 & 144.2 & 21.0 & 6.86 & 0.000 \\
\hline 33.0 & 64.6 & 21.0 & 3.08 & 0.002 \\
\hline 33.5 & -37.4 & 21.0 & -1.78 & 0.076 \\
\hline 34.0 & -86.8 & 21.0 & -4.13 & 0.000 \\
\hline 36.0 & 0.5 & 21.0 & 0.03 & 0.980 \\
\hline 42.0 & 113.9 & 21.0 & 5.42 & 0.000 \\
\hline 42.5 & 54.5 & 21.0 & 2.59 & 0.010 \\
\hline 43.0 & -110.9 & 21.0 & -5.28 & 0.000 \\
\hline 43.5 & -62.0 & 21.0 & -2.95 & 0.003 \\
\hline 44.0 & 80.5 & 21.0 & 3.83 & 0.000 \\
\hline 46.0 & -76.1 & 21.0 & -3.62 & 0.000 \\
\hline
\end{tabular}

\section{Regression Equation}

Nodule $=939.66-6.03$ Co Level_0

Count $\quad$ 95.88 Co Level_1 - 3.08 Co Level_2

- 53.63 Co Level_3 + 158.61 Co Level_4

+326.8 Thickness (mm)_2.0

+67.8 Thickness $(\mathrm{mm}) \_2.5$

+ 29.9 Thickness (mm)_3.0

- 144.2 Thickness (mm)_3.5

- 42.5 Thickness (mm) 4.0

- 237.9 Thickness (mm) 6.0

+ 99.8 Co Level*Thickness (mm)_0 2.0 
- 57.7 Co Level*Thickness (mm)_0 2.5

+ 37.9 Co Level*Thickness (mm) 03.0

+ 40.4 Co Level*Thickness (mm)_0 3.5

- 80.2 Co Level*Thickness (mm)_0 4.0

- 40.2 Co Level*Thickness (mm)_0 6.0

- 190.3 Co Level*Thickness (mm)_1 2.0

+ 29.6 Co Level*Thickness (mm)_1 2.5

+ 13.0 Co Level*Thickness (mm)_13.0

+ 7.8 Co Level*Thickness (mm)_1 3.5

+ 73.6 Co Level*Thickness (mm)_1 4.0

+ 66.3 Co Level*Thickness (mm)_1 6.0

+ 61.7 Co Level*Thickness (mm)_2 2.0

- 170.6 Co Level*Thickness (mm)_2 2.5

- 4.7 Co Level*Thickness (mm)_2 3.0

+ 51.2 Co Level*Thickness (mm)_2 3.5

+ 12.9 Co Level*Thickness (mm)_2 4.0

+ 49.5 Co Level*Thickness (mm)_26.0

- 85.1 Co Level*Thickness (mm)_3 2.0

+ 144.2 Co Level*Thickness (mm)_3 2.5

+ 64.6 Co Level*Thickness (mm) 33.0

- 37.4 Co Level*Thickness (mm)_3 3.5

- 86.8 Co Level*Thickness (mm)_3 4.0

+ 0.5 Co Level*Thickness $(\mathrm{mm}) \_36.0$

+ 113.9 Co Level*Thickness (mm)_4 2.0

+ 54.5 Co Level*Thickness (mm) 42.5

- 110.9 Co Level*Thickness (mm)_4 3.0

- 62.0 Co Level*Thickness (mm)_4 3.5

+80.5 Co Level*Thickness (mm)_4 4.0

- 76.1 Co Level*Thickness (mm)_4 6.0

Fits and Diagnostics for Unusual Observations

\begin{tabular}{ccccr} 
Obs & Nodule Count & Fit & Resid & \multicolumn{1}{c}{ Std Resid } \\
\hline 7 & 1516.0 & 1360.3 & 155.7 & $2.02 \mathrm{R}$ \\
31 & 1220.0 & 829.8 & 390.2 & $5.05 \mathrm{R}$ \\
41 & 1112.0 & 810.9 & 301.1 & $3.90 \mathrm{R}$ \\
51 & 823.0 & 655.6 & 167.4 & $2.17 \mathrm{R}$ \\
72 & 1122.0 & 941.2 & 180.8 & $2.34 \mathrm{R}$ \\
90 & 722.0 & 886.7 & -164.7 & $-2.13 \mathrm{R}$ \\
111 & 853.0 & 672.2 & 180.8 & $2.34 \mathrm{R}$
\end{tabular}

$R$ Large residual 


\section{B.1.2 General Linear Model: Ferrite versus Co Level, Thickness (mm) Method \\ Factor coding $(-1,0,+1)$}

Factor Information

\begin{tabular}{lccc} 
Factor & Type & Levels & Values \\
\hline Co Level & Fixed & 5 & $0,1,2,3,4$ \\
Thickness (mm) & Fixed & 6 & $2.0,2.5,3.0,3.5,4.0,6.0$
\end{tabular}

Analysis of Variance

\begin{tabular}{lccccc} 
Source & DF & Adj SS & Adj MS & F-Value & P-Value \\
\hline Co Level & 4 & 32404 & 8100.90 & 158.01 & 0.000 \\
Thickness (mm) & 5 & 20259 & 4051.77 & 79.03 & 0.000 \\
Co Level*Thickness (mm) & 20 & 4109 & 205.46 & 4.01 & 0.000 \\
Error & 270 & 13842 & 51.27 & & \\
Total & 299 & 70614 & & &
\end{tabular}

\section{Model Summary}

\begin{tabular}{cccc} 
S & R-sq & R-sq(adj) & R-sq(pred) \\
\hline 7.16015 & $80.40 \%$ & $78.29 \%$ & $75.80 \%$
\end{tabular}

\section{Coefficients}

\begin{tabular}{lccccc} 
Term & Coef & SE Coef & T-Value & P-Value VIF \\
\hline Constant & 30.130 & 0.413 & 72.88 & 0.000 & \\
Co Level & & & & & \\
0 & -9.147 & 0.827 & -11.06 & 0.000 & 1.60 \\
1 & -8.080 & 0.827 & -9.77 & 0.000 & 1.60 \\
2 & -6.797 & 0.827 & -8.22 & 0.000 & 1.60 \\
3 & 6.703 & 0.827 & 8.11 & 0.000 & 1.60 \\
4 & 17.320 & 0.827 & 20.95 & 0.000 & $*$ \\
Thickness (mm) & & & & & \\
2.0 & -12.090 & 0.924 & -13.08 & 0.000 & 1.67 \\
2.5 & -8.450 & 0.924 & -9.14 & 0.000 & 1.67 \\
3.0 & -1.390 & 0.924 & -1.50 & 0.134 & 1.67 \\
3.5 & 6.290 & 0.924 & 6.80 & 0.000 & 1.67 \\
4.0 & 4.370 & 0.924 & 4.73 & 0.000 & 1.67 \\
6.0 & 11.270 & 0.924 & 12.19 & 0.000 & $*$ \\
Co Level*Thickness (mm) & & & & & \\
02.0 & 3.61 & 1.85 & 1.95 & 0.052 & 2.67 \\
02.5 & 1.17 & 1.85 & 0.63 & 0.529 & 2.67 \\
03.0 & -0.79 & 1.85 & -0.43 & 0.668 & 2.67 \\
& & 174 & & &
\end{tabular}




$\begin{array}{llccccc}0 & 3.5 & 2.23 & 1.85 & 1.20 & 0.229 & 2.67 \\ 0 & 4.0 & 0.15 & 1.85 & 0.08 & 0.937 & 2.67 \\ 0 & 6.0 & -6.35 & 1.85 & -3.44 & 0.001 & * \\ 1 & 2.0 & -1.26 & 1.85 & -0.68 & 0.496 & 2.67 \\ 1 & 2.5 & -7.30 & 1.85 & -3.95 & 0.000 & 2.67 \\ 1 & 3.0 & 2.34 & 1.85 & 1.27 & 0.207 & 2.67 \\ 1 & 3.5 & 2.46 & 1.85 & 1.33 & 0.184 & 2.67 \\ 1 & 4.0 & 3.58 & 1.85 & 1.94 & 0.054 & 2.67 \\ 1 & 6.0 & 0.18 & 1.85 & 0.10 & 0.923 & * \\ 2 & 2.0 & -4.94 & 1.85 & -2.67 & 0.008 & 2.67 \\ 2 & 2.5 & -4.18 & 1.85 & -2.26 & 0.024 & 2.67 \\ 2 & 3.0 & -1.24 & 1.85 & -0.67 & 0.502 & 2.67 \\ 2 & 3.5 & 1.38 & 1.85 & 0.74 & 0.457 & 2.67 \\ 2 & 4.0 & 3.50 & 1.85 & 1.89 & 0.060 & 2.67 \\ 2 & 6.0 & 5.50 & 1.85 & 2.97 & 0.003 & * \\ 3 & 2.0 & 0.56 & 1.85 & 0.30 & 0.764 & 2.67 \\ 3 & 2.5 & 0.12 & 1.85 & 0.06 & 0.950 & 2.67 \\ 3 & 3.0 & -0.84 & 1.85 & -0.46 & 0.649 & 2.67 \\ 3 & 3.5 & -0.82 & 1.85 & -0.45 & 0.656 & 2.67 \\ 3 & 4.0 & -0.90 & 1.85 & -0.49 & 0.626 & 2.67 \\ 3 & 6.0 & 1.90 & 1.85 & 1.03 & 0.306 & * \\ 4 & 2.0 & 2.04 & 1.85 & 1.10 & 0.271 & * \\ 4 & 2.5 & 10.20 & 1.85 & 5.52 & 0.000 & * \\ 43.0 & 0.54 & 1.85 & 0.29 & 0.770 & * \\ 43.5 & -5.24 & 1.85 & -2.83 & 0.005 & * \\ 4 & 4.0 & -6.32 & 1.85 & -3.42 & 0.001 & * \\ 4 & 6.0 & -1.22 & 1.85 & -0.66 & 0.510 & *\end{array}$

\section{Regression Equation}

$$
\begin{aligned}
\text { Ferrite }= & 30.130-9.147 \text { Co Level_0 } \\
& -8.080 \text { Co Level_1 - 6.797 Co Level_2 } \\
& +6.703 \text { Co Level_3 } \\
& +17.320 \text { Co Level_4 } \\
& -12.090 \text { Thickness }(\mathrm{mm}) \_2.0 \\
& -8.450 \text { Thickness }(\mathrm{mm}) \_2.5 \\
& -1.390 \text { Thickness }(\mathrm{mm}) \_3.0 \\
& +6.290 \text { Thickness }(\mathrm{mm}) \_3.5 \\
& +4.370 \text { Thickness }(\mathrm{mm}) \_4.0 \\
& +11.270 \text { Thickness }(\mathrm{mm}) \_6.0 \\
& +3.61 \text { Co Level*Thickness }(\mathrm{mm}) \_02.0 \\
& +1.17 \text { Co Level*Thickness }(\mathrm{mm}) \_02.5 \\
& -0.79 \text { Co Level*Thickness }(\mathrm{mm}) \_03.0 \\
& +2.23 \text { Co Level*Thickness }(\mathrm{mm}) \_03.5
\end{aligned}
$$


+ 0.15 Co Level*Thickness (mm)_0 4.0

- 6.35 Co Level*Thickness (mm)_0 6.0

- 1.26 Co Level*Thickness (mm)_1 2.0

- 7.30 Co Level*Thickness (mm)_1 2.5

+ 2.34 Co Level*Thickness (mm)_1 3.0

+ 2.46 Co Level*Thickness (mm)_1 3.5

+ 3.58 Co Level*Thickness (mm)_1 4.0

+0.18 Co Level*Thickness (mm)_1 6.0

- 4.94 Co Level*Thickness (mm)_2 2.0

- 4.18 Co Level*Thickness (mm)_2 2.5

- 1.24 Co Level*Thickness (mm)_2 3.0

+ 1.38 Co Level*Thickness (mm)_2 $3.5^{*}$

+ 3.50 Co Level*Thickness (mm) 24.0

+ 5.50 Co Level*Thickness (mm) 26.0

+ 0.56 Co Level*Thickness (mm)_3 2.0

+ 0.12 Co Level*Thickness (mm) 32.5

- 0.84 Co Level*Thickness (mm)_3 3.0

- 0.82 Co Level*Thickness (mm)_3 3.5

- 0.90 Co Level*Thickness (mm)_3 4.0

+1.90 Co Level*Thickness (mm) 36.0

+ 2.04 Co Level*Thickness (mm) 42.0

+10.20 Co Level*Thickness (mm) 42.5

+0.54 Co Level*Thickness (mm)_4 3.0

- 5.24 Co Level*Thickness (mm) 43.5

- 6.32 Co Level*Thickness (mm)_4 4.0

- 1.22 Co Level*Thickness (mm)_4 6.0

Fits and Diagnostics for Unusual Observations

\begin{tabular}{ccccc} 
Obs & Ferrite & Fit & Resid & Std Resid \\
\hline 49 & 41.00 & 25.50 & 15.50 & $2.28 \mathrm{R}$ \\
81 & 5.00 & 23.00 & -18.00 & $-2.65 \mathrm{R}$ \\
91 & 3.00 & 30.80 & -27.80 & $-4.09 \mathrm{R}$ \\
101 & 9.00 & 30.00 & -21.00 & $-3.09 \mathrm{R}$ \\
102 & 16.00 & 30.00 & -14.00 & $-2.06 \mathrm{R}$ \\
141 & 0.00 & 20.70 & -20.70 & $-3.05 \mathrm{R}$ \\
151 & 15.00 & 31.00 & -16.00 & $-2.36 \mathrm{R}$ \\
181 & 2.00 & 25.30 & -23.30 & $-3.43 \mathrm{R}$ \\
191 & 3.00 & 28.50 & -25.50 & $-3.75 \mathrm{R}$ \\
201 & 11.00 & 34.60 & -23.60 & $-3.47 \mathrm{R}$ \\
251 & 35.00 & 49.20 & -14.20 & $-2.09 \mathrm{R}$ \\
261 & 32.00 & 46.60 & -14.60 & $-2.15 \mathrm{R}$
\end{tabular}

$R$ Large residual 


\section{B.1.3 General Linear Model: Pearlite versus Co Level, Thickness (mm) Method \\ Factor coding $(-1,0,+1)$}

Factor Information

\begin{tabular}{lccc}
\multicolumn{1}{c}{ Factor } & Type & Levels & Values \\
\hline Co Level & Fixed & 5 & $0,1,2,3,4$ \\
Thickness (mm) & Fixed & 6 & $2.0,2.5,3.0,3.5,4.0,6.0$
\end{tabular}

Analysis of Variance

\begin{tabular}{lccccc} 
Source & DF & Adj SS & Adj MS & F-Value & P-Value \\
\hline Co Level & 4 & 8132 & 2032.98 & 49.48 & 0.000 \\
Thickness (mm) & 5 & 2948 & 589.62 & 14.35 & 0.000 \\
Co Level*Thickness (mm) & 20 & 5360 & 268.00 & 6.52 & 0.000 \\
Error & 270 & 11095 & 41.09 & & \\
Total & 299 & 27535 & & &
\end{tabular}

\section{Model Summary}

\begin{tabular}{cccc} 
S & R-sq & R-sq(adj) & R-sq(pred) \\
\hline 6.41021 & $59.71 \%$ & $55.38 \%$ & $50.26 \%$
\end{tabular}

\section{Coefficients}

\begin{tabular}{lccccc} 
Term & Coef & SE Coef & T-Value & P-Value VIF \\
\hline Constant & 60.910 & 0.370 & 164.58 & 0.000 & \\
Co Level & & & & & \\
0 & 6.140 & 0.740 & 8.30 & 0.000 & 1.60 \\
1 & -0.493 & 0.740 & -0.67 & 0.506 & 1.60 \\
2 & 3.840 & 0.740 & 5.19 & 0.000 & 1.60 \\
3 & -0.393 & 0.740 & -0.53 & 0.596 & 1.60 \\
4 & -9.093 & 0.740 & -12.29 & 0.000 & $*$ \\
Thickness (mm) & & & & & \\
2.0 & 1.970 & 0.828 & 2.38 & 0.018 & 1.67 \\
2.5 & -1.030 & 0.828 & -1.24 & 0.214 & 1.67 \\
3.0 & 4.330 & 0.828 & 5.23 & 0.000 & 1.67 \\
3.5 & -1.090 & 0.828 & -1.32 & 0.189 & 1.67 \\
4.0 & 1.470 & 0.828 & 1.78 & 0.077 & 1.67 \\
6.0 & -5.650 & 0.828 & -6.83 & 0.000 & $*$ \\
Co Level*Thickness (mm) & & & & & \\
02.0 & -0.12 & 1.66 & -0.07 & 0.942 & 2.67 \\
02.5 & -8.42 & 1.66 & -5.09 & 0.000 & 2.67 \\
03.0 & 4.22 & 1.66 & 2.55 & 0.011 & 2.67 \\
& & 177 & & &
\end{tabular}




$\begin{array}{llccccc}0 & 3.5 & -1.76 & 1.66 & -1.06 & 0.289 & 2.67 \\ 0 & 4.0 & -0.72 & 1.66 & -0.44 & 0.664 & 2.67 \\ 0 & 6.0 & 6.80 & 1.66 & 4.11 & 0.000 & * \\ 1 & 2.0 & -8.49 & 1.66 & -5.13 & 0.000 & 2.67 \\ 1 & 2.5 & -2.99 & 1.66 & -1.80 & 0.072 & 2.67 \\ 1 & 3.0 & 0.95 & 1.66 & 0.58 & 0.565 & 2.67 \\ 1 & 3.5 & 3.67 & 1.66 & 2.22 & 0.027 & 2.67 \\ 1 & 4.0 & 2.61 & 1.66 & 1.58 & 0.116 & 2.67 \\ 1 & 6.0 & 4.23 & 1.66 & 2.56 & 0.011 & * \\ 2 & 2.0 & -4.62 & 1.66 & -2.79 & 0.006 & 2.67 \\ 2 & 2.5 & 4.68 & 1.66 & 2.83 & 0.005 & 2.67 \\ 2 & 3.0 & -0.48 & 1.66 & -0.29 & 0.772 & 2.67 \\ 2 & 3.5 & 1.84 & 1.66 & 1.11 & 0.267 & 2.67 \\ 2 & 4.0 & 0.68 & 1.66 & 0.41 & 0.682 & 2.67 \\ 2 & 6.0 & -2.10 & 1.66 & -1.27 & 0.206 & * \\ 3 & 2.0 & 6.11 & 1.66 & 3.69 & 0.000 & 2.67 \\ 3 & 2.5 & 7.31 & 1.66 & 4.42 & 0.000 & 2.67 \\ 3 & 3.0 & -0.85 & 1.66 & -0.51 & 0.609 & 2.67 \\ 3 & 3.5 & -3.93 & 1.66 & -2.37 & 0.018 & 2.67 \\ 3 & 4.0 & -3.29 & 1.66 & -1.99 & 0.048 & 2.67 \\ 3 & 6.0 & -5.37 & 1.66 & -3.24 & 0.001 & * \\ 4 & 2.0 & 7.11 & 1.66 & 4.30 & 0.000 & * \\ 42.5 & -0.59 & 1.66 & -0.35 & 0.723 & * \\ 43.0 & -3.85 & 1.66 & -2.32 & 0.021 & * \\ 4 & 3.5 & 0.17 & 1.66 & 0.10 & 0.917 & * \\ 4 & 4.0 & 0.71 & 1.66 & 0.43 & 0.667 & * \\ 4 & 6.0 & -3.57 & 1.66 & -2.15 & 0.032 & *\end{array}$

\section{Regression Equation}

$$
\begin{aligned}
\text { Pearlite }= & 60.910+6.140 \text { Co Level_0 } \\
& -0.493 \text { Co Level_1 }+3.840 \text { Co Level_2 } \\
& -0.393 \text { Co Level_3 } \\
& -9.093 \text { Co Level_4 } \\
& +1.970 \text { Thickness }(\mathrm{mm}) \_2.0 \\
& -1.030 \text { Thickness }(\mathrm{mm}) \_2.5 \\
& +4.330 \text { Thickness }(\mathrm{mm}) \_3.0 \\
& -1.090 \text { Thickness }(\mathrm{mm}) \_3.5 \\
& +1.470 \text { Thickness }(\mathrm{mm}) \_4.0 \\
& -5.650 \text { Thickness }(\mathrm{mm}) \_6.0 \\
& -0.12 \text { Co Level*Thickness }(\mathrm{mm}) \_02.0 \\
& -8.42 \text { Co Level*Thickness }(\mathrm{mm}) \_02.5 \\
& +4.22 \text { Co Level*Thickness }(\mathrm{mm}) \_03.0 \\
& -1.76 \text { Co Level }^{*} \text { Thickness }(\mathrm{mm}) \_03.5
\end{aligned}
$$


- 0.72 Co Level*Thickness (mm) 04.0

+ 6.80 Co Level*Thickness (mm)_0 6.0

- 8.49 Co Level*Thickness (mm)_1 2.0

- 2.99 Co Level*Thickness (mm)_1 2.5

+ 0.95 Co Level*Thickness (mm)_1 3.0

+ 3.67 Co Level*Thickness (mm)_1 3.5

+ 2.61 Co Level*Thickness (mm)_1 4.0

+ 4.23 Co Level*Thickness (mm)_16.0

- 4.62 Co Level*Thickness (mm)_2 2.0

+ 4.68 Co Level*Thickness (mm)_2 2.5

- 0.48 Co Level*Thickness (mm)_2 3.0

+ 1.84 Co Level*Thickness (mm)_2 3.5

+0.68 Co Level*Thickness (mm)_2 4.0

- 2.10 Co Level*Thickness (mm)_2 6.0

+ 6.11 Co Level*Thickness (mm)_3 2.0

+ 7.31 Co Level*Thickness (mm)_3 2.5

- 0.85 Co Level*Thickness (mm)_3 3.0

- 3.93 Co Level*Thickness (mm)_3 3.5

- 3.29 Co Level*Thickness (mm)_3 4.0

- 5.37 Co Level*Thickness (mm)_3 6.0

+ 7.11 Co Level*Thickness (mm) 42.0

- 0.59 Co Level*Thickness (mm)_4 2.5

- 3.85 Co Level*Thickness (mm)_4 3.0

+ 0.17 Co Level*Thickness (mm)_4 3.5

+ 0.71 Co Level*Thickness (mm)_4 4.0

- 3.57 Co Level*Thickness (mm)_4 6.0

Fits and Diagnostics for Unusual Observations

\begin{tabular}{ccccc} 
Obs & Pearlite & Fit & Resid & Std Resid \\
\hline 1 & 32.00 & 68.90 & -36.90 & $-6.07 \mathrm{R}$ \\
2 & 51.00 & 68.90 & -17.90 & $-2.94 \mathrm{R}$ \\
6 & 84.00 & 68.90 & 15.10 & $2.48 \mathrm{R}$ \\
9 & 83.00 & 68.90 & 14.10 & $2.32 \mathrm{R}$ \\
10 & 85.00 & 68.90 & 16.10 & $2.65 \mathrm{R}$ \\
11 & 29.00 & 57.60 & -28.60 & $-4.70 \mathrm{R}$ \\
21 & 60.00 & 75.60 & -15.60 & $-2.57 \mathrm{R}$ \\
61 & 30.00 & 53.90 & -23.90 & $-3.93 \mathrm{R}$ \\
71 & 30.00 & 56.40 & -26.40 & $-4.34 \mathrm{R}$ \\
121 & 47.00 & 62.10 & -15.10 & $-2.48 \mathrm{R}$ \\
122 & 48.00 & 62.10 & -14.10 & $-2.32 \mathrm{R}$
\end{tabular}

$R$ Large residual 


\section{B.1.4 General Linear Model: Carbides versus Co Level, Thickness (mm) Method \\ Factor coding $(-1,0,+1)$}

\section{Factor Information}

\begin{tabular}{lccc} 
Factor & Type & Levels & Values \\
\hline Co Level & Fixed & 5 & $0,1,2,3,4$ \\
Thickness (mm) & Fixed & 6 & $2.0,2.5,3.0,3.5,4.0,6.0$
\end{tabular}

Analysis of Variance

\begin{tabular}{lccccc} 
Source & DF & Adj SS & Adj MS & F-Value & P-Value \\
\hline Co Level & 4 & 11893 & 2973.31 & 37.59 & 0.000 \\
Thickness (mm) & 5 & 14662 & 2932.34 & 37.07 & 0.000 \\
Co Level*Thickness (mm) & 20 & 9543 & 477.15 & 6.03 & 0.000 \\
Error & 270 & 21359 & 79.11 & & \\
Total & 299 & 57457 & & &
\end{tabular}

\section{Model Summary}

\begin{tabular}{cccc} 
S & R-sq & R-sq(adj) & R-sq(pred) \\
\hline 8.89426 & $62.83 \%$ & $58.83 \%$ & $54.11 \%$
\end{tabular}

\section{Coefficients}

\begin{tabular}{lccccc} 
Term & Coef & SE Coef & T-Value & P-Value & VIF \\
\hline Constant & 8.997 & 0.514 & 17.52 & 0.000 & \\
Co Level & & & & & \\
0 & 2.94 & 1.03 & 2.86 & 0.005 & 1.60 \\
1 & 8.65 & 1.03 & 8.43 & 0.000 & 1.60 \\
2 & 2.87 & 1.03 & 2.79 & 0.006 & 1.60 \\
3 & -6.25 & 1.03 & -6.08 & 0.000 & 1.60 \\
4 & -8.21 & 1.03 & -8.00 & 0.000 & $*$ \\
Thickness (mm) & & & & & \\
2.0 & 10.10 & 1.15 & 8.80 & 0.000 & 1.67 \\
2.5 & 9.48 & 1.15 & 8.26 & 0.000 & 1.67 \\
3.0 & -2.96 & 1.15 & -2.57 & 0.011 & 1.67 \\
3.5 & -5.20 & 1.15 & -4.53 & 0.000 & 1.67 \\
4.0 & -5.96 & 1.15 & -5.19 & 0.000 & 1.67 \\
6.0 & -5.48 & 1.15 & -4.77 & 0.000 & $*$ \\
Co Level*Thickness (mm) & & & & & \\
02.0 & -3.44 & 2.30 & -1.50 & 0.136 & 2.67 \\
02.5 & 7.28 & 2.30 & 3.17 & 0.002 & 2.67 \\
03.0 & -3.38 & 2.30 & -1.47 & 0.143 & 2.67 \\
& & 180 & & &
\end{tabular}




$\begin{array}{llccccc}0 & 3.5 & -0.44 & 2.30 & -0.19 & 0.849 & 2.67 \\ 0 & 4.0 & 0.72 & 2.30 & 0.31 & 0.753 & 2.67 \\ 0 & 6.0 & -0.76 & 2.30 & -0.33 & 0.742 & * \\ 1 & 2.0 & 9.75 & 2.30 & 4.24 & 0.000 & 2.67 \\ 1 & 2.5 & 10.47 & 2.30 & 4.56 & 0.000 & 2.67 \\ 1 & 3.0 & -3.39 & 2.30 & -1.48 & 0.141 & 2.67 \\ 1 & 3.5 & -6.25 & 2.30 & -2.72 & 0.007 & 2.67 \\ 1 & 4.0 & -6.19 & 2.30 & -2.70 & 0.007 & 2.67 \\ 1 & 6.0 & -4.37 & 2.30 & -1.90 & 0.058 & * \\ 2 & 2.0 & 9.63 & 2.30 & 4.19 & 0.000 & 2.67 \\ 2 & 2.5 & -0.55 & 2.30 & -0.24 & 0.811 & 2.67 \\ 2 & 3.0 & 1.69 & 2.30 & 0.74 & 0.462 & 2.67 \\ 2 & 3.5 & -3.17 & 2.30 & -1.38 & 0.169 & 2.67 \\ 2 & 4.0 & -4.41 & 2.30 & -1.92 & 0.056 & 2.67 \\ 2 & 6.0 & -3.19 & 2.30 & -1.39 & 0.166 & * \\ 3 & 2.0 & -6.75 & 2.30 & -2.94 & 0.004 & 2.67 \\ 3 & 2.5 & -7.53 & 2.30 & -3.28 & 0.001 & 2.67 \\ 3 & 3.0 & 1.61 & 2.30 & 0.70 & 0.485 & 2.67 \\ 3 & 3.5 & 4.85 & 2.30 & 2.11 & 0.036 & 2.67 \\ 3 & 4.0 & 4.21 & 2.30 & 1.83 & 0.068 & 2.67 \\ 3 & 6.0 & 3.63 & 2.30 & 1.58 & 0.115 & * \\ 42.0 & -9.19 & 2.30 & -4.00 & 0.000 & * \\ 42.5 & -9.67 & 2.30 & -4.21 & 0.000 & * \\ 43.0 & 3.47 & 2.30 & 1.51 & 0.132 & * \\ 43.5 & 5.01 & 2.30 & 2.18 & 0.030 & * \\ 4 & 4.0 & 5.67 & 2.30 & 2.47 & 0.014 & * \\ 4 & 6.0 & 4.69 & 2.30 & 2.04 & 0.042 & *\end{array}$

\section{Regression Equation}

$$
\begin{aligned}
\text { Carbides }= & 8.997+2.94 \text { Co Level_0 } \\
& +8.65 \text { Co Level_1 }+2.87 \text { Co Level_2 } \\
& -6.25 \text { Co Level_3 } \\
& -8.21 \text { Co Level_4 } \\
& +10.10 \text { Thickness }(\mathrm{mm}) \_2.0 \\
& +9.48 \text { Thickness }(\mathrm{mm}) \_2.5 \\
& -2.96 \text { Thickness }(\mathrm{mm}) \_3.0 \\
& -5.20 \text { Thickness }(\mathrm{mm}) \_3.5 \\
& -5.96 \text { Thickness }(\mathrm{mm}) \_4.0 \\
& -5.48 \text { Thickness }(\mathrm{mm}) \_6.0 \\
& -3.44 \text { Co Level*Thickness }(\mathrm{mm}) \_02.0 \\
& +7.28 \text { Co Level*Thickness }(\mathrm{mm}) \_02.5 \\
& -3.38 \text { Co Level*Thickness }(\mathrm{mm}) \_03.0 \\
& -0.44 \text { Co Level*Thickness }(\mathrm{mm}) \_03.5
\end{aligned}
$$


+0.72 Co Level*Thickness (mm)_0 4.0

- 0.76 Co Level*Thickness (mm)_0 6.0

+ 9.75 Co Level*Thickness (mm)_1 2.0

+ 10.47 Co Level*Thickness (mm)_1 2.5

- 3.39 Co Level*Thickness (mm)_1 3.0

- 6.25 Co Level*Thickness (mm)_1 3.5

- 6.19 Co Level*Thickness (mm)_14.0

- 4.37 Co Level*Thickness (mm)_16.0

+ 9.63 Co Level*Thickness (mm)_22.0

- 0.55 Co Level*Thickness (mm)_2 2.5

+ 1.69 Co Level*Thickness (mm)_23.0

- 3.17 Co Level*Thickness (mm)_2 3.5

- 4.41 Co Level*Thickness (mm)_2 4.0

- 3.19 Co Level*Thickness (mm)_2 6.0

- 6.75 Co Level*Thickness (mm)_32.0

- 7.53 Co Level*Thickness (mm)_3 2.5

+ 1.61 Co Level*Thickness (mm)_3 3.0

+4.85 Co Level*Thickness (mm)_3 3.5

+4.21 Co Level*Thickness (mm)_34.0

+ 3.63 Co Level*Thickness (mm)_36.0

- 9.19 Co Level*Thickness (mm)_42.0

- 9.67 Co Level*Thickness (mm)_4 2.5

+ 3.47 Co Level*Thickness (mm)_4 3.0

+ 5.01 Co Level*Thickness (mm)_4 3.5

+5.67 Co Level*Thickness $(\mathrm{mm}) 44.0$

+4.69 Co Level*Thickness (mm)_4 6.0

Fits and Diagnostics for Unusual Observations

\begin{tabular}{ccccc} 
Obs & Carbides & Fit & Resid & Std Resid \\
\hline 1 & 57.00 & 18.60 & 38.40 & $4.55 \mathrm{R}$ \\
2 & 41.00 & 18.60 & 22.40 & $2.65 \mathrm{R}$ \\
9 & 0.00 & 18.60 & -18.60 & $-2.20 \mathrm{R}$ \\
10 & 0.00 & 18.60 & -18.60 & $-2.20 \mathrm{R}$ \\
11 & 63.00 & 28.70 & 34.30 & $4.07 \mathrm{R}$ \\
21 & 29.00 & 5.60 & 23.40 & $2.77 \mathrm{R}$ \\
61 & 70.00 & 37.50 & 32.50 & $3.85 \mathrm{R}$ \\
71 & 70.00 & 37.60 & 32.40 & $3.84 \mathrm{R}$ \\
81 & 35.00 & 11.30 & 23.70 & $2.81 \mathrm{R}$ \\
82 & 30.00 & 11.30 & 18.70 & $2.22 \mathrm{R}$ \\
91 & 34.00 & 6.20 & 27.80 & $3.29 \mathrm{R}$ \\
101 & 25.00 & 5.50 & 19.50 & $2.31 \mathrm{R}$
\end{tabular}

$R$ Large residual 


\section{B.1.5 General Linear Model: Nodularity (\%) versus Co Level, Position}

Method

Factor coding $(-1,0,+1)$

Factor Information

\begin{tabular}{lccc} 
Factor & Type & Levels & Values \\
\hline Co Level & Fixed & 5 & $0,1,2,3,4$ \\
Position & Fixed & 2 & First, Last
\end{tabular}

Analysis of Variance

\begin{tabular}{lccccc} 
Source & DF & Adj SS & Adj MS & F-Value & P-Value \\
\hline Co Level & 4 & 230.66 & 57.67 & 5.12 & 0.001 \\
Position & 1 & 54.76 & 54.76 & 4.86 & 0.030 \\
Co Level*Position & 4 & 76.14 & 19.04 & 1.69 & 0.159 \\
Error & 90 & 1014.00 & 11.27 & & \\
Total & 99 & 1375.56 & & &
\end{tabular}

Model Summary

\begin{tabular}{cccc} 
S & R-sq & R-sq(adj) & R-sq(pred) \\
\hline 3.35659 & $26.28 \%$ & $18.91 \%$ & $8.99 \%$
\end{tabular}

Coefficients

\begin{tabular}{lccccc} 
Term & Coef & SE Coef & T-Value & P-Value & VIF \\
\hline $\begin{array}{l}\text { Constant } \\
\text { Co Level }\end{array}$ & 94.620 & 0.336 & 281.89 & 0.000 & \\
0 & & & & & \\
1 & -0.520 & 0.671 & -0.77 & 0.441 & 1.60 \\
2 & 1.130 & 0.671 & 1.68 & 0.096 & 1.60 \\
3 & 0.630 & 0.671 & 0.94 & 0.351 & 1.60 \\
4 & -2.720 & 0.671 & -4.05 & 0.000 & 1.60 \\
& 1.480 & 0.671 & 2.20 & 0.030 & $*$
\end{tabular}

Position

First

0.740

0.336

2.20

0.030

1.00 
Last $\quad-0.740 \quad 0.336 \quad-2.20 \quad 0.030 \quad *$

Co Level*Position

$\begin{array}{lccccc}0 \text { First } & 0.260 & 0.671 & 0.39 & 0.699 & 1.60 \\ 0 \text { Last } & -0.260 & 0.671 & -0.39 & 0.699 & * \\ \text { 1 First } & -0.390 & 0.671 & -0.58 & 0.563 & 1.60 \\ \text { 1 Last } & 0.390 & 0.671 & 0.58 & 0.563 & * \\ \text { 2 First } & -1.390 & 0.671 & -2.07 & 0.041 & 1.60 \\ \text { 2 Last } & 1.390 & 0.671 & 2.07 & 0.041 & * \\ \text { 3 First } & 1.260 & 0.671 & 1.88 & 0.064 & 1.60 \\ \text { 3 Last } & -1.260 & 0.671 & -1.88 & 0.064 & * \\ \text { 4 First } & 0.260 & 0.671 & 0.39 & 0.699 & * \\ \text { 4 Last } & -0.260 & 0.671 & -0.39 & 0.699 & *\end{array}$

Regression Equation

Nodularity $=94.620-0.520$ Co Level_0 +1.130 Co Level_1

(\%) $\quad+0.630$ Co Level_2

- 2.720 Co Level_3 + 1.480 Co Level_4 + 0.740 Position_First

- 0.740 Position_Last +0.260 Co Level*Position_0 First

- 0.260 Co Level*Position_0 Last - 0.390 Co Level*Position_1

First

+ 0.390 Co Level*Position_1 Last - 1.390 Co Level*Position_2

First

+1.390 Co Level*Position_2 Last +1.260 Co Level*Position_3

First

- 1.260 Co Level*Position_3 Last +0.260 Co Level*Position_4 First

- 0.260 Co Level*Position_4 Last

Fits and Diagnostics for Unusual Observations

\begin{tabular}{cccccc} 
Obs & $\begin{array}{c}\text { Nodularity } \\
(\%)\end{array}$ & Fit & Resid & $\begin{array}{c}\text { Rtd } \\
\text { Resid }\end{array}$ & \\
\hline 11 & 100.00 & 93.10 & 6.90 & 2.17 & $\mathrm{R}$ \\
16 & 83.00 & 93.10 & -10.10 & -3.17 & $\mathrm{R}$ \\
77 & 79.00 & 89.90 & -10.90 & -3.42 & $\mathrm{R}$ \\
80 & 98.00 & 89.90 & 8.10 & 2.54 & $\mathrm{R}$ \\
$R$ Large residual & & & &
\end{tabular}




\section{B.1.6 General Linear Model: Nodule Count (N/mm2) versus Co Level, Position}

Method

Factor coding $(-1,0,+1)$

Factor Information

\begin{tabular}{cccc} 
Factor & Type & Levels & Values \\
\hline Co Level & Fixed & 5 & $0,1,2,3,4$ \\
Position & Fixed & 2 & First, Last
\end{tabular}

Analysis of Variance

\begin{tabular}{lccccc} 
Source & DF & Adj SS & Adj MS & F-Value & P-Value \\
\hline Co Level & 4 & 64428 & 16107.0 & 25.70 & 0.000 \\
Position & 1 & 14762 & 14762.2 & 23.56 & 0.000 \\
Co Level*Position & 4 & 3706 & 926.6 & 1.48 & 0.215 \\
Error & 90 & 56403 & 626.7 & & \\
Total & 99 & 139299 & & &
\end{tabular}

Model Summary

\begin{tabular}{crrr} 
S & R-sq & R-sq(adj) & R-sq(pred) \\
\hline 25.0339 & $59.51 \%$ & $55.46 \%$ & $50.01 \%$
\end{tabular}

\section{Coefficients}

\begin{tabular}{lccccc} 
Term & Coef & SE Coef & T-Value & P-Value & VIF \\
\hline Constant & 221.03 & 2.50 & 88.29 & 0.000 & \\
Co Level & & & & & \\
0 & -14.83 & 5.01 & -2.96 & 0.004 & 1.60 \\
1 & 10.42 & 5.01 & 2.08 & 0.040 & 1.60 \\
2 & 3.47 & 5.01 & 0.69 & 0.490 & 1.60 \\
3 & -37.48 & 5.01 & -7.49 & 0.000 & 1.60 \\
4 & 38.42 & 5.01 & 7.67 & 0.000 & $*$
\end{tabular}


Position

$\begin{array}{lccccc}\text { First } & 12.15 & 2.50 & 4.85 & 0.000 & 1.00 \\ \text { Last } & -12.15 & 2.50 & -4.85 & 0.000 & * \\ \text { Co Level*Position } & & & & & \\ \text { 0 First } & 6.65 & 5.01 & 1.33 & 0.187 & 1.60 \\ 0 \text { Last } & -6.65 & 5.01 & -1.33 & 0.187 & * \\ 1 \text { First } & -1.20 & 5.01 & -0.24 & 0.811 & 1.60 \\ \text { 1 Last } & 1.20 & 5.01 & 0.24 & 0.811 & * \\ 2 \text { First } & -4.35 & 5.01 & -0.87 & 0.387 & 1.60 \\ 2 \text { Last } & 4.35 & 5.01 & 0.87 & 0.387 & * \\ 3 \text { First } & -8.30 & 5.01 & -1.66 & 0.101 & 1.60 \\ 3 \text { Last } & 8.30 & 5.01 & 1.66 & 0.101 & * \\ 4 \text { First } & 7.20 & 5.01 & 1.44 & 0.154 & * \\ 4 \text { Last } & -7.20 & 5.01 & -1.44 & 0.154 & *\end{array}$

Regression Equation

$$
\begin{aligned}
\text { Nodule Count } \quad & 221.03-14.83 \text { Co Level_0 }+10.42 \text { Co Level_1 } \\
\text { (N/mm2) } & +3.47 \text { Co Level_2 } \\
& -37.48 \text { Co Level_3 }+38.42 \text { Co Level_4 } \\
& +12.15 \text { Position_First } \\
& -12.15 \text { Position_Last }+6.65 \text { Co Level*Position_0 First } \\
& -6.65 \text { Co Level*Position_0 Last } \\
& -1.20 \text { Co Level*Position_1 First } \\
& +1.20 \text { Co Level*Position_1 Last } \\
& -4.35 \text { Co Level*Position_2 First } \\
& +4.35 \text { Co Level*Position_2 Last } \\
& -8.30 \text { Co Level*Position_3 First } \\
& +8.30 \text { Co Level*Position_3 Last } \\
& +7.20 \text { Co Level*Position_4 First } \\
& -7.20 \text { Co Level*Position_4 Last }
\end{aligned}
$$

\begin{tabular}{|c|c|c|c|c|}
\hline Obs & $\begin{array}{c}\text { Nodule } \\
\text { Count } \\
\text { (N/mm2) }\end{array}$ & Fit & Resid & Std Resid \\
\hline 2 & 276.00 & 225.00 & 51.00 & 2.15 \\
\hline
\end{tabular}

Fits and Diagnostics for Unusual Observations 


$\begin{array}{cccccc}5 & 276.00 & 225.00 & 51.00 & 2.15 & \mathrm{R} \\ 9 & 166.00 & 225.00 & -59.00 & -2.48 & \mathrm{R} \\ 15 & 250.00 & 187.40 & 62.60 & 2.64 & \mathrm{R} \\ R & \text { Large residual } & & & & \end{array}$




\section{B.1.7 General Linear Model: Nodule Diameter $(\mu \mathrm{m})$ versus Co Level, Position}

Method

Factor coding $(-1,0,+1)$

Factor Information

\begin{tabular}{cccc} 
Factor & Type & Levels & Values \\
\hline Co Level & Fixed & 5 & $0,1,2,3,4$ \\
Position & Fixed & 2 & First, Last
\end{tabular}

Analysis of Variance

\begin{tabular}{lccccc} 
Source & DF & Adj SS & Adj MS & F-Value & P-Value \\
\hline Co Level & 4 & 62.633 & 15.658 & 9.03 & 0.000 \\
Position & 1 & 179.555 & 179.555 & 103.50 & 0.000 \\
Co Level*Position & 4 & 9.348 & 2.337 & 1.35 & 0.259 \\
Error & 90 & 156.140 & 1.735 & & \\
Total & 99 & 407.675 & & &
\end{tabular}

Model Summary

\begin{tabular}{crrr} 
S & R-sq & R-sq(adj) & R-sq(pred) \\
\hline 1.31715 & $61.70 \%$ & $57.87 \%$ & $52.72 \%$
\end{tabular}

\section{Coefficients}

\begin{tabular}{lccccc} 
Term & Coef & SE Coef & T-Value & P-Value & VIF \\
\hline $\begin{array}{l}\text { Constant } \\
\text { Co Level }\end{array}$ & 25.023 & 0.132 & 189.98 & 0.000 & \\
0 & & & & & \\
1 & 1.137 & 0.263 & 4.32 & 0.000 & 1.60 \\
2 & -0.058 & 0.263 & -0.22 & 0.827 & 1.60 \\
3 & 0.212 & 0.263 & 0.81 & 0.422 & 1.60 \\
4 & 0.045 & 0.263 & 0.17 & 0.865 & 1.60 \\
& -1.337 & 0.263 & -5.08 & 0.000 & $*$
\end{tabular}


Position

$\begin{array}{lccccc}\text { First } & -1.340 & 0.132 & -10.17 & 0.000 & 1.00 \\ \text { Last } & 1.340 & 0.132 & 10.17 & 0.000 & *\end{array}$

Co Level*Position

$\begin{array}{lccccc}\text { 0 First } & -0.140 & 0.263 & -0.53 & 0.596 & 1.60 \\ \text { 0 Last } & 0.140 & 0.263 & 0.53 & 0.596 & * \\ \text { 1 First } & -0.119 & 0.263 & -0.45 & 0.654 & 1.60 \\ \text { 1 Last } & 0.119 & 0.263 & 0.45 & 0.654 & * \\ \text { 2 First } & 0.047 & 0.263 & 0.18 & 0.858 & 1.60 \\ \text { 2 Last } & -0.047 & 0.263 & -0.18 & 0.858 & * \\ \text { 3 First } & 0.558 & 0.263 & 2.12 & 0.037 & 1.60 \\ \text { 3 Last } & -0.558 & 0.263 & -2.12 & 0.037 & * \\ \text { 4 First } & -0.346 & 0.263 & -1.31 & 0.192 & * \\ \text { 4 Last } & 0.346 & 0.263 & 1.31 & 0.192 & *\end{array}$

Regression Equation

$$
\begin{aligned}
\text { Nodule Diameter } \quad & 25.023+1.137 \text { Co Level_0 }-0.058 \text { Co Level_1 } \\
(\mu \mathrm{m}) & +0.212 \text { Co Level_2 } \\
& +0.045 \text { Co Level_3 }-1.337 \text { Co Level_4 } \\
& -1.340 \text { Position_First } \\
& +1.340 \text { Position_Last }-0.140 \text { Co Level*Position_0 First } \\
& +0.140 \text { Co Level*Position_0 Last } \\
& -0.119 \text { Co Level*Position_1 First } \\
& +0.119 \text { Co Level*Position_1 Last } \\
& +0.047 \text { Co Level*Position_2 First } \\
& -0.047 \text { Co Level*Position_2 Last } \\
& +0.558 \text { Co Level*Position_3 First } \\
& -0.558 \text { Co Level*Position_3 Last } \\
& -0.346 \text { Co Level*Position_4 First } \\
& +0.346 \text { Co Level*Position_4 Last }
\end{aligned}
$$

Fits and Diagnostics for Unusual Observations

Nodule

\section{Diameter}

\begin{tabular}{ccccrr} 
Obs & $(\boldsymbol{\mu m})$ & Fit & Resid & Std Resid & \\
\hline 11 & 31.842 & 27.641 & 4.201 & 3.36 & $\mathrm{R}$
\end{tabular}




\begin{tabular}{rrrrrr}
18 & 23.852 & 27.641 & -3.789 & -3.03 & $\mathrm{R}$ \\
33 & 23.549 & 26.424 & -2.875 & -2.30 & $\mathrm{R}$ \\
36 & 29.871 & 26.424 & 3.447 & 2.76 & $\mathrm{R}$ \\
59 & 29.215 & 26.529 & 2.686 & 2.15 & $\mathrm{R}$ \\
\multicolumn{2}{c}{ R Large residual } & & & &
\end{tabular}




\section{B.1.8 General Linear Model: Ferrite (\%) versus Co Level, Position Method}

Factor coding $(-1,0,+1)$

Factor Information

\begin{tabular}{lccc} 
Factor & Type & Levels & Values \\
\hline Co Level & Fixed & 5 & 0, 1, 2, 3, 4 \\
Position & Fixed & 2 & First, Last
\end{tabular}

Analysis of Variance

\begin{tabular}{lccccc} 
Source & DF & Adj SS & Adj MS & F-Value & P-Value \\
\hline Co Level & 4 & 3461.9 & 865.47 & 57.33 & 0.000 \\
Position & 1 & 1971.4 & 1971.36 & 130.59 & 0.000 \\
Co Level*Position & 4 & 544.1 & 136.03 & 9.01 & 0.000 \\
Error & 90 & 1358.6 & 15.10 & & \\
Total & 99 & 7336.0 & & &
\end{tabular}

Model Summary

\begin{tabular}{cccc} 
S & R-sq & R-sq(adj) & R-sq(pred) \\
\hline 3.88530 & $81.48 \%$ & $79.63 \%$ & $77.14 \%$
\end{tabular}

Coefficients

\begin{tabular}{lccccc} 
Term & Coef & SE Coef & T-Value & P-Value & VIF \\
\hline $\begin{array}{l}\text { Constant } \\
\text { Co Level }\end{array}$ & 81.400 & 0.389 & 209.51 & 0.000 & \\
0 & & & & & \\
1 & -9.400 & 0.777 & -12.10 & 0.000 & 1.60 \\
2 & -2.150 & 0.777 & -2.77 & 0.007 & 1.60 \\
3 & 5.850 & 0.777 & 7.53 & 0.000 & 1.60 \\
4 & -1.000 & 0.777 & -1.29 & 0.201 & 1.60 \\
& 6.700 & 0.777 & 8.62 & 0.000 & $*$
\end{tabular}


Position

$\begin{array}{lccccc}\text { First } & 4.440 & 0.389 & 11.43 & 0.000 & 1.00 \\ \text { Last } & -4.440 & 0.389 & -11.43 & 0.000 & * \\ \text { Co Level*Position } & & & & & \\ \text { 0 First } & 2.460 & 0.777 & 3.17 & 0.002 & 1.60 \\ \text { 0 Last } & -2.460 & 0.777 & -3.17 & 0.002 & * \\ 1 \text { First } & 0.810 & 0.777 & 1.04 & 0.300 & 1.60 \\ \text { 1 Last } & -0.810 & 0.777 & -1.04 & 0.300 & * \\ 2 \text { First } & -2.990 & 0.777 & -3.85 & 0.000 & 1.60 \\ 2 \text { Last } & 2.990 & 0.777 & 3.85 & 0.000 & * \\ 3 \text { First } & 2.260 & 0.777 & 2.91 & 0.005 & 1.60 \\ \text { 3 Last } & -2.260 & 0.777 & -2.91 & 0.005 & * \\ 4 \text { First } & -2.540 & 0.777 & -3.27 & 0.002 & * \\ 4 \text { Last } & 2.540 & 0.777 & 3.27 & 0.002 & *\end{array}$

Regression Equation

Ferrite $(\%)=81.400-9.400$ Co Level_0 - 2.150 Co Level_1 +5.850 Co Level_2 - 1.000 Co Level $3+6.700$ Co Level $4+4.440$ Position_First

- 4.440 Position_Last +2.460 Co Level*Position_0 First

- 2.460 Co Level*Position_0 Last +0.810 Co Level*Position_1 First

- 0.810 Co Level*Position_1 Last - 2.990 Co Level*Position_2 First

+2.990 Co Level*Position_2 Last +2.260 Co Level*Position_3 First

- 2.260 Co Level*Position_3 Last - 2.540 Co Level*Position_ 4 First

+ 2.540 Co Level*Position_4 Last

Fits and Diagnostics for Unusual Observations

\begin{tabular}{cccccc} 
Obs & $\begin{array}{c}\text { Ferrite } \\
(\%)\end{array}$ & Fit & Resid & Resid \\
\hline 1 & 90.00 & 78.90 & 11.10 & 3.01 & $\mathrm{R}$ \\
97 & 94.00 & 86.20 & 7.80 & 2.12 & $\mathrm{R}$ \\
\multicolumn{2}{l}{ L Large residual } & & & &
\end{tabular}




\section{B.1.9 General Linear Model: Pearlite (\%) versus Co Level, Position}

Method

Factor coding $(-1,0,+1)$

Factor Information

\begin{tabular}{lccc} 
Factor & Type & Levels & Values \\
\hline Co Level & Fixed & 5 & $0,1,2,3,4$ \\
Position & Fixed & 2 & First, Last
\end{tabular}

Analysis of Variance

\begin{tabular}{lccccc} 
Source & DF & Adj SS & Adj MS & F-Value & P-Value \\
\hline Co Level & 4 & 3461.9 & 865.48 & 57.33 & 0.000 \\
Position & 1 & 1971.4 & 1971.36 & 130.59 & 0.000 \\
Co Level*Position & 4 & 544.1 & 136.03 & 9.01 & 0.000 \\
Error & 90 & 1358.6 & 15.10 & & \\
Total & 99 & 7336.0 & & &
\end{tabular}

Model Summary

\begin{tabular}{cccc} 
S & R-sq & R-sq(adj) & R-sq(pred) \\
\hline 3.88530 & $81.48 \%$ & $79.63 \%$ & $77.14 \%$
\end{tabular}

Coefficients

\begin{tabular}{lccccc} 
Term & Coef & SE Coef & T-Value & P-Value & VIF \\
\hline Constant & 18.600 & 0.389 & 47.87 & 0.000 & \\
Co Level & & & & & \\
0 & 9.400 & 0.777 & 12.10 & 0.000 & 1.60 \\
1 & 2.150 & 0.777 & 2.77 & 0.007 & 1.60 \\
2 & -5.850 & 0.777 & -7.53 & 0.000 & 1.60 \\
3 & 1.000 & 0.777 & 1.29 & 0.201 & 1.60 \\
4 & -6.700 & 0.777 & -8.62 & 0.000 & $*$
\end{tabular}


Position

$\begin{array}{cccccc}\text { First } & -4.440 & 0.389 & -11.43 & 0.000 & 1.00 \\ \text { Last } & 4.440 & 0.389 & 11.43 & 0.000 & *\end{array}$

Co Level*Position

$\begin{array}{lccccc}\text { 0 First } & -2.460 & 0.777 & -3.17 & 0.002 & 1.60 \\ \text { 0 Last } & 2.460 & 0.777 & 3.17 & 0.002 & * \\ \text { 1 First } & -0.810 & 0.777 & -1.04 & 0.300 & 1.60 \\ \text { 1 Last } & 0.810 & 0.777 & 1.04 & 0.300 & * \\ \text { 2 First } & 2.990 & 0.777 & 3.85 & 0.000 & 1.60 \\ \text { 2 Last } & -2.990 & 0.777 & -3.85 & 0.000 & * \\ \text { 3 First } & -2.260 & 0.777 & -2.91 & 0.005 & 1.60 \\ \text { 3 Last } & 2.260 & 0.777 & 2.91 & 0.005 & * \\ \text { 4 First } & 2.540 & 0.777 & 3.27 & 0.002 & * \\ \text { 4 Last } & -2.540 & 0.777 & -3.27 & 0.002 & *\end{array}$

Regression Equation

Pearlite $(\%)=18.600+9.400$ Co Level_0 +2.150 Co Level_1 -5.850 Co Level_2 +1.000 Co Level_3 - 6.700 Co Level_ 4 - $4.4 \overline{40}$ Position_First

+4.440 Position Last - 2.460 Co Level*Position 0 First

+2.460 Co Level*Position_0 Last -0.810 Co Level*Position_1 First

+0.810 Co Level*Position_1 Last +2.990 Co Level*Position_2 First

- 2.990 Co Level*Position_2 Last - 2.260 Co Level*Position_3 First

+2.260 Co Level*Position_3 Last +2.540 Co Level*Position_4 First

- 2.540 Co Level*Position_4 Last

Fits and Diagnostics for Unusual Observations

Pearlite

\begin{tabular}{ccccrc} 
Obs & $(\%)$ & Fit & Resid & Std Resid & \\
\hline 1 & 10.00 & 21.10 & -11.10 & -3.01 & $\mathrm{R}$ \\
97 & 6.00 & 13.80 & -7.80 & -2.12 & $\mathrm{R}$ \\
R Large residual & & & &
\end{tabular}




\section{B.1.10 General Linear Model: Tensile Strength (MPa) versus Co Level, Thickness (mm)}

Method

Factor coding $(-1,0,+1)$

Factor Information

\begin{tabular}{lccc} 
Factor & Type & Levels & Values \\
\hline Co Level & Fixed & 5 & $0,1,2,3,4$ \\
Thickness (mm) & Fixed & 6 & $2.0,2.5,3.0,3.5,4.0,6.0$
\end{tabular}

Analysis of Variance

\begin{tabular}{lccccc} 
Source & DF & Adj SS & Adj MS & F-Value & P-Value \\
\hline Co Level & 4 & 12719 & 3180 & 1.98 & 0.100 \\
Thickness (mm) & 5 & 247730 & 49546 & 30.81 & 0.000 \\
Co Level*Thickness (mm) & 20 & 121946 & 6097 & 3.79 & 0.000 \\
Error & 170 & 273384 & 1608 & & \\
Total & 199 & 653203 & & &
\end{tabular}

Model Summary

\begin{tabular}{cccc} 
S & R-sq & R-sq(adj) & R-sq(pred) \\
\hline 40.1016 & $58.15 \%$ & $51.01 \%$ & $40.37 \%$
\end{tabular}

\section{Coefficients}

\begin{tabular}{lccccc} 
Term & Coef & SE Coef & T-Value & P-Value & VIF \\
\hline Constant & 698.57 & 3.04 & 229.49 & 0.000 & \\
Co Level & & & & & \\
0 & -1.48 & 5.72 & -0.26 & 0.796 & 1.77 \\
1 & -16.47 & 6.19 & -2.66 & 0.009 & 1.95 \\
2 & 6.58 & 6.45 & 1.02 & 0.309 & 2.09 \\
3 & 7.04 & 6.35 & 1.11 & 0.269 & 1.97 \\
4 & 4.34 & 5.69 & 0.76 & 0.447 & $*$
\end{tabular}


Thickness (mm)

$\begin{array}{cccccc}2.0 & -1.70 & 8.66 & -0.20 & 0.844 & 2.59 \\ 2.5 & -1.06 & 7.27 & -0.15 & 0.884 & 2.21 \\ 3.0 & 69.87 & 6.47 & 10.80 & 0.000 & 1.92 \\ 3.5 & -17.05 & 6.01 & -2.84 & 0.005 & 1.79 \\ 4.0 & -6.90 & 6.01 & -1.15 & 0.252 & 1.79 \\ 6.0 & -43.14 & 6.01 & -7.18 & 0.000 & *\end{array}$

Co Level*Thickness (mm)

\begin{tabular}{|c|c|c|c|c|}
\hline 02.0 & -55.1 & 16.1 & -3.42 & 0.001 \\
\hline 02.5 & 3.7 & 12.5 & 0.29 & 0.769 \\
\hline 03.0 & -1.9 & 12.1 & -0.16 & 0.875 \\
\hline 03.5 & 17.3 & 11.8 & 1.46 & 0.146 \\
\hline 04.0 & 8.8 & 11.8 & 0.74 & 0.460 \\
\hline 06.0 & 27.3 & 11.8 & 2.31 & 0.022 \\
\hline 12.0 & 12.1 & 17.8 & 0.68 & 0.498 \\
\hline 12.5 & -5.8 & 15.6 & -0.37 & 0.711 \\
\hline 13.0 & -15.6 & 12.3 & -1.27 & 0.208 \\
\hline 13.5 & -4.1 & 12.1 & -0.34 & 0.737 \\
\hline 14.0 & -17.3 & 12.1 & -1.43 & 0.154 \\
\hline 16.0 & 30.6 & 12.1 & 2.54 & 0.012 \\
\hline 22.0 & 56.2 & 20.7 & 2.71 & 0.007 \\
\hline 22.5 & -69.7 & 13.9 & -5.02 & 0.000 \\
\hline 23.0 & 41.7 & 13.5 & 3.10 & 0.002 \\
\hline 23.5 & -1.6 & 12.2 & -0.13 & 0.896 \\
\hline 24.0 & -21.3 & 12.2 & -1.74 & 0.083 \\
\hline 26.0 & -5.4 & 12.2 & -0.44 & 0.660 \\
\hline 32.0 & 12.3 & 16.3 & 0.75 & 0.452 \\
\hline 32.5 & 27.7 & 17.3 & 1.61 & 0.110 \\
\hline 33.0 & -12.5 & 14.2 & -0.88 & 0.380 \\
\hline 33.5 & -20.4 & 12.1 & -1.68 & 0.094 \\
\hline 34.0 & 6.7 & 12.1 & 0.55 & 0.584 \\
\hline
\end{tabular}




$\begin{array}{lccccc}36.0 & -13.8 & 12.1 & -1.13 & 0.259 & * \\ 42.0 & -25.5 & 15.1 & -1.69 & 0.093 & * \\ 42.5 & 44.0 & 13.0 & 3.40 & 0.001 & * \\ 43.0 & -11.8 & 12.5 & -0.94 & 0.349 & * \\ 43.5 & 8.8 & 11.8 & 0.75 & 0.457 & * \\ 44.0 & 23.1 & 11.8 & 1.96 & 0.052 & * \\ 46.0 & -38.8 & 11.8 & -3.28 & 0.001 & *\end{array}$

\section{Regression Equation}

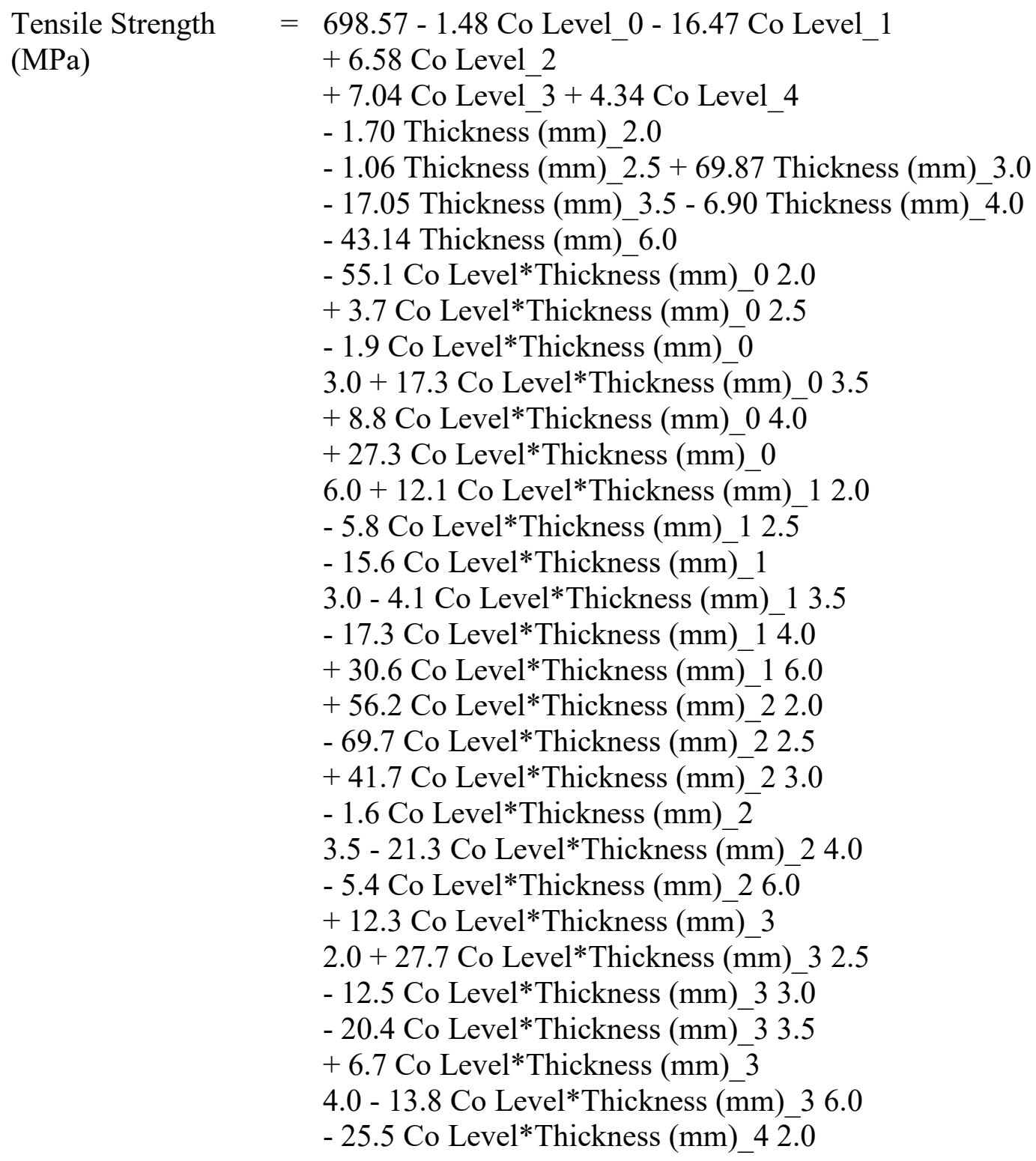




$$
\begin{aligned}
& \text { + 44.0 Co Level*Thickness (mm)_4 2.5 } \\
& \text { - 11.8 Co Level*Thickness (mm)_4 3.0 } \\
& \text { + 8.8 Co Level*Thickness (mm)_4 } \\
& \text { 3.5+23.1 Co Level*Thickness (mm)_44 } 4.0 \\
& \text { - 38.8 Co Level*Thickness (mm)_46.0 }
\end{aligned}
$$

Fits and Diagnostics for Unusual Observations

\section{Tensile Strength}

\begin{tabular}{ccccrl} 
Obs & (MPa) & Fit & Resid & Std Resid & \\
\hline 4 & 720.7 & 640.3 & 80.4 & 2.32 & $\mathrm{R}$ \\
6 & 600.8 & 699.7 & -98.9 & -2.64 & $\mathrm{R}$ \\
11 & 608.0 & 699.7 & -91.7 & -2.44 & $\mathrm{R}$ \\
50 & 595.9 & 675.3 & -79.4 & -2.28 & $\mathrm{R}$ \\
54 & 837.3 & 736.4 & 100.9 & 2.69 & $\mathrm{R}$ \\
65 & 529.4 & 661.0 & -131.6 & -3.51 & $\mathrm{R}$ \\
89 & 529.7 & 634.4 & -104.7 & -2.86 & $\mathrm{R}$ \\
94 & 742.5 & 816.8 & -74.3 & -2.03 & $\mathrm{R}$ \\
165 & 854.3 & 745.9 & 108.4 & 2.92 & $\mathrm{R}$ \\
168 & 640.5 & 745.9 & -105.4 & -2.84 & $\mathrm{R}$ \\
\multicolumn{7}{l}{ R Large residual } & & & &
\end{tabular}




\section{B.1.11 General Linear Model: Yield Strength (MPa) versus Co Level, Thickness (mm)}

Method

Factor coding $(-1,0,+1)$

Factor Information

\begin{tabular}{lccc} 
Factor & Type & Levels & Values \\
\hline Co Level & Fixed & 5 & $0,1,2,3,4$ \\
Thickness (mm) & Fixed & 6 & $2.0,2.5,3.0,3.5,4.0,6.0$
\end{tabular}

Analysis of Variance

\begin{tabular}{lccccc} 
Source & DF & Adj SS & Adj MS & F-Value & P-Value \\
\hline Co Level & 4 & 157862 & 39466 & 12.78 & 0.000 \\
Thickness (mm) & 5 & 1303354 & 260671 & 84.44 & 0.000 \\
Co Level*Thickness (mm) & 20 & 143576 & 7179 & 2.33 & 0.002 \\
Error & 170 & 524771 & 3087 & & \\
Total & 199 & 2113964 & & &
\end{tabular}

Model Summary

\begin{tabular}{cccc} 
S & R-sq & R-sq(adj) & R-sq(pred) \\
\hline 55.5598 & $75.18 \%$ & $70.94 \%$ & $63.56 \%$
\end{tabular}

Coefficients

\begin{tabular}{lccccc} 
Term & Coef & SE Coef & T-Value & P-Value & VIF \\
\hline $\begin{array}{l}\text { Constant } \\
\text { Co Level }\end{array}$ & 567.04 & 4.22 & 134.45 & 0.000 & \\
0 & & & & & \\
1 & 10.78 & 7.92 & 1.36 & 0.176 & 1.77 \\
2 & 13.85 & 8.57 & 1.62 & 0.108 & 1.95 \\
3 & 18.60 & 8.94 & 2.08 & 0.039 & 2.09 \\
4 & 13.04 & 8.80 & 1.48 & 0.140 & 1.97 \\
& -56.28 & 7.88 & -7.14 & 0.000 & $*$
\end{tabular}


Thickness (mm)

$\begin{array}{cccccc}2.0 & 80.3 & 12.0 & 6.70 & 0.000 & 2.59 \\ 2.5 & 52.6 & 10.1 & 5.22 & 0.000 & 2.21 \\ 3.0 & 85.96 & 8.96 & 9.59 & 0.000 & 1.92 \\ 3.5 & -41.55 & 8.32 & -4.99 & 0.000 & 1.79 \\ 4.0 & -33.29 & 8.32 & -4.00 & 0.000 & 1.79 \\ 6.0 & -144.09 & 8.32 & -17.32 & 0.000 & *\end{array}$

Co Level*Thickness (mm)

\begin{tabular}{|c|c|c|c|c|c|}
\hline 02.0 & -17.9 & 22.3 & -0.80 & 0.423 & 4.03 \\
\hline 02.5 & 26.4 & 17.3 & 1.52 & 0.130 & 3.02 \\
\hline 03.0 & -15.4 & 16.7 & -0.92 & 0.357 & 2.81 \\
\hline 03.5 & 12.3 & 16.4 & 0.75 & 0.453 & 2.78 \\
\hline 04.0 & -13.4 & 16.4 & -0.82 & 0.414 & 2.78 \\
\hline 06.0 & 8.1 & 16.4 & 0.49 & 0.622 & $*$ \\
\hline 12.0 & 31.3 & 24.7 & 1.26 & 0.208 & 4.75 \\
\hline 12.5 & -86.2 & 21.6 & -3.99 & 0.000 & 4.07 \\
\hline 13.0 & -4.4 & 17.0 & -0.26 & 0.795 & 2.92 \\
\hline 13.5 & 26.3 & 16.7 & 1.57 & 0.117 & 2.90 \\
\hline 14.0 & 14.4 & 16.7 & 0.86 & 0.389 & 2.90 \\
\hline 16.0 & 18.6 & 16.7 & 1.11 & 0.267 & $*$ \\
\hline 22.0 & 14.3 & 28.7 & 0.50 & 0.620 & 6.12 \\
\hline 22.5 & -27.6 & 19.2 & -1.44 & 0.153 & 3.47 \\
\hline 23.0 & 51.8 & 18.7 & 2.77 & 0.006 & 3.27 \\
\hline 23.5 & -10.2 & 16.9 & -0.60 & 0.549 & 2.96 \\
\hline 24.0 & -6.8 & 16.9 & -0.40 & 0.688 & 2.96 \\
\hline 26.0 & -21.5 & 16.9 & -1.27 & 0.206 & * \\
\hline 32.0 & 17.0 & 22.6 & 0.75 & 0.454 & 4.15 \\
\hline 32.5 & 53.9 & 23.9 & 2.25 & 0.026 & 4.81 \\
\hline 33.0 & -12.4 & 19.7 & -0.63 & 0.529 & 3.51 \\
\hline 33.5 & -38.0 & 16.8 & -2.26 & 0.025 & 2.94 \\
\hline 34.0 & 18.2 & 16.8 & 1.08 & 0.280 & 2.94 \\
\hline
\end{tabular}




$\begin{array}{lccccc}36.0 & -38.7 & 16.8 & -2.30 & 0.023 & * \\ 42.0 & -44.6 & 20.9 & -2.14 & 0.034 & * \\ 42.5 & 33.5 & 18.0 & 1.87 & 0.064 & * \\ 43.0 & -19.5 & 17.3 & -1.12 & 0.263 & * \\ 43.5 & 9.6 & 16.4 & 0.58 & 0.560 & * \\ 44.0 & -12.4 & 16.4 & -0.76 & 0.448 & * \\ 46.0 & 33.4 & 16.4 & 2.04 & 0.043 & *\end{array}$

\section{Regression Equation}

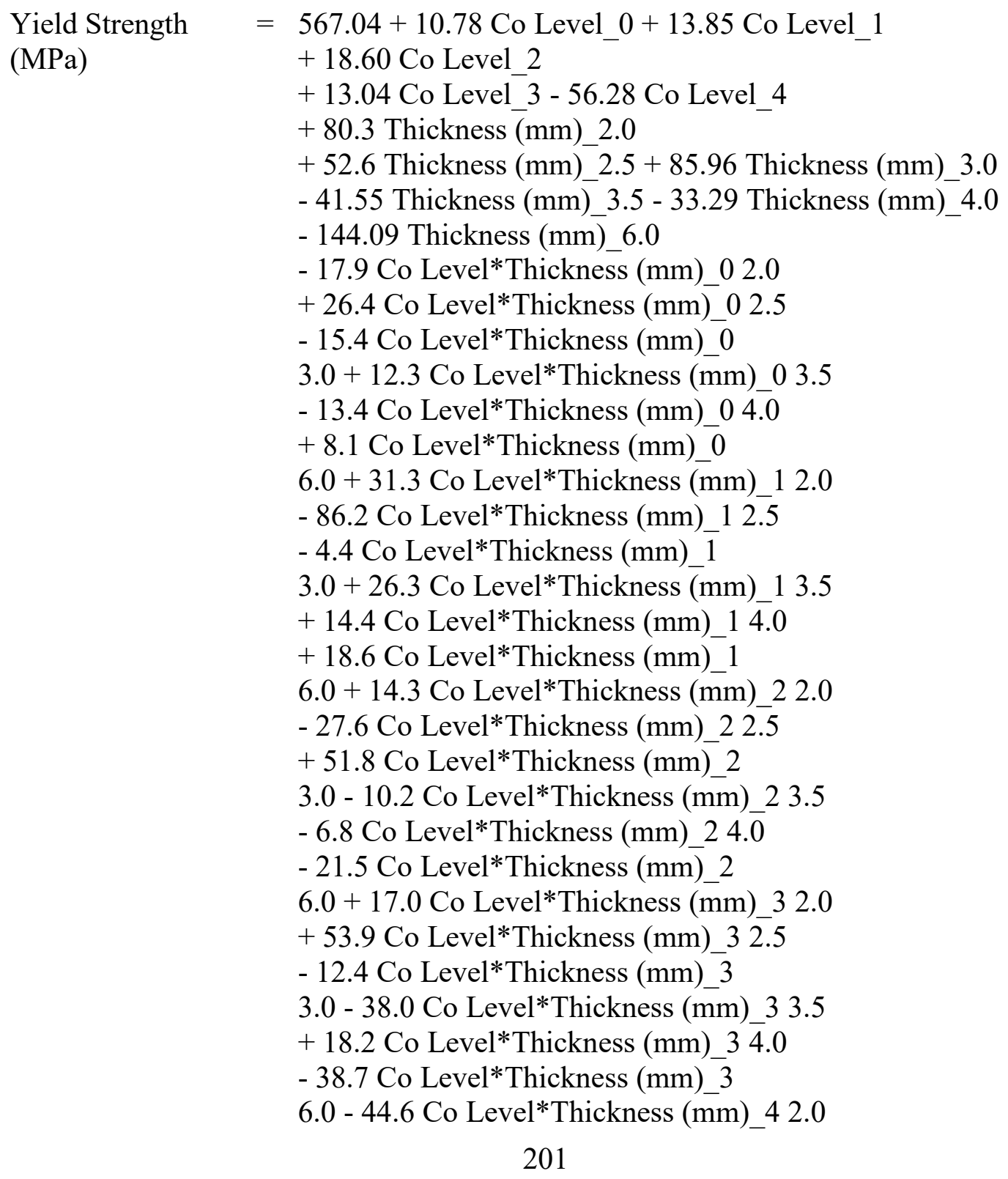




$$
\begin{aligned}
& \text { + 33.5 Co Level*Thickness (mm)_4 } 2.5 \\
& \text { - 19.5 Co Level*Thickness (mm)_4 } \\
& \text { 3.0 +9.6 Co Level*Thickness (mm)_4 } 3.5 \\
& \text { - 12.4 Co Level*Thickness (mm)_4 } 4.0 \\
& \text { + 33.4 Co Level*Thickness (mm)_4 } \\
& \text { 6.0 }
\end{aligned}
$$

\begin{tabular}{|c|c|c|c|c|c|}
\hline Obs & $\begin{array}{c}\text { Yield } \\
\text { Strength } \\
\text { (MPa) }\end{array}$ & Fit & Resid & Std Resid & \\
\hline 13 & 770.6 & 648.3 & 122.3 & 2.35 & $\mathrm{R}$ \\
\hline 14 & 452.5 & 648.3 & -195.8 & -3.77 & $\mathrm{R}$ \\
\hline 16 & 760.4 & 648.3 & 112.1 & 2.16 & $\mathrm{R}$ \\
\hline 48 & 341.0 & 547.3 & -206.3 & -4.29 & $\mathrm{R}$ \\
\hline 51 & 709.7 & 547.3 & 162.4 & 3.37 & $\mathrm{R}$ \\
\hline 53 & 554.1 & 662.4 & -108.3 & -2.08 & $\mathrm{R}$ \\
\hline 94 & 604.6 & 723.4 & -118.8 & -2.34 & $\mathrm{R}$ \\
\hline 96 & 874.4 & 723.4 & 151.0 & 2.98 & $\mathrm{R}$ \\
\hline 97 & 858.6 & 723.4 & 135.2 & 2.67 & $\mathrm{R}$ \\
\hline 130 & 535.5 & 653.6 & -118.1 & -2.38 & $\mathrm{R}$ \\
\hline 131 & 799.9 & 653.6 & 146.3 & 2.94 & $\mathrm{R}$ \\
\hline
\end{tabular}

Fits and Diagnostics for Unusual Observations 


\section{B.1.12 General Linear Model: Elongation (\%) versus Co Level, Thickness $(\mathrm{mm})$}

Method

Factor coding $(-1,0,+1)$

Factor Information

\begin{tabular}{lccc} 
Factor & Type & Levels & Values \\
\hline Co Level & Fixed & 5 & $0,1,2,3,4$ \\
Thickness (mm) & Fixed & 6 & $2.0,2.5,3.0,3.5,4.0,6.0$
\end{tabular}

Analysis of Variance

\begin{tabular}{lccccc} 
Source & DF & Adj SS & Adj MS & F-Value & P-Value \\
\hline Co Level & 4 & 174.86 & 43.715 & 87.96 & 0.000 \\
Thickness (mm) & 5 & 604.29 & 120.858 & 243.17 & 0.000 \\
Co Level*Thickness (mm) & 20 & 95.78 & 4.789 & 9.64 & 0.000 \\
Error & 170 & 84.49 & 0.497 & & \\
Total & 199 & 1013.22 & & &
\end{tabular}

Model Summary

\begin{tabular}{cccc} 
S & R-sq & R-sq(adj) & R-sq(pred) \\
\hline 0.704989 & $91.66 \%$ & $90.24 \%$ & $88.93 \%$
\end{tabular}

\section{Coefficients}

\begin{tabular}{lccccc} 
Term & Coef & SE Coef & T-Value & P-Value & VIF \\
\hline Constant & 2.0130 & 0.0535 & 37.62 & 0.000 & \\
Co Level & & & & & \\
0 & -0.558 & 0.101 & -5.55 & 0.000 & 1.77 \\
1 & -0.846 & 0.109 & -7.78 & 0.000 & 1.95 \\
2 & -0.364 & 0.113 & -3.21 & 0.002 & 2.09 \\
3 & -0.029 & 0.112 & -0.26 & 0.794 & 1.97 \\
4 & 1.797 & 0.100 & 17.98 & 0.000 & $*$
\end{tabular}


Thickness (mm)

$\begin{array}{cccccc}2.0 & -1.374 & 0.152 & -9.02 & 0.000 & 2.59 \\ 2.5 & -1.312 & 0.128 & -10.26 & 0.000 & 2.21 \\ 3.0 & -0.947 & 0.114 & -8.33 & 0.000 & 1.92 \\ 3.5 & 0.026 & 0.106 & 0.25 & 0.803 & 1.79 \\ 4.0 & 0.002 & 0.106 & 0.02 & 0.987 & 1.79 \\ 6.0 & 3.605 & 0.106 & 34.15 & 0.000 & *\end{array}$

Co Level*Thickness (mm)

\begin{tabular}{|c|c|c|c|c|}
\hline 02.0 & 0.266 & 0.283 & 0.94 & 0.348 \\
\hline 02.5 & 0.420 & 0.220 & 1.91 & 0.058 \\
\hline 03.0 & 0.376 & 0.212 & 1.77 & 0.079 \\
\hline 03.5 & 0.167 & 0.208 & 0.80 & 0.424 \\
\hline 04.0 & -0.047 & 0.208 & -0.22 & 0.823 \\
\hline 06.0 & -1.182 & 0.208 & -5.68 & 0.000 \\
\hline 12.0 & 0.708 & 0.314 & 2.26 & 0.025 \\
\hline 12.5 & 0.642 & 0.274 & 2.34 & 0.020 \\
\hline 13.0 & 0.412 & 0.216 & 1.90 & 0.059 \\
\hline 13.5 & -0.288 & 0.212 & -1.36 & 0.177 \\
\hline 14.0 & -0.138 & 0.212 & -0.65 & 0.516 \\
\hline 16.0 & -1.336 & 0.212 & -6.30 & 0.000 \\
\hline 22.0 & 0.371 & 0.364 & 1.02 & 0.310 \\
\hline 22.5 & 0.164 & 0.244 & 0.67 & 0.503 \\
\hline 23.0 & 0.014 & 0.237 & 0.06 & 0.952 \\
\hline 23.5 & -0.138 & 0.214 & -0.65 & 0.519 \\
\hline 24.0 & -0.281 & 0.214 & -1.31 & 0.192 \\
\hline 26.0 & -0.129 & 0.214 & -0.60 & 0.547 \\
\hline 32.0 & -0.146 & 0.287 & -0.51 & 0.613 \\
\hline 32.5 & -0.114 & 0.304 & -0.38 & 0.707 \\
\hline 33.0 & -0.217 & 0.250 & -0.87 & 0.387 \\
\hline 33.5 & -0.021 & 0.214 & -0.10 & 0.923 \\
\hline 34.0 & -0.728 & 0.214 & -3.41 & 0.001 \\
\hline
\end{tabular}




$\begin{array}{llllll}36.0 & 1.225 & 0.214 & 5.74 & 0.000 & * \\ 42.0 & -1.199 & 0.265 & -4.53 & 0.000 & * \\ 42.5 & -1.112 & 0.228 & -4.88 & 0.000 & * \\ 43.0 & -0.585 & 0.220 & -2.66 & 0.009 & * \\ 43.5 & 0.280 & 0.208 & 1.35 & 0.179 & * \\ 44.0 & 1.194 & 0.208 & 5.75 & 0.000 & * \\ 46.0 & 1.422 & 0.208 & 6.85 & 0.000 & *\end{array}$

\section{Regression Equation}

Elongation $=2.0130-0.558$ Co Level_0 -0.846 Co Level_1 - 0.364 Co Level_2

(\%) - 0.029 Co Level_3 $+1 . \overline{79} 7$ Co Level_4 $-1 . \overline{374}$ Thickness (mm)_- 2.0

- 1.312 Thickness (mm)_2.5 - 0.947 Thickness (mm) 3.0

+0.026 Thickness $(\mathrm{mm}) \_3.5+0.002$ Thickness $(\mathrm{mm}) \_4.0$

+3.605 Thickness $(\mathrm{mm}) \_6.0+0.266$ Co Level*Thickness $(\mathrm{mm}) \_0$

2.0

+0.420 Co Level*Thickness (mm)_0 2.5

+0.376 Co Level*Thickness (mm)_0 3.0

+0.167 Co Level*Thickness (mm)_0 3.5

- 0.047 Co Level*Thickness (mm)_0 4.0

- 1.182 Co Level*Thickness (mm)_0 6.0

+0.708 Co Level*Thickness (mm)_1 2.0

+0.642 Co Level*Thickness (mm)_1 2.5

+0.412 Co Level*Thickness (mm)_1 3.0

- 0.288 Co Level*Thickness (mm)_1 3.5

- 0.138 Co Level*Thickness (mm)_14.0

- 1.336 Co Level*Thickness (mm)_16.0

+0.371 Co Level*Thickness (mm)_2 2.0

+ 0.164 Co Level*Thickness (mm)_2 2.5

+ 0.014 Co Level*Thickness (mm)_2 3.0

- 0.138 Co Level*Thickness (mm)_2 3.5

- 0.281 Co Level*Thickness (mm)_24.0

- 0.129 Co Level*Thickness (mm)_2 6.0

- 0.146 Co Level*Thickness (mm)_32.0

- 0.114 Co Level*Thickness (mm)_3 2.5

- 0.217 Co Level*Thickness (mm)_3 3.0

- 0.021 Co Level*Thickness (mm)_3 3.5

- 0.728 Co Level*Thickness (mm)_34.0

+ 1.225 Co Level*Thickness (mm)_36.0

- 1.199 Co Level*Thickness (mm)_4 2.0

- 1.112 Co Level*Thickness (mm)_4 2.5

- 0.585 Co Level*Thickness (mm)_4 3.0 


$$
\begin{aligned}
& \text { + 0.280 Co Level*Thickness (mm)_4 3.5 } \\
& \text { + 1.194 Co Level*Thickness (mm)_4 4.0 } \\
& \text { + 1.422 Co Level*Thickness (mm)_4 } 6.0
\end{aligned}
$$

Fits and Diagnostics for Unusual Observations

\begin{tabular}{ccccrl} 
Obs & $\begin{array}{c}\text { Elongation } \\
(\%)\end{array}$ & Fit & Resid & Std Resid & \\
\hline 28 & 3.685 & 1.648 & 2.037 & 3.09 & $\mathrm{R}$ \\
115 & 2.729 & 5.125 & -2.396 & -3.63 & $\mathrm{R}$ \\
120 & 7.024 & 5.125 & 1.899 & 2.88 & $\mathrm{R}$ \\
154 & 8.769 & 6.815 & 1.954 & 2.96 & $\mathrm{R}$ \\
157 & 5.209 & 6.815 & -1.606 & -2.43 & $\mathrm{R}$ \\
176 & 4.967 & 2.278 & 2.689 & 4.12 & $\mathrm{R}$ \\
178 & 5.653 & 4.117 & 1.536 & 2.33 & $\mathrm{R}$ \\
189 & 3.010 & 5.006 & -1.996 & -3.03 & $\mathrm{R}$ \\
191 & 6.696 & 5.006 & 1.690 & 2.56 & $\mathrm{R}$ \\
193 & 7.117 & 8.838 & -1.721 & -2.61 & $\mathrm{R}$ \\
198 & 10.557 & 8.838 & 1.719 & 2.61 & $\mathrm{R}$ \\
R Large residual & & & &
\end{tabular}




\section{B.1.13 One-Way ANOVA: Tensile Strength (MPa) versus Co Level}

Method

Null hypothesis All means are equal

Alternative hypothesis Not all means are equal

Significance level $\quad \alpha=0.05$

Equal variances were assumed for the analysis.

Factor Information

\begin{tabular}{lcc} 
Factor & Levels & Values \\
\hline Co Level & 5 & $0,1,2,3,4$
\end{tabular}

Analysis of Variance

\begin{tabular}{lccccc} 
Source & DF & Adj SS & Adj MS & F-Value & P-Value \\
\hline Co Level & 4 & 1695 & 423.8 & 1.25 & 0.304 \\
Error & 50 & 17019 & 340.4 & & \\
Total & 54 & 18714 & & &
\end{tabular}

\section{Model Summary}

\begin{tabular}{cccc} 
S & R-sq & R-sq(adj) & R-sq(pred) \\
\hline 18.4493 & $9.06 \%$ & $1.78 \%$ & $0.00 \%$
\end{tabular}

\section{Means}

\begin{tabular}{ccccc}
$\begin{array}{c}\text { Co } \\
\text { Level }\end{array}$ & $\mathbf{N}$ & Mean & StDev & 95\% CI \\
\hline 0 & 11 & 454.93 & 19.81 & $(443.75,466.10)$ \\
1 & 11 & 460.23 & 24.79 & $(449.05,471.40)$ \\
2 & 12 & 462.75 & 15.05 & $(452.05,473.45)$ \\
3 & 9 & 473.09 & 12.48 & $(460.74,485.44)$ \\
4 & 12 & 462.32 & 17.09 & $(451.62,473.01)$ \\
Pooled StDev $=18.4493$ &
\end{tabular}




\section{B.1.14 One-Way ANOVA: Yield Strength (MPa) versus Co Level}

Method

Null hypothesis All means are equal

Alternative hypothesis Not all means are equal

Significance level $\quad \alpha=0.05$

Equal variances were assumed for the analysis.

Factor Information

\begin{tabular}{lcc} 
Factor & Levels & Values \\
\hline Co Level & 5 & $0,1,2,3,4$
\end{tabular}

Analysis of Variance

\begin{tabular}{lccccc} 
Source & DF & Adj SS & Adj MS & F-Value & P-Value \\
\hline Co Level & 4 & 2995 & 748.8 & 4.46 & 0.004 \\
Error & 50 & 8397 & 167.9 & & \\
Total & 54 & 11393 & & &
\end{tabular}

Model Summary

\begin{tabular}{cccc} 
S & R-sq & R-sq(adj) & R-sq(pred) \\
\hline 12.9594 & $26.29 \%$ & $20.39 \%$ & $10.98 \%$
\end{tabular}

Means

\begin{tabular}{ccccc}
$\begin{array}{c}\text { Co } \\
\text { Level }\end{array}$ & $\mathbf{N}$ & Mean & StDev & $\mathbf{9 5 \%}$ CI \\
\hline 0 & 11 & 287.19 & 10.27 & $(279.34,295.04)$ \\
1 & 11 & 288.50 & 18.50 & $(280.65,296.35)$ \\
2 & 12 & 297.24 & 8.49 & $(289.72,304.75)$ \\
3 & 9 & 303.85 & 9.91 & $(295.17,312.52)$ \\
4 & 12 & 304.91 & 14.59 & $(297.40,312.43)$ \\
Pooled StDev $=12.9594$ &
\end{tabular}




\section{B.1.15 One-Way ANOVA: Elongation (\%) versus Co Level}

Method

Null hypothesis All means are equal

Alternative hypothesis Not all means are equal

Significance level $\quad \alpha=0.05$

Equal variances were assumed for the analysis.

Factor Information

\begin{tabular}{ccc} 
Factor & Levels & Values \\
\hline Co Level & 5 & $0,1,2,3,4$
\end{tabular}

Analysis of Variance

\begin{tabular}{lccccc} 
Source & DF & Adj SS & Adj MS & F-Value & P-Value \\
\hline Co Level & 4 & 18.86 & 4.716 & 1.67 & 0.172 \\
Error & 50 & 141.33 & 2.827 & & \\
Total & 54 & 160.20 & & &
\end{tabular}

Model Summary

\begin{tabular}{cccc} 
S & R-sq & R-sq(adj) & R-sq(pred) \\
\hline 1.68127 & $11.77 \%$ & $4.72 \%$ & $0.00 \%$
\end{tabular}

Means

\begin{tabular}{ccccc}
$\begin{array}{c}\text { Co } \\
\text { Level }\end{array}$ & $\mathbf{N}$ & Mean & StDev & 95\% CI \\
\hline 0 & 11 & 17.256 & 1.789 & $(16.238,18.275)$ \\
1 & 11 & 16.858 & 1.313 & $(15.840,17.876)$ \\
2 & 12 & 18.216 & 2.070 & $(17.241,19.191)$ \\
3 & 9 & 16.751 & 1.865 & $(15.625,17.876)$ \\
4 & 12 & 17.963 & 1.247 & $(16.988,18.938)$ \\
Pooled StDev $=1.68127$ &
\end{tabular}




\section{B.1.16 General Linear Model: HV versus Co Level, Position Method}

Factor coding $\quad(-1,0,+1)$

Factor Information

\begin{tabular}{lccc} 
Factor & Type & Levels & Values \\
\hline Co Level & Fixed & 5 & $0,1,2,3,4$ \\
Position & Fixed & 2 & First, Last
\end{tabular}

Analysis of Variance

\begin{tabular}{lccccc} 
Source & DF & Adj SS & Adj MS & F-Value & P-Value \\
\hline Co Level & 4 & 5135.1 & 1283.79 & 34.50 & 0.000 \\
Position & 1 & 800.9 & 800.89 & 21.52 & 0.000 \\
Co Level*Position & 4 & 521.3 & 130.31 & 3.50 & 0.011 \\
Error & 90 & 3348.9 & 37.21 & & \\
Total & 99 & 9806.2 & & &
\end{tabular}

Model Summary

\begin{tabular}{cccc} 
S & R-sq & R-sq(adj) & R-sq(pred) \\
\hline 6.1 & $65.85 \%$ & $62.43 \%$ & $57.84 \%$
\end{tabular}

Coefficients

\begin{tabular}{lccccc}
\multicolumn{1}{c}{ Term } & Coef & SE Coef & T-Value & P-Value & VIF \\
\hline $\begin{array}{lcccc}\text { Constant } \\
\text { Co Level }\end{array}$ & 187.090 & 0.610 & 306.70 & 0.000 & \\
0 & & & & & \\
1 & -11.94 & 1.22 & -9.79 & 0.000 & 1.60 \\
2 & -1.99 & 1.22 & -1.63 & 0.106 & 1.60 \\
3 & 0.16 & 1.22 & 0.13 & 0.896 & 1.60 \\
4 & 4.11 & 1.22 & 3.37 & 0.001 & 1.60 \\
& 9.66 & 1.22 & 7.92 & 0.000 & $*$
\end{tabular}


Position

$\begin{array}{cccccc}\text { First } & -2.830 & 0.610 & -4.64 & 0.000 & 1.00 \\ \text { Last } & 2.830 & 0.610 & 4.64 & 0.000 & *\end{array}$

Co Level*Position

$\begin{array}{lccccc}0 \text { First } & -3.52 & 1.22 & -2.89 & 0.005 & 1.60 \\ \text { 0 Last } & 3.52 & 1.22 & 2.89 & 0.005 & * \\ \text { 1 First } & 0.73 & 1.22 & 0.60 & 0.551 & 1.60 \\ \text { 1 Last } & -0.73 & 1.22 & -0.60 & 0.551 & * \\ \text { 2 First } & 1.78 & 1.22 & 1.46 & 0.148 & 1.60 \\ \text { 2 Last } & -1.78 & 1.22 & -1.46 & 0.148 & * \\ \text { 3 First } & -1.67 & 1.22 & -1.37 & 0.174 & 1.60 \\ \text { 3 Last } & 1.67 & 1.22 & 1.37 & 0.174 & * \\ \text { 4 First } & 2.68 & 1.22 & 2.20 & 0.031 & * \\ \text { 4 Last } & -2.68 & 1.22 & -2.20 & 0.031 & *\end{array}$

Regression Equation

$$
\begin{aligned}
\text { HV }= & 187.090-11.94 \text { Co Level_0 - } 1.99 \text { Co Level_1 + 0.16 Co Level_2 } \\
& +4.11 \text { Co Level_3 } \\
& +9.66 \text { Co Level_4 }-2.830 \text { Position_First }+2.830 \text { Position_Last } \\
& -3.52 \text { Co Level*Position_0 First }+3.52 \text { Co Level*Position_0 Last } \\
& +0.73 \text { Co Level*Position_1 First }-0.73 \text { Co Level*Position_1 Last } \\
& +1.78 \text { Co Level*Position_2 First }-1.78 \text { Co Level*Position_2 Last } \\
& -1.67 \text { Co Level*Position_3 First }+1.67 \text { Co Level*Position_3 Last } \\
& +2.68 \text { Co Level*Position_4 First }-2.68 \text { Co Level*Position_4 Last }
\end{aligned}
$$

Fits and Diagnostics for Unusual Observations

\begin{tabular}{ccccrc} 
Obs & HV & Fit & Resid & Std Resid \\
\hline 19 & 197.00 & 181.50 & 15.50 & 2.68 & $\mathrm{R}$ \\
74 & 182.00 & 195.70 & -13.70 & -2.37 & $\mathrm{R}$ \\
91 & 209.00 & 196.90 & 12.10 & 2.09 & $\mathrm{R}$ \\
\multicolumn{5}{l}{ L Large residual }
\end{tabular}




\section{B.1.17 General Linear Model: Absorbed Energy (J) versus Co Level, Temperature $\left({ }^{\circ} \mathrm{C}\right)$ - V-notched samples}

Method

Factor coding $(-1,0,+1)$

Factor Information

\begin{tabular}{lccc} 
Factor & Type & Levels & Values \\
\hline Co Level & Fixed & 5 & $0,1,2,3,4$ \\
Temperature $\left({ }^{\circ} \mathrm{C}\right)$ & Fixed & 4 & $-40.0,-20.0,0.0,22.6$
\end{tabular}

Analysis of Variance

\begin{tabular}{lccccc} 
Source & DF & Adj SS & Adj MS & F-Value & P-Value \\
\hline Co Level & 4 & 153.85 & 38.461 & 68.21 & 0.000 \\
Temperature $\left({ }^{\circ} \mathrm{C}\right)$ & 3 & 1666.90 & 555.634 & 985.47 & 0.000 \\
Co Level ${ }^{*}$ Temperature $\left({ }^{\circ} \mathrm{C}\right)$ & 12 & 27.57 & 2.297 & 4.07 & 0.000 \\
Error & 160 & 90.21 & 0.564 & & \\
Total & 179 & 1938.53 & & &
\end{tabular}

Model Summary

\begin{tabular}{cccc} 
S & R-sq & R-sq(adj) & R-sq(pred) \\
\hline 0.750885 & $95.35 \%$ & $94.79 \%$ & $94.11 \%$
\end{tabular}

Coefficients

\begin{tabular}{lccccc} 
Term & Coef & SE Coef & T-Value & P-Value & VIF \\
\hline $\begin{array}{l}\text { Constant } \\
\text { Co Level }\end{array}$ & 9.1592 & 0.0560 & 163.65 & 0.000 & \\
0 & & & & & \\
1 & 1.244 & 0.112 & 11.11 & 0.000 & 1.60 \\
2 & 0.396 & 0.112 & 3.54 & 0.001 & 1.60 \\
3 & 0.499 & 0.112 & 4.46 & 0.000 & 1.60 \\
4 & -1.198 & 0.112 & -10.70 & 0.000 & 1.60 \\
& -0.941 & 0.112 & -8.40 & 0.000 & $*$
\end{tabular}


Temperature $\left({ }^{\circ} \mathrm{C}\right)$

$\begin{array}{lccccc}-40.0 & -4.8311 & 0.0969 & -49.84 & 0.000 & 1.50 \\ -20.0 & -0.0463 & 0.0969 & -0.48 & 0.634 & 1.50 \\ 0.0 & 1.4884 & 0.0969 & 15.35 & 0.000 & 1.50 \\ 22.6 & 3.3890 & 0.0969 & 34.96 & 0.000 & *\end{array}$

Co Level ${ }^{*}$ Temperature $\left({ }^{\circ} \mathrm{C}\right)$

$\begin{array}{lccccc}0-40.0 & -0.411 & 0.194 & -2.12 & 0.036 & 2.40 \\ 0-20.0 & 0.148 & 0.194 & 0.76 & 0.446 & 2.40 \\ 00.0 & 0.577 & 0.194 & 2.97 & 0.003 & 2.40 \\ 022.6 & -0.313 & 0.194 & -1.62 & 0.108 & * \\ 1-40.0 & -0.119 & 0.194 & -0.61 & 0.540 & 2.40 \\ 1-20.0 & 0.387 & 0.194 & 2.00 & 0.047 & 2.40 \\ 10.0 & -0.159 & 0.194 & -0.82 & 0.413 & 2.40 \\ 122.6 & -0.109 & 0.194 & -0.56 & 0.574 & * \\ 2-40.0 & -0.303 & 0.194 & -1.56 & 0.120 & 2.40 \\ 2-20.0 & -0.518 & 0.194 & -2.67 & 0.008 & 2.40 \\ 20.0 & 0.767 & 0.194 & 3.95 & 0.000 & 2.40 \\ 222.6 & 0.055 & 0.194 & 0.28 & 0.777 & * \\ 3-40.0 & 0.630 & 0.194 & 3.25 & 0.001 & 2.40 \\ 3-20.0 & 0.039 & 0.194 & 0.20 & 0.841 & 2.40 \\ 30.0 & -0.770 & 0.194 & -3.97 & 0.000 & 2.40 \\ 322.6 & 0.101 & 0.194 & 0.52 & 0.603 & * \\ 4-40.0 & 0.203 & 0.194 & 1.05 & 0.296 & * \\ 4-20.0 & -0.056 & 0.194 & -0.29 & 0.773 & * \\ 40.0 & -0.414 & 0.194 & -2.13 & 0.034 & * \\ 422.6 & 0.266 & 0.194 & 1.37 & 0.171 & *\end{array}$

Regression Equation

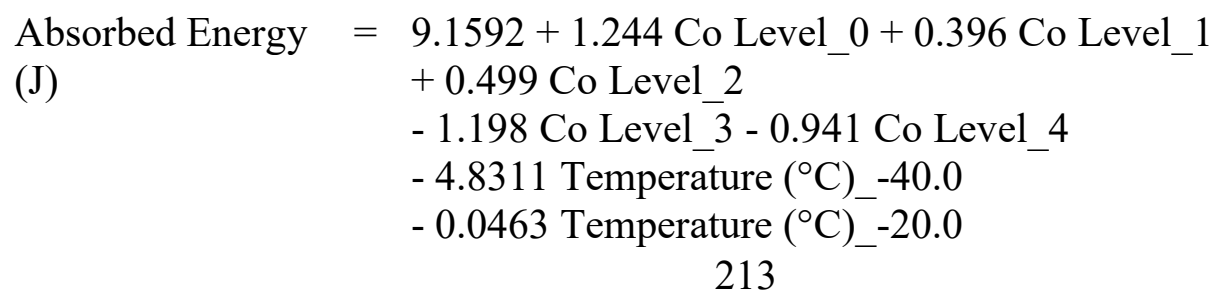


+1.4884 Temperature $\left({ }^{\circ} \mathrm{C}\right) \_0.0$

+3.3890 Temperature $\left({ }^{\circ} \mathrm{C}\right) \_22.6$

- 0.411 Co Level*Temperature $\left({ }^{\circ} \mathrm{C}\right) \_0$

$-40.0+0.148$ Co Level*Temperature $\left({ }^{\circ} \mathrm{C}\right) \_0-20.0$

+0.577 Co Level*Temperature $\left({ }^{\circ} \mathrm{C}\right) \_0.0$

- 0.313 Co Level*Temperature $\left({ }^{\circ} \mathrm{C}\right) \_022.6$

- 0.119 Co Level*Temperature $\left({ }^{\circ} \mathrm{C}\right) \_1-40.0$

+0.387 Co Level*Temperature $\left({ }^{\circ} \mathrm{C}\right) \_1-20.0$

- 0.159 Co Level*Temperature $\left({ }^{\circ} \mathrm{C}\right) \_10.0$

- 0.109 Co Level*Temperature $\left({ }^{\circ} \mathrm{C}\right) \_122.6$

- 0.303 Co Level ${ }^{*}$ Temperature $\left({ }^{\circ} \mathrm{C}\right) \_2-40.0$

- 0.518 Co Level*Temperature $\left({ }^{\circ} \mathrm{C}\right) \_2$-20.0

+0.767 Co Level*Temperature $\left({ }^{\circ} \mathrm{C}\right) \_20.0$

+0.055 Co Level ${ }^{*}$ Temperature $\left({ }^{\circ} \mathrm{C}\right) \_22.6$

+0.630 Co Level*Temperature $\left({ }^{\circ} \mathrm{C}\right) \_3-40.0$

+0.039 Co Level*Temperature $\left({ }^{\circ} \mathrm{C}\right) \_3-20.0$

- 0.770 Co Level*Temperature $\left({ }^{\circ} \mathrm{C}\right) \_30.0$

$+0.101 \mathrm{Co}$ Level*Temperature $\left({ }^{\circ} \mathrm{C}\right) \_322.6$

+0.203 Co Level ${ }^{*}$ Temperature $\left({ }^{\circ} \mathrm{C}\right) \_4-40.0$

- 0.056 Co Level*Temperature $\left({ }^{\circ} \mathrm{C}\right) \_4-20.0$

- 0.414 Co Level*Temperature $\left({ }^{\circ} \mathrm{C}\right) \_0.0$

+0.266 Co Level*Temperature $\left({ }^{\circ} \mathrm{C}\right) \_422.6$

Fits and Diagnostics for Unusual Observations

\begin{tabular}{|c|c|c|c|c|c|}
\hline Obs & $\begin{array}{r}\text { Absorbed } \\
\text { Energy (J) }\end{array}$ & Fit & Resid & Std Resid & \\
\hline 42 & 10.194 & 11.874 & -1.680 & -2.37 & $\mathrm{R}$ \\
\hline 69 & 10.434 & 11.913 & -1.479 & -2.09 & $\mathrm{R}$ \\
\hline 74 & 7.253 & 8.679 & -1.426 & -2.01 & $\mathrm{R}$ \\
\hline 77 & 10.794 & 8.679 & 2.115 & 2.99 & $\mathrm{R}$ \\
\hline 128 & 6.692 & 8.116 & -1.424 & -2.01 & $\mathrm{R}$ \\
\hline 147 & 2.620 & 4.605 & -1.985 & -2.80 & $\mathrm{R}$ \\
\hline
\end{tabular}




\section{B.1.18 General Linear Model: Absorbed Energy (J) versus Co Level, Temperature $\left({ }^{\circ} \mathrm{C}\right)$ - Unnotched samples}

Method

Factor coding $(-1,0,+1)$

Factor Information

\begin{tabular}{lccc} 
Factor & Type & Levels & Values \\
\hline Co Level & Fixed & 5 & $0,1,2,3,4$ \\
Temperature $\left({ }^{\circ} \mathrm{C}\right)$ & Fixed & 4 & $-40.0,-20.0,0.0,22.6$
\end{tabular}

Analysis of Variance

\begin{tabular}{lccccc} 
Source & DF & Adj SS & Adj MS & F-Value & P-Value \\
\hline Co Level & 4 & 7960 & 1989.98 & 23.56 & 0.000 \\
Temperature $\left({ }^{\circ} \mathrm{C}\right)$ & 3 & 12252 & 4084.15 & 48.36 & 0.000 \\
Co Level*Temperature $\left({ }^{\circ} \mathrm{C}\right)$ & 12 & 4106 & 342.20 & 4.05 & 0.000 \\
Error & 160 & 13512 & 84.45 & & \\
Total & 179 & 37831 & & &
\end{tabular}

Model Summary

\begin{tabular}{cccc} 
S & R-sq & R-sq(adj) & R-sq(pred) \\
\hline 9.18978 & $64.28 \%$ & $60.04 \%$ & $54.80 \%$
\end{tabular}

\section{Coefficients}

\begin{tabular}{lccccc} 
Term & Coef & SE Coef & T-Value & P-Value & VIF \\
\hline $\begin{array}{l}\text { Constant } \\
\text { Co Level }\end{array}$ & 104.254 & 0.685 & 152.20 & 0.000 & \\
0 & & & & & \\
1 & 0.16 & 1.37 & 0.11 & 0.910 & 1.60 \\
2 & 3.57 & 1.37 & 2.61 & 0.010 & 1.60 \\
3 & 8.57 & 1.37 & 6.26 & 0.000 & 1.60 \\
4 & -11.59 & 1.37 & -8.46 & 0.000 & 1.60 \\
& -0.71 & 1.37 & -0.52 & 0.606 & $*$
\end{tabular}


Temperature $\left({ }^{\circ} \mathrm{C}\right)$

$\begin{array}{lccccc}-40.0 & -12.94 & 1.19 & -10.91 & 0.000 & 1.50 \\ -20.0 & -1.28 & 1.19 & -1.08 & 0.282 & 1.50 \\ 0.0 & 6.12 & 1.19 & 5.16 & 0.000 & 1.50 \\ 22.6 & 8.11 & 1.19 & 6.83 & 0.000 & *\end{array}$

Co Level ${ }^{*}$ Temperature $\left({ }^{\circ} \mathrm{C}\right)$

$\begin{array}{lccccc}0-40.0 & 4.80 & 2.37 & 2.02 & 0.045 & 2.40 \\ 0-20.0 & -2.73 & 2.37 & -1.15 & 0.252 & 2.40 \\ 0-0.0 & -2.16 & 2.37 & -0.91 & 0.363 & 2.40 \\ 022.6 & 0.09 & 2.37 & 0.04 & 0.971 & * \\ 1-40.0 & 7.84 & 2.37 & 3.30 & 0.001 & 2.40 \\ 1-20.0 & 2.27 & 2.37 & 0.96 & 0.341 & 2.40 \\ 10.0 & -6.96 & 2.37 & -2.93 & 0.004 & 2.40 \\ 122.6 & -3.14 & 2.37 & -1.33 & 0.187 & * \\ 2-40.0 & 1.81 & 2.37 & 0.76 & 0.446 & 2.40 \\ 2-20.0 & 0.73 & 2.37 & 0.31 & 0.759 & 2.40 \\ 20.0 & 2.85 & 2.37 & 1.20 & 0.231 & 2.40 \\ 222.6 & -5.39 & 2.37 & -2.27 & 0.024 & * \\ 3-40.0 & -3.00 & 2.37 & -1.26 & 0.208 & 2.40 \\ 3-20.0 & -4.97 & 2.37 & -2.09 & 0.038 & 2.40 \\ 30.0 & 1.67 & 2.37 & 0.70 & 0.483 & 2.40 \\ 322.6 & 6.30 & 2.37 & 2.65 & 0.009 & * \\ 4-40.0 & -11.45 & 2.37 & -4.83 & 0.000 & * \\ 4-20.0 & 4.70 & 2.37 & 1.98 & 0.049 & * \\ 40.0 & 4.61 & 2.37 & 1.94 & 0.054 & * \\ 422.6 & 2.15 & 2.37 & 0.91 & 0.366 & *\end{array}$

Regression Equation
Absorbed Energy $=104.254+0.16$ Co Level_0 +3.57 Co Level_1
(J) + 8.57 Co Level_2
- 11.59 Co Level_3 - 0.71 Co Level_4
- 12.94 Temperature $\left({ }^{\circ} \mathrm{C}\right)_{-}-40.0$
- 1.28 Temperature $\left({ }^{\circ} \mathrm{C}\right) \_-20.0+6.12$ Temperature $\left({ }^{\circ} \mathrm{C}\right) \_0.0$ 216 
+8.11 Temperature $\left({ }^{\circ} \mathrm{C}\right) \_22.6$

+4.80 Co Level ${ }^{*}$ Temperature $\left({ }^{\circ} \mathrm{C}\right) \_0-40.0$

- 2.73 Co Level*Temperature $\left({ }^{\circ} \mathrm{C}\right) \_0-20.0$

- 2.16 Co Level*Temperature $\left({ }^{\circ} \mathrm{C}\right) 00.0$

+0.09 Co Level*Temperature $\left({ }^{\circ} \mathrm{C}\right) \_022.6$

+7.84 Co Level*Temperature $\left({ }^{\circ} \mathrm{C}\right) \_1-40.0$

+2.27 Co Level*Temperature $\left({ }^{\circ} \mathrm{C}\right) \_1-20.0$

- 6.96 Co Level*Temperature $\left({ }^{\circ} \mathrm{C}\right) \_10.0$

- 3.14 Co Level*Temperature $\left({ }^{\circ} \mathrm{C}\right) \_122.6$

+1.81 Co Level*Temperature $\left({ }^{\circ} \mathrm{C}\right) \_2-40.0$

+0.73 Co Level ${ }^{*}$ Temperature $\left({ }^{\circ} \mathrm{C}\right) \_2-20.0$

+2.85 Co Level $*$ Temperature $\left({ }^{\circ} \mathrm{C}\right) \_20.0$

- 5.39 Co Level*Temperature $\left({ }^{\circ} \mathrm{C}\right) \_222.6$

- 3.00 Co Level*Temperature $\left({ }^{\circ} \mathrm{C}\right) \_3-40.0$

- 4.97 Co Level ${ }^{*}$ Temperature $\left({ }^{\circ} \mathrm{C}\right) \_3-20.0$

$+1.67 \mathrm{Co}$ Level $*$ Temperature $\left({ }^{\circ} \mathrm{C}\right) \_30.0$

+ 6.30 Co Level*Temperature $\left({ }^{\circ} \mathrm{C}\right) \_322.6$

- 11.45 Co Level*Temperature $\left({ }^{\circ} \mathrm{C}\right) \_4-40.0$

+4.70 Co Level*Temperature $\left({ }^{\circ} \mathrm{C}\right) \_4-20.0$

$+4.61 \mathrm{Co}$ Level $*$ Temperature $\left({ }^{\circ} \mathrm{C}\right) \_40.0$

+2.15 Co Level*Temperature $\left({ }^{\circ} \mathrm{C}\right) \_422.6$

Fits and Diagnostics for Unusual Observations

\begin{tabular}{cccrrr}
\multicolumn{3}{c}{ Absorbed } & & & \\
Obs & Energy (J) & Fit & Resid & Std Resid & \\
\hline 4 & 131.06 & 112.60 & 18.46 & 2.13 & $\mathrm{R}$ \\
26 & 133.16 & 115.54 & 17.62 & 2.03 & $\mathrm{R}$ \\
121 & 109.22 & 86.41 & 22.80 & 2.63 & $\mathrm{R}$ \\
128 & 88.64 & 106.96 & -18.32 & -2.11 & $\mathrm{R}$ \\
132 & 133.82 & 106.96 & 26.86 & 3.10 & $\mathrm{R}$ \\
162 & 120.45 & 101.69 & 18.76 & 2.16 & $\mathrm{R}$ \\
R Large residual & & & &
\end{tabular}




\section{B.1.19 General Linear Model: Ksc MPa $\sqrt{m}$ versus Co Level, Temperature $\left({ }^{\circ} \mathrm{C}\right)$}

Method

Factor coding $\quad(-1,0,+1)$

Factor Information

\begin{tabular}{lccc} 
Factor & Type & Levels & Values \\
\hline Co Level & Fixed & 5 & $0,1,2,3,4$ \\
Temperature Fixed & 4 & $-40.0,-20.0,0.0,22.6$
\end{tabular}

Analysis of Variance

\begin{tabular}{lccccc} 
Source & DF & Adj SS & Adj MS & F-Value & P-Value \\
\hline Co Level & 4 & 143.91 & 35.978 & 3.28 & 0.017 \\
Temperature & 3 & 293.72 & 97.907 & 8.93 & 0.000 \\
Co Level*Temperature & 12 & 69.94 & 5.829 & 0.53 & 0.886 \\
Error & 63 & 690.45 & 10.960 & & \\
Total & 82 & 1214.98 & & &
\end{tabular}

Model Summary

\begin{tabular}{cccc} 
S & R-sq & R-sq(adj) & R-sq(pred) \\
\hline 3.31052 & $43.17 \%$ & $26.03 \%$ & $0.00 \%$
\end{tabular}

\section{Coefficients}

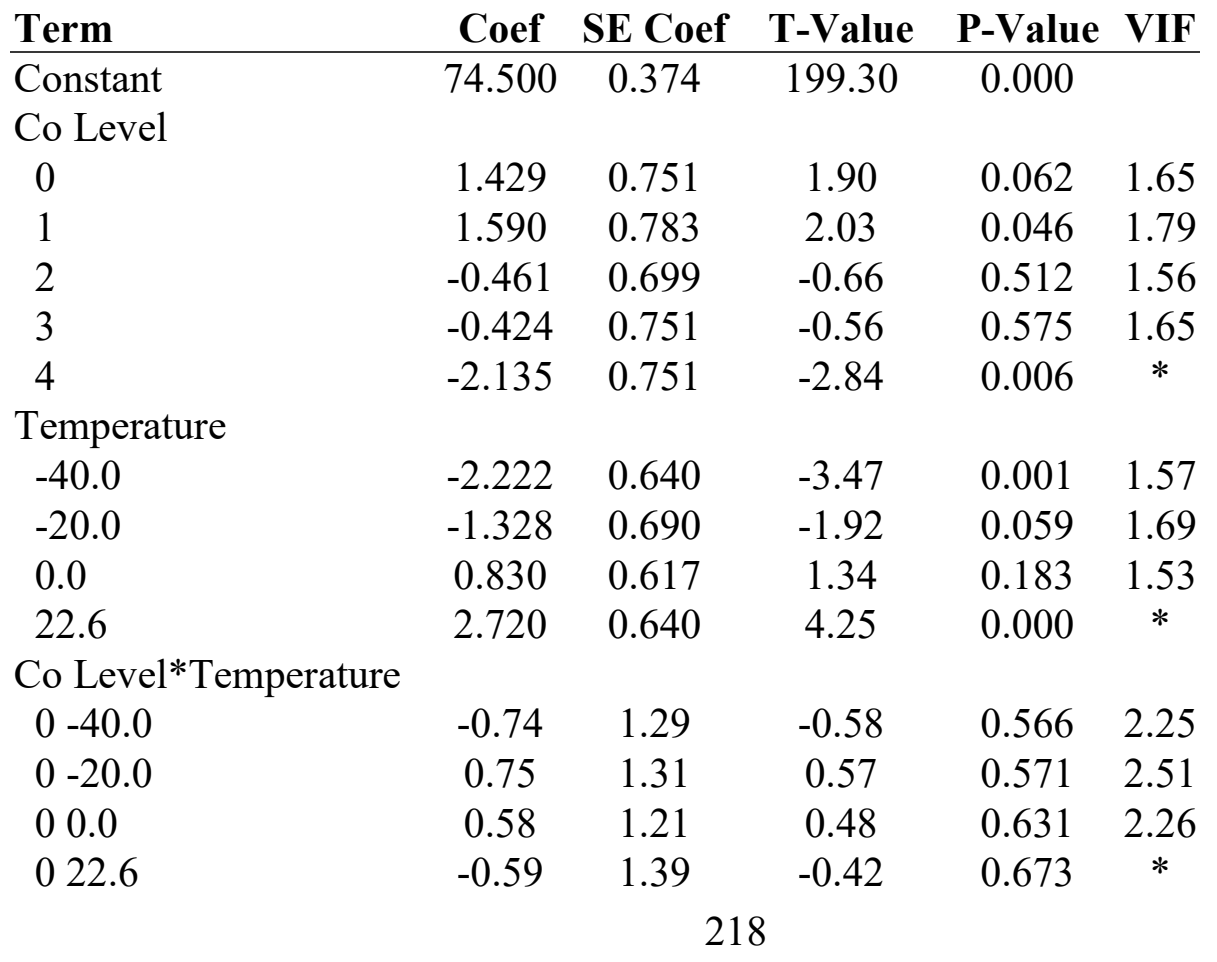




$\begin{array}{llcccc}1-40.0 & -0.45 & 1.24 & -0.36 & 0.718 & 2.37 \\ 1-20.0 & -0.09 & 1.61 & -0.05 & 0.957 & 3.55 \\ 10.0 & 1.39 & 1.23 & 1.13 & 0.262 & 2.48 \\ 122.6 & -0.85 & 1.31 & -0.65 & 0.516 & * \\ 2-40.0 & 0.55 & 1.26 & 0.44 & 0.664 & 2.45 \\ 2-20.0 & 0.37 & 1.22 & 0.30 & 0.765 & 2.57 \\ 20.0 & -0.61 & 1.18 & -0.52 & 0.608 & 2.40 \\ 222.6 & -0.31 & 1.19 & -0.26 & 0.797 & * \\ 3-40.0 & -0.46 & 1.22 & -0.38 & 0.708 & 2.30 \\ 3-20.0 & -1.34 & 1.41 & -0.95 & 0.346 & 2.91 \\ 30.0 & -0.83 & 1.28 & -0.65 & 0.519 & 2.52 \\ 322.6 & 2.63 & 1.29 & 2.04 & 0.045 & * \\ 4-40.0 & 1.11 & 1.39 & 0.80 & 0.429 & * \\ 4-20.0 & 0.32 & 1.31 & 0.24 & 0.811 & * \\ 40.0 & -0.54 & 1.28 & -0.42 & 0.673 & * \\ 422.6 & -0.88 & 1.22 & -0.72 & 0.473 & *\end{array}$

\section{Regression Equation}

$$
\begin{aligned}
& \mathrm{KJC}=74.500+1.429 \text { Co Level } 0 \\
& \mathrm{MPa} \sqrt{\mathrm{m}}+1.590 \mathrm{Co} \text { Level_1 }-0.4 \overline{6} 1 \mathrm{Co} \text { Level_2 } \\
& \text { - 0.424 Co Level_3 - 2.135 Co Level_4 } \\
& \text { - } 2.222 \text { Temperature_-40.0 } \\
& \text { - } 1.328 \text { Temperature }-20.0 \\
& +0.830 \text { Temperature_0.0 } \\
& +2.720 \text { Temperature_22.6 } \\
& \text { - 0.74 Co Level*Temperature_0 -40.0 } \\
& \text { + 0.75 Co Level*Temperature_0 -20.0 } \\
& \text { + } 0.58 \text { Co Level*Temperature_0 } 0.0 \\
& \text { - 0.59 Co Level*Temperature_0 } 22.6 \\
& \text { - 0.45 Co Level*Temperature_1 -40.0 } \\
& \text { - 0.09 Co Level*Temperature_1 -20.0 } \\
& +1.39 \text { Co Level*Temperature_1 } 0.0 \\
& \text { - 0.85 Co Level*Temperature } 122.6 \\
& +0.55 \text { Co Level*Temperature_2 -40.0 } \\
& \text { + 0.37 Co Level*Temperature_2 -20.0 } \\
& \text { - 0.61 Co Level*Temperature_2 } 0.0 \\
& \text { - 0.31 Co Level*Temperature_2 } 22.6 \\
& \text { - 0.46 Co Level*Temperature_3 -40.0 } \\
& \text { - 1.34 Co Level*Temperature_3 -20.0 } \\
& \text { - } 0.83 \text { Co Level*Temperature_3 } 0.0 \\
& \text { + 2.63 Co Level*Temperature_322.6 } \\
& \text { + } 1.11 \text { Co Level*Temperature_4 -40.0 } \\
& \text { + 0.32 Co Level*Temperature_4 -20.0 }
\end{aligned}
$$


- 0.54 Co Level*Temperature 40.0

- 0.88 Co Level*Temperature 422.6

Fits and Diagnostics for Unusual Observations

\begin{tabular}{ccccr} 
Obs & KJC MPa $\sqrt{ }$ m & Fit & Resid & \multicolumn{1}{c}{ Std Resid } \\
\hline 6 & 84.37 & 77.96 & 6.41 & $2.24 \mathrm{R}$ \\
17 & 66.62 & 74.20 & -7.59 & $-2.56 \mathrm{R}$ \\
23 & 71.15 & 77.34 & -6.19 & $-2.09 \mathrm{R}$
\end{tabular}

$R$ Large residual 


\title{
B.2 Effect of Cobalt in Solid Solution Strengthened Ferritic Ductile Iron
}

\author{
B.2.1 General Linear Model: Nodule Diameter versus Co Level, Position \\ Method \\ Factor coding $(-1,0,+1)$
}

Factor Information

\begin{tabular}{lccc} 
Factor & Type & Levels & Values \\
\hline Co & Fixed & 4 & $0,2,3,4$
\end{tabular}

Level

Position Fixed 2 FIRST, LAST

Analysis of Variance

\begin{tabular}{lccccc} 
Source & DF & Adj SS & Adj MS & F-Value & P-Value \\
\hline Co Level & 3 & 111.42 & 37.140 & 10.03 & 0.000 \\
Position & 1 & 121.43 & 121.425 & 32.78 & 0.000 \\
Co & 3 & 12.48 & 4.161 & 1.12 & 0.354
\end{tabular}

Level*Position

$\begin{array}{llll}\text { Error } & 32 & 118.54 & 3.704\end{array}$

Total $\quad 39 \quad 363.87$

Model Summary

\begin{tabular}{cccc} 
S & R-sq & R-sq(adj) & R-sq(pred) \\
\hline 1.92470 & $67.42 \%$ & $60.30 \%$ & $49.10 \%$
\end{tabular}

\section{Coefficients}

\begin{tabular}{lccccc} 
Term & Coef & SE Coef & T-Value & P-Value VIF \\
\hline Constant & 25.330 & 0.304 & 83.24 & 0.000 & \\
Co Level & & & & & \\
0 & 2.260 & 0.527 & 4.29 & 0.000 & 1.50 \\
2 & 0.275 & 0.527 & 0.52 & 0.605 & 1.50 \\
3 & -0.097 & 0.527 & -0.18 & 0.856 & 1.50 \\
4 & -2.439 & 0.527 & -4.63 & 0.000 & $*$ \\
$\quad \begin{array}{l}\text { Position } \\
\text { FIRST }\end{array}$ & -1.742 & 0.304 & -5.73 & 0.000 & 1.00 \\
LAST & 1.742 & 0.304 & 5.73 & 0.000 & $*$ \\
$\begin{array}{l}\text { Co } \\
\text { Level*Position }\end{array}$ & & & & & \\
0 FIRST & 0.005 & 0.527 & 0.01 & 0.993 & 1.50 \\
0 LAST & -0.005 & 0.527 & -0.01 & 0.993 & $*$ \\
& & & 221 & &
\end{tabular}




$\begin{array}{lccccc}\text { 2 FIRST } & -0.109 & 0.527 & -0.21 & 0.837 & 1.50 \\ \text { 2 LAST } & 0.109 & 0.527 & 0.21 & 0.837 & * \\ \text { 3 FIRST } & -0.732 & 0.527 & -1.39 & 0.174 & 1.50 \\ \text { 3 LAST } & 0.732 & 0.527 & 1.39 & 0.174 & * \\ \text { 4 FIRST } & 0.837 & 0.527 & 1.59 & 0.122 & * \\ \text { 4 LAST } & -0.837 & 0.527 & -1.59 & 0.122 & *\end{array}$

Regression Equation

Nodule $=25.330+2.260$ Co Level_0

Diameter +0.275 Co Level_2

- 0.097 Co Level_3

- 2.439 Co Level_4

- 1.742 Position FIRST

+1.742 Position LAST

+0.005 Co Level*Position_0 FIRST

- 0.005 Co Level*Position_0 LAST

- 0.109 Co Level*Position_2 FIRST

+0.109 Co Level*Position 2 LAST

- 0.732 Co Level*Position_3 FIRST

+0.732 Co Level*Position_3 LAST

+0.837 Co Level*Position_4 FIRST

- 0.837 Co Level*Position_4 LAST

Fits and Diagnostics for Unusual Observations

\begin{tabular}{|c|c|c|c|c|}
\hline Obs & $\begin{array}{c}\text { Nodule } \\
\text { Diameter }\end{array}$ & Fit & Resid & $\begin{array}{r}\text { Std } \\
\text { Resid }\end{array}$ \\
\hline 6 & & 29.32 & 3.471 & \\
\hline 40 & 20.097 & 23.797 & -3.700 & -2 \\
\hline
\end{tabular}

$R$ Large residual 


\section{B.2.2 One-way ANOVA: Tensile Strength (MPa) versus Co Level}

Method

Null hypothesis

All means are equal

Alternative hypothesis

Significance level

Not all means are equal

Equal variances were assumed for the analysis.

Factor Information

\begin{tabular}{lcc} 
Factor & Levels & Values \\
\hline Co Level & 4 & $0,2,3,4$
\end{tabular}

Analysis of Variance

\begin{tabular}{lccccc} 
Source & DF & Adj SS & Adj MS & F-Value & P-Value \\
\hline Co Level & 3 & 15556.1 & 5185.37 & 813.51 & 0.000 \\
Error & 20 & 127.5 & 6.37 & & \\
Total & 23 & 15683.6 & & &
\end{tabular}

\section{Model Summary}

\begin{tabular}{cccc} 
S & R-sq & R-sq(adj) & R-sq(pred) \\
\hline 2.52469 & $99.19 \%$ & $99.07 \%$ & $98.83 \%$
\end{tabular}

Means

\begin{tabular}{ccccc} 
Co Level & N & Mean & StDev & 95\% CI \\
\hline 0 & 6 & 578.470 & 2.045 & $(576.320,580.620)$ \\
2 & 6 & 611.56 & 2.76 & $(609.41,613.71)$ \\
3 & 6 & 635.927 & 0.942 & $(633.776,638.077)$ \\
4 & 6 & 643.86 & 3.58 & $(641.71,646.01)$
\end{tabular}

Pooled StDev $=2.52469$ 


\section{B.2.3 One-way ANOVA: Yield Strength (MPa) versus Co Level}

Method

Null hypothesis

All means are equal

Alternative hypothesis

Significance level

Not all means are equal

Equal variances were assumed for the analysis.

Factor Information

\begin{tabular}{lcc} 
Factor & Levels & Values \\
\hline Co Level & 4 & $0,2,3,4$
\end{tabular}

Analysis of Variance

\begin{tabular}{lccccc} 
Source & DF & Adj SS & Adj MS & F-Value & P-Value \\
\hline Co Level & 3 & 1996.90 & 665.635 & 172.16 & 0.000 \\
Error & 20 & 77.33 & 3.866 & & \\
Total & 23 & 2074.23 & & &
\end{tabular}

\section{Model Summary}

\begin{tabular}{cccc} 
S & R-sq & R-sq(adj) & R-sq(pred) \\
\hline 1.96632 & $96.27 \%$ & $95.71 \%$ & $94.63 \%$
\end{tabular}

Means

\begin{tabular}{ccccc} 
Co Level & N & Mean & StDev & 95\% CI \\
\hline 0 & 6 & 492.286 & 1.850 & $(490.611,493.960)$ \\
2 & 6 & 508.603 & 1.982 & $(506.929,510.278)$ \\
3 & 6 & 516.417 & 1.379 & $(514.743,518.092)$ \\
4 & 6 & 512.05 & 2.49 & $(510.38,513.73)$
\end{tabular}

Pooled StDev $=1.96632$ 


\section{B.2.4 One-way ANOVA: Brinell Hardness (HB) versus Co Level}

Method

Null hypothesis

All means are equal

Alternative hypothesis

Significance level

Not all means are equal

Equal variances were assumed for the analysis.

Factor Information

\begin{tabular}{lcc} 
Factor & Levels & Values \\
\hline Co Level & 4 & $0,2,3,4$
\end{tabular}

Analysis of Variance

\begin{tabular}{lccccc} 
Source & DF & Adj SS & Adj MS & F-Value & P-Value \\
\hline Co & 3 & 2890.97 & 963.657 & 515.86 & 0.000 \\
Level & & & & & \\
Error & 32 & 59.78 & 1.868 & & \\
Total & 35 & 2950.75 & & &
\end{tabular}

Model Summary

\begin{tabular}{cccc} 
S & R-sq & R-sq(adj) & R-sq(pred) \\
\hline 1.36677 & $97.97 \%$ & $97.78 \%$ & $97.44 \%$
\end{tabular}

Means

\begin{tabular}{ccccc} 
Co Level & N & Mean & StDev & 95\% CI \\
\hline 0 & 9 & 203.333 & 0.707 & $(202.405,204.261)$ \\
2 & 9 & 207.111 & 0.601 & $(206.183,208.039)$ \\
3 & 9 & 223.000 & 1.225 & $(222.072,223.928)$ \\
4 & 9 & 222.889 & 2.261 & $(221.961,223.817)$
\end{tabular}

Pooled StDev $=1.36677$ 


\section{B.2.5 One-way ANOVA: HV versus Co Level}

Method

Null hypothesis

All means are equal

Alternative hypothesis

Significance level

Not all means are equal

Equal variances were assumed for the analysis.

Factor Information

\begin{tabular}{lcc} 
Factor & Levels & Values \\
\hline Co Level & 4 & $0,2,3,4$
\end{tabular}

Analysis of Variance

\begin{tabular}{lccccc} 
Source & DF & Adj SS & Adj MS & F-Value & P-Value \\
\hline Co Level & 3 & 11604.9 & 3868.30 & 395.40 & 0.000 \\
Error & 36 & 352.2 & 9.78 & & \\
Total & 39 & 11957.1 & & &
\end{tabular}

\section{Model Summary}

\begin{tabular}{cccc} 
S & R-sq & R-sq(adj) & R-sq(pred) \\
\hline 3.12783 & $97.05 \%$ & $96.81 \%$ & $96.36 \%$
\end{tabular}

\section{Means}

\begin{tabular}{lrrrc} 
Co Level & N & Mean & StDev & 95\% CI \\
\hline 0 & 10 & 257.100 & 2.807 & $(255.094,259.106)$ \\
2 & 10 & 271.000 & 2.789 & $(268.994,273.006)$ \\
3 & 10 & 295.900 & 2.998 & $(293.894,297.906)$ \\
4 & 10 & 297.40 & 3.81 & $(295.39,299.41)$
\end{tabular}

Pooled StDev $=3.12783$ 


\section{B.2.6 General Linear Model: Impact Toughness (J) versus Co Level, Temperature $\left({ }^{\circ} \mathrm{C}\right)$}

Method

Factor coding $\quad(-1,0,+1)$

Factor Information

\begin{tabular}{lccc} 
Factor & Type & Levels & Values \\
\hline Co Level & Fixed & 4 & $0,2,3,4$ \\
Temperature Fixed & 4 & $22.4,50.0,100.0,150.0$
\end{tabular}

Analysis of Variance

\begin{tabular}{lccccc} 
Source & DF & Adj SS & Adj MS & F-Value & P-Value \\
\hline Co Level & 3 & 35165 & 11721.8 & 104.54 & 0.000 \\
Temperature & 3 & 53902 & 17967.2 & 160.24 & 0.000 \\
Co & 9 & 18471 & 2052.3 & 18.30 & 0.000
\end{tabular}

Level*Temperature

$\begin{array}{llll}\text { Error } & 32 & 3588 & 112.1\end{array}$

Total $\quad 47 \quad 111126$

\section{Model Summary

\begin{tabular}{cccc} 
S & R-sq & R-sq(adj) & R-sq(pred) \\
\hline 10.5889 & $96.77 \%$ & $95.26 \%$ & $92.74 \%$
\end{tabular}

\section{Coefficients}

\begin{tabular}{lccccc} 
Term & Coef & SE Coef & T-Value & P-Value & VIF \\
\hline Constant & 66.23 & 1.53 & 43.33 & 0.000 & \\
Co Level & & & & & \\
0 & 40.93 & 2.65 & 15.46 & 0.000 & 1.50 \\
2 & 7.25 & 2.65 & 2.74 & 0.010 & 1.50 \\
3 & -19.52 & 2.65 & -7.37 & 0.000 & 1.50 \\
4 & -28.66 & 2.65 & -10.83 & 0.000 & $*$ \\
Temperature & & & & & \\
22.4 & -46.57 & 2.65 & -17.59 & 0.000 & 1.50 \\
50.0 & -15.28 & 2.65 & -5.77 & 0.000 & 1.50 \\
100.0 & 21.54 & 2.65 & 8.14 & 0.000 & 1.50 \\
150.0 & 40.31 & 2.65 & 15.23 & 0.000 & $*$
\end{tabular}

Co

Level*Temperature

$\begin{array}{lccccc}022.4 & -12.59 & 4.59 & -2.75 & 0.010 & 2.25 \\ 050.0 & 23.54 & 4.59 & 5.13 & 0.000 & 2.25 \\ 0100.0 & 6.96 & 4.59 & 1.52 & 0.139 & 2.25 \\ & & & 227 & & \end{array}$




$\begin{array}{llccccc}0 & 150.0 & -17.90 & 4.59 & -3.90 & 0.000 & * \\ 2 & 22.4 & -11.70 & 4.59 & -2.55 & 0.016 & 2.25 \\ 2 & 50.0 & 9.94 & 4.59 & 2.17 & 0.038 & 2.25 \\ 2 & 100.0 & 31.75 & 4.59 & 6.92 & 0.000 & 2.25 \\ 2 & 150.0 & -29.99 & 4.59 & -6.54 & 0.000 & * \\ 3 & 22.4 & 7.65 & 4.59 & 1.67 & 0.105 & 2.25 \\ 3 & 50.0 & -21.73 & 4.59 & -4.74 & 0.000 & 2.25 \\ 3100.0 & -15.07 & 4.59 & -3.29 & 0.002 & 2.25 \\ 3 & 150.0 & 29.15 & 4.59 & 6.36 & 0.000 & * \\ 4 & 22.4 & 16.64 & 4.59 & 3.63 & 0.001 & * \\ 4 & 50.0 & -11.74 & 4.59 & -2.56 & 0.015 & * \\ 4 & 100.0 & -23.64 & 4.59 & -5.16 & 0.000 & * \\ 4 & 150.0 & 18.74 & 4.59 & 4.09 & 0.000 & *\end{array}$

\section{Regression Equation}

Impact $=66.23+40.93$ Co Level 0

Toughness + 7.25 Co Level_2 - 19.5̄2 Co Level_3

(J)

- 28.66 Co Level_4

- 46.57 Temperature_22.4

- 15.28 Temperature 50.0

+21.54 Temperature_100.0

+40.31 Temperature 150.0

- 12.59 Co Level*Temperature_0 22.4

+ 23.54 Co Level*Temperature 0

$50.0+6.96$ Co Level*Temperature 0 100.0

- 17.90 Co Level*Temperature_0

150.0

- 11.70 Co Level*Temperature 2

$22.4+9.94$ Co Level*Temperature 2

$50.0+31.75$ Co Level*Temperature_2

100.0

- 29.99 Co Level*Temperature_2

150.0

+ 7.65 Co Level*Temperature_3 22.4

- 21.73 Co Level*Temperature_3 50.0

- 15.07 Co Level*Temperature_3

100.0

+ 29.15 Co Level*Temperature 3

150.0

+ 16.64 Co Level*Temperature_4 22.4

- 11.74 Co Level*Temperature_450.0

- 23.64 Co Level*Temperature 4

100.0 
+ 18.74 Co Level*Temperature_4 150.0

Fits and Diagnostics for Unusual Observations

\begin{tabular}{|c|c|c|c|c|}
\hline \multicolumn{3}{|c|}{$\begin{array}{c}\text { Impact } \\
\text { Toughness }\end{array}$} & \multicolumn{2}{|r|}{ Std } \\
\hline Obs & (J) & Fit & Resid & Resid \\
\hline 2 & 68.58 & 48.00 & 20.58 & $2.38 \mathrm{R}$ \\
\hline 26 & 154.14 & 135.67 & 18.47 & $2.14 \mathrm{R}$ \\
\hline 32 & 27.50 & 53.19 & -25.69 & $-2.97 \mathrm{R}$ \\
\hline
\end{tabular}




\section{Macro file used for Metallography in ImageJ}

// Microstructural Analysis Tool

// Created by Karl Warsinski, Michigan Technological University

macro "Iron Analysis Action Tool -

Cdd0o1265oc133o5e34odd55C00fT3510CT9510.Tb510ITe510.T0e10TT4e10eT8e10sT de10t" \{

run("Iron Analysis");

\}

macro "Iron Analysis" \{

//Prompt for sample ID and types of analysis

title = "Unknown";

types = newArray("Graphite Only", "Graphite and Ferrite/Pearlite", "Ferrite/Pearlite Only");

Dialog.create("New Analysis");

Dialog.addString("Sample ID:", title);

Dialog.addString("Operater Name:", title);

Dialog.addChoice("Phases:", types);

Dialog.addCheckbox("Carbides Present?", false);

Dialog.addCheckbox("Show graphite data?", false);

Dialog.addMessage("\n Carbides will be subtracted from the matrix for Ferrite/Pearlite analysis.")

Dialog.addNumber("Minimum Particle Diameter", 6, 1,4,"microns");

Dialog.show();

sample $=$ Dialog.getString () ;

user $=$ Dialog.getString();

phases $=$ Dialog.getChoice () ;

carbides $=$ Dialog.getCheckbox();

showData $=$ Dialog.getCheckbox () ; 


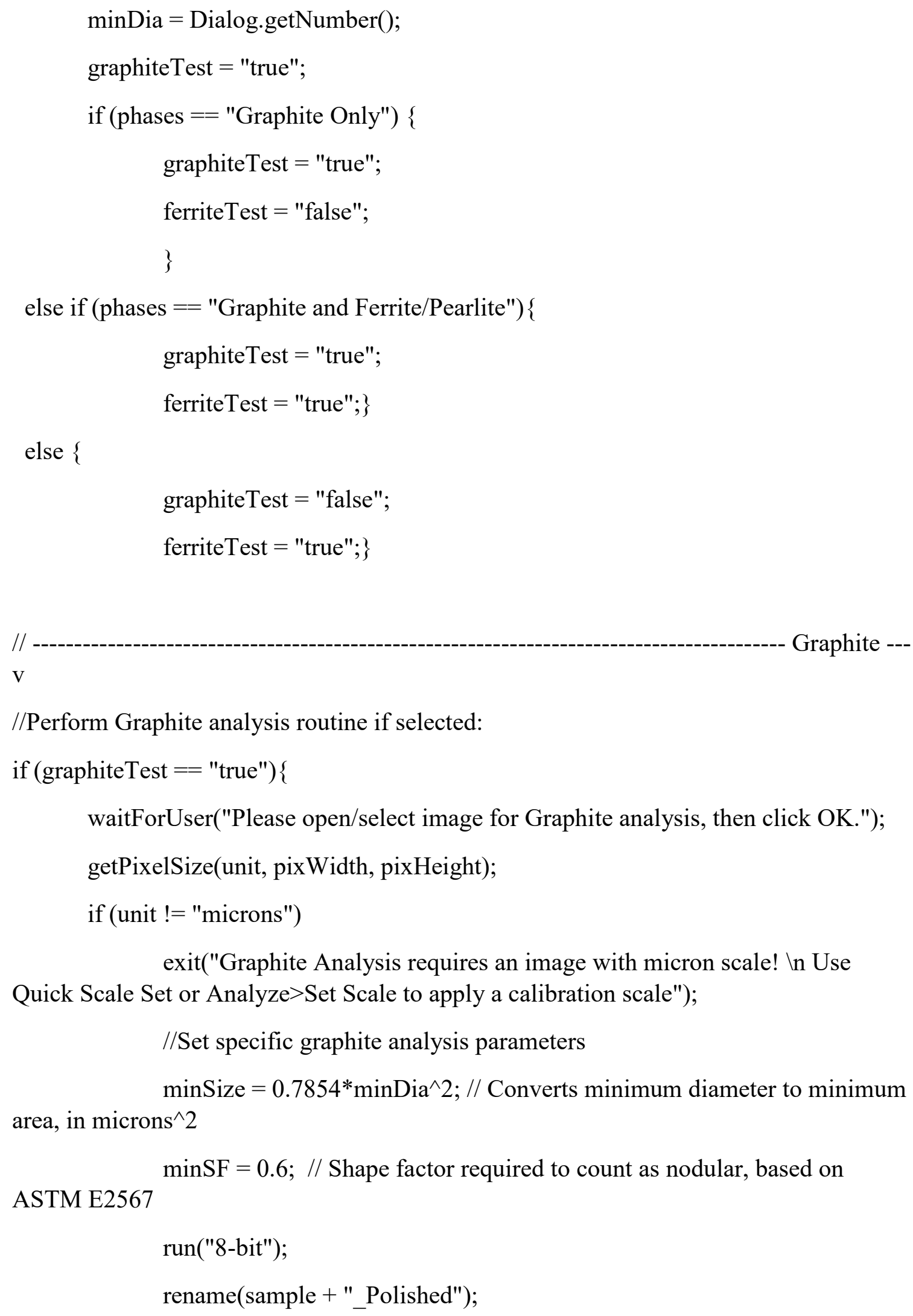


//Enhance image and start graphite selection

run("Enhance Contrast", "saturated=0.4 normalize");

setThreshold(0,68,"Red");

run("Threshold...");

//Message window to hold macro while threshold is set

waitForUser("Use Threshold bar to highlight graphite in red.");

selectWindow("Threshold");

run("Close");

//Convert image and clean up particles for measurement

run("Make Binary", "thresholded remaining black");

//run("Fill Holes");

run("Analyze Particles...", "size=78.53982-Infinity circularity=0.00-1.00

show=Nothing display clear exclude");

//run("Summarize")

//Restore polished image

run("Revert");

//Classify Graphite Structure

particles $=$ nResults;

getStatistics(areaTotal);

fractionGraphite $=$ ColumnSum("Area")/areaTotal*100;

graphiteSize = ColumnSum("Feret")/particles;

sphericity = ColumnSum("Round")/particles;

noduleCount $=0$;

areaNodular $=0$;

for $(\mathrm{a}=0 ; \mathrm{a}<$ nResults; $\mathrm{a}++)\{$

if (getResult("Round",a) >=0.5) \{

noduleCount $=$ noduleCount +1 ;

areaNodular $=$ areaNodular + getResult("Area",a); 
\}

nodularitybyArea $=100 *$ areaNodular/ColumnSum("Area");

nodularitybyCount $=100 *$ noduleCount $/$ particles;

noduleDensity $=1000000 *$ noduleCount/areaTotal;

//Graphite Form (ISO 945) -- Average roundness determines which form particles are classified as:

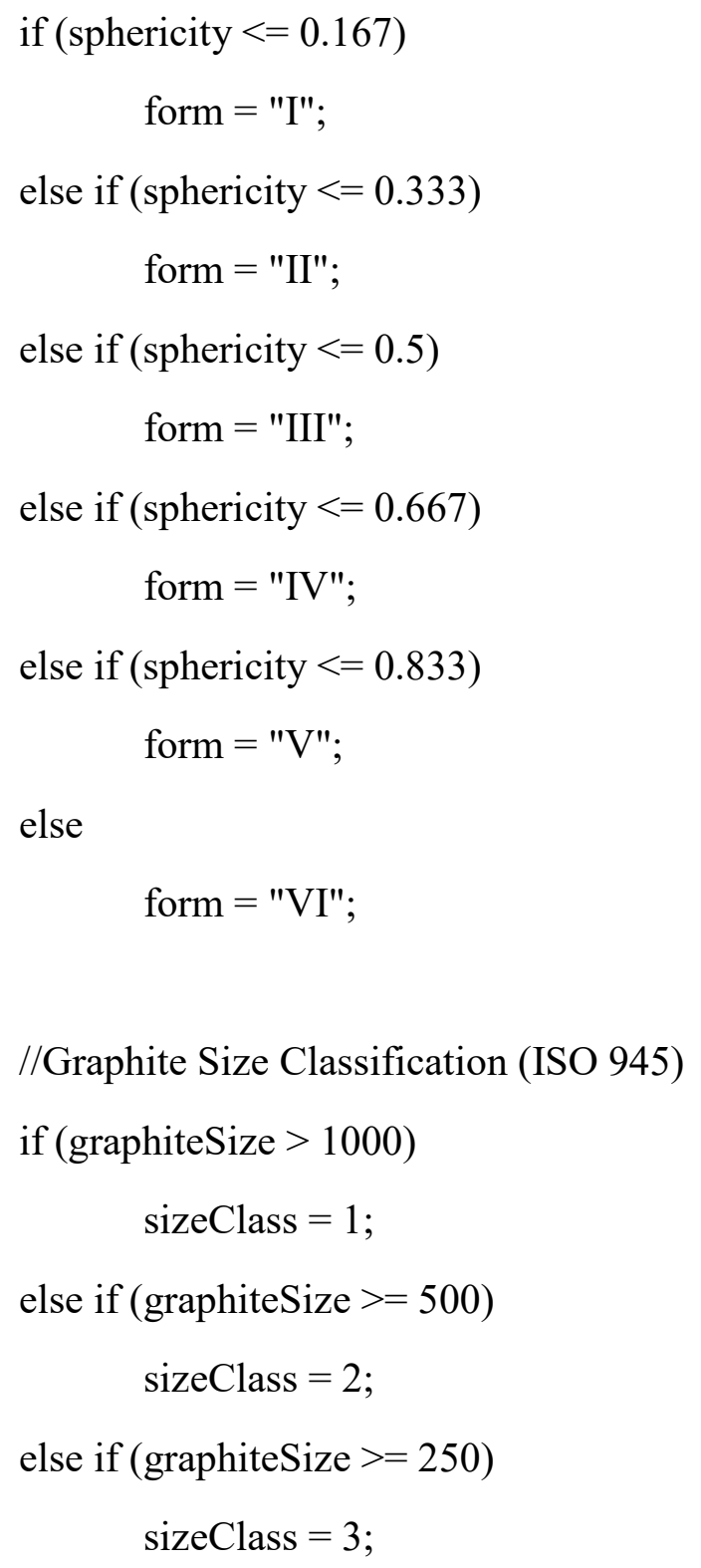




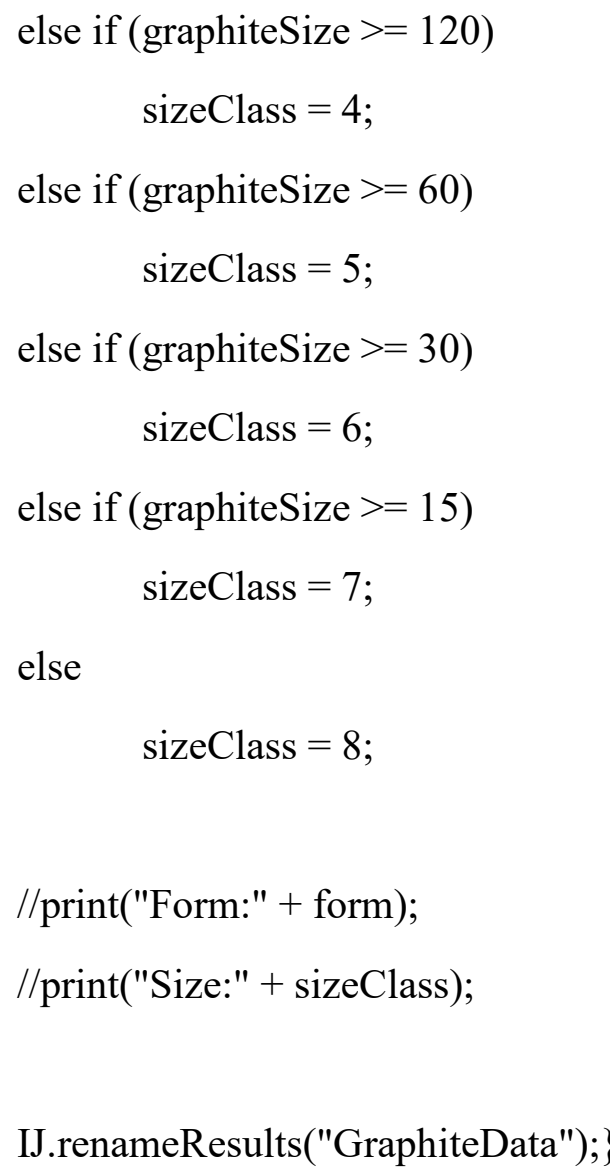

else $\{$ fractionGraphite $=0 ;\}$

//Analyze matrix microstructure, if selected:

if (ferriteTest=="true") \{

path = File.openDialog("Select Etched Image");

open(path); // open the file

rename(sample+"_Etched");

-- Carbide Measurement ---V

//Select Carbides if necessary

if $($ carbides $==$ true $)\{$

setTool(3); 
msg="Draw Outline Around Each Carbide Grain \n InHold down shift key to make multiple outlines";

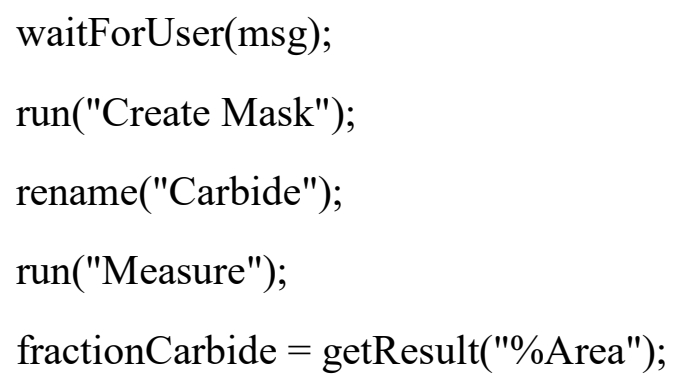

//Message window to hold macro while threshold is set waitForUser("Please adjust threshold to highlight Ferrite in red, then click OK. In If carbides have been selected, they will be automatically subtracted."); selectWindow("Threshold"); run("Close");

//Convert and clean up particles for measurement run("Create Mask"); rename("Ferrite"); 


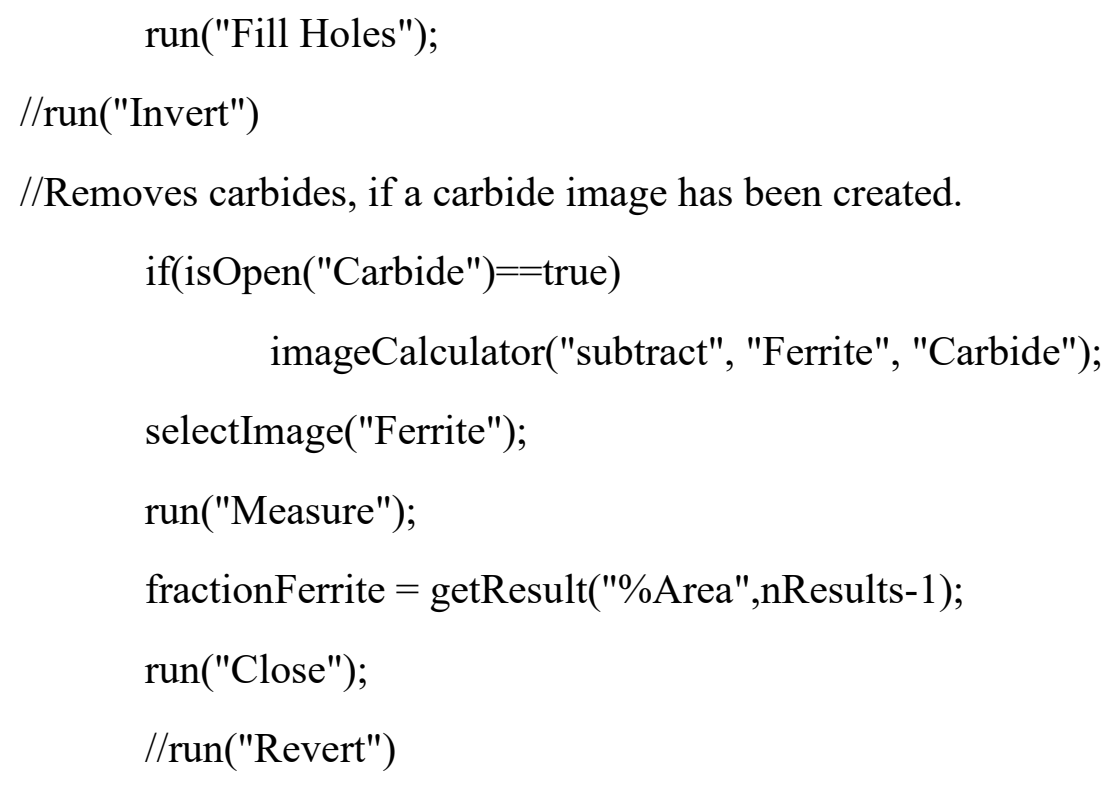

